\title{
6.0.
}

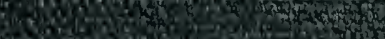

want

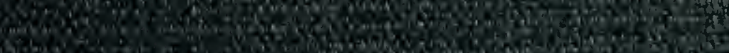
Whow

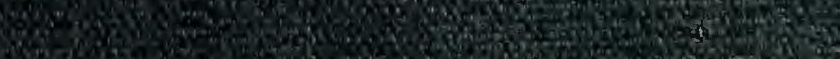

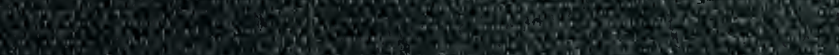

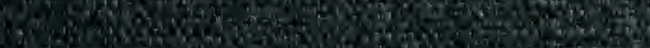

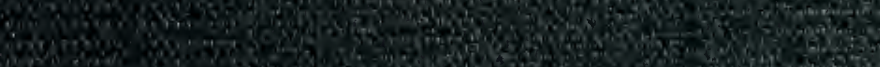

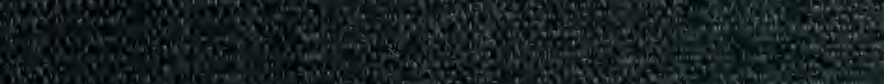

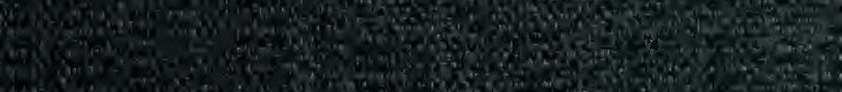

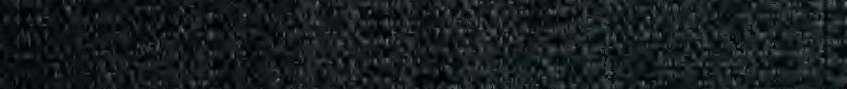
3. Y

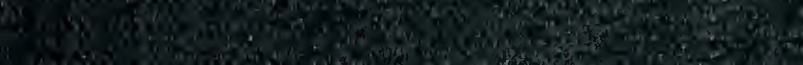

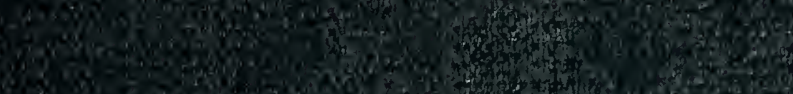

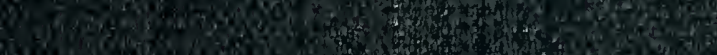
8.

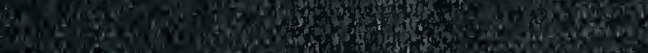

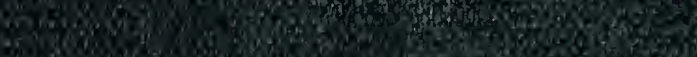

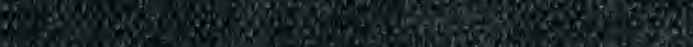

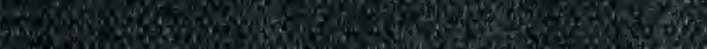

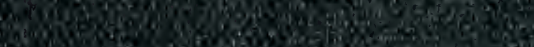

Wowo 30.

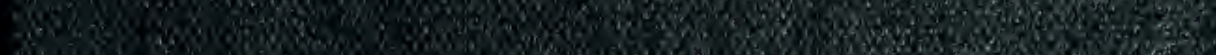
WW. W6- 5 .

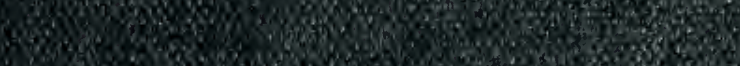

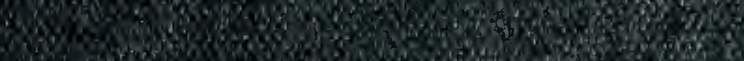
W.

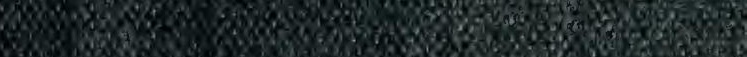
Wo Worserse 


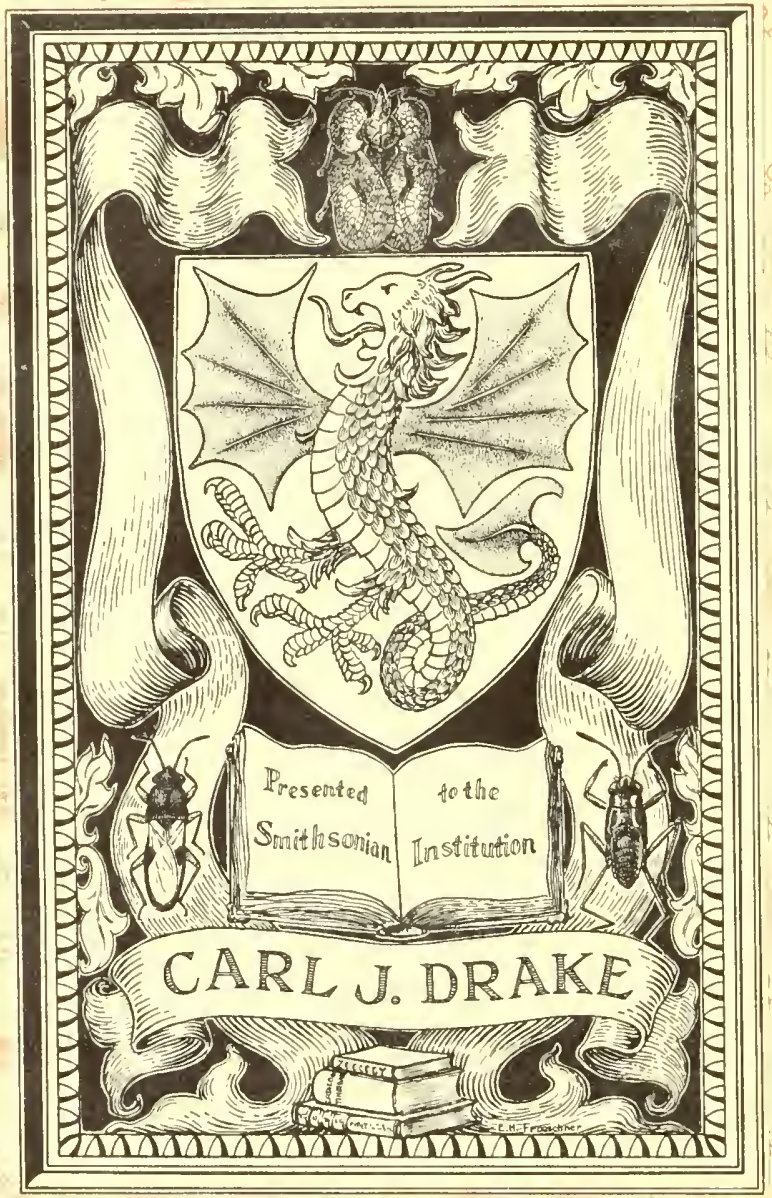





Con forake 


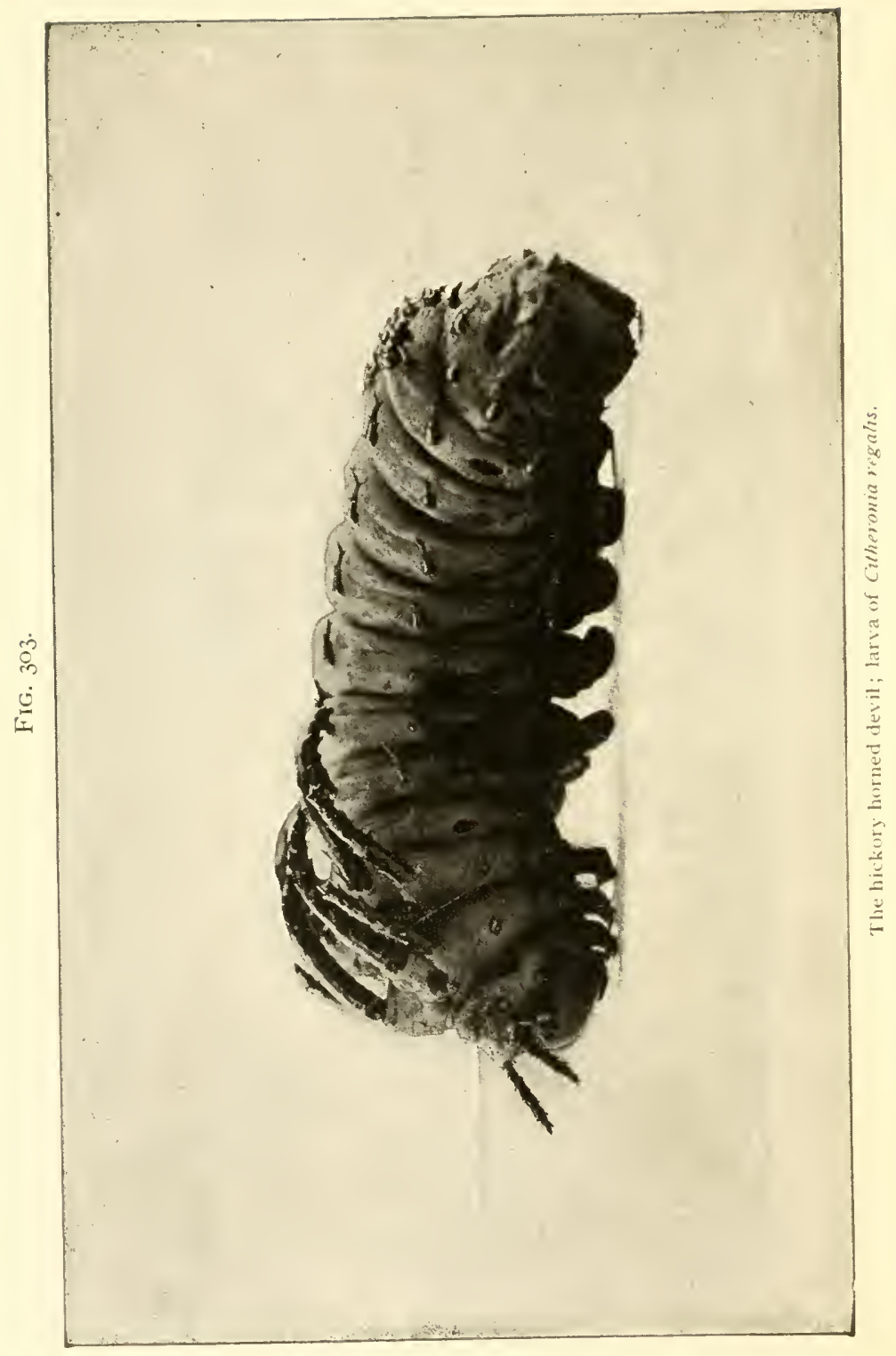




\section{ECONOMIC ENTOMOLOGY}

нок тик

FARMER AND FRUIT-GROWER, AND

FOR USE AS A TEXT-BOOK IN AGRICULTURAL SCHOOLS

AND COLLEGES

BY

JOHN B. SMITH, Sc.D.

Professor of Entomology in Kutgers College: Entomologist to the New Jersey Agricultural College Experiment Station and the New Jersey State Board of Agriculture; President of the Association of Economic Entomologists, of the Brookly' Entomological Society, and of the New Jersey State Microscopical Society; Fellow of the American Association for the Advancement of Science, etc., etc.

[Second Ferised Edition.]

ILLUSTRATED

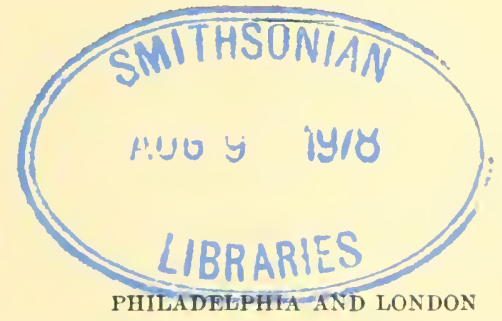

J. B. LIPPINCOTT COMPANY 
Copyright, I 896 ,

By J. B. Lippincott Company.

COPYRIGITT, I906,

By J. B. Lippincott Company.

Electrotypez ano Printed oy J. B. Lippincott Company, Philadelphia, U.S.A. 


\title{
CONTENTS.
}

\author{
PAKT I \\ STRUCTURE AND CLASSIFICATION.
}

CHAPTER 1.

The General Structure of Insects . . . . . . . . i I

CHAPTER II.

T he Head and its Appendages ........... I4

CHAPTER III.

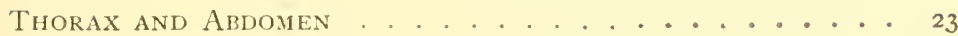

CHAPTER IV.

Muscles, Digestion, and Circulation . . . . . . 27

CHAPTER V.

The Respiratory Strtem. . . . . . . . . . . 33

CHAPTER VI.

Nervous System and Senses of Insects . . . . . . . . 39

CHAPTER VII.

The Reproductive Sistem

CHAPTER VIII.

Growth and Methimorphosis. . . . . . . . . . 48 


\section{PA RT II. \\ THE INSECT WORLD.}

CHAPTER I.

PAGE

General Classifichtion . . . . . . . . . . 52

CII I PTER II.

The THYsantrel . . . . . . . . . . . . 55

C HAT'TR IH.

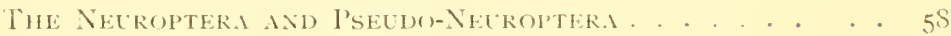

ORder EPHEMEROPTERA . . . . . . . . . . 59

ORDER OUGNATA . . . . . . . . . . . . . 60

ORDER Plecopteri . . . . . . . . . . . . . 63

Order Platypterd . . . . . . . . . . . . . 64

Order Neuropter.1............. . . . . 72

CHAITER IV.

THE ORTHOPTERA.

C II A TER V".

The Henuptera, or Bugs. .

I (1)

CHAPTER VI.

THE COLEOPTERA, oR BeEtles . . . . . . . . . . . I64

CHAPTER VII.

THE LepldopterA . . . . . . . . . . . . . . . 240

CHA PTER V'III.

Tile Dipteri, or Flies

CHAPTER IX.

The Hyienoptera . 


\section{PAIR T I I I.}

INSECTICIDES, PREVENTIVES, AND MACHINERY.

$$
\text { CHAPTER I. }
$$

Predaceous Insects, Parasites, and Fungous Diesases . . 418

CHAPTER II.

Farm Practice to prevent Insect Attack ...... 423

CHAPTER III.

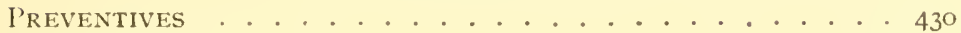

CHAPTER IV.

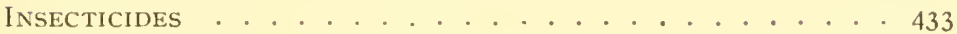

CHAPTER V.

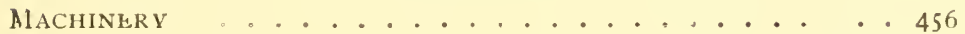





\section{ACKNOWLEDGMENTS.}

THe illustrations in this book are derived as follows: Electrotypes were loaned for the purposes of the work by the Agricultural College Experiment Station of New Jersey, of figures Nos. $4,5,6,7$, II, I $3,14,15,28,29,30,32,34,35,36,37,38,39$, $4 \mathrm{I}, 43,44,45,50,53,64,72,83,84,85,88,89,95,99$, IO3, IO4, I05, II 4, I 27, I 28, I 29, I 30, I 3 I, I 32, I 33, I 34, I 36, I 37, I 38 , I $42,143,144,146,147,149,157,158,160,161,162,164$, I66, I67, I70, I7I, I72, 173, I7ł, I75, I76, I78, I79, I80, I8I, I82, I83, I 88,189 , I90. I92, I94, 195, 200, 201, 202, 204, 206, 21 2, $2 \mathrm{I}+, 216,2 \mathrm{I} 7,2 \mathrm{I} 8,2 \mathrm{I} 9,22 \mathrm{I}, 222,225,227,228,229,230,23 \mathrm{I}$, $232,233,234,236,238,239,241,242,243,246,247,255,263$, $264,265,274,278,279,28 \mathrm{I}, 283,286,287,288,289,290,29 \mathrm{I}$, $296,297,298,299,300,307,314,321,332,333,334,341,342$, $343,349,350,35 \mathrm{I}, 352,357,362,366,368,369,375,377,380$, $386,387,392,393,394,395,396,397,398,399,401,409,410$,

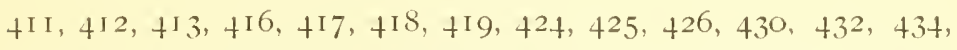
$435,437,438,4+0,4+1,4+t,+45,4+6,447,4 t^{8}, 449,450,45 t$, $455,457,45^{8}, 459,460,46 \mathrm{I}, 462,463,464,465,466,467,468$, 469. $47 \mathrm{I}, 473,47+$.

By the courtesy of the Secretary of Agriculture and of the Division of Illustrations in the United States Department of Ayriculture, electrotypes were obtained for figures Nos. 22, 23, 48 , $56,58,73,74,75,76,8$ I $, 82,86,87,90,91,92,93$, Іо0, Іо I, II 2, II6, II7, I18, I 20, I 2 I, I 22 , I24, I 48, I5I, I 52, I68, I 93 , I 98, 209, 223, 224, 226, 244, 245, 292, 293, 294, 295, 3I5, 3I 6 , $3^{18}, 339,340,35^{8}, 360,363,364,365,37 \mathrm{I}, 374,376,383,389$, $390,391,402,404,405,406,407,408,43 \mathrm{I}, 452,475$.

The J. B. Lippincott Company kindly loaned the following from Saunders's "Insects Injurious to Fruits" : Nos. 55, 59, 60,

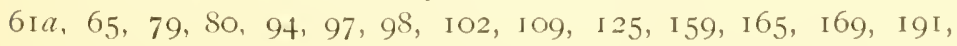
I 97, I99, 203, 2II, 213, 220, 240,254, 259, 270, 27I, 275, 276, 
$277,284,302,308,309,310,311,312,313,324,325,326,327$, $328,329,330,331,337,338,347,353,354,367,372,373,400$, $403,422,428,429,4+3$; and from French's "Butterflies of the Eastern United States,' Nos. 253, 260, 261, 262, 268, 269, 273.

From Prof. Lawrence Bruner, of the University of Nebraska, were purchased electrotypes of figures Nos. 1, 26, 31, 33, 42, 46, 47,5 I, 52, 6I b, 62, 68, 70, 7 I, 96, IO7. I IO, I I 5, I39, I 40, $1+$ I, $156,163,186,256,319,320,335,336,355,421,433$.

From Houghton, Mifflin \& Co., publishers of the " Riverside Natural History,' 'were purchased Nos. 1 2, I 7, 77, 78, I06, I77, $378,4 \mathrm{I} 4,423,45 \mathrm{I}, 472$.

From the Entomological Society of Ontario electrotypes were obtained for figures Nos. 207, 208, 258, 420, 456.

From the Cornell Experiment Station, through the kindness of Mr. M. V. Slingerland, electrotypes were secured of figures Nos. 40, I I $9,145$.

Mr. G. C. Davis, of the Agricultural Experiment Station of Michigan, furnished stereotypes of figures Nos. I96, 235, 30 I, $370,388,439$.

Prof. Herbert Osborn, of the Iowa Agricultural College, kindly loaned for reproduction figures Nos. Io8, 356, 382 .

Dr. Otto Lugger, State Entomologist of Minnesota, supplied electrotypes of figures Nos. $280,427,4+2$.

Dr. F. H. Snow, of Lawrence, Kansas, loaned for reproduction figures Nos. 123, 210.

Mr. F. M. Webster, of the Ohio Experiment Station, permitted the reproduction of figures Nos. $205,237$.

Mr. A. D. Hopkins, of the West Virginia Experiment Station, granted the same favor for figures Nos. $3^{8} 4$ and 385 .

Dr. A. S. Packard kindly supplied electrotypes of figures Nos. I 6 and 470 .

To Dr. G. Brown Goode, Director of the United States National Museum, I owe electrotypes of figures Nos. 27 and 38 I.

From Mrs. C. V. Riley were purchased electrotypes of figures Nos. I I and $36 \mathrm{r}$.

Dr. J. A. Lintner, State Entomologist of New York, kindly supplied an electrotype of figure No. 282.

Prof. S. A. Forbes was equally courteous concerning figure No. 187 . 
Prof. C. P. Gillette loaned for réproduction figure No. I 50.

Mr. Frank Sempers, of Philadelphia, kindly gave figure No. 49.

Mr. H. G. Hubbard, of Washington, obligingly loaned figure No. 359 .

The following are originals, and were especially prepared for this work: Nos. 2, 3, 8, 9, I 8, 19, 20, 21, 24, 25, 54, 57, 63, $66,67,69$, I 33, I 26, I 35, I 53, I 54, I 55, I $84,185,2$ I $5,248,249$, 250,25 I, 252, 257, 266, 267, 272, 285, 304, 305, 306, 322, 323 , $3+4,345,346,348,379,415,436,453$. Of these original figures, some are photographs, others are from drawings by the author, some are redrawn, and a few are duplications of published figures where no plates were known to be in existence.

To all who have in any way aided in the preparation of this work, and especially to Dr. L. O. Howard, of Washington, who kindly read my chapter on Hymenoptera, and Prof. Lawrence Bruner, who kindly read my chapter on Orthoptera, I tender my sincere thanks. 



\section{INTRODUCTORY.}

InSECT injury to agricultural products amounts each year to millions of dollars, and, as a whole, shows a tendency to increase rather than otherwise. It is not only the actual devouring of plant tissue that causes loss; the effect upon the product may be to reduce its grade, or make it more or less unsalable and unprofitable. In the competition for markets, the grower of the best will always have an advantage; first-class fruits and vegetables rarely fail to bring some profit, where low-grade products cannot be sold at any price; and no fruit that is wormy, defaced, or otherwise injured by insects ever ranks as first-class.

Progressive farmers have long been aware of this, and the science of economic entomology has grown up in response to their demands for information concerning insect depredation and for means of protection against it. It is a science far from systematized as yet; made up of fragments published here, there, and everywhere, rarely complete in themselves and often contradictory as to the remedial measures suggested. There have been efforts, more or less successful, to compile books of information concerning the insects attacking certain crops or kinds of crops; but there is not now in existence any work which gives the agriculturist and student of economic entomology that basic knowledge that enables him to recognize the nature of the insect he finds causing injury, or makes it possible to decide what sort of remedies should be applied. In other words, the underlying facts upon which the scientific application of remedial or preventive measures is based are not accessible to the very class that most needs them.

In this book an attempt is made to present these matters com. pletely enough to give a foundation upon which further information may be added; for whatever changes maỹ occur in our 
battery of insecticides, the philosophy of their application will remain the same. To do this it is necessary to give an outline of the characteristics of insects generally ; of those features that distinguish them from all other animals, and of those peculiarities upon which we must base our hope of conquering them. Enough of the structure is described to show how they are built up, and all the different orders are referred to, so that the intelligent reader may recognize at least the group to which a specimen belongs and may be able to determine whether or not an injurious species is in hand. The direct needs of the agriculturist have been kept constantly in mind; but the effort has been to give also a general information on the subject of insect life, and the work should be useful to students in all save advanced college courses, where technical or systematic studies outrank all others. 


\section{AN ECONOMIC ENTOMOLOGY.}

PART I.

\section{STRUCTURE AND CLASSIFICATION.}

\section{CHAPTER I.}

THE GENERAL STRUCTURE OF INSECTS.

INSECTS are animals made up of a series of rings or segments stiffened by a hard substance called chitine, and connected by a membrane which allows of more or less freedom of motion between them in one or more directions. In this they agree with the worms, differing from them, however, in the adult stage, in that the segments are grouped into three regions; the head, thorax, and abdomen, as shown in the diagrammatic sketch of the grasshopper. In the larval stage of many insects these regions are not well marked, and they resemble worms decidedly, but nearly always have a distinct head and more or less distinct legs. If neither head nor legs are visible, the larva are chunky and maggot-like or grub-like, rarely long and cylindrical. In fact, we have very few terrestrial worms in our country, and most of the so-called "worms" are really insect larvæ.

As a rule, an insect is made up of thirteen rings, counting the head, and in the larval stage they are usually easy to make out, especially in caterpillars, which may be abundantly secured at any time during the summer. In the adult they are often more or less obscure. Following the head we have three segments which form the thorax or trunk, and these bear all the organs of locomotion in the adult. In the larva, when organs of locomotion are present, one pair of legs is found on each of these segments. 
Nine rings are assigned to the abdomen, though some of them n1ay be modified into structures facilitating egg-laying or other special purposes. In the adult no appendages of any kind, except ovipositors, anal filaments, or cerci, are found; but in the larva, where there is often no real separation between thorax and abdomen, the latter may bear organs of locomotion which differ in their general appearance and structure from the true legs, and are therefore called "false feet," or pro-legs. The number of these pro-legs sometimes enables us to recognize the order to which a larva belongs, where it otherwise closely resembles another. For instance, all the true caterpillars are larvæ of Lepidoptera, or butterflies and moths, and these never have more than four pairs of pro-legs at the middle of the body and one pair on the last segment, making, with the true legs, eight pairs in all. In the larvæ of the sawflies, a family of the Hymenoptera in which the resemblance to caterpillars is very close, there are at least five pairs of pro-legs at the middle and one pair at the end of the body, or no less than nine pairs of legs instead of eight as before.

No insect has more than two pairs of wings, and these are attached to the second and third thoracic segment. Some have only a single pair, as in the true flies, and then they are on the second or intermediate segment. The prothorax, or first segment, never bears wings. Each thoracic segment bears a pair of legs, which are themselves divided into joints or segments, and their structure will be described more in detail later on.

This division into three distinct regions and the limitation to six legs in the adult separate the insects from crustaceans, like lobsters, crabs, shrimps, and the like, and from the spiders; none of which have the head separate from the thorax, while all have eight legs instead of six. An insect in the adult stage is therefore a jointed animal, the rings, thirteen in number, separated into a head of one, a thorax of three, and an abdomen of nine segments; moving by means of three pairs of jointed legs. Some differences between "larva" and "adult" have been spoken of, and it has been indicated thereby that at different periods of their lives insects are unlike in appearance. This branch of the subject is exceedingly interesting, and will be treated more fully in Chapter VIII. It is only necessary to say here that, in speak- 


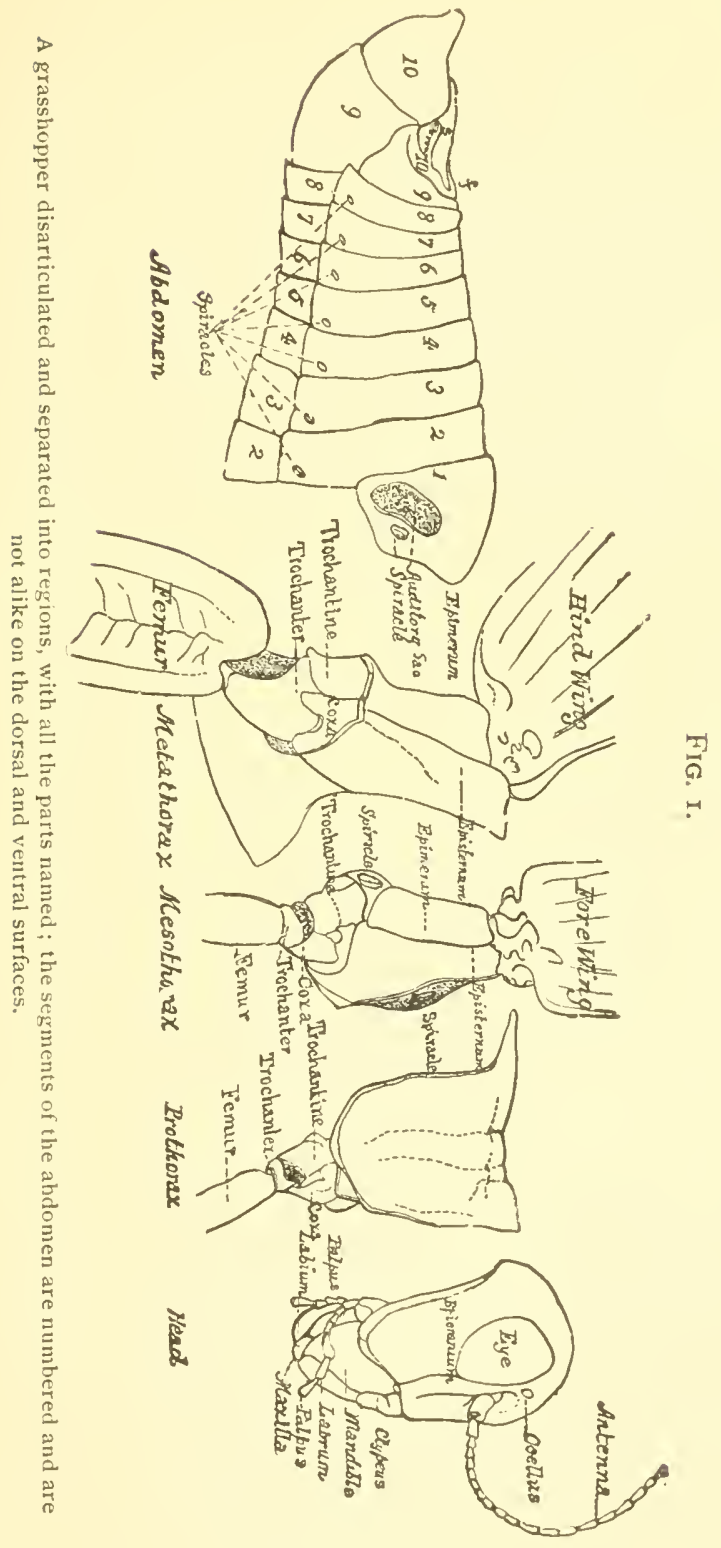


ing of the difference between larva and adult, reference is particubarly made to those forms in which the two stiges are totally unlike each other in appearance. Some of them resemble each other throughout their entire life, and here the term "nymph", is often employed instead of larva.

It remains to say a few words concerning the chitine, which forms so large a part of the outer skeleton or crust. This sub-

Fig. 2.

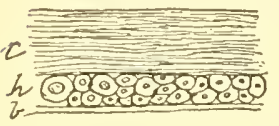

Section through insect crust, showing layers of chitine at $c$, the cellular layer or hypodermis at $h$, and basal membrane at $b$. stance is found in insects and in certain of the crustaceans, and is a flaky, horny, or shell-like material which may become very hard, and is impenetrable to most liquids not absolutely corrosive in character. The importance of this fact it is necessary to recognize in our selection of insecticides, because nothing that we can apply with any safety to the plant is sufficiently active to eat through or penetrate the outer skin into the insect bocly except under peculiarly favorable circumstances. None of the oils penetrate it readily, even gasoline, benzine, or kerosene being resisted. Alcohol, chloroform, and ether are also unable to make their way through any but a very thin coating.

\section{CHA PTER II.}

THE HEAD AND ITS APPENDAGES.

THE head of an insect bears structures of great interest fron the economic stand-point, and of these the mouth parts are the most important. In most cases a glance at the structure of the mouth gives a clue to the food habits of the species, and may convict a culprit whose work has been discovered, or determine the character of the remedy to be applied.

Roughly speaking, two types of mouth structure are found in insccts, - the biting or mandibulate, and the sucking or haustellate; though there are modifications of both which are somewhat intermediate in character.

In the typical "mandibulate" or biting mouth, the mandibles 
or upper jaws are distinct and prominent. They work horizontally, from side to side, instead of vertically, or up and down, as is the case in the higher animals, and their form and general shape often furnish an indication to the character of the species, - that is, whether it is predaceous, living upon ani mal food, or whether it is phytophagous, feeding upon plant tissue. This alone, in some orders, suffices to tell us whether we have to deal with a friend or an enemy. If the jaws are rather long, sharp-pointed, with slender, sharp teeth on the inner side (Fig. 3, $c, d$ ), it may be safely classed as predaceous; if they are broad, stout, concave within, the edges meeting broadly, even if toothed, or if they are gouge-shaped (Fig. 3, a, e), we can say with great confi-
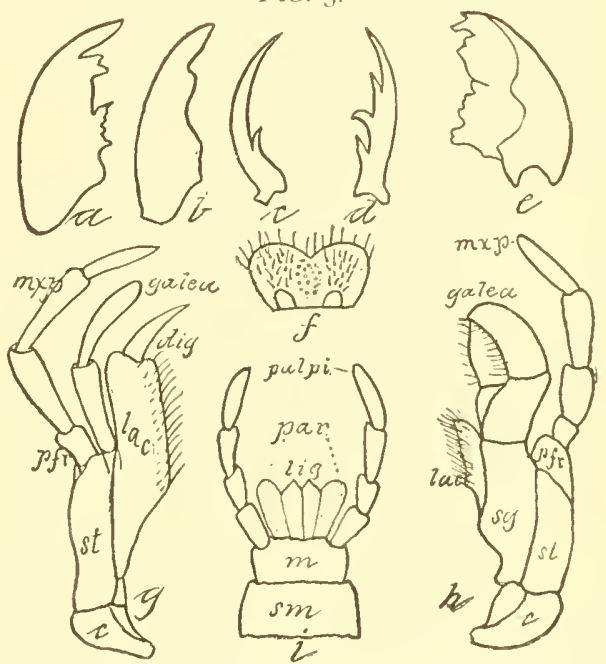

Mouth parts of a mandibulate insect: different tvpes of mandibles at $a, b, c, d, e$; $f$, the labrum-epipharynx: $g, h$, types of maxillæ; the cardo at $c$; stipes, st; subgalea, $s g$; galea as marked ; palpus bearer, $p f r$; palpus at $m x p$; lacinia at $l a c$; and digit us at $d i g ; i$, the labium with sub-mentum, $s m$, mentum, $m$, ligula, lig, paraglossa, par, and palpi.

dence that the species feed upon vegetable tissue. Of course some uncertiinty may result in intermediate types (Fig. 3, b) ; but the rule holds good generally, and where it leaves a doubt, some other character will readily determine the question.

Forming the front of the mouth and covering the base of the mandibles is the upper lip, or labium; on the inner side of which there is usually a sensitive structure, the epipharynx, which contains the organs of taste, and corresponds as nearly as may be to the palate in higher animals. It has no special function in feeding, and often seems to form part of the front of the head itself. Below the mandibles we have a second pair of jaws or maxilla, 
much more complicated in structure, and made up of a number of more or less well-marked smaller pieces, which vary considerably in form and shape according to the food habits of the insect. Attached to each maxilla is a palpus, or feeler, which often bears organs of special sense, and is probably used by the insect to recognize the character of its food. In function this maxilla is auxiliary to the mandibles, which cut and tear the food, and deliver it in coarse shape to the maxillæ. These assort and break it up yet more to better its mechanical condition, and deliver it to the labium, or lower lip, which also takes part in mixing the food. There are great differences in this maxillary structure, corresponding to the food habits; and there may be teeth, brushes, or other appendages suited to the requirements of the insect. It is rarely necessary to study these in detail, and Fig. 3 illustrates sufficiently a typical form, with all the parts named.

The labium, or lower lip, closes the mouth opening beneath, forming its floor, on which is another sensitive surface, the hypopharynx, which may be compared in function to the tongue of the higher animals. As a rule, this labium is much less complex than the maxilla, and it may be only a single piece or plate, though, like the maxilla, furnished with a pair of palpi or feelers. A typical labium is shown at Fig. 3, and the names of the parts are given. Close study shows that originally the labium was made up of just as many parts as the maxilla, but they have grown together, in the course of time, for the more complete closure of the mouth opening.

Insects with the mouth as above described, no matter what their feeding habits, are always susceptible of being poisoned through their food; that is, they may be reached by means of stomach poisons. Sometimes, of course, they feed in such positions that we cannot apply the poison satisfactorily, - c.g., inside of plant tissue; but this does not alter their susceptibility; it simply means that we cannot take advantage of it.

Of the haustellate or sucking mouth there are several varieties, functionally quite diverse and indicating difference in habit.

Butterflies and moths differ from all other insects in having the mouth formed into a flexible tube, coiled like a watch-spring under the head and between the labial palpi, which are the only visible mouth appendages present. The mandibles have disap- 
peared entirely, and all the other structures have been so modified that nothing remains except this flexible sucking tube. I use the term "tube," although it is not such in reality, being made up of two hollow crescents, more or less firmly held together, so that, practically, it serves all the purposes of a complete tube. When the insect feeds the tongue is extended, the muscular structure being accommodated in the walls of each half of the tube. Fig. 4 illustrates a section through a butterfly tongue, showing the way in which the two parts are united. At its tip there are often more or less developed processeswhich serve as taste cups, and also to assist in gathering up the minute globules of nectar.

A tongue of this FIG. 4.

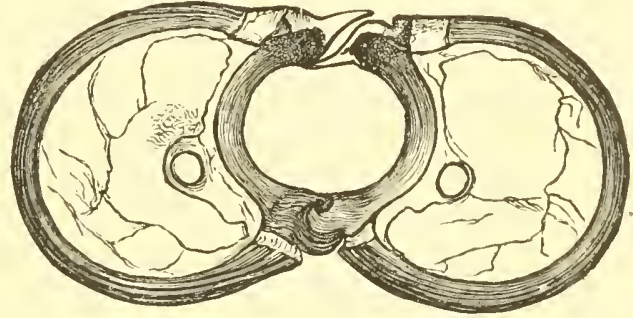

Section through a butterfly tongue. description indicates a type which can never be harmful to vegetation, because it is not fitted for either piercing or eating plant tissue; but it is, on the contrary, of direct use in pollenizing flowers. Butterflies and moths are never injurious in the adult stage, however much their larvæ may offend; but many are especially adapted for pollenizing certain flowers. Thus the "Hawk-moths," with tongues five and six inches in length, are able to reach to the very base of flowers like the petunias, evening primrose, "Jimpson weed," and many orchids.

A widely different type of sucking mouth is found among the "bugs," or Hemiptera. Here, instead of a flexible tube, there is a jointed, rigid beak or rostrum, made up of either three, or tour segments, inside of which run four pointed lancets. This beak is not a complete tube, but narrowly open in front and at the tip, to permit the protrusion of the lancets. Insects with this structure gain their food by piercing the plant tissue and sucking the juices, and such a structure always leaves its possessor open to the suspicion of being injurious. As a matter of fact, many of the Hemiptera are really predaceous upon other insects; but, as 
a rule, they will bear close watching. One thing is certain, however: no insect with this type of mouth structure can be reached by means of a stomach poison. Destruction through its food is,

Fig. 5 .

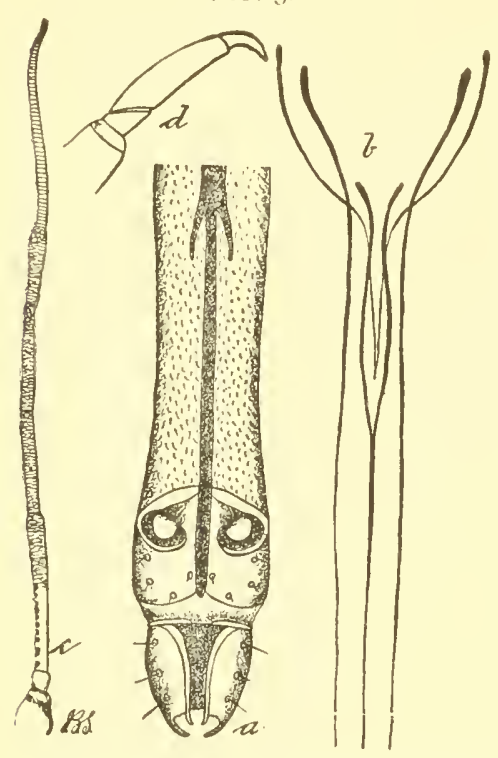
therefore, absolutely impossible, because we cannot poison the plant juices by any method thus far at our command. An insect of this kind is incapable of eating any solid food what. ever, and no matter how thoroughly covered with a corrosive poison the outside of our plants may be, it would get none, since it only punctures the tissue without absorbing any portion of the outer surface. Thus the determination of the type of mouth structure often limits or decides the character of the remedy to be used in destroying the insect.

Among the Diptcra, or flies, we have a number of interestMouth parts of a plant-louse. $-a$, the ing modifications of the suck-
jointed beak; $b$, the lancets, much enlarged; ing mouth. One series is fur$c$ and $d$ illustrate the feeler and foot.

nished with lancets similar to

those in the bugs, but more numerous, representing different mouth structures, and not always carried into the head itself. The sucking structure is also quite different, and never forms a rigid, jointed beak. Mosquitoes and horse-flies are examples of this kind; but gradually the lancets disappear, and in most of the flies only the sucking lip, often greatly and interestingly developed, remains. The common house-flies and blow-flies are types of this modified form, and are capable of taking liquid food only, though often seen attacking solids. If the mouth of a fly be examined under the microscope, there will be seen at the tip of the lip a series of deep grooves, stiffened with chitinous loops, and armed with sharp projecting edges. When the fly wishes to feed on a solid, it scrapes the surface by means of these rasp-like projec- 
tions, securing a small amount of fine shreds and scraps. These it moistens with a drop of saliva, which has great solvent properties, and then draws up the mixture by means of a sucking or pumping stomach. Liquids are taken in the sime waty, and the insects may be said to lap as well as suck their food. Flies as adults are not injurious to vegetation, whatever may be said of their larve; but some of those fitted for piercing, like the mosquitoes, horse-flies, and gnats, are often troublesome or injurious to stock, and occasionally render regions infested by them searcely habitable for man.

The bees seem to combine the features of at biting and sucking Fig. 6.

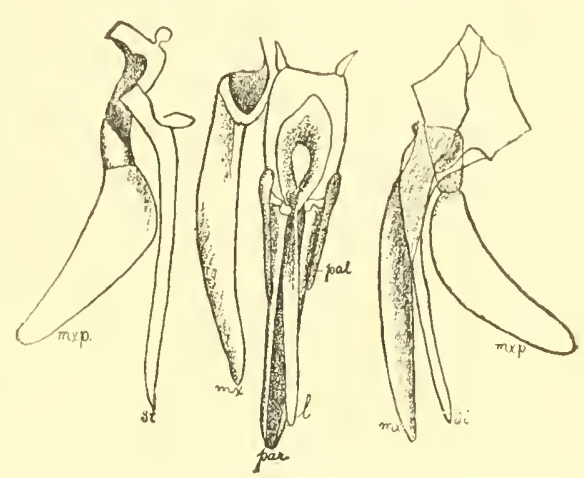

Piercing mouth structures of a "horse-fly": the sucking lip is omitled. Much enlarged. mouth; the mandibles being fully developed and the labium greatly elongated, that they maty gather the nectar upon which they feed and which they store, even from the deepest flowers. This modification will be more fully described in speaking of the bees themsclves.

All the types of mouth structures above described and figured are derived from one original form by gradual morlifications of the different pieces; but this can be traced only in a long series of preparations from many different f.milies and species.

Next to the mouth parts, the most important appendages of the head are the antenne or feelers. These are variable in form, and in certain orders their structure inclicates, unfailingly, the food habits of the insect. They are made up of a variable number of joints, differing greatly in their proportion to each other, in their shape, and in their functions. Ordinarily the antenna are intended as tactile organs,- that is, for touching, as the common name "feeler" indicates; but it is very certain that other sensory structures are also located there. The perception of odors, or the sense of smell, is a very important function, and 
more than likely there is also a sense of hearing connected with them. In some of the nocturnal moths they are broadly feathered or pectinated, much more prominently in the male than in the female. It is believed that the reason for this is that the insects are compelled to find their mates entirely by the sense of

FiG. 7 .

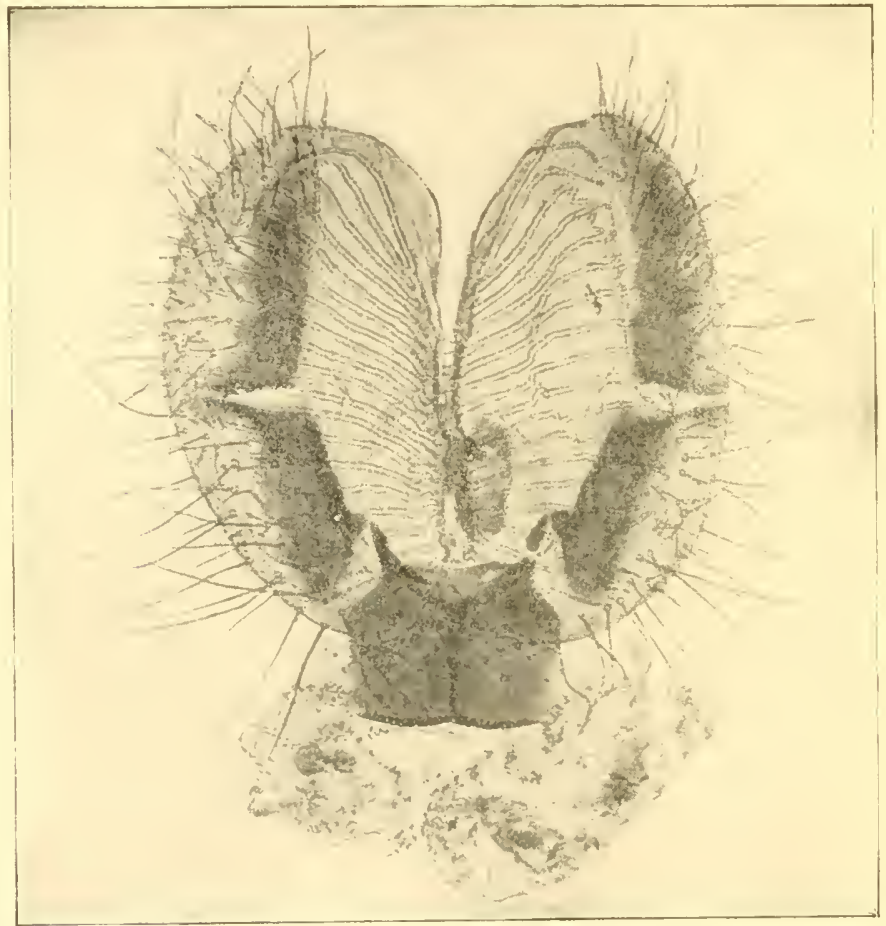

Tip of the mouth of a lapping fly, showing the pseudo-trachea on the inner face of the lips. Much enlarged.

smell. That it is not food they seek is proved by the fact that where these feelers are most developed the mouth parts are often entirely aborted and the insect takes no food at all. Certain "carrion beetles," also nocturnal in habit, are attracted for long distances to their food, and, even where purposely hidden, they find it without difficulty ; proving that the sense of smell alone is used. It may be convenient to consider here a few of the com- 
mon types of antemnal structure, which occur in all insects, that they may be referred to hereafter without especial description.

The antennæ are said to be filiform, or thread-like, when the joints are nearly even throughout, cylindrical, tolerably equal in length, and similar in general appearance. A serrate or sawtoothed antenna has the joints more or less triangular in shape and so fitted that one margin resembles the toothed eclge of a saw. Quite frequently antennæ of this type are distinctly flattened. From such a serrated form we pass gradually into the

FIG. 8,

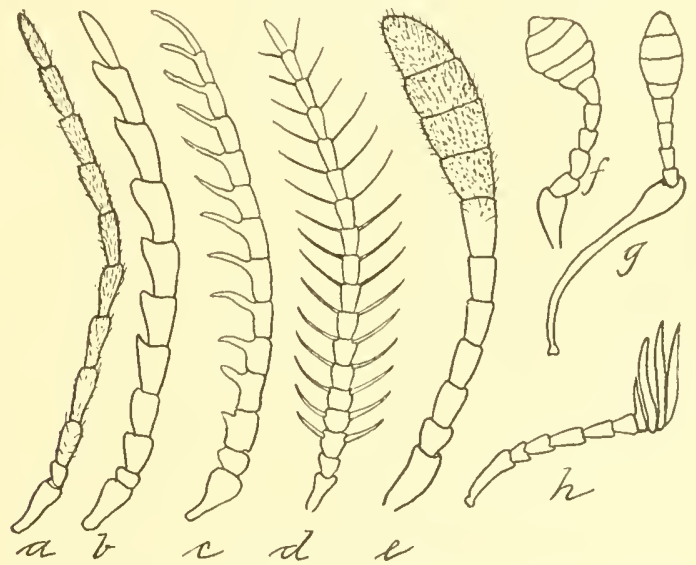

Antennal types. $-a$, filiform and pubescent ; $b$, serrate ; $c$, singly pectinate; $d$, bipectlnate; $e$, clavate; $f$, capitate; $g$, geniculate; $h$, lamellate.

pectinated or comb-toothed type, where the joints are furnished laterally with processes of variable length. When both sides of the joints have these processes the antenna is said to be bipectinated or feathered; when the processes become very slender, almost hair-like, and exceedingly numerous, it is said to be plumose. A feeler is clubbed, or clavate, when the joints toward or at the tip suddenly or gradually enlarge to form a more or less evident club or bulb, and this type is widely distributed in all the orders, a variety of terms being in use to indicate the particular form of the club. A lamellate feeler has at its tip a series of elongate, flattened or leaf-like joints, usually applied close together to form a solid mass that conceals and protects 
the delicate sensory structure on the inner surface. An antenna is moniliform, or bead-like, when the joints are more or less spherical and set together in such a way as to resemble a series of beads on a string.

As a rule, the antennæe are straight, without break from base to tip ; but occasionally they are geniculate, or elbowed; that is to

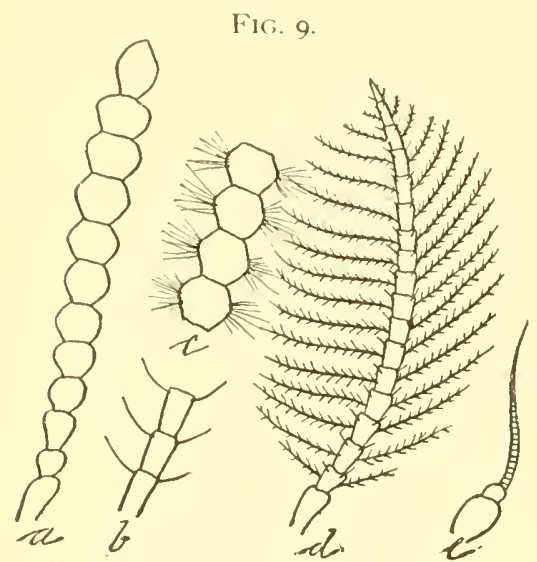

Antennal types: $a$, moniliform ; $b$, joint siliated say, there is one very long basal joint, the "scape," followed by a series of smaller

FIG. 10.

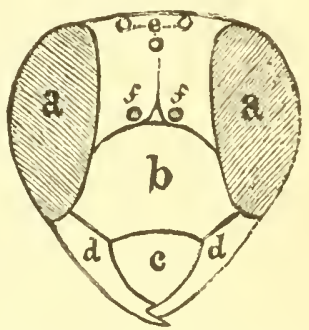

Head of wasp, to show regions: $a$, compound eyes; $b$, clypeus; $c$, labrum; $d$, mandibles; $e$, ocelli ; $f$, place where antennæe are inserted.

segments set in at right angles to it. Usually an elbowed antenna is also clubbed at the tip, and so we divide the structure into "a scape" at the base, the "club" at the tip, and the "funicle" embracing the intervening portion.

The feelers may be clothed with fine, soft, more or less dense hair, and are then pubescent; or furnished with lateral hairs of moderate length set in regularly, and are then ciliated or fringed; or they may have single or bunches of stiff bristly hair, and are then said to be bristled, or bristle tufted.

These are all the movable appendages of the head, and there remain only the organs of sight, which are perhaps better considered under the heading of sense organs. It is only necessary to say here that the compound eyes are often very prominently developed, and that they are usually set at the sides, often forming the greater portion of the head itself. The ocelli, on the other hand, are always very small structures; in the adults, never more than three in number, and quite variably arranged. 


\section{CHA P T ER III.}

\section{THORAX AND ABDOMEN.}

The thorax, or middle region of the body, is, as has been already stated, composed of three rings, termed in their order the pro-, meso-, and metathorax; meaning fore, middle, and hind thorax. These rings vary greatly in their proportion to each other: it is rare that they are equally well developed, and whenever this is the case it indicates a low type of insect, - that is to say, one very little specialized. Usually they are grown together to some extent, and this tendency continues until we find in the flies and bees the entire thoracic region apparently composed of one solid mass, - the rings being not at all movable upon each other. Insects of this type are highest in the scale and the most specialized. In other orders, notably the Coleoptera, or beetles, the prothorax only is free and well developed, the two other rings being united together and not movable one upon the other. This forms a sort of intermediate type, and the rank of insects is determined, to some extent, by the development of this region of the body.

If the thorax of a grasshopper, a beetle, or a wasp be rather closely examined, it will be found that it is made up of a large number of little pieces, divided by impressed lines, and sometimes these pieces are movable one upon the other. They are called sclerites, and a sclerite, whenever that term is used, always means a solid piece bounded by impressed lines, or sutures, as they are termed. Perliaps " seams" better represents the actual case than "lines," because they mark the places where pieces have been joined together, even if the joint be now a solid one. Though these pieces seem confused at first sight, yet there is a distinct plan in their arrangement, and, while it is not necessary to go much into detail, it is well to know at least the regions of the segments and the terms applied to them. In Fig. I I will be found an illustration of the under side of a beetle, in which all the sclerites of that part of the body are named. Those who wish a more accurate knowledge can compare a series of 
FIG. II.

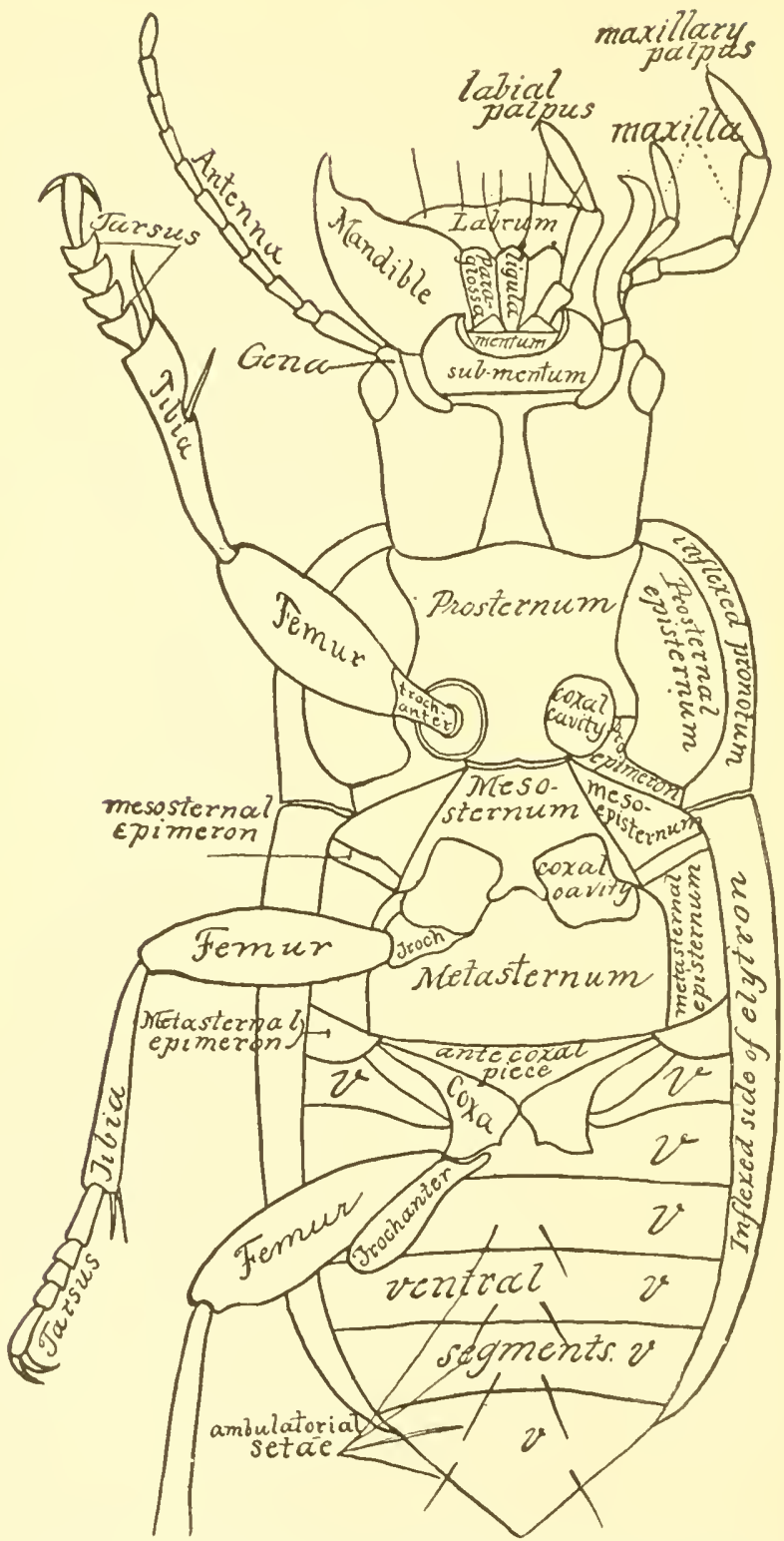

A beetle, Harpalus caliginosus, from the under side, with all the pieces named. 
insects with this figure, and by identifying the different pieces observe for themelves what modifications have taken place. The upper side is always called the dorsum, or dorsal surface, while the under side, between the legs, is the stermu, or breast. Laterally, between the sternum and the dorsum we find the pleurum, which is a region rarely referred to in general description. The "dorsum," " dorsal surface," and "sternum," on the other hand, are terms of frequent occurrence in the literature of economic entomology, and it is well to know exactly what is meant by them.

As has been previously said, all the organs of locomotion in the adult insect are attached to the thoracic segments; never more than three pairs of legs, one pair to each segment, and usually two pairs of wings, borne on the meso- and metathorax. The prothorax never bears wings, and, when only a single pair is present, as occurs normally in the flies, or Diptera, this is on the meso- or middle thoracic segment.

Of the wings, or organs of flight, all that need be said here is, that they are more or less membranous, flattened, and stiffened by "veins" or chitinous rods. They vary greatly in character, and must be especially described for each order, their general structure being all that it is necessary to give here. In their origin wings are merely collapsed sacs,--that is, each is a bladder-like outgrowth from the body wall, that assumes definite form, but remains filled with liquid until ready to assume its final shape. Then it is gradually distended to full size, the liquid is absorbed, and the walls of the bladder unite and become so closely welded together that it is impossible afterward to separate them. The wing seems like a single thin membrane, or horny shell, as the case may be, and the veins appear like hollow rods or cylinders, though originally they were mere thickened grooves on opposite sides of the distended bladder. The arrangement of the veins, or "venation," is of very great importance in classification, but needs no particular exposition here.

The legs, always six in number in the adult, are jointed, or made up of a definite number of parts or pieces. They are fixed into the thorax at the sides of the sternum, or between the breast and the sides, and are fitted into a body cavity by means of a ball-and-socket joint, giving a great range of motion. The ball 
portion belongs to the leg and is called a " coxa," and the socket is the "coxal cavity." Attached to the coxa is the "femur," or thigh, usually the stoutest part of the leg, and corresponding to the same portion of the leg in the higher animals, most of the muscular system being found in it. It is often strengthened at the base by a small supplementary piece called the "trochanter," which sometimes forms an intermediate segment between coxa and femur, and may be even two-jointed, as in the parasitic Hymenoptera. At the end of the femur is attached the "tibia," or shank, which varies greatly in structure according to the hathits of the insect, being modified for digging, tearing, swimming, clasping, or other special functions. It is armed in many ways, and becomes an index to the life history of the insect, furnishing, also, many good characters of use in classification. Economically, it is useful in that it is a guide from which we can often get an idea of the kind of existence that the insect leads, whether it is a digger, a swimmer, or a carnivorous type. The terminal part of the leg is the "tarsus," or foot, and this is also jointed, - five joints being usulal, though variations frequently occur. The last joint is armed with a pair of claws, and between them we may have "pulvilli," or small pad-like structures, by means of which flies and other insects cling to smooth surfaces and are able to walk back downward on ceilings. The differences in the leg structure are easily seen with a little experience, and in some orders, notably the Coleoptera, they serve to divide the insects into large groups or series.

The abdomen normally contains nine segments, but these are rarely all distinct. As a rule, one or more are modified to form sexual organs or appendages, or shields, or other accessory structures. It sometimes happens that the segments on the dorsal, or upper, and ventral, or under, side do not correspond, one part of the ring being lost or modified. In the adult the abdomen never bears organs of locomotion, and, as a rule, no appendages of any kind, except an ovipositor in the female of certain groups, or a pair of claspers in the male. In some of the lower orders it bears jointed filaments or appendages resembling feelers, and these are called "cerci." Only in the lowest of all types do we find traces of rudimentary legs on the abdominal segments, indicating a relationship between the insects and myriapods. 


\section{CHA PTER I V.}

MUSClES, DIGESTION, ANI CIRCULATION.

InSECTs have no internal skeleton or bony structure, the body wall serving for the attachment of muscles and to protect the inner organs.

Cutting transversely through the thorax of an insect at its middle, we find the greatest portion of the body cavity occupied by muscles, which are arranged in bundles attached to the entire inner surface of the body wall, proceeding to all the appendages, and thus providing the power that moves the animal. Centrally, the alimentary canal occupies a part of the body cavity, its size

F1G. I2.

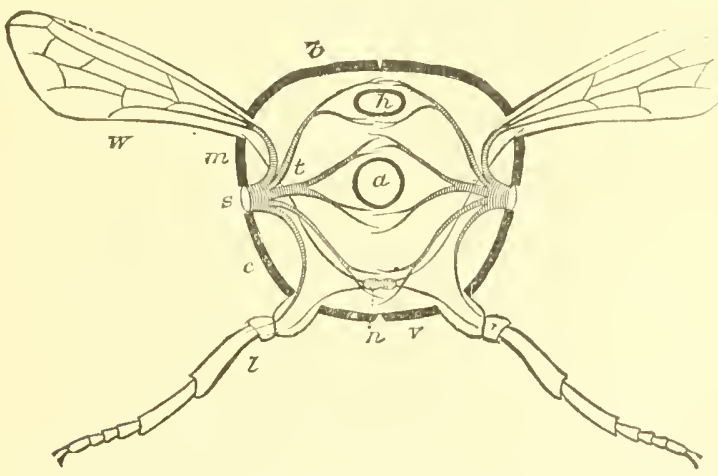

Ideal section through an insect.- $a$, alimentary canal; $h$, heart; $n$, nerve-cord; $s$, stigmata ; $t$, tracheal tubes; $l$, legs; $x^{\prime}$, wings.

depending considerably upon the kind of insect in hand. Just below the dorsal surface is a small tubular structure, at once the heart and only blood-vessel, while just above the ventral surface is a white, knotted cord,-the nervous system. Laterally, there is an opening on each side, from which a ringed tube leads into the body, dividing and subdividing almost immediately into innumerable branches, and this is the respiratory or breathing system. Frequently we find around the atimentary canal a considerable fatty mass, while everywhere through the insect body 
we meet with a whitish or slightly greenish liquid, much more abundant in the larva than in the adult; and this is the blood. These various systems are of economic importance, for upon our full understanding of some of them depends the success with which we can apply insecticides of a certain character.

Perhaps the least important in this view is the muscular system. It has been stated that the muscles are found in the form of bands, which extend from the body walls to the various appendages, and, of course, they are numerous and strong in proportion to the power required. Thus, for a leaping insect the muscles moving the legs are very much more developed than they are in an insect which simply walks or runs, and in a running insect they are better developed than in one that simply walks or moves slowly. Where powerful appendages must be moved, as for instance the mandibles or jaws, several bundles of muscles frequently converge to a chitinous point or tendon, which in turn is attached to the appendage, and thus a great amount of force is exerted at one point, the muscular attachments on the body wall covering a considerable surface and converging all their effectiveness upon one lever only. It is this arrangement that gives some insects the gnawing power to burrow in the hardest woods, and to cut through foreign substances, like lead, in order to escape from captivity.

Under the microscope it is found that the ultimate structure of insect muscle does not differ in essentials from that of the higher animals; that is to say, it is made up of narrow fibres divided into cells, and transversely striated. The voluntary muscles of insects are, therefore, practically like the voluntary muscles of the higher animals or of men.

The digestive system is of much more importance from the economic stand-point. On a previous page it has been shown that two general types of feeding habits exist, the chewing and the sucking, and the digestive system changes somewhat as the needs of the organism vary. The mandibulate type, in which the insect chews its food and subsists upon more or less solid material, will be first considered. Mlost insects in the larval stage, and sometimes also as adults, are voracious feeders, seeming determined to devour as much as they can possibly contain, in the shortest possible time; and the food is in such cases rather 
FIG. I3.

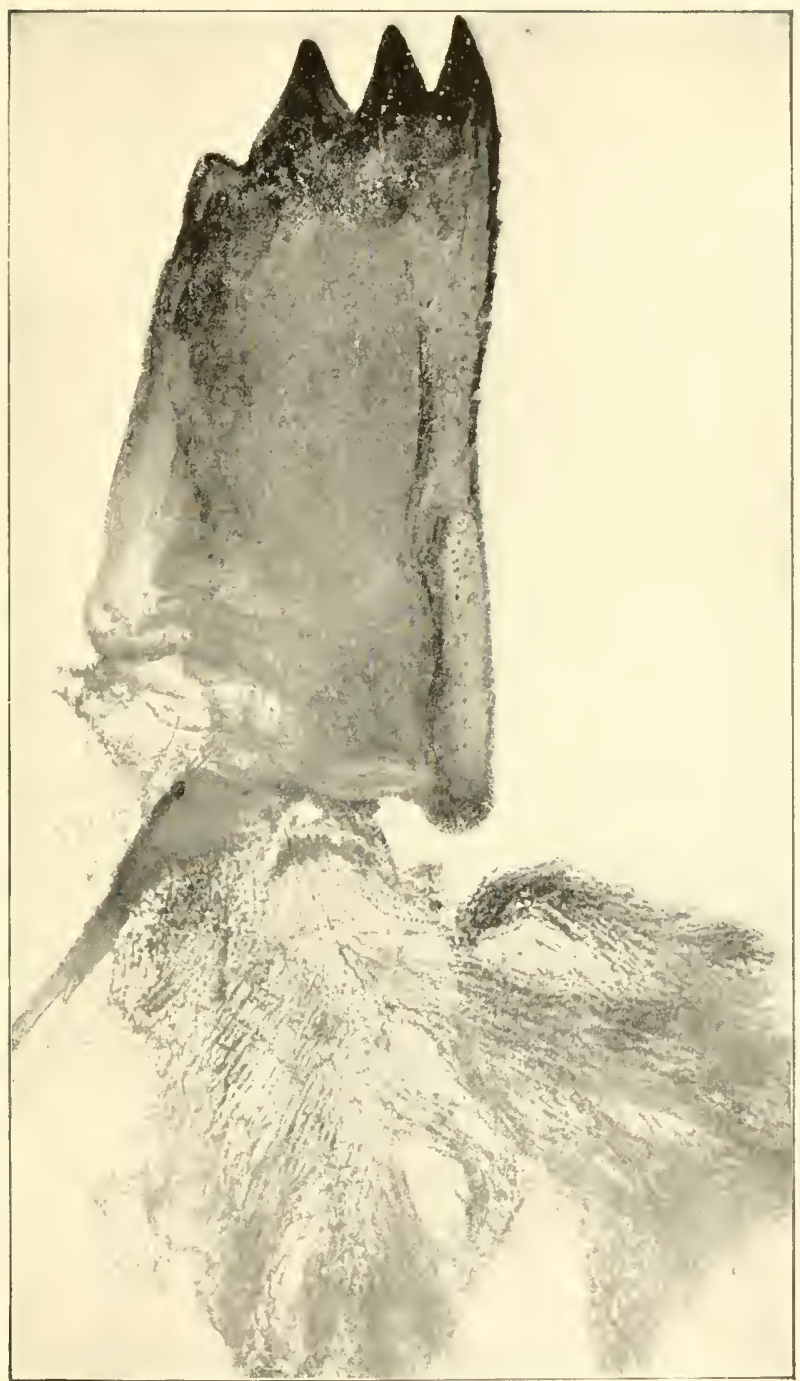

Mandible of a carpenter-bee, with bundles of muscular fibres attached, each bundle converging to a tendon, and the latter attached to a mandibular process. 

FIG. I4.

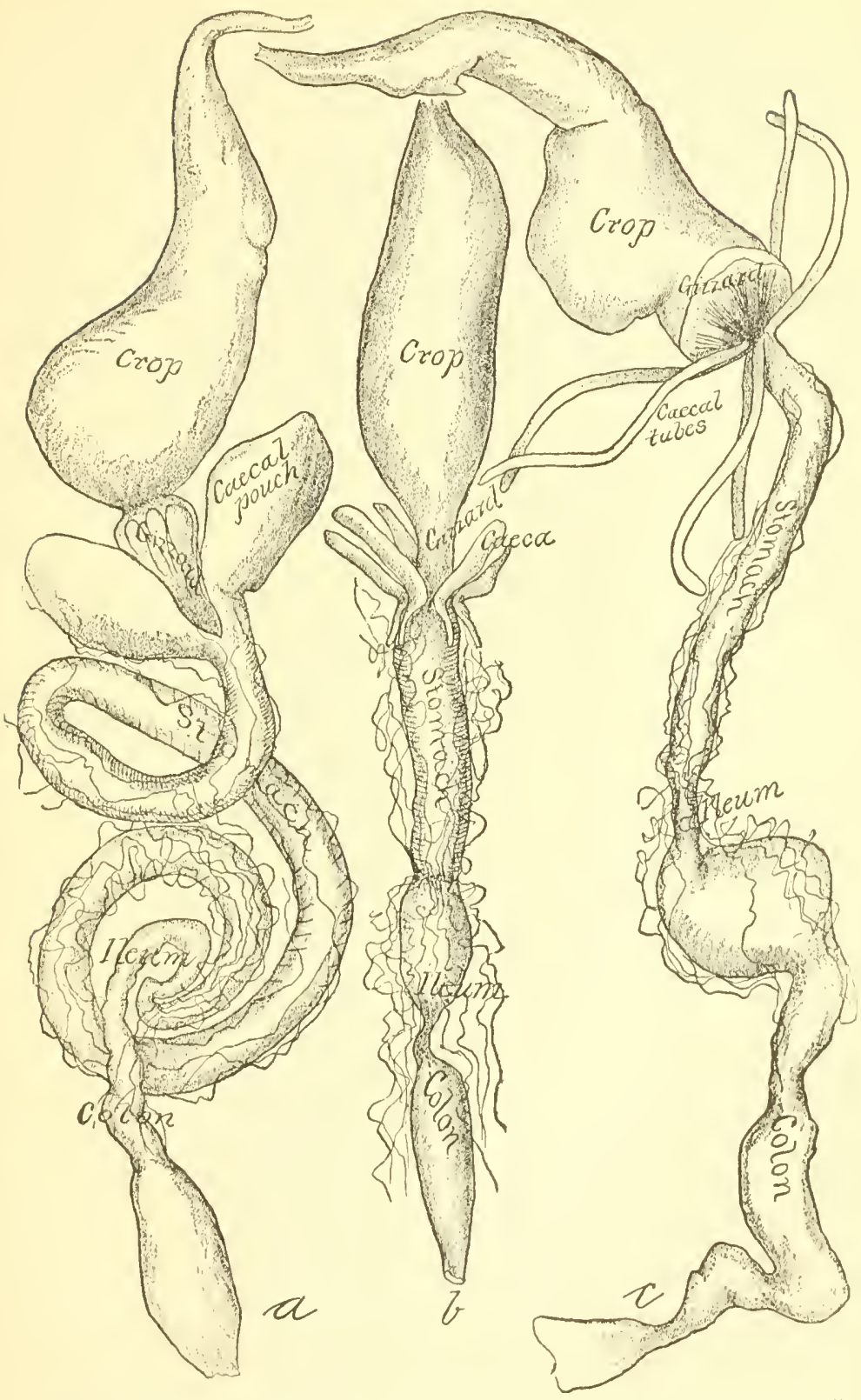

Digestive systems : of a katydid, at $a$; of a grasshopper, at $b$; and of a roach, at $c$. All the parts are named save the thread-like Malpighian tubules. 
coarsely ground up by the mouth parts, and forced through the gullet or asophagus into the crop. The osophagus is simply a slender tube, usually straight or only a little bent, at the mouth of which salivary glands open, and the food, mixed with saliva, passes through it into the crop. This crop is a more or less muscular, but always distensible sac, and usually the largest single organ in the body. It is used, primarily, as a place to store food when the insect has the opportunity of obtaining it, and is capable of containing a comparatively enormous amount of material. At its posterior end it opens into a gizzard, or grinding stomach, and this receives the food in small quantities, to be further reduced and put into better mechanical condition for assimilation. For this purpose it is armed with a complicated set of plates and teeth, not alike in any two species, while its muscular coatings are dense and powerful, giving great twisting and grinding force. Sometimes the gizzard is well developed and prominent; but often it is greatly reduced, appearing as little more than a slight specialization of the end of the crop. Its development depends very largely upon the character of the food and the feeding habits. Insects that eat indiscriminately all sorts of material, like roaches and crickets, have it best developed. From this gizzard the food, now in excellent mechanical condition, passes into the true stomach, or chylific ventricle, receiving at its mouth the secretions of the cacal tubes or pouches. This secretion is digestive in character, like a similar liquid in higher animals, and assimilation begins in this part of the system. The stomach varies greatly in length in the different kinds of insects, and as much in relative size and the strength of its muscular coating. At its posterior end we find the long and slender Malpighian tubules, which often envelop the whole system in a veritable net-work of fine, thread-like masses. These structures are supposed to represent kidneys and to have a similar excretory function. They open at the junction of the stomach with the ileum, or small intestine, and in this the assimilation or absorption of food products is completed, the remnant being forced into the large intestine, or colon, where it is prepared for excretion through the rectum. A pair of glands near the end of the rectum secretes a mucus, probably intended as a lubricant only.

The salivary glands vary in number, and one or more may be 
modified for special purposes; as in some of the piercing insects like bugs or the mosquitoes, where an irritant poison is secreted, or in certain beetles, where the saliva has both a staining and a burning effect upon the skin, or in many larva, where the secretion forms a silk when hardened by exposure to the air. The anal glands may be similarly modified, but much more rarely than those at the anterior end of the body. In the "Bombardier beetle" their secretion volatilizes suddenly when expelled into the air, and forms a blue smoke, like the discharge from a small cannon. In Hymenoptera, including bees and wasps, the secretion is poisonous, and accessory to the functions of the sting. More rarely a silk is produced from these glands. Taken altogether, the digestive system varies greatly in length, being sometimes a straight tube only, the various portions very incompletely divided off. In other cases it is quite complex, coiled upon itself, the parts well defined, and the system as a whole two or three times the length of the entire insect, different kinds of structure being found in the various parts. The figures given herewith illustrate some of these differences.

In the sucking or haustellate type the essential structure of the alimentary canal and the differentiation of the parts are much

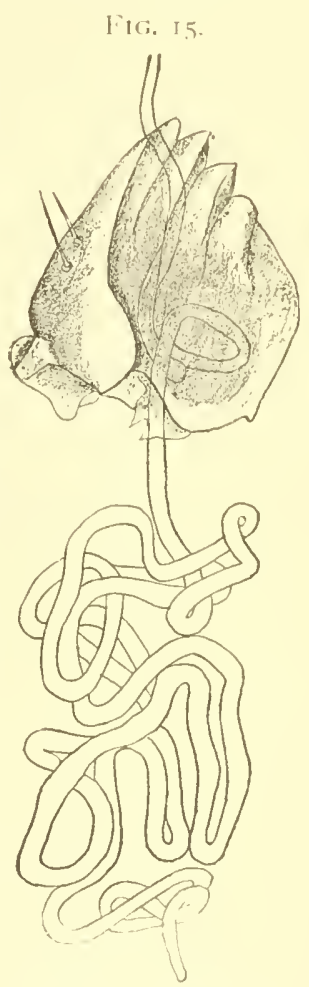

Salivary gland of the caterpillar of Melitia ceto. modified for silk spinning: mandible of the same. alove.

the same. There is, however, a great reduction in the size of the gizzard, which is very often entirely wanting. If present, the armature is reduced to a mere ridging, or a slight, irregular thickening of the walls of the posterior end of the crop. In the Lepidoptera there is often a peculiar accessory pouch, which seems to serve the purpose of a storage reservoir, or secondary crop, and this is attached by a narrow neck to the opening of the true crop. In the bees the crop is unusually elastic. and capable 
of enormous distention compared with the size of the insect, and this is to accommodate the honey collected by the insects to be carried into the hive.

In the use of poisons acting through the stomach, the arsenic, which is usually employed, is taken in with the food and generally carried into the chylific ventricle before it becomes effective. In the crop the food is generally too dry to cause the necessary solution of the caustic properties of the arsenic, which is necessarily applied in its least soluble form; but by the time it has passed through the gizzard and has reached the stomach, becoming moistened and mixed with the secretions that have been already mentioned, it becomes active. Some insects are able to take a very large quantity of poisonous material without injury ; succumbing only after two or three days to the effects of a poisonous meal. It is probable that in such cases the digestive liquids exercise a less solvent effect upon the toxic mixture.

Ordinarily, digestion in insects is exceedingly rapid. Among caterpillars, for instance, feeding is often almost continuous, and twenty-four hours are sufficient to pass through the entire digestive system food two or three times the weight of the larvæ themselves.

FiG. 16.

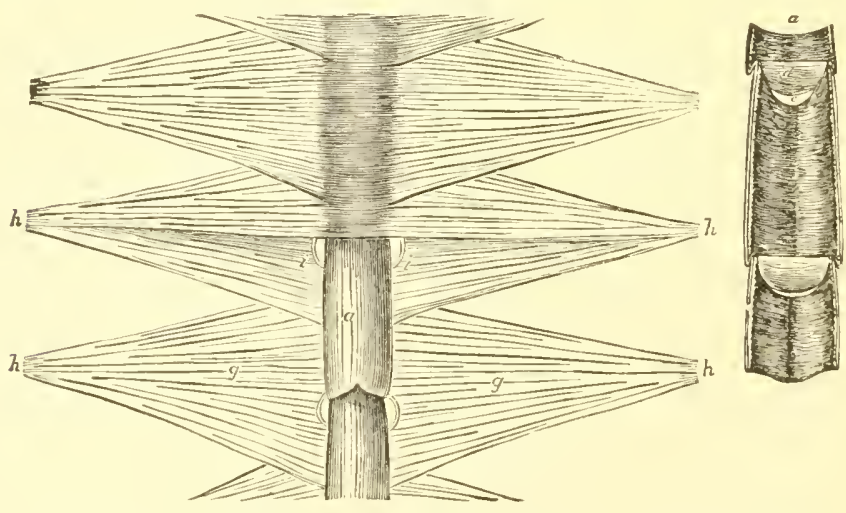

Heart of a stag-beetle, showing the wings and chambers: at the side, the interior of a clamber, to show the valves.

Insects have no system of arteries and veins, and only one real blood-vessel, which serves also as the heart. This, as has been 
indicated, lies just under the back, and in a cavity formed by a series of peculiar triangular muscles known as the "wings of the heart ;" and these serve to prevent undue pressure upon it. The organ is simply a long tube, open at both ends, and divided into a variable number of chambers, into which the blood is admitted at the sides, at intervals along its length. The heartbeat consists of a wave of contraction beginning at the posterior end, forcing the blood forward and out into the head. Sometimes one wave is completed before another one starts, and sometimes two or even three waves may be on the road at one time. Sometimes the beat is exceedingly sluggish, and sometimes, in active insects, it is very rapid. After the blood has been forced out of the heart it first bathes the head parts, and then makes its way between the muscles and other organs through the body carity and into the appendages. Part of it bathes the alimentary canal, where it receives the products of digestion, and these are carried everywhere and assimilated by the various tissues, the blood eventually finding its way back to the heart, to begin its journey anew. The fact that there is no closed system of blood circulation is peculiar, and in this insects differ from all the higher animals. It necessitates a very decided modification of the respiratory or breathing system, and this forms the subject of the next chapter.

\section{CHAPTER V.}

\section{THE RESPIRATORY SYSTEM.}

THE respiratory or breathing system of insects is adapted to the system of blood circulation. It is important from the economic, as well as interesting from the scientific, stand-point, for upon this rests the basis for the application of contact inse ticides.

Insects have no lungs, and nothing which at all corre:, onds to them. They have no means of taking in air at tho head or through the mouth; but breathe from the sides, where there is a series of breathing-pores, or spiracles, through which the air is taken into the body cavity. Typically, one pair of spiracles 
occurs on each body segment; but ats a matter of fact some of the segments, especially in the adult, lose them, the insect depencling upon a more limited number as the main trunks become enlarged. The insect blood requires oxygen, ats in the higher animals, and, as there are no lungs to which the blood can be carried, it is necessary that the air itself should be taken to all parts of the body, and this is accomplished by means of tubes called trachea. Trachea occur in insects, in spiders, and in myriapods, all of which are, therefore, called "Tracheates." Spiders have eight legs instead of six as in the true insects, and have the head and thorax combined in one piece or cephalothorax. They have also a ciecided tendency to the formation of lung-sacs. The "myriapods" or "centipedes" are more wormlike in structure, and are furnished with many legs, - one or two pairs on each body segment,- -sometimes exceeding one hundred in number.

One tracheal trunk or tube starts from each spiracle, and begins at once to divide and subdivide, sending its ramifications to all parts of the body, eren to the tips of all appendages, so that air permeates every part of the insect, and tracheal tissue is present everywhere. The structure of these tubes is interesting : they consist of a membranous cylinder, stiffened by chitinous rings or spirals, in appearance very much like the closely-coiled springs in automatic shade-rollers. This gives rigidity to the tubes, keeping them always open, while at the same time it allows the utmost freedom of motion. A serie; of longitudinal tubes on each side of the bocly unite the main trunks from each spiracle, and in some cases there are transierse tubes joining the longitudinal trachex. The entire system is thus connected in one or two ways, and at a pinch an insect is able to get its air supply from one spiracle only and from almost any part of its body.

Where so many openings into the insect body exist there must, necessarily, be some arrangement for protecting them and preventing the entrance of foreign material. There is, therefore, a great variety of sifting structures, their character depending largely upon the habits of the insects. There may be a series of teeth or spurs on each side of a narrow, irregular slit ; a series of hairs or bristles crossing in front of the opening; a covering 
FIsi. I7.

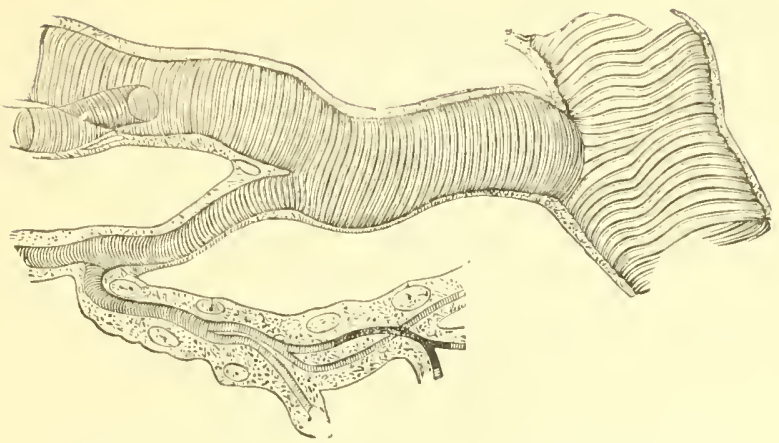

Tracheal tube, showing the structure and methods of branching.

FIG. 18.

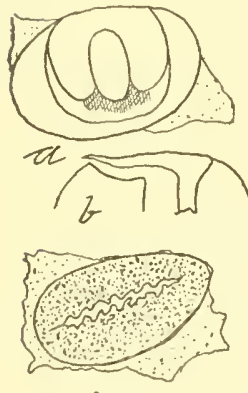

$c$
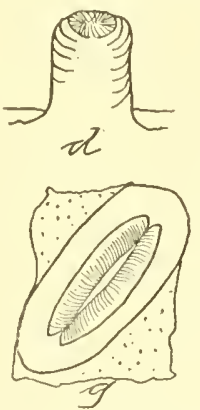
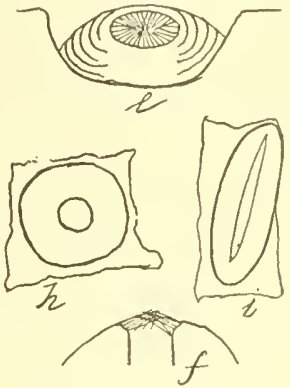

Spiracles and their protection.- $a$, plate-like covering of white grubs, cross-sec tioned at $b$, to show how air enters; $c$, a toothed slit; $d$, spiracle set on a teat-like process; $e$, conical spiracle set in a pit, protected by crossed hairs as shown at $f$ in section ; $g$, lip-like spiracle; $h$ and $i$, unprotected round or slit-like openings.

FIG. I9.

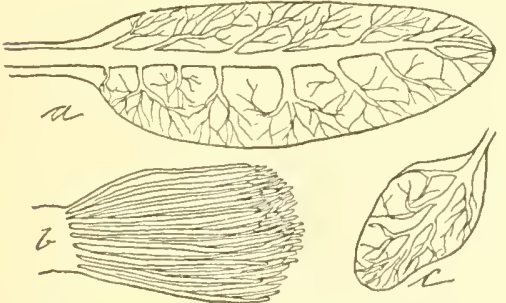

Tracheal gills.- $a$, leaf-like anal plate os Igrion. $b$, thread-like tuft of Corydalus; $c$. late-like gill of Ephemera.
FIG. 20.

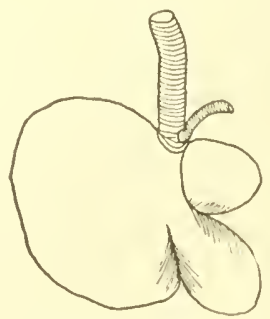

Air-bladder at end of tracheal tube in Bombus. 
shield, beneath which the air must enter, or some other variety" of screen,-ill intended to sift out of the air the foreign particles which might injure the insect. Yet it is through these spiracles that most of the contact insecticides must act, as will be more fully detailed hereafter. In many heavy insects there are attached to the trachee numerous air-sacs or bladders, the object of which is to reduce the specific gravity of the insect to enable it to fly more readily. A common example is the well-known "May-beetle" or "June-bug," which has the entire body cavity filled with such little bladders. If one of these beetles be watched when it emerges from its hiding-place carly in the evening, it will be noted that it first crawls to the top of some blade of grass or twig, or even upon a stone, and rests there a few minutes. If it be closely observed it will be seen to be pumping in air,that is to say, the body pulsates rapidly, and the abdomen seems continually to increase in size. This is because the insect is filling the air-bladders, and, as soon as this has been accomplished, it tries its wings, causing the preliminary "whirr" which is so familiar to the observer in the early evening of a June day. After two or three trials the insect becomes confident of its ability to sustain itself, and flies off heavily, with a steady hum. If such a beetle be found at mid-day and thrown into the air it will fall heavily, and will be absolutely unable to sustain itself in flight until it has had an opportunity to inflate its air-sacs.

While the vast majority of all insects are air-dwellers, yet many live underground, a very large number in water, and a considerable percentage in decaying or excrementitious matter, where pure air is very difficult or impossible to obtain. All sorts of devices to enable them to breathe under such conditions have been developed, and in all cases without any essential modification of the system. Underground dwellers usually find air sufficient for their needs in the earth in which they live, and the development here is principally in the direction of more perfect coverings for the spiracles to prevent the entrance of dirt.

Among insects living in or under water, or spending a portion oi their life there, we note a great variety of modifications. Miany beetles, and some insects of other orders, have the wingcovers dome-shaped, and so closely fitted that they are able to carry a little supply of air between them and the abdomen. 
When this supply is exhausted of oxygen, the insect rises to the surface, allows the drop of tainted air to escape, and at the sane time takes in another bubble of pure air. It is then supplied for another period, varying in length in the different species. Certain other forms have the body covered with very fine hair, so dense that the water cannot penetrate it, and these carry a thin film of air that surrounds them entirely while they are in the water; they really do not get wet at all. This air supply must usually be renewed from time to time; but occasionally oxygen is absorbed from the water itself, and the filmy covering is thus kept constantly purified. Yet other insects have their surface so absolutely smooth and polished that the water cannot touch it, and here also a slight film of air may be carried about. There are other devices to the same end, which it is needless to specialize, and we pass to those insects that never come to the surface at all, and yet secure a sufficient supply of oxygen. These creatures are mostly larwæ, and in them we note the development of structures resembling the gills of fishes in function. That is, in certain leaf-like or thread-like appendages there are a great number of very fine tracheal tubes with very thin walls. Through them the insect absorbs the oxygen contained in the water itself, and we have exactly the same process that we find in the fishes, except that here air instead of blood is brought into contact with the oxygen in the water. These gill-like appendages vary greatly in number and shape, but do not differ in furction, and will be further described when necessary in connection with the insects themselves.

Yet another iype of structure is found where the absolute connection with the air really never ceases, - that is to say, the insects have a rigid or an extensile tube attached to the anal end of the body, and this they keep pointing above the surface while they walk about on the bottom of the ponds. Insects so provided are inhabitants of shallow water, and the tubes rarely exceed an inch or an inch and a half in length. The common "rat-tailed larvæ," often found in the filthiest of all excrementitious material, are good examples of this method of breathing. They may be entirely imbedded in the pasty mass; but the tip of the "tail" is kept above the surface to enable them to secure fresh air. Finally, we have those cases where insects live 
in the water, yet get all their air from above it without any power of storing. This is the case with creatures like the mosquito larræ, which are unable to breathe without coming to the surface. They have only a single spiracle at the tip of the body, and are compelled to rise to the surface at intervals to breathe, and, having done so, are able to sustain life beneath it for only a short time afterward.

This much for the general characteristics of the respiratory system; it remains to show how it is important from the economic stand-point. It has been previously said that the insect crust is of chitine, which is impervious to a great variety of ordinarily penetrating substances. It resists alcohol, chloroform, ether, the light mineral oils, benzine, turpentine, kerosene, and other similar substances; acetic acid penetrates slowly and so does carbolic acid. This accounts for the difficulty which we find in clestroying many insect eggs, for there are no openings in them that are sufficient for the penetration of these substances, and they are unable to act through the egg-wall itself. To get it liquid insecticide to kill an insect by contact, it must be forced into the body through the spiracles, or they must be so gummed or clogged as to close them completely, thus preventing the insect from breathing at all. Kerosene is the most reliable of the penetrating liquids, and even where the spiracles are well protected this material penetrates into the smallest openings. It has the advantage of actually wetting everything; that is to say, it is not repelled by small hairs, as globules of water would be, and therefore, as it really comes into direct contact with them, is enabled to work its way through the spiracles. That is what makes the kerosene so much better than any watery mixtures alone; for whatever the material extracted by or dissolved in water, it may perhaps be repelled by the insect body, and never have the opportunity of exercising an effect. The various soaps act in another way; as the moisture evaporates, a film of sticky or gummy material remains which clogs the spiracles, and thus chokes the insect by depriving it of air. Soapy mixtures also wet and stick well to insects through the caustics they contain, and which have the power of cutting the repellent material of their bodies.

In some kinds of insects the spiracles are so feebly protected 
that dry insecticides penetrate them reaclily, if finely ground: and all such are effective in proportion to their fine mechanical condition, enabling them to enter the trachex through the sieve of the spiracles. Thus, sawfly larva or "shugs," like the "eurrant-worm" and "pear-slug," succumb readily to dry hellebore, pyrethrum, or even fine road dust. Many parasites may be reached in this wiy, and some animals and all fowls keep themselves tolerably free from vermin by frequent dustings. This is not the place to go into the effectiveness of insecticides; but it may be repeated that contact poisons usually act through the spiracles only. Dry powders are effective in proportion to their fineness and to their peculiar poisonous properties; liquids are effective in proportion to the thoroughness with which they are applied, and to their penetrating or elogging characters.

Caustics and chlorides act differently, and may actually corrode a thin insect erust. But this matter also comes more appropriately under another heading, and will not be further discussed here.

\section{CHA PTER VI.}

\section{NERYOUS SYSTEM AND SENSES OF INSECTS.}

THE nervous system in insects consists of a series of white disks or ganglia lying on the bottom of the body cavity, eonnected by a double cord extending the full length of the insect. Insects have no true brain; as do the higher animals, and the ganglion situated in the head, which is usually called "brain," is larger than the others simply because of the great number of special organs-eyes, antennx, and mouth parts-that must he innervated from it. In its structure it is precisely like the other ganglia, though in some of the social types there is an appearance of specialization. Nerve-fibres start from all ganglia in every direction, and all parts of the bocly are reached; the nervous system in one direction being exeeelingly well developed. In the larval forms and in the lower types, a ganglion is present in every segment of the boly, including the head; and thus each segment contains its own nerve-centre, the cords from 
which are primarily sent out to the organs and appendages lying within that particular segment. In adults there is a tendency to a union of the thoracic ganglia, and in the abdomen two are usually confluent toward the anal end of the body. The digestive

FIG. 21 .
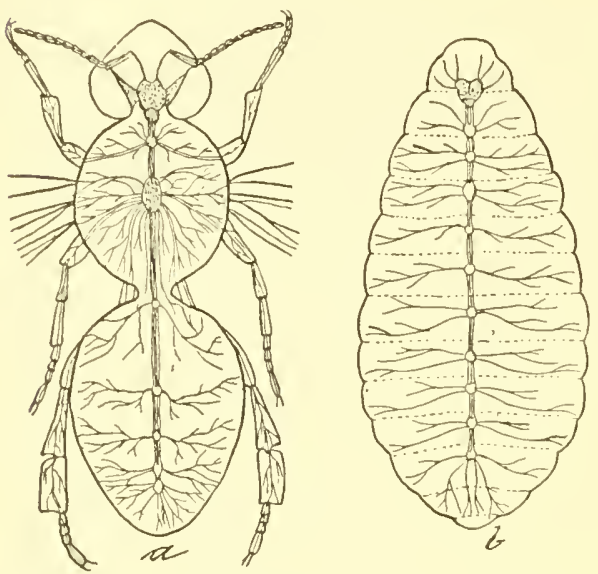

Nervous system of the honey bee at $a$, and of its larva at $b$. system is usually innervated by a special ganglion, and has its own, partly distinct system. In the higher insects the thoracic ganglion is the most important in the body for the life of the insect, and if this be cut or destroyed the insect dies at once. Any other ganglion may be cut without producing immediate death, and the brain, using that term for the ganglion con-

tained in the head, may be entirely removed without necessarily killing the insect itself.

While, as stated, the nervous system is well developed and all the organs are well furnished with nerve endings, yet it is probable that insects are not particularly sensitive. The oft-cited case of the butterfly that was captured and pinned while alive, then escaped from the collector, and returned at once to its feeding among the flowers without apparent inconvenience, is known to most readers. If a dragon-fly be captured and held by the wings loosely, so as to prevent its escape but not to injure it, and the tip of its abdomen is then presented to its mouth, it proceeds at once to eat it as far as it can reach, without any apparent knowledge of what it is doing. It will thus devour, with the greatest portion of the abdomen, half its digestive system, nearly half its entire nervous system, and a large part of its heart; yet, if it be then released, it will fly off, little 
the worse, except that it is unable to balance itself. Insects may lose a considerable number of their members without apparent inconvenience: a fly may lose a leg or two without seeming in the least worried, or one or both of its wings may be torn off without causing death or even a manifestation of pain.

I once made a series of experiments to test, not so much the sensibility of flies, as the effect that cutting the various organs would exercise upon it. I found that if I cut off the abdomen completely, the fly would live for twenty-four hours thereafter; with practically no digestive system, with very little nervous system, and with most of its heart gone. Turning the matter, I cut off the head, and found that it would live without a head for just about as long a time as it would without an abdomen. Of course death was bound to result from this mutilation in time, but the interesting feature is that no apparent symptom of pain was developed. I found, however, that just as soon as I cut the large ganglion in the middle of the thorax I terminated life. Whatever sentimental feeling there may be in the matter of causing unnecessary pain, there is no reason to believe that insects have any well-developed sensitiveness, as we understand that term. The character of the insect nervous system is so entirely different from our own that we are left without real guides in our interpretation of the various sensory structures. Man judges most things by himself, and where this guide fails he is at a loss, and cannot be certain that he interprets what he sees correctly.

The eyes are perhaps the most prominent and best understood of the organs of special sense. They are of two kinds, simple and compound, and both may be present in the same species. The simple eyes are termed ocelli, and consist of a more or less convex, often bead-like lens or facet, by means of which an image is thrown on a retina, and thus transferred to the perceptive centres. In larve simple eyes, or ocelli, are the rule, except in types with incomplete metamorphosis, where the eyes resemble those of the adults. In larvæ the simple eyes may be situated at almost any point on the head; but usually they are grouped at the sides: sometimes only a single ocellus at each side, sometimes a group of a dozen or more, forming the rudiments of a compound eye. In adults there are rarely more than three ocelli, usually situated in a triangle either close together or widely sep- 
arated; or there may be only two, one on each side, near the bate of the antenua, as is usual in butterflies and moths.

liki. 22 .
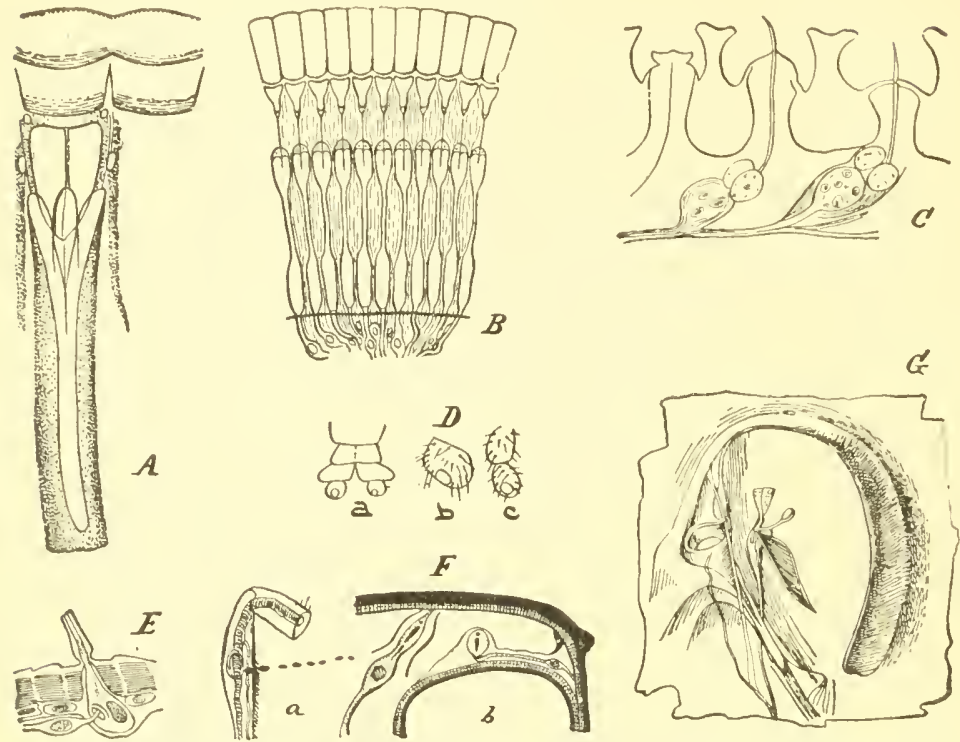

Sensory organs of insects.- $l$, one element in eye wi a roach; $h$, section of compound eye : $C$, organs of smell in May-beetles; $D$. sense org:ns in abdominal appendages; $F$, sensory ear; $F$, ear on foreleg of locust; $(;$, ear found un the hasal segment of grasshopper abdomen. All greally enlarged.

Compound eyes are so termed because they are made up of a great number of simple eyes, or ucelli, set very close together. If the head of a bee or house-fly is examined, it will be noted that the brown eyes occupy a very large portion of its surface, and if one of those eyes be viewed under the nicroscope it will be found to be faceted, or to consist of thousands of little hexagonal disks, resembling in appearance the top of a honeycomb. Each one of these facets represents a complete eye, capable of forming an image upon its own little retina, and the combination of all the little retinal pictures is what a fly or other insect sees. In some cases the eyes are so enormous that the msect can sec everything going on in front, at each side, above and beneath, and even back, except directly behind it. It is difficult for us, who are able to see in one direction only, to 
imagine the sort of picture an insect pereeives, and we are by no means certain how well or how poorly it really does sece. We know only that larval forms and low types, provided with ocelli only, see very feebly and indefinitely, and can do little more than discriminate between light and darkness. Many insects have no eyes at all, living under such circumstances as to make them useless.

That insects hear follows almost inevitably from the fact that many of them "sing," - that is, produce some sort of noise. What those organs of hearing are is not so certain in all cases, nor where they are situated, since we camnot confine our search for ears to the head alone. In the Orthoptera they have been locited with a reasomable clegree of certainty : in the grasshopper the ears are on each side of the basal segment of the abdomen, while in the locusts and crickets they are on the anterior tibize. Essentially, these ears consist of a tense membrane stretched over a cavity, and connected by means of little processes, corresponding somewhat to the bones of the human ear, with a bulb-like vesicle and a large auditory nerve. In most other orciers no similar structures are found, and the sense of hearing is located in the antennie, or feelers, of which more will be said later on.

Insects are able to discriminate as between foods, and the sense of taste is undoubtedly developed to some extent ; but the taste which seems agreeable to their sense would be to us, in many instinces, the vilest conceivable. No true tongue, as this organ exists in the vertebrates, is found among insects ; but on the upper side of the lower lip there is often a finely papillate surface, set with little fleshy pegs and processes communicating with nerve fibres, and this represents the nearest approach to the tongue of the higher animals. It is called the hypophoryx, and is not always present. Beneath the labrum, or upper lip, we often find a separate, flat, similar piece, and this is the epipharynx, corresponding in function to the palate of the higlier animals.

Nothing resembling a nose is found among insects, and yet the sense of smell seems very highly developed. Insects often discover their food with uncring certainty, even when concealed from sight. Among the nocturnal species, where sight can play but a small part at hest, the sense of suell seems most highly developed, and usually more in the male than in the female This is due to the fact that the males, as a rule, seek their mates, 
and so keen is this sense that they discover the presence of the female, even when confined in a breeding-cage, if a window be left open. Sometimes male wood-borers will sit around a spot on the bark for a considerable time awiting the emcrgence of a female, which their keen sense tells them is fully developed and ready to make her way out. Carrion feeders discover their food when concealed from sight, and almost before decay has set in. So far as we have been able to ascertain, the olfactory organs are situated in the antennæ, and form small pits or depressions, from which usually arise specialized hairs, bristles, or pegs, as the case may be.
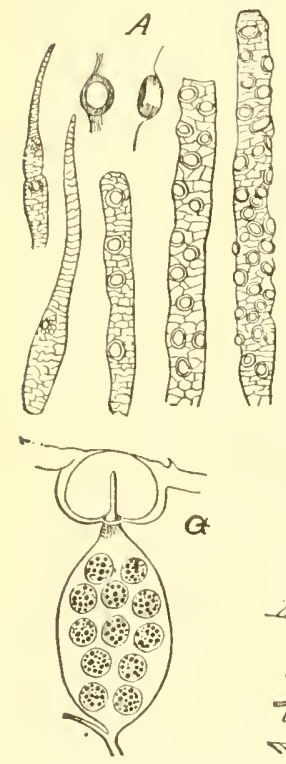

FIG. 23.
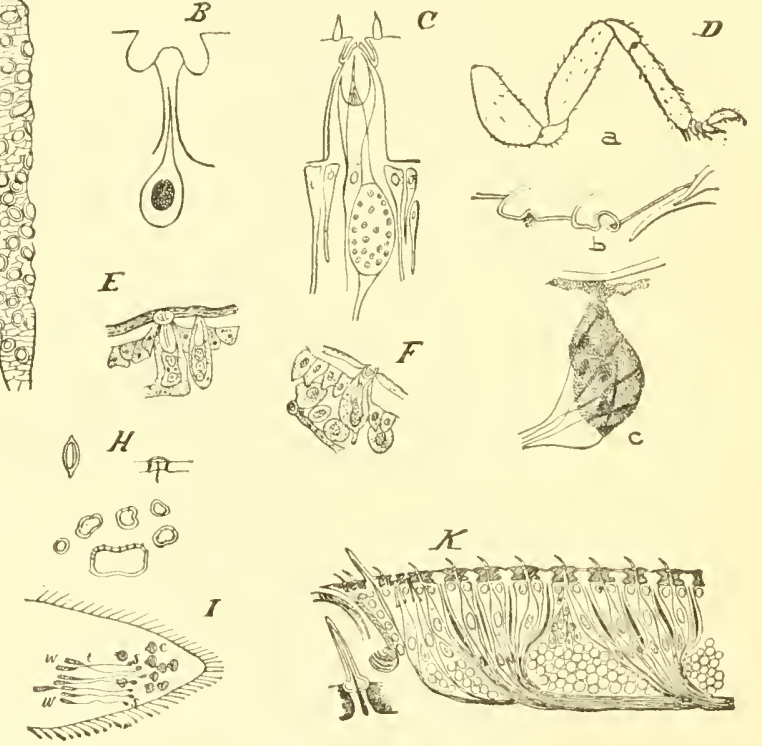

Sensory organs of insects.- $A$, sensory pittings in plant-lonse antenna ; $B$, organ of smell in May-beetle: $C$, same in wasp: $D$, sensory organs in Temes flaripes; $E, F$, organs of taste in a wasp; $G$, organ of smell in grasshopper; $H$, sensory depressions on the tihia of Termes: $I$, terminal joint of antenna of an ant; $K$, section through the antenna of a honey-bee, showing supposed olfactory organs. All greatly enlarged.

The sense of touch is located popularly, and I think correctly, in the antenne ; but it is quite certain that tactile hairs exist all over the body of the insect, more leveloped in some than in others, and most, perhaps, in larval forms. These structures always consist of specialized hairs or bristles, and end in a nerve cell. 
It is probable that in the antennæ we have a sense of perception which is able to discriminate between atmospheric vibrations, and in this way the same or similar structures may serve as organs of hearing, smell, and touch. That is to say, it is probable that there is no such sense in insects as the power to discriminate between smells, but that each is able to recognize certain definite kinds of odors which do produce an effect upon it. So it is also likely that only sounds of certain descriptions are recognized, and these sounds may even be such as the human ear is not capable of perceiving. We are far from understanding the senses of insects, but the above outline is all that is necessary for our present purpose.

\section{CHAPTER VII.}

THE REPRODUCTIVE SYSTEM.

THE rate of increase among insects is often very great. It is nothing unusual to hear a farmer say that on one day his plants were frce from insects, or nearly so, while a week thereafter everything seemed to be swarming. As a matter of fact, this is frequently diue to a failure to observe the insects in the first place, either in the stage in which they then existed or on account of their small numbers; but it remains true, nevertheless, that insects are often exceedingly prolific. The number of eggs laid by a female often runs up to one thousand, or even more, while the number of eggs within the power of a Termite queen is beyond all calculation. If it were not for their natural checks, insects would soon overrm the world. In one year not one green thing would be left on the face of the earth, and not one living being other than insects would exist. These natural checks consist largely in sudden changes or abnormally high or low temperature, in unusual moisture or drought, or in a combination of two or more of these factors. Diseases often attack insects, and genuine epidemics occur, sweeping off millions in one stage or the other. The natural enemies are legion ; many vertebrates are largely dependent for their food upon insects, and this is especially true of birds and reptiles, some of which subsist upon insects exclusively. A large proportion of the insects themselves 
are predaceous, and live upon others of their kind; great numbers are parasites, their prey being other insects of all orders, and in this way forms that depend upon plant life for their subsistence are kept within definite bounds. These bounds, though they may vary from year to year, never change much except where man interferes. This subject will be touched upon in another place more fully.

Except in rare instances insects are of two sexes, male and female, and we nowhere find among them true hermaphrodites. In the plant-lice and gall-wasps we have apparent exceptions; but these are only apparent.

In the female the most prominent sexual organs are the ovaries. These consist of two sets of tubes, one in each side of the abdomen, usually below the digestive system, united

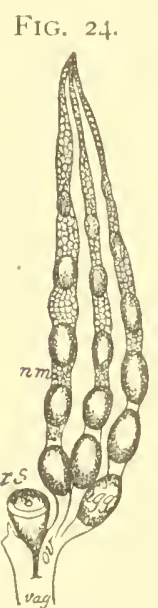

Ovarian tubes of one side, in Polistes, showing eggs in all stages of development, with nutritive cells, $n m$, between; $r s$, seminal receptacle: ov, oviduct ; vag, vagina. at their base into one larger tube called the oviduct; the two oviducts unite, just before opening outwardly, into a single chamber called the vagina. The vagina opens outwardly at the end of the body, sometimes without special modification, sometimes by means of a flexible or extensile tube, sometimes as a long, rigid cylinder, and occasionally in the form of a sting. These structures, be they rigid or otherwise, are always called ovipositors, and their function is to place the egg into the position necessary for its best development. Associated with this system are a number of glands, the use of which is either to give a sticky coating to the egg, enabling it to adhere to the leaf or other point at which it is laid, or to supply a poisonous secretion, where such is necessary for defence or for stupefying prey. There is also a little sac, attached by a slender duct to the vagina, at about the point where the two oviducts unite. This is the seminal receptacle, and in this is received the seminal fluid of the male: from it the eggs are fertilized as they pass from the oviduct into the vagina on their way through the ovipositor. In some insects these receptacles are very large, especially where 
copulation takes place in the fall, and the female, living through the winter, does not begin to liy eggs until some time in spring. The eggs have at one end small openings termed micropyles, and through these the spermatozoa find their way into the egg to fertilize it. In the ovarian tubes a variable number of cells are developed, and these grow rapidly, each cell eventually forming an egr. The number of tubes and the number of cells in the tubes vary within wide limits in the different species. In some they are rigidly limited, and the insects are able to lay omly a definite number of eggs; in uthers the cells are so numerous that a definite number seems unlikely. Before the female has been impregnated the ovarian tubes are very slender and occupy only a little space in the abdomen. When the eggs develop, however, the ovaries increase in size until, finally, the abdomen is almost entirely occupied by them, and is often enormously distended.

In the male the ovaries are replaced by the testes, which also are more or less coiled tubular structures, and these tubes, like the ovaries, unite together on each side into a larger tube, which in turn are combined into a single organ, usually more or less horny in structure, - the penis.

Reproduction among insects is, therefore, in its essentials, like that of the higher animals. The only difference is that as the life period is shorter, the eggs must all be laid within a definite time, and they are very much greater in number. It further proves that we have a definite development in

Fili. 25 .

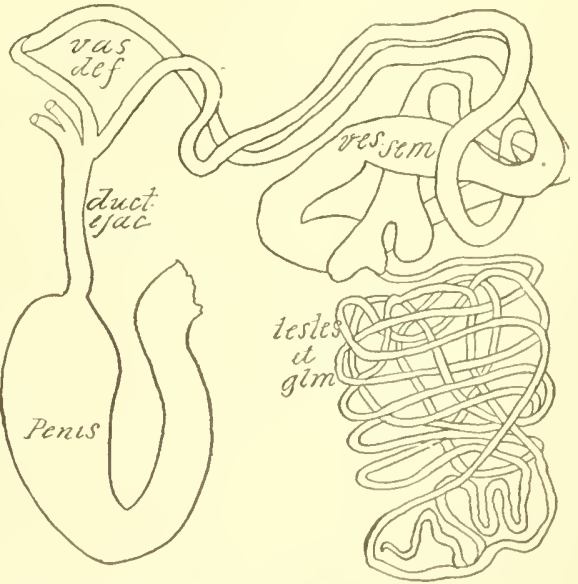

Male organs of May-beetle.-One side only beyond the ductus ejaculatorius, cinct. ejac.; glm., mucus glands; ves, sem., seminal vesicles; vas. def., vasa deferentia.

msects as in higher animals, and that with them also, like pro duces like, - that is to say, the product of the egg when fully de- 
veloped will be like the parent that laid it, and never anything else. Insects are as a rule unable to reproduce until they have reached the adult stage, and the few apparent exceptions may not be real when all the factors are understood. An insect, when once adult, never changes into one of a different kind; so a beetle can never change into a cricket, nor a small fly into a larger one.

\section{CHA P T E R VIII.}

\section{GROWTH AND METAMORPHOSIS.}

InsECTS grow only in the larval stage, and moult, or change their skin, every time there is an increase in size. As has been stated, the insect crust is rigid and inelastic, and extension is possible only by the expansion of the membrane between the rings. When a growing insect reaches the extent of the elasticity in its covering, a new skin forms beneath the old one, and the latter splits, allowing the newly-clad and much larger specimen to crawl out of it. In this respect insects resemble crabs, lobsters, and other crustaceans.

The terms larva, pupa, and adult have been several times used in the previous chapters, and need more explanation. Most insects undergo, in the course of their life, a series of changes or transformations, in which their form, appearance, and habits are often so diverse that the different stages could not be recognized as belonging to one species without definite, continued observation. These changes are termed metamorphoses, and they include the egg, larval, pupal, and adult stages. With few apparent exceptions, all insects begin in an egg stage, and the method in which this egg is developed has been already described. In this stage, whether it be long or short, the creature is undeveloped and quiescent, except for the changes going on within, and which do not result in outward movement. In rare cases the eggs are not extruded from the body of the insect, but fertilization takes place in the ovary, the larve hatching within the abdomen of the mother.

From this egg comes in due time a larva, a minute creature 
which may or may not resemble the parent that laid it. Assuming that it does, it is without trace of wings. It grows apace, moults as often as necessary, and at last attains very distinct wing pads. It is now in the pupal stage, and with the next moult the wings become fully developed. It is then adult and fitted to reproduce its kind. This sort of metamorphosis is said to be incomplete, because there is no inactive stage, and because there is always a close resemblance in all stages. The larvæ are quite usually termed nymphs, and differ from the adults only in size, in the absence of wings, and in the undeveloped sexual characters. A peculiarity of this method of growth or moulting is worthy of incidental mention. When the insect moults, it is not the outer

FIG. 26.
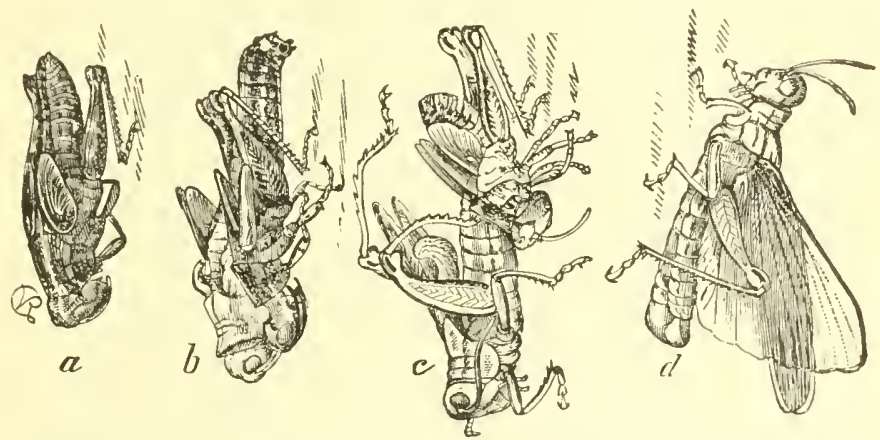

Moulting of a grasshopper.- $a$, nymph ready to change; $b$, the skin split along the back and the adult emerging ; $c$, continues the process, and at $d$, the adult insect drying out.

skin alone that is afiected : all the most delicate mouth parts with their hairs and processes are cast and replaced by a new covering; the lining of a large proportion of the digestive system is shed, and the inner coat or surface of the tracheal tubes is renewed, so that practically the insect gets, in part, a new digestive system and a new breathing apparatus, every time it increases in size. The number of these moults varies in the different orders, and even in species of the same order. There may be as few as three or four, and there may be twenty or more. We can sometimes modify the normal number by changing the circumstances under which the insects live. Thus, the larva of the common Dermestid found in museum cases normally moults four times 
before it is ready to change to a pupa. I have confined several larve in vials, closed them tightly with rubber stoppers, and supplied a small amount of foorl. In these dry vials larvæ have lived for months, in one case more than a year, and apparently as a mere pastime they moulted at intervals, so that in one vial there were eight or ten cast skins, more than doubling the ordinary number of changes. Withal the insects did not increase in size, simply because no more food was supplied.

Where the metamorphosis is complete, there hatches from the egg a grub, caterpillar, slug, maggot, or other crawling or wormlike creature, quite unlike the parent. Growth continues, as before, by moulting, until the full size has been attained, and then feeding ceases. The larva now seeks some retired spot, sometimes spinning a silken covering termed a cocoon, and then changes to a chrysalis or pupa. The term chrysalis is used in the butterflies, where it is free and often prettily ornamented, and the term pupa in most other cases. In this stage it is inactive and rests quietly for some time. The character of the future insect is usually more or less clearly defined, but occasionally it resembles neither the larva that formed it nor the adult insect which is to come from it. In clue time the adult emerges as a butterfly, moth, beetle, fly, or bee, and no trace remains of the previous larval condition. Insects never grow after they reach the adult stage, but remain of exactly the same size as when first they emerged from the pupa. Thus, as has been indicated in the previous chapter, large flies are never the parents of small flies, nor do small flies ever grow to become larger flies.

This cycle of change in an insect is termed its life history, which it is sometimes very difficult to work out. Scarcely two species are alike in habit during all their lives, and a complete knowledge of the full life cycle and the habits in all stages is essential to an intelligent application of remedial or preventive measures.

It is often possible to reach an insect easily in one stage, or at one period, where it is naturally protected cluring all others. So we may, sometimes, by a little change in farm practice, or by taking advantage of some preference on the part of the insect, avoid injury. To ascertain all these facts and to suggest the treatment indicated, is the work of the economic entomologist. Watching the transformations of an insect is a delightful task, 
and one that can be easily accomplished in most cases by any one possessing a little patience. In leaf-feeding insects all that is necessary is to bring in a supply of food with the larva upon it, and keep it in a box r. cage, renewing from time to time, so that fresh food may be always avaliable. In the bottom of the

FIG. 27.

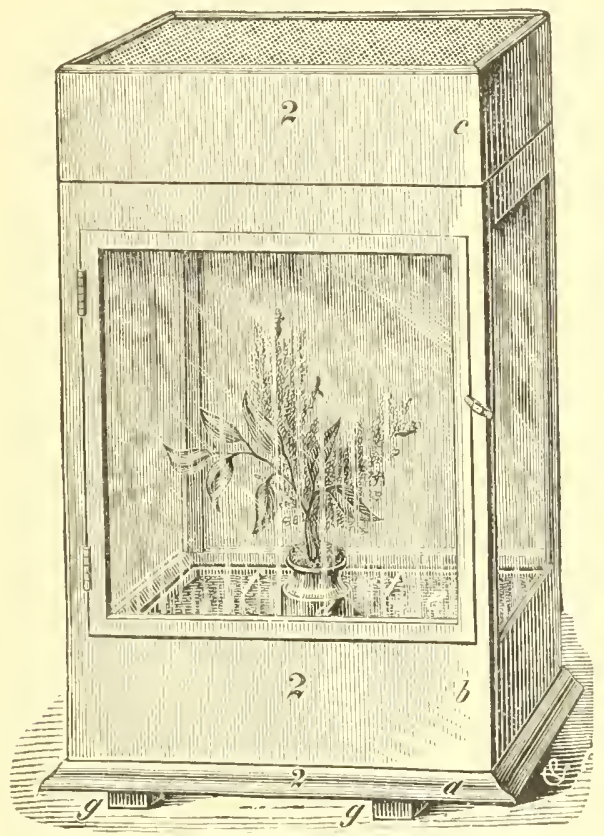

A breeding-cage of the Riley pattern.

box there should be three or four inches of clean sand for the benefit of those forms that go underground to change to a pupa, and in due time the caterpillar or slug will, under the observer's very eyes, change to a butterfly, beetle, or other insect, according to the character of the larva. 


\section{PART Ir. \\ THE INSECT WORLD.}

\section{CHA P TER I.}

\section{GENERAL CLASSIFICATION.}

THose structures which are of economic importance and, incidentally, those that are used in classification have been described in the first part.

Classification is the arrangement of the insects into series which are so related to each other that a species never before seen may be recognized, and its place ascertained from certain, easily discernible, structural characters.

Insects that agree in structure usually have similar habits, and by placing an example into its systematic position, the probable life cycle becomes also known, and its exact life cycle can be more easily and intelligently traced out.

The divisions used are orders, families, genera, and species. The term sub- may be prefixed to either, to indicate a division not marked enough to claim full rank.

A species consists of individuals which agree with each other in appearance, structure, and life history, mating freely, producing progency, which resemble the parents, and which are themselves fertile. An assemblage of such species agreeing in general characters forms a genus, and this is a more or less uncertain division, depending somewhat upon the opinion of the systematic student. A series of genera agreeing in form, structure, and life listory makes a family, and families are united into orders.

For the clivision into orders, use is made of wings and mouth structures and of the transformations.

For convenience in ready classification the Linnzean orders are here adopted, though some of them have been properly sub- 
divided. The new orders are referred to, however, in the proper place.

Lowest of all are the Thysunura, including "bristle-tails," "spring-tails," "fish-moths," and the like. They never become winged or develop even a trace of wings. The mouth parts are small, retracted, usually formed for biting, but sometimes so undeveloped as to be almost without type. The metamorphosis is incomplete; incleed there is only a simple increase in size, and nothing really worthy of the term development. In most cases the abdomen bears a pair or more appendages at the tip, from which some of the common names are derived.

Next come the Neuroptera, or nerve-winged insects. These have four well-developed wings, membranous, more or less transparent, and so crossed by numerous veins that they seem reticulated or netted: from which character they derive their name, which means nerve-winged. The mouth parts are mandibulate, usually well developed, but sometimes almost obsolete. In its broadest sense the order includes " May-flies," "dragonflies," " caddice-flies," “ white ants," " stone-flies," " lace-wing flies," and the like. There are, however, two types of metamorphosis,-one complete, the Neuroptera proper, and the other incomplete, the Pseudo-neuroptera. It is here that most of the new ordinal divisions have been made.

A step in advance are the Orthoptera, or straight-winged insects, such as roaches, crickets, katydids, and grasshoppers. They have two pairs of well-developed wings, - the first or anterior usually narrow and a little thickened or parchment-like; the second or posterior broader, plaited or folded like a fan beneath the anterior pair. The mouth parts are formed for biting, and the metamorphosis is incomplete.

The order Hemiptera, or "half-winged" insects, includes all the true "bugs ;" and to members of this series only the term "bug" is properly applied, according to entomological opinion. The order is always distinguishable by the mouth structure, which is haustellate, and consists of a jointed beak, concealing two pairs of slender, pointed lincets. The metamorphosis is incomplete. The term Hemiptera, or "half-winged," is derived from the fact that in the typical series the primaries are thickened at base and thin or membranous at tip. In it we have such creatures as the 
"chinch-bug," "squash-bug," and others of equal note. The term Homoptera, or "similar-winged," is used for that series in which the fore-wings are uniform in texture, as in the plant-lice and Cicadas.

The order Coleoptera contains the beetles, and the name, meaning "sheath-winged," is due to the fact that the anterior wings are hard and horny, unfitted for flight, and used only as a sheath or covering for the posterior pair. The moutl parts are mandibulate, and the metamorphosis is complete.

An easily recognized order is the Lepidoptera, or "scalywinged," including the butterflies and moths. Here wings and body are covered with minute scales, easily rubbed off and resembling colored dust. The mouth parts are haustellate, and form a coiled tongue, which is usully concealed beneath the head, but can be readily extended at the will of the insect. The metamorphosis is complete.

Equally recognizable are the Diptera, or " two-winged" flies. The single pair of wings is characteristic, and with it are associated mouth parts varying much in type, but never mandibulate nor forming either a coiled tongue or jointed beak. The metamorphosis is complete.

The Hymenoptera, or "transparent winged" insects, include bees, wasps, ants, and the like, and stand at the head of the Class Insecta. They have two pairs of transparent wings, with only a few veins; the posterior smaller than the anterior. The mouth parts are mandibulate, but the tongue is often developed as a lapping organ, and sometimes greatly enlongated. The metamorphosis is complete.

To show the differences succinctly the following table may be of use :

Insects which never become winged, have the mouth feebly developed and the metamorphosis incomplete

THYSANURA. All others are winged:

With four transparent wings, which are net-reined and flat; mouth parts mandibulate and well developed; the metamorphosis, either incomplete ............... PSEUdo-Neuroptera. or complete . . . . . . . . . . . . NEUROPTERA.

With the fore-wings narrow and sonsewhat thickened; the posterior folcled fan-like, or plaited; month mandibulate; transformations incomplete

ORTHOPTERA. 
With fore-wings thickened at base, thin at the tip; mouth parts forming a jointed beak : transformations incomplete . . HEMPTER.1.

With the fore-wings uniform in texture; moutl parts and transformations as before. . . . . . . . . . . . Honoptera.

The fore-wings are horny, and useless for flight, serving only as a corering for the posterior pair; mouth mandibulate; metamorphosis complete

COLEOPTERA.

All the wings and the body covered with scales; mouth parts developed into a long coiled tongue; transformations complete LEPIDOPTERA.

The wings transparent, with only a few longitudinal veins; mouth mandibulate, the tongue formed for lapping; transformations complete . . . . . . . . . . . . . HymenopterA.

Two wings only; mouth parts hanstellate; transformations complete

DIPTERA.

\section{CHAPTER II.}

THE THYSANURA.

Spring-tails, Bristle-tails, Fish-moths, etc.

UNDER this term are grouped a number of lowly insects which never become winged, and can hardly be said to have any real transformations. Most of them are small, soft bodied, with feebly developed mouth parts, and live in damp earth, among decaying vegetable matter. Some live under bark of dead or decaying trees, or in decaying wood, while in rare instances species are found preferring dry and warm localities. Among those that live in damp places are forms without eyes, and with no dereloped tracheal system, the necessary oxygen being absorbed through the skin itself. Compound eyes are developed in a few instances only, though ocelli are usually present.

Peculiar to the order are certain abdominal appendages. In some cases these are in the form of rudimentary abdominal legs, indicating a relationship to the Myriapods or Centipedes; but more often they consist of bristles or filaments attached to the anal segment. In the simplest form they consist of long, manyjointed appendages, whose function may be tactile, similar to that of the antennæ.

A good example of this type is the little creature known to 
house-keepers as the "fish-moth," or "silver fish." It is one of the few species that prefers a dry, warm locality, and is found

FIG. 28.

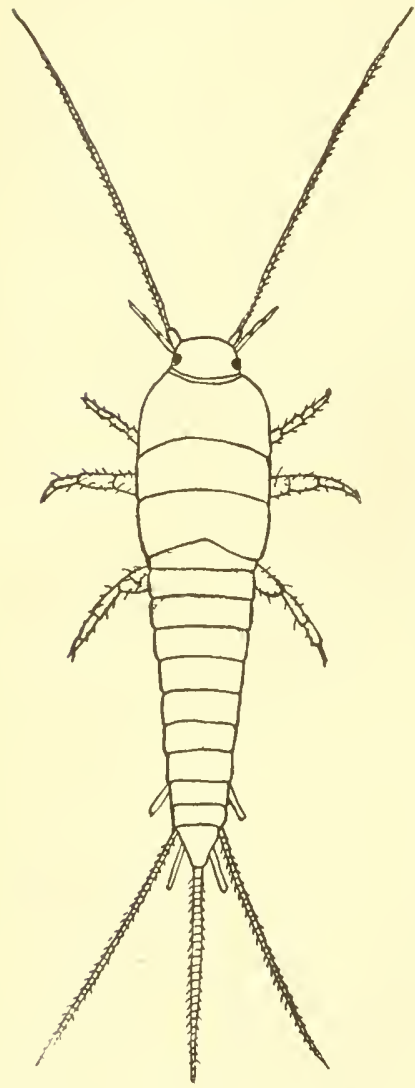

Bristle-tail or fish-moth; Lepisma sp. in cupboards and closets, hiding in crevices, and running rapidly when disturbed. It is about one-quarter of an inch in length, oblong, a little pointed towards both ends, and has the body covered with minute, silvery-white, glistening scales. It is one of the largest species belonging to the order, feeding upon starchy substances and food remnants. It sometimes becomes troublesome in libraries, gnawing the calendered surface of leaves and bindings and defacing them. The insect can scarcely be said to be injurious, but it is often annoying, and may be driven out by a free use of pyrethrum, dusted in corners and crevices.

A much more common type is the "spring-tail," so named from the fact that the anal appendages consist of two short, bristle-like processes, arranged to enable the insect to leap or spring. They are normally bent under the body, held in place by a catch-like organ until the insect desires to move suddenly, when the catch or spring is released, sending the insect forward a surprisingly long distance. When excited it progresses by a series of rapid leaps of this kind, its course being decidedly erratic because no two of the springs are made in the same direction.

"Spring-tails," or Podurids, are found in moist localities, wherever decaying vegetable matter occurs. In manure beds they often occur in millions, and on warm days may come to the surface in astounding numbers. I have seen a forcing bed cov- 
ered nearly half an inch in depth by a solid mass of these little creatures not one-sixteenth of an inch in length. Frequently a

FIG. 29.

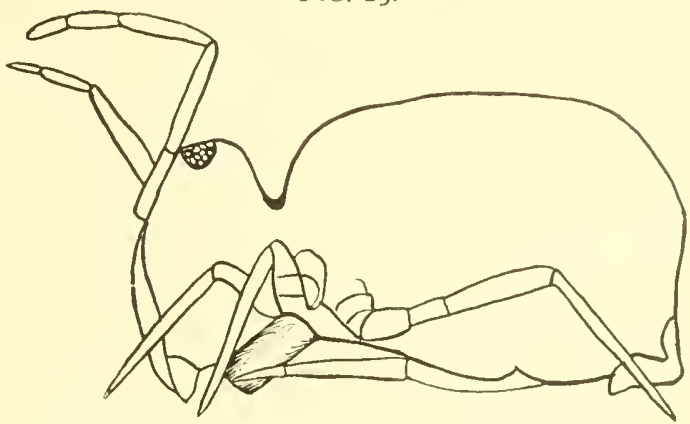

Papyrus species: showing spring curved under the body.

sudden rise of water on meadow or bog land drives them out of their hiding-places, and they leap about on its surface for a time as readily as they do on land. I have seen, on cranberry bogs reflowed late in May, square rods of the surface so densely covered that nothing of the water was visible.

They are often found in damp cellars, on any vegetable matter stored there, and are sometimes accused of promoting decay. In the fields a cut potato placed underground may attract dozens of specimens that feed upon the juices of the raw surface, and they have been therefore accused of producing scabby potatoes. They are of all colors, but usually slate-gray or yellowish, the markings sometimes quite pretty and distinct.

As a matter of fact, these insects are never injurious. Healthy vegetable tissue is not attacked by them, and their mouth parts are adapted for feeding on soft or moist tissues only : Fig. 30.

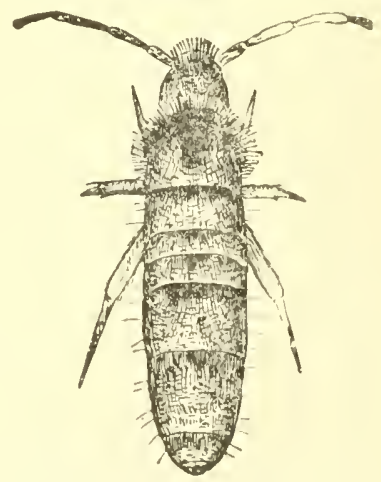

A Podurid, or spring-tail, lound on manure beds. hence a decayed or bleeding spot attracts them. They are sure to occur in manure and on manured land, and can be kept out to a large extent by using only mineral 
or " commercial" fertilizers. In the manure itself they are beneficial rather than otherwise, hastening its decay by changing the form of the more resisting portions.

It sometimes happens that, when found associated with decay or rot of stored produce, the insects are accused of causing it ; but they always follow and never precede or cause the diseased appearance.

\section{CHA PTER III.}

THE NEUROPTERA AND PSEUDO-NEUROPTERA.

May-flies, Dragon-flies, Stone-flies, Caddice-flies, etc.

The old term Neuroptera comprised all insects with four more or less transparent wings, reticulated or netted with numerous longitudinal and transverse veins, and the mouth parts formed for biting. As thus defined the order was easy of recognition, and, practically, the division is convenient here, for nowhere in this series are any species injurious to field crops. We find troublesome species among the parasites, and the Termites, or "white ants," are injurious under some circumstances; but, as a broad statement, subject to a few exceptions, it is correct to say that no Neuroptera are injurious to field crops, and no apprehension need be felt whatever the numbers in which they may appear.

It was early found that under this term insects quite different in life habits were included, some having complete and some incomplete metamorphoses. The order was then divided, the term Iseudo-neuroptera being applied to those forms in which the transformations are incomplete. The division is a good one; but, as there is nothing in the adult to indicate to the tyro the nature of the changes it undergoes, it was not always easy to decide to which order a given insect belonged. More recently the series has been yet further divided, and we have now somewhat compact groups of net-veined insects which may be recognized without much trouble. "These will be referred to in order under their modern names. 


\section{Order EPHEMEROPTERA.}

This order includes what are known as "May"" or "dayflies," the names indicating either the time at which they first appear or the brief period of their adult life. "May-flies" occur most abundantly during spring or early summer, in the vicinity of lakes, ponds, and rivers. They are readily recognized by their fragile body, terminated by two or three long, thread-like appendages, and by their large, frail wings, the posterior much smaller than the anterior. They fly at night, and are readily attracted to light, dozens being often seen hovering around a single street lamp. I have seen bushels of them at the base of electric lights on the banks of the Ohio, and the shores of the Great Lakes are sometimes covered with heaps six inches or more in depth, so that the stench from the decaying bodies becomes nearly insupportable. The head is large, the eyes are round and prominent, and the forelegs are conspicuously long and stout; but the

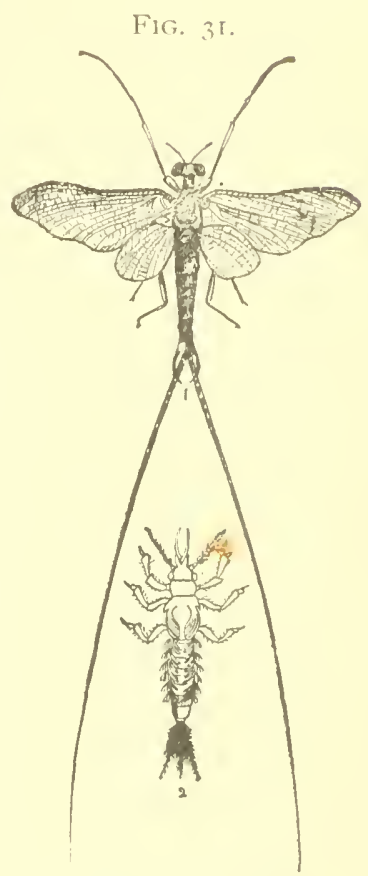

May-fly and its larva. feelers are reduced to mere rudiments, and the mouth parts are atrophied and utterly useless for feeding purposes.

In the May-flies we have the survival of an ancient type, their generalized structure indicating a low place in the scale of development. The eggs are laid on the surfice of the water and sink gradually to the bottom. From them hatch narrow, clongateoval, more or less flattened larva, furnished laterally and sometimes at the end of the body with gill-tufts, living in the mud ooze of river and lake bottoms, under stones, or among aquatic plants. They feed on all sorts of minute animal life, and probably also upon the low forms of vegetation on submerged stones or sticks. They grow slowly, moult frequently, and live from 
one to three years in this condition. Wing-pads gradually appear, and eventually the adults emerge and fly away, only to shed their skins once more in the very act of flight. I have seen their delicate, pure-white exuria float about over the Ohio River in such numbers as to resemble a fall of snow. This moulting of the adult is peculiar to the Ephemerids, who mate soon after it occurs, deposit their eggs, and before morning perish, - their life-work accomplished.

Not all forms are so short-lived, however, some requiring several days to complete oviposition; but their inability to feed indicates a brief existence at best. The number of species is large, and the number of specimens immense, indicating an active, aquatic insect life at least as great as that found in the air or on the dry land. While the larva feed on smaller creatures, they are in turn devoured by fishes, who find in them an important article of food, and in this view only are they of any economic importance.

\section{Order ODONATA.}

Under this head come the dragon-flies, or, as they are often termed, “devil's darning-needles," “spindles," or "snakedoctors." Many superstitious beliefs are connected with these insects, and there is a general indisposition to handle them, because of their supposed ability to sting. The insects are common about ponds and streams, flying rapidly over the surface of the water, occasionally darting down to touch its surface, and delighting always in the bright sunshine.

The body is long and slender, fitted with an enormous head principally occupied by the eyes, and with two pairs of long narrow wings, which are similar in size and appearance. In some species there are leaf-like appendages at the end of the abdomen, and these are erroneously supposed to be weapons of offence. The legs are stout, clothed with spines and spurs, as well as with long claws at the tip. The mouth is formed for biting, the mandibles and maxillæ being greatly developed and sharp-toothed, for tearing their prey.

They are, as has been indicated, predaceous, and capture their food during flight, their powerful wings and legs enabling them to overtake and grasp any creature that comes within the range of their huge eyes. Flies and mosquitoes are the usual victims, and 
hence the term "mosquito hawk" has also been applice to them.

It has been suggested that dragon-flies might be artificially propagated to lessen the mosquito pest; but this is not feasible, because they fly only during the day, while the mosquito is decidedly more a creature of the night. No dragon-fly voluntarily remains in woods, except along streams and in open glades, yet here mosquitoes lurk by the million. The proposition looks well at first sight, but is not practical.

FIG. 32 .

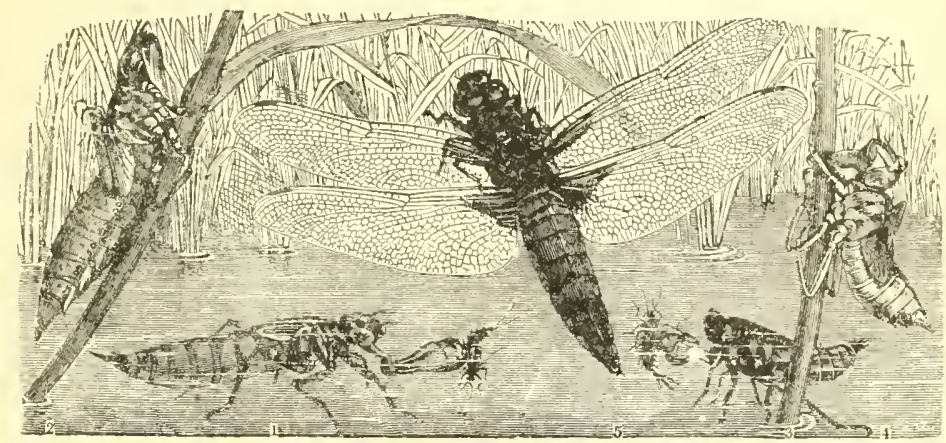

Dragon-fly and its development.--Larva and pupa feeding at I and $3 ; 2$, nymph ready: to change; 4 , a pupa skin from which 5, the adult, has emerged.

The early stages are passed under water, and the larvæ are ugly creatures, somewhat resembling the adults, but without wings. They move sluggishly among the aquatic vegetation, or on the mud of the bottom, strongly resembling the latter in color. They do not swim readily, but some are able to propel themselves by drawing into the posterior part of the digestive tract a quantity of water and then expelling it forcibly. This process really answers a double purpose, for this same tract is supplied with numerous fine tracheal tubes through which oxygen is drawn from the water: two functions, respiration and locomotion, being thus curiously combined. Respiration is also carried on by means of leaf-like anal appendages, in which trachea ramify in all directions, forming gill-like structures. As the larva grow, wing-pads appear, and when these are fully developed the pupal stage has been reached; the insects continuing active, however, 
until realy for the change to the adult. Then they crawl up the stem of sonse water plant, or upon a projecting stone, and soon the skin splits and the imagos emerge. A few minutes suffice to harden and dry the newly-developed adults, then with spread wings they sail away on a new career, in a new medium.

In habit the larve are as predaceons and voracious as the adults, and their prey consists of any aquatic forms which they can capare, -mosepuito larrae forming (puite a staple article of diet. It an been alreatly indicated that they are not very active creatures, and prey is captured by simply wating in the mud or on a mossy stone until it comes within reach. Their color renders them ahnost in isible under such conditions, and nature has furnished a renarkably extensile mouth structure, by means of which they are able to reach out some distance and seize whatever creature may be passing near. It is the labium, or lower lip, that is modified for this purpose, and is supplied with a double linge which can be straightened out rapidly to bring into play a pair of large, slender, and pointed jaws at its tip. When this structure is retracted it is invisible, covering the other mouth parts entirely and hicling them. The term "mask" has therefore been applied to it.

Oviposition varies with the species, and is interesting. The sexes pair during flight. The male has the organs of copula-

F16. 33 .
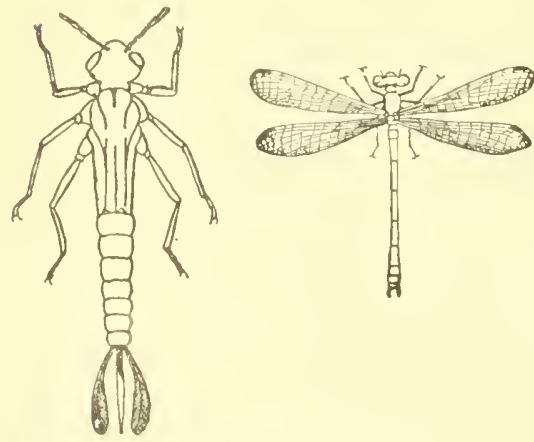

species of Agrion and its larva; the latter with anal gill-tuils.

fomale drops a little mass upon the surface, ancl copulation is resumed, the process being repeated until all the eggs are laid. domen, while the opening of the testes is at the tip. Before pairing he fills the seminal pouch at the base of the abdomen, then grasps the female by the neck with a pair of anal claspers, and she curves up the tip of her abdomen into contact with the opening to the seminal duct of the male. As the eggs are fertilized the pair descend to the surfice of the water, the tion at the base of the ab- 
In some species the female when impregnated crawls under water, down the stem of some aquatic plant, and lays her egg's on stones, plants, or even in the mud. By folding the wings backward, close to the body, a film of air is gathered which keeps the insect dry and supplies it with a sufficient amount of oxy"gen for a temporary return to its old medium.

The order contains no injurious species, because all are predaceous; but, on the other hand, nome are markedly beneficial, because, though they devour an enormous number of other insects, these are not usually species destructive to farm crops.

\section{Order PLECOPTERA.}

The ordinal term signifies "plaited wing," and is used because the hind wings are longitudinally folded or plaited beneath the

FIG. 34 .
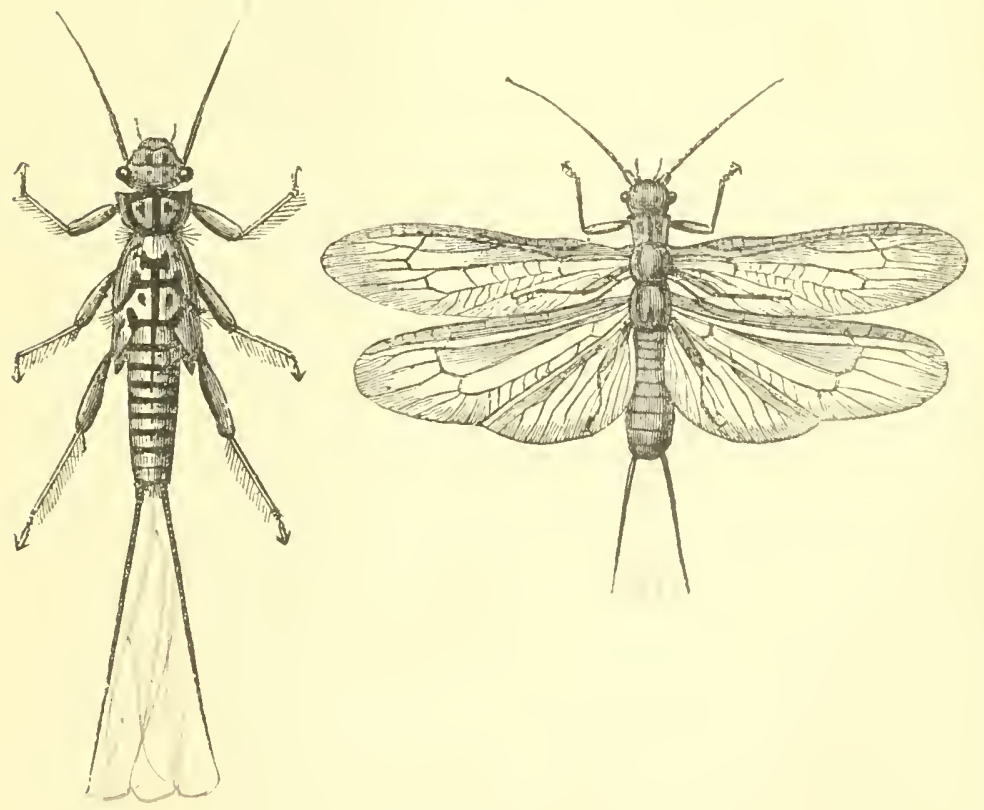

Stone-fly, Prola bicaudata, and its larsa.

anterior pair, which rest flat upon the back. The insects themselves are called "stone-flies," and are loosely jointed, flattened. 
the thoracic parts large and not closely united, the wings exceeding the abdomen in length. In texture they are rather soft, and the antenne are long and many-jointed. They frequent the margins of streams and running ditches, preferring damp, shady localities. The mouth parts are mandibulate, but their food habits are not well known. They are not injurious, and are economically important only as food for fishes. The eggs are laid in masses upon the surface of the water, through which they sink to the bottom. The larvæ are flattened, live among and under stones, feeding upon vegetation, and probably also upon such small, soft-bodied creatures as come in their way. The legs are well developed and of nearly equal size. The antennæ are long and slender. There are usually slender, hairy appendages at the end of the abdomen, and on the under side are tufts of gilllike structures serving for respiration. In some species these gills persist even in the adult, forming a remarkable exception to the general rule that adult respiration is through spiracles only. One natural family the Perlida, comprises the entire order.

\section{Order PLATYPTERA.}

The ordinal term signifies " flat winged," or " broad winged," and in those forms in which wings are present the secondaries are not folded or plaited, but lie flat over the body, covered by the primaries. The mouth parts are mandibulate, the thoracic rings are loosely jointed, and as a rule the insects have a flattened appearance. In most cases the head is large and prominent, wider than the thoracic rings.

Three distinct families, using that term loosely, are grouped in this order, differing greatly from each other, all of some economic importance, and requiring more detailed consideration.

\section{Family TERMITIDE.}

Termites, or "white ants," as they are called, from their appearance and habits, occur all over the United States, but are more common southward. They are separated as a distinct order under the term Isoptera, meaning similar-winged, and are interesting from their social organization, which is complicated, several forms or castes existing in each colony. All our species live in and feed upon woody or fibrous material, though extend- 
ing their galleries through the soil, often for great distances, and also inhabiting underground chambers.

In woodland almost any $\log$ or decaying tree will be found swarming with these dirty yellowish-white insects, about onefourth of an inch long, readily recognizable by their large heads and oval, obtuselyterminated abdomen. They are wingless, and when exposed to light seek at once to make their way back into darkness. These are workers, and blind; they never voluntarily come out of their galleries, ali their wandering being in tunnels of enormous length run over or under ground in every direction from the main nest. If they must reach a point to which they cannot

FiG. 35 .
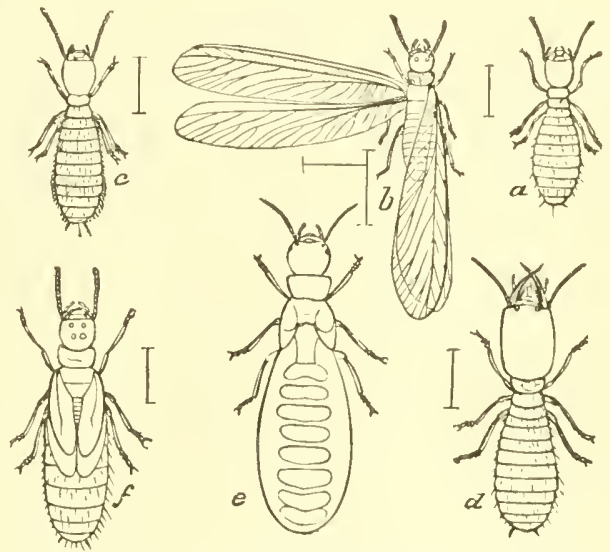

Temes flavipes,- $a$, larva ; $b$, winged male; $c$, worker; $d$, soldıer: $e$, female; $f$, pupa.

burrow, they build a covered way of earth mixed with saliva, woody and excrementitious matter. These workers are the most familiar to the casual observer, and form much the greater proportion of the inhabitants of a nest or colony. They have distinct, hard, brown mandibles, not excessive in size, and can be thus readily distinguished from the soldiers, which are larger, with proportionately larger heads and very largely developed mandibles. The sotdiers form a standing army whose duty it is to protect the community; therefore, if we disturb a colony the workers at once run away, leaving the field to the soldiers, wh are impotent enough in the daylight, blindly gnashing their jaw but are no doubt useful in the ordinary routine of Termite life Early in spring we find, in addlition, larger, winged inclividual. chestnut-brown in color, and these are the true sexed forms, male and female. On a bright, warm day, when spring is well advanced, these individuals, which by the bye are furnished 
with eyes, leave the parent-nest in great numbers and fly about, enjoying for a few brief hours the sun and air. They are then said to be "swarming," and select their mates, returning to the surface before the setting of the sun. Out of the vast numbers leaving the nest few survive the day of flight. They have numerous enemies, and, even if they escape these, must depend upon being found and adopted by some valgrant workers before they are able to form a colony. The sexed individuals-king and queen-are helpless, can do nothing for themselves, and are not permitted to return to their old home. This serves to keep the insects in cleck, for the chances of starting a new colony are very small. Let us assume, however, that a pair is adopted and housed, the workers at once building a proper habitation for the royal pair. Reproduction begins immediately, and the female, now stripped of wings by her own act, gradually enlarges, the abdomen ultimately becoming a mere egg-sac. Such a queen becomes the mother of the colony, and she is tolerably prolific: sixty eggs a mintute have been counted, making a possible output of over eighty thousand in a single day! The workers take entire charge of the eggs and resulting young, feeding and tending them until they are able to take part in the ordinary work of the colony. Both males and females are represented among the larval forms, but it seems to depend entirely upon the nurses as to what caste is to result. They are able at will to arrest development and to produce whatever forms are needed in the community. Thus workers and soldiers are each of both sexes, but the sexual organs never become developed or functional. A certain proportion are allowed to develop fully, and these furnish the annual swarms. If the queen becomes old or unable to supply the colony with a sufficient number of young, the workers provide for a number of "complemental" males and females. These never become winged, reaching only the pupal stage in which the wing-pads appear, and they never leave the nest, but pair within it, the female laying fertile eggs, though never in such numbers as a perfect queen. Therefore, several of these complemental pairs may inhabit a colony, and there may be no real queen at all. Curiously enough, no queen of our common species has ever been found, and we are yet in ignorance of just where the royal chamber is situated. 
Termites become injurious in one of two ways: they either eat into wood-work of rurniture and buildings, or they attack growing plants. In the Northern and Eastern United States they confine themselves to dead wood, and we have only a single species,-Termes favipes; but in the South and Southwest they attack living plants, among them orange-trees and sugar-cane. In buildings they sometimes live in beams, weakening them to such an extent as to threaten or actually cause collapse. Not many years ago some of the heavy wooden supports of the Boston State House were found infested, and more recently a building in Cleveland, Ohio, was invaded, requiring prompt measures to prevent accident. They also attack stored products in general, skilfully concealing their presence by leaving the outer surface untouched. Thus, in a pile of old records stored in a vault of the United States Department of Agriculture, a large proportion was found badly injured, though no external trace appeared. In the United States National Museum is a mass of black linen thread from a South American store-house in which the outer form of a pile of skeins is accurately preserved, while all below is a mass of hard, black galleries. These are made of the partly digested and excreted thread itself; and so we find that in the galleries in logs or trees the walls are composed of partly digested wood-fibre.

Termites are often found in decaying stumps, and sometimes in the roots and stems of weak and dying plants; in the latter case often hastening or inducing death. In the Southern States they are more abundant and troublesome, attacking sugar-cane and also eating the bark of orange-trees at the crown.

REMEDIAL MEASURES.

Where the insects are found in buildings, injecting bisulphide of carbon into their galleries will destroy them. They should be traced to their outside nest, if possible, and, when found, this should be destroyed. Frequently an old stump of some large tree may be a centre from which a district becomes infested, and the bisulphide should be liberally employed wherever the insects are observed in numbers.

On growing plants the bisulphide is also useful in many instances; but here, too, the effort should be made to discover the

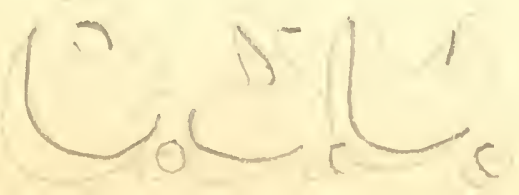


central colony, rather than to protect individual trees or plants. Hot water has been recommended, but is not so effective as the bisulphide. Dead stumps and partly dead, infested plants should be removed and burnt, to deprive the insects of congenial quarters.

The true home of the Termites is in the tropics, where they are pests of the first magnitude. In Africa some of the species are mound-builders, erecting turreted structures from ten to fifteen feet in height, made up of earth and partly digested wood and other fibre.

\section{Family psocide.}

To this family belong the minute "book-lice" often found in dusty corners, under loose paper, in collections, and in other dry localities. They are always small, resembling somewhat a "Termite" in miniature, very active, running backward or forward with equal facility, and furnished with very long, slender

F1G. 36 .

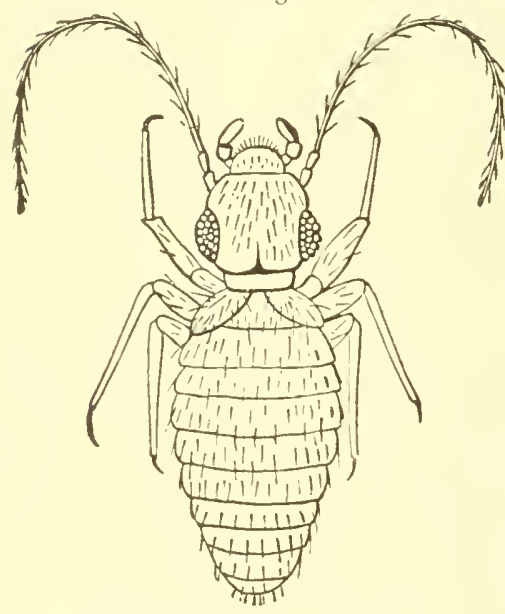

A book-louse, $\times 25$ diameters. antennæ or feelers. The head is very large, with small, coarsely granulated compound eyes. The mouth organs are mandibulate, but not at all prominent, and fitted for gnawing rather than biting,-whence the insects have been called Corrodentia or "'gnawers." They are white or clirty-yellow in color, and look just enough like true lice to be mistaken for them under some circumstances. Occasionally conditions favor their increase in houses, and almost in a day it will be overrun, beds and bedding being especially favored, to the horror of the housewife, who almost invariably mistakes their true character. Several times within my experience I have received these creatures with anxious entreaties for a remedy, and equally anxious requests for secrecy. The Psocids may be always distinguished from para- 
sites by their very rapid motions and their long antennæe or feelers. Their food is starch, where they can get it, or dry animal or vegetable matters, and they can be driven out by a free use of naphthaline crystals. Their injury in libraries is done by eating the starched surface of bindings, plates, and pages, and so disfiguring them.

The forms just described are all wingless throughout their entire life, Atropos (Clothilla) divinatoria and A. pulsatoria being common species. In some mysterious way the term "deathwatch" has been applied to these creatures, and they have been credited with making the ticking sound often heard at night in old houses, and which is supposed to give warning of a death to come.

But there are some winged forms, and these somewhat resem-

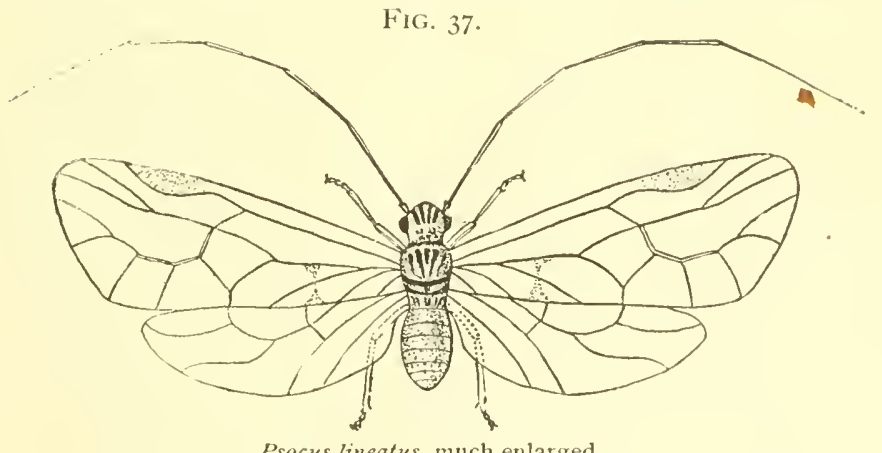

Psocus lineatus, much enlarged.

ble overgrown plant lice, differing, of course, by the mandibulate mouth. These winged Psocids sometimes occur in great numbers on the bark of trees, in my experience most often on cherry and orange, where they feed upon lichens and other dry vegetable matter. They sometimes create alarm when great numbers are noticed by the farmer; but none of them are in the least injurious. They are more cylindrical in appearance than the wingless forms, and the thoracic parts are better developed and larger than the head, which bears the same coarsely granulated eyes and long antennæ. When a group of specimens is disturbed they run in every direction, and often drop to the ground rather than use their wings in flight. Altogether, this family 
contains insects that simulate injurious forms, while doing little or no actual damage themselves.

\section{Family MALLOPHAGIDA:}

The literal meaning of this term is "wool eater," and it appropriately expresses the habits of some of the species. All members of this family are parasitic, and are known as biting lice; never sucking blood, but feeding upon young hair, feathers, skin-scales, clots of blood, and scabby or other scurfy material found on the skin or among hair and feathers. They infest warm-blooded animals only, and principally birds, whence the term "bird-lice" has been erroneously applied to the entire group. All the common farm animals except the pig are infested

FiG. 38.

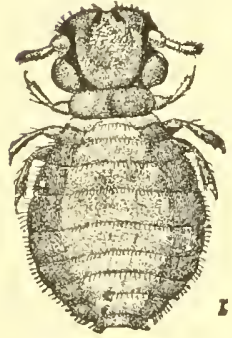

$a$

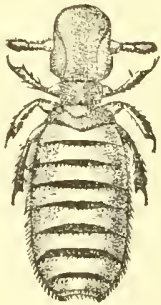

b

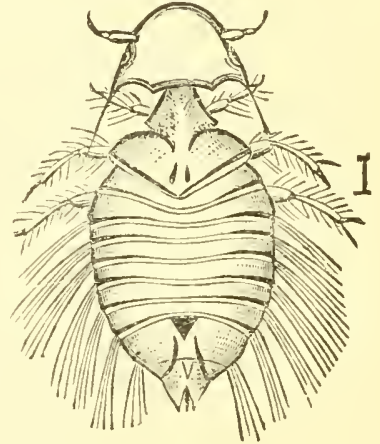

Biting-lice.- $a$, dog-louse, Trichodectus latus; $b$, sheep-louse, Trichodectus spharocephalus; c, turkey-louse, Goniodes stylifer.

by some species of this family, and all the poultry or fowls are troubled to a greater or less extent.

The insects are all small, flattened, with large, prominent head, often bulging eyes, and short antenne or feelers. The legs are short and stout, fitted for holding to and moving among hair or feathers, and the abdomen is oval. No trace of wings is ever developed.

The eggs are fastened to the hair or feathers of the host, and in a few days the young emerge, not differing from their parents except in size and sexual immaturity. The entire life is thus 
passed on the host, and the insects usually spread from one animal to the other on occasions of contact, or through litter into which some specimens may crawl or be thrown. They also cruwl upon the wood-work of coops and stables, and thence upon such animals as may rest against it.

The only way to reach these insects is by means of poisons acting through the respiritory system, and this is not difficult, because the spiracles are not well protected. Barn-yard fowls will keep themselves tolerably free if furnished with plenty of finc dust. The finer it is the more effective, and the birds will so thoroughly powder themselves that few of the parasites can escape. Cleanliness on the roosts and in hen-houses is imperative, and a liberal use of whitewash and occasionally of kerosene on all the wood-work is useful. A badly infected house may be cleaned by shutting it up tight for twenty-four hours, and evaporating in a shallow dish a few ounces of bisulphide of carbon. This kills all, save eggs, and the treatment should, therefore, be renewed a week later to reach such as may have hatched since that previously made. It has also been recommended to hang small open vials of bisulphide below the perches, and this, it is asserted, kills the parasites without discommoding the fowls.

On fam animals greasy mixtures may be successfully employed, or carbolic or tobacco washes or dips. For larger animalshorses, cows, or mules-a thorough grooming with comb and brush, dipping the brush into a kerosene emulsion diluted five times so as to moisten all parts of the body, is decidedly the best method. This must be duplicated a week later to reach any that may have hatched from eggs since the previous treatment. On large herds, badly infested, the kerosene emulsion, cliluted nine times, is simply sprayed on the animals as they pass through a narrow opening, the application renewed at intervals of a week, until no more lice appear.

With so considerable a range of remedial and preventive measures no serious trouble from these parasites need be apprehended, and it remains only to urge again the utmost cleanliness everywhere as the best of all preventive measures.

All the neuropterous orders heretofore treated have had the metamorplosis incomplete, and are therefore classed as pseudo- 
or false-neuroptera. While they are not directly followed in the classification by the true neuropterous series, yet for convenience they may be so arranged here, and not entirely without reason, because they are descendants of the same stock.

\section{Order NEUROPTERA.}

As this term is now limited it includes only those nerveor net-winged forms with complete metamorphosis in which the biting mouth parts are well developed and not prolonged. The thoracic parts are large, frequently the prothorax is distinctly separated and square, and the entire insect is somewhat flattened.

Of this type are the larye forms like Corydalus and Chauliodes, and the peculia: Raphidia found on the western coast, members of the family Sialida. The head is large and broad, the mandibles well or, as in the male Corydalus, even enormously developed. the antenne long and many jointed; in Chauliodes pectinated. The prothorax is always distinct, square or oblong, in Raphidia very long and narrow, the other thoracic segments well developed and loosely held together. The abdomen is soft in texture, and as a whole the forms appear loosely jointed. The broad wings lie nearly flat on the back and much exceed the tip of the abdomen, the hind pair being partially folded at rest. The eggs of Corydalus are laid in masses on leaves or sticks, coated with a water-proof secretion, and from them hatch flattened six-foutcd larva, which live under stones or other shelter on the bottom of rumning streams. They are furnished with gill tufts, through which they obtain oxygen, and prey on whatever insects or larve may come within their reach. In turn they are preyed upon by fishes, and the larvæ of the Corydalus comutus, or "dobson," make excellent bait, being locally known as "hellgrammites." When full-grown they come to the edge of the stream and, under stones or other shelter, change to quiescent pupa, in which all of the limbs are free and the form of the future adult is fully shown.

The species of this family are interesting, but of no sort of economic importance.

Not so the next family, the Hemerobiide, which contains numerous species of interest, all of them predaceous and beneficial to 
FIG. 39 .
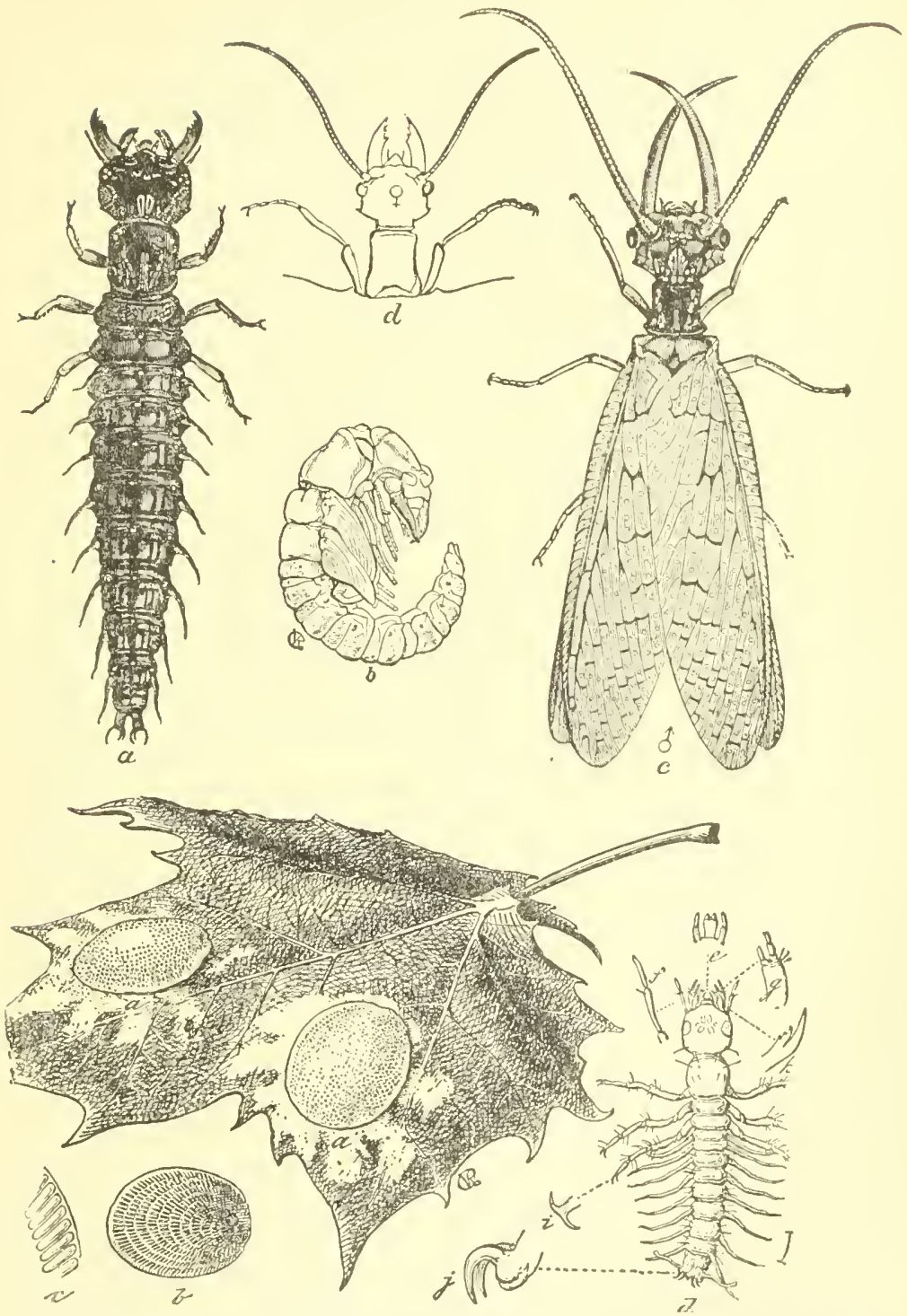

The "hellgrammite" or "dobson" in all its stages.- Ipper series: $a$, the larva $b$, the epupa; $c$, the male adult; $d$, the head of the female: in the lower series the leaf bears egg masses at $a a$, enlarged at $b c ; d$, the larva just hatched, with details from $e$ to $j$. 
the farmer. There are several sub-families, which together are termed "lace-winged flies," from their delicate, findy-reticulated or netted wings, which lie flat and are not folderl. The insects are slight, and in the species allied to Hemerobius the colors are brownish or smoky. They are less common than the forms allied to Chrysopa, which are green, with long antenne and prominent, bright, yellowish-brown eyes, which have given them the name "golden-eyed flies" in some localities. They are commonly found in fields or along the edges of woods, and emit, when hanelled, a peculiarly sickening odor which is quite unmistakable when once known. In the adult stage the insects feed little or not at all ; but the larvit, known as "aphis lions," feed almost constantly, their prey being small, soft-bodied insects of all kinds, aphids or plant-lice ranking as special favorites.

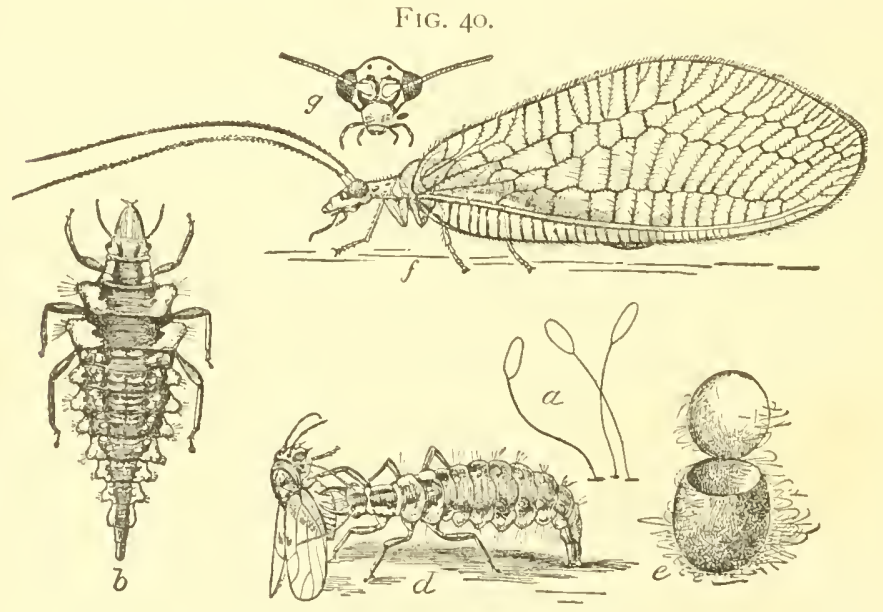

A lace-winged tly, Chrysopa oculata.- $a$, the eggs; $b$, the larva ; $d$, same, liceding on a pear-psylla; $e$, cocoun, from which $f$, the acluh, has escapecl; $g$. lsead of adult in front, enlarged.

The entire life history of the insects is interesting. The female in ovipositing touches the end of the abdomen to the surface, usually a leaf,-upon which the eggs are to be laid, and then elevates her body about a quarter of an inch, emitting at the same time a riscid thread which hardens on exposure to the air. At the tip of this the egg is fastened, and we gret thus a little 
grove of eggs on stilts. 'This is supposed to insure their safety from wandering predaceous forms that might otherwise feed upon them. When the larva hatches it climbs down the slender thread, and attacks and feeds upon the first suitable specimen it can find,--usually a young plant-lowes. Now, here is another peculiarity : it does not chew or tear its prey, but holds it firmly; sucking the juices by means of grooves on the inner sicle of the large mandibles, which are closed by the slender maxilla. The larva grows rapidly, becoming rather more than a quarter of an inch in length, narrow, spindle-shaped, pointed at the anal extremity, the head distinct and with prominent sickle-shaped mandibles. IVhen full-grown it spins, by means of anal glands, a perfectly spherical, white, silken cocoon of very dense texture, and small in proportion to the larva. It resembles a moderate sized pearl in form and appearance, and when the adult is ready to emerge, a circular lid is lifted off to give the matured pupa exit. Comparing the fully developed insect with the cocoon from which it issued, the marvel is great that it was ever packed away in so small a space.

These insects are really of much practical value, frequenting, as many of them do, tilled fields and orchards, feeding upon larva, plant-lice, and similar creatures. They become injurious, however, in some parts of California, where they attack and destroy coccinellid or lady-bird larve.

Somewhat closely allied in all stages to the Hemerobiidu are the Myrmeleonide, or "ant-lions," but they are larger, with longer and narrower wings, and clubbed antenne. As before, the adults are graceful, harmless creatures, which fly mostly at night, while the larva are predatory, resembling the "aphislions' in structure, save that they are broader and chunkier in appearance. They are also peculiar in that many of them capture their prey in pits or traps.

In constructing its trap, the larva usually selects a spot of moderately compact, fine sand, and excavates a funnel-shaped pit with the sides as steep as the sand will lie. It remains buried and invisible in a little gallery at one side of the bottom, in wait for any unlucky creature that may come within reach. Ants are the most frequent victims, from their wandering habits and their tendency to investigate, a pause at the brink resulting in a slip of 
simd and a tumble into the jaws of the enemy. Shoukl the ant recover a footing before reaching the bottom, a shower of sancl,
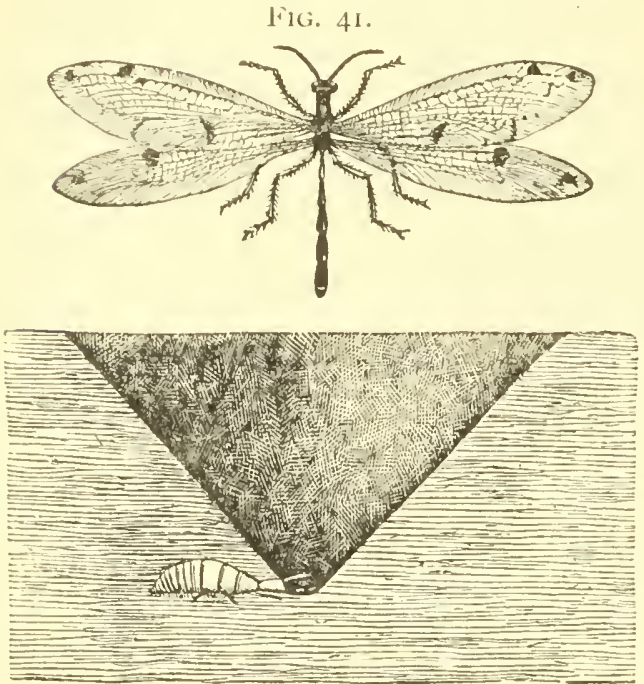

Mrymeleo species, - The adult above; the larva in its pit, which is shown in section. sent by the vigilant larva below, overwhelms and bring: it down to itsdeath. When the juices are exhausted, the enpty shell is throw out and the pit is repaired for other victims. Sometimes pits are made in saw-dust or friable leaf mold and some make no pits at all.

The adults are of two rather distinct series: the first with short antenure which

thicken rather gradually toward the tip, including . My meleo: the second with long, slender antenne, enlarging suddenly into a flattened club. The head is laryer and the body more robust, covered with stiff bristly hair, viving the insects a fierce appearance. The most common genus is Ascalaphus, and the larval habits are not known, though it is probable, from what we learn of forcign species, that they do not build pits or traps. Though interesting, the family is of no economic importance.

An odd family is the Mantispida, so named from the peculiar resemblance which they bear to the Orthopterous genus Ilantis. The species are not common, and are easily recognized by the enormonsly developed forelegs, which are fitted for grasping, and are inserted into a long and slender prothorax. They are predaceous, while their larve are parasitic in the egg-sics of spiders. The egers are laid on stalks, as with the "lace-wings," and the slender larve that hatch from them live through the winter without food, becoming active agim in spring, when they seek the 
egg-sacs of I ycosid or running spiders. The larva, that succeeds, enters the sac and begins feeding upon the eges, oratually losing its active form and becoming clumsy and grub-like. The pupa forms within the larval skin, and after midsummer the alult appears.

Very curious creatures are the Panorpida, or "scorpionflies," usually ranked as an order under the term Mecoptera. They have netted wings similar to but more robust than the " lace-wings," but have the mouth prolonged into a beak, at the end of which the biting parts are situated. In the genus Panorpa the males have a pair of huge anal forceps, curved up some-

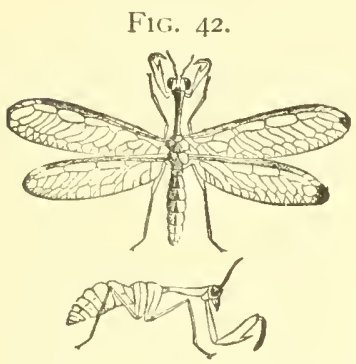

Mantispa species.-Showing the legs and body from the side.
FIG. 43 .
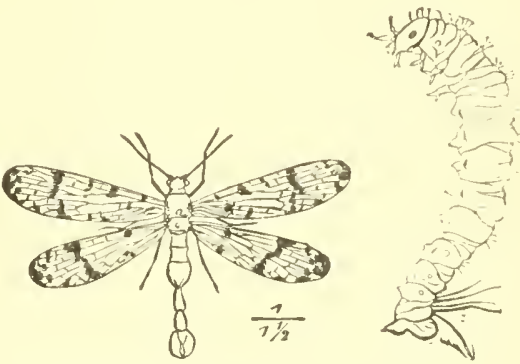

A Panorpa, or scorpion-fly, and its larva.

what like the sting of a scorpion, and from this the common name is derived. As a matter of fact, the insects are entirely harmless save to others of their kind, for they are predaceous. The genus Bittacus is narrower winged, with unusually long legs, looking somewhat like a crane-fly at first sight. Species belonging to the genus Boreus occur on the snow in very early spring. The larver, so far as we know them, are predaceous and resemble caterpiltars in appearance; they have eight pairs of fleshy prolegs, however, while no true caterpillar ever has more than five. None of the species are common and none are of practical importance to the farmer.

The "caddice-flies" have also been elevated to ordinal rank under the name Trichoptera, or " hairy-winged." The adults have moderately developed bodies, with large wings, which are more or less densely clothed with hair, the first pair often thicker 
than the second, which are folded beneath them. Both wings have numcrous longitudinal veins connected by only a few crossveins, losing the reticulated appearance of the more typical Neuroptera, and resembling more closely some of the lower moths, for which, indeed, some of the smaller forms may be easily mistaken. The mouth parts, however, though rudimentary, are mandibulate in type, and there is no approach to the coiled tongue of the Lepidoptera. The antennx are very long and slender, resembling hairs rather than jointed organs.

The species are found frequently in great numbers along the banks of streams, ponds, or ditches, in which the larval life is passed. The larva are caterpillar-like, with three pairs of unusually well-developed legs, and live in cases which they make of bits of sticks, moss, leaves, stones, slells, or other material, held together by silken threads with which the entire inside of the habitation is lined. Frequently the cases are roughly and irreg. ularly constructed; but as often they are marvels of skilled work-

Fig. 44 .

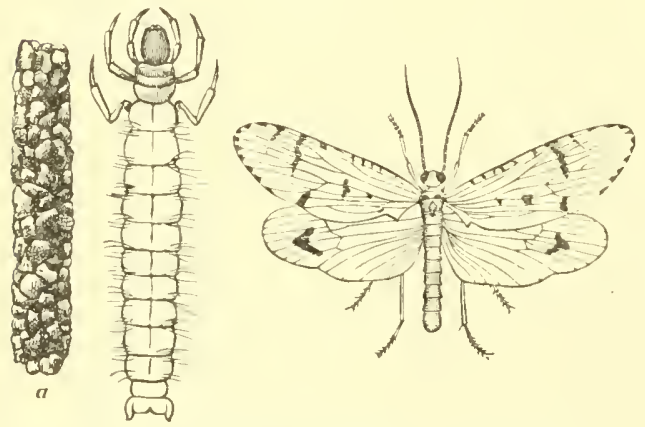

A caddice-fly, Limmophilus thombicus, its larva, and at a the larval case.

manship. Small stones are fitted so carefully that no break as large as a needle-point occurs, and sometimes they mimic shells so closely that conchologists have been deceived into believing them such. In these cases the larvæ live, and from them they obtain their common name "caddice" or case-flies. Whatever the form of the case, the insect lives in and carries it about everywhere throughout the larval life, crawling about under water by means of the large legs and keeping the soft, white, hind body constantly protected. Some live in ponds or sluggish streams, others in rapid brooks and torrents; some are vegetarians, some are predatory, feeding on other larvie or even on small fish. Some forms con- 
struct effective nets in which very young fish become entangled and fall easy victims to the insect fishermen. Streams in which these kinds of caddice-flies are abundant are not easily stocked with fish unless the fry is so well grown as to be out of danger from this source. Practically, the insects are of no importance to the agriculturist.

\section{CHAPTER I V.}

THE ORTHOPTERA.

Grasshoppers, Crickets, Katydids, etc.

THE order Orthoptera, or "straight-winged" insects, includes those forms with biting mouth parts and an incomplete metamorphosis, commonly known as "earwigs," "'grasshoppers," "locusts," "crickets," and "roaches."

The distinctive characters, aside from those just mentioned, are that the fore-wings are firmer in texture than the secondaries, and that the latter are folded fan-like, or plaited, when at rest. They are then covered by the primaries, which are usually narrow and of little use in flight, resembling in this respect the wingcovers of the beetles, and here termed "tegmina." With few unimportant exceptions the insects belonging to this order are herbivorous, and among them are some of the most destructive pests to agriculture, such as the migratory locusts or grasshoppers, which have been known and dreaded since the dawn of history, and the "Rocky Mountain locust," of evil repute in our own country.

First come the Forficulide, or ear-wigs, generally accepted as forming a separate order under the name Dermaptera (skinwing) or Euplexoptera (well-folded wing). They differ from all the other Orthoptera by having a pair of anal forceps and by their resemblance to the Staphylinida, a family of half-winged beetles. The wing-covers are short and thick, not extending to the middle of the flattened abdomen, and the large hind wings are first plaited fan-like around a point near the middle of the anterior margin, and are then transversely folded into a neat little 
packet, which is tucked away under the fore-wings by means of the anal forceps. Some of the species, however, lack the wings entirely, in which case the peculiar anal forceps and the beetlelike form distinguish them quite readily.

\section{FIG. 45.}
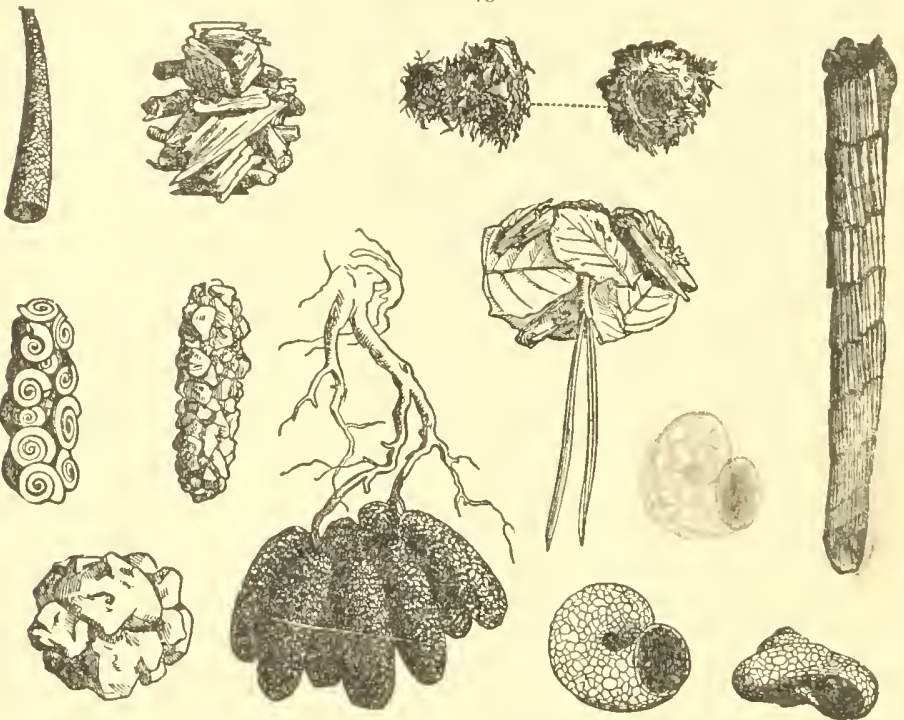

Cases or caddices, made by the larva of Trichoptera, illustrating differences of shape as well as varieties of material used.

Except in the South, ear-wigs are rare in the United States, and not injurious. In parts of Europe and in sub-tropical and tropical countries they are sometimes abundant and frequently annoying, eating at night into flowers in which they hide during the day. In vine- and flower-covered honses or arbors they are sometimes a nuisance, and their long, slender form and nocturnil habits have given rise to the unfounded belief that they crawl into the ears of sleepers and kill them. The female lays a small number of eggs only, and broods over or watches them until some little time after they are hatched.

The more typical Orthoptera may be conveniently divided into series by their leg structure and method of locomotion, as follows : 
I. The Cursoria, or "runners," with stout, long legs fitted for rapid motion, - like the roaches.

2. The Raptoria, or "graspers," in which the forelegs are developed into grasping organs and the insects are predaceous, -in strong contrast to all the others of the order.

3. The Ambulatoria, or "walkers," in which the legs are long and slender, useful for deliberate progress only.

4. The Saltatoria, or "jumpers," which have the hind legs anusually long and well developed, fitted for leaping,-like grasshoppers and crickets.

FiG. 46.
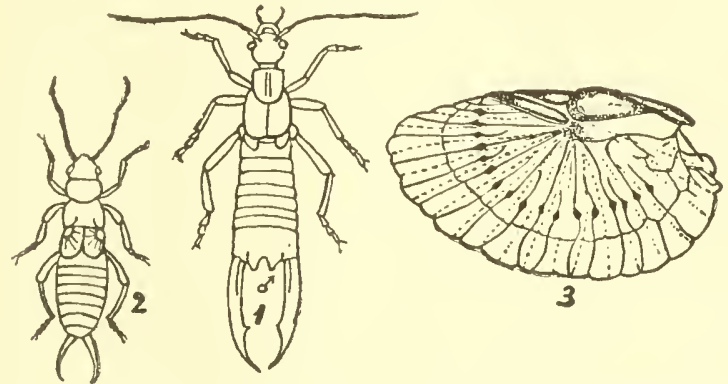

Ear-wig.-I, mature male; 2 , nymph; 3 , the wing, showing the radiate type of pleating.

The Cursoria, or "runners," belong to the family Blattida, or roaches. They are flattened; rather soft, repulsive creatures, with long, powerful, spiny legs; long, slender, filiform antennæ, and the head bent under the body so as to locate the mouth parts between the front legs. They are brown or yellow in color, are nocturnal in habit, and live under bark or in crevices, for which their flattened form suits them peculiarly well.

Roaches eat almost anything, or are practically omnivorous. They are among the most ancient type of insects, and are yet disgustingly common in the tropics, their numbers decreasing northwardly until only a few cosmopolitan forms are found domesticated in houses.

A peculiar feature in the life history is the method of oviposition. The eggs mature at about the same time, and are closely packed into a somewhat bean-shaped case, which the female carries about with her, partially protruding from the end of the abdomen, for sevcral days. It is then deposited intact in some 
convenient crevice, and very soon thereafter the young issue. Modifications of this habit occur, and in some cases the eggs act-

FiG. 47.

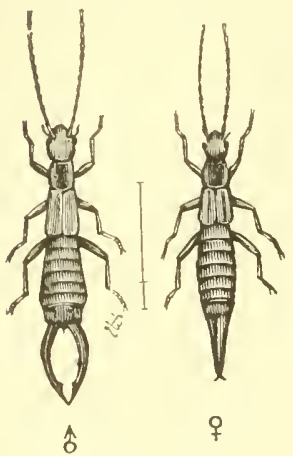

Forficula teniata, male and female. ually hatch within the body of the mother, who thus becomes viviparous.

I am not aware that roaches ever become injurious to growing crops in our country ; but two species are certainly great nuisances in houses, - the "Croton bug," Phyllodromia germanica, and the "black beetle," Periplaneta orientalis. Both are introduced and almost cosmopolitan forms. The former is small, averaging about half an inch in length, and is winged in both sexes. The latter is larger, varying between threefourths and one and one-fourth inches, with short wings in the male and mere rudiments in the female.

The most satisfactory way of dealing with these insects is by means of a phosphorus paste, spread upon bits of soft bread and placed near their haunts, all other food particles being carefully put out of reach. A short period of such treatment will usually prove effective. Almost as good is a mixture of equal

FIG. 48.

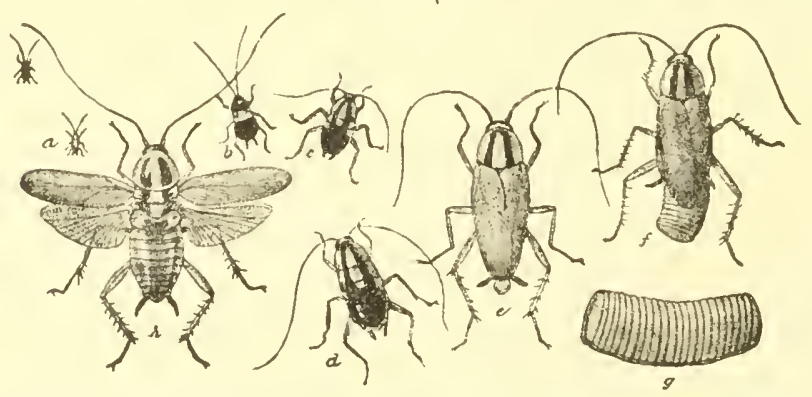

The Croton bug, Phyllodromia germanica.- $a$, first stage; $b$, second stage; $c$, third stage; $d$, fourth stage; $e$, adult ; $f$, adult female with egg-case; $g$, egg-case, enlarged ; $h$, adult with wings spread. All natural size except $g$.

parts of finely powdered chocolate and borax, dusted into the crevices where the insects hide. The mixture should be intimate, and is best made in a mortar, so that with each part of 
chocolate, of which the roaches are very fond, they will get also a particle of borax, which is poisonous to them. This mixture has proved successful in many instances within my own experience, and has the advantage of being cheap as well as non-poisonuus to man.

The Raptoria, or "'graspers," form one family, the Mantida, as odd in appearance as their habits are unusual. They are clumsy, heavy-bodied insects, with short, broad wings, the middle and hind-legs rather weak, but with an unusually long and slender prothorax, to which is attached a pair of huge forelegs, armed with sharp spurs and spines. The head is usually much broader than the prothorax, with prominent, often globular eyes, short antennæ, and so set as to be capable of lateral motion. It is, in fact, the only type capable of turning its head!

The insects are, as a rule, sluggish, those occurring with us incapable of rapid motion, depenaing entirely upon such prey as

FIG. 49 .

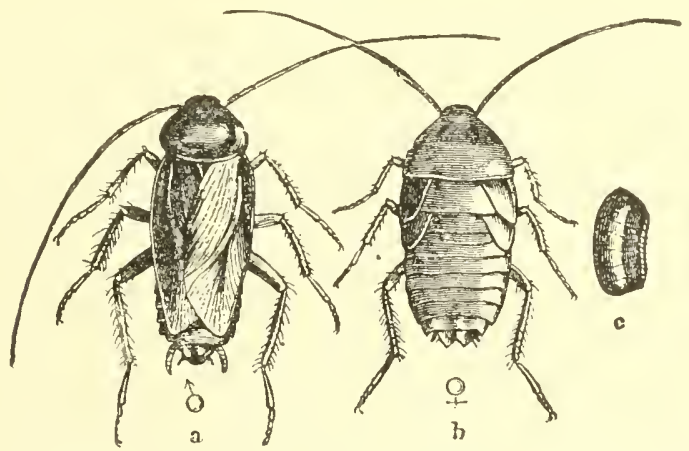

The Oriental roach, Periplaneta orientalis, $-a$, the male; $b$, the female; $c$, egg-case.

comes within easy reach, and securing this through their often remarkable resemblance to the vegetation among which they lurk. In other countries there are some more active species, capable of pursuing and capturing their prey. Their colors are green or yellowish, like leaves, or brownish, like bark ; the wingcovers sometimes mottled and roughened to mimic an irregularity or overgrown injury on a trunk or branch. Thus con- 
cealed, they rest, body close to the surface, prothorax elevated, and forelegs held in the attitude of prayer, whence the term "praying mantes," Mantis religiosa, which is applied to a for-

F1G. 50.

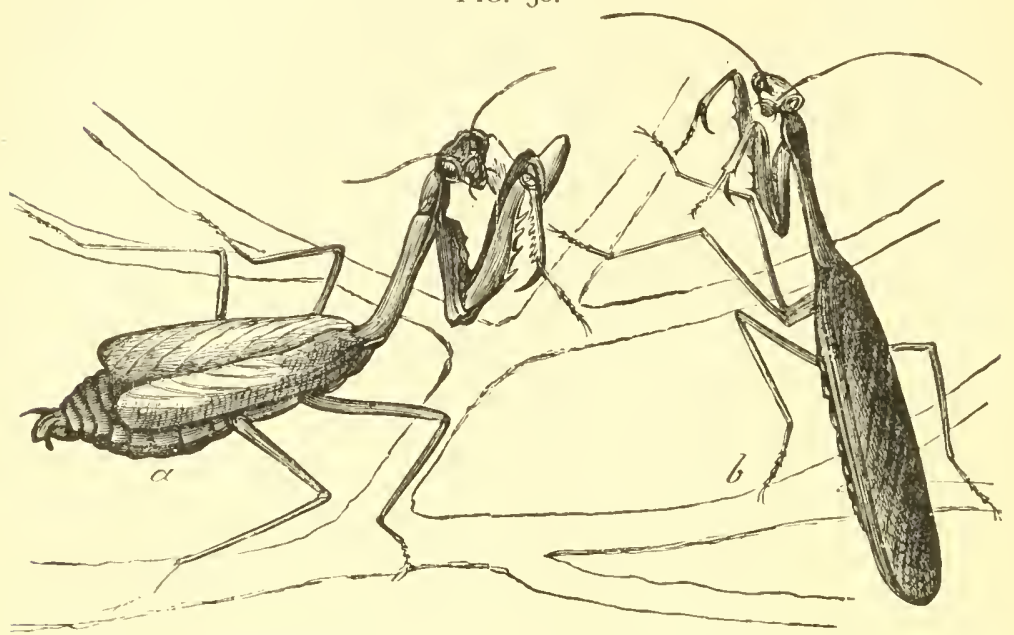

Slagmomantis carolina.- $a$, the female; $b$, the male.

eign species. But prayer is far from the object in view, as any small insect that happens within reach learns to its cost. A sudden clasp wounds and crushes it into helplessness, and the llantis then leisurely devours its victim, the forelegs serving admirably as hands in the operation.

The eggs are laid in a mass on twigs or branches, held together by a peculiar silken fibre which encases and protects each egg as well as the entire cluster.

The predaceous habit excludes these insects from the category of injurious forms; but they are not sufficiently common in our country to be of any practical advantage. They are southern in geographical range, and only one species, Stagmomantis carolina, is rarely found north of New Jersey on the Atlantic coast.

The Ambulatoria, or "walkers," include a series of very curious species, popularly known as "walking-sticks" and "walking-leaves," represented in our fauna by a few species velonging to the family Phasmida. The true home of these 
forms is in the tropics, where we find excellent examples of protective mimicry in the development of wings so colored and veined that the insects cannot be easily distinguished from the foliage upon which they feed. Our own species have mere rudiments of wings only; but have very long, slender bodies, antennæ, and legs. When at rest, with long legs fully stretched out, the resemblance to a bare twig or a torn leaf is perfect.

The insects move slowly and awkwardly, feeding on the foliage of a variety of forest trees, and are occasionally quite destructive. They do not extend north of the Middle States on the Atlantic Coast, but occur everywhere in the Central and Southern States, reaching northwardly in the Mississippi Valley much further than in the East. So far as I am aware, they never attack field or orchard crops, and are not strictly injurious to agriculture, though they may be to forestry. Unlike the families previously mentioned, they take no care of their eggs, but the females drop them at random upon the ground. It has been said that in a badlyinfested piece of woodland the pattering of the eggs as they fall from the trees sounds like rain.

Thoroughly and carefully burning over infested woodland during some favorable period in winter will prove effective in case remedial measures become necessary; spraying with arsenites can be resorted to for the protection of single or small groups of trees.

In the Saltatoria, or "jumpers," we find the most destructive species, and they separate readily into three families: the Acridide, or "short-horned grasshoppers ;" the Locustida, or "long-horned grasshoppers" and "kitydids ;" and the Gryllide, or " crickets," which have long horns or antennit like the Locustide,

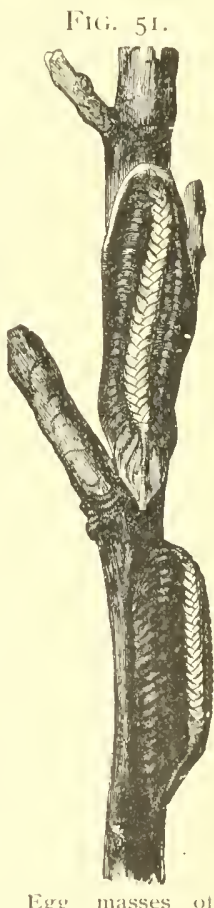
stagmomantis car olina, from above and from side. but cylindrical instead of flat, sword-like ovipositors.

The Acridida, or short-horned grasshoppers, are among the most common and best known of our insects, flying up or jumping out of the way, however one turns, among grass or low herb- 
Fig. 52.

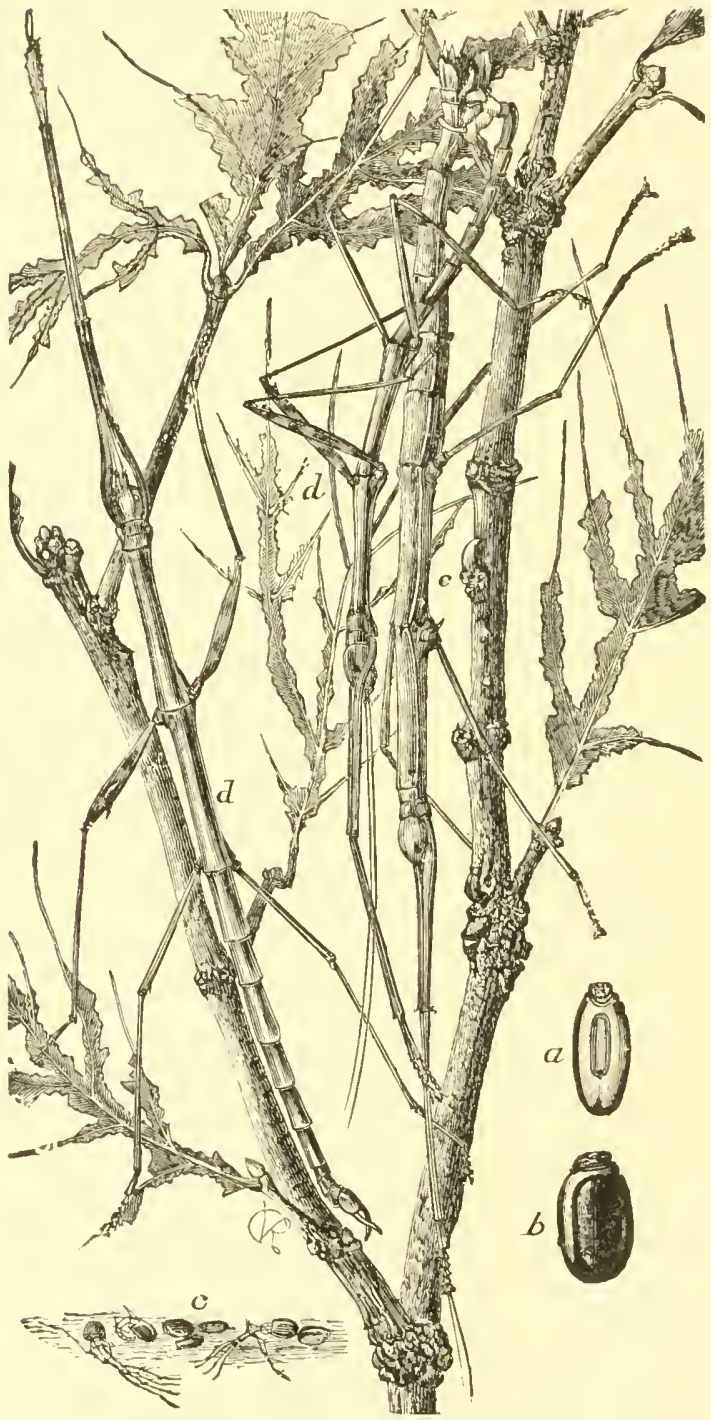

Walking-sticks, Diapheromera femorata. $-a$ and $b$, the eggs, enlarged, from the eage and side; $c$, young just hatching; $d$, the male, and e the female adult. 
age in roads, fields, or meadows, but not favoring dark woods. They have no external ovipositor, but the female is furnished with four horny valves, between which the eggrs pass, and which are also useful in making the hole, in soil or wood, into which the eggs are laid. The term "short-horned," as applied to these insects, is relative, and means that the antennæ are moderately stout, the joints well marked, and the whole member not as long as the entire insect, - in fact, rarely even half as long. A curious

Fig. 53 .

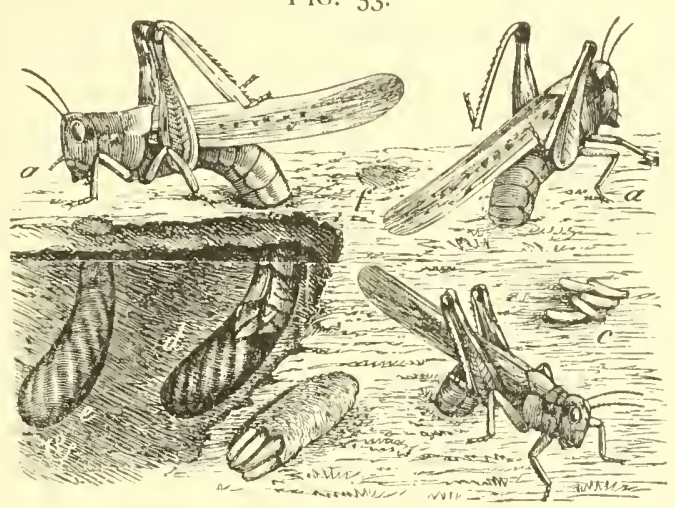

Rocky Mountain locust ovipositing. $-a, a$, females with abdomen inserted in the soil; $b$, an egg-pod broken open and tying on the surface; $c$, a few scattered eggs; $d$, section of soil removed to show eggs being put in place; $e$, an egg-pod completed; $f$, an eggpod sealed over.

character is a pair of ears situated one on each side of the basal segment of the abdomen, and we therefore expect and do find that most of the species are capable of making some kind of song or noise, though this ability is confined to the male.

A series of species characterized by a very receding front, meeting the vertex of the head in an acute angle, is referred to the sub-family Tryalince, of which there are many species throughout our country, none of then abundant enough to be injurious. They are partial to low, sedgy land or meadows, especially on sandy soil, and I have met with the species most abundantly near the sea, or on the sandy plains not far inland. Some species are common on or near cranberry bogs, but are not injurious.

Quite a series of species is referred to the sub-family $Q$ idipodina, 
and these differ from the preceding in that the front meets the top of the head in an even, obtuse curve. The species are usually long-winged, and the thorax is either crested or rough and tuberculate, with somewhat prominent and sharp angles. Quite usually the hind wings are brilliantly red or yellow and black, sometimes blue, and frequently contrasting in color. To this sub-family belong those species that fly early in spring and

FIG. 55 .

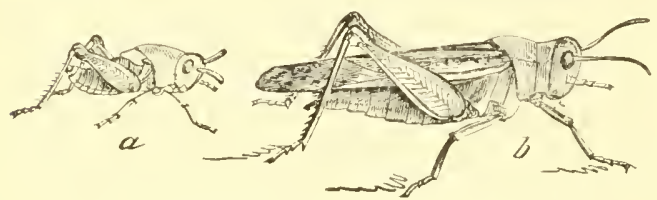

Chortophaga viridifascia.- $a$, larva; $b$, adult.

have wintered in an immature stage, ready for the transformation to the adult form as soon as the weather permits. Good examples of such species are the green-striped locust (Chortophaga viridifascia), which occurs over a large part of the United States, and has the hind wings without strong contrasts; and the large, red-winged Hippiscus discoideus, which is more southern in its range, not extending north of New Jersey. Species of this kind are most frequent in barren, sandy, or partly desert regions, and few ever become injurious.

Among the troublesome forms are the "Carolina locust," Dissosteria carolina, and the long-winged locust, Dissosteria longipennis; the first found throughout the United States, and easily recognized by its large size and the ample, black, yellow-bordered hind wings; the latter a similar but somewhat longer-winged western species, usually confined to the Rocky Mountain region, but sometimes migrating for considerable distances from their normal breeding-places. These species deposit their eggs in the ground in the fall and the young hatch in the spring.

The "Carolina locust" is often met with in late fall, clinging fast to the tops of plants, killed by a fungous disease which ordinarily keeps the species within bounds. It is further conspicuous by its habit of poising a few feet from the surface, and making a continuous "whirring" or rasping sound.

The sub-family Acridina is one of great extent, containing those grasshoppers that have become famous by their evil deeds, 
Fig. 5 s.

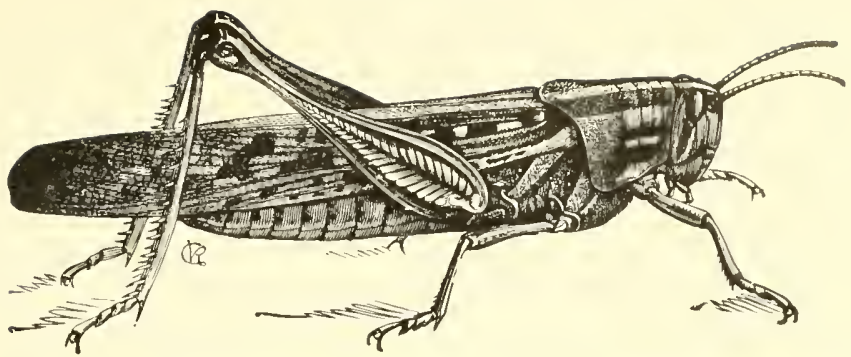

FIG. 57 .

Fig, 6o.
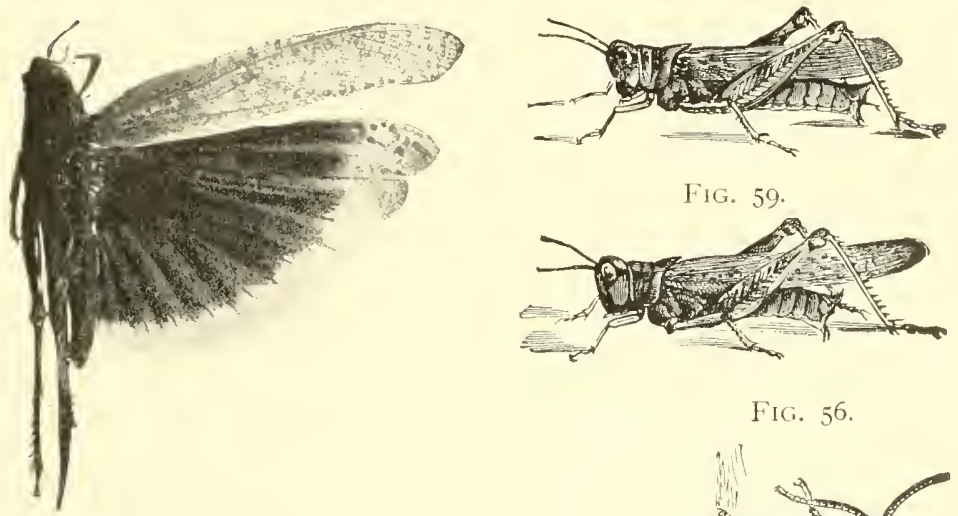

FIG. 59 .

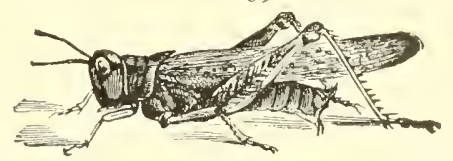

FIG. 56 .

FiG. $5+$.
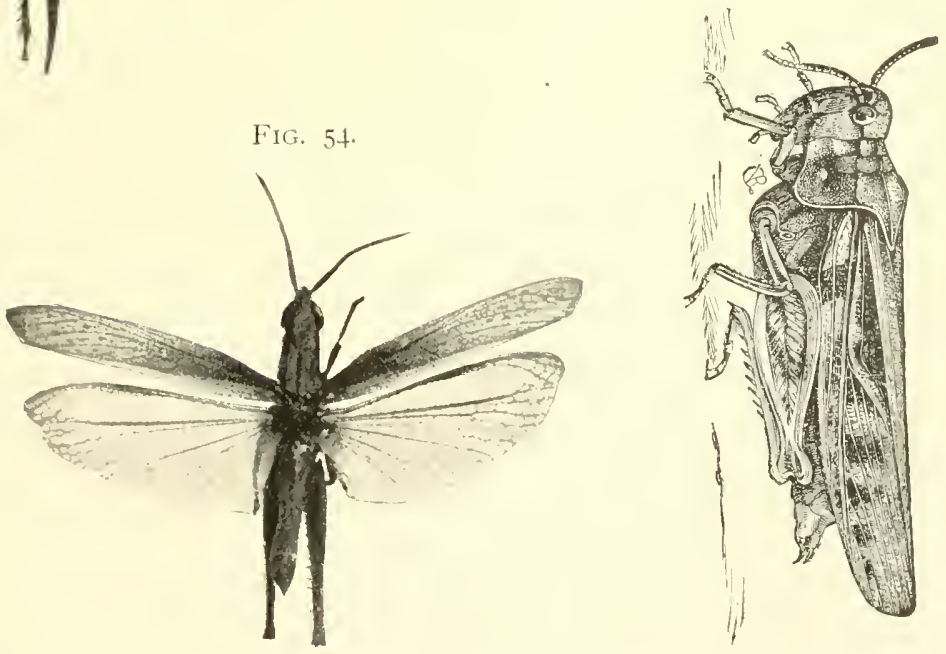

Fig. 54, Syrbuia admirabilis. Fig. 56, Hippiscus discoidens, Fig. 57, Dissosteira carolina. Fig. 59, Schistocerca americana. Fig. 59, Melanoplus spretus. Fig. 60, Melanoplus atlanis. 

and it differs from the preceding in having the breast between the anterior legs produced into an obvious tubercle or printed process. The prothorax is usually smooth and quite even, rarely ridged or crested or even angulated, and the hind wings are not often contrastingly coiored.

The typical genus Acridium of older authors contained the long-winged forms, which, hatching in great numbers in their natural haunts, sometimes find food insufficient, and are seized with a migratory mania that impels them to rise, by what seems common consent, and fly to fresh fields and pastures new. Such swarms may number uncounted millions of specimens, and they leave a wake of devastation which only those who have seen can appreciate.

The species described in biblical history is the Schistocera peregrimum, or true migratory locust, and is strongly resembled, except in size, by the Schistocerca americana of the Eastern United States, which is common and sometimes destructive in the South, but becomes more rare northwardly, until in Central New Jersey it is but occasionally seen. In all the species of Acridium the wings are longer than the abdomen, and in the males the tip of the abdomen is not swollen. The sexes in these insects are easily distinguished, hecause the female abdomen terminates in four pointed, horny valves, or pieces, no trace of which is found in the males.

Perhaps this is a convenient place to describe the life history of grasshoppers, or Acridizda, in general. The eggis are most frequently laid in the ground, though sometimes in partly decayed wood, the horny valves already mentioned serving to make the holes. The species that oviposit in the ground select a moderately hard or compact soil where obtainable, not too densely covered with vegetation, and then force the abdomen into it as deeply as possible. When this is accomplished the eggs are laid, each coated with a gummy secretion which causes it to adhere to its neighbor and to form a pod, extending ahmost to the surface. The hole is then closed, and becomes indistinguishable except on close examination. In this state they remain through the winter, the young hatching during the following spring or early summer. The term nymph rather than larva is employed for these young, unfledged grasshoppers, and 
in this stage their travelling powers are limited, though their appetite is not. Yet even now they are able to cover considerable distances if a short food supply makes it necessary. The wing pads, which become visible early in the nymphal hife, increase in size until the insect is ready for its final change, and when this occurs its powers for destruction are multiplied by the new facility in travelling. In some species the wings never become developed even in the adult; but these are easily distinguished from the immature stages of winged forms, because in the latter the rudiments of the hind wings always cover those of the forewings, while in adults, even when the wings are mere stumps, the secondiries are always overlaid or covered by the others.

Our best-known migrating forms belong to the genus Melanoplus, in which the anal extremity of the males is enlarged and swollen. Here we find the Melanoplus spretus, or "Rocky" Mountain locust," which in years past has caused ruin in many States west of the Mississippi, and even yet does much injury and periodically threatens disaster. The home of this species, about which volumes have been written, is on the high, dry, eastern slopes of the Rocky Mountains, and in some regions west of these mountains in Idaho and Utah. There it breeds abundantly each year, frequently extending into the adjacent regions to obtain food and maintaining itself for some time. As a result of any unusual increase in numbers with a corresponding failure of food-supply, emigration may become necessary, and the long, broad wings of the species suffice to carry it even to the Mississippi River, ranging north and south from Minnesota to Texas. But in these moist eastern regions the insect cannot thrive, and from millions of eggs laid only a small proportion of weakly larve appear, which usually die before they mature.

An allied but shorter-winged form is the Melanoplus atlanis, or "lesser locust," which occurs commonly over all the more northern United States, while the 11. femur-rubrum, or "redlegged locust," is much the most common eastern species, sometimes doing considerable injury to crops.

Among the more common short-winged forms we have in the East species of Paroxy'a, in which the males are smaller and ready fliers, the females much larger, with wings covering half the abdomen, and used rather as aids in leaping than as organs 
of actual flight. The species of Pezotettix and allied genera are short-winged in both sexes, are of medium or small size, and prefer cool or shady spots on mountain sides, among rocks, at the edges of woods, or in similar localities, hence never become economically important. The species are most numerous in the West and South.

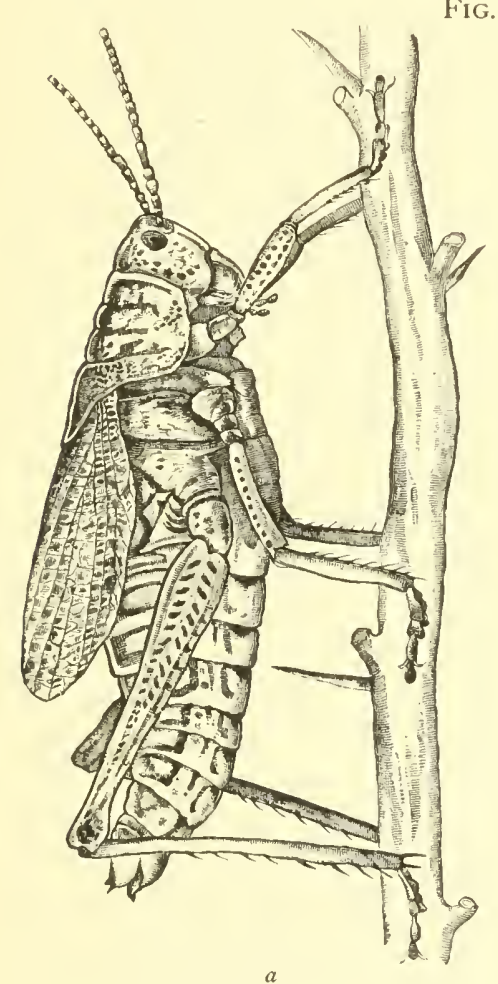

FIG. 6I.

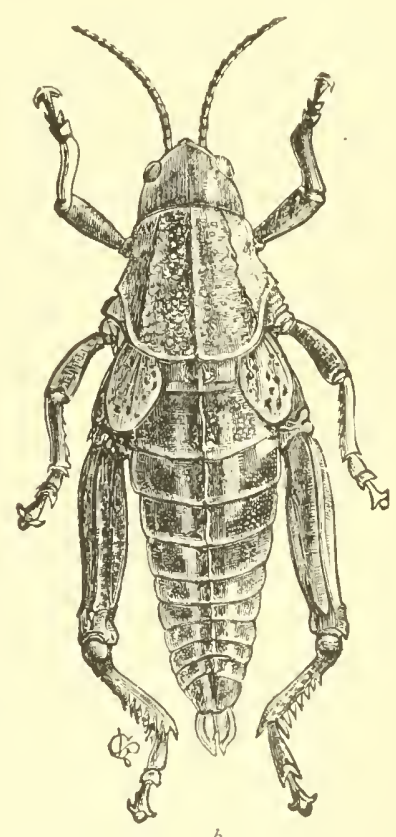

Lubber grasshoppers.-a, Dictyophorus reticulatis; $b$, Brachystolu magna.

Two very large and clumsy species occur, both known as "lubbers;" one in Florida, short-winged, yellow and black, is Dictyophorus reticulatis, - the other, a IVestern plains species, dirty-brown in color, and with mere rudiments of wings, also known as the "Buffalo grasshopper," is Brachystola magna.

Last to be mentioned in this series are the "yrouse locusts," or Tettigince. These remarkable little creatures have the pro- 
thorax very much developed and extended backward so as to cover a large part or even all of the abdomen. They frequent banks of streams and moist places, resembling in color Fig. 62. the deat leaves or muddy flats where they often occur,

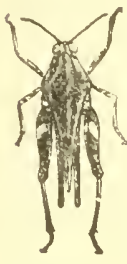

Tettix and they are powerful leapers. Many of the species are found as adults early in spring, while I have found others in September. None of them are known to be injurious.

\section{REMEDIES.}

The question of remedies against the "locust," or short-horned grasshopper, is an important one, not always easy of solution. As the country is brought into more complete cultivation the "grasshopper" pest will naturally decrease, injury from the migrating forms only remaining to be dreaded.

In the general life history it was said that a large proportion of the esgs are laid in fall, remaining unhatched cluring the winter. The young nymph, or larra, is a feeble insect, able to dig to the surface through the way opened by the pod, or through loose soil, but scarcely otherwise. Fall-plowing the infested land is therefore a most effective remedy. If the pods are deeply correct, the young die attempting to get to the surface; if lightly corered or exposed, their natural enemies find them easily : and when the pods are broken, rain and sumshine induce decaly or disease, and the eggs never hatch. Where grasshoppers other than the migratory forms are troublesome, systematic fall-plowing will effect a prompt reduction in their numbers. Special or limited localities, like cranberry bogs, are sometimes infested, and in such cases turkeys are effective. They prefer grasshoppers to almost any other food, and, if allowed to run where such abound, will eat nothing else. In some cases the arsenites may be used to protect crops which are easily sprayed, and occasionally "driving" will answer for the fledged insects.

Larval forms in grass or short regetation can be collected in large pans or "hopper-lozers," drawn by men or horses, and coated with coal-tar, crude petroleum, or other sticky substance, and of all these the crude petroleum is to be preferred.

As against the migratory forms in their permanent breeding grounds, I have no suggestion to make here. The subject has 
been treated at great length in the reports of the U. S. Entomological Commission and of the U. S. Department of Agriculture, and these must be consulted : the methods discussed and recommended are too numerous for reference here. In the invaled regions fall plowing to destroy the eggs and the use of the "hopper-dozer's" on the young are indicated.

Under some circumstances, when the number of grasshoppers is not too great, they may be destroyed, or a large measure of protection may be secured, by tempting them with poisoned bran, of which they seem to be rather fond. It should be composed of bran and Paris green, at the rate of one part of Paris green to fifty by weight of bran, thoroughly moistened with sugar water. Cabbage patches can often be protected in this way against grasshoppers that come from uncultivated land, and there are other cases where such a measure is of value. Individual judgment must determine those cases.

The Locustide are "long-horned grasshoppers," " meadow grasshoppers," and "katydids," distinguished at once by very long, slender antenna, rarely shorter than, and usually much exceeding, the body. They are green in color as a rule, with slender legs and thin wings, and we find them a vast array of musicians, - always the males only, - the sound-producing structure occupying a triangular area at the base of the fore-wings, where they overlap. Here one or more of the veins is elevated and ridged on each wing, and by rubbing these ridged surfaces together a strident sound is produced, intensified by a membrane tightly stretched between them. The pitch and volume of the "song" are regulated by the development of veins and membrane as ryell as of the tegmina, no two specics being alike in this respect. Special students of the family soon learn to recognize the sounds made by the different species as certainly as ornithologists know birds by their song. The

FiG. 63.

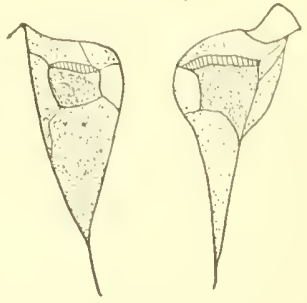

Overlapping portion of the base of the wing in Conocephalus, showing the ridged veins and sound-producing organ. ears through which the songs appeal to the courted females and competing males are situated on the fore tibice, and are essentially like the same organs found on the abdomen of the Acridida. 
Another feature peculiar to this family is the exserted, prominent, blade-like ovipositor of the female, which indicates an essentially lifferent method of oviposition. This, in fact, exists, for the eggs are mostly laid in plant tissue,-usually in the stems of reeds and grasses, among which some forms abound, - sometimes in woody tissue; rarely in leaves, the edges being split to receive them; and only occasionally are they laid externally. Certain cricket-like species are exceptions, and oviposit in the ground.

The most prominent, from their large size, are the species loosely termed "katydids," - insects which are familiar by their song, but are not always personal acquaintances, because they are most active and noisy in the evening, and prefer trees and shrubs to more modest plants. The true "katydid" is Cyrtophyllum concarum, much the heaviest in build of all our species, with very broad concave wing-covers and an unusually developed sound-producing structure. In fact, the entire forewings are immense sounding-boards, enabling the insect to make itself heard at great distances. It produces its characteristic note three or four times in succession, with slight intervals only, bearing thus a semblance to "Ka-ty-did" or " Ka-ty-did-n't :" occasionally it merely rasps out "Ka-ty."

This species litys its ovate, slightly convex eggs into the twigs or trunks of trees late in fall, and the young appear during the early summer following.

One of the most common of the large species, found over a great part of the Northern United States, is the Aicrocontrum retincrois, replaced in the South by the allied M. laurifolium, which lay their large eggs externally in regular rows on the edges of leaves, on twigs, or on any sort of likely or unlikely place,e.g., the pulley-strap of a sewing-machine. The Southern species is the more common, and in Florida becomes injurious to young orange-trees by eating the foliage. They can be kept in check on such trees by collecting and destroying the eggs during winter, by collecting the insects themselves, or by spraying the foliage with one of the arsenites.

The genus Scudderia contains smaller, narrower-winged species, in which the tegmina are not expanded in the middle and the ovipositor is curved sharply upward. They frequent shrubs 


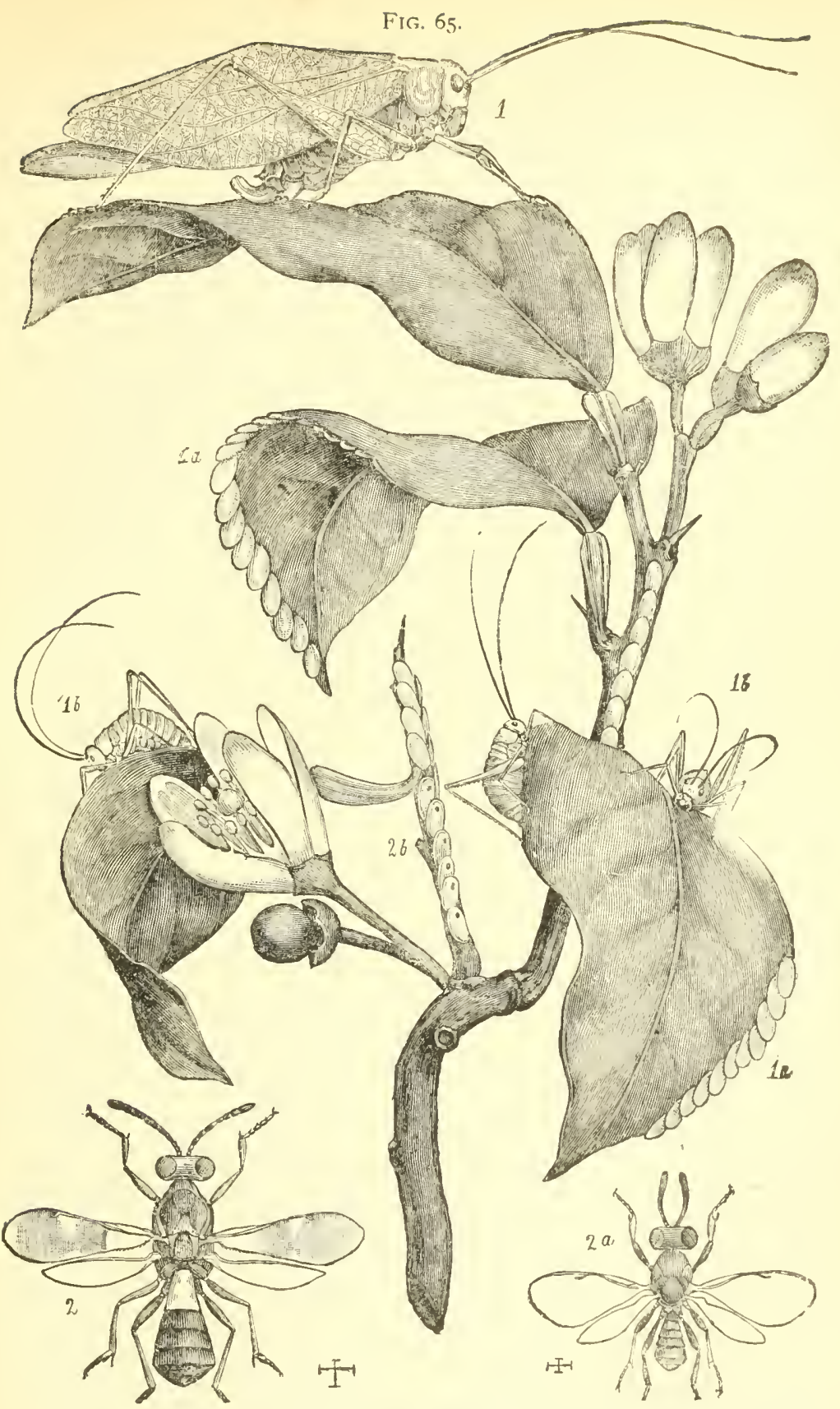

The Southern katydid, Microcentrum laurifolium.-1, the female adult; $1 a$, eggs laid on leaves and twigs of orange; $t b$, the young katydids; 2 and $2 a$, fernale and male Eupelmus mirabitis; parasites on the eggs at $2 b$. 
and low vegetation, often near marshy or boggy land in sandy districts. The egge are sometimes laid in the edges of leares, singly, between the upper and under surfaces, and are so thin that they can be perceived with difficulty only. They swell, however, very considerably before hatching.

In New Jersey species of this genus sometimes do great injury on cramberry bogs, eating out the seed-capsule of the berries and rejecting the pulp. A single specimen may eat, at one meal, the seed-capsules of five or six berries, and in a week lalf a peck may be destroyed or remlered unmarketable.

Turkeys exercise a good effect here also, the insects recognizing the presence of an enemy in a very short time and learing the bogs. A good method of lessening the injury is to burn oser the ground around the infested district to destroy the eggs. Nature itsclf cloes much to check increase, the number of specimens areraging about the same from year to year; so any intelligent interference by man must be to his advantage, and a destruction of the dropped leaves, especialiy of oak, which may contain eggs, will be a gain.

Next in size and musical ability are the "cone-nosed grasshoppers," Conocephahus, with very long antenne, very long hind legs, very long and narrow fore-wings, and a pointed, conically. projecting head. In the female the ovipositor is as long as or longer than the rest of the body. These insects may be quite common, yet rarely seen, because of their resemblance to the reeds, grasses, and other vegetation among which they live. They do not become active until late in the afternoon, and may be located by their loud, shrill, long-sustained song. Then, quictly waiting until it is resumed, the male may be seen with wings rapidly vibrating and usulally near his mate, for whose benefit all this concert is produced. The egress are laid in the stalks of the reels and grasses among which the insects live: hençe late mowing of infested meadlows, or burning over, during the winter, swampy or marshy spots in which they breed will keep them in check when they become troublesome.

Close relatives of the above are the smaller, green meadow grasshoppers, largely members of the genera Orchelimum and Xiphidium, - the former with curved, the latter with a straight ovipositor in the female. These species all prefer moist lands 
Fig. 68.

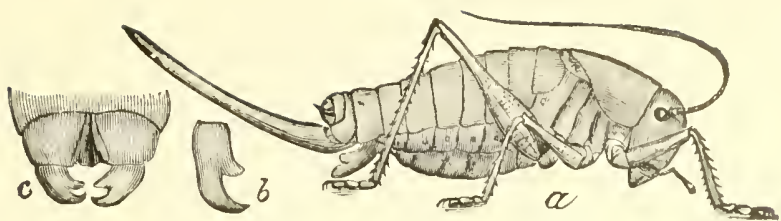

Fig. 64.

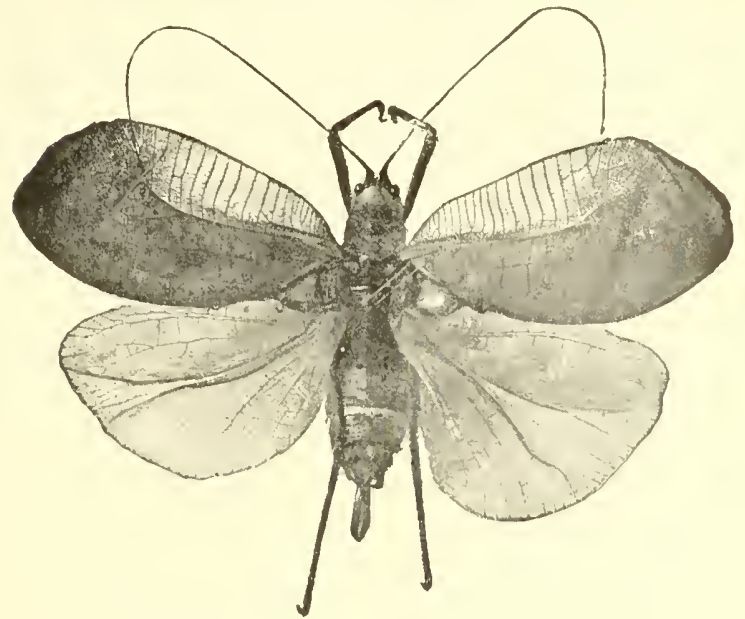

FIG. 66.

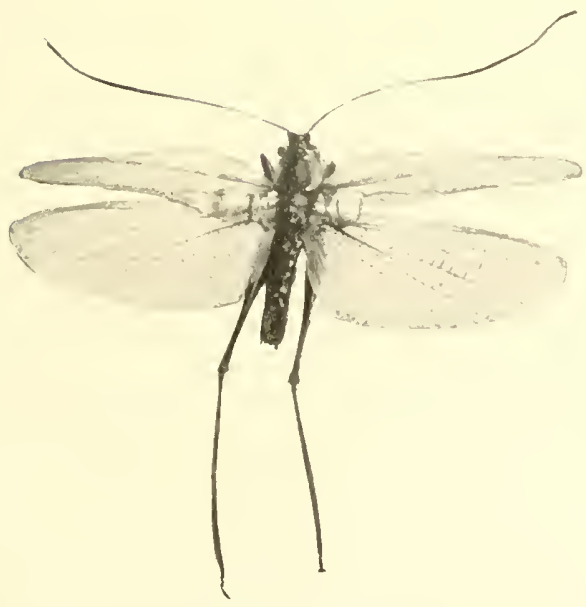

FIG. 67.

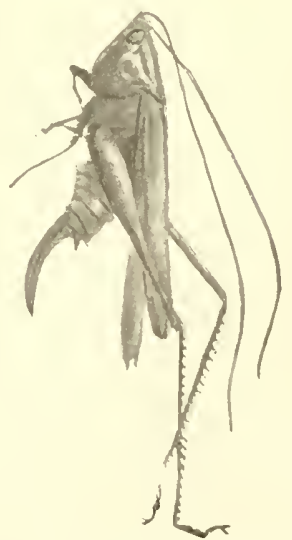

Fig. 64, the katydid, Cyrtophyllum concazum. Fig. 66, Orchelmmum vulgare, male. Fig. 67, Orchelimum vulyare, female, from side. Fig. 68, Mormon cricket, Anobrus simplex: $a$, female; $b, c$, anal parts of the male. 

with rank vegetation abounding in reedy grasses, in which they lay their eggs, and among which they sport and sing, except during midday. They are especially fond of eating the seeds of grasses, and sometimes become troublesome from this habit. The late mowing and burning suggested for Conocephalus will answer in this case as well.

We find quite a departure from the normal type in a series of wingless or short-winged species erroneously called "crickets," and, more correctly, "shield-backed grasshoppers." In the Eastern United States these are rare, found under stones or rubbish in woods, sometimes in caves. Some are blind, and others have equally interesting structures, but are of little or no economic importance. From their peculiar humped shape some are known as "camel crickets." In the West these species become more abundant, and, at the base of the Rocky Mountains, extending up into the foot-hills, they find their true home. Here the "Mormon cricket," Anabrus simplex, occasionally multiplies so greatly that it migrates to the plains below, destroying everything in its path. As the insects are wingless they move but slowly, and may be often checked by ditching in their path. They are very pugnacious, with cannibalistic tendencies, falling upon and devouring any injured comrade, and indulging in free fights when driven into a corner. A plowed field in their course forms a barrier difficult for them to pass, and in such an army of the insects can be materially reduced or exterminated by means of heavy rollers.

Yet more cricket-like are the clumsy, large-headed species of Stenopalmatus, known on the Pacific Coast, where they occur, as "sand-crickets." They are sometimes quite plentiful, but have not been known as injurious, since they are partly carnivorous in their food-habit.

The crickets belong to the family Gryllida, and differ from the Locustida in that they have the wings laid flat on the back, the fore-wings abruptly bent down at the sides, and, in the female, have the ovipositor cylindrical or needle-like, instead of flattened or sword-like. This ovipositor usually has a little enlargement, somewhat resembling a spear-head, just before the tip, which facilitates placing the egg. The males are even greater musicians than the Locustida, the entire wing-covers being modified into a 
stridulating organ. Here the sound is produced by the ridged edge of one wing-cover scriping over the ridged veins of the other, setting into vibration the membraneous spices in both wings. The ear is situated on the fore-tibia, as in the Locustida.

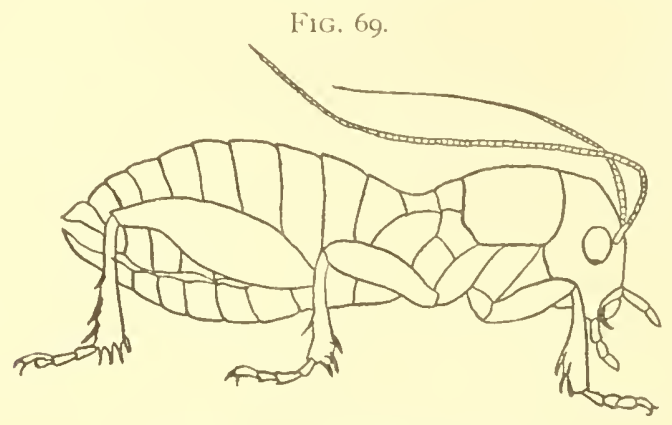

A sand-cricket, Stenopalmatus species.

The mole-crickets are curious, subterranean creatures, with small heads and powerful forelegs, developed somewhat like the corresponding organs in the mole. The larger, more common species belong to the genus Gryllotalpa, and are more frequent

Fig. 70 .

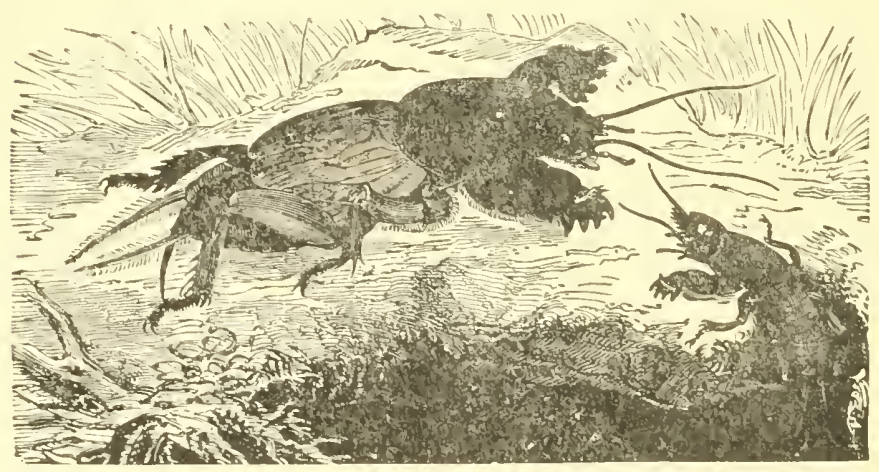

Mole-crickets, Gryllotalpa species.

in the South and Southwest, where they occasionally injure field crops. They are strictly nocturnal in habit, and remain during the day in their burrows, in which a chamber is excavated to contain the eggs. 
When they are sufficiently numerous to be troublesome, the insects may be attracted to the sweetened and poisoned bran mixture heretofore mentioned, and this will usually check injury.

The field-crickets, species of Gryllus, well known to all, are found nearly everywhere, even in houses. They are usually darkbrown or blackish in color, with large, broad heads, and rather short though powerful hind legs. They are very active, and jump about so errat ically that it is not

Fig. 7 I.

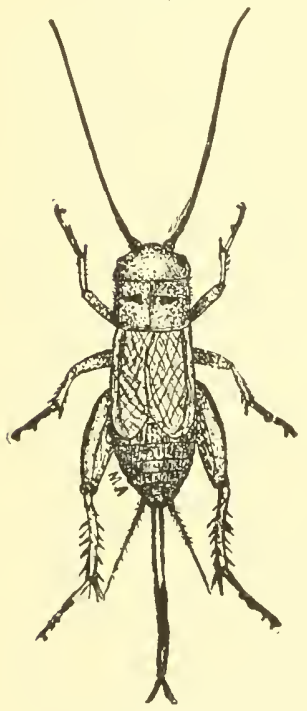

A field-cricket, Gryllus species.
F1G. 72.
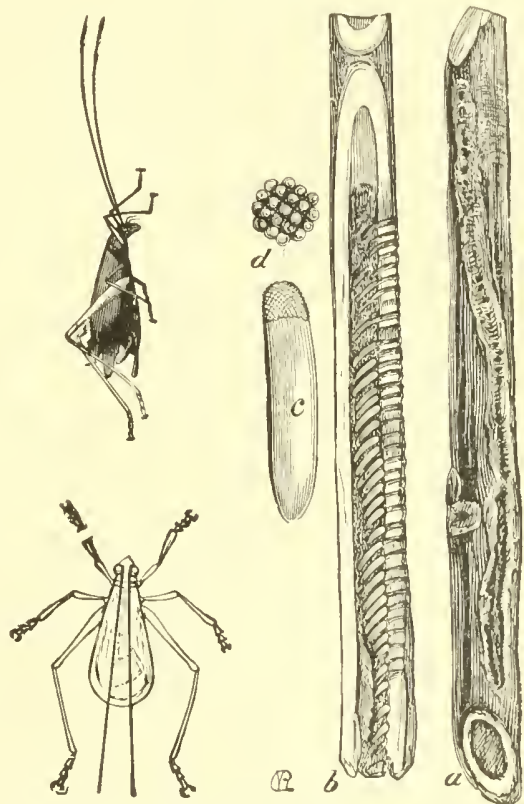

Thetree-cricket, (Econthus nizews, female from the side, male from above. $-a$, blackberry cane showing egg punctures; $b$, the same, split, to show the arrangement of the eggs; $c$, egg, very much enlarged; $d$, its tip, yet more enlarged.

always an easy task to capture the specimens. There is less trouble in the fall, when the female is ovipositing in warm, sandy spots, and the male is watching her, keeping up a constant singing during the operation. As a rule the species winter in the egg state, but occasionally nymphs and adults survive, and a solitary and melancholy chirp in spring now and then tells of such a speci men. Most of the species are plant-feeders, yet rarely attack 
green vegetation; fruits like cranberries are occasionally eaten into, and sometimes roots or tubers are attacked; but the injury is rarely of economic importance.

Crickets are pugnacious as a rule, occasionally eating their companions, or such other soft-bodied specimens as fall in their way, while "cricket-fights" are not unknown in the lists of sports.

The tree-crickets, Ecanthus, are more slender and graceful than any of the preceding. and more ready fliers. They are green, yellowish, or graty in color, and live on trees or shrubs. feeding chiefly upon plant-lice and other soft-bodied insects of various kinds. They lay their eggs in the stems of pithy plants like blackberry and raspberry, puncturing the wood by means of their powerful, auger-like ovipositor. Quite often these punctured canes die, but practically little damage is done unless the insects are much more abundant than I have ever seen them. In either blackberry or raspberry canes the punctures are so readily seen, especially in spring, that they can be cut out while trimming and the whole brood destroyed. This is indeed the best method of dealing with these graceful creatures, who have little resemblance, except in essential structure, to their lowly and sordid cousins of the field.

\section{CHA PTER V.}

THE HEMIPTERA, OR BUGS.

THE term Hemiptera means half-winged, and is primarily applied to insects in which the wing-covers are partly thick and leathery and partly thin and membraneous, the latter texture obtaining towards the apex. The term becomes inapplicable, however, in those insects which, agreeing otherwise in structure with the half-winged species, have the anterior wings of the same texture throughout, whether like that of the hind wings or decicledly thicker. To distinguish the two series the terms Heteroptera, meaning "different wing," and Homoptera, meaning "equal wing," are applied. Besides these there is another division which has no wings at all, and, owing to the fact that 
the species live and feed upon animals, this is called Parasitica. All these agree, however, in the essential character of the order, which is found in the structure of the mouth parts. Throughout all series we find the head prolonged into a jointed beak or rostrum, obsolete only in the Parasitica, and within, protected by it, is a series of three or four slender, needle-like lancets. The beak is open in front, and the lancets may be protruded at the tip. In most species, when the insect is feeding, the lancets are so deeply inserted that the beak bends at or about the middle, Seaving them entirely free except at the tip. In other cases, among predaceous types, the beak is too rigid to bend thus, and it, as well as the lancets, is forced into the tissues upon which the insect feeds. It is to insects of this order only that the entomologist applies the term "bug," and when he uses that word he always refers to one of the Hemiptera. It has been indicated that the creatures gain their food by piercing and sucking, and this is a radically different method from anything found heretofore. We have now insects that are incapable of chewing food, and subsist only upon liquids which must be drawn from living tissue, be it animal or vegetable. A large proportion of the spe. cies is injurious; but there are also groups of predaceous habit, feeding upon other insects in whole or in part, that may be considered beneficial. In their development the insects belong to that series in which the metamorphosis is incomplete; but there is an exception in the males of certain bark-lice, where there is a real, quiescent pupal stage.

Before going further on this subject it is necessary to refer to the peculiar little species known as Thrips, and belonging to the family Thripida. They are now as a rule, and properly, separated from the true Hemiptera under the ordinal terms Thysanoptera, meaning fringe-winged, or Physopoda, meaning bladderfooted. They are always small in size, slender, active, with the head so narrow that they seem pointed at both ends. The wings are laid longitudinally on the back, and are very narrow, transparent, without veins or with mere rudiments, but with lengthy fringes, which give them a characteristic and peculiar appearance. The feet are not terminated by pointed claws as usual, but by small, bladder-like dilations of the terminal joints. They run and fly readily, and some of them jump much as do spring-tails. 
The mouth structure is in some respects intermediate between that of the true bugs, as already described, and that of the mandibulate type; but there are no Fis. 7.3 .

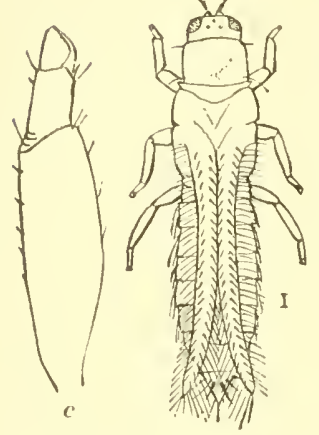

c

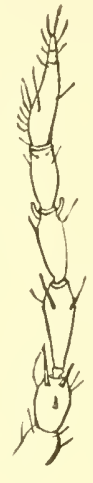
true mandibles, and the insects cannot chew their food, hence come naturally, for our purpose, into this order.

The species of Thrips are often seriously injurious to vegetation. They sometimes attack onions in great numbers, puncturing the succulent leaves, and everywhere leaving a small yellow dot. As these increase in number the leaf loses vitality, the top itself turns yellow, and in serious cases the rich green of a normal onion field is changed to a peculiar, sickly yellow. The insect is yelluwish when immature, and blackish-brown when the wings are developed.

Cibbages sometimes suffer in a similar manner. The insects in this case are yellow, and congregate in large numbers on the lower side of the outer leaves, and as these become dry and wither they move to those nearer the centre.

Grass is often attacked by them, and here they cause one form of what is known as "silver top." Wheat, oats, rye, and other grains are often victimized, and, indeed, there are few plants not liable to infestation, even tobacco appearing among the sufferers.

These insects thrive best in hot, dry weather, hence become more dangerous as the plants are less able to resist them, and our effort must be in the direction of aiding the crop as well as destroying the insects. Contact poisons are indicated here, as against the true Hemiptera, and either the kerosene emulsion, diluted ten times, or the whale-oil soap, one pound in four gallons of water, is satisfactory. Plenty of cold water, where it is ivailable, acts very well on a small scale; but no application is feasible on large fields of cereals or grass. Here stimulation only can be resorted to to give the plants additional vigor, and har- 
vesting should be done as soon as possible to check the increase of the pests.

Many species of Thrips are found on tlowers, many also under the bark of trees, and some forms are said to be predaceous. Their life habits are not well known, but a large number winter in the adult stage under such shelter as they can find,-hence, cleanliness on the farm is indicated.

For a better unclerstanding of the characters of the more typical Hemiptera, we will take up the families separately; and first the Parasitica. By taking up this series before the others it is not to be understood that they are higher in the scale, nor, on the other hand, much lower in type; but it is simply a matter of convenience. Parasites, because of their habits, are often said to be "low ;" but it is a question whether this is true, because parasitism is an acquired character, and the insects are really much specialized for their habit of life and well adapted to it. IVe have in a previous chapter considered the biting lice, and found that they feed more particularly upon surface structures. The sucking lice, as the term inclicates, obtain their food by piercing the skin and sucking the animal juices or blood. The mouth differs from that of the other bugs in that the proboscis is fleshy and unjointed, capable of being withdrawn into the head or extended, and within it are two protrusible lancets only. At its base is a circlet of hooks, by means of which the insect anchors itself firmly in the skin of the infested animal. The legs are "scansorial," or fitted for climbing, - that is to sily, they are short, heavy, set at the sides of the thorax, and the tarsus is modified into a stout, slightly curved claw, opposed like a thumb to the end of the tibia, which in turn is broadened at the tip and a little excavated. Thus, between the end of the tibia and the tarsus, the insect is able to grasp a hair so tightly that it is sometimes easier to pull it from the skin than to dislodge the parasite. Here we have another example of insects that clo not change in appearance throughout their life: they simply increase in size and become adult when the sexual organs are fully cleveloped. Warm-blooded animals only are infested by these sucking lice, man being included under this general term.

Three species are found on the human animal: one, Pcdiculus capitis, infesting the head, glues its eggs, which are known as 
Fig. 74 .

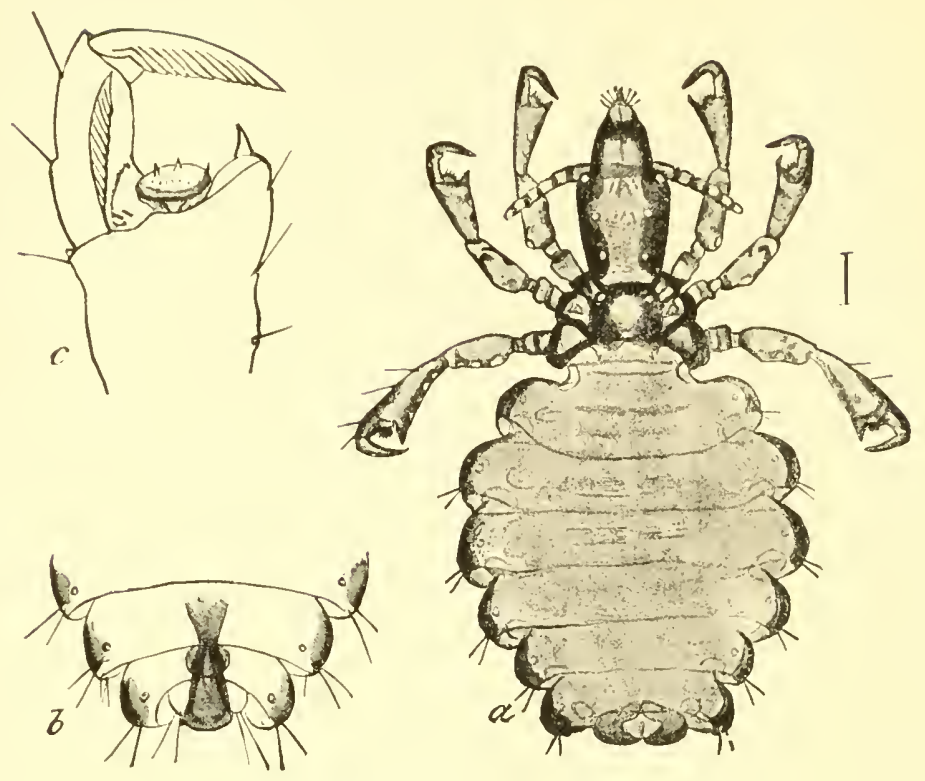

Hog-louse, Hamatopinus urius: the scansorial claw at $c$.

FIG. 75 .
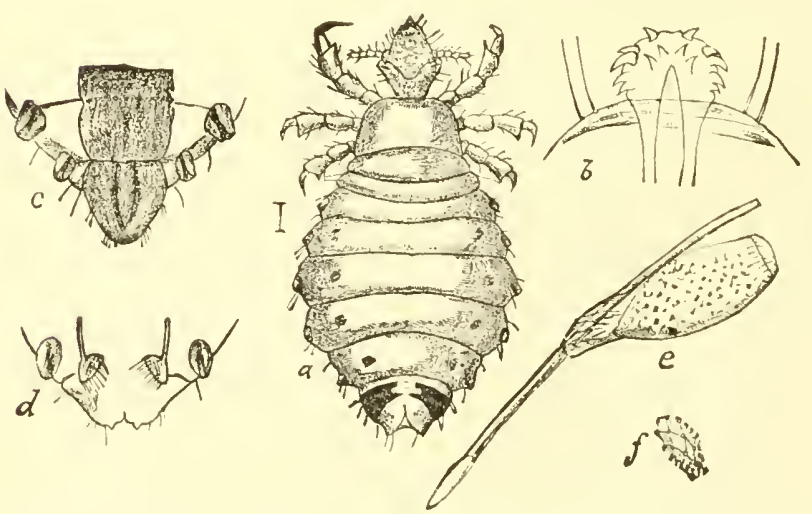

Ox-louse, Hamatopinus eurysternus: $b$, mouth opening ; $c, d$, anal details ; $e$, egg, attached to a hair. 
" nits," to the hair; one, Pediculus vestimenti, found on the body, known as the "body-louse," or to soldiers as "graybacks," lives in and lays its eggs in the seans of clothing, where they are protected; the last, Phthirius inguinalis, known as the "crab-louse," infests the pubic region and armpits. The latter fastens its eggs to the hair among which it lives, and this is perhaps the general rule throughout the series.

Domestic animals of all kinds are infested by lice; but it is not necessary to study the species in detail, since their habits are much the same, and the method of treatment is identical. For the head-louse on man nothing is better than a thorough application of lard, vaseline, or other greasy material. It should be applied at least twice at intervals of a few days, because the treatment does not kill eggs, and eggs unhatched at the first treatment would not be affecterl.

As against the body-louse, the application of mercurial ointment in the seams of the clothing answers every purpose. This has proved effective in camps and hospitals, where the insects sometimes increase with marvellous rapidity.

As against the "crab-louse," the mercurial ointment may be applied directly to the infested spots, and here also several applications are necessary to reach the insects as they hatch from the eggs. Their vitality is great, and that of the eggs is yet greater. Clothing, no matter how carefully washed, may still remain infested with eggs, protected as they are in the seams, unless actual boiling is continued for a considerable period of time. Where lice infest animals the latter can sometimes be cleared by simply giving them an opportunity to dust themselves.

Fig. 76.

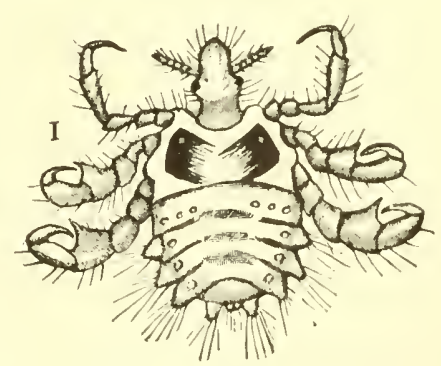

Crab-louse, Phthirins ingunalis. Dogs, donkeys, less frequently horses, and other animals, may be often seen in dusty roads, rolling about in evident enjoyment, and one result of this powdering is a comparative freedom from insect parasites for some time thereafter. Infested animals nay be treated as suggested for the head-lice in man,-that is, some 
heary oil or grease shoukl be applied thoroughly. It will add wo the effect of the mixture if a little carbolic acid is added, but it is not essential, thongh desirable to prevent rancidity if animal fat is useel. The kerosene emulsion, used with a brush or currycomb in cleaning anmals, is also effective ; in fact, the treatment suggested for the biting lice is also applicable here.

The section Ifomoptera contains scale-insects, bark-lice, mealy bugs, plant-lice, tree-hoppers, leaf-hoppers, frog-hoppers, and others whose very names proclaim their character. Nowhere do we find predaceous forms, or such as can be accounterl beneficial to the agriculturist. To be sure, we have among the Coccids the cochineal and lac insects, but these are fully as injurious as any other to plant life, and are useful simply because man is able to make better use of them than of the plants upon which they feed.

The family Coccida includes scale-insects and mealy bugs, curious in their life history as well as injurious to cultivated plants. The males, unlike other Hemiptera, have a complete metamorphosis and only a single pair of wings, the secondaries disap. pearing or reduced to mere hooks. They are singular, furthermore, in that the mouth parts are replaced in the adult stage by a pair of eyes. The female is always wingless throughout her entire life, generally grub-like and stationary, covered with some sort of waxy scale or by a powdery or cottony secretion.

Mealy bugs derive their name from the fact that they are covured by a white, powdery substance, which is really a granulated wax and a secretion of the insects thenselves. They move about reely, and are furnished with all sorts of odd processes at the sides of the body, or with long filaments at the end. They are not usually common in the North except in greenhouses and on in-door plants, but become more abundant southward, where outloor plants are also infested, orange-trees in Florida being particularly troubled. To this series of mealy bugs the cochineal insect, Cocus cacti, belongs. It is a native of Mexico, but has been cultivited in other countries, feeding upon species of cactus. Specimens have been found in Florida, and it is more than likely that it occurs not uncommonly in the semitropical part of the pennsula. It also occurs in California. The dye is simply the immature female insect, which is brushed off the plants, killed, and dried, and has never been equalled for brilliancy and 


\section{FIG. 77}

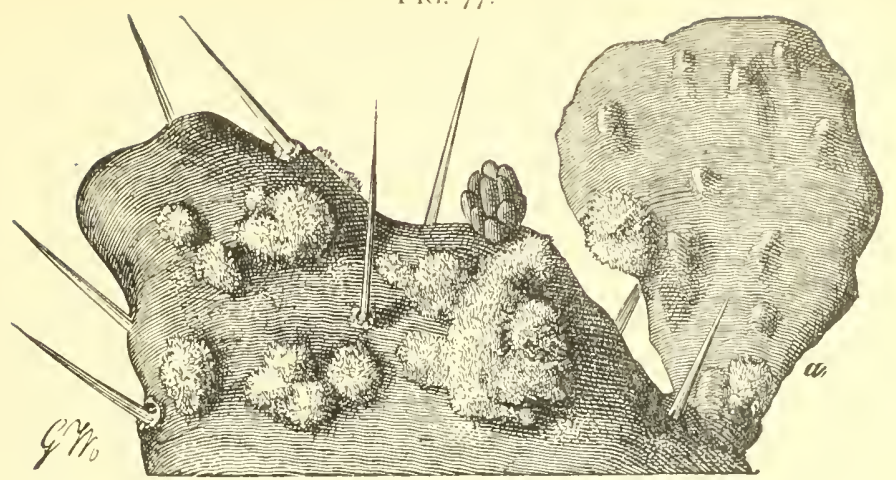

FIG. 78 ,

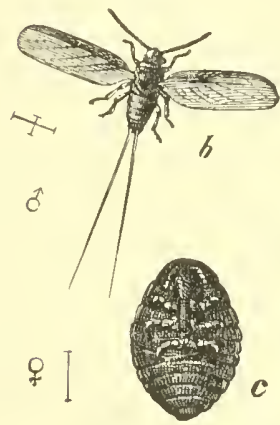

FIG. 79 .

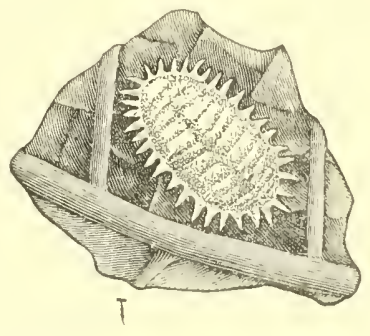

FIG. So.
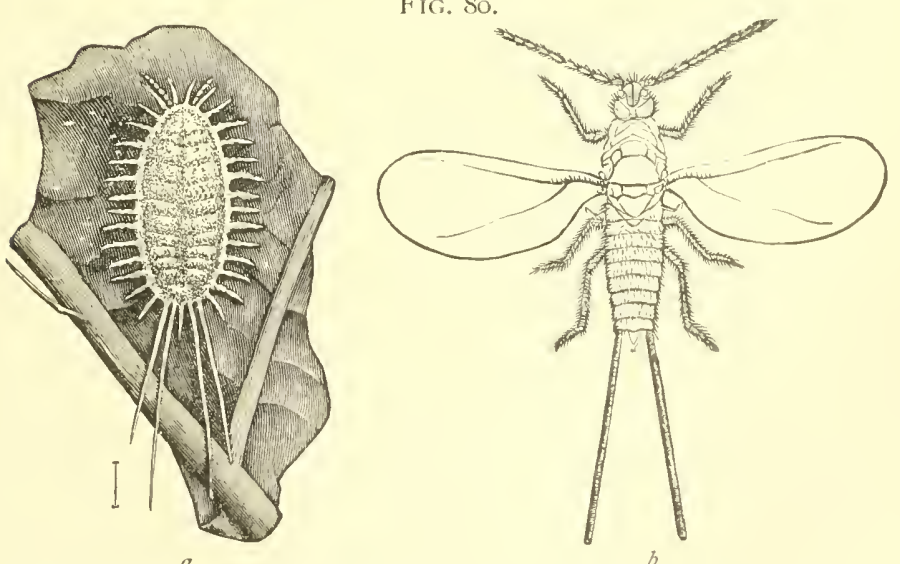

Cochineal and mealy bugs.-Fig. 77, cochineal, Coccus cacti, on cactus, Fig. 78 , $b$, adult male: $c$, adult female, with cottony masses removed. Fig. 79, mealy bug, Dactvlopius destructor. Fig. 8o, Dactvlopius longiflis: $a$, the larva; $b$, the winged male 
permanence. Aniline dyes and colors are superseding it, however, because of their cheapness and the greater ease with which they may be obtained.

Mealy bugs are easily destroyed by contact poisons, almost any soapy solution killing them readily. A very dilute kerosene emulsion answers every purpose, and even a weak salty solution is satisfactory. I have used both kainit and muriate of potash dissolved in water at the rate of an ounce in a quart, and it has been perfectly effective where entire plants have been dipped into it. A tobacco decoction, one pound in one gallon of water, is also useful, and not dangerous to the most delicate plants. Where house-plants are troubled the tobacco water is very convenient, or common insect-powder may be used at the rate of an ounce in two quarts of water, and sprayed on with an atomizer. Where applications are to be made on a large scale, the diluted kerosene emulsion is the most satisfactory, one part in fifteen of water being ordinarily sufficient.

Next comes a series where the excretions are in the form of waxy scales, which sometimes become hard, brittle, and beautifully ribbed. The female forms a sort of sac of these waxy scales, and in it the eggs, mixed with a very fine powder, are contained. This type is also rather more common southwardly or in warm countries, the few species that occur in the North being rather scarce and generally confined to weeds. The "cottony cushion scale," Icerya purchasi, which has caused such injury in California, belongs here, and we have several allied species in Florida, and yet more in the West Indies. All these insects gain their food by sucking the plant juices, and their power of injury is magnified by their enormous productiveness.

Perhaps this is a good place to speak somewhat at length on this " cottony cushion scale," and the measures taken against it by introducing foreign predaceous species. The very remarkable success that has attended the introduction of "lady-birds" (Coccinellidæ) from Australia has led many persons to the belief that insects of similar character might be introduced from other countries to deal with some of our native species, and much time has been wasted and some money spent by ill-considered schemes of this description. The factors that caused success in the case of the Icerya were: Ist, an insect introduced from a 
foreign country where it was on the whole rather scarce and kept in check by natural enemies; $2 \mathrm{~d}$, its introduction into America, where these natural enemies did not exist, and where the insect found favorable opportunity for multiplying ; $3^{\mathrm{d}}$, the introduction of some of its foreign parasites and of the predaceous insects

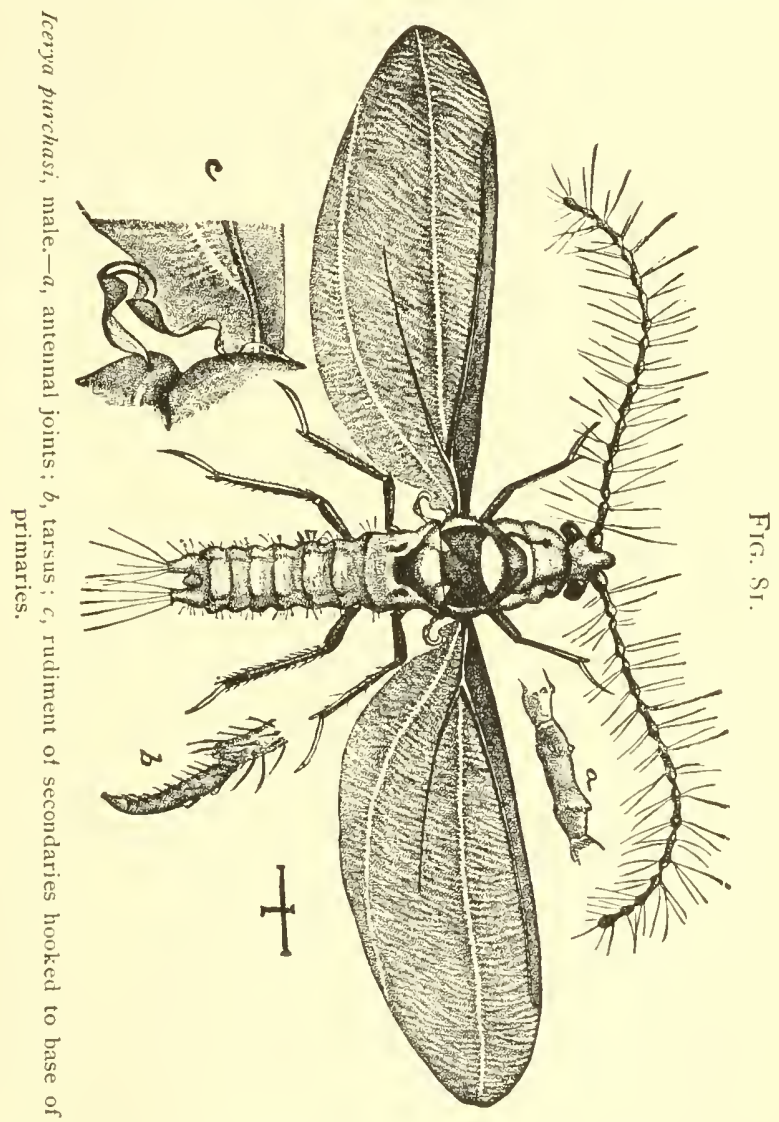

feeding upon the species; lastly', and most important of all, the Australian lady-bird recognized no other insect among those found in California as proper food, and naturally confined itself entirely to these scales. The contest was unequal, and the scales lost rapidly, soon becoming nearly or quite exterminated. The 
chances are now that the lady-birds will follow them and become scarce or extinct, unless they show the power of adapting them-

Fig. S2.

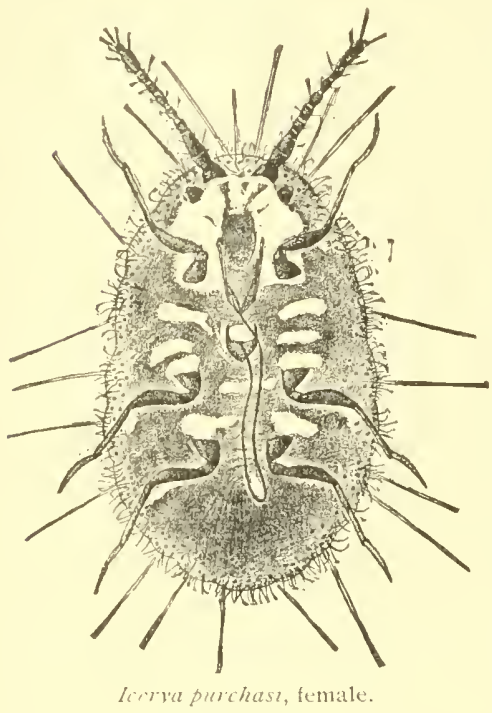
selves to surroundings, and find other food to their liking; but while they have been useful as against the Icery' $a$, and may have entirely destroyed it, we cannot hope that they will be equally successful in coping with our native insects, who have long since adapted themselves to their surroundings in such a way as to make it unlikely that any introduced species will be effectual in seriously lessening their numbers. Insects of this character are susceptible of treatment with the kerosene emulsion, although, where they occur in such numbers as did the Icerya in California, this treatment becomes exceedingly expensive and practically useless.

A curious series of species is found in the genus kermes, often found on oaks, and resembling at first sight galls or even small snail-shells, their texture being almost as brittle as if composed of lime. They are never economically important, but curious enough to deserve mention here.

Next come what are known as "soft scales," usually of considerable size and readily visible. Quite commonly they are convex or nearly hemispherical, rarely quite regular in outline, and sometimes ribbed or ridged. In most instances they are brown in color, not very rigid in texture, and easily crushed; whence the term "soft scales." We have a number of injurious species, and perhaps none more common than the "cottony maple scale," Pulvinaria inmmerabilis. Though called the maple scale, and found most frequently on that tree, yet it is by no means rare on grape, and often common on the Virginia creeper. Sometimes it occurs on other plants as well, and is occasionally 
numerous enough to require treatment. It usually attractsattention in spring, when white cottony masses become numerous on twigs or leaves, increasing in size until they are one-fourth of an inch or more in length, and only slightly less in diameter, though irregular in outline. The mass seems cottony, but is actually a wax or grum, for, if a bit is taken with a forceps it can be drawn out into strings of considerable length. When of this size it forms a bedding for innumerable, rustybrown, minute eggs. which have been laid by the female insect under the brown scale which seems to form the head of the mass at-

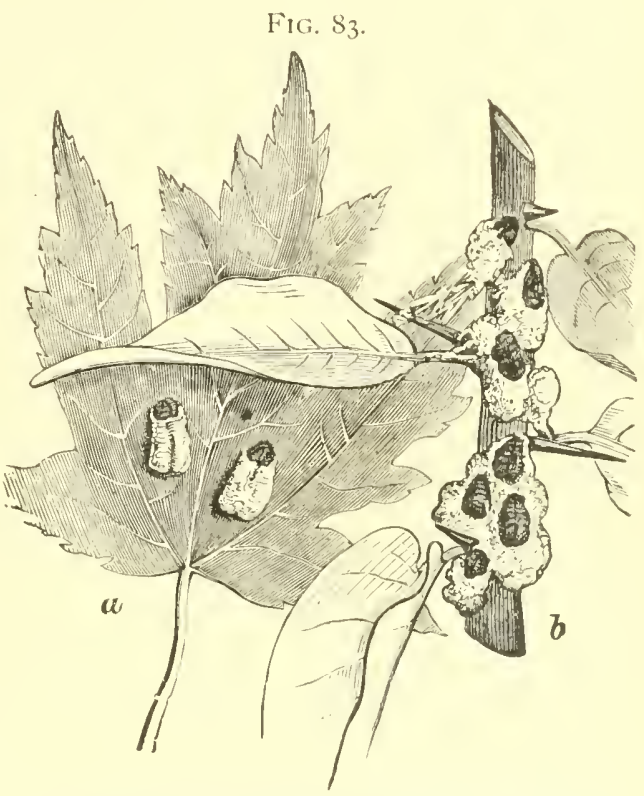

Cottony maple scale, Pulvinaria imnumerabilis, showing, at $a$, the female on a leaf and, at $b$, same on a twig. tached to the twig.

From these eggs minute, crawling larva hatch, much like the eggs in color, and which separate in every direction in what seems to be a moving mass of fine dust particles. In a day or two each larva inserts its beak into a leaf or twig, and commences the formation of a little, flattened, oval, somewhat mottled scale. They remain thus, feeding and increasing in size, and as they increase the scales enlarge. The males come to maturity in the latter part of the summer, appearing as minute, two-winged flies, furnished with long anal filaments. They mate with the females which remain under the scale, and these, before the leaves fall, migrate to the twigs or branches, where they fasten themselves to pass the winter. Feeding is resumed in spring, when the sap begins to circulate, and then the egg masses begin to form. Before the 
cottony sccrction becomes visible the female scale is less than one-eighth of an inch in length, very convex, a little irregular, and mahogany-brown in color. As the egg mass increases in size the scale is lifted posteriorly, until finally the insect adheres only by its beak and by the sticky nature of the cottony mass.

\section{F1G. 84 .}

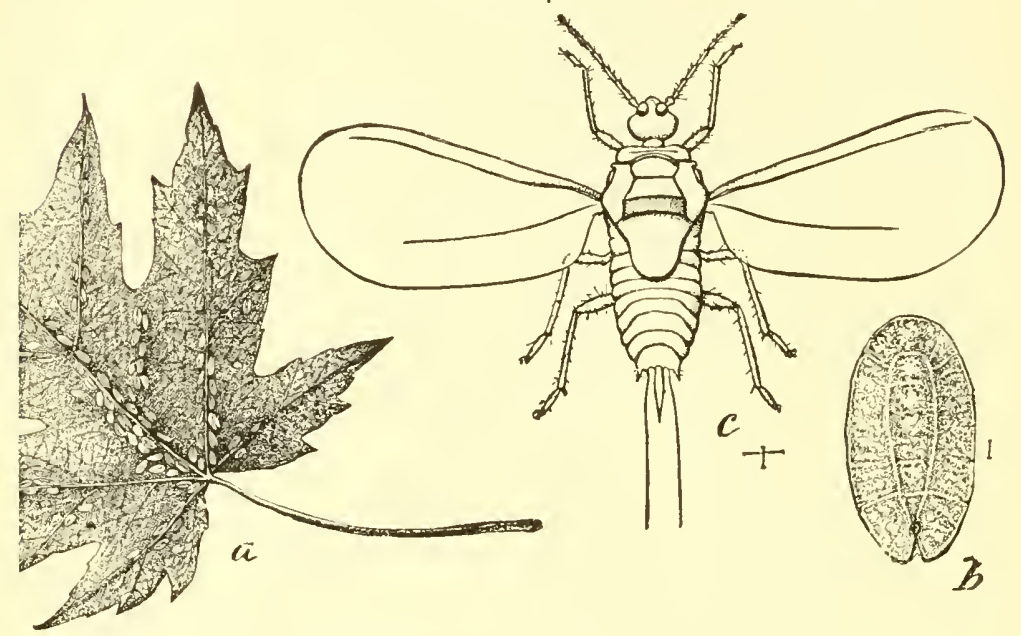

Cottony maple scale. $-a$, leaf covered with scales; $b$, male scale; $c$, adult male.

We have other species of similar character in which there is no cottony mass protecting the eggs, but the life history is essentially the same. These "soft scales" mostly belong to the genus Lecanium, and are much more common southwarlly and in conservatories. Citrus fruits and olives are especially subject to soft-scale attack, and the "black scale," Lecanium olca, is in California the most troublesome of all and the most injurious. In the genus Ceroplastes the scale is formed of waxy layers, sometimes quite pretty in pattern. These are found only in the extreme South, and are not especially troublesome.

The matter of remedies will depend entirely upon circumstances. On garden plants or shrubs the scales may be mechanically removed during the winter. They do not adhere closely, are easily dislodged, and are of a size sufficient to be readily seen. Not all, however, pass the winter in the adult condition. In some 
cases, instead of a female, an egg mass will be found beneath the scale; but in either case mechanical dislodging results in the destruction of the insects. Very often a little judicious pruning or trimming, done during the winter, will give relief, because the insects usually settle on the terminal twigs, and it might easily be that none of the larger branches contained living scales or eggs. In conservatories the mechanical method is, all things considered, the best. It may take a little more time, but it is thoroughly effective, and when carefully done there may be almost total exemption until scales are again introduced with new plants.

This is a good place to say that no plant should be placed in a garden or conservatory until it has been thoroughly cleaned of all scales found on twig or fo-

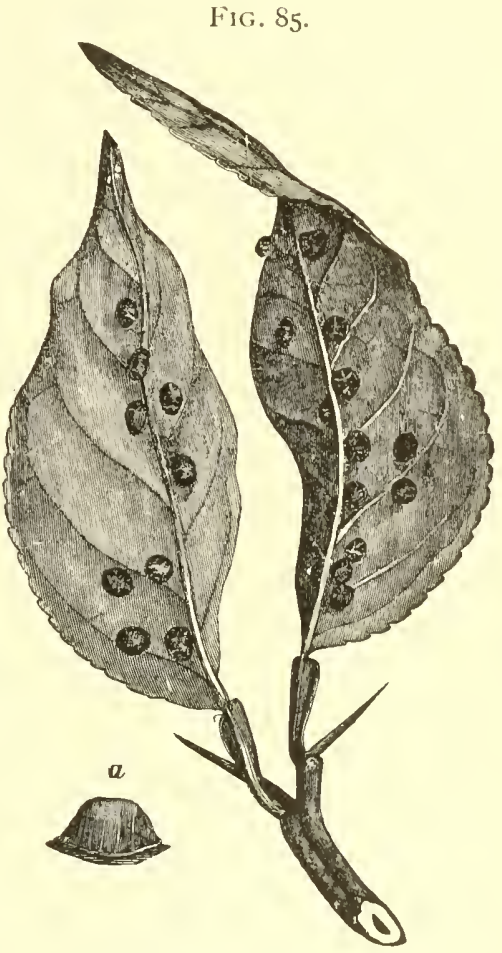

Lecanium hemisphericum, on orange-leaves, natural size : $a$, female scale, enlarged. liage, and a soft tooth-or hand-brush, with moderately strong soapsuds, forms a good outfit for doing the work. Where winter treatment is inadvisable or impossible, applications should be made when the larva emerge from the eggs and before they fasten themselves to leaves or twigs. There is no difficulty in killing the young with either soapsuds or kerosene emulsion, but-and here is the important point - the application must be made before the insect is protected by a scale, or when the scale is yet very thin and newlyformed. Kerosene will penetrate the waxy mass of the maple scale, but it will not certainly kill the eggs contained in it yet 
if soapsuds be used to dilute the emulsion, instead of water, the cottony mass will be so impregnated with soap, and become so compact, that the young will be unable to make their way out. Therefore, in this case, dilute three quarts of kerosene emulsion with one pound of whale-oil soap dissolved in eight gallons of water.

The most troublesome of all scale insects belong to the Diaspina, or " armored scales," and these are generally small in size. They are, as a rule, only a little convex, occasionally even flattened, and in texture are more like membrane or parchment than wax. All kinds of shapes occur, and there is considerable variation in life history. In one point they all agree,-after the active larve have once become fixed and covered with a scale. they never leave their position, except when the males emerge as adults and visit the surrounding females. In general the life history of the insects is as follows: the larve, whether hatched from the eggs or born alive, crawl about for a few hours, or at most a day or two, seeking a convenient place to fix. They are always minute, flattened, oval creatures, with six legs, a pair of distinct feelers, and a curious, long, sucking mouth. This is soon inserted into the plant tissue, and from that time the insect is a fixture. Little waxy filaments begin to exude from the body, which soon coalesce, or run together, forming a first covering or scale over the soft larva. The insect soon moults, and the cast skin forms part of the scale, the resulting creature being legless and without power of motion. There is one additional moult, after which the sexes are very different in appearance. The male shows antennæ, legs, and wings well marked, and is indeed a perfect pupa, while the female is even more grub-like than before, rudiments of antennæ only being visible. The second cast skin of the female also forms a part of her scale, and there is nearly always some difference in shape between the sexes, the male being not only smaller, but narrower. Shortly after the change to the pupa the male becomes adult, and in this series has the end of the abdomen prolonged into a style or pointed process, sometimes equalling in length the rest of the insect, though usually shorter. Antenuxe and wings are both prominent, and as a whole the insect is curious and excecdingly fragile in appearance. Its life is probably short, though long enough to accon- 
plish its mission, - the fertilization of the female. After this the life histories differ greatly; sometimes the female lives througld the winter in the partly-grown or adult condition; sometimes she lays eggs which fill up the entire space beneath the scale, the insect itself shrivelling up until scarcely a trace remains. Sometimes living young are brought forth, and there may be one or several broods. Hence it is necessary to study each species in detail before we can say much on the subject of remedies. It is obviously beyond the province of this book to describe all the injurious species, and general statements only are possible.

Fig. 86.

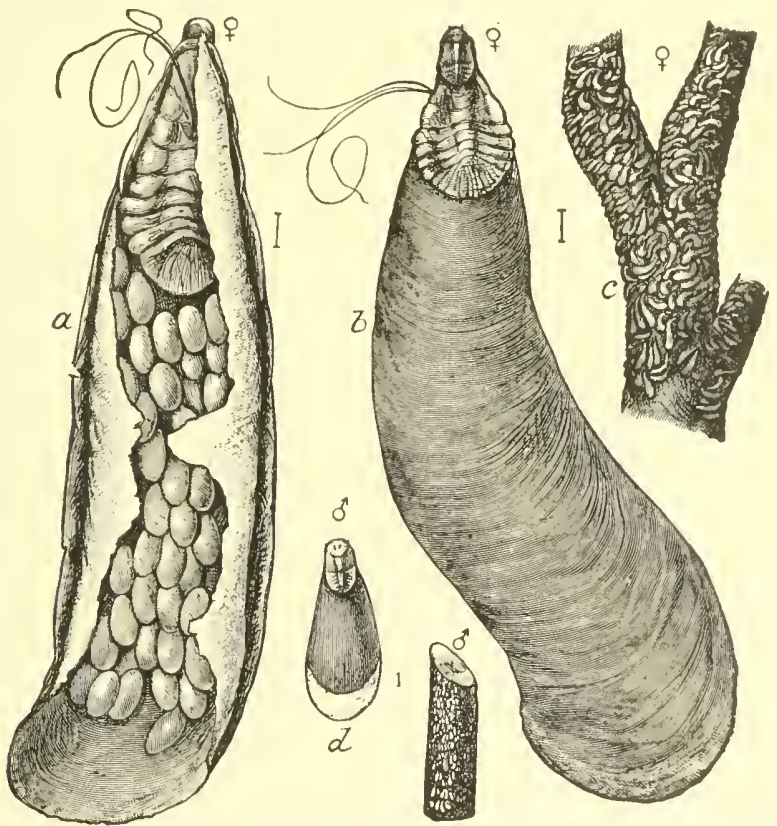

Oyster-shell scale, Mytilaspis pomorum. $-a$, female scale, from beneath, filled with eggs; $b$, same, from above; $c$, twig infested by female scales; $d$, male scale and a twig infested therewith.

Perhaps the most common forms of this series are the "oystershell" bark-lice, of which we have several species, deriving their common name from the fact that the scales have a marked resemblance to the shells of some oysters. In the Northern United States Mytilaspis pomonm is the common form, infesting apple 
and other fruit trees, willow, lilac, and a great variety of other plants. It is perhaps uncertain whether all are really one species, but for our present purpose we may consider them so. There is one brood only, and they winter in the egg state, the larva appearing in spring, the time depending upon the weather. In the South there may be two broods, but I believe that there are few exceptions to the rule that wintering takes place in the egg stage. On orange and other citrus plants we have species closely resembling that on the apple, and not distinguishable except on

\section{FIG. 87.}

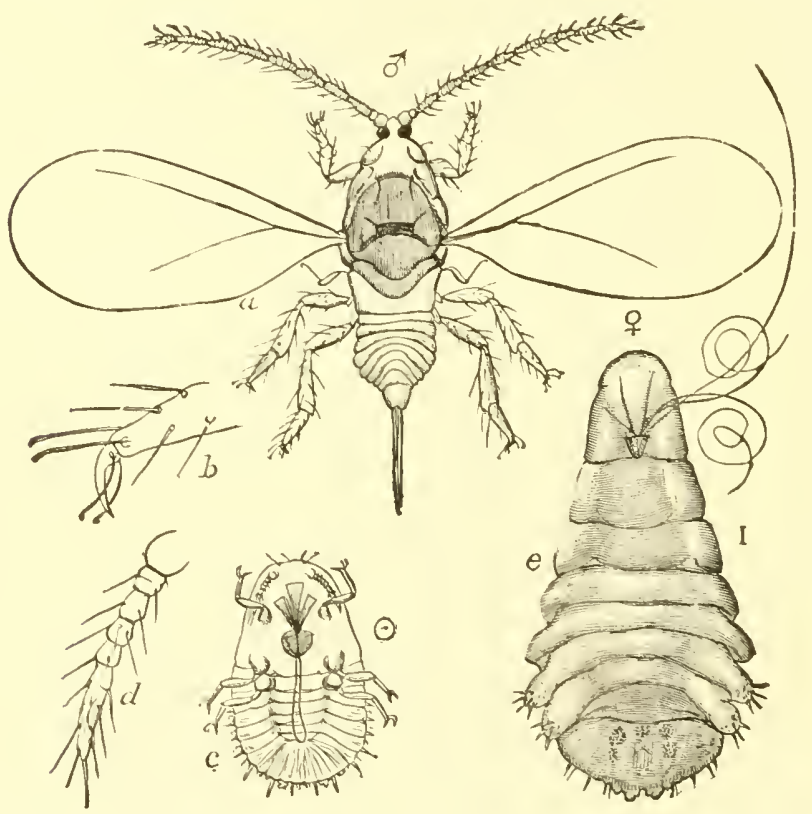

Mrtzlaspos pomonum.- $a$, male; $b$, its tarsus; $c$, young larva; $d$, its antenna; $e$, female.

close examination, even by the specialist. These scales sometimes cover twigs and large branches completely ; even the leaves are often infested, and not infrequently the fruit itself becomes more or less covered. It is not unusual to see in market oranges and lemons more or less spotted by these oyster-shell scales, and I have seen lemons from Mediterranean countries with the skin almost entirely hidden by them. 
FIG. SS.
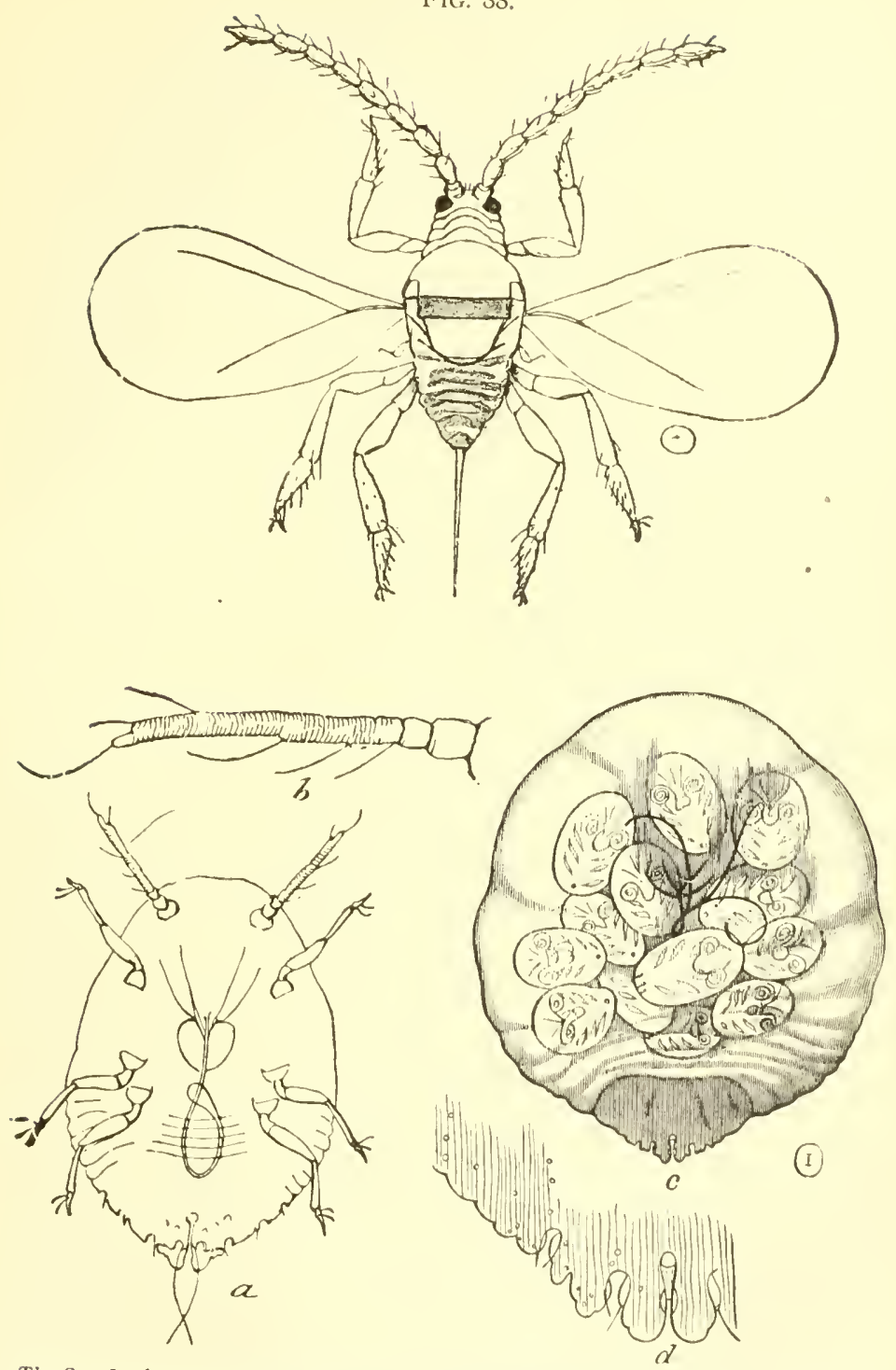

The San José scale : winged male above; $a$, young larva, just hatched; $b$, its antenna; $c$, female, showing the forming young through the body wall; $d$, outline of anal plate of female : all very much enlarged. 
In our treatment of these insects we must either apply exceedingly caustic winter washes, to corrode the scale and allow the egrgs to be washed out by rain or destroyed by other climatic influences, or we nust apply contact insecticides when the eggs hitch or the larve emerge from beneath the scales.

Some of on destructive species belong to the genus Aspidiotus, and these have the scale nearly circular in outline, with the remnants of the cast larval skins showing through at or near the midclle and forming a sort of nipple-like prominence. The male scales are decidedly smaller than those of the female, and somewhat more oval or oblong. The "red scales" of the orange in Cilifornia and in Florida belong to this genus; but perhaps the most troublesome of all is the A. perniciosus, or San José scale. As this species is now widely distributed and very injurious where it uccurs, its life history may be given in some detail.

The insect winters on the infested trees in the larval state, and usually about balf grown, both sexes being found. Males mature soon after spring opens, - in the latitude of Philadelphia, about the end of May, but depending somewhat upon the season. On or about the Ioth of June the females become fully developed, and begin to bring forth living young. That is to say, the species is viviparous, and produces no eggs. The larva do not differ essentially from those of other scales, and fix in from twelve to thirty-six hours, depending somewhat upon circumstances. At that time a thin white pellicle forms, which soon turns yellow, and a little later becomes gray around the edges. The insect is then a fixture, and continues its growth much as previously clescribed, but reaches the adult condition, and is ready to reprocluce, in a little more than a month. This short period enables it to mature several broods, and during the entire summer, and until late fall, reproduction continues, - the broods becoming mixed, and all stages being present continuously upon the plants soon after summer opens. With such a life history the insect is exceedingly difficult to control, and practically we are reduced to winter work, as will be hereafter pointed out. The scale infest all the usual deciduous fruit-trees, roses, currants, gooseberies, -in fict the entire order Rosacea, and occasionally occurs on chestunt, walnut, and elm. It is probable that yet other plants are subject to infestation, and this omnivorous habit and the 
wonderful power of reproduction make the scale especially dangerous.

In the genus Diaspis the scales are more ovil, and the cast larval skins are at or near the margin rather than toward the middle, while the males are long and slender. A common example is the $D_{i}$ aspis rose, found on roses and other plants belonging to the same natural family. The scale is pure white and very conspicuous, measuring nearly an eighth of an inch in diameter.

Yet more oval, with the cast larval skins at the smaller extremity, are species of Chionaspis, and a good example is the "scurfy" scale," C. furfurus, common on pear and apple. A similar species is found on pine and

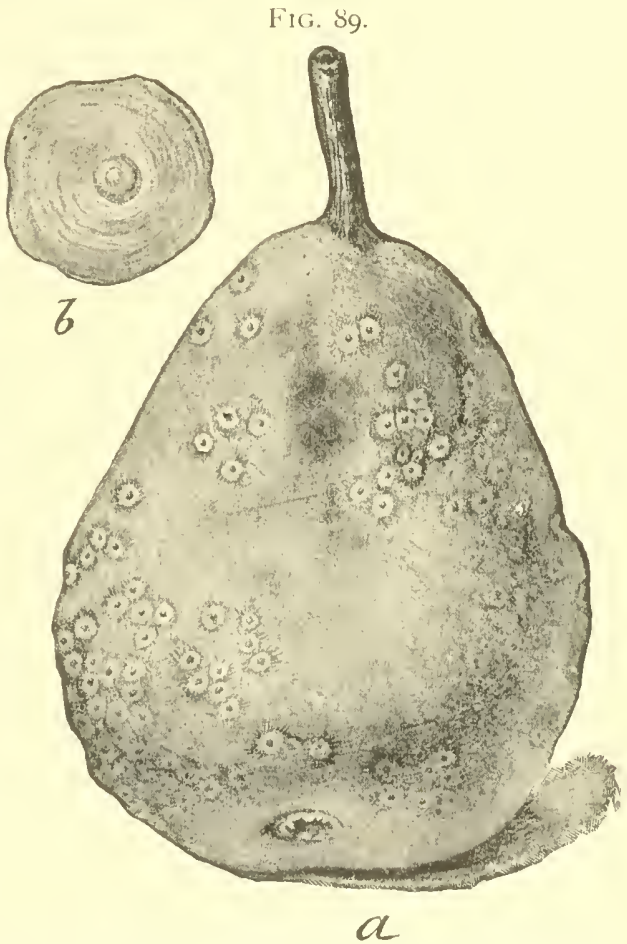

San José scale on a California pear, natural size; the scale itself enlarged at $b$. spruce throughout the United States. These species may have one or two generations, according to latitudes, but ususally winter in the egg state.

Some of the species have the curious habit of boring under bark, thus passing a large part of their- life out of sight, becoming more dangerous by that fact, since trees may be badly infested and the cause of sickness not even suspected by the farmer.

It is practically impossible to even mention all the injurious scales of house, conservatory, or orchard plants, and it is not 
really necessary, since the treatment to be adopted is nearly the same in all cases. On deciduous trees, where the scales remain during the winter upon trunks and branches, and where the trees become dormant, the scales are best treated cluring the winter. At that time there is no foliage to interfere, and we can use much stronger washes than would be safe during the summer, or when the tree is active. I have already called attention to the fact that it is difficult to penetrate insect tissues with ordinary liquids, and it has been found impossible in practice to obtain good results in the destruction of scale insects except by means of caustics.

FiG. 9o.

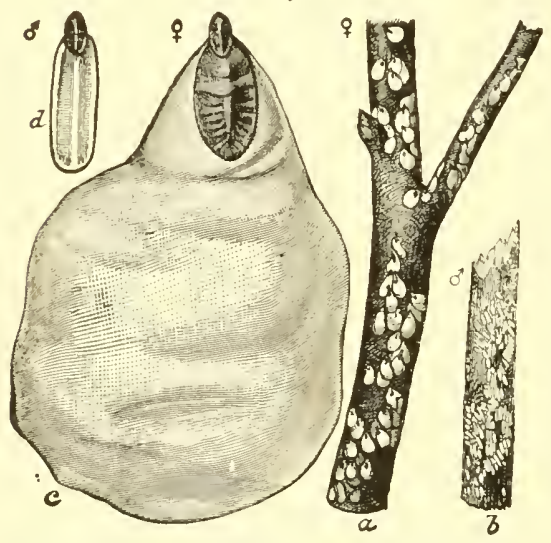

The scurfy scale, Chionaspis furfurus. $-a$, twig infested by female scales; $b$, with male scales; $c$, female; $d$, male scale, much enlarged. Potash and soda have been used with good effect even in a simple watery mixture, but more satisfactorily in the form of very caustic soap. Whale, or other fish-oil soap, at the rate of two pounds in one gallon of water, as a winter wash, has proved absolutely effective against the San José scale and the oyster-shell bark-louse, two of the most resistant of the armored scales. The simple muriate of potash used as a fertilizer has proved effective against the scurfy scale, while common laundry soap has been efficient against others of the softer species. The common soaps are all caustic, and, when applied at the strength indicated, the scale is shrivelled, lifted, and partially corroded, so that the oily mixture works its way beneath, into absolute contact with the insect. Or it is raised at the edges and washed off by the rains, carrying with it either eggs or young, as the case may be. In fact, where the eggs hibernate winter applications act only by exposing them, so that they are easily washed away by rains and scattered, under no proper condition to hatch. Or, should they hatch, the larvæ are able in rare instances only to get upon the 
proper food-plant. In the case of plants which do not lose their foliage at any period, or in conservatories, or where winter treatment for any reason is not feasible, we must attack the insects when the larve are crawling about, and before they are fixed. At that time, while not protected by a scale, they may be easily killed, almost any of the contact insecticides being effective. Soapsuds, a dilute kerosene emulsion, or a mixture of both, are satisfactory, and a good formula is : kerosene emulsion one part, soapsuds ten parts, the suds being of the strength of one pound of soap to six gallons of water. Whale or other fish-oil soap is better than common laundry soap, and the latter is better than high-grade articles containing only a minimum amount of caustic. This would not hurt any except very delicate plants, while it would be absolute death to larval scales. It is useful in the conservatory on palms, which are often much infested, and for some of these it might be well to reduce the amount of kerosene to one part of the emulsion with from twelve to fifteen parts of soapsuds. Where the insects are viviparous, or bring forth living young, the spraying must be done systematically, at intervals of four or five days, until no more young appear. On out-door plants the same mixture may be used, but the spraying, if the larvæ come from eggs, need not be done more than twice, since as a rule the eggs hatch at about the same time. On the Pacific Coast lime, salt, and sulphur mixtures, and various resin washes, have proved effective, but they are troublesome to make, and hardly cheaper, all things considered, than the soap mixtures above referred to. They act largely by sealing the scales to the tree, so that the young cannot emerge or the adults are stifled; hence they are most effective where rains are few and far between. The formulæ for their preparation will be found in the chapter on insecticides, where their range of usefulness is also stated.

The species belonging to the family Aleyrodida resemble scale insects in the immature condition, but are not fixed to the plants, and in the adult stage both sexes are winged, somewhat resembling minute plant-lice. The striking character by which they may always be recognized is a covering of white, flour-like powder, which renders them easily visible upon the leaves. They are not common on out-door crops in the North, but are not infrequent on house or conservatory plants, becoming more 
abundant and correspondingly more troublesome southward. A species sometimes occurs in considerable number on orange. As the insects live exposed in all stages, they are easily reached by contact poisons, and of these the kerosene emulsion is usually the most satisfactory. It kills them in all stages at moderate strength,
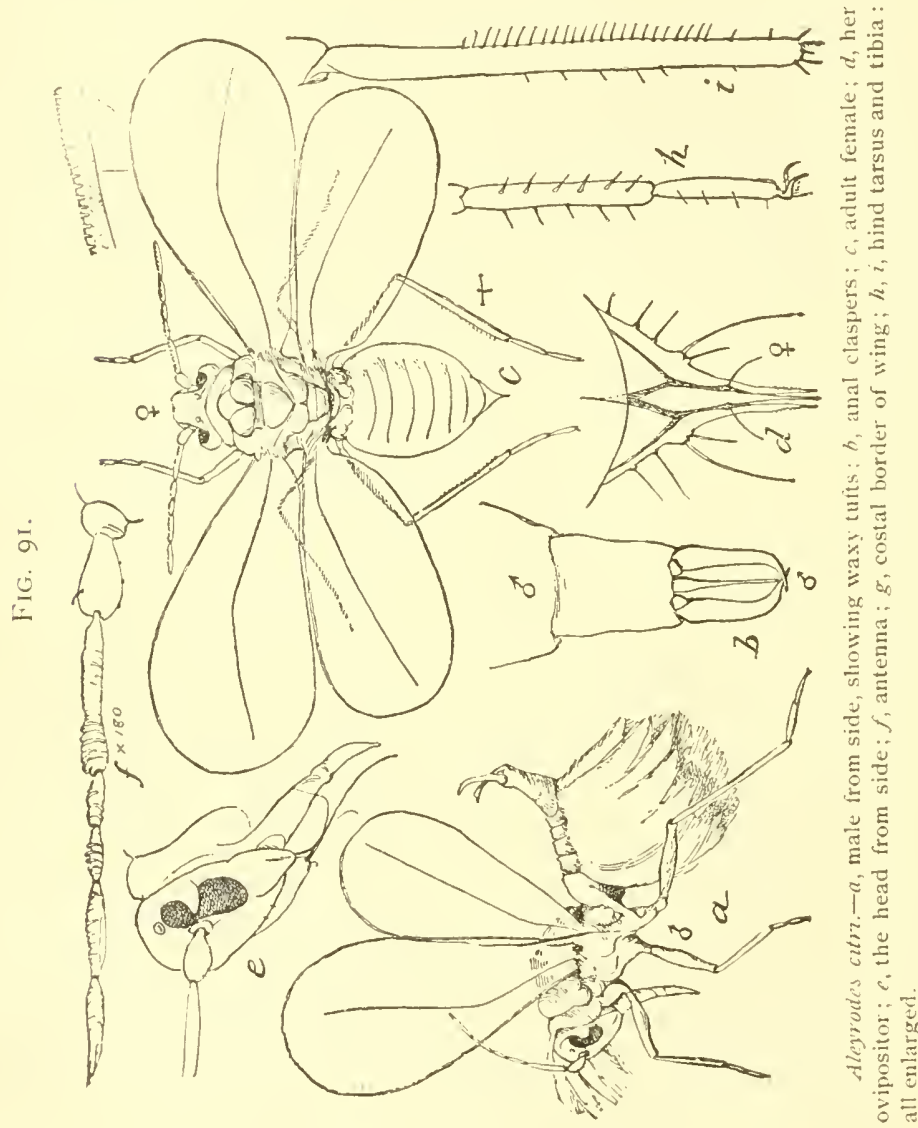

one part of emulsion in ten or twelve parts of water being ordinarily sufficient. Whale-oil soap is quite as effective, and is preferable on some house or conservatory plants, while even the pyrethrum extract is useful on a small scale, and is, perhaps, the cleanest of all on house-plants. 
It is a short step from the Aleyrodide to the plant-lice, belonging to the family Aphidida. Plant-lice are well known to agriculturists by the injury they cause, and they are interesting to the naturalist from their life history. Here we have the most striking apparent exception to the general rule that insects are developed from eggs, and yet perhaps the exception is more apparent than real. At all events, parthenogenesis, or repro. duction without the intervention of a male, occurs normally in a large percentage of the species. Of course there are many differences in life habits, but a general account, covering most of the cases, is all that can be attempted here. As a rule, plant-lice

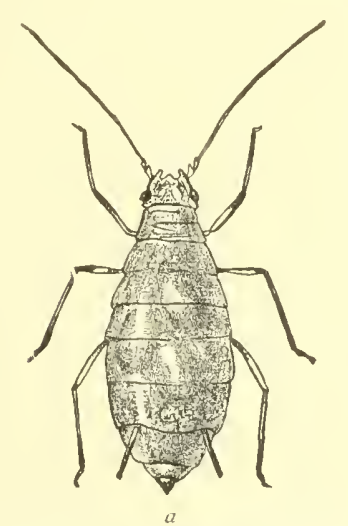

FIG. 92 .

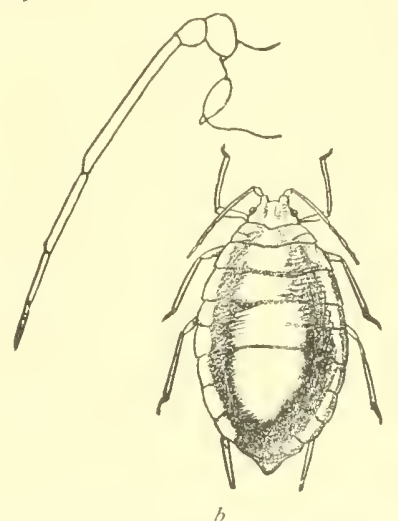

$a$, female hop-louse, showing eggs through skin; $b$, the stem-mother that starts the transformation; much enlarged.

winter in the egg stage; but this is subject to many exceptions, especially in the warmer parts of the country. Early in spring, as soon as there is a trace of reviving vegetation, these eggs hatch. The insect that now appears is wingless, and usually remains so, but grows rapidly by sucking the plant juices, and soon begins to produce living young. It is called a "stemmother,' because it is the source from which numerous generat: nn issue during the season. All the young born by this stemmother are, like herself, without sex; that is, they are neither males nor sexually-developed females. The rate at which they are born varies, but as many as eight living young hatve been 
observed within a period of twenty-four hours from one specimen, and it is not unusual to find, early in the season, a single large louse surrounded by a group of anywhere from a dozen to twenty or even more small specimens. The rate of growth also varies, depending upon the weather; indeed weather conditions, early in the season, frequently determine the question of whether or not certain species are to become injurious lateron. A warm, moist temperature favors their development, and reproduction goes on at a rapid rate. Correspondingly, cold, wet weather checks development, and may even destroy a large number, especially of the young. Plant-lice, in their younger stages, are exceedingly susceptible to sudden changes of temperature, and at almost any time in the season a sudden drop of from fifteen to twenty degrees, accompanied by a rain, will prove fatal trs a great proportion of them. But assuming that all is favorable, the young that were first brought forth are in turn ready to reproduce in five or six days, and they also form little colonies; this method of reproduction continuing as long as food is plenty and the weather mild. Experimentally, reproduction of this kind has been continued for several years in succession, without any tendency to develop sexed individuals or to produce eggs. At almost any time after the first generation, specimens may become winged, and these fly to other localities, forming new colonies wherever suitable food is found. In this way they spread, and, though they may have started from a single favorable locality, yet in the course of a few weeks they may cover many hundreds of acres. Exactly what determines the formation of wings in some specimens and not in others is not known. We do know, however, that the progeny of a single individual is variable, and that while some become winged others do not; but whether winged or wingless, the specimens are equally without sex, and all are viviparous, or bring forth living young. As the summer advances, reproduction becomes less rapid. Plants tend to dry, the supply of sap is not so plenty, and these features become more marked through the autumn months until, with the approach of cold weather, plant growth entirely ceases. It becomes necessary now to provide for the continuation of the species during winter, and sexed forms are developed. The males are usually winged and appear a short time before the females, which 
differ by the lack of wings and the usually small size compared with the normal sexless form. Pairing takes place as soon as the female is sexually mature, and in a very few days afterwards eggs are laid. In many instances the egg supply is exceedingly small, indeed there may be one only matured by a female. Even this may remain within the body of the parent, who simply dries up, the skin shrivelling around and forming a protection to the ovum. More usually several eggs are produced, and these of large size in proportion to the size of the insect that lays them. They are green or greenish-brown

FiG. 93 .

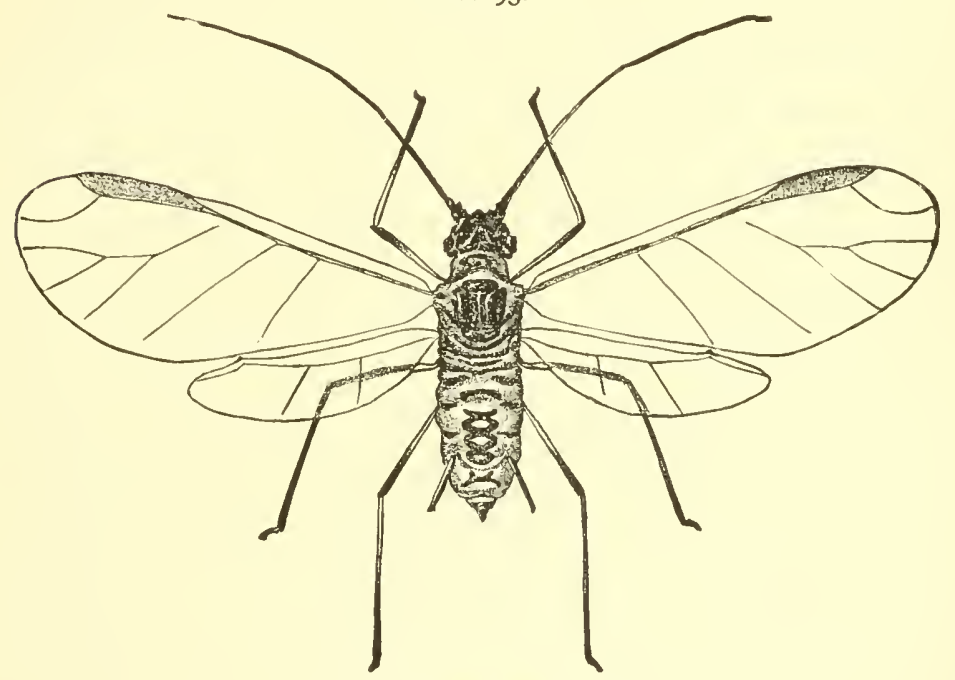

Hop-louse, male; return migrant.

in color when laicl, sometimes yellowish, and frequently darken to black. They are placed in sheltered situations on plants, and, in the case of orchard trees, are usually found at the tips of twigs, around the buds, or on the leaf-scales, where vegetation will first start in the spring following. They are very firm in texture and very resistant to insecticides; in fact, it is impossible to destroy them except by the most caustic mixtures. It has been already indicated that there are many exceptions to this general life history, anc one kind of exception we find where species feed dur. 
ing the summer upon at plant which dies down to the ground, feaving nothing through the winter. In such cases there is an alternate food-plant, upon which the winter and early spring are passecl. From this the insects migrate in early summer and to it they return when cold weather sets in. Such a case we have in the hop-louse, which spends the summer upon the hop, increasing greatly in number in favorable seasons and often causing much injury. When the vines mature and die, males develop, and all the lice fly to plum-trees. Here the female is born, the sexes mate, and eggs are laid. In the spring two or more gencrations mature upon the plum, and, when the vines are again well started, winged forms develop and migrate to their summer foot-plant. This sort of migration is not unusual, although it lats not been traced out in many cases.

Another example we find in the "melon-louse," which has a consiclerable range of food-plants, including cotton, orange, strawberry, and nearly all the common weeds of our fields. If circumstances favor their increase in spring, winged forms are produced which migrate and settle upon melon fields, providing for colonies during the summer.

The scientific problems connected with this method of reproduction and spread are of great interest, but camnot be entered upon here; the mere statement of the case being sufficient for practical purposes. Plant-lice are so commonly known that a detailed description of their appearance is unnecessary ; but it is well to call attention to the presence of a pair of little tubes or curnicles near the end of the abdomen, projecting from the upper surface. These are called honey-tubes, and from them is excreted a sweetish liquid known as honey-dew. Sometimes, when food is abmondant and the insects are active, the amount of sap they pump out of the plants is so great that, in order to ease themselves, they voicl it in little streans through the anus, as well as in chrops through the honey-tubes. Thus the leaves of infested plants become sticky or glazed with a sweetish liquid, on which a black fungus rapidly develops, the leaf being frequently killed by simply choling to death. Sometimes the regetation beneath a tree becomes thoroughly conted in the same way, or, when sharle-trees in cities are infested, the parement becomes wet and slippery with the visciel liquicl. This honey-dew is often attractive 
to bees and wasps, who feed greedily upon it, and is yet more tempting to ants, whose relations to plant-lice merit more than a passing notice, since they are of clecided economic importance.

It is a common thing to see ants crawling over leaves infested by plant-lice, and it is often considered well that this should be so, under the erroneous impression that the ants feed upon plantlice. In some cultivated fields ant-hills abound enrly in spring, the little mounds scarcely rising above the surface, being seen everywhere. We next find, shortly after, plant-lice infesting the roots or leaves of the growing crop. In truth, ants are protectors of plant-lice; they are fond of their sweet excretion, and favor their increase and development in every possible way. The plant-lice seem to realize that they have nothing to fear, and readily yield to the ants of their sweets whenever approached for that purpose. Some species of aphids are incleed practically dependent upon ants for their existence. Where some of them lay their eggs we have not yet been able to learu, but perhaps they simply drop them to the ground, where their color and size render them invisible to our eyes. The ants find, gather, and carry them into their galleries, where they store them until spring. When vegetation starts and all conditions are favorable, the eggs are taken where they can hatch normally, the young lice being afterward carried to the plants upon which they are to feed. An instance nearly like this, save that the young are carried over winter, we find in the lice infesting corn roots, and undoubtedly there are many others.

The study of plant-lice is difficult by reason of the matters already set out, and it sometimes requires years to supply a missing link in their life history. The differences between them are not always well marked, and the tendency has been to recugnize species as distinet when they feed on different food-plants. This basis has proved erroncous, however, and now the wonder is to find how many food-plants a single species may actually have.

It has been mentioned that a number of plant-lice feed upon roots, and some species pass their entire life underground. Such are the Rhizobiince, which sometimes become distinctly injurions, as, for instance, when they occur on the roots of lettuce, in grreen houses and out-doors. Sometimes they are found on the roots of trees or shrubs, quite usually attended by ants, which provide 
for their distribution. As they never come to the surface, so far as we know, they are never winged, and are usually dull white in color, or with a slight tinge of green. The body is covered with a whitish powder and lacks honey-tubes.

FIG. 94.
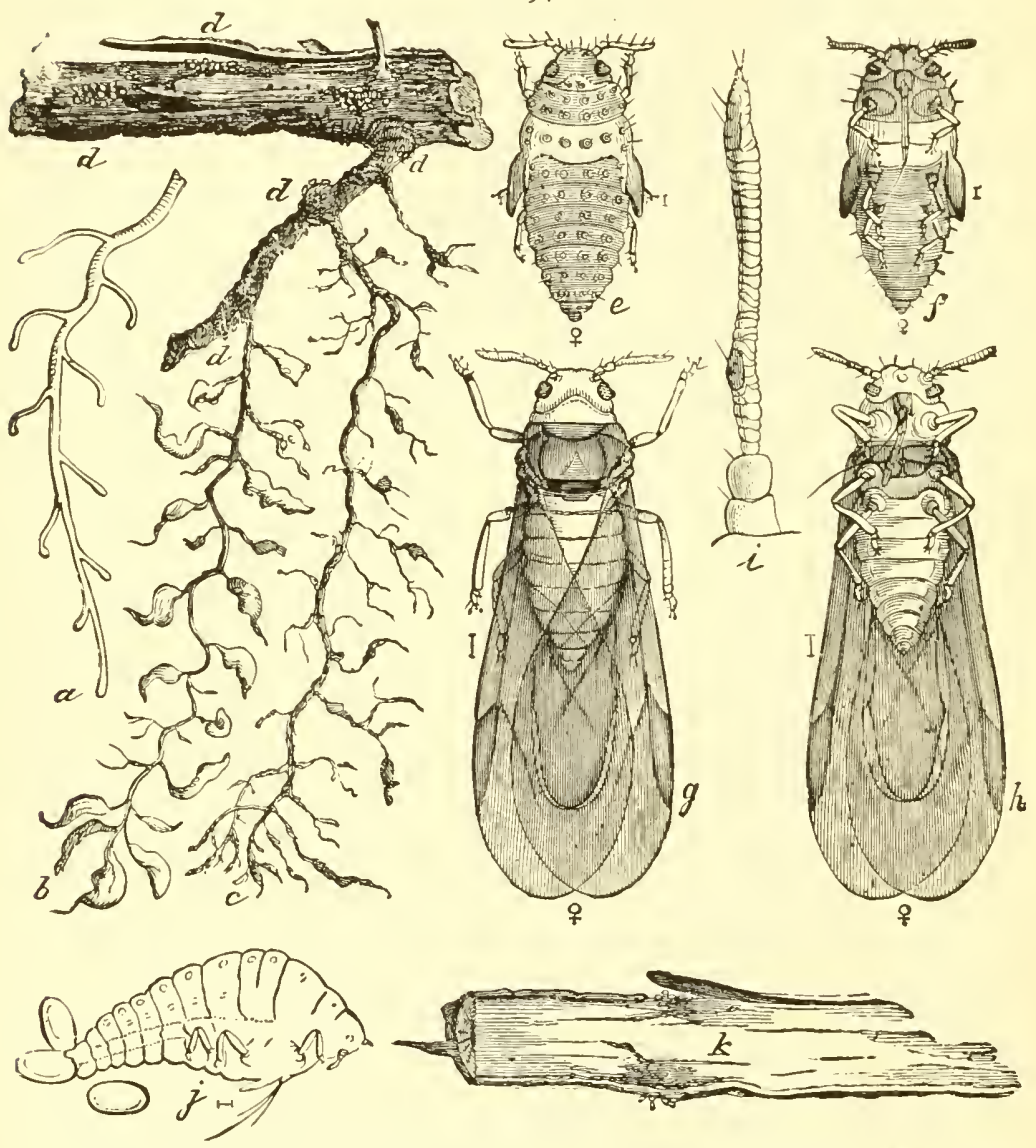

Phylloxera vastatrix.-a. unaffected rootlet of grape; $b$, rootlets with newly-formed galls; $c$, same. wth old and dried-up tissue; $d d$, groups of the lice on roots and rootlets; $e, f$, female pupa, from above and below; $g, h$, winged females; $i$, an antenna $j$, oviparous wingless fenale and her eggs; $k$, root showing location of the eggs.

An advance upon those root-living species is found in Phyl'oxera, which belongs with Chermes in a sub-family, Chermesina, 
distinguished by having only two discoidal veins on the forewings. The grape Phylloxera is known by reputation all over the world, and its ravages in European countries have called forth volumes of print. It has been thoroughly studied in our own country by Dr. C. V. Riley, among others, and from his works the following life history is taken.

The insect winters on the roots of grape, mostly as a young wingless form. This starts growth in spring, rapidly increases in size, and soon commences to lay eggs, the young from which, like their mothers, remain wingless, are also sexless, and also lay eggs; and so we may have a series of generations of similar creatures, no true sexes becoming developed, no wings appearing, and reproduction being entirely through unfertilized eggs. Sometimes, in midsummer, some individuals acquire wings, and thus we get migrating forms, which issue from the ground while yet in the pupa stage, and, as soon as they become winged, fly and spread to other vineyards in the vicinity. Eggs are then laid, usually on the under side of the leaves, from three to eight being the range, while five is perhaps the usual number. They are of two sizes, of which the larger produce females, the others males, and they come from the eggs fully developed and ready to reproduce. These curious creatures have become modified for the one purpose of reproducing their kind, and can neither feed, for the mouth is aborted, nor fly, for they have no wings. After copulation a single egg, almost as large as the insect itself, is developed in the female, and from it hatches a form which is like the type which started the cycle early in the season. Curiously enough, it occasionally happens that some of the wingless forms which remain underground also lay eggs of two different sizes, producing males and females, and thus it appears that winged forms are not really necessary to the continuation of the species. Quite usually wingless individuals abandon the roots and crawl up the stems to the leaves, where they form the galls, which are the most prominent external indications that a vine is infested. I have seen vineyards in New York and New Jersey in which almost every leaf showed these galls, yet withal no real injury had been done. In other words, most of the native American vines are able to sustain the attack of the species. This is not true of the vines in Europe, where this insect has 
been introduced, and, after a long series of experiments with insecticides, none of which proved satisfactory, resort was finally had to American stocks upon which the foreign varieties were grafted. This has proved effectual to an extent; but it seems that, in the course of time, the period varying somewhat, even

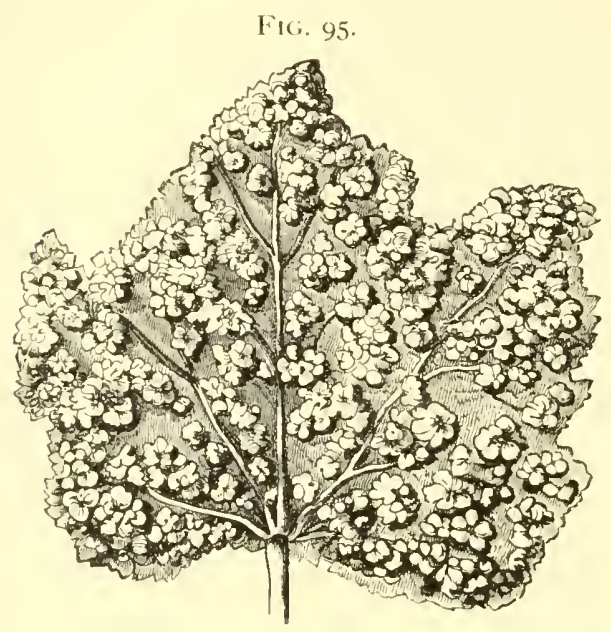

Galls of Phylloxera on grape-leaf.

American stocks lose their exemption in Europe and become gradually subject to injury from the Ply. loxera attacks.

We have a number of species of this same genus infesting a great variety of plants not of economic interest. Perhaps the most common is that which forms large, blisterlike galls on hickory leaves, so prominent as to attract attention from even the most casual observer. If one of these galls be cut open, the inside will be found lined with numerous minute, yellow insects, with dusky wings which lie folded flat over the back, and in this particular the Phylloxera differs from the typical aphids, which have the wings vertical when at rest.

The subject of dealing with underground pests, or plant-lice which feed upon roots, is one of importance, upon which the last word has not yet been said. As against the Phylloxera, bisulphide of carbon has proved useful, injected by means of a proper instrument into the ground at about the level of the roots and allowed to permeate the soil. The fumes are deadly to insects, and where they reach them in any but the egg stage, kill. The Phylloxera does not require attention in our country at the present time, and no large space need be given the subject of remedies against it. The matter is different when we consider the species which infest other cultivated plants; whether Rhizo- 
biini, or forms like the "peach-louse" or the "woolly applelouse," where they may be on leaves, twigs, and roots at one or different times. Bisulphide of carbon can be used with good effect in such cases; but it is rather an expensive application, and there is an element of danger that makes it desirable to employ something equally effective yet less liable to injure vegetation. Very satisfactory results have been obtained with tobacco, some under my own observations, some reported by other trained observers, and it seems fairly well proved that trenching around an infested tree, and filling into the trench a liberal supply of ground tobacco, refilling the trench immediately after, will have the effect of clearing the roots of these pests. This has been used more particularly against the peach aphids, and has been almost uniformly successful. Tobacco is a good fertilizer, and many dealers carry the coarsely ground product as part of their stock in trade. It is rather expensive as a fertilizer, but cheap as an insecticide, and a double value is obtained because besides killing the lice it also stimulates the trees or other plants. The use of tobacco, therefore, where root-lice are troublesome, is good farm practice. It may be well to say, however, that little or no benefit is derived from the use of stems spread upon the surface, or dug in, because there is not a sufficiently rapid extraction of the nicotine, and this is, after all, the killing agent. The ground material on the other hand gives up its nicotine readily to a small quantity of moisture, and it will be quickly carried down and around the roots of the plants, into direct contact with the insects. In land infested by root-lice the use of commercial fertilizers is indicated. It has been found by experience that salty mixtures kill plant-lice more or less rapidly, and therefore. where root-lice are present, potash in the form of kainit and nitrogen in the form of nitrate of soda are advisable. I have frequently noticed that on land where these fertilizers are used underground insect life is scant, and direct experiments have proved that this condition of affairs is largely due to the salty fertilizers introduced into the soil. As against peach-lice in light soil, ten pounds of kainit to a five- or six-year-old tree of good size is about right, and the material should be spread on the surface evenly as far as the roots are likely to extend.

In the more normal plant-lice the wings are better developed, 
and we find differences in the form of the honey-tubes which are of generic or cren sub-family value. Thus, we have some species of Pemphigus entirely without them, or with very small, mere tubercle-like structures. They live on a variety of trees, but perhaps more abundantly on poplar, and make galls, which are sometimes spherical and nearly half an inch in diameter. If we cut one of them after midsummer, we find it full of plant-lice,

Fig. 96.

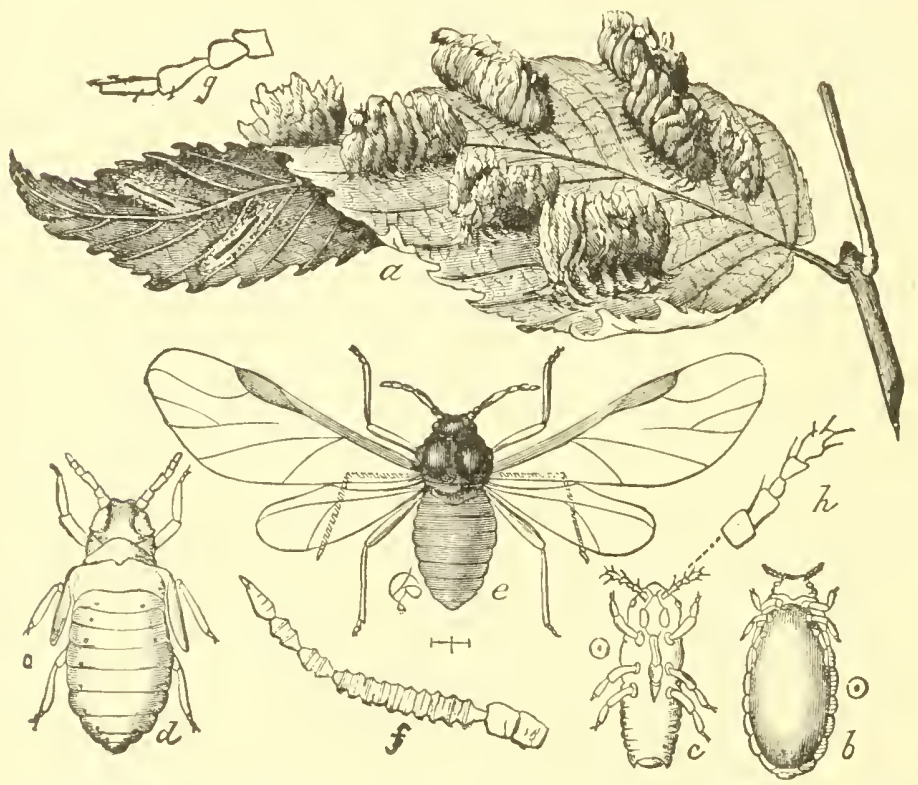

Cock's-comb gall on elm, Colopha ulmicola.- $a$, elm-leaf showing galls; $b$, winter egg, covered by the skin of the true female; $c$, larva just hatched; $d$, pupa; $e$, winged adult.

the progeny of the single specimen which caused the growth of the gall early in the season. There are many other gall-producing lice, perhaps the best-known being the Colopha ulmicola, found on elm, and forming the "cock's-comb" gall. The popular name fairly describes the appearance of the abnormal growth, which is an inch or more in length and about one-quarter of that in height. None of these gall-making species are abundant enough to be seriously troublesome; but quite the contrary is true of the 
"woolly plant-lice," betonging to the genus Schizoneura. 'These cover thenselves with a secretion resembling fine cottony fibre, which conceals them more or less completely. Thus there may appear to be tufts of cot ton attached to leaves or twigs, beneath each of which we find, however, a great mass of plant lice busily en gaged in feeding. The " alder - blight" and " beech-blight" are lue to species of this kind, and more important than all is the "appleblight," or " the woolly apple-louse." This species, Schizoneura lanigera, has been introFIG. 97.

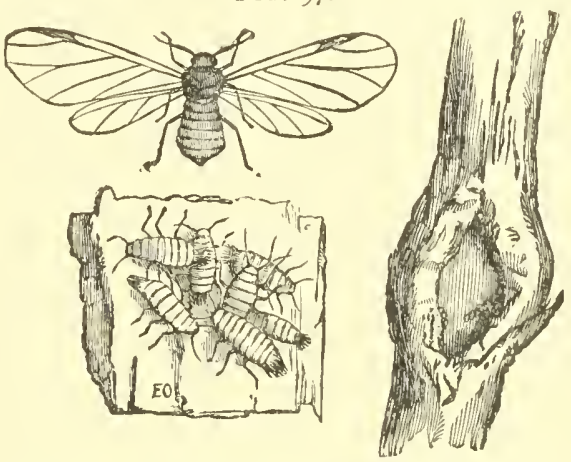

Woolly apple-louse, Schizonima lanigera: show ing a group of specimens on bark, a crevice on a lrank, in which they congregate, and a winged form.

duced into other countries, and is known in England and Australia as the "American blight." Young trees are frequently injured by these aphids, which gather in masses on the trunks, and canse the death of the bark below the point of attack. 'The eggs may be found singly in the bark crevices during winter, completely enveloped in the dry skin of the female, and from them appear, in spring, agamic, wingless forms, which bear living young. This method of reproduc. tion continues until the winged type, which

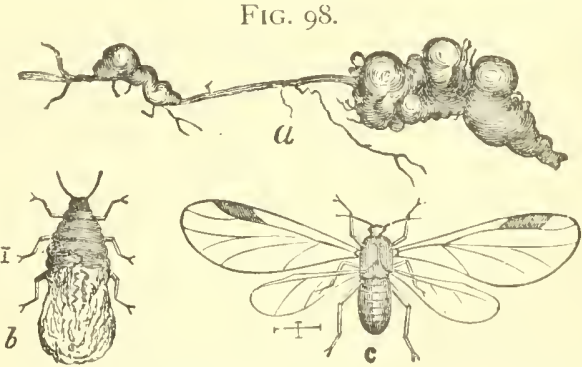

Schizonewra langera root form, $-a$, galls caused by them on apple-roots; $b$, wingless, wax-coated form; . winged form.

spreads to other localities, is produced in late smmmer. The sexed forms are wingless and mouthless, the female producing only a single egg; but in the southern parts of our country it 
is not unusual for the insects to survive winter in the adult con. dition, without producing a winter egg. One form of the species works deep underground on the fibrous roots; and this is most difficult to deal with, and often causes the death of the attacked trees. When they appear on the trunk, treatment with either whale-oil soap or kerosene emulsion will be effective, and the underground form can be reached with bisulphide of carbon, or by a liberal use of the tobacco or kainit, as recommended on a previous page.

We have a number of species that attack our common orchard and farm crops, like the cherry-aphis, Myzus cerasi, the peachlouse, Aphis persicae-niger, the apple-louse, Aphis mali, the hop-louse, wheat-louse, melon-louse, and others of equal reputation. Almost every species requires different treatment, and it is difficult to lay down general rules. Cabbage-lice, which frequently do great injury, can be kept down by the prompt removal of all plant remnants left in the field after the heads are taken out and disposed of. On the stumps the insects continue to breed and live during the winter, if not disturbed, either as eggs or adults; therefore, remove, use up, or destroy them as soon as may be. In pits where cabbage is kept to obtain seed the year following, a great number of lice pass the winter safely, but a free use of bisulphide of carbon will result in their destruction, so that the plants may be set without infestation in spring. An equally important point is keeping down all cruciferous weeds like mustard, shepherd's-purse, and the like, because on these the insect flourishes as well as on cabbage; therefore, clean culture, not only in the fields but along fences and roads, will pay over and over again. The corn-root louse can best be attacked through its guardian ant, which colonizes the helpless forms upon the roots in spring. Late fall-plowing the corn-fields is indicated here, that the nests of the ants may be destroyed at a season when they are unable to rebuild them. In those sections where fertilizers must be used, the kainit and nitrate of soda, already referred to, will prove effectual. The "apple-louse" and "cherrylouse," though different in appearance and habits, have a similar life history, and both pass the winter in the egg state, the eggs being laid on young twigs close to the buds. It is good policy to trim a tree on which there are many eggs pretty thoroughly in 
winter, the cuttings, of course, to be promptly destroyed. Thus the number of individuals to start new infestation in spring will be greatly reduced. They breed agamically throughout the summer, and bring forth the sexed individuals late in fall or early in winter. I found them in New Jersey still ovipositing during the first week in December. Where pruning is not desirable, much can be done by spraying the trees, as soon as the eggs have hatched, with kerosene emulsion,- say, one part in twelve or thirteen of water. Both of these species lay a number of eggs, but how many has not, I believe, been actually determined. The species that infests hops has been already mentioned, and the best remedy against it is the total destruction of the vines immediately after the hops have been gathered, which will head off the production of the sexes. If this is delayed, spraying the plum-trees in fall or early in the spring before the hop-vines have made much start will be of great advantage. When the insects infest such plants as wheat, rye, or oats, it becomes difficult to adopt measures likely to be of much benefit. They multiply so rapidly, and the task of spraying a wheat-field is so enormous, that it is hardly worth while to recommend it. In such cases we must stimulate, to assist the plants in outgrowing injury, by applying such readily soluble fertilizers as nitrate of soda. This gives additional vigor to the plant, enabling it to sustain the attacks of the insect and mature a crop as well. Harvesting should not be delayed longer than absolutely necessary, unless it is observed that the enemies of the plant-lice are getting the better of them, and in that case nothing will be lost by leaving the grain as long as desirable. The aphid infesting cucumber-and melon-vines has been recently determined to be the same as one of those infesting oranges, and as that which frequently injures cotton. It has also been found on the strawberry; and seems, indeed, to be a very general feeder, passing the winter upon such wild plants as remain more or less green. Under favorable circumstances it increases rapidly in spring, and a migration starts to cultivated fields. Against this insect on melon-vines we can use bisulphide of carbon, covering the plants with a bowl or other covering, and evaporating a small quantity beneath it. This will kill the aphids in about an hour, and, though the process is slow, it has the advantage of being completely effective. 
While, as has been stated, we cannot lay down general rules as to the treatment of all plant-lice, there are a few points that are always important. In the first place, the earlier the insects are dealt with, the more chance there is for the application to be effective. Plant-lice should be treated just as soon as they are noticed; the longer the delay the weaker the plants become, and the greater the thoroughness required to reach all the specinens.

As a general insecticide, nothing is better than the kerosene emulsion, which, when diluted ten times with water, kills all the young forms and adults of the green species. It has been fonnd by experiment that black or brown species are much more diffcult to destroy, and one part of emulsion in six or eight parts of water is more likely to be effective. Fish-oil soap is effectuve at the rate of one pound in six gallons of water; or, as against the brown species, one pound in four gallons of water. Thoroughness of application is always essential. It must be remembered that these poisons act by clogging the spiracles, or by entering into the body through them. Unless the application is thorough, the insects may be weakened but not killed, or, if rendered helpless for a time, they may recover, and a second dosing becomes necessary where one, more thoroughly applied, would have been sufficient. Where it is not advisable to apply either of the materials mentioned, we can use tobacco with good prospects of success, either as a decoction or a very finely ground powder. In greenhouses, tobacco is a standard remedy, and its frequent application results in keeping them moderately free from these pests. It may be applied as already described, but is more usually burnt to make a smoke, which is poisonous to the insects. A milder method is to keep the steam-pipes covered with moist stems, so as to produce a nicotine-laden atmosphere. Very often plant-lice appear in forcing-beds, and these we can generally destroy with bisulphide of carbon placed in a shallow dish and left in the covered beds overnight. Greenhouse benches mat be rid of the pests in the same way, covering the plants for two or three hours with a frame or box, and evaporating a small quantity of the bisulphide. A fumigating-box made of wood, canvas, tin, or other material, large enough to contain potted plants of good size, should be in every greenhouse and nursery. A number of pots of infested plants may be placed in such a box, 
the door closed, and bisulphide evaporated from a vessel hung up just below the top of the box. As the vapors descend, they will kill the insects infesting the plants, which may then be sent out free from all insect troubles. One dram of liquid per cubic foot of space will be about the right quantity not likely to hurt vegetation, while killing all lice by the time the liquid has entirely evaporated.

The "jumping plant-lice" are so called from their habit of leaping readily, though, as a matter of fact, their resemblance is rather to the tree-hoppers, and most of all they recall a miniature

FIG. 99.
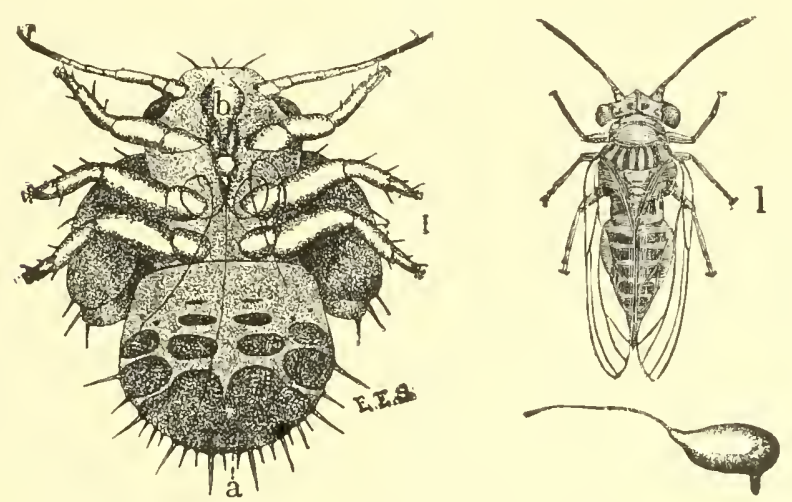

The pear-psylla - $a$, pupa from under side, showing the thread-like piercing lancets; to the right, a winged adult and stalked egg.

cicada. They all belong to the family Psyllide, some species of which are exceedingly troublesome, - e.g., the "pear-psylla," Psylla pyricola. This infests pear-trees in the more northern parts of the country, extending south to Maryland, though south of New York State it occurs in isolated patches only. It does its injury, first, by sucking the juices of the plant and so weakening it; second, it exudes honey-dew in such quantity as actually to close the pores of the leaves and young bark, over which a fungus forms and checks growth. It commonly attacks the stalk of the fruit, or the twig just where it is fastened, and the result is nearly always a cessation of growth in the pear itself. The species has several broods during the season, but winters as 
an adult in any araii.uble shelter, - under loose bark of trees, under rubbish, and, in fact, wherever there is an opportunity to hide. The application of whale-oil soap early in spring, just as the buds begin to swell, will generally kill the insects, which are then ready to emerge from winter quarters. Good practice is to scrape all the loose bark from the trees during the winter, and burn it; wash at that time with a potash or strong kerosene mixture, and in spring use the whale-oil soap at the rate of one pound in one gallon of water, being careful to confine the spraying to the trmik and larger branches. If this is thoroughly done, it forms a film over the trunk which no insect will voluntarily pierce. A liberal application of whitewash is also advantageous, and should be put on with a knapsack sprayer and Vermorel nozzle.

We have many species belonging to this family, some of them gall-makers on the hackberry, or Celtis; but none others occur in sufficient numbers to be of economic importance.

The "tree-hoppers" belong to the family Membracila, and contain many odd-looking types. The general shape has been compared to a beech-nut, and the most prominent part is always the thorax, which may be produced into a curved horn forward, into a broad hump, into a pair of curved lateral horns, into a double hump, or into a dozen other forms. The species occur on trees, shrubs, vines, and indeed on vegetation generally, though rarely in great numbers. Some species excrete honeydew, some lay their eggs in white frothy masses on plants, and a few are attended by ants, thus resembling the plant-lice. Only a few are troublesome, and of these are the "buffalo treehoppers," belonging to the genus Ceresa. They derive their common name from the fact that the thorax is cut off square anteriorly, and projects into two short, lateral, curved horns, which give it a fanciful resemblance to the massive front of a buffalo. The head is small and scarcely noticeable, the horns not being recognized at first as really belonging to the thorax. This insect causes injury by laying its eggs in slits on twigs of apple- and other fruit-trees. There appears to be almost a poisoning of the plant tissue, because the wounds, thongh apparently slight, do not readily heal over, but rather open up the year following, giving rise to an abnormal swelling, weak and morbid in character, unable to sustain the weight of any fruit that occurs 
beyond it, and ready to break in the first high wind. On old or large trees the insects are rarely langerous, because their injury results in only a little pruning, but on young trees they maly cause deformities; hence, if the insects are noticed in a young orchard, it will be advisable to go over it carefully during the winter, to trim out all infested twigs or branches, burning the

FIG. IOO.

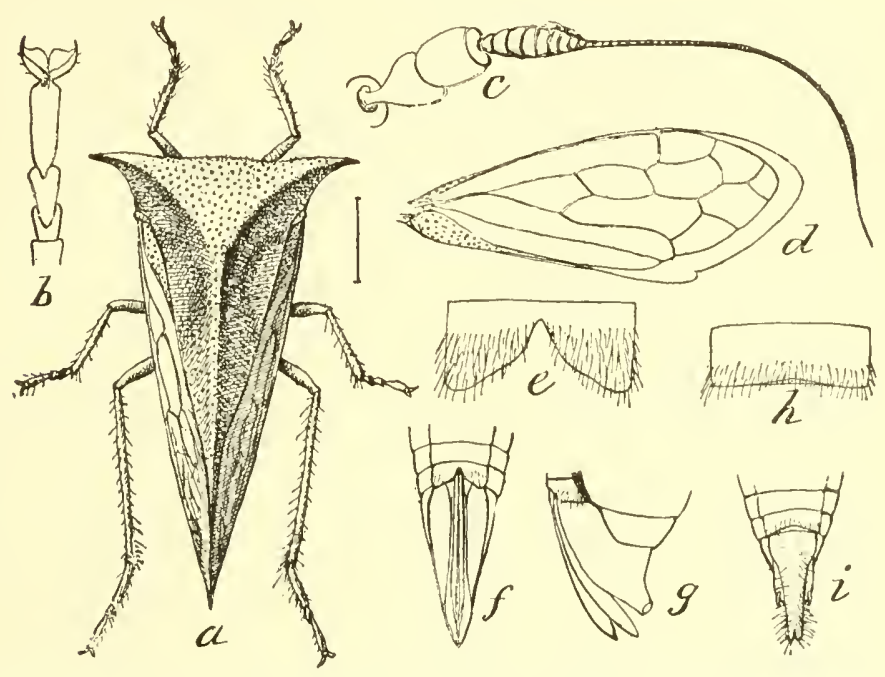

Buffalo tree-hopper, Ceresa bubalus.- $a$, adult; $b, c, d$, tarsus, antenna, and wing; $f, g$, tip of abdomen, showing ovıpositor.

cuttings to destroy the eggs. Active insecticide applications are hardly indicated.

Next come the cicadas, or "harvest-flies," often miscalled locusts, and the largest of the Homoptera. They are easily known by their broad, transparent wings, the large head with prominent eyes set on each side, and by their intensely shrill, loud song. which during midsummer forms one of the common sounds of the country. The author of this concert is the "dog-day harvest-fly," greenish in color, more or less marked with black. The noise is produced by an elaborite drumming and resonating structure on the under side of the thorax and abdomen of the 
males, who alone are musical, giving rise to that oft-quoted old saying, -

\footnotetext{
"Happy the cicadas' lives, For all have voiceless wives."
}

The plan of the sound-organs can best be described by comparing to a slightly convex-bottomed tin pan, which makes a

F1G. IOI.

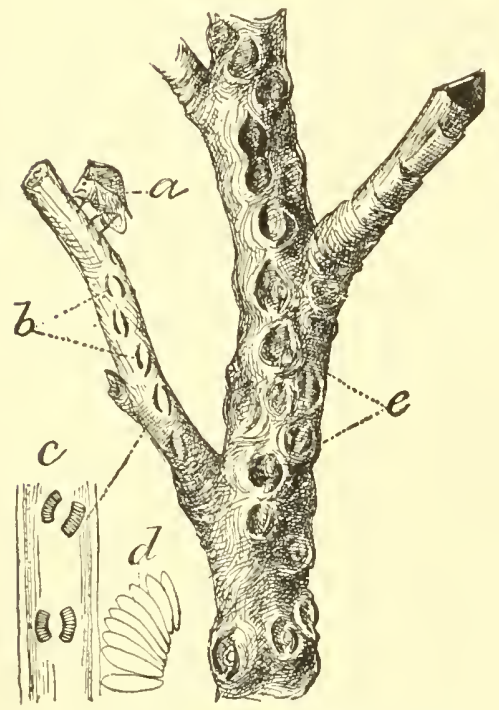

$a$, Cevesa bubalus, ovipositing in slits $b$; the eggs, $d$, arranged as at $c$; old, scarred punctures shown at $e$.
FIG. 102.

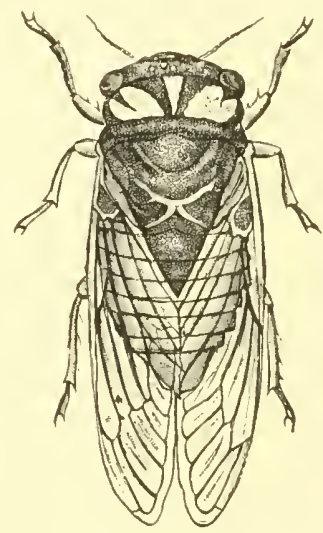

The dog-day harvest-fly, Cicada tibicen.

snapping noise whenever the bottom is forced to change from convex inwardly to convex outwardly. By an exceedingly rapid snapping of the convex "drum" of the cicada, the continuous shrilling sound is produced, intensified and modified by the various tense membranes more or less surrounding it.

The most famous species of this family is the "periodical cicada," or "seventeen-year locust," Cicada septendecim. It is of especial interest from the unusually long larval period, remaining in the Middle and Northern States sixteen years beneath 
the surface of the ground, feeding on the juices of roots, and transforming in the spring of the seventeenth year into a winged adult. No less than twenty-two broods have been tabulated in the United States, chiefly through the efforts of the late Dr. C. $\mathrm{V}$. Riley, so that we know approximately how each is distributed, and are able to foretell with certainty when the insects will appear and about what territory they will cover. A further point of

FIG. 103.

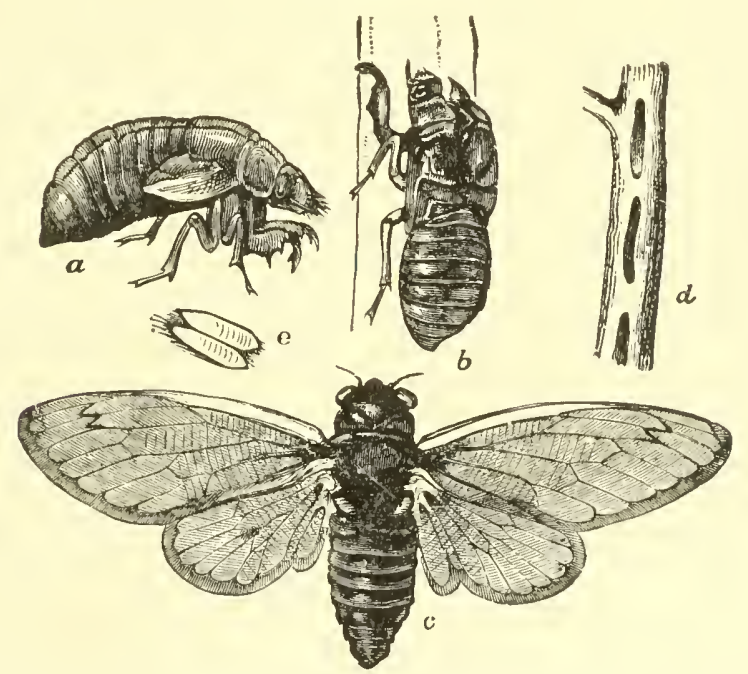

The periodical cicada, $C$. septendecim. $-a$, pupa, ready to change: $b$, pupa-skin from which the adult $c$ has emerged; e, eggs, taken from the egg-punctures $d$.

interest is that in the more southern States the period of development is somewhat shorter, thirteen years only being required to bring the insect to maturity. Much confusion was caused in arranging the broods until this fact was understond : but experiments have now been made in transferring eggs of the thirteenyear variety to northern regions, and eggs of the seventeen-year variety to southern regions; the object being to ascertain whether climate would affect the larval period in the first generation. These experiments have not yet terminated. This cicada makes up for the long intervals at which it occurs by the enormous numbers in which it appears, and in a "locust" year its loud 
song may be heard at all periods of the day and until late into the night, from the end of May to nearly the end of June, louder and more intense on warm or hot days. No injury is done by the insects in feeding, but their egg laying habits often cause

FIG. IO4.

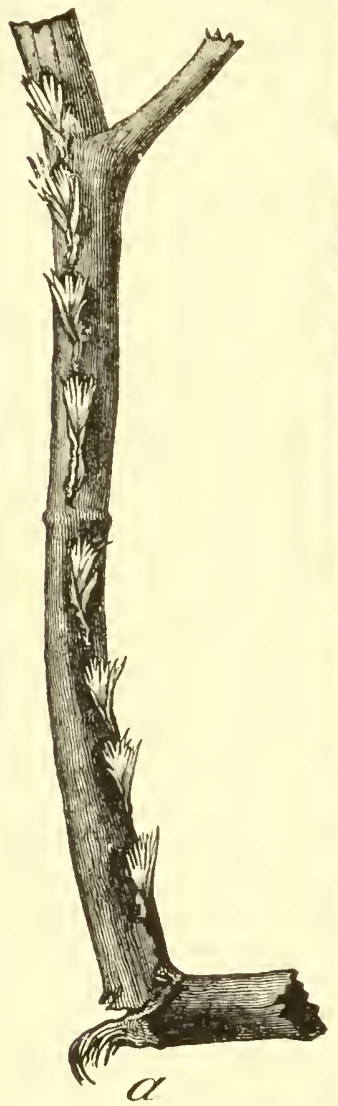
considerable trouble. Though the larva feed under ground, the eggs are laid in the twigs and branches of trees; a series of slits being cut by the powerful ovipositor of the female, forming smooth chambers in which the eggs are arranged in series. There is nothing to be done when such a brood occurs except take the injury and make the best of it. Of course valuable plants or trees can be protected by mosquito-netting, but my statement applies to ordinary farm and or chard crops. The fact that we know when the insects are to appear makes it possible for the fruit-grower to guard himself to some extent by not setting out young stock. On old trees no serious injury will be done, and if no pruning is attempted during the winter preceding, the insects will probably find an abundance of useless twigs to oviposit in. Young trees, however, are sometimes so injured as to make them practically useless, either by completely spoiling the shape, or by so weakening the main branches

Cicada egg-punctures: at $a$, freshly made; at $b$, old and distended. that they never become strong enough to bear a proper top. Wherever the English sparrow has been introduced, the period ical cicada is doomed. These birds seem to have an intense hatred for the insects, attacking and pulling them to pieces in 
the most wanton manner. Near the large cities where the spar rows are numerous, entire broods have already been destroyed. In $\mathrm{r} 889$ the insects appeared in large numbers in Prospect Park, Brooklyn, and in the surrounding woodland, but in an entire day's careful search I found only a single branch containing eggs!

That it may be known in a general way where and when these insects may be expected, the following record of the broods is

FiG. 105.

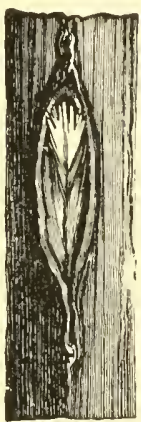

a

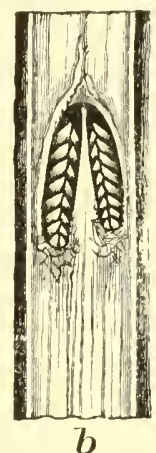

b

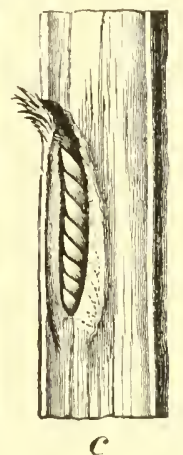

c

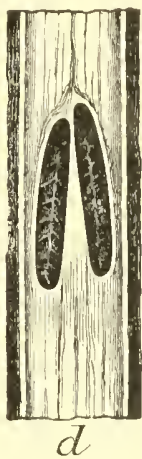

Cicada egg-punctures, seen at $a$, from outside; $b$, cut down on puncture to show the two chambers; $c$, side view of an egg-chamber; $d$, a pair of egg-chambers from which the eggs have been removed.

given, with the date of last appearance, the time when they may be next expected, and the country covered by them. The statement is made up from the reports and bulletins of the United States Department of Agriculture.

BRoOD I. last appeared in 1893: will appear again in 1910. Occurs in Massachusetts and Connecticut in small numbers.

BRood II. appeared last in 1895 ; will appear again in I 908. It covers the northwestern part of Georgia, and appears at thirteen-year intervals. No very definite limits have been assigned to it.

BROOD III., originally supposed to occur in Ohio in 1887 , was based on erroneous information.

BROOD IV. is of the thirteen-year variety, appeared last in I883, and will appear again in I896, covering parts of Florida. 
Alabama, Mississippi, and Tennessee, but it seems not to be very numerous.

BROOD V. occurred last in I888 and will appear next in 1905. It covers parts of Southern Wisconsin, Northern Illinois, the eastern third of Iowa, the northwest counties of Indiana, and the more southern part of Michigan. This brood is very numerous in individuals.

BROOD VI. occurred last in I 984 and will occur again in 1897 , being of the thirteen-year race. It occurs in the southwestern part of Mississippi and extends into Louisiana, infesting a comparatively small territory only.

BRoOD VII. occurred last in 1885, and will occur again in I 898 , being also of the thirteen-year race. It occurs in Southern Illinois, Kansas, Missouri, Georgia, Louisiana, Arkansas, Mississippi, and Tennessee.

BROOD VIII. appeared last in I889, and will appear again in 1906. It covers a portion of Soutiern Massachusetts, a large part of Long Island, extends along the Atlantic Coast to the Chesapeake Bay and for some distance into Pennsylvania, Kentucky, IVest Virginia, Ohio, Indiana, and Illinois.

BRoOD IX. occurred last in I89I and will appear again in 1908. It occurs in parts of Nebraska and probably in portions of Colorado, though it has not yet been satisfactorily limited.

Broon X. occurred last in 1888 and will appear again in I90I, being of the thirteen-year race. It has been recorded from Texas, but is yet a doubtful brood, requiring fuller observations than have been made to substantiate it positively.

Brood XI. occurred in 1893 and will occur again in 19 Io. It is a large one, covering parts of North Carolina, Virginia, Maryland, Illinois, and Indiana, although not the entire State in any instance.

BrooD XII. occurred last in 1894 and will make its next appearance in I9Ir. It extends along both sides of the Hudson for its full length, into Southern New York, Connecticut, through the entire State of New Jersey, and into Pennsylvania, Ohio, Michigan, North Carolina, Virginia, Maryland, and Delaware.

BROOD XIII. appeared in 1895 and will appear again in I9I 2 It occurs throughout a large part of Iowa, and probably a portion of Illinois and Missouri. 
Brood XIV. will appear in 1 896, and covers Western Missouri, extending into Kansas, Arkansas, Iowa, Northern Texas, and Indian Territory.

Brood XV. will occur in 1897 in Western Pennsylvania and Ohio, extending into Kentucky and West Virginia.

Brood XVI. appeared last in I893 and will appear again in I906, being of the thirteen-year race. It occurs in the northern portion of Georgia, but its limits are not well defined.

BROOD XVII. will appear next in 1898 and at intervals of seventeen years thereafter. It occurs in Wisconsin, the northern part of Ohio, Pennsylvania, and parts of New York, as well as isolated localities in New Jersey. The brood is a small one, however, especially in the southern part of its range, and apparently dying out.

BROOD XVIII. occurred in 1894 and will occur again in 1907 , being of the thirteen-year race. It is a very well-recorded one, and covers Southern Illinois, nearly all of Missouri, Louisiana, Arkansas, Indian Territory, Kentucky, Tennessee, Mississippi, Alabama, Georgia, North and South Carolina.

BROOD XIX. occurred last in IS82 and will occur again in I 899. It is a small one and confined to a few counties in Central and Northern New York, - that is, Monroe, Livingston, Madison, Yates, and, perhaps, those immediately adjoining.

BROOD XX. appeared last in $\mathrm{IS}_{3}$ and will appear again in I 900. It occurs in Western New York and Pennsylvania and Eastern Ohio. It is a small brood and does not attract attention.

BROOD XXI. occurred last in 1884 and will occur again in I90I. It covers parts of North Carolina, Virginia, and West Virginia, and may possibly occur in Massachusetts (Martha's Vineyard) as well.

BROOD XXII. appeared last in 1885 and will appear again in 1902. It occurs on Long Island, in New York, New Jersey, Pennsylvania, Delaware, Maryland, District of Columbia, Virginia, West Virginia, North Carolina, Tennessee, Georgia, Ohio, Kentucky, Indiana, Illinois, Michigan, and Wisconsin. Brood VII, of the thirteen-year race, and Brood XXII., of the seventeenyear race, come in contact in Southern Illinois and Northern Georgia, and it may happen, as it did in r885, that these two broods appear during the same year at the same place. 
The Fulgorida, or "lantern-flies," contain some very remark. able and striking species in tropical countries, but are sparsely

FIG. I06.
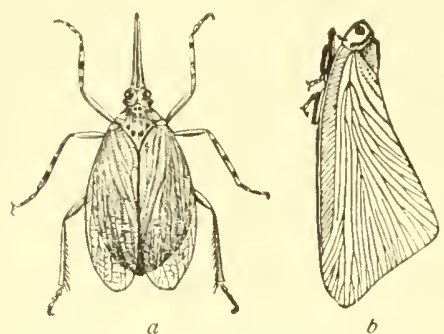

Fulgorida, or lantern-flies, $-a$. Scolops sulcipes; $b$, Peciloptera truncaticorns; twice natural size. represented by somewhat rare species in our fauna. Perhaps the most common of our forms are species of Ormenis, pale green or whitish, having somewhat the appearance of small wedges, the broad wing-covers being flattened vertically. They may be found on the under side of leaves of various plants, particularly grape, sucking the juices, preferably from the larger veins or ribs. None of them are injurious, and the family is mentioned only that our common species may be recognized.

The "spittle-insects," or "frog-hoppers," of the family Cercopida, resemble some forms of tree-hoppers in their habit of

FiG. 107.

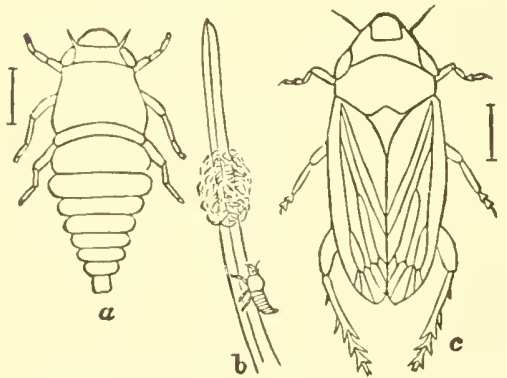

Cercopid, or spittle-insect.- $a$, larva, enlarged; $b$, same, natural size, on a leaf bearing "frog-sptttle;" $c$, the adult, enlarged. laying the eggs in little, frothy, white masses. These masses of "frog-spittle" are often noticed in grass lands, but their true character is rarely understood. Unlike the "tree-hoppers," the Cercopida never have hornlike processes or projections, but are usually squat, somewhat angular, yet flattened creatures, whose popular name, "frog-hoppers," has been obtained by the somewhat fanciful resemblance of the insects to a frog when just ready to leap. Few of these species, so far as I have any information, are sufficiently injurious to be of economic importance. They feed on a great variety of plants, but are rarely common on cultivated crops.

It is different with the "leaf-hoppers," or Jassida, which are 
small, slender insects with the wing-covers narrow and slightly thicker than the broad hind wings, which are the only effective organs of flight. The thorax is broad and square, the head usually short and very broad, in most cases somewhat crescentshaped, with prominent eyes occupying a large part of the sides. If we examine the insects on the under side it appears as if the beak or rostrum came out from the breast between the front legs, so much is the head curved under. The antenne are very short and bristle-like; the legs are well developed, the hind pair especially being very long and powerful, set with spines on the tibix,

\section{Fig. Io8.}

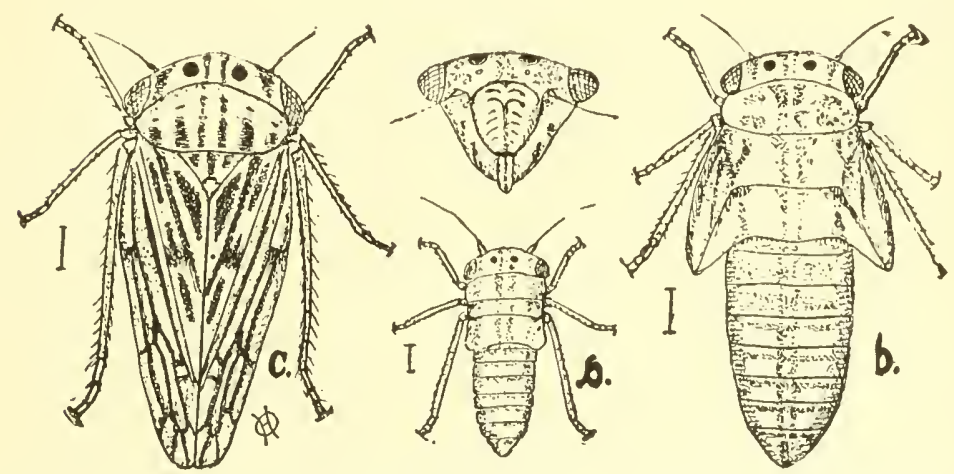

Development of a Jassid, Agallia singunolenta.- $a$, larva; $b$, pupa; $c$, adult; also head of same from below.

somewhat as in the grasshoppers, and like them the insects are powerful leapers. This they are in all stages, but as adults they are also ready fliers, and hence difficult to capture. Many of them are common and, feeding on cultivated plants, are injurious. As in other families, there is considerable difference in the life history of the species; but of most of those of economic importance it may be said that they pass the winter in the adult stage, hiding in all sorts of rubbish or in crevices, wherever they find opportunity. Some time in spring they leave their winter quar. ters, attack the plants upon which they feed, and lay eggs. The number of hibernating individuals is usually not very great, but they lay a large number of eggs, and the young and future broods become troublesome. One of the best-known species is that 
found on grape-vines, which causes the leaves during the latte: part of the summer to become marked with brown spots, sometmes in such numbers that they become confluent and the entire leaf is "burnt." If we tap a leaf at this time swarms of little creatures, not exceeding an eighth of an inch in length, prettily

Fig. 109.
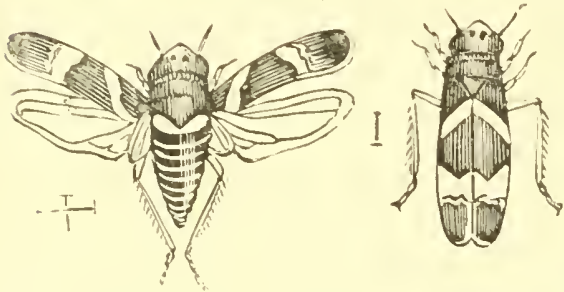

The grape-leaf-hopper, finthroneura vitis; at rest, and with wings cxpanded. marked with green, rosyred, and yellow; will fly or jump from them. Earlier in the seasor. they are yellow or green ish, without wings, bu jump readily if disturbed. On roses we find a similar appearance, and here the species are green or yellowish, without much marking. Nany are the crops infested by these little hoppers, and, though there are good characters by which they can be distinguished scientifically, yet to ordinary observation they appear much alike, except in size and color.

The methods of preventing injury are much the same for all species. In the first place, where experience has shown that the insects are likely to occur during the summer, all rubbish should be disposed of in the course of the winter preceding. This can be done by collecting and burning, or by plowing under very early and cultivating so as to leave a clean field. Loose bark, dead branches, twigs, or scaly fence-posts should all be attended to, and piles of dead grass or weeds along fences or in corners should be burnt or otherwise destroyed. In this way much can be done to prevent the insects from getting a start. When the larve are first noticed great success has been attained in vineyards by walking along the sides of vines strung on wires, disturbing then to start the insects, which jump wildly and readily. A shingle or palm-leaf fin smeared on both sides with coal-tar or insect-lime should be kept in constant motion near the vines, and by this fanning a great quantity of the jumping larve will be drawn to the smeared surfaces and destroyed. This method is practical, and has been found effective within my own experience; so large a proportion of the insects being captured in the course of two 
days that subsequently they were not noticeable. If this method cannot for any reason be used, the kerosene cmulsion dihuted ten times may be applied, and the vines should be disturbed as the spraying is done. If a Vermorel nozzle is used, it can be held a little distance from the vines and will hit the insects while they are in the air, either jumping or Hying. The wetting done in this way is as effective as when clone on the leaves, and there is even more chance of hitting them in the air than at rest. So the effort should be to fill the air around the vines, for some little distance, with the fine mist-like spraly so easily produced by the Vermorel nozzle. This method should also be made use of if the insects are found in numbers after they are winged. It is applicable in many cases, but hardly practical where insects feeding upon wheat or similar plants are to be dealt with. It has been found that the adults are attracted to light, and the electric arclight, particularly, destroys myriads of them. I have seen in a single globe no less than one pint of leaf-hoppers, and the number included in that measure is alnost impossible of estimate. The unfortunate feature in this method is that the damage to vegetation has been done when it takes effect, and it is in the line of preventing injury during the year ensuing, which can be accomplished as readily by the winter treatnent. In fact, cleaning up during winter is strongly insisted upon, and will pay many times over. A great number of leaf-hoppers are found in grass lands, where they do much more injury than is generally supposed,-an experiment in lowa seeming to prove that just about one-half the crop is destroyed in badly infested fields. The experiment was made by setting off two patches of equal size, as nearly equal in all respects as could be made, leaving the one untreated and collecting the leaf-hoppers from the other. Cattle were pastured on both parcels, and that on which the insects were collected supported just double the number. The insects were collected by means of shallow pans coated with tar, drawn by man or horse-power, and in jumping or flying up before it they alighted immediately belsind the elge, upon the tar. It requires very few such collections to practically exterminate the pests on a tract of land, but of course the question remains whether it will pay. On grass lands winter treatment is hardly practicable. and collecting in pans is perhaps the only available method. 
The sub-order Heteroptera contains those species of bugs in which the upper wings are thickened toward the base and the

FIG. IIO.

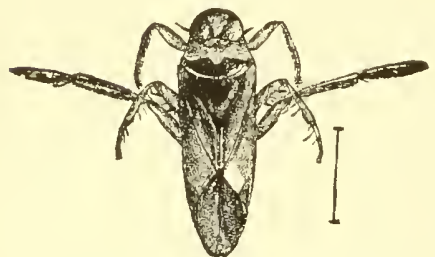

A water-boatman, Notonecta species. terminal portion is membraneous and veined. We have a large number of species belonging here, and some large series may be entirely left out of consideration. Such, for instance, are the aquatic families, all of which seem to be carnivorous in habit, whether they live on the surface of the water or beneath it. One of the water-boatmen, a species of Corisa, may be mentioned, because its eggs are used as food in Mexico. These eggs are nearly white in color, about one-tenth of an inch in diameter, and laid in great numbers on sedges, where they are collected by the

FIG. III.

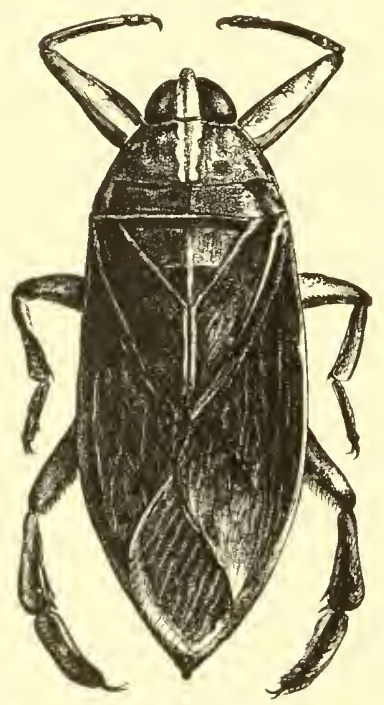

Belostoma americana. natives. Judging from the usual odor of the bugs and from the taste of such eggs as are sometimes involuntarily eaten on fruits, it requires a specially-developed gustatory apparatus to enjoy a meal of this character. This suggests the fact that one of the peculiarities of this suborder is the more or less marked presence of odors, differing somewhat in kind, but all of them intensely disagreeable. In bed-bugs we have one type in marked perfection, while in the "squash-bug" we find an excellent illustration of another.

One of the water-bugs that sometimes attracts attention is a huge creature, two or three inches in length, broad in proportion, livid gray in color, flattened above, with a short beak and very large, thickened forelegs, often drawn in considerable numbers to electric lights. It is the Belostoma americana, which lives in ponds and 
streams, where it feeds on other insects and small fish, destroy. ing large numbers. During the night the winged individuals leave the ponds, pair, and fly to new localities to lay their eggs. So abundantly do they occur that they sometimes become nuisances near electric lights, and have been termed from this fact "electric-light bugs."

Sometimes we find slender, spider-like creatures of a brown color scudding over the surface of the water at a rapid rate, and

FIG. II 2.

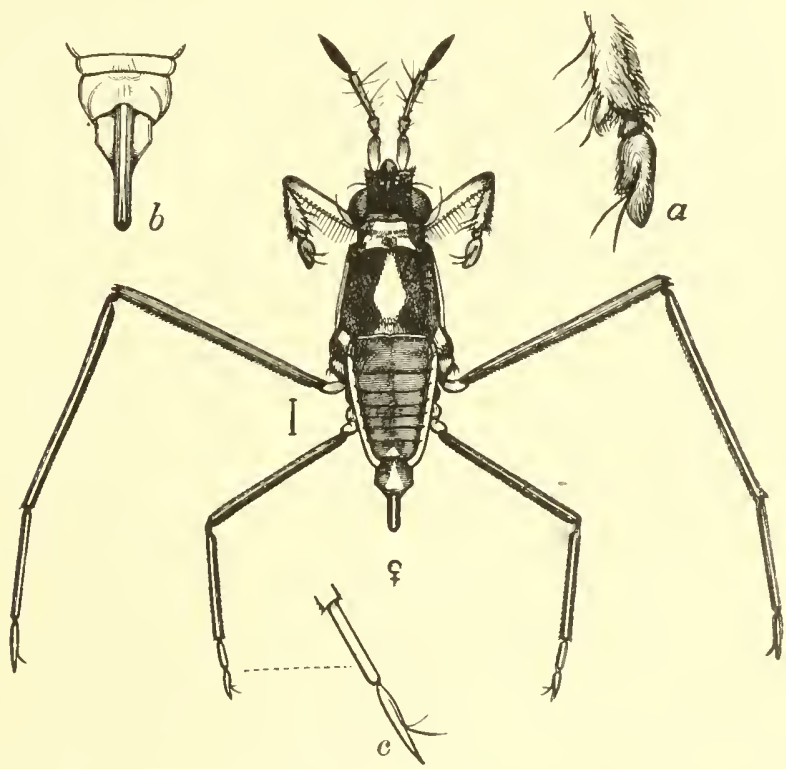

A water-strider, Rheumatobates rileyi, female. $-a$, anterior tarsus; $b$, ovipositor; $c$, hind tarsus.

these are "water striders," or Hydrobatida. They are interesting because some of them pass their entire lives upon the ocean, miles from land. These are said to feed upon the juices of such dead fish and other animals as they find on the surfice, and probably also on the floating masses of sea-weed occurring in equatorial regions where they are most common.

The first family of economic importance among the terrestrial species is the Reduviida, containing species of quite large size, 
distinguished by a comparatively small, narrow head with promi. nent eyes, and by a short, very stout, curved, pointed beak, which rests, when not in use, in a little groove between the front legs. The insects are strongly built, with legs usually well developed, and, as they are predaceous, are to be regarded as

Fig. II3.

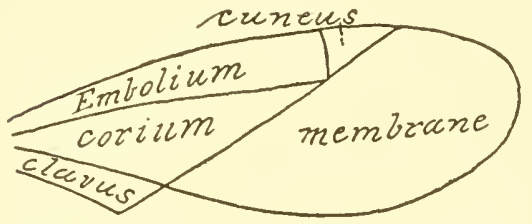

Wing of Heteropteron with all the regions named.

friends. The very small head and short, slightly curved, pointed beak, serve to distinguish them from the plant-feeding species. They readily puncture the skin of any one handling them carelessly, and the "bite" is exceedingly painful, the poison injected in to the wound being intensely irritating, and sometimes causing considerable swelling, with pain lasting for days. One of the species has adapted itself to life in houses, feeding upon flies and bed-bugs. The young have the curious habit of coating themselves with particles of dust or fibre which conceals them perfectly from casual observation. A similar species, Conorhinus sanguisugis, nearly an inch in length, is found in houses in the Southern States, - not to feed on bed-bugs, however, but as a bed-bug itself. It is especially inclined to bite children, and many cases of supposed spider-bites are believed by Dr. Leconte to be really due to this insect. He also states that he has known a patient to suffer from the effects of such a "bug" bite for nearly a year. Fortunately, the insects are not very common, their large size and black color, with red markings, making them easily visible and readily destroyable.

The largest species occurring in the Eastern United States is the so-called "wheel-bug," Prionidus cristatus, and this becomes more common southwardly. It lays its curious, jug-like eggs in hexagonal masses on bark of trees, fences, or any other convenient locality, and the adult, which is brown in color, is one of the most readily recognized of our species. The thorax has a semicircular crest, the edge of which is toothed, so that, viewed from the side, it has somewhat the appearance of a segment of a circular saw. It attacks all sorts of insects, piercing them with its 
powerful beak and sucking their juices. There are other species of the same general appearance common everywhere, and some even maintain themselves in our cities, feeding upon the larva injuring shade-trees. I have noticed certain of them in New Brunswick destroying the larvæ of the elm-leaf beetle in large

FIG. II4.

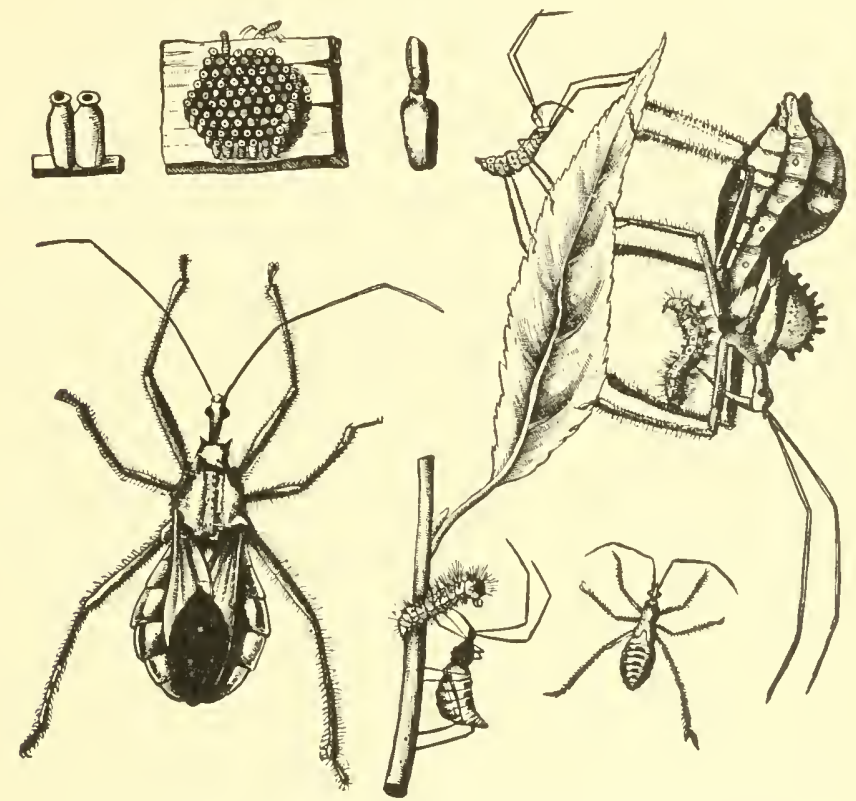

The wheel-bug, Prionidus cristatus, in all its stages; natural size.

numbers. Taking it altogether, we find in this family mainly forms that are beneficial to the farmer.

There are a few other common species, also predaceous in character, but much smaller and more slender than the preceding, belonging to the family Nabida. Our common species of the genera Nabis and Coriscus are yellowish in color, flattened above and rather roughened, with long legs, but otherwise resembling in head and beak the usual predaceous form. except that the beak is longer and more slender. They are found on flowers and leaves, preying upon almost anything that they can conquer. 
A rery curious, chunky little species, with the sides of the abdomen much elevated, and the forelegs much broadened and fitted for clisping, belongs to the genus Phymata and the family Phymatida. It is yellow and brown in color, and has the habit

Fig 115

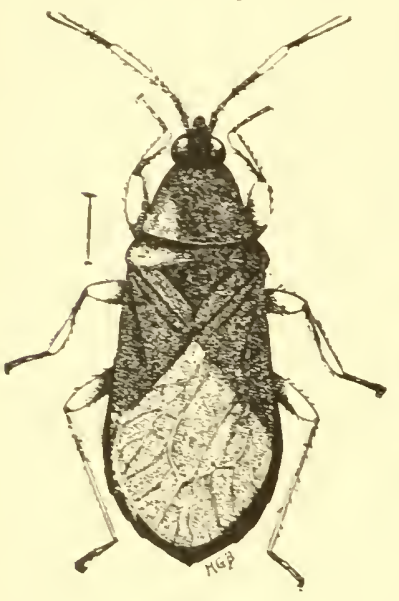

liabis twase of placing itself in the centre of certain flowers, in such a manner as to seem a part of the Hower itself. It is thus in position to seize any unlucky insect that comes within reach, and, although it is scarcely a quarter of an inch in

FIG. II6.

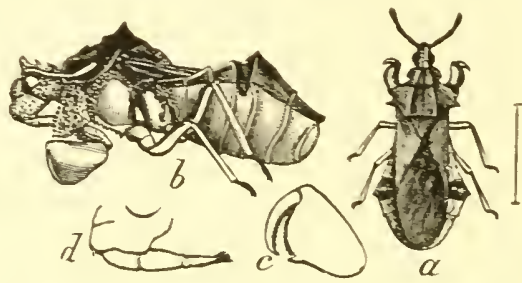

Phymata erosa, $-a, b$, adult, from above and side; $c$, front leg; $d$; beak

length, it is sufficiently powerful to hold and conquer even honer-bees. Butterflies are frequently its rictims, and it is one of the oddest forms in this order.

We sometimes find on the under side of leaves of tree and shrub, little whitish, flat creatures, with gauze-like, broad wingcovers, and a broad, gauze-like expansion covering the thorax. These belong to the family. Tingitida and are among the prettiest species in the order. There is no difficulty in recognizing them in the adult stage, by their lace-like or reticulated covering, which is sometimes banded with brown or spotted. Beneath this corering the insects are black or brown. and occasionally they increase sufficiently to do some injury to the plants upon which they feed. The adults usually live through the winter and lay their egos in spring: but sometimes eggs are laid in fall, and the insects winter in that stage. For shelter, fullen leaves are usually emplosed, or the adults creep uncler loose bark scales or into crevices, and we must agan recommend winter wort in clear- 
ing up rubbish of all kinds, or plowing it under. Where this is done there will be no necessity for active treatment in summer. They may be destroyed at that time, however. by the application of the kerosene emulsion diluted ten times, or by the whale-oil soap used at the rate of one pound in four gallons of water.

Perhaps no insect is better known than the "bed-bug," Acan. thia lectutlaria, which occurs, especially in hotels, throughout the country. It is wingless, very much flattened, broadly oval in shape, and red brown in color. It is able to crawl into the narrowest crevices, and no bedstead has yet been made which does not afford it shelter. It is nocturnal in habit, seeking its prey at night and occasionally making life miserable. Where a house becomes thoroughly infested, specimens are found under baseboards, beneath loose paper, in cracks in the plaster, and in fact wherever there is an opening large enough to insert the blade of a thin knife. They multiply rapidly

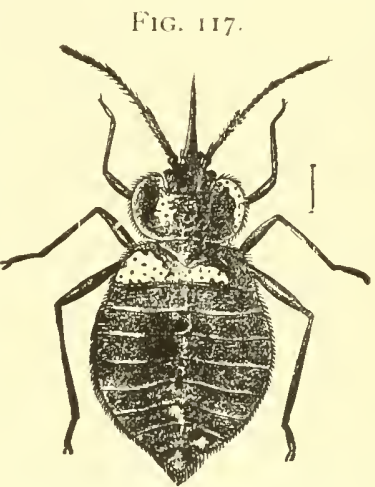
and are able to do without food for a The bed-bug, Acantha lectulara considerable period. In houses that have been long abandoned, bed-bugs of all sizes may sometimes be found, perfectly transparent as if they had been ahways with out food. It is probable, therefore, that they are able to subsist upon some substance other than human blood. Where they are accidentally introduced into a house and confined to beds, there is nothing better for use than kerosene or gasoline. It should be liberally applied in joints, crevices, and wherever there is the least opening, so as to reach the bottom before the material soaks into the wood. A single thorough application of this kind usually proves successful, although it would be better to renew it a week afterward, to reach forms that have hatched from eggs since the previous application: for in my experience neither kerosene nor gasoline destroys the eggs with certainty. Another effective remedy is corrosive sublimate dissolved in alcohol, and this has the advantage of being more lasting, remaining effective for some time after it is applied. It is, however, exceedingly 
poisonous, and must be used with that fact in mind. Professor Comstock states that where, in travelling, "one is forced to lodge at places infested by these insects, or by fleas, protection from them can be had by sprinkling a small quantity of pyrethrum powder between the sheets of the bed on retiring."

Rather closely allied to the bed-bug in structure, if not in labit, are a number of very small, flat species, with fully developed wing-covers, which are usually found on flowers, feeding upon yet smaller insects and perhaps also on eggs. They belong to the family Anthocorida, and the most common is a minute black in

FIG. IIS.

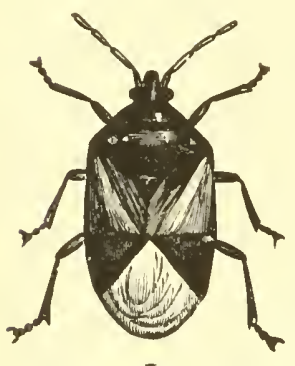

I

Triphleps insidiosus, the "insidious flower-bug." sect with yellow-tipped wings, known as the "insidious flower-bug," Triphleps insidiosus, credited with feeding among others upon the insects in Phylloxera galls.

Now follow the Capsida, containing a long series of species softer in texture than most of those heretofore described. They are plant bugs par excellence, found on vegetation of all kinds, frequently in very great numbers, and feeding upon their juices. The wing covers are soft and flexible throughout, though thickened basally. They puncture leaf, twig, stem, or flower, and, where these punctures have been made, there is usually a drying of the tissue which interrupts the nourishment of the plant and often causes injury. As a rule, the species are green or yellowish in color, sometimes black speckled, and occasionally with reddish markings. In form they vary, being sometimes broadly oval, sometimes quite narrow. The antennæ are usually long and prominent, and the "buggy" odor is well developed. We have a number of species abundant enough to be injurious, and the question of dealing with them is sometimes complicated. The insects winter in different stages; often as an egg laid in twigs, as with the "four-lined plant-bug,", Pecilocapsus lincatus, attacking among others currant and gooseberry bushes. The application of insecticides to kill plant-bugs has been found unsatisfactory. They resist even the kerosene emulsion quite strongly, and in order to kill adults it cannot be diluted more than five times. Even against immature forms a. 
very strong mixture is necessary, and not more than six or seven parts of water can be added if a good effect is expected. In the case of the four-lined bug already mentioned, the knowledge that it lays its eggs near the tips of currant and other twigs suggests a careful winter pruning, the cut twigs and branches to be burnt, and in this way injury may be prevented during the year following. This measure is successfully used where shrubby
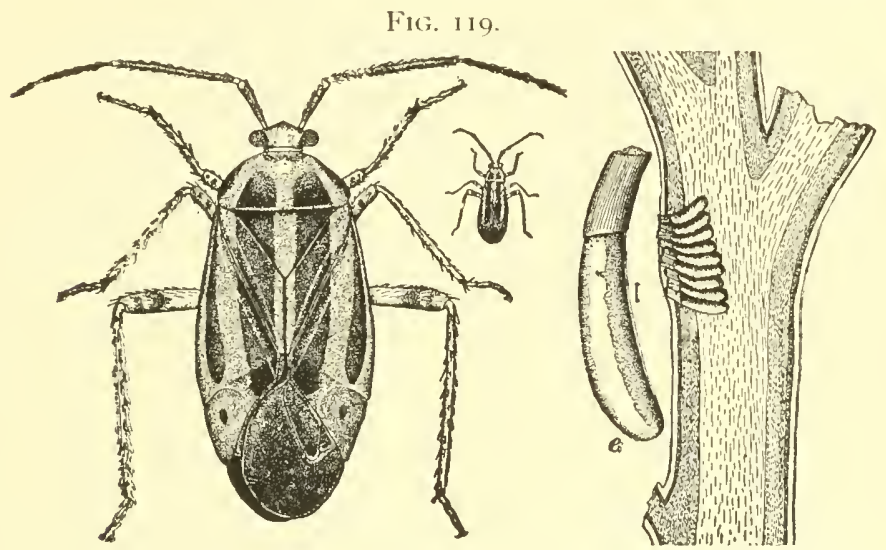

Pecilocapsus lineatus, four-lined plant-bug, natural size and enlarged: also egg mass in currant, and, at $e$, a single egg, greatly enlarged.

or woody plants are attacked ; but on succulent annuals, collecting the insects in the morning, before they have become active, by shaking them into some sort of receptacle, is the most satisfactory method.

In the Cotton belt there was no more troublesome insect, some years ago, than the "red-bug," or "cotton-stainer," Dysdercus suturellus, so named from the fact that its excrement, voided in the opening bolls, stained the cotton red, and thus caused it to become of inferior value. Since cotton-seed has become almost as valuable as the cotton itself, and is now completely used up, it has been found that these insects have become practically harmless. It seems that they were enabled to multiply unduly in the heaps of decaying cotton-seed, and since at present no such heaps exist they cannot increase so rapidly. They also attack oranges in Florida, and Professor Comstock recommends that they be 
trapped by placing small heaps of cotton-seed in the groves, to attract them where they can be easily destroyed with pure kerosene.

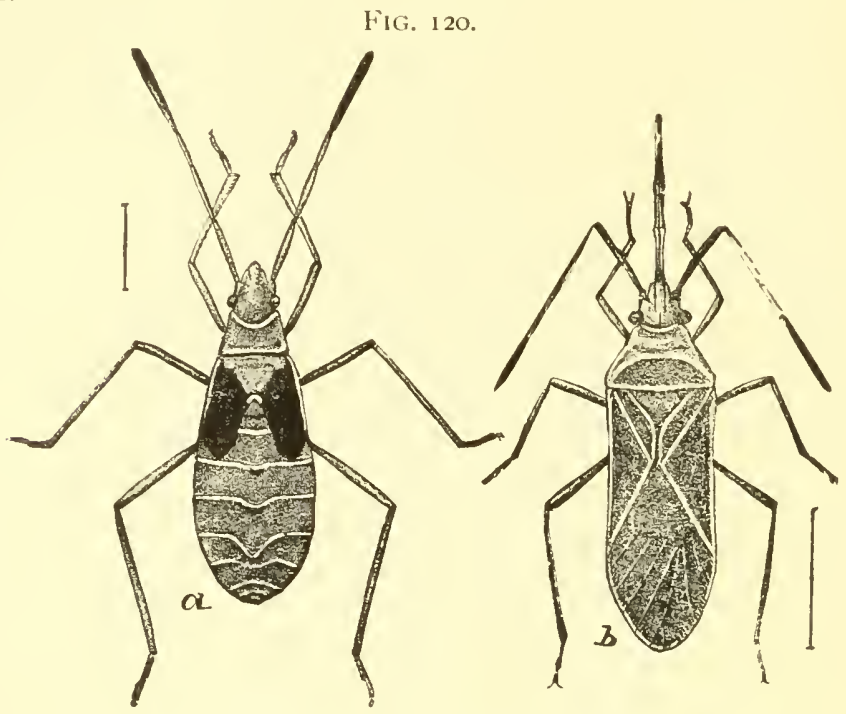

Dysdercus suturellus.- $a$, pupa: $b$, adult.

In the family Lygaida we have species that are oblong in shape, rounded behind and flattened above. They have quite

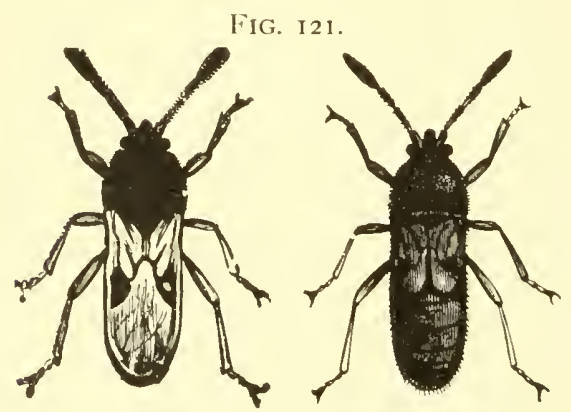

The chinch-bug, Rlissus leucoplerus; long and short-winged forms, enlarged. long beaks, a moderatesized head, and all of them are regetable feed. ers. The body is rather hard, and the insects are often brilliantly or gaudily colored, black and red, in the strongest possible contrast, being favorite combinations. Some become nearly an inch in length, though most of them are much smatler.

The best known of the species is the "chinch-bug," Blissus leucopterus, less than one-fifth of an inch in length, blackish- 
brown in color, and with soft white wing-covers, which make it quite conspicuous. It feeds on grass crops of all kinds, in cluding grain and corn, and causes enormous injury annually. It can hardly be said that we have any entirely satisfactory means of controlling this pest at the present time. Elaborate experiments have been made in some of the Central States with a fungous disease to which the insects are subject, but the outcome has hardly equalled expectations. We know positively that they hibernate in the adult stage, hidng everywhere, and appearing in spring to oviposit just beneath the soil upon roots, or on stems at or above the surface. It is said that a single female lays about five hundred eggs. The brood becomes adult in midsummer. or thereabouts, and there is then a tendency to migrate, particularly if the original infestation was in wheat, which is by that time mature and does not suit them as food. Corn or any other grass crop in the vicinity is then attacked, though corn is favored because of its juiciness. Elaborate publica. tions on this insect and the means for its control have been issued by the United States Department of Agriculture, and

FiG. 122 .
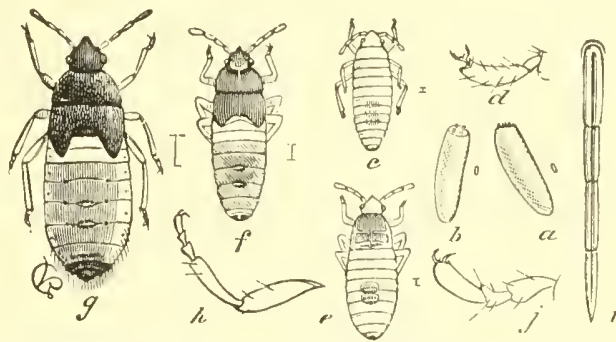

Chinch-bug.- $a, b$, egg ; $c$, newly-hatched larva: $r, f$ lari further advanced; $g$, pupa; $h$, leg; $i$, beak ; $j$, tarsus.

by the Experiment Stations in Illinois, Kansas, and other States in the grain and corn-raising districts of the country. The recommendations generally narrow down to a thorough clearing up in winter to destroy as far as may be the hibernating adults. When the migrations commence from wheat to corm, protection may often be obtained by trenching. The insect. do not readily resort to flight even when adult, but rather march from field to field, and, by interposing a trench which is not easily crossed, and where the insects can be destroyed by means of tar or kerosene, fields may be protected. As this subject is yet under consideration by so many students, it will not be 
necessary to go into details here. The agriculturist in the regions subject to chinch-bug attack should in each case inform himself of what results have been reached, and what recommendations are made by the Experiment Station in his own State. It need only be added that the character of the weather frequently determines the increase of the insects, dry warm weather favoring, and wet cold weather being unfavorable to their development.

In the family coreide we have species of moderate or large size, many of them very curious in form and shape, some of them carnivorous, but others vegetarian and more or less injurious. They are oblong, rounded behind, the head rather small, with long antenne, and a beak of morkate length. They are flattened above, but very convex beneath, so that a section through the insect would show an appearance nearly resembling an equilateral triangle. The legs are usually of moderate length, but sometimes become curiously enlarged, the hind legs especially being subject to leaf-like expansions, giving the insects a decidedly odd and bizarre appearance. They are brown in color, sometimes black-marked, sometimes with reddish variegations, and altogether, perhaps, they resemble most nearly the Reduviide, from which they are easily distinguished by the larger head and

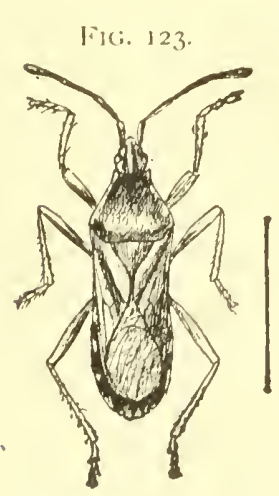

The squasli-bug, Anasa tristis. the longer, flattened, four-jointed beak. All the members of this family may be looked upon with suspicion, because, although a number of them do undoubtedly feed upon other insects, yet some of these very predaceous forms have also been observed feeding upon plants, and it is more than likely that they vary their dict as occasion serves. A typical representative of the injurious forms is the well-known "squash-bug," Anasa tristis, which attacks cucurbit vines of all kinds and sometimes does notable injury. The insect is dull grayish-brown in color, the tips of the wing-covers darker, while the edges are somewhat paler. It is between one-half and three-fourths of an inch in length, quite a ready flier, but with rather weak legs, and therefore at poor runner. It is also called the "stink-lug," because of a peculiarly 
offensive musky odor, which is quite lasting and noticeable even after stained hands have been thoroughly washed. We fund the aclult late in fall, and it remains in that condition during the winter, under bark of trees, under rubbish, in barns and similar locilities. A large number are destroyed by one cause or another during this period, but some survive, and in the spring lay upon the squash or other cucurbit vines patches of unusually large, almost goldenbrown eggs. The little fellows that hatch from them are much shorter and broader in proportion than the adults, maturing some time during midsummer, and providing thus for a second generation. Only two broods occur in the Middle States, though they overlap somewhat, making it appear as if breeding continued during the entire summer and early fall. The punctures mate by this insect in feeding seem to have a peculiaty poisonous effect upon the plants, young vines especially being apt to succumb to even a few specinens. This is another of the cases where cleanliness becomes advantageous, and constitutes also a method of avoidling injury to a great extent. It has been found that the second brood does not mature until quite late in fall, and, seemingly, only those that become adult after the beginning of September have any tendency to go into winter quarters. It should be the object of every grower afflicted by these insects to destroy the cucurbit vines just as soon as he has all the crop he wants from them. This can be done by plowing under thoroughly, or by raking out and burning the vines. In either case the immature bugs starve to death and never develop) into adults. If this practice is followed by all growers, in localities where raising cucurbits is an industry, there is little danger of trouble from the insects. In kitchen gardens, and on a small scale, injury may be prevented by first picking off the bugs wherever they are noticed and, later, picking off those parts of the leaves containing eggs. The eggs are laid on the mnder side, and are so prominent that looking for them is a matter of little difficulty, no cluster esciping a more than casual glance.

Now comes a series of broat, heavily-lutilt bugs, in which the scutellum is greatly elongated and covers a large part of the abdomen. In this, the I'entatomide, the cularged scutellum is triangular, and has a lateral groove into which the edges of the wing-covers fit when not in use. Ifere also we have some species 
that are predaceous and others that are plant-feeders, and, as in the preceding case, it is difficult to say always whether the species are beneficial or injurious. They will all stand watching, at any rate, but, fortunately, not many of them occur in great numbers. Perhaps the must marked exception is the "harlequin cabbage-bug," Murgantia histrionica. This is one of the most serious pests to cabbage in the Southern States, being found in

Fir: 124.

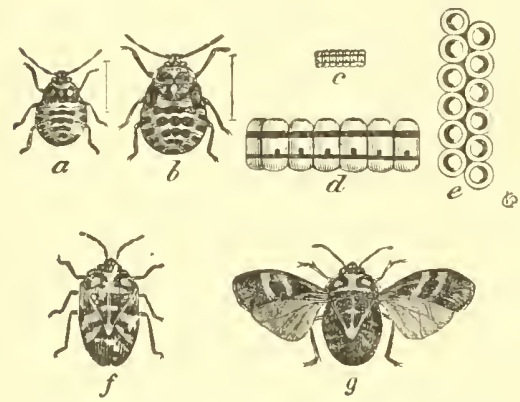

Harlequin cabbage-bug, Murgantia histron$i c \bar{i},-a, b$, larva and pupa; $c, d, e$, eggs, natural size and enlarged, from side and top : $f, g$, adult. small numbers on Long Island, in the southern part of New Jersey, and then increasing rapidly in number and destructiveness throughout the South and Southwest. These also winter in the adult stage, and egg-laying begins quite early in the spring. They are said to pass through all their stages in two weeks, and it can be readily seen that there is room for a number of generations in the course of the season. Practical experiments seem to prove that fighting the adults early in spring is most effective. Mustard seems to be their favorite food-plant, and it is recommended to plant rows of mustard between the cabbage rows for the purpose of attracting the old bugs. They can be sprayed there with pure kerosene, which kills them readily, and if it also kills the mustard, no great harm is done; or, they can be collected in pans in the morning, before they have become active, and in this way they will be sufficiently reduced in number to prevent them from becoming troublesome later on. Of course this is another of the remedies that depends for its greatest success upon conbined action. It has also been recommended that the hibernating bugs be trapped in early spring under turnip or cabbage leaves, preserved for that purpose during the winter.

The allied famly Cydnida is interesting, having the legs formed for digging, though otherwise resembling the preceding. Their lood habits are not well known; but none of them are injurious. 
A very curious series is the Corimelanida, or "negro-bugs," distinct by their usually small size, their intense black colors, which occasionally have a bluish or greenish tinge, and by their very convex form. The scutellum covers nearly the entire upper surface of the body, and the insects are quite generally mistaken for small beetles. They may be found on plants of all kinds and sometimes in considerable numbers, but noticeable injury is rarely inflicted. Their most disagreeable habit is laying eggs on a number of the small fruits, like blackberry and raspberry, and if these are crushed FIG. I25.

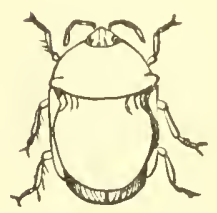

Flea-like negrobug, Corimelcena pulicaria, enlarged. in eating, an excessively disagreeable, "bed-buggy" taste is noticed.

The last family of this order to which we call attention, even though it is not injurious, is the Scutellerida, the species of which are yet more oval, though perhaps less convex than the preceding. As before, the scutellum covers nearly the whole of the abdomen, but these species are often brightly colored. They are moderate in size or quite large, and are southern and western, a few species only being rarely found northward.

Taking it altogether we have in the heteropterous series of the Hemiptera forms which gain their food by sucking juices, and in perhaps the majority of instances the juices of plants. Yet, taking it altogether, there are comparatively few seriously injurious species, and, if we except the "chinch-bug," they do not begin to compare with their homopterous brethren in the amount of injury they do to farm crops. The insects are nearly all difficult to deal with, as they resist insecticides quite strongly. No weak mixtures affect them, and even the kerosene emulsion cannot be diluted more than three or four times, if any large proportion of adults are to be killed. Stomach poisons are out of the question, of course, and we are thus reduced to mechanical means or farm practice to avoid trouble. These methods have been indicated in the course of the chapter, and need no formal repetition. 


\section{CHAPTER VI.}

THE COLEOPTERA OR BEETLES.

THE Coleoptera, "horn-winged" insects, or beetles, are distinguished by the hard, horny, or tough, leathery texture of the fore wings or elytra, which meet in a straight line down the middle of the back, and are not used in flight, serving as wingcovers only. They vary greatly, and are numerous in specimens and species, over twelve thousand kinds having been described from the United States and British America alone. They are as diverse in habit as in size and form, some being among the most dangerous enemies of agriculture, while others are among the most useful.

It seems at first sight as if the recognition of beneficial or injurious forms among so many would prove a hopeless task, and yet we find it in most cases possible to say at a glance whether a

FIG. I26.
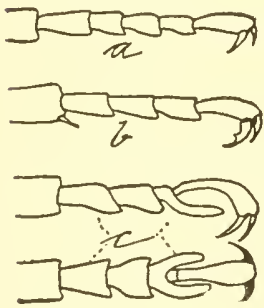

Tarsi in Coleoptera.$a$, normally five-jointed; $h$, normally four-jointed; $c$, four-jointed, with the third joint deeply lobed, from side and from above. given specimen is herbicorous, i.e., plantfeeding, or camivorous, i.e., flesh-feeding and predaceous.

All beetles are mandibulate and chew their food; but in one series the head is more or less prolonged into a snout or beak, at the end of which the much reduced mouth parts are situated. These are the Rhynchophora, or "snout-beetles," all of which are plantfeeders and injurious, or likely to prove so.

The true Colcoptera, in which the head is not prolonged into a beak, we can separate by the structure of the tarsi or feet. Normally there are five joints or segments to each pair of feet; but there are many departures from this rule, one large series having four apparent joints only, of which the third is lobed or deeply notched. The species in which this structure obtains are all plant-feeders; either on leaves or in stems, trunks, branches, or roots; often in dead, though more usually in living tissue. In no other case 
is the structure of the tarsi alone an absolute guide to the food habits; but if we turn to the antennæ or feelers we obtain an additional basis.

Roughly speaking, the beetles, other than those already separated off, may be divided into filicomia, or those in which the antennæe are more or less thread-like, and which are usually carnivorous; clavicornia, in which they enlarge toward the tip or terminate in a more or less marked club, which are rarely carnivorous and usually scavengers; serricomia, where the joints are somewhat flattened ancl widen toward the tip, so that one margin resembles to a greater or less degree the toothed edge of a saw, which are feeders upon vegetation, as a rule; lamellicornia, in which there is a leaf-like club at tip, which are always vegetable feeders; and monilicornia, where the joints are more or less oval or globular and set so as to appear like a string of beads.

The terms filicornia and monilicomia are not in general use at the present time. The latter series has the hind tarsi four-jointed and the anterior and micldle five-jointed, whence they are now termed Heteromera, or "different-jointed," to distinguish them from the "Isomera," where all feet have the same number of segments. But they are not uniform in habit, so that the determination of an insect as belonging to this heteromerous series does not at once determine whether it is friend or foe. For the filicomia the term Adcphaga is used, from the usually predaceous habits.

Following the usual order of systematic arrangement, a comprehensive statement of the differences is as follows :

I. Series with the head not prolonged into a snout, true Coleoptera.

$a$, The antennae filiform, or thread-like, the tarsi with five joints on all feet

- Adephaga.

$b$, The antenne thickening outwardly into a more or less well-formed club, tarsi with an equal though varying number of joints on all feet

Clavicornia.

$c$, The antennæe serrate or saw-toothed, the tarsi usually five-

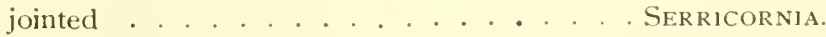

$d$, The antennæ with a lamellate or leaf-like club at tip, the tarsi five-jointed . . . . . . . . . LAMELLICORNIA.

$e$, The antennx somewhat variable, the tarsi four-jointed, the third deeply lubed or cleft . . . . . . . . . P1нторнаGa. 
*, The antennæ variable, though usually moniliform ; fore and middle tarsi five-jointed, hind tarsi four-jointed . . HETEROMERA. 2. Series with the head prolonged into a more or less prominent snout, hence called snout-beetles or weevils . . . . RHychophoka.

In the Adephaga there are many species of predaceous habit in the larval as well as adult stage, of which a few more common types may serve as examples.

The "tiger-beetles," or Cicindelida, are moderately large, very active and graceful species, that run rapidly and fly readily. Most of them frequent sandy or open spaces, their colors often matching their surroundings with marvellous accuracy. On the seashore they are white, or gray with white hairs and lines, and on the marshes or mud-flats the prevailing colors are dull mousegray, without contrasting lines. Early in spring a bright-green species is found at the margin of woods or in shaded lanes, prominent on the bare ground for an instant, but lost to sight at once, when startled, in a tuft of grass or on a moss-covered stone or $\log$.

The larvæ are uncouth creatures, rarely seen unless sought for. They make vertical burrows in sandy soil or along roads, and there wait for passing prey, their round flat head closing the opening completely, while their eyes are so set as to command the near surroundings. They are humped posteriorly, and on the hump curved spines are set, which may be forced into the burrow wall to maintain a position at any height, and to resist without effort any ordinary attempt to pull them out of their den. Though these "tigers" are exceedingly voracious, they are of little benefit to the agriculturist, because they do not frequent cultivated fields or orchards.

The Carabida, or " ground-beetles," run to black and brown colors without prominent markings, and are usually more or less flattened. They live under stones, sticks, leaves, or shelter of any kind, in fields and along the edges of woods, more rarely in the woods themselves, and sometimes under loose bark or even among leaves. They are of a retiring disposition, and seldom stir abroad until after dark, when the majority fly readily. Many of them are attracted to light, and are recognizable, when they strike the table or other flat surface, by the rapidity with which they run, by their prominent mandibles, and slender, moderately- 
FIG. I29.

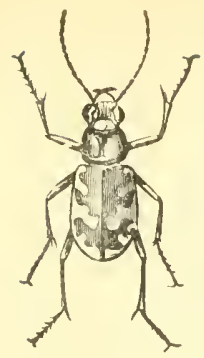

FJG. I3I.

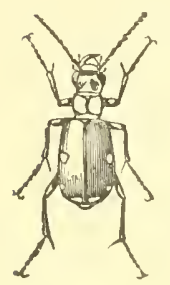

FIG. 133.

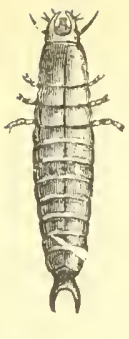

FIG. I38.

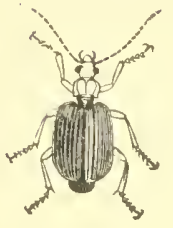

FiG. I30.
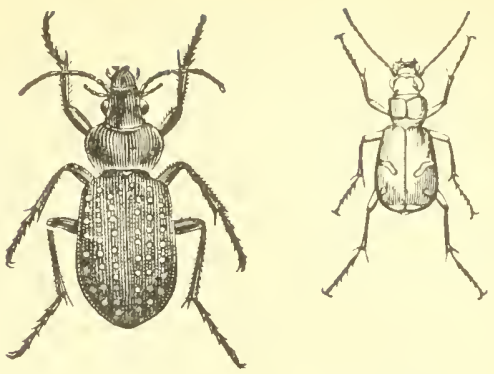

FIG. I28.

FIG. I27.

FIG. I32.

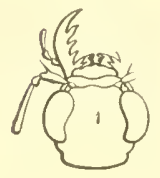

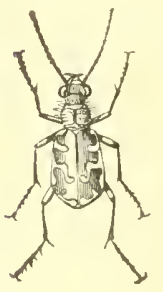

FIG. I37.

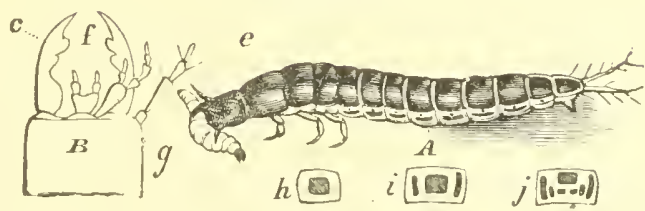

FIG. 135 .

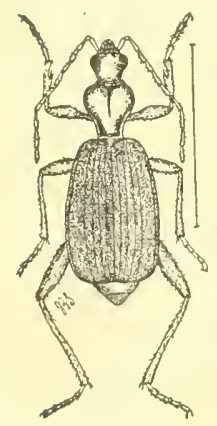

FIG. 134 .

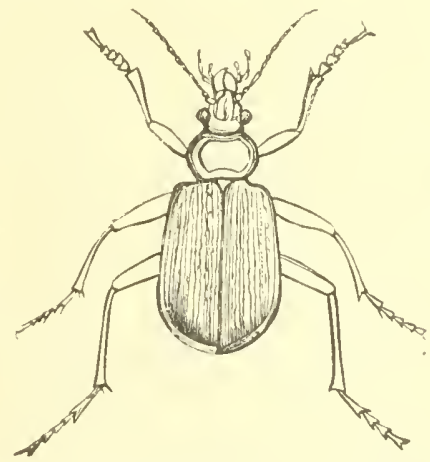

FIG. I 36 .

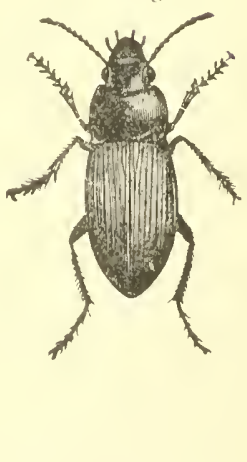

Tiger-beetles and ground-beetles.-Fig. 127, larva of Cicindela. Fig. 128, head of ricindela, to show mandible. Fig. I29, C. generosa. Fig. I30, C. purpurea. Fig. I31, C. sexguttata. Fig. I32, C. repanda. Fig. 133, Calosoma calidum and its larva. Fig. 134, C. scrutator. Fig. 135, Brachinus fumans. Fig. 136, Harpalus catiginosus. Fig. 137, larva of Harpahus, devouring larva of plum-curculio. Fig. 138, Lebia grandis. All except Fig. 135 about natural size. 
long antennze. Some of them are dirty clay-yellow in color, with the disk of the wing-covers marked with black or brown.

We have only a few species belonging to the genera Carabus and Calosoma, in marked contrast to the great number found in European fields, none of our large forms having found life in tilled land tolerable. The species of Calosoma often ascend trees and feed on caterpillars, the term "caterpillar hunters" having been in consequence applied to them; but some of the smaller species also have similar habits. In orchards they are sometimes found hidden just beneath the surface of the soil, close to the base of the trees.

The "Bumbardier beetles," belonging to the genus Brachinus, may be especially mentioned becatuse of their peculiar power of emitting a puff of bluish vapor from the anus when suddenly disturbed. They have the body, head, and thorax reddish, the elytra blue, and are found under stones along the edgres of roads and near woodlands, or, more rarely, in the loose rubbish at the base of trees.

A series of very much flattened species frequents flowers, feeding upon the minute insects abundant there, and these are sometimes red and blue, or even brilliant metallic green, with the wingcovers squarely cut off behind so as to expose the tip of the abdomen. Among these is the Lebia grandis, a moderate-sized species, with yellowish-red head and thorax, and blue elytra, that makes itself useful by feeding upon the eggs and larve of the Colorado potato-beetle.

But the great majority of our species are moderate in size, and of powerful build, black or nearly so, lurking under all sorts of rubbish in field and orchard, frequently in large numbers, yet rarely observed, and ready at all times to pounce upon any softbodied larve that come within their range of vision. These belong to the genera Pterostichus, Inisodactylus, Amara, Harpalus, Agonoderus, or their close allies, and they are decicledly important factors in checking the unclue increase of certain species which must go underground to complete their transformations, -e.g., the "plum-curculio," " pear-midge," and others. Their larvæ are even more retiring and less frequently seen, but live in similar situations. They are slender, more or less flattened, of nearly equal width, with six short legs, a pair of prominent 
mandibles, and a pair of bristly processes at the anal end of the body.

Two other families belonging to the Adephaga are aquatic in the larval as well as adult stage, and are as predaceous as their terrestrial relatives.

The Dytiscide and their larvæ have been termed "watertigers," and the larger species attack small fish as well as insects. In form they are oval and somewhat flattened, and they may often be seen rising to the surface of quiet pools or spring-holes, head down, releasing a bubble of air, and then, after remaining for a little time, with the anal extremity above the surface, again starting for the bottom. There is con-

FIG. I39.
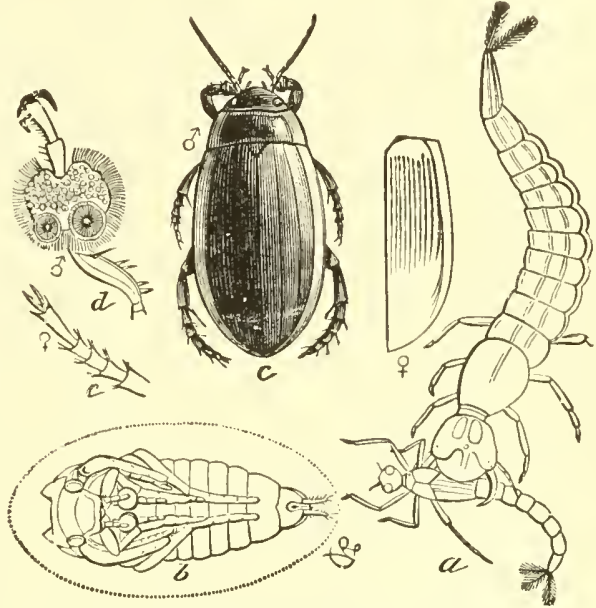

A water-tiger, Dytiscus marginalis.- $a$, larva, devouring an Agrion larva; $b$, pupa; $c$, male beetle, the elytra of the female at side; $d$, anterior tarsus of the male, with sucking disks; $e$, tarsus of the female: $a, b, c$, about natural size.

siderable space between the wing-covers and the abdomen in these species, and this is utilized as a reservoir for the air which the insect breathes beneath the surface. When it becomes impure the beetle rises again to the surface, releases the vitiated air, and takes in a new supply.

This ends the series Adephaga, and no practically injurious forms exist in it ; all are more or less beneficial by reason of their predaceous habits. Under some circumstances a few of the species eat pollen, and after midsummer some have been found gnawing grass-seed; one or two species have even been found eating into the kernels of corn, so there appears to be a tendency to vary to a vegetable diet under certain conditions. In fact it has been demonstrated that in many species some vegetable matter is regularly eaten ; yet, as this feeding is not of a character 
injurious to the agriculturist, the series may be, as a whole, accounted beneficial.

In the Clanicomia we have a much greater diversity of form, and many families, differing widely in habit, and some of these are economically important.

Fig. 140.

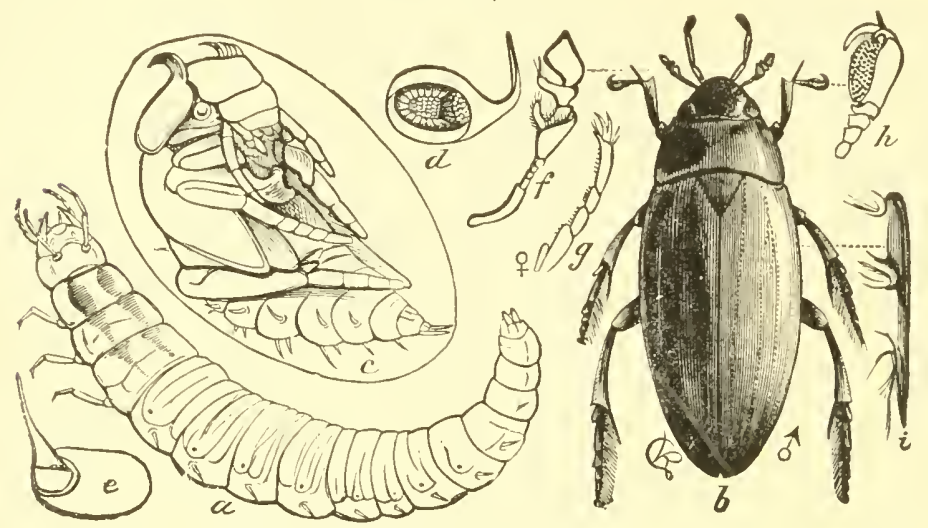

A water-scavenger, Hytrophitus tringula is.- $a$, the larva; $b$, male adult ; $c$, pupa ; $d$, opened, and $e$, closed egg case; $f$ to $i$, enlarged structural details of the adult.

First, joining to the aquatic Adephaga there are two families of aquatic Clavicornia, the Hydrophilida, or "water-scavengers,"

FIG. I I I.

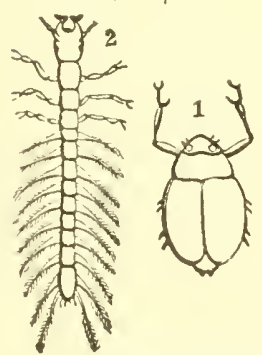

A "whirligig"-beetle (1) and its larva (2) : natural size. and the Gyrinida, or "whirligig-beetles." The former resemble the water-tigers in general appearance, but are more convex above and more flattened below, usually with brightly-polished wing-covers. The difference in the form of the antennæe will easily prevent confusing the families.

The Gyrinide cannot be mistaken. They are black or bronzed, oval, shining, with unusually long forelegs, and disport themselves in swarms on the surface of ponds and streams, darting here and there, or sometimes swimming rapidly in large or small, regular or irregular circles, whence they derive their " whirligig" appellation. They are predaceous in all stages, but of no agricultural value from their strictly aquatic habits. 
The family Silphida, containing what are popularly known as "carrion" and "burying beetles," is in sharp contrast to any. thing heretofore spoken of, and here the antennæ are capitate, i.c., terminated by a spherical or ovate knob abruptly formed, like a head. The beetles are usually found on or about carrion of all kinds, though some of the smaller forms live in decaying fungi. In the large species there are two distinct types, represented on the one hand by the genus Silpha, in which the species

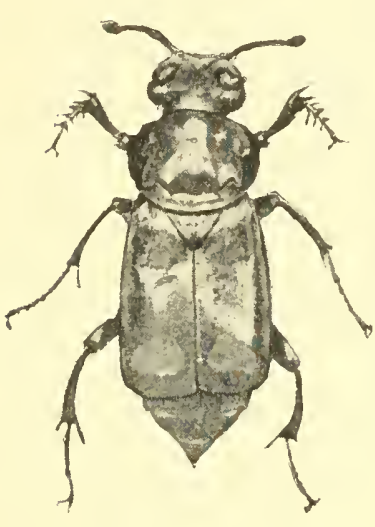

$a$

FIG. 142.
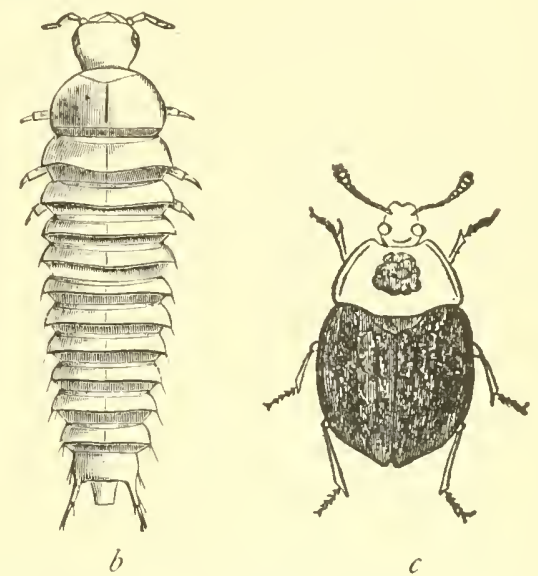

Carrion beetles.- $a$, Necrophorus americana; $b$, larva of Silpha lapponica; $c$, Silpha americana.

are much flattened and proportionately very broad, with small heads, and on the other by the genus Necrophorus, in which the species are much more heavily built, narrower, not flattened, and with large heads. These are the true "burying" beetles, and derive the name from their habit of excavating bencath small dead animals and gradually sinking them below the surface level. Then the females lay their eggs in and the larvæ live upon the buried and decaying creatures. The other carrion beetles make no pretence of burying their prey, but lay their eggs at once, and the larvæ feed upon it from below, usually making a short burrow in the soil for shelter, though this is not universal. In both types the larvæ are black, flattened, broadly oval, and with 
the segments distinctly marked at the edges. These beetles have the sense of smell wonderfully dereloped, and I have frequently covered a small, freshly-killed animal with a box of wood or tin, only to find next morning a number of the insects beneath it. The species are generally noctumal, and as scavengers are useful, or at least innoxious.

The large series of "rove-beetles," or Staphylinida, is peculiar in the short wing-covers, which leave more than half the

Fig. 143 .

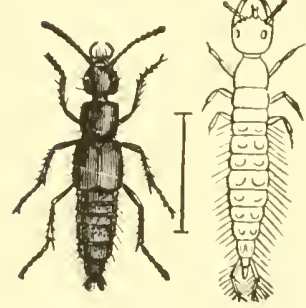

Rove-beetle and its larva. abdomen exposed. The species are always long and comparatively narrow, usually with a large head and well-developed mandibles, and live in all sorts of fermenting, decaying, or excrementitious animal or vegetable matter. Most of them are small, and many are found beneath bark, in fermenting sap, or in fungi, while the larger forms are often found in or under animal excrement, or on or under carrion. In short, the species are scavengers, with a tendency to a predatory habit in some cases, and never any disposition to feed upon growing vegetation. They may thus be accounted either actively beneficial or at least not injurious, and as scavengers they aid in reducing organic matter into condition for assimilation by plant-iife.

The next family meriting attention from its economic interest is the Coccinellide, or, as the species are commonly termed, "lady-bugs" or "lady-birds." Scientifically these insects are distinguished by having the tarsi three-jointed only ; but practically they are recognizable by their oval or round form,-always convex, sometimes almost hemispherical, - and by their colors. which are either of some shade of red with black spots and markings, or black, with red or yellow spots. The species are never large, sometimes very small; but in almost all cases are predaceous, their prey consisting chiefly of plant-lice or scale insects. The larve, which have the same feeding habits, are usually fusiform, with a small head and quite long legs. They are often prettily colored, sometimes with spiny warts or processes, and may be seen running about wherever plant-lice abound. Patches of from fifteen to forty of the yellow eggs 


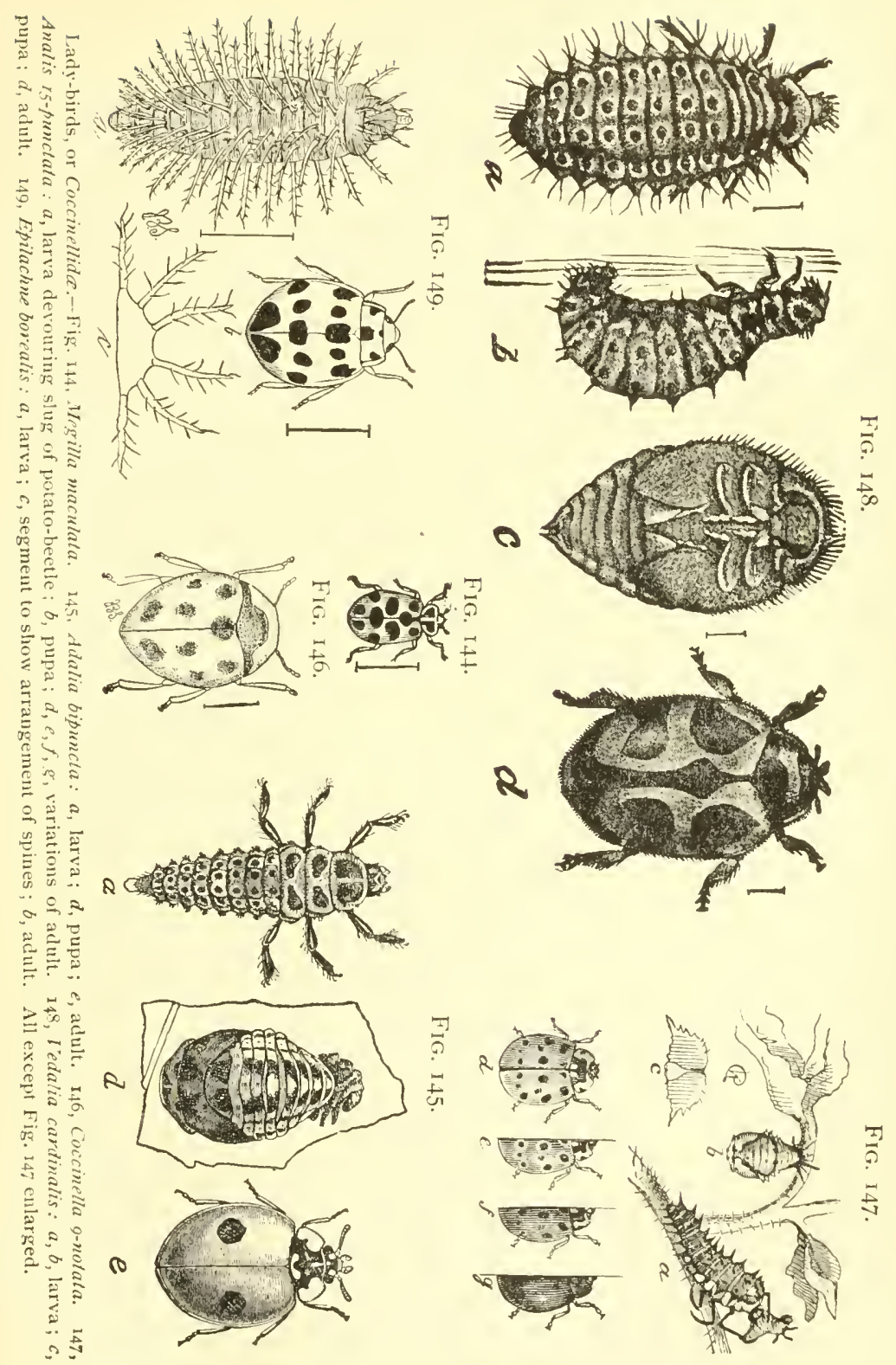


laid by the beetles are often seen in abundance on infested plints.

The species of Megilla and Hippodamia are more oval and less convex than usual, and some of them have been found feeding on pollen or even seeds, when their natural prey wats scarce; yet I have observed these same species doing yeoman's work in the destruction of plant-lice on melon-vines.

The genera Adalia and Coccinella contain the more hemispherical types, and among the most common are the " 9 -spotted ladybird," Coccinella 9-notata, which is one of the larger species, and the "2-spotted lady-bird," .tdalia bipuncta, which is the smaller and perhaps most frequently seen in gardens and even houses. Among the largest of our forms is the "I5-spotted lady-bird," Anatis 15-punctata, interesting from its color variations, ranging from creamy-white with distinct black spots to uniform mahogany brown.

Opening quite a distinct series of species, which are black, with red or yellow spots, is the "twice-stabbed" lady-bird, Chilocorus biaulnerus, in which the litva is spiny. This is black, almost hemispherical, with a somewhat ovite red spot on each wing-cover, and is found throughout the United States. Its chief food, in the larval as well as the adult stage, consists of scale insects, and it is one of the most effective checks on that kind of plant pest, under favorable circumstances ridding individual trees completely.

We have other similar but smaller species, sometimes with numerous yellow spots on the wing-covers, and most of them have the scale-eating habit to a greater or less extent. The species of Pcntilia are uniformly black and very small, less in size than most of the scale insects upon which they prey; but they, as well as their minute spiny larvæ, are great feeders, especially upon the eggs and larve. The destructive San Jose scale has no more persistent or effective enemy than this kind of small lady-bird.

The species of Scymnus are also small, usually recognizable by their fine pubescent or hairy clothing and black colors. There is a tendency to red-tipped wing-covers or red thorax, and these forms also prey largely upon scales. To this family belong the Australian species of Vedalia, Orcus, and Rhizobius, introduced 
to destroy the also imported "cottony cushion-scale," Icerya purchasi. The relation of these species has been already discussed when speaking of the scale, and will be again referred to in Part III. of this work.

There are few rules without exceptions, and so we find sinners among the lady-birds also, - all belonging to the genus Epilachne. The species are large, hemispherical, and yellow, with black spots. The larve arc also yellow, elongate oval, with long branched spines. E. borealis is the Northern and Eastern species attacking cucumber, melon, and similar vines, while E. cormpta is found in the West and Southwest, injuring beans. A curious feature in E. borealis is the manner in which the adult marks out a circle at the edge of a leaf and feeds within it until all usable tissue is exhausted, before proceeding to another place to repeat the operation.

As these injurions species feed openly in all stages, they can be reached without trouble by any of the arsenites.

The family Erotylide contains some very prettily marked species of quite diverse forms, most of which feed in or on fungi, or may be found under loose bark, and are, therefore, innoxious. In the grenus Languria, however, we find an exception, since their larvæ live in the stems of clover and other plants. They are very slender, almost cylindrical, from one-fourth to

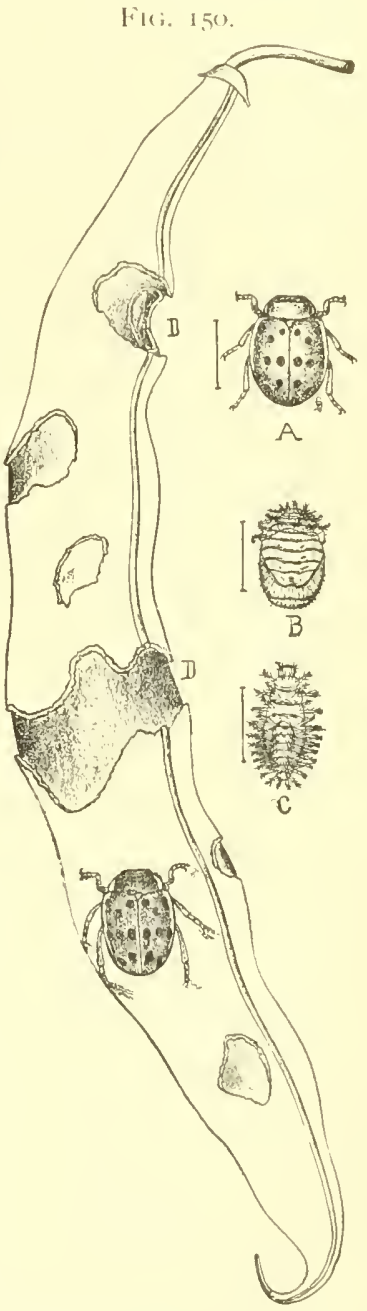

Epilachne conrupla.-A, aduit ; $B$, pupa; $C$, larva; $D$, injury on bean.

one-half an inch in length, and have the wing-covers blue or 
black, while the thorax is usually more or less red or yellow () ur common clover-feeding species is L. mozardi. It is rarely that any species becomes abundant enough to do noticeable in-

Fic. 151 .
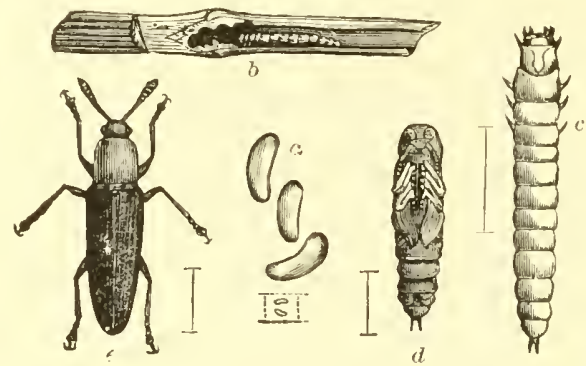

里

Languria mozardi.- $a$, egg; $b$, larva in clover stem; $c$, larva; $d$, pupa; $e$, adult.

jury; but in clover, if a sufficiently large infested area occurs, prompt close cutting or turning under the sod will be most effective in checking present and preventing future injury.

The Cucujida are elongate and very much flattened beetles, fitted to live under bark of trees or in the narrow crevices where FIG. I52.
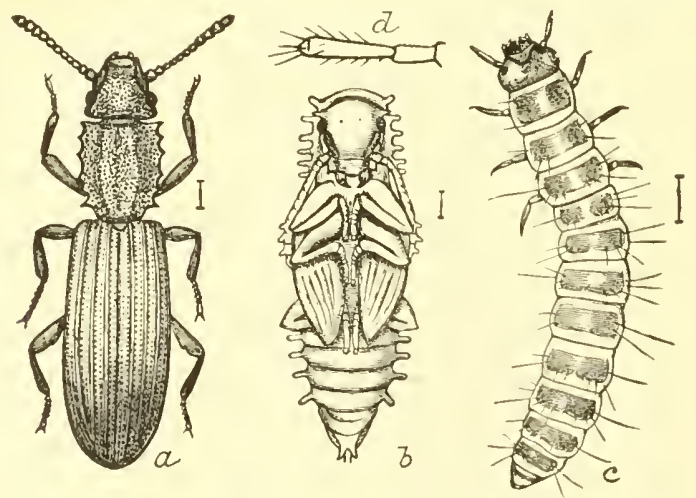

Silvanus surinamensis. $-a$, beetle; $b$, pupa; $c$, larva.

they are usually found. Some of the species of Silvanus, notably $S$. surinamensis, a brown species, hardly more than one-eighth. 
inch in length, with the edges of the thorax toothed, are exceptions in habit, though not in form, and often infest granaries, mills, and stables. The adult as well as its larva is frequently found in mangers or in neglected little masses of meal, flour, or grain, in which they breed. Cleanliness is the best remedy when these insects become abundant : allow no partly emptied boxes or bags to lie about, keep current supplies covered or tied up, and sweep out corners at short intervals. Bisulphide of carbon, where its application is possible, is an effective remedy, readily destroying the beetles as well as their larva.

FIG. 153.

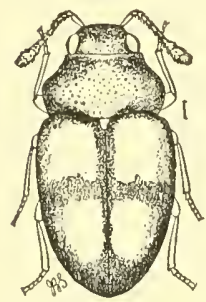

Atomaria ephippiata.
FIG. 154

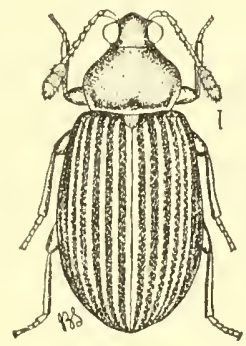

Corticaria pumila.
FIG. I55.

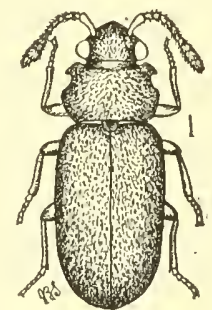

Cryptophagus croceus.

There are other, yet smaller beetles found in similar situations in less numbers, and these belong to allied families. They may be brown, not more than one-sixteenth of an inch in length, with an oval body and narrow thorax, and then they are probably species of Corticaria : they may be of similar color, but with the thorax and body more nearly of a width, and then they may belong to Atomaria or Cryptophagus; or they may be equally minute but flattened, black, with red or yellow spots or bands on the elytra, and then they probably belong to Litargus. All may be treated as above suggested.

We have a series of robust, small or moderate-sized beetles, usually broad but sometimes narrowly oval, with small retracted head, slender, moderately long legs, capable of being so closely folded upon the breast as to be almost invisible, and with the unpleasant habit of feeding upon dried animal substances, such as furs, skins, woollens, museum specimens, meats, and the like. 
These belong to the family Dermestide, which contains such nuisances as the "larder-beetles," "carpet-beetles," and "mu-

Fig. 156

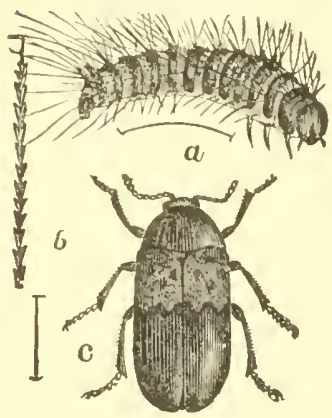

The larder-beetle, Dermesles lardarius. - $a$, larva; $b$, a single hair from larva; $c$, adult heetle. seum-beetles." The elytra, which cover the abdomen completely, are black or gray, usually ornamented with white or colored scales, which sometimes form quite pretty markings.

The "larder-beetle," or "baconbeetle," Dermestes lardarius, is rather more than one-fourth of an inch long, and easily recognizable by having the anterior half of the wing-covers pale brown or yellowish, its livery else being of a sombre black or dark gray. The larva is nearly half an inch in length, rather narrow yet plump, and clothed with rather dense, long, brown hairs. It feeds on stored provisions of all kinds, on hides, skins, or other similar substances, and is occasionally quite troublesome in smoke-houses. Cleanliness, plenty of air, tight receptacles, and close-meshed wire netting on the

Fig. 157 .

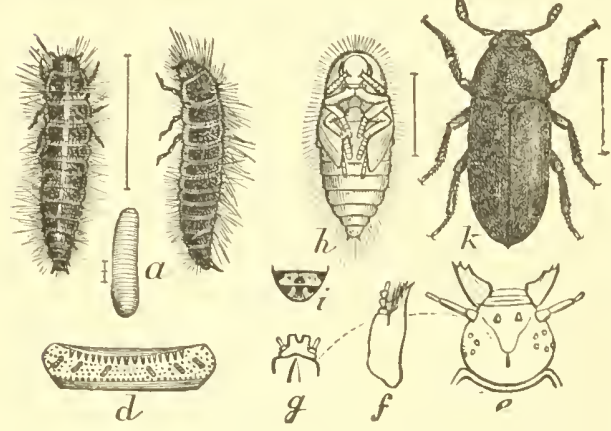

Leatluer-beetle, I) comestes zulpinus.-u, larva; $h$, pupa $k$, adult ; $d$ to $i$, details of larva. covers or doors of pantries and boxes are the best preventives, supplemented by destruction of the beetles and larve wherever noticed. Govel results are often obtained by leaving a tempting bit in an exposed position, which will act as a trap, attracting beetles and lariot where they can be easily found and restroyed. Several other species, similar in size but differently marked, have similar habits, and among them the "leather-beetle," D. vulpinus, has been responsible 
for much mischief in tanneries and factories producing leather goods. Where fumgation is possible, bisulphide of curbon may be employed with good effect, while gasoline readily destroys both beetles and larva where it can be brought into contact with them.

Larva similar to those above described, but much sinaller, are often found in museum collections on mounted animals, eating the skins, hair, and feathers, and in entomological collections, destroying the specimens entirely. The beetles from these larva are smaller and more ovate, and belong to the genera Trogoderma or Megatoma. They are often found on flowers

Fig. I5s.

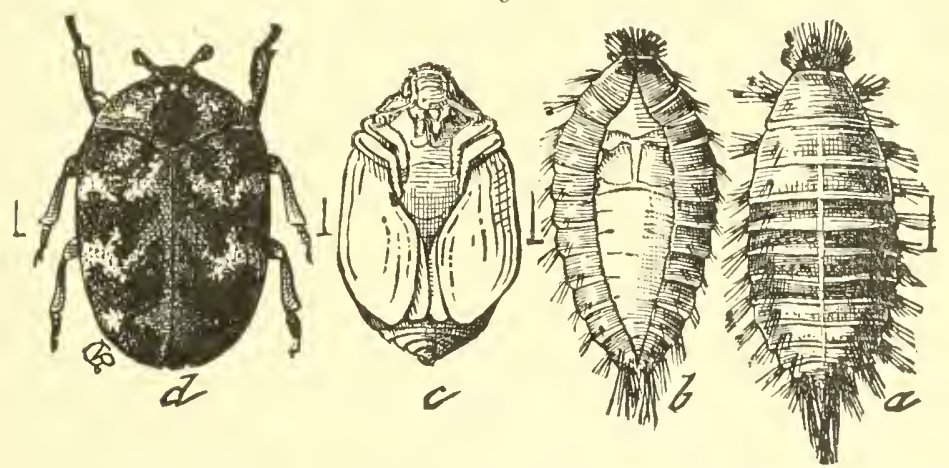

The carpet-beetle, Anthrenus scrophularia., $a$, larva; $b$, larval skin split to expose the pupa within it ; $c$, pupa; $d$, beelle.

in this stage, in company with species of Anthrenus, in which the larva are stomter, more clumsy, equally clothed with hairs, but with the ability to expand two larger tufts posteriorly. Anthrenus also contains museum pests as well as the "carpetbeetle," A. scrophularia, which feeds on woollens in the larval condition, and is then better known as the "buffalo-moth," from its tufted appearance. The beetles are very broadly oval, with brick-red scales along the middle of the wing-covers, and two irregular white scaly bands transversely across the elytra. I have found them very early in spring uncler the loose bark of trees where they had passed the winter. Later they fly into open windows, and lay their eggs wherever they find a supply of 
woollens. For this household pest a liberal use of napthaline in crystals or balls, in trunks and clusets, is advisable as a preventive. Where woollen garments are to be stored through the summer they should be first thoroughly beaten or brushed and sumed out, then wrapped in stout paper with the edges pasted, or in cotton sheeting well sewed. Then, if laid away in boxes or trunks, or lung in elosets with napthaline crystals between the layers, or on the shelves, or among the bundles, little danger is to be feared. Where carpets are infested, it is best to have them taken up, thoroughly beaten and cleaned, and the floors thoroughly cleansed before they are relaid. Where this is undesirable for any reason, gasoline may be used with satisfactory results. Except on the cheapest fabrics it may be safely used in liberal quantities without danger of injuring either texture or colors, and wherever the liquid comes into contact with either beetle or larva it kills at once. Eggs, however, are not clestroyed, and close watch must be kept for a week at least, when a second application may be found necessary to reach the larve hatched since the first was made. Another method, almost equally good but more troublesome, is to place a wet cloth over the infested patches and press over it with a very hot flat-iron, the object being to drive hot steam or vapor through the fabric and thus, practically, to cook the insects. In collections, tight boxes or cases and a free use of napthaline or bisulphide of carbon, or both, are essential.

Unity of habit in this family is marred by Byturus unicolor, a little yellowish species which is densely covered with short silky hair, and feeds in the blossoms of the red raspFin. 159. berry, where also its eggs are laid. The larve

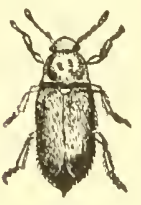

Buturus unicolor, enlarged. are white, nearly naked, and are found on the inside of the berry when picked. The species has not become seriously troublesome as yet, and is mentioned here chiefly because of its unique liabits.

The Histeride are small, oval, shining, very hard, black, bronzed or greenish beetles, with the wing-covers cut off squarely behind, leaving the last segments of the abdomen exposed. The legs are broad and flat, fitted for digging, and the head is small, yet with quite prominent sharp 
mandibles and capitate antenuæ. They are mostly scavengers, the larva white and somewhat maggot-like, occurring on, in, or under all sorts of excrementitious or decaying animal or vegetable

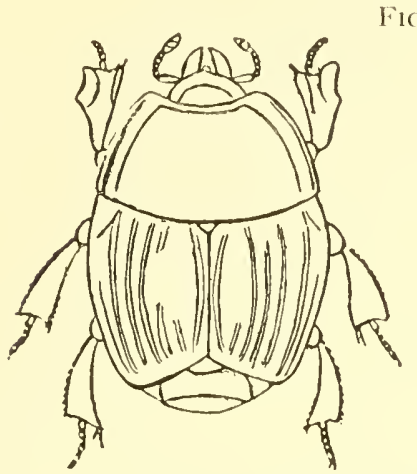

FiG. I60.

Hister arcuatus and Hister bimaculatus, much enlarged.

matter, in over-ripe fungi or fruit, or under the loose bark of trees. They are of no practical importance to the agriculturist.

The Nitidulida, or "sap-beetles," are also small, more or less flattened, always with the tip of the abdomen exposed beyond the wing-covers, and with the legs not specialized for digging purposes. They feed in all stages on decaying or fermenting sap or fruits or in fungi, and some of them are found also on carrion. As a whole, while the species are quite numerously represented and often seen,

FiG. I6I.

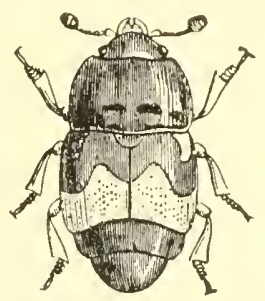

Carpophilus hemipterus, enlarged.
FIG. I62.

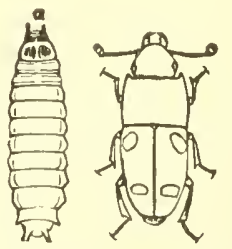

Ips fasciatus and its larva, enlarged. yet they are not either markedly beneficial or injurious.

Somewhat similar habits are met with in the Trogositida, which are also flattened creatures, most of them living under bark. Some of the species of Tenebrioides, however,-black beetles about one-fourth of an inch in length, with square thorax and large head, known as "cadelles" - are found in stables, barns, and mills, feeding on grain, meal, and flour. They are 
rarely very numerous, and may be kept in check as recommended on a previous page for the Cucujida.

There are other small families in the clavicorn series, some of them interesting enough to the entomologist, but none of in-

pertance econonically

Fig. 163 .
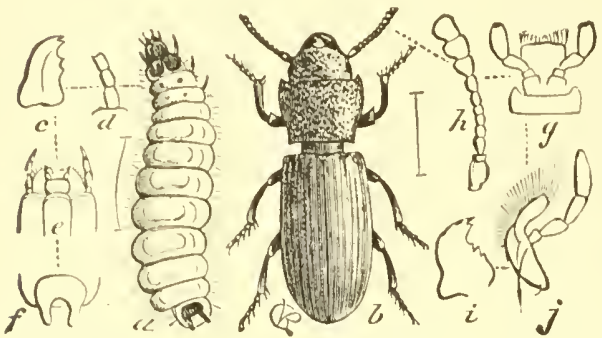

Tenebrioiles conticalis, the "carlelle."- $a$, larva; $b$, adult; $c$ toj, structural delails. or likely to attract the attention of the casual observer; hence hardly suljects for description here.

The Serricornia, on "sim-horned" serie's, begins with the family Dascrllider, contain ing mostly small forms found on dead or dying trees or branclies, in which the larve probably live. None are of economic importance, a fact which is also true of the next family, Rhipicerida. This latter, indeed, contains only five species, all accounted rarities in collections, and believed to breed in cedars.

"The family Elateride, "spring beetles," "click-beetles," or "snapping-beetles," contains numerons troublesome forms, and is easily distinguishable in all its stages. The beetles have the prothorax very loosely jointed to the rest of the body, and on

FIG. 16.4.

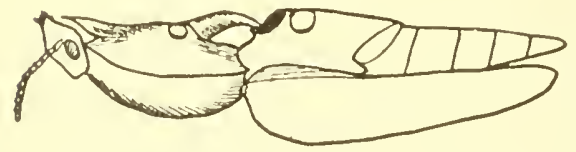

An lilater from side, to show the prosternal process. the under sicle a curved process fits into a cavity of the meso-thorax. When a specimen is placed on its back it bends the extremities so as to raise the middle of the body from the surface, and to bring the tip of the curved process to the edge of the cavity. A sudden release of muscular tension reverses matters, sends the insect into the air a few inches, and this "snapping" or jumping performance is repeated until it aliglits on its feet. In the larval stage the tern " wire-worms" expresses the appearance and texture of the creature, and brings to mind at once an agent of destruction hardly surpassed in the 
insect world. Scarcely a farmer can be found who has not been troubled to some extent by "wire-worms," and many a remedy recommended as infallible has been tried and found wanting in actual practice. We have two series of species, one of which

FIG. 165 .

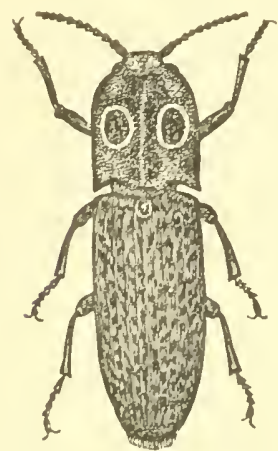

FIG. I66.

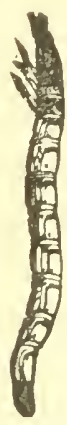

Fig. 167.

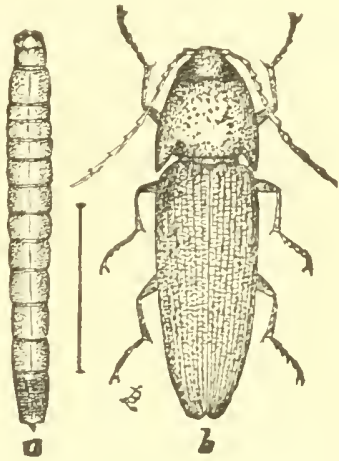

Fig. If 5 , the eyed Elater, flums oculatus. Fig. 166, wood-boring wire-worm, from side. Fig. $167, a$, larva; $b$, adult click-beetle.

feeds in decaying wood, the other underground on the roots of plants; of these the first may be left out of consideration altogether, though in it may be found the species of Alans, our largest and most prominent forms. The history of the subterranean species is in general as follows: The beetles appear quite early in spring, and may be noticed in fields where a sod has been turned down, during the first days of May, or earlier in the Southern States. They fly quite rapidly in mid-day, copulate, and later seek a place to oviposit. During May or June, earlier or later, according to the species, the eggs are laid in grass-land or where there are plenty of weeds,-in other words, wherever vegetation, especially of a grassy character, is abundant. The larvæ hatch by midsummer and feed upon roots, growing but sluwly and requiring, indeed, in many cases, two or three years tr) complete their development. Pupation takes place in fall, and usually the change to the adult also takes place before winter sets in, though they remain quiet, and do not voluntarily emerge until the spring following.

This brief sketch does not apply in its entirety to all the subterranean forms even, but it applies very well to the majority 
of the injurious species. The noteworthy points are the early appearance and oviposition of the beetles, the two- or three-year life of the larva, and the pupation and change to adult in fall; all of which must be considered in the methods of treatment to be adopted.

The direct application of insecticides is usually impracticable, and the texture of the larva is so dense that most contact poisons are of little or no avail, salt in large quantity having proved the most effective. Stomach poisons are not easily applied, but on an experimental scale it has been found that sweetened dough placed beneath the surface attracts them, and this can be poi soned and used as a trap. Practically, methods of cultivation calculated to avoid injury are most satisfactory. Grass land known to be infested should be plowed in fall, and while this will not clestroy any large proportion of the larve, it will kill most of the pupæ and beetles then in the ground, so if the practice be continued for a series of years the insects will be gradually run out. Wherever feasible, crimson clover should be used as a sod crop, as this is sown in late summer after the beetles have oviposited and may be harvested and plowed under shortly after the beetles have laid eggs, practically preventing the development of the larvæ, especially if a crop little or not at all subject to wire-worms follows the clover. In fact, frequent change of crops is a most satisfactory measure if the land be not allowed to remain in grass more than one year, and if corn or potatoes clo not directly follow the sod. In light soil the salty fertilizers exercise a very beneficial effect when properly applied, and sometimes an advantage may be gained by keeping the land in sod as long as possible, where grass is needed as a crop. When it has "run out," plow in fall; in spring, after cultivating and preparing for the new crop, fertilize heavily, using kainit for potash and nitrate of soda, so far as possible, for nitrogen. At least one thousand pounds of kainit per acre should be used, and this seems exceedingly disagreeable to the insects at all ages, and fatal to the younger forms. Conditions vary so much in different parts of the country, and rotations are so diverse in character, that it is impossible to suggest any course that will be universally applicable, except the fall plowing. The suggestions above made should be sufficient, however, to guide the intelligent farmer in 
adopting the practice best suited to secure exemption in his case. It may be added, however, that the fertilizers will not prove satisfactory unless applied as directed,-i.e., in one heavy application and when the ground is bare.

The species of the family Buprestida resemble the clickbeetles in general form, but the prothorax is firmly articulated to the rest of the body, so that the insects have no "springing" powers, and the colors are metallic. The beetles vary much in appearance, but the larve resemble each other closely, being always flattened in form, with greatly enlarged anterior segments. They are usually known as "flat-headed borers," sometimes as "hammer-heads," and infest not only trees but shrubs, vines, and sometimes even herbaceous plants. Some of the species prefer dead or dying wood, some attack healthy plants only, while others, and perhaps the majority, are somewhat indifferent, yet are oftener found in weak than in healthy and vigorous trees.

Our largest Eastern species belong to the genus Chalcophora, the larva mostly feeding on conifers, though two of them feed on deciduous trees like the sycamore. The beetles have the elytra quite deeply and irregularly furrowed, while the colors are bronze, brown, or blackish. I have

FIG. I68.

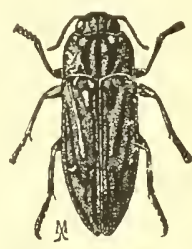

Chalcophora vir giniensis. found the larvæ in quite old and decaying logs, but they are said to attack healthy trees as well, and to cause occasional injury.

The genus Dicerca contains robust species, sometimes narrowing so strongly toward the tip as to seem almost tailed. The wing-covers are decidedly convex, irregularly corrugated, or even reticulated, with elevated spots, and the colors are bright bronze-brown, often with greenish or brassy reflections. They are rarely common, but infest a variety of trees, among them peach, plum, apricot, cherry, hickory, oak, and pine.

The genus Buprestis contains flattened species with even strix or ridges, and they are often of a brilliant blue, green, or golden metallic color, occasionally spotted and banded with yellow or brown.

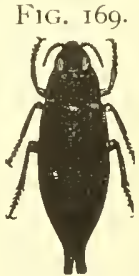

Dicerca diz'aricala. The larve feed mostly in conifers, but some also infest deciduous trees, none thus far in dangerous numbers. In Melanophila the 
wing covers are nearly smooth or with fine punctulations only, and the larve also feed principally in conifers.

In the genus Chryobothris we have forms that are quite flattened abuve, the wing-covers with irregular depressions and elevations, the prothorax with curved

Fic. I 1 ().

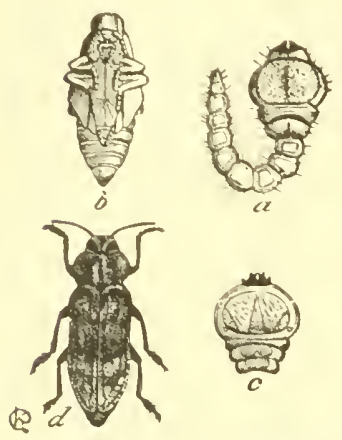

The that-heal apple-borer, (\%)rsobothres femoratal $-a$. arva; $b$, pupa ; $d$, adult. sides and narrower behind. Here belong most of the troublesome species, including $C$. femorata, the "flat-headed apple-borer," which, despite its common name, attacks a great variety of trees. The larva makes irregular channels and chambers in the sap-wood, boring into the solid tissues a short distance only, just before pupation, and this describes also the habits of many of the other species of this genus. The eggs are laid on the bark in June or July, and the larva live from one to three years before coming to maturity. Pupation occurs shortly before the period at which the adults emerge.

The genus 1 grilus contains species differing from any of those heretofore mentioned by their slender, cylindrical form, the head squarely truncate, or cut off in front, the elytra much narrowed at tip. As a rule, the species are dull brownish-bronze in color, the prothorax

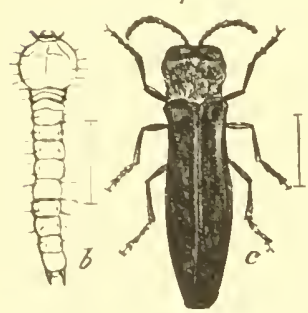

llackbersy-cane borer. lerilus ruficolles - $b$, lats:a. aduit. sometimes brassy or red-bronzed, and none is better known than the "rednecked blackberry-borer," Agrilus ruficollis, the author of the "gouty gall" on that plant. The larva in this genus are umusually long and flattened, the segments strongly marked, the "head" not mucl wider than the body, and the anal forks distinct, differing in each species.

Returning to the blackberry-borer, it is goud practice to cut out all galled canes early in spring and burn them. Trimming is done at this time as a matter of regular cultivation, and the galls are then easily seen. No "galled" 
cane ever ripens a fair set of berries, and it might as well be cut out at once. Another satisfactory method is to cut off all the new shoots at the surface of the ground about the end of June. At this time all the beetles have laid their eggs, and the shoots which come up in July cannot become infested. The best results will be obtained by combining both methods. Cutting the new

F1G. 172 .

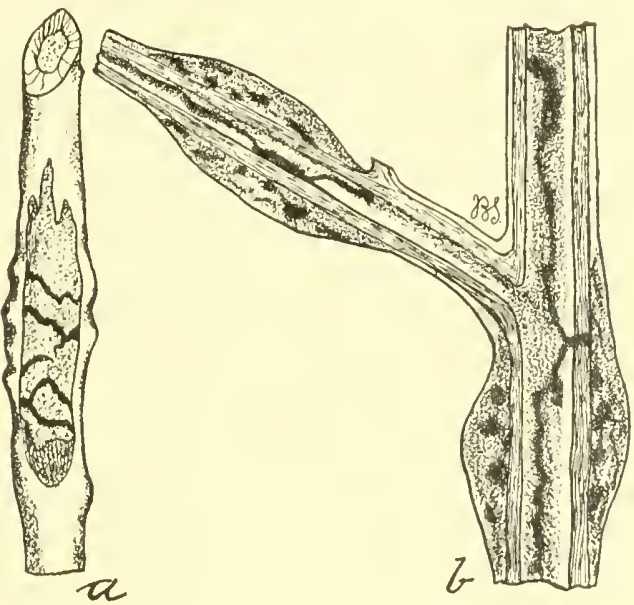

Blackherry-gall maker.- $a$, gall just beginning to form over recent borings; $b$, section through an old stem to show the character of the gall.

shoots causes the death of the young larve, which are unable to subsist on dead wood, and being footless are unable to migrate to new stalks.

Another species of Agrilus seriously injurious in parts of the Eastern United States is the "sinuate pear-borer," A. simuatus, imported from Europe within recent years. This feeds between bark and wood in pear-trees, making immensely long zig-zag galleries, finally girdling the tree and killing it. It lives two years in the larval stage.

In general we are very helpless against boring larve once they get into the trunk of a tree. Cutting out is a tedious process, even if the location of the larva is easily discoverable, which it often is not. We must, therefore, try to prevent their entrance, 
and this may be done more or less completely by mechanicul means. As against the larger species-i.e., against all except Agrilus-a wire mosquito netting loosely encircling the trunk, so as not to touch it anywhere, is a complete protection. The insects lay their eggs under a bark scale, or on smooth bark gnaw a little hole in which the egg is laid, and if access to the bark be prevented they seek other localities. The wire must be tied at

\section{FIG. 173.}

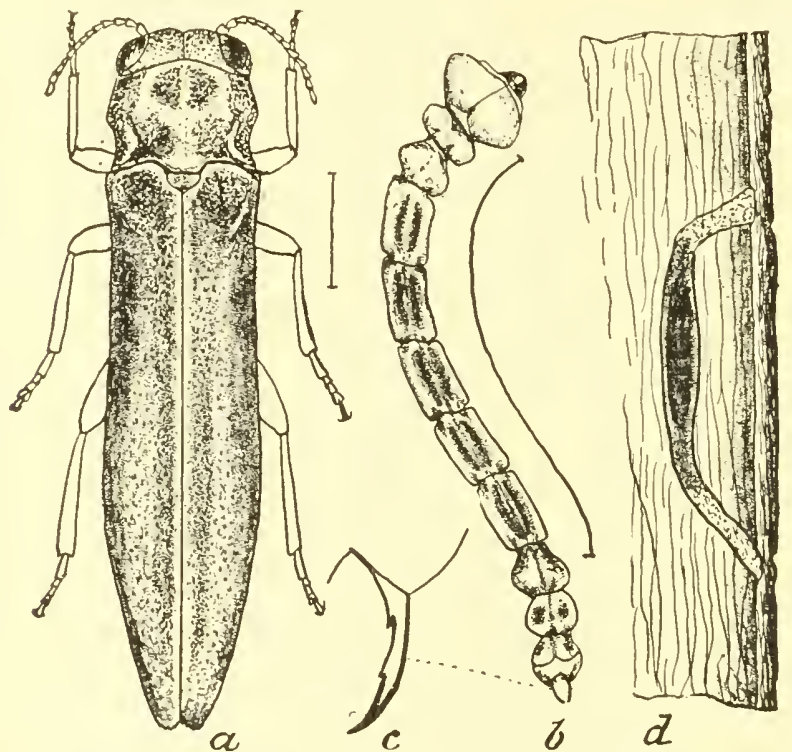

The sinuate pear-borer, Agrilus sinuatus.-a, beetle; $b$, larva; $c$, its anal fork; $d$, pupal chamber with pupa in position.

the top to prevent beetles getting under it, and must extend underground an inch or so. In this way we not only prevent new infestation, but any beetles that may emerge from the trunk will be hopelessly imprisoned and will die without a chance to reproduce.

Instead of wire netting, tarred paper or even newspapers tightly wrapped around the trunk to the branches will answer an excellent purpose, needing renewal each year, however, where the wire netting lasts several seasons. Thorough whitewashing 
offers a large measure of protection, since the adults will not voluntarily eat through a coat of it, and the larvæ cannot do so

FIG. 174.

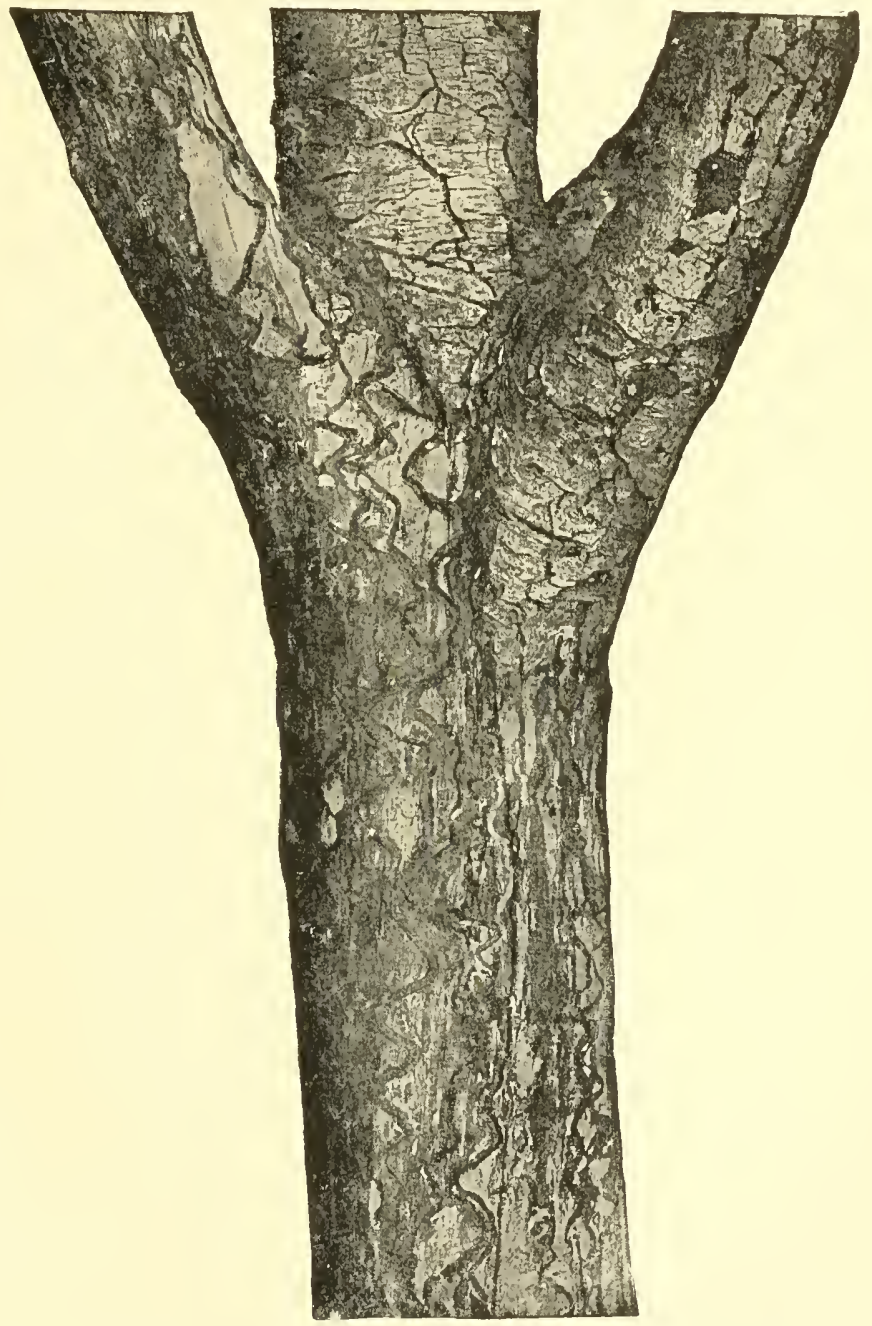

Work of the sinuate pear-borer on a Bartlett pear-tree: about one-fourth natural size. when first they emerge from the egg. The whitewash can be 
applied with a knapsack pump through a V'crmorel nozzle, and a little Paris green adds greatly to its effectiveness. It should be renewed every week or two until the mildle of July, when the danger from these flat-headed borers may be considered at an end, and it has the advantage of protecting the branches as well as the trunk. The admixture of a little glue or salt will improve it: adhesive and lasting qualities.

A strong fish-oil soap, say one pound in one gallon of water, is also effective and may be applied in the same manner. It forms a film of soap over the bark, and is repellent to the beetles as well as fatal to the young larve. The admixture of an ounce of crude carbolic acid to a gallon of suds is advantageous. This mixture should not be applied to leaves or on young shoots, as it would probably cause injury. As these methods are all preventive rather than remedial, they must be promptly and thoroughly applied, and success will be in proportion to the thoroughness with which the work is done. Instead of any of the preceding methods, "insect lime" or "dendrolene" may be with proper precautions employed on the trunks and larger branches, and, practically, this is the best material for use against the "sinuate pear-borer." It can be easily applied, remains effective for weeks, and one application, properly made at the right time, will protect the trees for the season. As against the pear-borer, it should be applied not later than May I $5^{\text {th, }}$ and kept intact until June

FIG. 175.
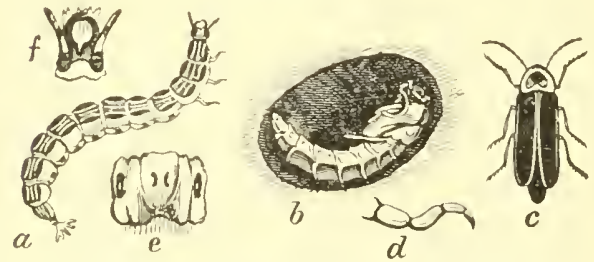

Fire-fly, Photinus proals - $a$, larva; $b$, pupa in cell; $c$, adult ; $d$ to $f$, structural details of larva. I 5 th, when all clanger from that pest is over. Reference should be made to the chapters on insecticides and preventives for further details as to applications.

In the next series, the Lamprrida, there are no species injurious to vegetation, though, under the name "fire-flies," some of them are well known. The beetles are usually slencler, somewhat flattened above, with a more or less retracted head, and are of a soft leathery texture. The "fire- 
flies " are first noticed in June in the more northern and central portions of the United States, and have the terminal scgments of the abdomen on the under side of a bright sulphur-yellow color, which at the will of the insect glows with a phosphorescent light of considerable illuminating power. They hide during the diay on the foliage of plants or in crevices, and begin their flight with the deepening of the twilight. In some species the female is without wings and remains on the ground among the grassthe "glow-worm." The larva are predaceous, and some of them live on snails.

Belonging to the same family, but of a diumal habit and without the illuminating power, are the "soldier-beetles," belonging to the genera Chauliognathus and Telephorus, distinguished also by having a more prominent head and large, round eyes. These mily be found on flowers, where they probably feed on pollen, but are of direct benefit by aiding in pollination. The Firi, $: 76$. larvæ are even more de-
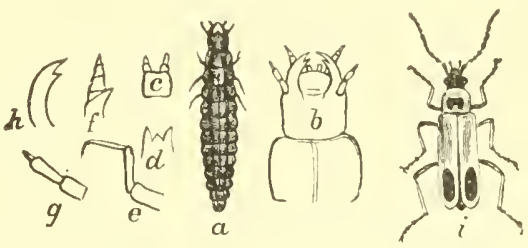

Soldier-beetle, Chauliognulhus pennsylianicus. $-a$, larva; $b$, its head enlarged: $c$ to $h$, structural delails; $i$, beetle, natural size.

cidedly useful, being predaceous and feeding largely on softbodied grubs and the like. They are long and slender, flattened above and somewhat narrowed at each end, or fusiform, the edges of the segments quite prominently marked. They are especially effective against such creatures as the larve of the plum curculio when they enter the ground to pupate, and a large proportion are thus disposed of annually.

The species belonging to the family Malachiida resemble the Lampyrids in the soft body texture and leathery wing-covers, but they are much shorter and broader, the broadest part of the body coming near the end of the wing-covers. The antennæ are short, a little enlarged at the tip, and often curiously knotted in the male. Many of the species have soft, orangecolored vesicles, capable of being protruded from the sick of the body. They are usually found on flowers and feed on wher insects or insect eggs, probably doing much good in this way. 
The larve of only a few species are known, and these are predaceous.

Next come the Clerida, many of which are also flower-beetles, but with longer legs, more prominently enlarged antennæ, more

FIG, I7\%.

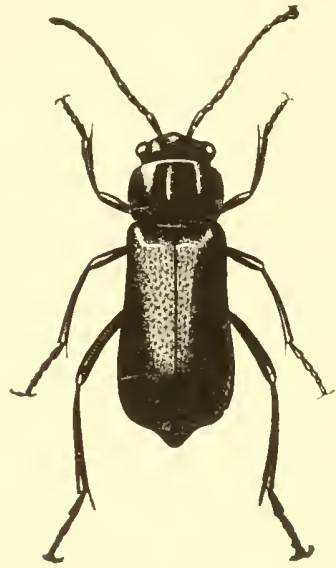

Malachus marginicollis: much enlarged. slender cylindrical form, and much firmer texture. They are bright colored, as a rule, often prettily banded, and sometimes quite abundant. Many species are found on

Fig. 178 .

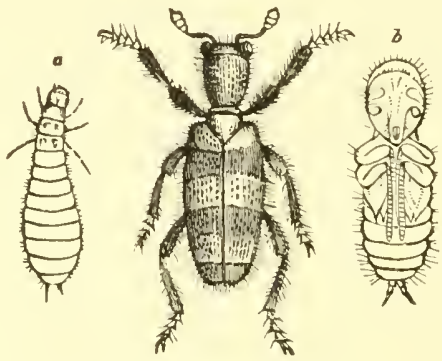

Clenus apivorus, $-a$, larsa; $b$, pupa ; beetle central: all enlarged.

the trunks of trees, running about rapidly and somewhat resem bling ants. Their larvæ in such cases prey upon wood-boring insects, principally such as live in sap-wood, and they are slender,

Fic. I79.
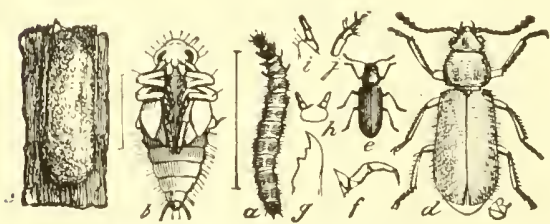

Red-legged ham-beetle, Corynetes mfipes.-a larva; $b$, pupa; $c$, cocoon; $d$, e, beetle, enlarged and natural size; $f$ to $j$, structural details. with short legs and a prominent, somewhat pointed head. They are extremely useful in keeping in check bark-beetles and other borers, and are thus worthy of our distinguished consideration. Most of the other species are also predaceous in the larval stage, but hardly beneficial, since they live in the nests of bees, devouring both the larvæ and the food stored for them. Clerus apivorus 
infests the hives of the common honey-bee, and is more or less of a nuisance in some localities.

The almost inevitable exception occurs in this family also, and the species of Corynetes, blue or part blue and part orange in color, live upon dead or dry animal matter, often attacking provisions. The "red-legged ham-beetle," C. rufipes, is of this type, and will serve to illustrate the series. The measures recommended as against the Dermestide will answer here as well.

In the family Ptinide we have an aggregation of oddities difficult of general definition, save that as a rule the species are small, with retracted head, more or less cylindrical firm body, and firm wing-covers. They feed in the larval as well as adult condition on clry animal or vegetable matter, though some species attack green vegetation. Many live in dead branches or twigs, and only a few are of sufficient interest to be especially noted. Of these is the "death-watch," Sitodrepa panicea, so named from the ticking sound frequently made by the beetle when working in wood, which superstition has interpreted as a warning of approaching death. It works also in a great variety of other substances, ranging from gunwads to roots of hellebore and old books, as a fleshy, white, grub-like larva, with a brown head and a surface covered with short, brown, bristle-like hairs. Where the nature of the article admits of such treatment, exposure to the fumes of bisulphide of carbon is a good remedy, as is also saturating with gasoline or benzine. A liberal use of paint with plenty of turpentine is indicated in other cases, and sometimes mere cleanliness following the destruction of hopelessly infested material will answer every purpose.

Of the same general shape, but larger and broader, with smooth instead of striated wing-covers and a "humped" form, is the Lasioderma serricorne, popularly known as the "tobacco-" or "cigarette-beetle." It is a great lover of tobacco in all its forms, the larva relishing plug, long or fine cut, chewing or smoking, in cigarette, cigar, or leaf, almost equally well, and injuring it materially for the human user of the "weed." The matter is an important one to manufacturers, who deal with it in a variety of ways ; but it does not particularly interest the farmer.

Among the wood-feeders the species of Bostrychus and Sinoxylon are of interest, their larvæ sometimes boring into fruit-trees. 
Fig. ISก.

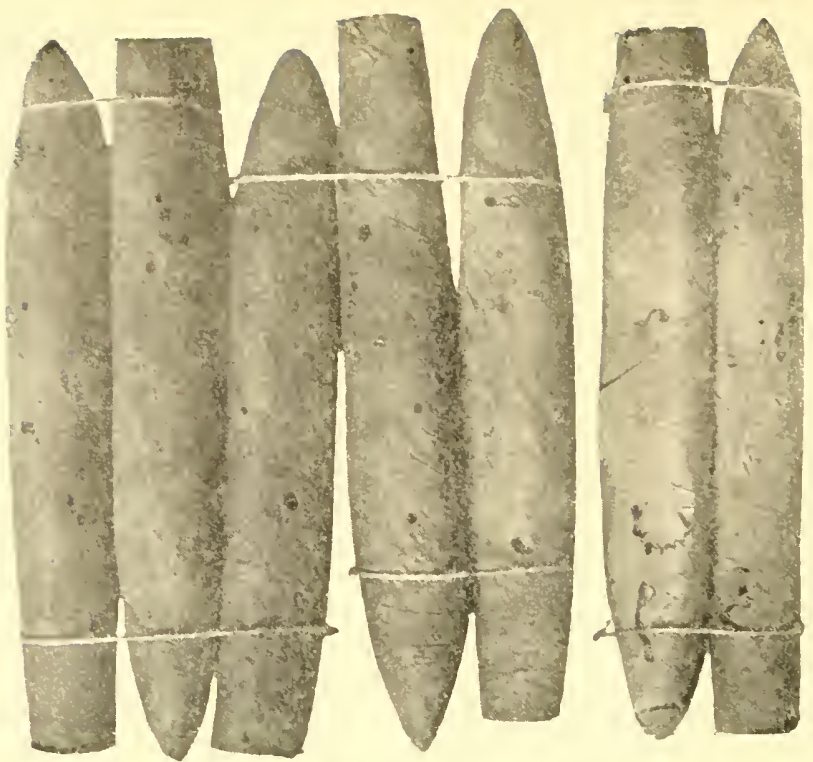

FIG. ISI.
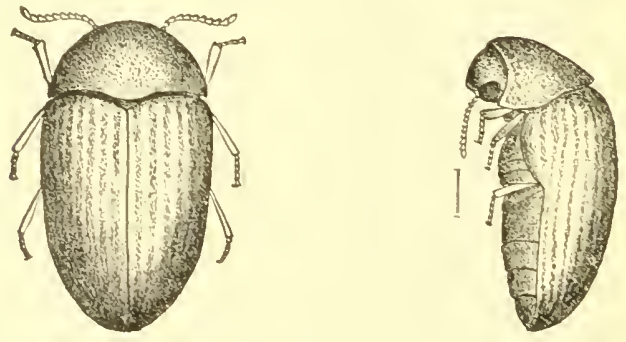

FI(j. IS2,
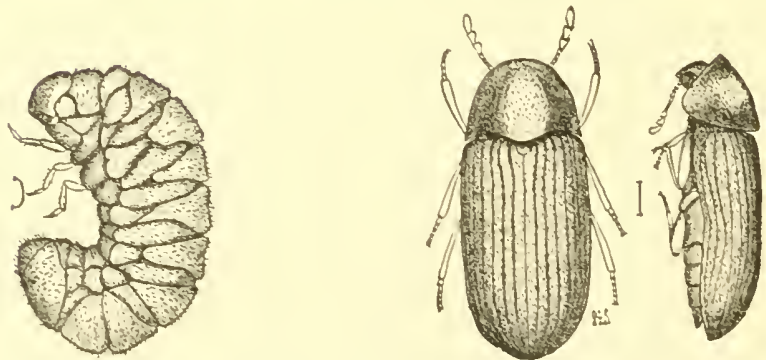

Fig. Itin, cigars injured by the tobacco-bectle, Lasioderma serricome; holes show where the beetles issued. Fig. Ist, Lasioderma serricurne. from above and side. Fig. I 82 , the "death-watch," Sitodrepa panicea, larva and beetle, from above and side; much enlarged. 
The "apple-twig borer," Amphicents bicaudatus, is about the only species needing especial remark, and this beetle bores into small apple-twigs in carly spring, entering close to a bind and making a channel several inches in length, apparently for food and shelter merely. It remains in these burrows a short time only, and then lays its eggs in the dead or dying roots of "cat-

Fic. $18_{3}$.
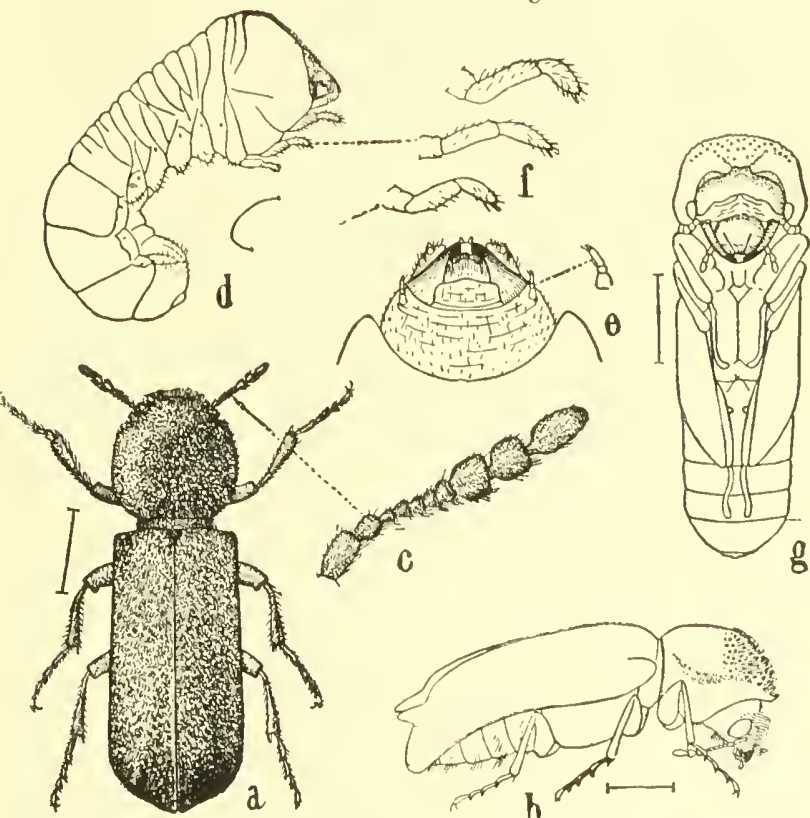

Apple-twig horer, Amphicens bicumalus.- $a$, heetle, from above; $b$, same, in outline, from side; $d$, larva; $g$, pupa; $h$, same in larval hurrow: $c, e, f$, structural delails.

brier," or "greenbrier" (Smilax sp.), or in dead shoots of grape. The insects rarely appear in troublesome numbers, and then good practice is to look after neglected vineyards or grape tangles in near-by woods, and after brier thickets, which latter are an abomination at best and should be destroyed.

There are other Serricorn families, small both in size and in the number of species they contain, but they are mostly rare, of no economic importance, and need not be referred to here even by name. 
The next large series is the Lamellicomiu, where the antennae terminate in a lanellate or leaf-shapect club. All the species are feeders upon vegetation, living or deat, green or in a stage of decily, and in all calses the larve are "white grubs," large or small, smoeth or hairy, but always "white grubs." These can be generally described as having a large, yellow, or brown head, with prominent mandibles and long palpi, legs that are quite long, mokerately stout, with distinct claws at the tip, usually also

Fic. 18.4 .

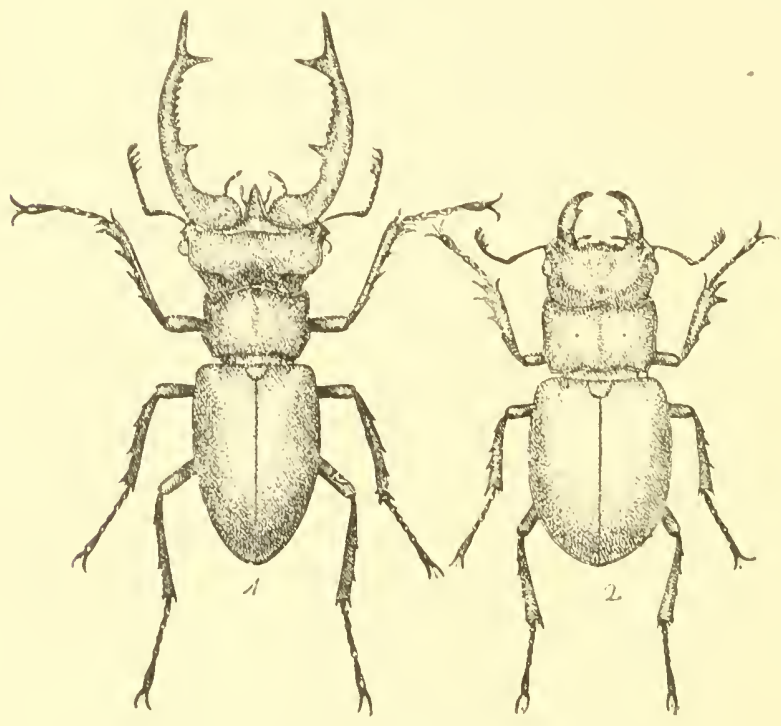

sitag-bectles,-1, Lucanus elaphus, mate: 2, L. dama, male.

clothed with hatir, a body that is cylindrical, stout, wrinkled, somewhit curved or even crescent-shaped, ending rather abruptly in a more or less enlarged, obtuse, terminal bulb. As a rule, the color is dirty yellowish white, but it may become pink, greenish, or even blackish, the hinder portion always showing durker because of the excrementitions mass which shows through the transparent tissue.

Two families belong to this series, of which the Lucanida, or stag-bectles, ate of no economic importance though of much 
popular interest. They differ from the Scarabceide in that the leaves of the club are separated and cannot be made to form a solid club or mass.

()ur most common "stag-beetle" is the Luacanus dama, in which the mandibles of the mak are much enlarged and sickleshaped; whence the common term "pinching-bug." It oecurs throughout the Middle and Central States, becoming more rare to the North and losing interest in the South in favor of its more prominent relative, the L. elaphus, which in the male has mandibles almost as long as itself, and branched like antlers, yielding in this respect, however, to its European congener, the l.. cervus, or original "stag-beetle." Quite a different-looking creature is the Passalus cormutus, perhaps the most common of all the members of this family, though not always readily found. It is coal-black, shining, with a large square thorax and a small head armed with a slort curved horn. All these species and all the larve of this family feed in decaying wood, and preferably in stumps or in roots. Thus their function is rather as scavengers, and never as destroyers of vegetable life. The larva of the Passalus cornutus is interesting, because it has four legs only, one pair being entirely aborted.

In the family Scarabaide the leaves of the antennal club are always close together when at rest, but can be spread out fan-like at the will of the insect, exposing the mumerous sensory pittings with which they are closely set. The legs are always fitted for digging.

At the beginning we med a series of species that are scavengers, living on Fili. 185 .

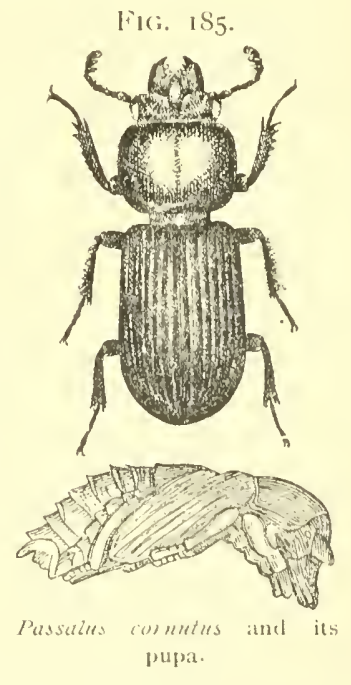
decaying or excrementitious matter. Some of them are large and have the curious habit of making balls of clung, in each of which an egg is laid. The balls are then buried beneath the surface, and each furnishes sufficient food to bring one larva to maturity. When the ball is made up on a road or other lard surface, the insects roll it to some more suitable place, and have 
therefore received the popular name "tumble-bugs." The

Fic. I 86 .

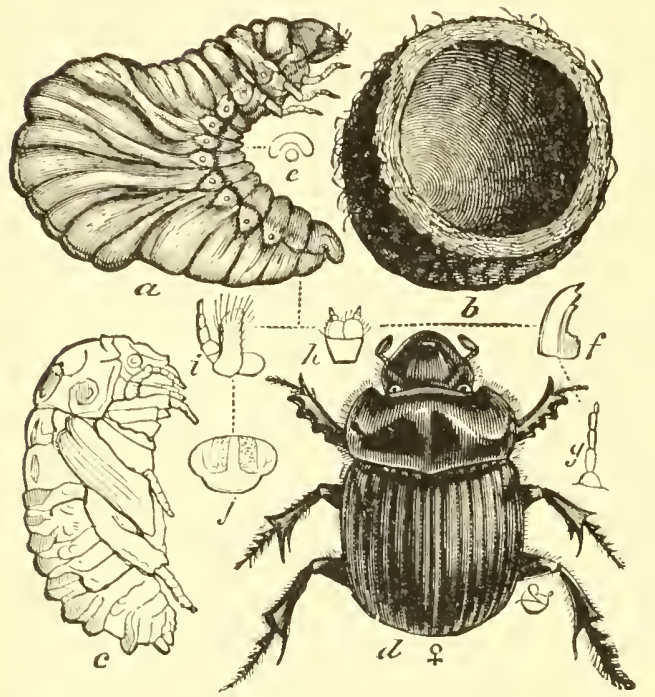

A "tumble-bug," Copris carolina.-a, larva; b, the cell in which it lived; $c$, pupa; $d$, female beetle; $e$ to $i$, structural details.

beetles are usually blackish or bronze brown in color, but sometimes brilliantly metallic blue, green, coppery, or bronzed, and often we find in the male a prominent, curved horn on the top of the head, and angular processes on the thorax.

Other large or moderate-sized species make holes close to or under droppings in fields. working mostly at night, and leaving evidences of their presence in the shape of little piles of fresh dirt next to or even on top of the droppings; cow-dung being the favorite food. These beetles

Fig. I87.

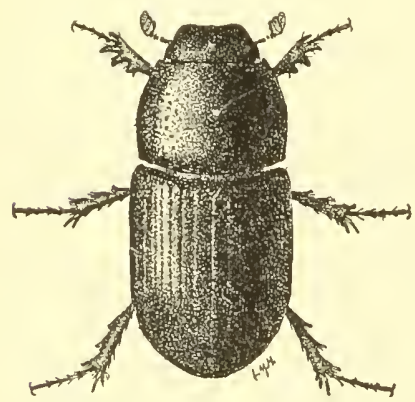

Aphodius granarius, much enlarged. usually have deeply striated wingcovers, are more stockily built than those previously mentioned, and belong mostly to the genus Geotrypes.

A series of small, more slender or oblong, black or reddish beetles is often found in considerable numbers burrowing in or under excrement, and these have similar habits and are referable to the genera Aphodius or Atcinius.

Very often large, clumsy "white grubs" are found in manure heaps, and these are larvæ of 
beetles belonging to this series. None of them are in any way injurious.

The exception in food habits in this family is found in the genus Trox, containing oblong, very convex species, with rough, tuberculate or pitted wing-covers, and a deeply furrowed thorax. They are usually more or less incrusted with dirt, are found feeding under old skins, bones, or hoofs, and are, as scavengers, at least innoxious.

The more typical "leaf-chafers" are of diverse forms, often common and economically important. Among the first we reach

FIG. ISS.

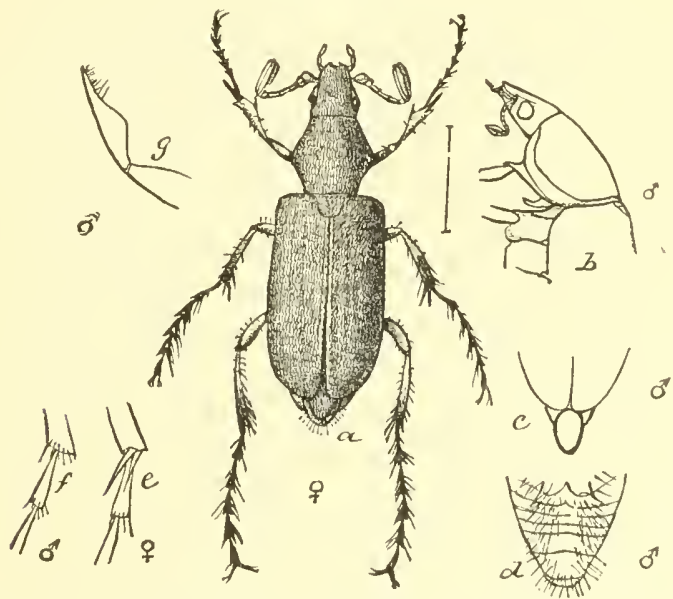

Rose-chafer, Macrodacivlus subspinosus. - $a$, beetle; $b$, head and thorax, in outline, from side; e to $g$, structural detaits.

the genus Macrodactylus, of which the "rose-chafer," or "rose-buy" is a member. This appears in June at about the time roses and grapes come into blossom, and eats their flowers in preference to anything else.

Occasionally, for a series of years, the insects appear in everincreasing abundance, until the swarms are so great that they ruin not only vineyards but orchards and gardens, eating ahnost every kind of fruit and flower. In the presence of such swarms we are almost helpless, and insecticides are of no possible use. No contact poison kills them, and the arsenites or other stomach 
poisons act too slowly, as two or three days suffice to ruin a vineyard. Lest this seem strange, I will state that I have seen on hundreds of acres of vineyard every vine bearing multitudes, and every bunch of blossoms from two to ten, or even more beetles. I have counted over twenty on a single apple, and a full-blown rose may bear as many as thirty or even more. Weare reduced

FIG. IS9.

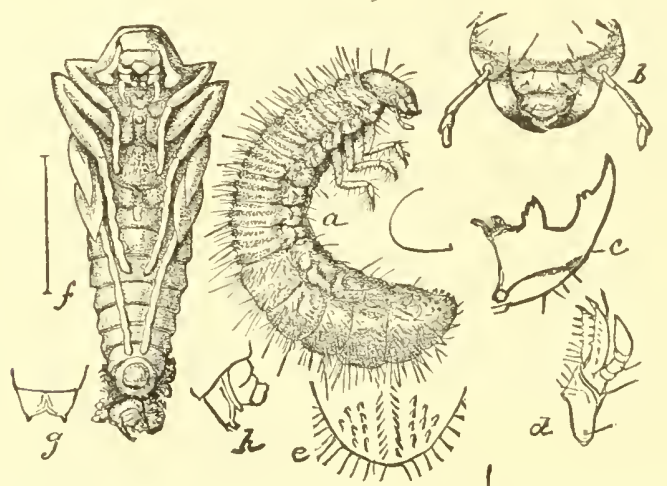

Larva, $a$, and pupa, $f$, of rose-chafer; $b$ to $e, g, h$, structural details.

to actually collecting the specimens from the vines by means of funnel or umbrella-shaped collectors, adapted to the method of cultivation in use. They drop readily when the vines are jarred, and the collector should be so made as to roll them to the centre and into an attached pail containing kerosene. This must be done not only daily, but continuously for several days until the flight is over or the grapes have set, for well-set grapes are rarely eaten. Fortunately, a period of abnormal increase seems to be followed by a period of decrease, though the lengths of the periods have not been ascertained. The larve feed in light land on the roots of various plants, but principally on grass. They pupate in spring, shortly before changing to the adult condition, and by ploughing infested sod at this time a large proportion can be destroyed. When only moderate numbers occur, lime often serves to protect the plants, or, better, the Bordeaux mixture, which is distasteful to them.

The "May-beetles," or "June-bugs," sometimes termed “cockchafers," are much larger, and mostly members of the genus 
Lachnosterna. They fly at night, are readily attracted to light, and often come into roons, clumsily and noisily bumping against all sorts of obstructions until they eventually strike something which sends them heavily to the floor. We have many species more or less resembling each other, and all chestnut brown or yellowish in color. Some years they are very abundant and cause injury by eating the foliage of trees or shrubs. I have found them eating pieces out of the stalks of recently set apples

FiG. 190.
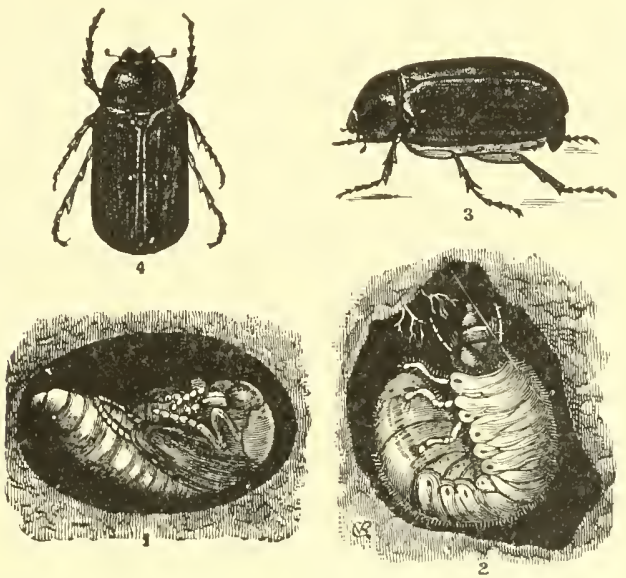

May-beetle,-1, pupa in earthen cell; 2, larva or white grub; 3,4 , beetle, from side and above.

and pears, causing the fruit to wilt and drop. The larve live on grass and other roots, and are typical "white-grubs." Cultivated crops are frequently attacked and much injury is sometimes caused. The larval period has not yet been satisfactorily determined for all species, and varies, as does also the time for changing to the adult condition. Frequent rotation and fall ploughing are to be recommended, and where grass lands are infested, heavy top-dressings of kainit and nitrate of soda have proved beneficial. Wherever ploughing is done in infested fields, chickens should be encouraged to follow in the furrow to pick up the grubs.

Where young trees are to be protected from the beetles, jarring them into an umbrella two or three times early in the evening 
will prove effective, as they clo not fly much after nine o'clock, exeept on unusually warm and sultry nights.

Frepuently we find on grape and Virginia-creeper, during midsummer, a small chafer with clay-yellow, rather shining, and striated wing-covers, feeding upon the leaves. This is the Anomala lucicola, which varies also to a shining black. It is occasionally numerous enough to canse notable injury, but

Fig. 191.
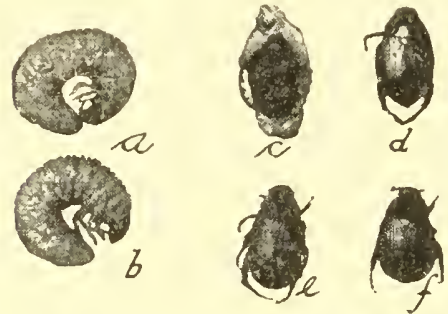

Anomala lucicola-- $a, b$, larva; $c$, pupa in larval skin; $d, e, f$, adult beetles.
Fil. I92.

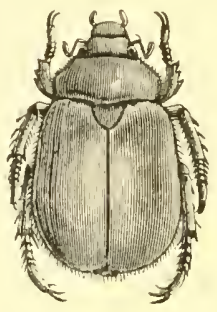

froldsmith beetle, Cotatpa lanigera.

yields readily to any of the arsenites. The larvæ live in light soil, feed upon the roots of grasses, and pupate in late fall, the adult forming soon after and remaining within the cast larval skin until ready to emerge in early summer.

Also found during the day on grape foliage, or flying toward it during early evening, is a large, shining, tan-yellow chafer, with eight black spots, two on the thorax and six on the wingcrvers. This is the Pelidnota punctata, or "spotted vine-chafer," which feeds upon the leaves, but rarely does noticeable injury. The larve feed upon decaying roots and stumps, and I have taken both larra and pupa out of a rotten ceelar trunk.

Swamp-willow in the East is the food of Cotalpa lanigera, a beetle very similar in size and shape to the preceding, but of a beautiful shining, lemon yellow, the head glittering with a golden sheen, hence known as the "groldsmith beetle." Beneath it is of a burnished copper color, densely clothed with white woolly hrir. It is not injurious, and mentioned here only because of its beauty. Some of its allies in the Southwest and in the tropics are of the most brilliant golden and silvery tints. 
A beetle that sometimes does considerable injury to sugar-cane and corn in the Southern States is the "sugar-cane beetle," I, igyrus rugiceps. Unfortunately, we do not yet know its entire life history, and, as the injuries seem to have been rather local and occasional, it may be that it will not prove of wicle or general importance. No satisfactory method of dealing with it is known at present.

In the genera Xyloryctes, Strategus, Dynastes, and Philcurus, we have a series of species more or less bizarre in form, with curious horns and processes on head or thorax or both, but not of economic interest, since neither beetles nor larve are found on cultivated plants. Ash furnishes food for several of the spe. cies in both larval and adult form.

Beginning with the genus Allorhina, we have a series of beetles that frequent flowers, feeding on pollen, but largely repaying what they devour by the benefit they confer in pollenizing.

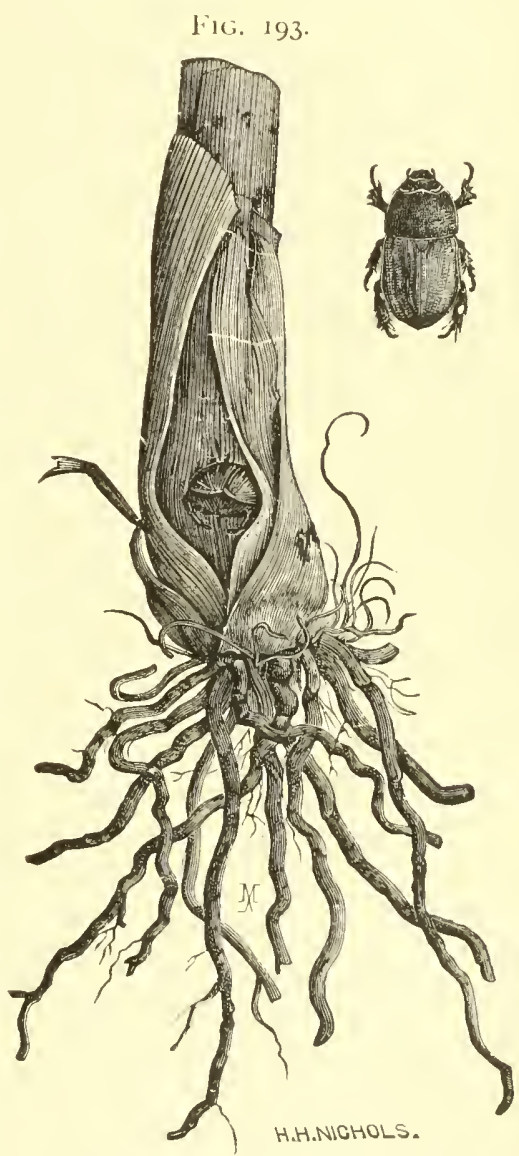

Ligyrus rugiceps.-The beetle and its work. Sometimes, however, they prefer ripening fruits or even corn when in milk, and then become troublesome. Belonging to this genus Allorhina are velvety-green and dull-brown beetles, an inch or more in length, which fly during the day with a buzzing sound somewhat like a bumble-bee, and usually close to the surface of the ground, except where they attack fruit. Yet I have 
seen hundreds of them flying about among half a dozen plumtrees, apparently injuring nothing but possibly themselves. Their larva, however, feed on grass roots and are often troublesome on lawns. They are quite large creatures and very hairy, with a fashion of travelling on the back instead of the legs, when removed from their congenial soil. Heavy top-dressings of kilinit and tobacco have proved about as effective as anything in (lealing with these insects, though on a small scale the kerosene emulsion diluted ten times, and then washed into the soil by rain or frequent waterings, has proved effective. On any large area

FIG. I94.
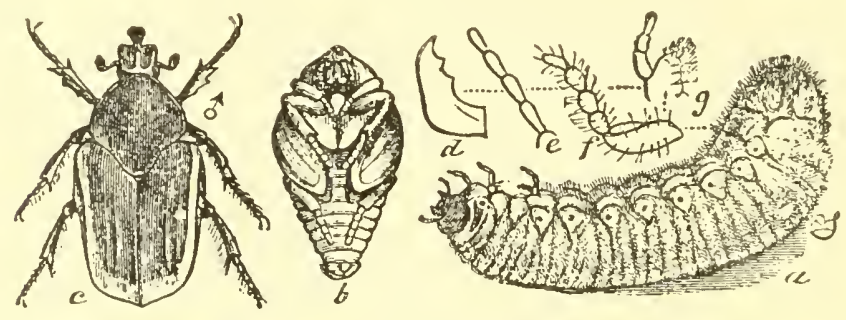

Allorhina nitida.-a, larva; $b$, pupa; $c$, adult ; $d$ to $g$, structural details of larva.

this process would probably be too expensive. The species is more common southward, and is more likely to become troublesome on lawns, in parks, and in gardens than in the field.

To this same yroup belongs the "Indian Cetonia," Euphoria inda, which is one of the earliest of our Eastern beetles, flying in April or May over sandy or bare spots, close to the ground. At this time it is sometimes found on flowers, but remains only a few days. In early September a new brood appears, and this is occasionally troublesome, the beetles eating into ripe fruits or into corn. They have never yet appeared in such numbers, however, as to make remedial measures necessary.

Taken as a whole, the Lamellicorns contain no directly beneficial insects, and the white-grub larva are in many cases injurious when they feed on the roots of cultivated plants. Where it variety of cultivated crops follow each other, there is little chance for their excessive development, and frequent rotation is therefore indicated, with as short a period in grass as may be. As 
the beetles in most cases appear in spring and oviposit late in May or in June, land bare at that time will probably escape. Fall sowing of crimson clover, to be turned under by the middle of May or before, will in some cases protect the land and act as a green manure if required; or it may be allowed to remain until mature to make hay, and, if then ploughed and put into potatoes or some crop which the white-grubs do not attack, such as are then in the ground will be starved out. Where white-grubs are abundint, strawberries should not follow sod or other grass crop directly, and the beds should be kept clean, at least through the second year. Where the culprits are species of Lachnostema, fall ploughing is indicated, since this will turn out the newly-formed beetles at ain unseasonable period, and will cause their death in most cases.

We now reach the great series of Phytophaga, in which the tarsi are apparently four-jointed, the third joint deeply lobed. Two families belong here, - the Cerambycida, or long-horned beetles, and the Chrysonindida, or leaf-beetles. The "longhorned " beetles are so named from their usually well-developed, slender antennæ, rarely shorter than the body, and often several times as long. They are usually more or less cylindrical, often with a vertical head, and always with well-developed mandibles.

The larva are wood-borers, using that term in a somewhat loose sense to include roots and the more solid parts of a few herbaceous plants, and are always cylindrical, the segments well marked, those immediately behind the head considerably enlarged, while anally they often taper quite abruptly. They are known as "round-headed" borers to distinguish them from the "flatheaded " larva of the Buprestide, and the jaws, though rather small, are powerfully developed, fitted for cutting the hardest wood-fibre. In food habits the insects vary greatly, some attacking only dead or dying tissue, while others infest sound trees only. Perhaps in most cases they do best in somewhat weakened trees which their ravages soon kill entirely.

Among our largest species are the Prionids in which the margin of the thorax is thin, sharp, and often toothed, and our most common species, extending over a large part of the United States, is Orthosoma brumnem, an oblong, somewhat flattened, brown species, from one and one-half to two inches or more in 
length. It is not economically important, unlike the "broadnecked Prionus," P. laticollis, whose larve in blackberry are known as "giant root-borers." The beetle is black, robust, broader than usual, with a broad, toothed thorax, and from one to two inches in length. The larvæ are immense, nearly three inches for a full-grown female, and they feed in the roots of a

\section{FIG. 195 .}
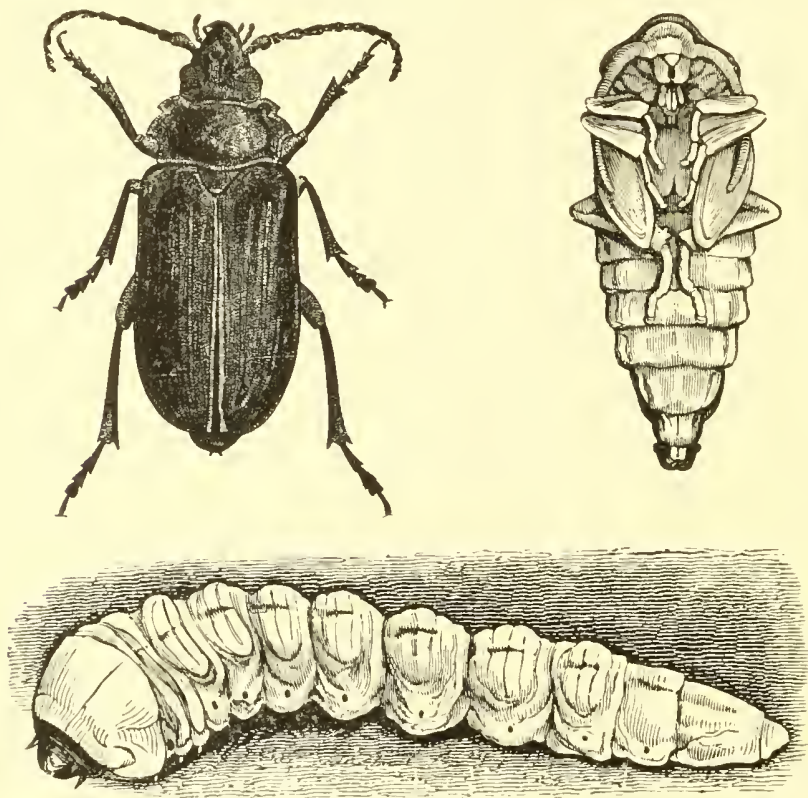

The "giant root-borer," Prionus lalicollis.-Larva, pupa, and adult.

variety of trees and plants, including chestnut, oak, cherry, apple, grape, and blackberry. They require three years to reach maturity, and are sometimes decidedly troublesome. There is no way of reaching the larvæ except to dig them out, and in blackberry fields the sudden wilting of part or all of a hill indicates almost infallibly the presence of one or more, which should then be founcl and destroyed at once. Grape and apple stand the injury better, but when a tree becomes badly infested nothing remains but to take it out and burn it. Even large trees are 
sometimes killed, an old cherry-tree, fully eighteen inches in trunk diameter, which died rather suddenly, having the root absolutely riddled in every direction by a dozen or more of these immense creatures.

The species of Phymatodes are much smaller, a little flattened, with an oval thorax and a tendency to blue and ycllow colors. The larve feed only in dead or dying wood: $P$. amanus, a bright biue species with yellow thorax. attacking dead shoots of grape, while $P$. varius and $P$. variabilis live under the bark of oak cordwood. The beetles appear in spring and lay their eggs in dying wood or in wood cut during the winter, often in such numbers that the bark is com-

FIG. 196.

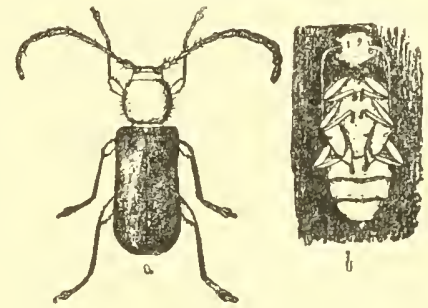

Phymatode's amonus: pupa and adult. pletely loosened by the larvæ and will, next spring, slip off in its entirety. They are hence called "bark-slippers" by woodmen. In the Southern States they infest tan-bark, sometimes injuring it considerably. Cutting the trees during the summer. after the beetles have disappeared, or very early in fall will put the bark and wood in such condition that it will not be attractive the season next following.

The species of Elaphidion are narrow, brown beetles, covered with whitish, somewhat mottled pubescence, and have long and rather stout antennæ. They are known as "oakpruners," because the larva of several species bore into twigs and branches of oak and, when nearly full grown, girdle them from the inside, so that the first high wind of early winter breaks them off, carry. ing the larva to the ground.

Fig. 197.

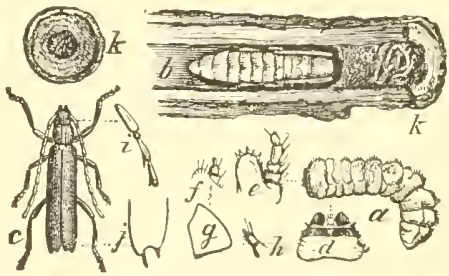

The oak-pruner, Elaphidion parallelum. $-a$, larva; $b$, pupa in its burrow ; $c$, beetle: $k k$, cut ends of the twig; $d$ to $i$, structural details.

Transformation is completed in the June or July following. Often, during late summer, the wilting of a twig or small branch indi- 
. cates the presence of such a larva. Apple-trees are sometimes attacked, and the best measure for general adoption is the systematic gathering and burning of all fallen twigs and branches during the winter. The insects are not confined to terminal branches only, but sometimes attack the trunks of young shoots or trees after a fire has been over the ground and scorched them, and in such cases the larve make no effort to girdle.

In the genus Cyllene we have moderate-sized species that are dark velvety brown or blackish, with bright golden-yellow bands. Of these, C. pictus infests hickory not uncommonly, ancl appears in spring, while C. robinice infests the locust, and appears in fall. This latter is a serious pest, and makes growing locusts simply impossible in many localities. As soon as a tree

FIG. 198.

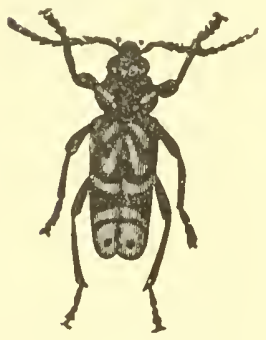

Plagionolus speciosus. attains a moderate size it is riddled with the large holes made by the larvæ, and leads but a sickly life for a few years thereafter, eventually dying down to the ground. The beetles themselves frequent the flowers of golden-rod, and may be collected there in great numbers, the females resorting to the locusts only when ready to oviposit. An allied, yet larger and prettier, species, Plagionotus speciosus, bores into maple, but is usually somewhat rare and has not proved injurious until very recently in some parts of New Hampshire, where certain shade-trees suffered.

We sometimes find a small larva belonging to this series boring into the branches and smaller shoots of currant-

FIG. 199.

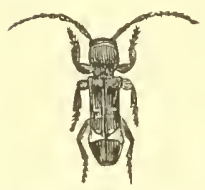

American currant-borer, Psenocorus supernotatus, enlarged. bushes, and early in spring these change to a small, brown, somewhat flattened beetle, rarely exceeding one-quarter of an inch in length, clothed with white hair grouped to form two white spots towards the end of the wing-covers. This is the Psenocorus supernotatus, which is occasionally abundant enough to be troublesome. It can be licld in check by close pruning during the winter, the cuttings to be burnt before spring opens to destroy the contained larvæ.

In late spring or early summer some of the terminal shoots 
of apple-trees may suddenly wilt and the leaves become brown and dry, the fruit, if any, dropping to the ground. These wilted shoots will be found hollowed out, and the culprit is the larva of another little brown longicorn, about one-quarter of an inch in length, quite robust and cylindrical, the wing-covers a little mottled with rather long, pale hair. It is a species of Eupogonius which has not figured much in economic literature, because its injuries rarely amount to more than a light summer pruning. On smaller trees the infested shoots can be cut and destroyed and on larger trees careful winter pruning is indicated.

A well-known orchard pest is the round-headed apple-borer, the larva of the Saperda candida. It attacks quince in prefer-

FIG. 200.
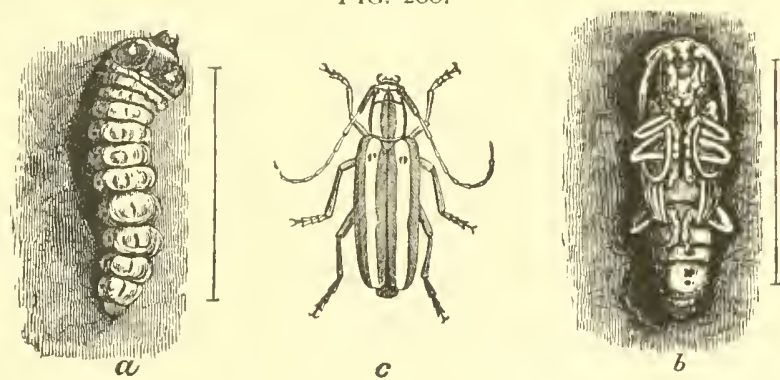

Round-head apple-borer, Saperda candida.-a, larva; $b$, pupa; $c$, adult.

ence even to apple, but is more rarely found in pear. The beetle appears late in June or early in July, depending somewhat upon latitude, and lays its eggs on the trunk, as near to the surface of the ground as possible, under a loose bark-scale or in a little hole gnawed by its mandibles. The larva lives for a year in the sap wood, then bores into the trunk, up or down, sometimes some distance below the surface, and in the spring of the third year changes to a beetle. Trees of quite large size are killed in a very few years, and for some time before are sickly and do not properly mature a crop of fruit. All sorts of remedies and devices have been proposed, cutting out the larva being the one most relied upon even yet. This means, in many cases, making an additional large wound in the tree, and sometimes the remedy is worse than the disease. The best method of protection, and 
this applies as well to other species infesting tree-trunks, - e.g., the locust-borer, - is mechanical, the trunk being covered or coated by some material impenetrable, repellent, or destructive of or to the adults, thus preventing oviposition. The most satisfactory and lasting measure, ali things considered, is covering the lower portion of the trunk with wire mosquito-netting, tying at the top and hilling up against it at the bottom. The netting should extend at least two feet up the trunk and above that a coat of whitewash should be maintained luring the danger season. Other measures, equally useful here, have been already referred to when speaking of the "flat-headed borers."

In the genus Oncideres we find a curious and interesting egglaying habit: the beetle lays an egg in a twig or branch, and then girdles it at a little distance below, eating

F1G. 203.

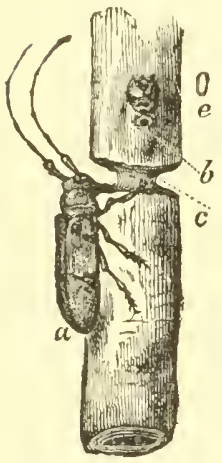

The "twig-gird. ler," Oncideres cin. qulatus. $-a$, beetle at work; $b$, eggpuncture; $c$, girdling done by beetle; e, egg. so far through that a high wind brings it down. The twig wilts at once and the woorl is then in the exact condition desired by the larva, which undergoes its transformations undisturbed by growth or undesired moisture. Sometimes shade-trees are attacked; but merely gathering and burning the fallen wood keeps the insects in check.

There are many other longicorns in our fauna, nearly six hundred species being listed in the catalogues, and many are beautiful as well as interesting. The few species referred to here do not even illustrate all the different types, but are all that are sufficiently injurious to be referred to at any length. Wooded regions furnish the greatest variety of species, and all portions of the trees furnish support for their larve.

The family Chrysomelida, or leaf-beetles, contains species that, in the main, feed upon leaf-tissue in the larval as well as adult stages, and many of them attack cultivated crops. The beetles may be distinguished by the tarsal structure already described, by their usually moderate or small size, short antennæe which are not situated on frontal prominences, and by their usually margined, not cylindrical prothorax. The larvæ vary 
FIG. 20I.
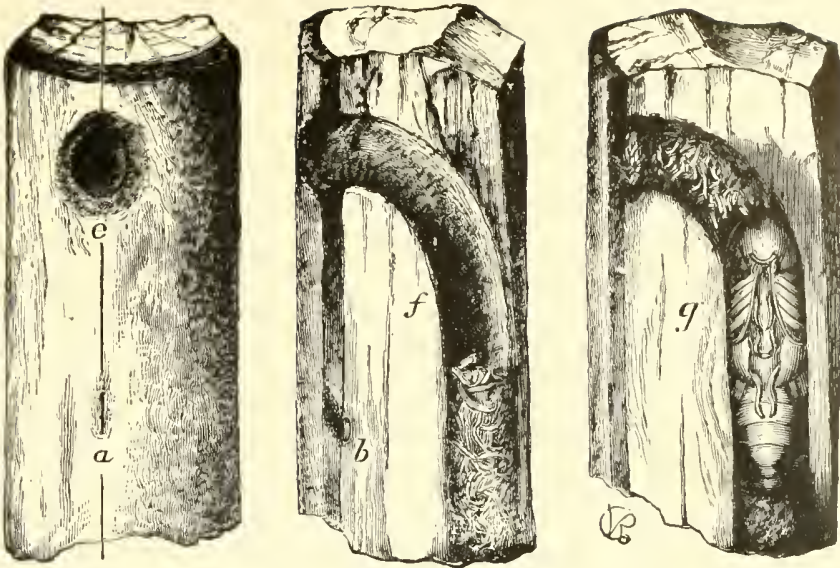

Work of the round-head apple-borer, Saperda candida.-a, puncture in which egg is laid; $b$, same in section; $e$, hole from which bectle has emerged; $f$, same in section; $g$, pupa in its cell.

Fig, 202.

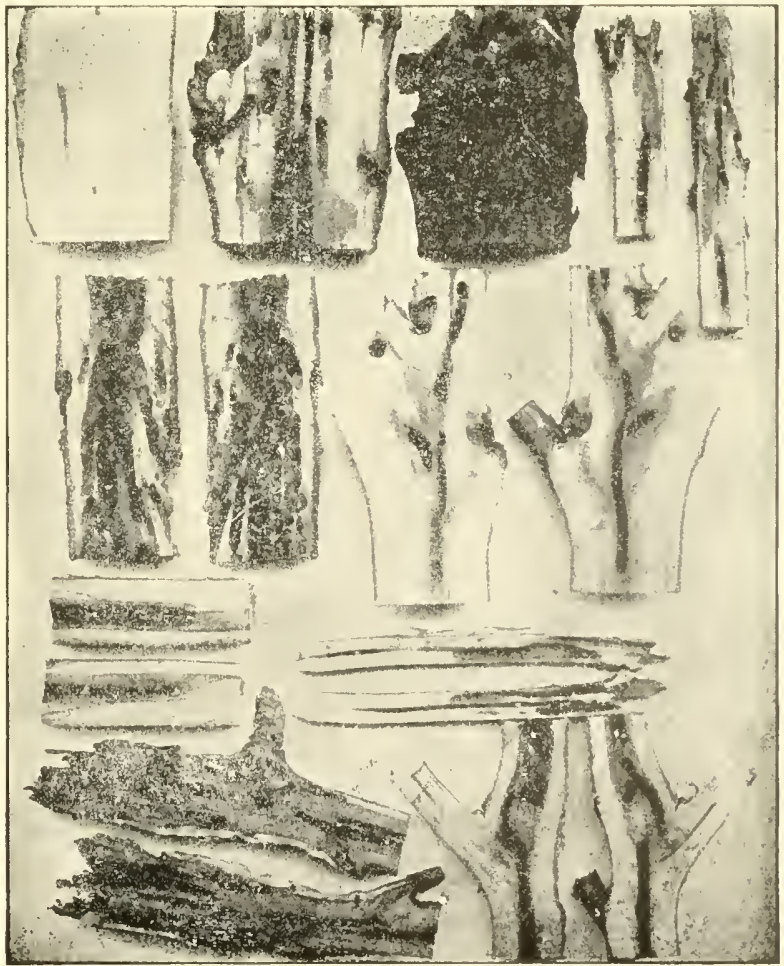

Work of the locust-borer, cyllene robinice. 

considerably in form and habit, but are often more or less viscid, and are then termed slugs.

Belonging to the genus Lema is a little series of species, several of which feed upon the potato, and of these the best known is the Lema 3-lineata, or "3 lined potato-beetle." It is yellow in color, the head and thorax much narrower than the body, and the wing-covers have three broad, black stripes. It is rarely abundant now-a-days, though at one time a somewhat important species, and it may be easily controlled by the use of the arsenites. In fact it is the treatment adopted for the better-known " Colo. rado " beetle that has in a large measure exterminated the I.cma.

Somewhat allied in form are two species of Crioceris, both feeding on asparagus, and both introductions from Europe. The common "asparagus-beetle," C. asparagi, is about one-fourth of an inch in length, the wing-covers black with red or yellow markings, the thorax red with black dots. It hibernates as an adult, and appears early in spring, eating into the asparagus shoots and laying its eggs upon them. These eggs are black and quite long, cylindrical, set on end so as to project from the shoots in every direction. The larvæ hatch soon thereafter, and are slimy, greenish slugs, with black dottings, a blackish head, and black legs. They often do great injury, particularly on young plants. On beds where cutting is done, a tew shoots should be allowed to grow as traps during the cutting season, and on these the majority of beetles will oviposit. In a week they should be cut and destroyed, other shoots being allowed to take their place, to be similarly treated thereafter. If this practice is kept up for a month, no injury need be anticipated later on, as the species will be too much reduced in numbers to become troublesome. No volunteer aspara-

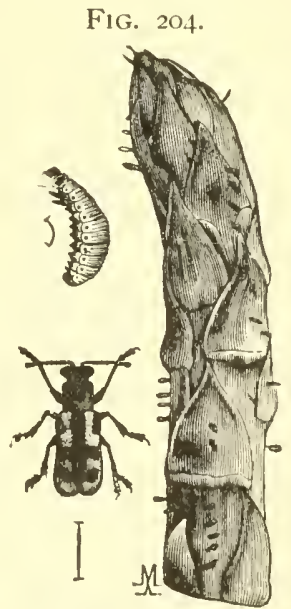

Asparagus-beetle, Crioceris asparagi: larva, adult, and shoot with eggs. gus should be permitted, as otherwise the insects will multiply there. In young beds the beetles cannot be checked, because spraying the feathery leaves is impracticable, but after the larre 
develop, they may be readily brushed off with a stıck in the middle of a hot day and iew of them ever get back, a short period on the hot soil proving fatal. The work can be done very rapidly, and is needed two or three times only to secure entire protection. Where a field of old shoots becomes badly infested by larvie, much benefit may be derived by a thorough dusting with fresh, dry slacked lime early in the morning while the plants are yet a little moist with dew. The lime, if properly prepared, is sufficiently caustic to burn holes into and kill the slimy larve. As new specimens are constantly hatching, this dusting must be done several times at short intervals, but is sure to prove effective if thoroughly carried out.

The "r2-spotted asparagus beetle," C. I2-punctatus, is somewhat larger and more robust, uniformly reddish in color, with twelve black spots on the wing-covers. It is as yet less common than its ally and not so widely distributed, but may be treated in much the same way.

The species of Fidia are robust, rather long-legged creatures, covered with short hair, giving them a more or less marked gray appearance, and they feed largely upon grape. Fidia viticida has proved locally injurious in Ohio, and, as the species occurs over a large portion of our country, it may break out anywhere at almost any time. The beetle feeds upon the foliage, eating irregular holes on the upper surface in June. Eggs are laid on the trunk of the vine or on the branches in any available crevice, and the larve drop to the ground when hatched, making their way beneath it as best they may, to the rootlets upon which they feed. Remedial measures have not as yet proved very satisfactory, but spraying with a strong arsenical mixture, using lime to avoid burning the foliage, will kill many of the beetles. Cultivating the ground so as to have a loose powdery top soil without crevices leading to the roots, which should also be covered as deeply as possible, will prevent many of the larve from reaching their feeding place.

Strawberry plants are sometimes injured by whitish larve feeding upon the roots, and from these are produced small, shining, black or brownish beetles belonging to Paria aterrima, or certin allied species popularly known as "strawberry rootborers." The best measures here are clean culture and frequent 
change of location for the strawberry beds. The insects are rarely troublesome in the Eastern, but often injurious in the Central States. Old beds should be ploughed out and destroyed as soon as they have been picked, and when new beds are set out care should be used in selecting plants free from insect attack. Where a two-year picking rotation is used and the old plants are immediately destroyed, the species are not able to increase excessively. The arsenites may be satisfactorily used to kill th:

FiG. 205.
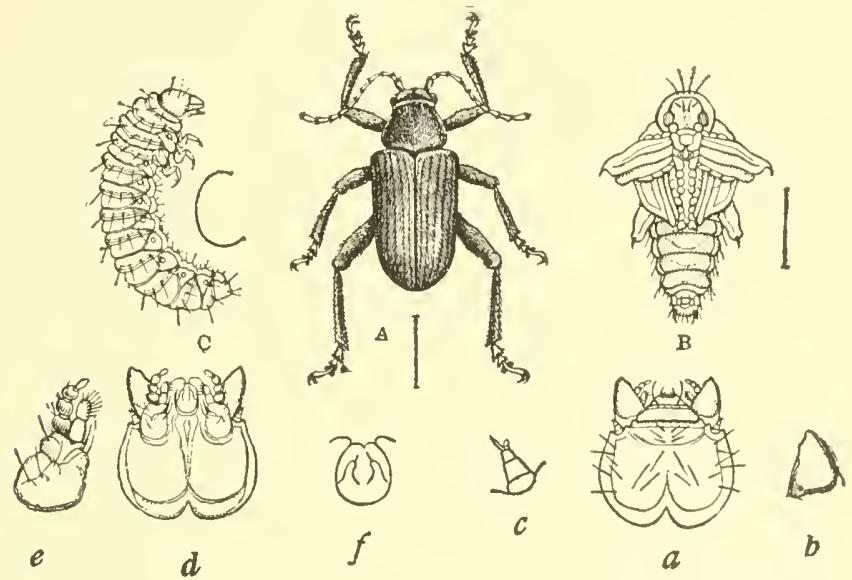

Grape-root-worm, Fidia viticida.-A, adult; $B$, pupa; $C$, larva; the other letters refer to details of larval structure.

adults when they are noticed feeding upon the foliage. Using commercial fertilizers instead of barn-yard manure is also to be recommended.

Perhaps the best-known species of this family is the "potatobug," or "potato-beetle," or " ro-lined bectle," or " Colorado potato-beetle," Doryphora ro-lincata. No description of this insect is necessary, the figures serving to illustrate all its stages sufficiently well. The insects winter underground as adults or pupe, and the beetles emerge early in spring, attacking the young plants as soon as they show above ground, and laying eggs for the livid-reddish larva. About midsummer these have matured a second brood of beetles, and a second brood of larvæ 
follows shortly thereafter, resulting in a fall supply of beetles, which, as a rule, hibernate. Sonetimes a third partial brood of larva reaches the pupal state, and hibernates in that condition. The arsenites are well-known and approved remedies, used at the rate of one pound in from seventy-five to one hundred gallons of water, and several machines especially intended for spraying potato-fields are on the market. The insect maintains itself unchecked, because, while active war is waged against the first

Fig. 206.
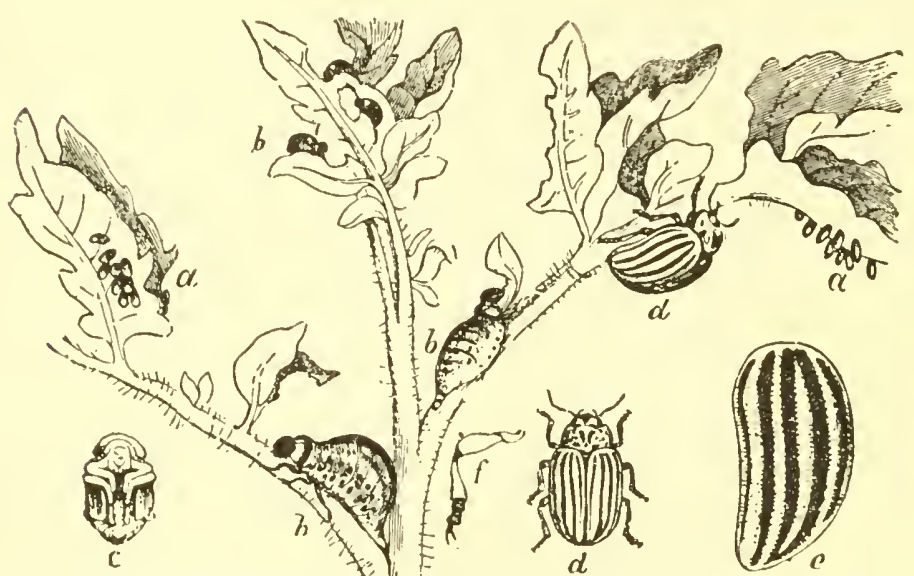

The Colorado potato-beetle, Doryphor $a$ ro-lineat $a,-a, a$, egg patches; $b, b, b$, larve in different stages of growth ; $c$, pupa; $d$, beetle; $e$, its elytra enlarged.

brood, little attention is paid to the second, and this is usually allowed to mature and provide for a new crop the year following. Spraying should be done first as soon as the beetles begin feeding, to prevent oviposition if possible; it should be done a second time when larva appear generally, and it should be done as often thereafter as beetles or larva are noticed infesting the plants.

The species of Diabrotica are rather slender, with long antemax ; of a green or yellow color, with black spots or stripes. The adults feed on leaves, flowers, or pollen, but the larva, which are white and slender, usually feed in the roots or stems of plants. One of our most common forms, D. vittata, is known as "the striped cucumber-beetle," and is yellow with black stripes on the 
wing-covers. It feeds on all kinds of cucurbit vines, and on many other plants as well, doing injury by eating into the stem of the young shoots at or below the surface, where it has a tendency to hide during the middle of the day. The larvæ live in the main roots underground, making short galleries, which, if numerous, weaken or even kill the plant. The beetles winter as adults. A free use of tobacco dust around young vines or other injured plants is usually protective, though in some localities the farmers resort to "driving." They do this before the middle of the day, sowing air-slacked lime with the wind, and this seems to be sufficiently offensive to the insects to induce them to leave for fields to the leeward, where they, of course, become doubly injurious unless also driven off. Planting an excess of seed to distribute the injury is a common practice, and so is starting the plants in baskets and setting them out when well established and able to resist injury. Melon and other cucurbit vines should always be plowed out, raked up, and destroyed as soon as possible after the crop is off, to destroy any larvæ that may be then in the roots.

An allied and equally common species, feeding as an adult upon a great variety of plants, is the D. I2-punctata, or "I2spotted Diabrotica." This is somewhat larger than the preceding, with a more oval body, and has twelve black spots on the greenish-yellow wing-covers. The larva feeds on the roots of a variety of plants and becomes injurious to corn in the Southern States. There are two broods, and the beetles winter in the adult stage. No direct remedy is known, but good cultivation and a liberal application of stimulating fertilizers is advisable to enable the corn-plant to resist and outgrow attack. Clean culture is the greatest essential, and this of itself will do much to reduce injury.

The "corn-root Diabroticil" of the Western and Central States is of a uniform, pale-green color, named D. longicomis, from its long antennæ, and its larva has proved a serious pest to corn. The complete life history of the insect is known, and as it winters in the egg state in corn-fields, simple rotation is all that is necessary to destroy the species. It can never become injurious unless corn follows corn year after year, and even a single year without corn serves to completely rid a field of the pest. 
FIG. 209.

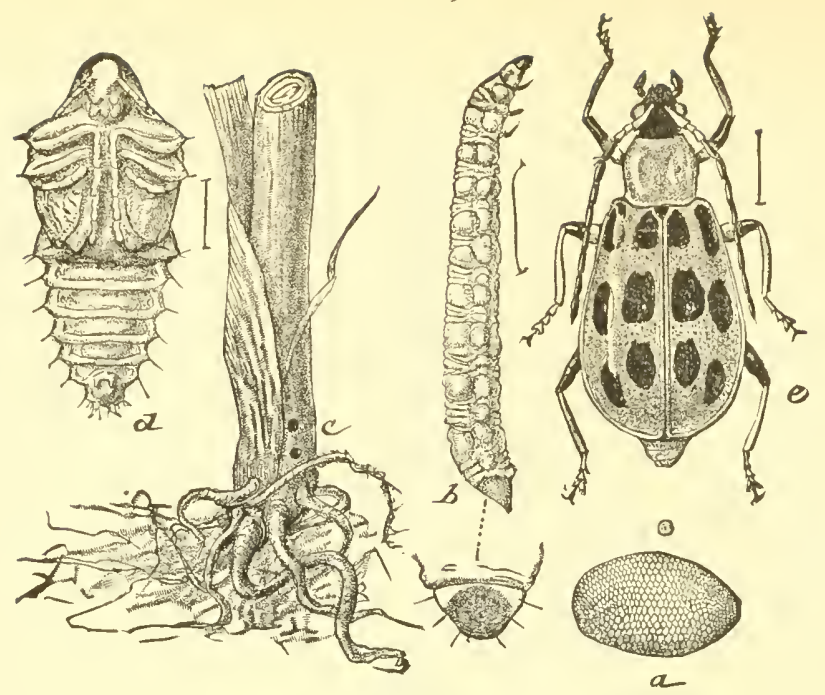

FIG. 210.
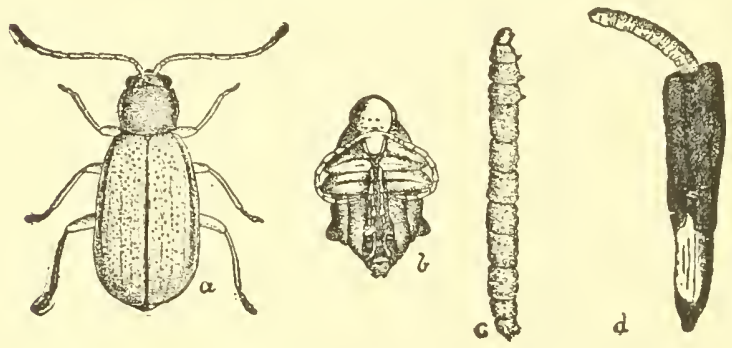

FIG. 2II. FIG. 207.
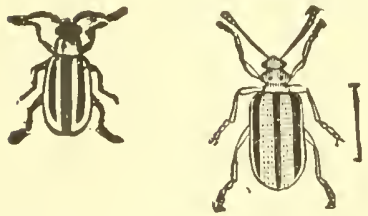

FIG. 2 I 2.

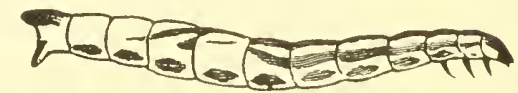

FIG. 208.

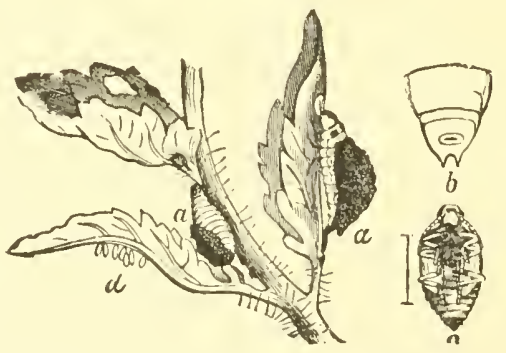

Fig. 207, Lema trilineata. Fig. 208, $a, a$, larve; $c$, pupa; d, eggs of Lema tritineata. Fig. 209, Diabrotica r2-punctata: $a$, egg; $b$, larva; $c$, injury in corn-stalk; $a$, pupa; $e$, beetle. Fig. 210 , Diabrotica longicomis: $a$, adult; $b$, pupa; $c$, larva; $d$, same in its case, Fig. 2II, Diabrotica vittala. Fig. 212, larva of same. Fig. 213, its pupa. 
The genus Galeruca contains a series of rather small, oblong species, mostly dirty clay-yellow in color, and more or less black marked or spotted. Of these none is more troublesome than the "elm-leaf beetle," Galeruca xanthomelana, which is another of our undesirable importations from Europe. It is rather greenish yellow when fresh, with two black stripes on the wing-covers. It hibernates as a beetle wherever it can find shelter, and attacks the leaves of elms in spring as soon as they are well grown, eating irregular round holes, so they soon look as if loads of shot had been fired through them in every direction. The yellow, bottle-shaped eggs are laid in double rows on the under sides of the leaves, and from them hatch the yellow, black-spotted larvæ, covered with little bristly tufts of hair. In the northern part of its range, including the red shale of New Jersey, a single brood is normal, but south of this, and including an extension into Long Island, the insect has two broods annually, and at Washington or further south may have three or even more. As against these insects the arsenites are effective, and the trees should be sprayed, preferably with the arsenate of lead, just as soon as the beetles begin feeding. The object is to destroy as many of the hibernating forms as possible, and to prevent egglaying in large part. A second spraying should be given when the eggs begin hatching, to destroy the young larvæ, and in serious cases a third spraying a week or ten days thereafter will be beneficial. When the larva are fuli grown they descend the trunk to the ground, where they change to bright-yellow pupæ among the grass or rubbish on the surface. Here they may be destroyed by hot water, kerosene, strong soap-suds, lime, or other suitable substances, and the second brood, where such occurs, may thus be materially lessened. Where there are two broods or more, repeated sprayings will be necessary, extending throughout the summer. If these methods are generally adopted the insect can be satisfactorily controlled. Protecting a few trees only among many that are neglected will always be difficult and can be at best only partly successful.*

* For detailed information concerning the treatment of trees in cities or towns, or on a large scale, the publications of the United States Department of Agriculture and of the New Jersey Experiment Station should be consulted. 

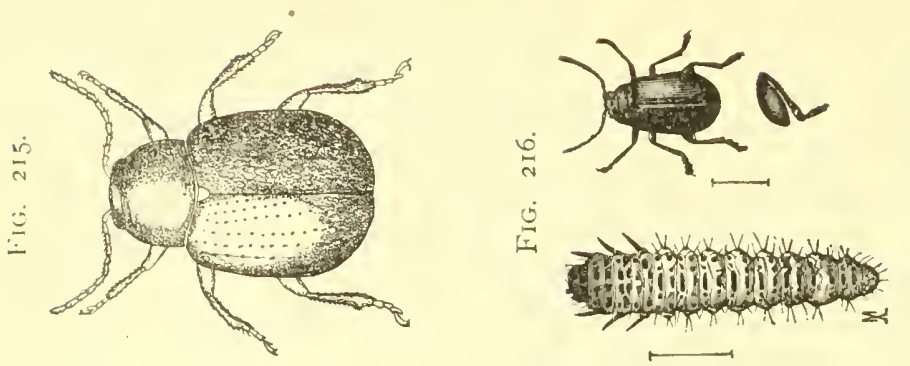

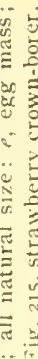

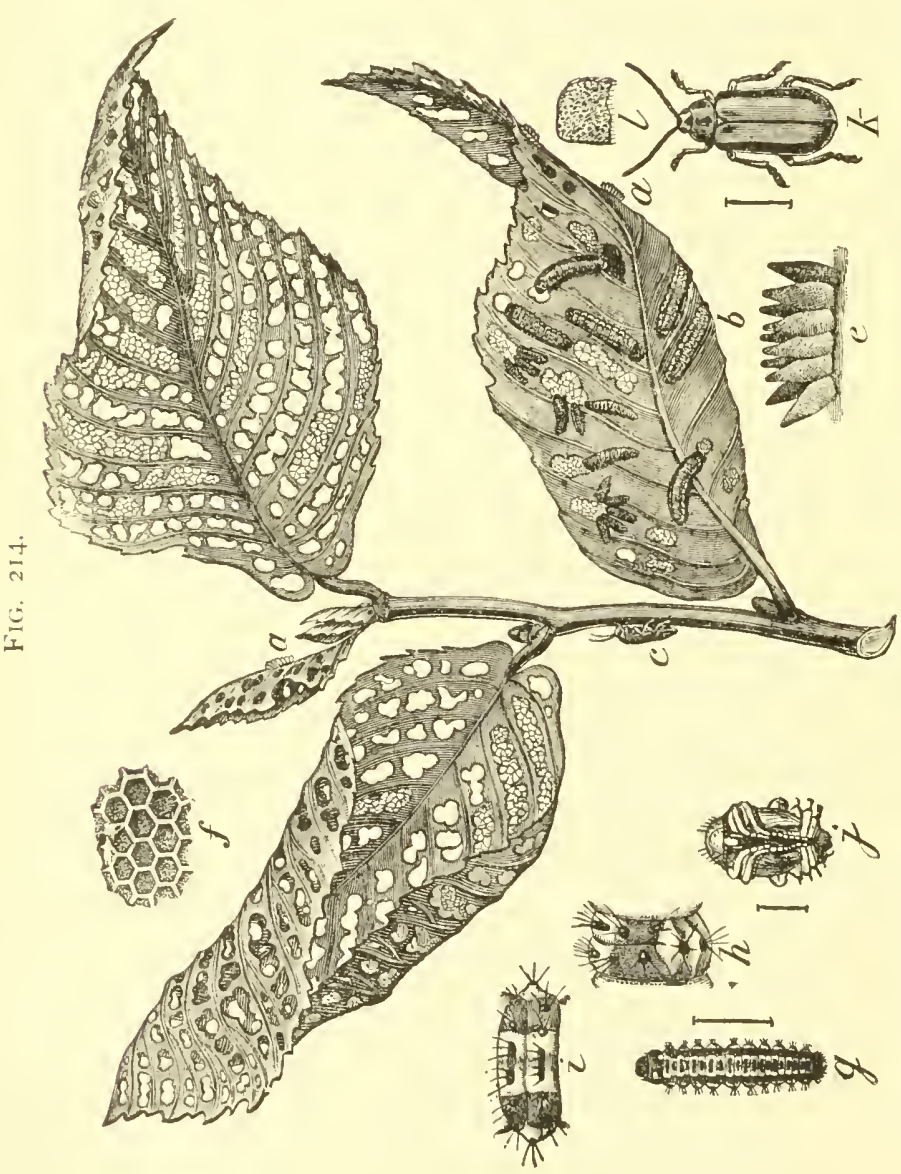

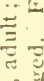

$=$

$\therefore \frac{\approx}{\pi} \bar{\nu}$

$\Xi \equiv$

…

$4 \pm \sqrt{2}$

$\div$

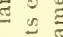

$0 \%$ का

... 5

\& 8

¿

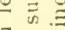

프

ư. $\ddot{\nu} \cong$

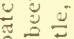

or

of …

$=\frac{2}{3}$

$\therefore \div$

$\therefore$.

$\approx \cong$

츤

$\approx \div$ 겅

$\approx$

跣

¿

$\approx \approx-1$

$\Sigma=b$

< $\leq 1$

$\pm \pm$

$\$$ or

$\approx$ bo

¿

E்

क 5

से

bo

a क 
Distinct from all the forms hitherto mentioned are the "flea. beetles," so called because of their greatly enlarged hind femora, giving them the power of making sudden leaps ending in flight. IVe have many species, and some of them are decidedly injurious and troublesome to deal with.

The grape flea-beetle is a well-known species called Haltica chalybea, from its steel-blue color, and it feeds both as adult and larva on the leaves of the grape. The larve are blackish and slender, slug-like and somewhat viscid, feeding in company during a great part of their growth. They are easily controlled by any stomach poison, and the Bordeaux mixture, applied as a fungicide, seems to be effective in keeping them in check.

The genera Crepidodera and Epitrix contain a number of small species, among which the "cucumber flea-beetle," or "potato-flea," Epitrix cucumeris, easily ranks first. As a small black beetle, it eats little round holes into the leaves of potato, tomato, egg-plant, and a variety of other solanaceous plants, as well as into those of melon, cucumber, and other cucurbitaceous vines. Potatoes seem rather the favorite food, and where the beetles and their little holes are numerous the leaves turn brown and die, checking the growth of the plant, and hence of the crop. The larvæ are leaf- and stem-miners, but do little or no damage. Usually Paris-green and London-purple are satisfactory remedies, and it has been observed that the Bordeaux mixture acts as a deterrent when liberally used, serving thus the double purpose of checking insect injury and plant disease. Tobacco is also a very satisfactory material used as a decoction, but is scarcely economical except on a small scale or in gardens.

The "sweet-potato flea," Chatocnema confinis, is an interesting, if troublesome, small, bronzed beetle, attacking the leaves of the young plants just after they have been set out, and eating little channels along the veins, finally making the net-work so complete that the leaves shrivel and dry. If the vines get a fair start, they outgrow the injury very rapidly, but cold, wet weather. by retarding growth, sometimes enables the insects to kill them. Dipping the plants before they are set out in the arsenate of lead mixture, at the rate of fifteen ounces to fifty gallons of water, will prove a satisfactory protection without danger of injury to the 

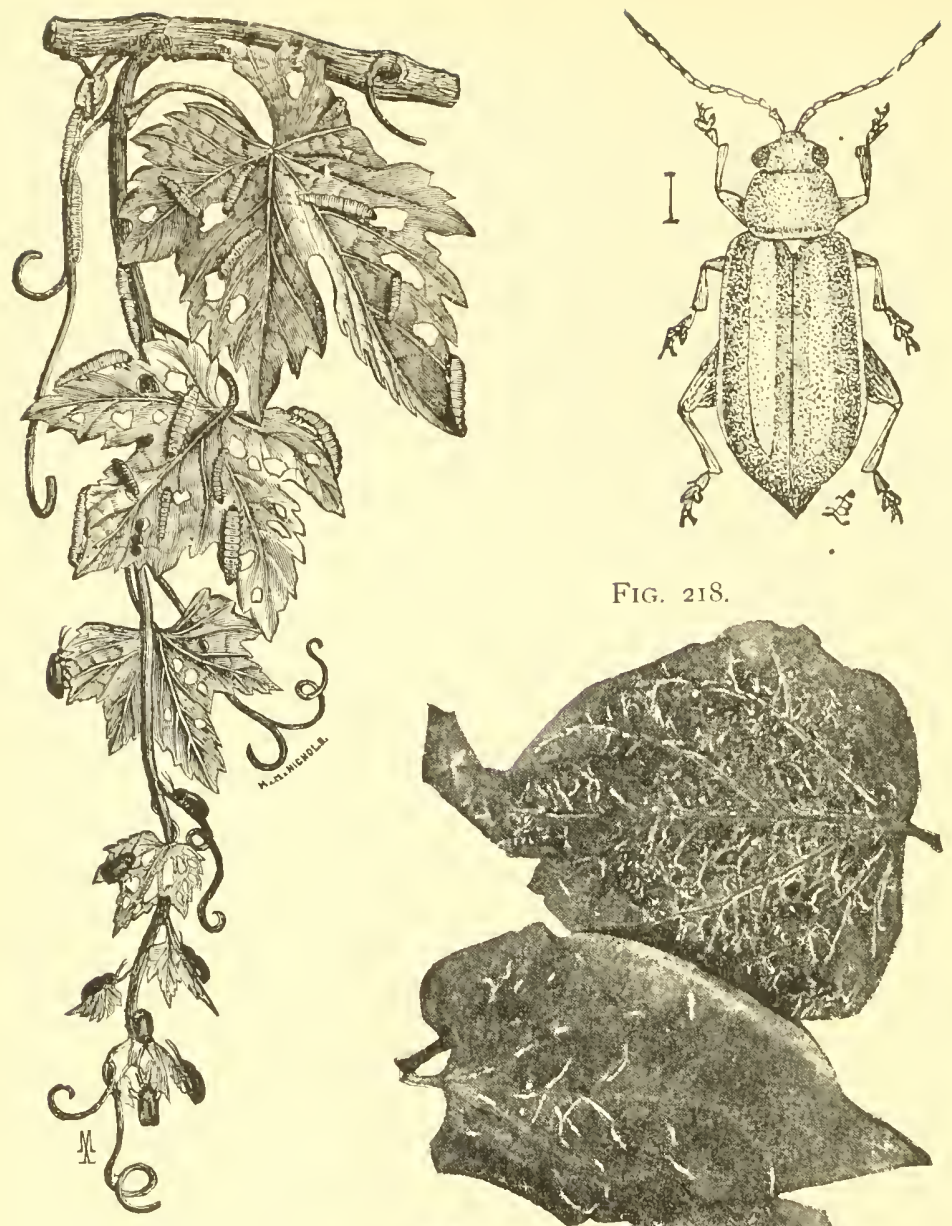

FIG. 218.

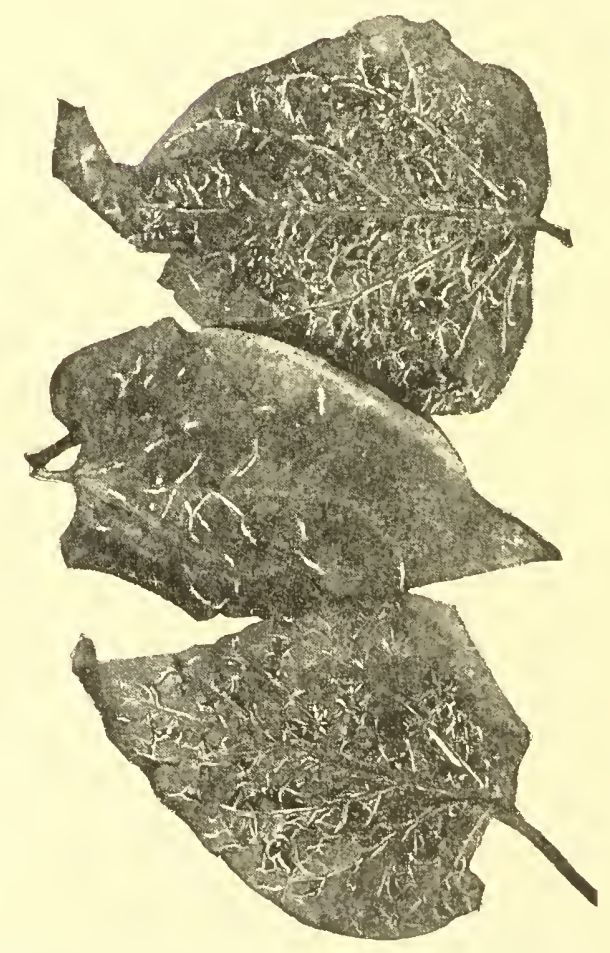

Pig 218 , work of the sweet-potato flea on the leaves. Fig. 219, pale-striped flea-beetle, Systena blanda. Fig. 220. the rosy Hispa, Odontota rosea. 
plants. Or they may be thoroughly sprayed with the Bordeaux mixture immediately after being set out.

Of somewhat larger size and more slender, graceful form are the species of Systena, and of these, S. blanda, the "pale-striped flea-beetle," has become best known by reason of its injury on a great variety of plants, inciuling sugar-beets. As with the other "fleas" it is injurious in the beetle stage only, and, as a rule, in early summer on young plants. I have seen it ruin an entire field of carrots, and have found it on melons, potatoes, beets, and pig-iveed in equal abundance. Its life history has not been published, but its larva is said to feed upon corn-roots. This is certainly not universally true, and its native food-plant in the early stages remains to be ascertained. As with other leaf-feeding forms, we are referred to the arsenites, or, as a means of protection only, to air-slacked lime, which will drive the beetles to wild plants, leaving the lime-dusted crop free.

In the genus Phyllotreta we find another series of small species not exceeding one-eighth of an inch in length, ordinarily black in color, with yellow stripes or spots on the wing-covers. The FIG. 221. most common species in the East is the "wavy-striped fleabeetle," $P$. vittata, in which there is a distinct yellow stripe through the middle of each elytron. The adults feed upon the leaves of cabbage, radish, mustard, and others of the cruciferæ, while the larve live as miners in the tissues of the same plants. In dealing with this species the important points are clean culture and keeping down all cruciferous weeds. If in addi-

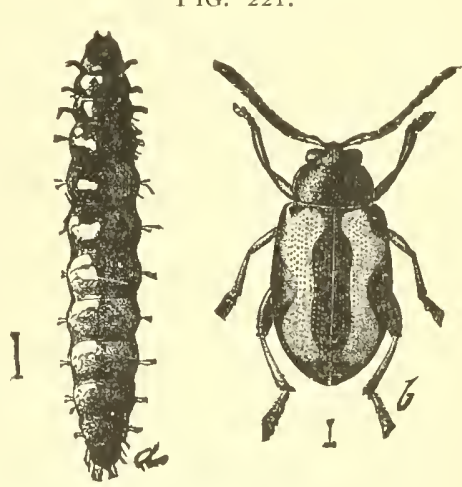

Striped flea-beetle, Phullotela villata... $a$, latva; $b$, aclult.

tion all crop remnants are promptly gathered and destroyed, no serious danger need be apprehended.

Following the flea-beetles is a series of very curious, somiewhat wedge-shaped insects, the Hispide, in which the antennce are thickened, and the elytra, or wing-cosers, broaden to the tip, 
where they are rather abruptly terminated. The larve are leafminers, and perhaps the most common species is the Odontota dorsalis, or locust-beetle, which occurs abundantly on the leaves in carly summer, and is orange in color, with a broad black stripe on the centre of each elytron. The eggs are covered with a little mass of excrement, and are laid singly, few leaves containing more than two or three. Not much real injury is done by any of the species, and the suggestion that the adults feed exposed and succumb readily to the arsenites is all that is necessiry on the subject of remedies.

The atult Cassida are called "tortoise-beetles," or, by the sweet-potato grower, "golden bugs." They are characterized by their broad, almost quadrate form, flat uncter and convex upper side, and by the more or less metallic-yellow or golden. color of the elytrit and upper surface generally. Most of the species feed upon Concoloulus, to which natural family the sweet-

Fig. 222 .

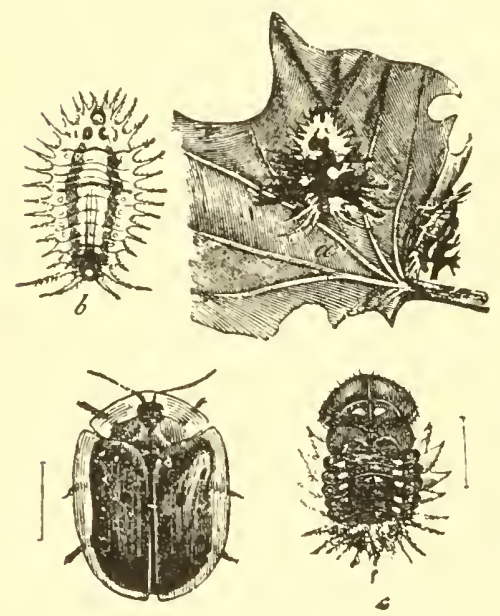

Coptocyla aurichaliea, - a, larve, or peddlers, with their packs; $b$, larva with pack removed; $c$, pupa. potato belongs, and the latter is about the only eultivated erop suffering from the attacks of insects of this series. The beetles hibernate and appear in the sweetpotato fields as soon as the crop is set out, eating irregular holes in the leaves, and laying their eggs, encased in a mass of excrement, on the under surface. The larve are known as "peddlers," because they have piled upon a pair of anal forks all the cast skins and a part of their excrement, forming a sort of shelter, umbrella. or "pack," to which latter resemblance they owe the common name. The most abunciant form is the Cassida bivittata, or "two-striped tortoise-beetle," so named from the two black stripes on each wing-cover. Following closety is the Coptocycla 
aurichalcea, so named because of its resemblance to a drop of molten gold. The injury is done by these species just after the plants are set out and before they get a start. Where the season is unfavorable to rapid growth, some plants may be killed, but under ordinary conditions they are soon out of danger. Good practice is to set only large, well-developed plants, or to dip everything before setting out in the arsenate of lead mixture recommended against the flea-beetles. Finally, it has been found that chickens are fond of the insects in all stages, and by turning loose a sufficient number in the fields after the plants have been set out practical exemption is secured.

The bean-and pea-weevils constitute a little family by themselves under the term Bruchida. They agree with the leafbeetles in general structure, but have a small head, prolonged into a blunt snout, a very obese abdomen, exposed at the tip by the short, square wing-covers, and much enlarged hind legs, which are not used for leaping. They are ahways small and usually more or less ashen-gray in color, covered with whitish hair or scales, which form variably evident markings on

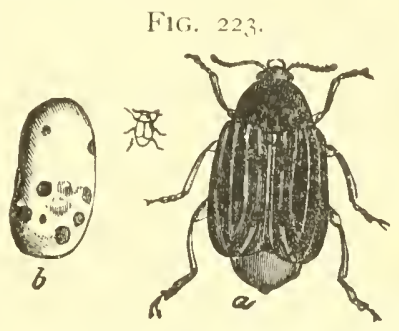

Bean-weevil, Bruchus fabc, much enlarged; $b$, an infested bean. the wing-covers. The beetles are often found in dried seeds of leguminous plants,_peas, beans, lentils, or the like, -and are sometimes seriously injurious in the stored product, lessening also or destroying the germinating power. The beetles come out normally in the spring, and after pairing the females lay their eggs in the young pods of the plants affected by them. The larvæ work their way into the forming seed and grow very slowy, the species varying somewhat in the details of their life history. Our only method of controlling the insects is in the stored product, or seed, and here by means of bisulphide of carbon we can kill larvæ as well as adult beetles, in any moderately tight receptacle. The rule should be, gather the entire crop and allow nothing to remain in the field; plant only sound seed, and never under any circumstances throw away "weevilly" peas, beans, lentils, etc. They should always be burnt, or otherwise 
completely destroyerl. Wild as well as cultivated plants are infested, though we do not know that insects infesting our garden varieties are carried over by other wild species.

FIG. 224.

\section{Sid}
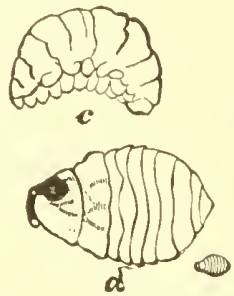
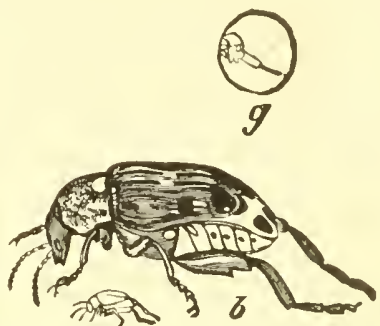

Pea-weevil, Rruchus pisi.-c, larva; $d$, pupa; $b$, adult ; all enlarged.

We now reach the series Hctcromera, or beetles in which the fore and middle tarsi have five joints, while the posterior are four-jointed only. We have rather a large number of families, many with a few species only, and as a whole they are feeders in or on decaying or dry vegetable tissue, whether herbaceous, woody, or fungoid in character. There are exceptions, of course, but that is the rule.

The Tencbrionida, or "darkling-beetles," contain species ranging from quite small to very large, found under all sorts of

IIG. 225.

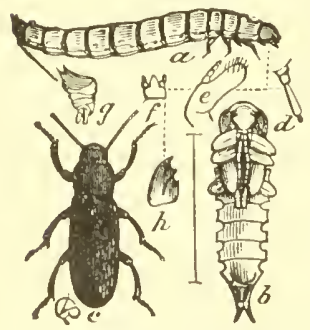

The meal-worm, Tencbrio molitor. $-a$, larva ; $b$, pupa: $c$, adult ; $d$ to $h$, structural cletails. with a square thorax and deeply ridged wing-covers. The larve are known as "meal-worms," and feed upon grain or meal remnants in barn, stable, or other sheltered bark of trees, on fungi, or under stones, among dry vegetable matter. There is no uniformity in appearance, but in most instances the antenne are more or less moniliform, or bead-like. The majority of our species are Western, occurring in their greatest variety in the Rocky Mountain region, but none, so far as I know, trouble green vegetation. The typical genus Tencbrio contains black or brownish, somewhat flattened species, conditions, but most frequently beneath 
spots. They are often bred by bird-fanciers in large numbers, and only need plenty of food to multiply rapidly. They rarely do serious injury, but are not pleasant to have around, and may be easily controlled by cleanliness, supplemented in extreme cases with bisulphide of carbon. A few other small, brown forms, among which the species of Tribolium may be mentioned, occur under like circumstances, but are amenable to the same treatment.

FIG. 226.

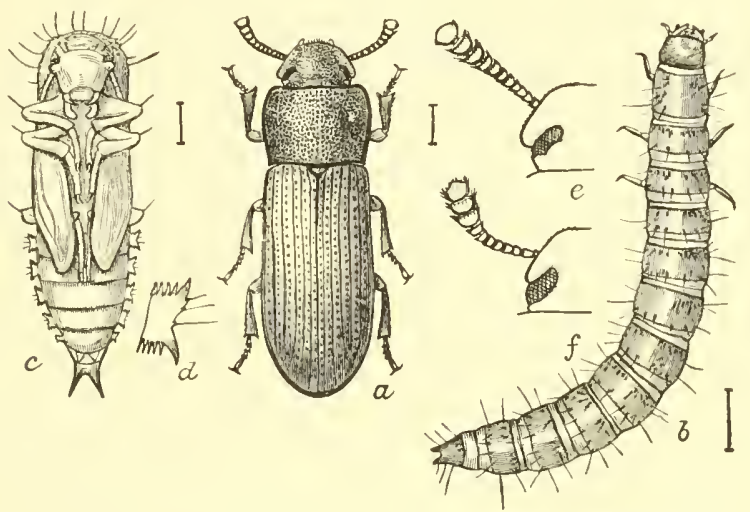

Tribolium confusum. $-a$, adult ; $b$, larva ; $c$, pupa : $e$, head, with antenna ; $f$, same of T. fentugineum.

Perhaps the most interesting, and economically the most important of this series, are the "blister-beetles," or Mcloida. The name "blister-beetles" is from a peculiar property possessed by them of raising blisters on the human skin. This is due to a substance called "cantharidin," found in the juices of all the species to a greater or less extent. The species generally used in medicine comes from Spain, hence the insects are also known as "Spanish flies." The beetles are rather soft-bodied, with broad heads, the antennæ often knotted in the males, the thorax narrow and cylindrical, the wing-covers extending well down the sides. Some of the species are brightly colored and banded, occasionaliy metallic bronze or coppery, and all of them are leaffeeders. Among the common eastern species several attack potatoes, and of these a yellow and black-striped form, Epicauta vittata, is known as the "old-fashioned potato-bug." Asters 
Fici. 227.

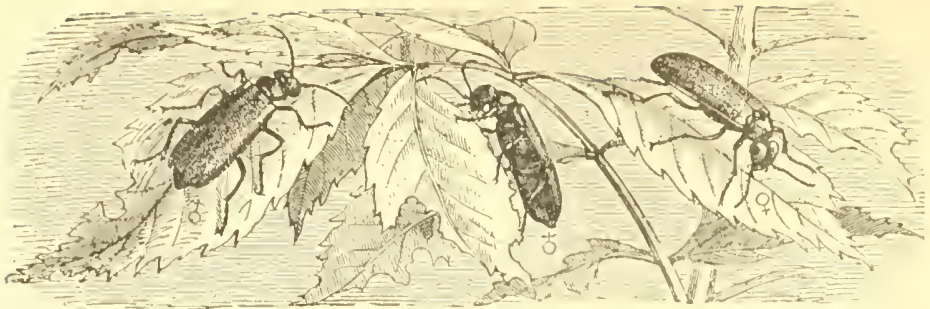

Fici. 22 S

I"I (i. 220
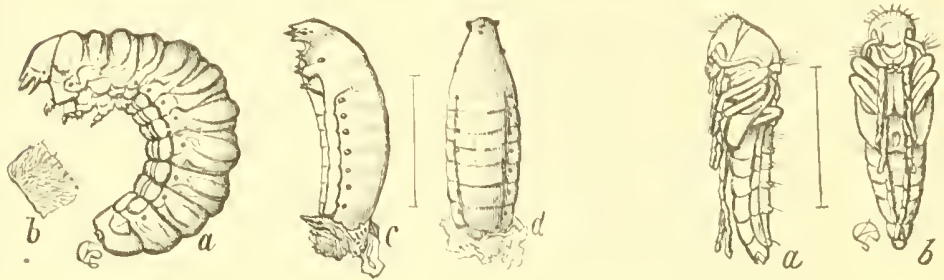

Fici. 230 .

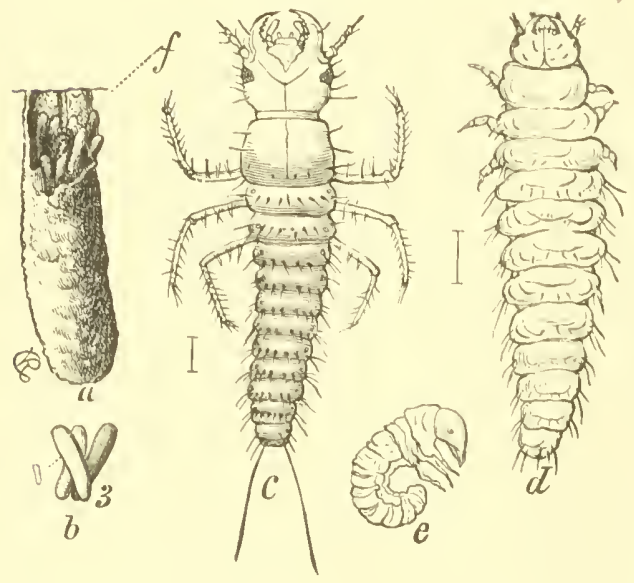

liig. 231 .

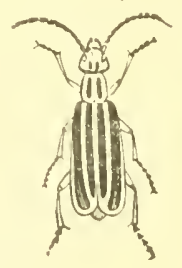

liki 232.
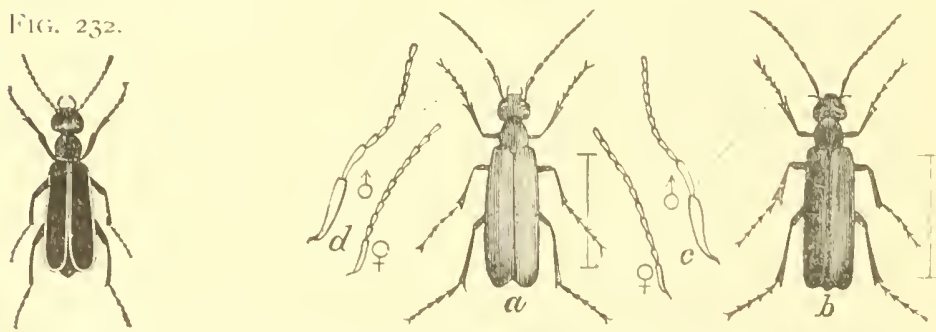

Meloidie, or "hlister-beetles."-Fig. 227. Spanish fly, Lvtla vesicatoria. Fig. 22S, Fpicauta rittata: $a$, second larva: $c, d$, coarctata larva, irom back and side. Fig. 220. $a$ and $b$, true pupa of same, from side and front. Fig. $230, a$, grasshopper egg-pod; $b$. a few eggs from same : $c$, triungulin; $d$, carabidoid larva $c$, scarabidoid larva. Fig. 231 adult Fpicauta zittata. Fig. 232 , Epicaula cinerea. Fig. $2 \hat{3} 3$, a, Macrobasis unicolor; b, Epicauta pennsylvanica. 
and other flowers are injured by a black species with graly-edgecl elytra, Fpicauta cincrea, and among fickl-crops beets are, after potatoes, the chief sufferers. The beetles appear quite suddenly in large numbers, and some species disappear almost as quickly, while others linger several days. A uniformly black form, Iipicauta pennsylianica, is often found in considerable numbers on the flowers of the golden-rod in August and September, while a uniformly gray species, Macrobasis unicolor, is common on the false indigo.

The life history is interesting, and the species may be divided into two series, those living in the nests of burrowing bees and those living in grasshopper eggs. In the first series the eguss are laid on flowers, and from each hatches an active little creature with long legs, prominent jaws, and large head, which is known as a "triungulin." It rums about the flowers until the proper kind of bee comes along, gains a foothold on this, and, buried among the hairy clothing, allows itself to be transported to the bee nest. There it quits its unconscious host, makes its way into one of the completed cells, devours first the cag or young larva, and then completes its own transformations, feeding upon the stores now without another owner. This type is only indirectly of economic interest, but is rather injurious than otherwise.

In the second series the egg is laid either on a plant or on the ground, but in either case a trimgulin similar to that above described results, and this has the power of existing without food for several days, while hunting for a grasshopper egg-pod. When such a one is found its wanderings are over, and it begins feeding at once. When it moults its large head and long legs disappear, and it resembles a Carabid larva, with ovate body, small head and jaws, and short legs ; it is now in the "carabidoid" stage. Again it moults, and now the resemblance is to a small "white grub," for which reason this has been termed the "scarabidoid" stage. When all the grasshopper eggs are devoured, our larva is full grown, ccases feeding, and shrinks into its own hardened skin, forming a coarctate stage, or pseudopupa, in which it winters. In spring it cmerges from this covering, is active a short time without feeding, and then enters the true pupal stage, in which it resembles other Coleoptera. In 
this stage it remains until the proper conditions occur, and then joins its companions in a seemingly concerted movement to arise and assume the beetle stage. 'This uniformity of development explains the sudden appearance of the insects in large numbers, and their power to cause mischief is derived from it, since the farmer does not often realize the nature of the invasion until considerable injury has been done. In the larval stage they are beneficial, in so far as they feed upon the eggs of grasshoppers. but it is questionable whether this benefit overbalances the damage they do as aclults, and I never hesitate to advise prompt measures for their destruction. The best of these is a thorough application of one of the arsenites as soon as the insects appear, adding milk of lime to make the poison stick better and to discourage feeding. In small patches the beetles can be gathered in pans early in the day, or they may be driven to a layer of straw, the latter to be set on fire when the insects become entangled among it. The last is the least desirable of the measures, though under some circumstances rery effective. In all cases, promptness is essential.

"The Rhynchophora, or "snout-beetles," are separated into a number of families which need not be particularly described here, but all agree in having a more or less evidently produced beak or snout, at the end of which the small mouth parts are situated. The terms " curculios" and "weevils," in addition to that above given, are rather indiscriminately applied to species of this series. All the snout-beetles are vegetable feeders in both larval and adult stages, and, therefore, more or less injurious. Many of the larve are internal feeders, and, therefore, white or yellowish, usually with short, bristly hair, a brown head, and no feet. As a rule, they are somewhat curved and terminate rather bluntly, a little like "white grubs," but without the peculiar, large, terminal segment. It will be necessary to restrict our mention to the most troublesome forms, and the first of these, in systematic order, is "Fuller's rose-beetle," Aramigus fulleri.

This beetle, which has a short, obtuse snout, and is of a clark, smoky brown color, lays its eggs in little masses under any sort of shelter on rose-bushes, and the resulting white, grub-like lirve feed on the tender roots of the plants. The insect is, essentially, a green-house pest, and often weakens the plants, su 
as to render unprofitable if it does not kill them. The beetles are long-lived, and hide during the day on the under side of the leaves on which they feed. Hence, collecting and destroying them is the most satisfictory remedy, while the use of a tobacco extract on the ground will act both as a fertilizer and to destroy the subterranean larve.

The clover-leaf beetle, Phytonomus punctutus, is another quite large species, dull brown in color, with indefinitely striped wing-

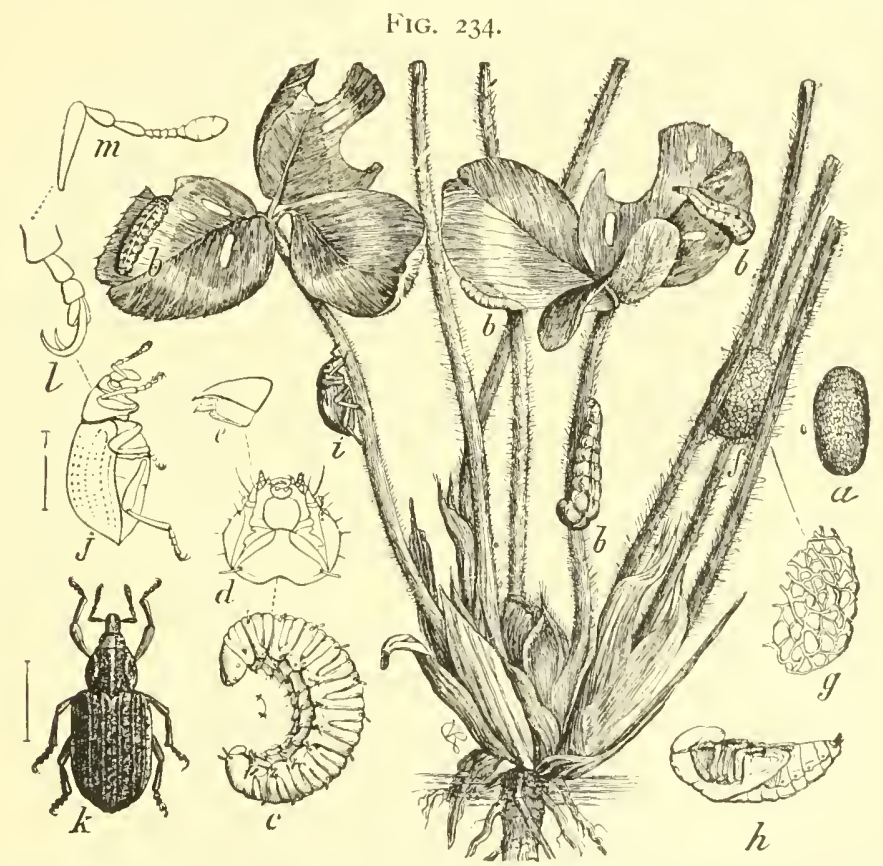

Clover-leaf beetle, Phytonomus punctatus, - $a$, egg ; $b, b$, larvie feeding; $c$, very yourg larva; $f$, cocoon, its net-like character shown at $g ; h, 1$ upa; $i$, heetle, on clover-stalk; $k$, same, enlarged; other letters refer lo structural details.

covers, and a short, stout beak. The larva is green, its form well shown in the figure, and it feeds chiefly at night, eating irregular holes in the leaves. When full grown it forms a peculiar net-like cocoon at or a little beneath the surface of the gromul and pupates, becoming adult a few days thereafter. The insects hibernate in the larval stage, and their injury becomes manifest 
quite early in the season, often threatening entire destruction of the crop when they are nearly full grown. Fortunately, nature hats provided a check for this insect in at fingons clisease which in most localities carries off the larre annually, just Fik. 235. before they mature, leaving only a comparatively

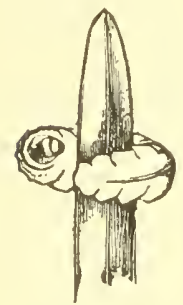

1) is a a e d larva of cloverleai beetle. small proportion w perpetuate the species. As this disease seems to occur in seasons of all kinds, and irrespective of climatic conditions, it can be easily introduced into any locality in which the insects become destructive. Affected larve curl themselves round a spear of grass or on the edge of a leaf and die, first swelling somewhat and becoming gray in color; then they collapse and become black, eventually forming a small, dried, black mass, utterly indistinguishable in character.

The "white-pine weevil," Pissodes strobi, is one of the most serious enemies to that tree, and in the more northern States attacks the leading shoots, in young trees spoiling their shape completely. The insect has been studied, and a full account

FIG. 236.
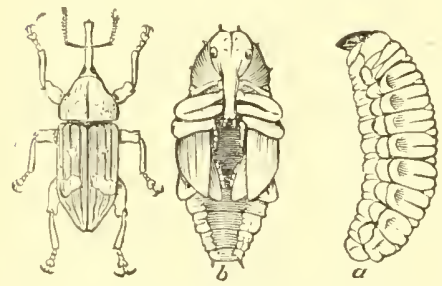

White-pine weevil, Pissodes strobi.-a, its larva; $b$, its pupa. is given in the Fifth Report of the United States Entomological Commission, dealing with forest insects, but no satisfactory remedial measures are proposed. In parks or gardens small ornamental trees can probably be protected by keeping the leading shoots sprayed during the spring with a carbolated soap-wash, to which Paris green has been added at the rate of one pound in one hundred and fifty gallons of water. Other infested shoots should be gathered and burnt. The report above cited is so full on the subject of forest insects belonging to this series that only those infesting cultivated crops need be cliscussed here.

Early in the season we find on the leaves and stems of rhubarb a rather long, cylindrical weevil, Limus concawus, with a short heavy snout, entirely covered by an easily rubbed off, rusty powder. It is also remarkable for its exceedingly firm texture, 
making it difficult to pierce with any ordinary pin. It bores little holes in the leaf and flower stems of the plant, laying an egg in each, from which hatches in due time a wlite, grub-like larva, which feedis in the plant tissue. Where the leaves are regularly cut for market, little trouble is experienced. All old leaves not needed by the plant should be removed and destroyed, so that after midsummer none of the early leaves should remain on the plants. If this practice is constantly carried out no injury need be apprehended. The natural food-plant is said to be dock.

In the genus Anthonomus small species predominate, and the colors are modest, but their powers of injury are by no means in proportion to their size. One of the most troublesome is the "strawberry-weevil,"
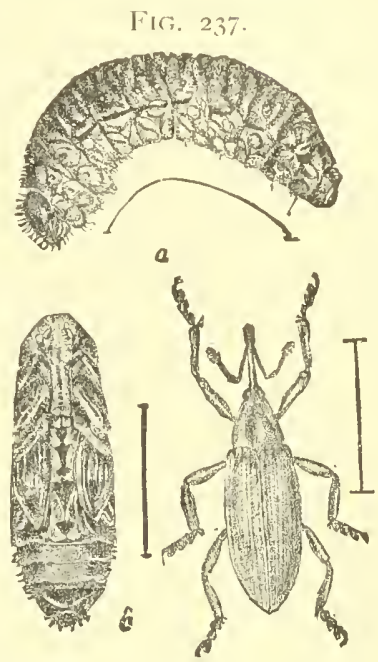

Rhubarb-beetle, Lixus concavns. $-a$, its larva; $b$, pupa. t. signatus, which appears as a small, blackish beetle, with gray pubescence, when the buds are developing, and lays an egg in each, afterward puncturing the flower-stalk below the bud so as to check development. The lirva feeds upon the pollen in the unopened bud, and finds it sufficient to attain its full growth, changing to a beetle in midsummer. The insect attacks a number of other flowers in the same way, not even confining itself to one natural family, and its injury to strawberries is of a somewhat intermittent character, becoming worse for a number of years, then stopping suddenly for no apparent reason. Only staminate, or pollen-bearing, varieties are attacked, and the Sharpless is, perhaps, the most seriously infested. By planting chiefly

Fig. $23 \mathrm{~S}$.

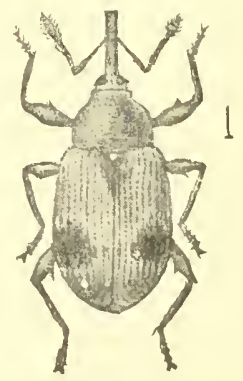

Strawberry-weevil. Anthonomus signatus. pistillate varieties, the staminate rows may be protected by cheap coverings until the buds are ready to open, and even if a small 
crop only is obtained on the pollenizers, the main crop will be safe without protection. Insecticicles have not proved markedly. useful in this case.

Other species of this genus have proved more or less troublesome, notably A. quadri-gibbus, on apple, but none of these

\section{FIG. 239.}

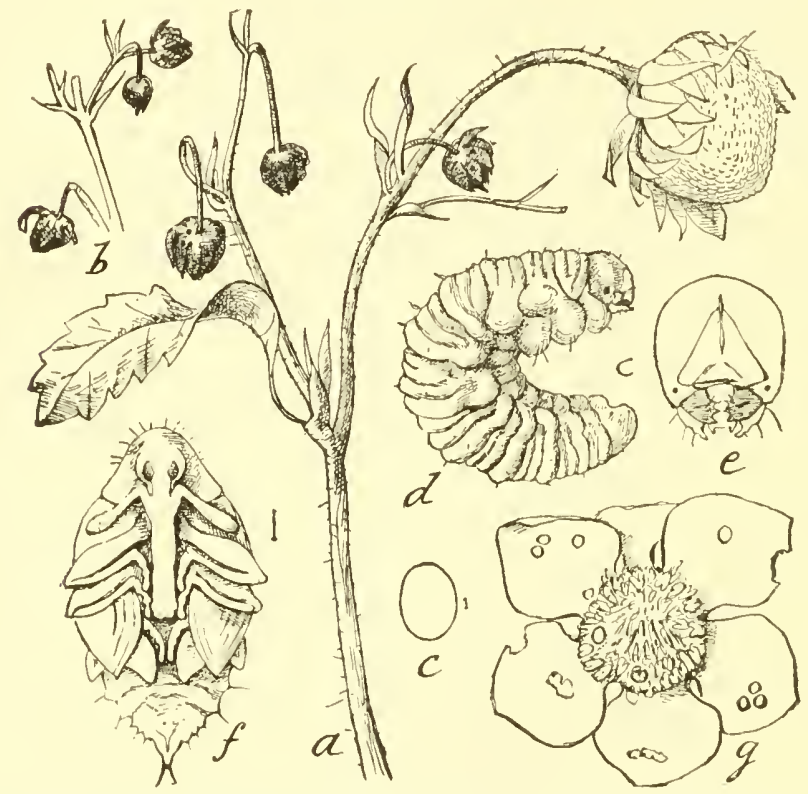

Work of the strawberry-weevil.-a, shoot of strawberry-plant bearing punctured buds, $b$; the egg at $c$; larva at $d$; pupa at $f$; at $g$ an open strawberry-flower showing the holes eaten by the leetles.

recuire more attention here, and the next species in order is Conotrachelus nemphar, the redumbtable "plum-curculio." Next to the "codling-moth," this is, perhaps, the most serious of the orchard pests, and it ranks above it in the difficulty attending its control. The beetle itself is less than one-fourth of an inch in length, chunky in appearance, brown, with black and gray mottlings, and with four elevated exerescences on the wingcovers. The beetle hibernates and appears in early spring, feeding first upon the unopened buds and afterwarl upon the young 
leaves of plum, peach, apricot, cherry, apple, and pear. When the fruit has set and become of the size of a marble, the insect makes a crescent-shaped slit, elevating a small flap from the surrounding tissue, and in this it lays an egg. The latter hatches in a few days, and the whitish, grub-like larva bores at once to the seed capsule, causing the fruit to fall from the tree and rot in the plum, peach, apricot, and cherry, though, except in the plum, this dropping is not universal. Apples and pears do not drop as a result of curculio injury, and, except in a few varieties of apples, the larva is unable to mature in the fruit remaining on the tree. In apples and pears that drop from other causes, the larva develops freely. By mid. summer, growth is complete, the larvæ leave the now decayed FiG. 240 .

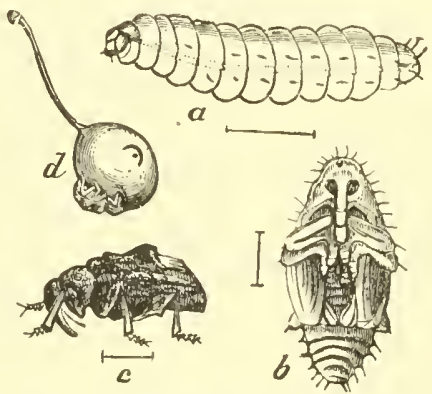

Plum-curculio, Conotrachelus nenuphar.- $a$, larva; $b$, puya; $c$, adult ; $d$, beetle at work on a young plum, slowing a crescent mark.

fruits and go underground to pupate, changing to the adult, or beetle, form a short time thereafter. These go into hiding almost immediately, and are not again seen until the spring following. Remedial measures in this case have not proved entirely satisfac tory. The larva is beyond reach of all insecticides, and can be destroyed only by persistent and thorough gathering of all fallen fruit at intervals of a few days throughout the early part of the summer. Chickens, turkeys, hogs, or sheep accomplish the same purpose less completely and lessen if they do not prevent injury. The beetles may be reached by spraying the trees before the buds open with one of the arsenites, destroying them before they have a chance to oviposit. Spraying may be continued after the fruit has set, to kill the beetle while eating out its crescesits. Some part of the fruit is always injured, though a sufficiently large percentage to pay for the insecticide application is usually saved. Jarring the trees every day or two over a sheet or other receptacle has been practised with good success, as the beetles drop readily and lie quietly for some time, especially early in the day, allowing themselves to be easily gathered 11 p and destroyed. 
This is one of those cases where persistent and unversal practice is desirable to obtain the best results.

An allied but larger species of the sanne genus without the elevations on the wing covers is C. crataegi, which attacks the quince and sometimes does conviclerable injury, much as the $C$. nenuphar does on the fruits abore enumerated. The same measures ane indicated here also.

The potato-stalk borer, Trichobaris 3-notata, is a small ashgray weevil about one-sixtl of an inch in length, with a black

Fig. 2.11.
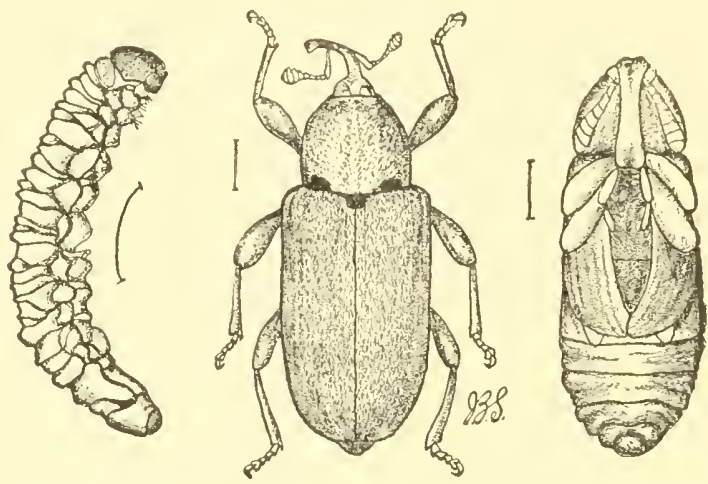

Potato-stalk borer, Trichobaris trinotata.-Larva, pupa, and adult.

snout and three small black spots at the base of the wing-covers. It lays its eggs into the stems and larger branches of the potato, horse-nettle, Jimpson-weed (Datura stramonium), and, perhaps. other Solanacex, and the white larva feed there until after midsummer, changing to pupe at about the time when the potatovines mature, and to adult beetles a short time thereafter. The beetles remain in their larval burrows during the winter, and may be easily destroyed by burning the vines immediately after the potatoes are harvested.

The species of Balanimus are known as nut-weevils, are of quite large size, clay-yellow in color, and with an exceedingly long and slender, black beak or snout. By means of this they puncture the burrs of young chestnuts, the husks of hickory and walnuts, and the green coverings of young acorns, reaching near the centre of the nut itself, and placing an egg in the hole so 
made. The larva hatches and the little wound through which the egg was laid heals so completely that no trace of it is visible

FIG. 2.12.

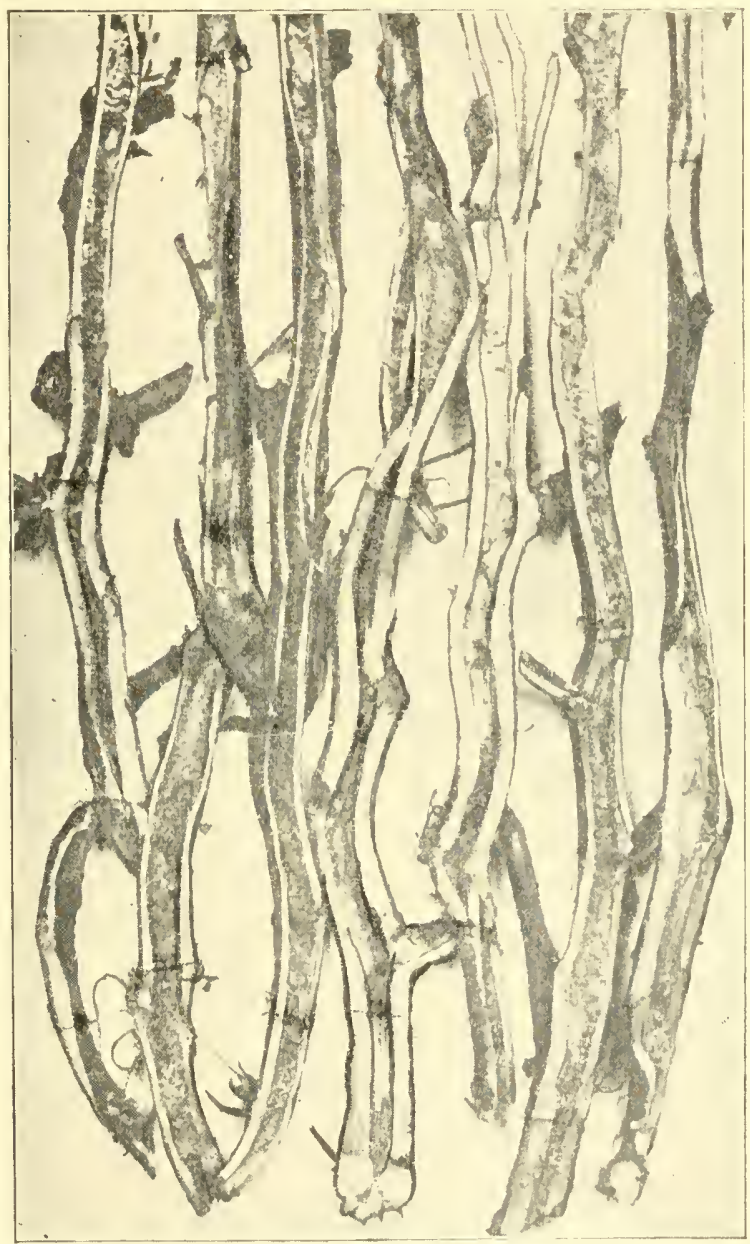

Work of the potato-stalk borer, Trichobaris 3 -notata, in potato-vines.

in the fully developed fruit. When the nut is ripe and drops to the ground the larva is full grown, and eats a round hole in the 
shell through which it makes its way and goes underground to pupate. Thus it winters, and the beetles emerge in spring when

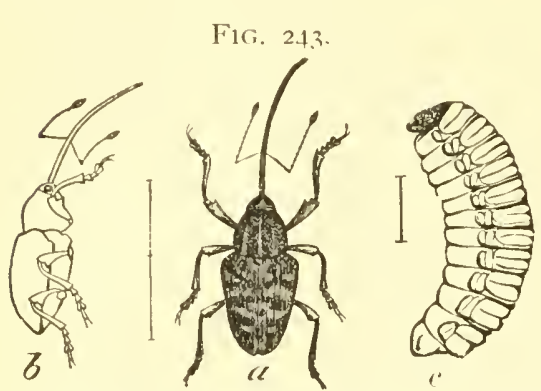

Chestnut-weevil, Bulaninus rectus. $-a$, from above; $b$, in outline, from side; $c$, larva. the nut-trees are in bloom. Considerable injury is sometimes caused in cultivated chestnut groves, and the only way to avoid it is to gather the nuts systematically as soon as they fall, and either ship them at once, or store them in tight boxes or barrels, from which the larve cannot escape when they come out. They will then be found at the bottom when the nuts are removed, and may be easily killed.

In many localities corn is attacked soon after it shows above ground by insects known as "corn bill-bugs." These belong to the genus Sphenophoms, and are black or brown, rarely gray in color, varying from one-fourth to half an inch in length, with very thick and hard wing-covers, which are ridged and punctured, as is also the thorax. They hide during the day in the soil at the base of the corn-plants, and kill them by boring little round holes in the stem. They are most frequent after timothy, especially on old sod, or when corn follows sedges or bulb-rooted grasses. It is in such places that the larvie live naturally, pupating in fall or early spring, and the beetles, finding on spring ploughed land that their natural food is gone, attack the corn, which replaces and is nearly enough like it to be to their taste. The period of injury is usually short, and by delaying replanting a little, the new shoots escape attack. Fall ploughing old timothy sod or sedge-land is always indicated, and will generally serve to reluce, if it does not entirely prevent, injury.

To this same series belongs the largest of our weevils, the Rhynchophorus palmarum, or "palm-weevil," which often exceeds an inch in length and whose fat, white larva, boring in palm, is said to be quite a delicacy to the taste of the aborigines of Central and South America.

Much resembling it in shape but hardly exceeding one-eighth 
of an inch in length are the grain weevils, belonging to the genus Calandra. These are almost cosmopolitan, and infest stored grains of all kinds. They are black or brown-red in color, quite slender, and on a very small scale resemble the " corn bill-bugs" in sculpture. They can be easily controlled by the use of bisulphide of carbon poured on the grain in bins or other receptacles,

F1G. 244 .
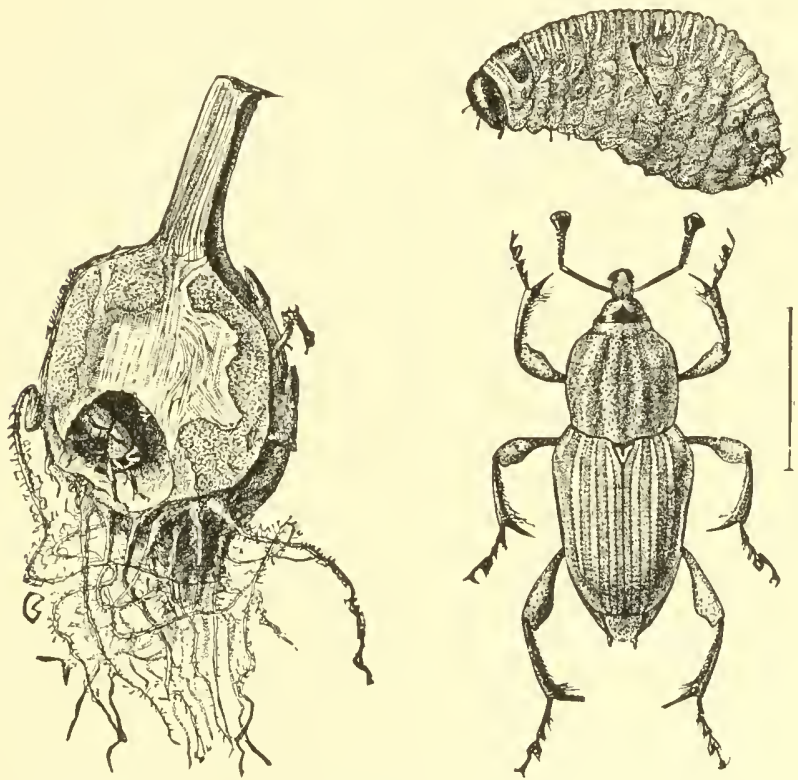

Sphenophorus ochreus.-Adult, larva, and work in roots of. Scirpus.

covering with canvas or similar material to prevent the too rapid escape of the fumes which gradually permeate the entire mass of grain, killing everything in it.

Closing the series we have the bark-beetles, or Scolytids, some of them called shot-hole borers from the little round holes with blackened edges which they make in wood and bark. Many species make prettily-figured burrows between the bark and sapwood, while others bore inte the solid wood, making longer or shorter galleries. Most of the species attack forest-trees, and for them reference should be had to Dr. Packard's work already cited. 
These beetles differ from all the other weevils in their cylinfrical form and very short snout, which is scarcely more than at slight prolongation of the head, and they are usually of small sizc, most of them not exceeding one-eighth of an inch in length.

$$
\text { Fis. } 245 .
$$

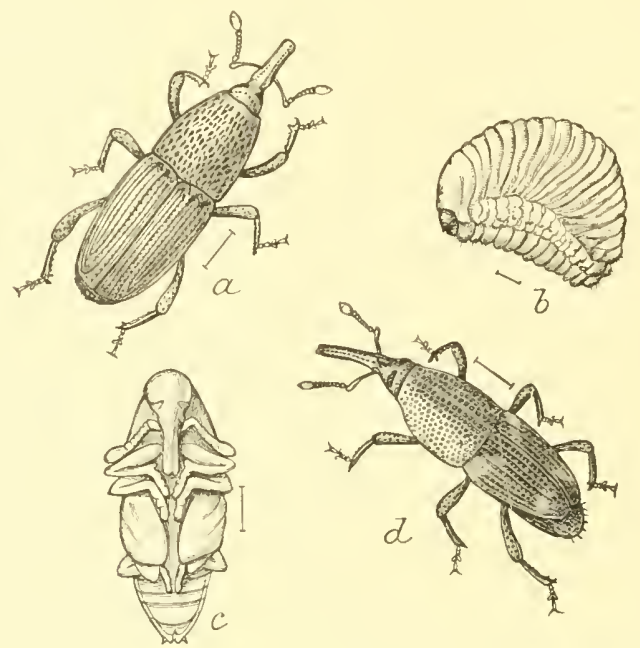

Calandra granaria.-a, adult ; $b$, larva ; $c$, pupa ; $d, c$. oryza, adult.

Scolytus mgulosus, the "fruit-bark beetle," is, perhaps, the best known, and certainly the most important economically, attacking deciduous fruit-trees of almost all kinds. The black parent beetles appear in early spring, and bore little round holes through the bark to the sap-wood. They then make a central burnow, on each side of which little notches are made to receive the soft white eggs. The larve hatch very soon, and at once begin to make little burrows of their own, diverging as they move from the parent channel, and gradually enlarging them as they increase in size. When full grown they form a slightly enlarged chamber, in which they pupate, and when they transform to beetles, make their way out through little round holes in the bark. The whole period of development does not exceed a month, and there may be several broods during the summer from the same tree, the numerous galleries eventually girdling and killing it. 
Fire, 247.

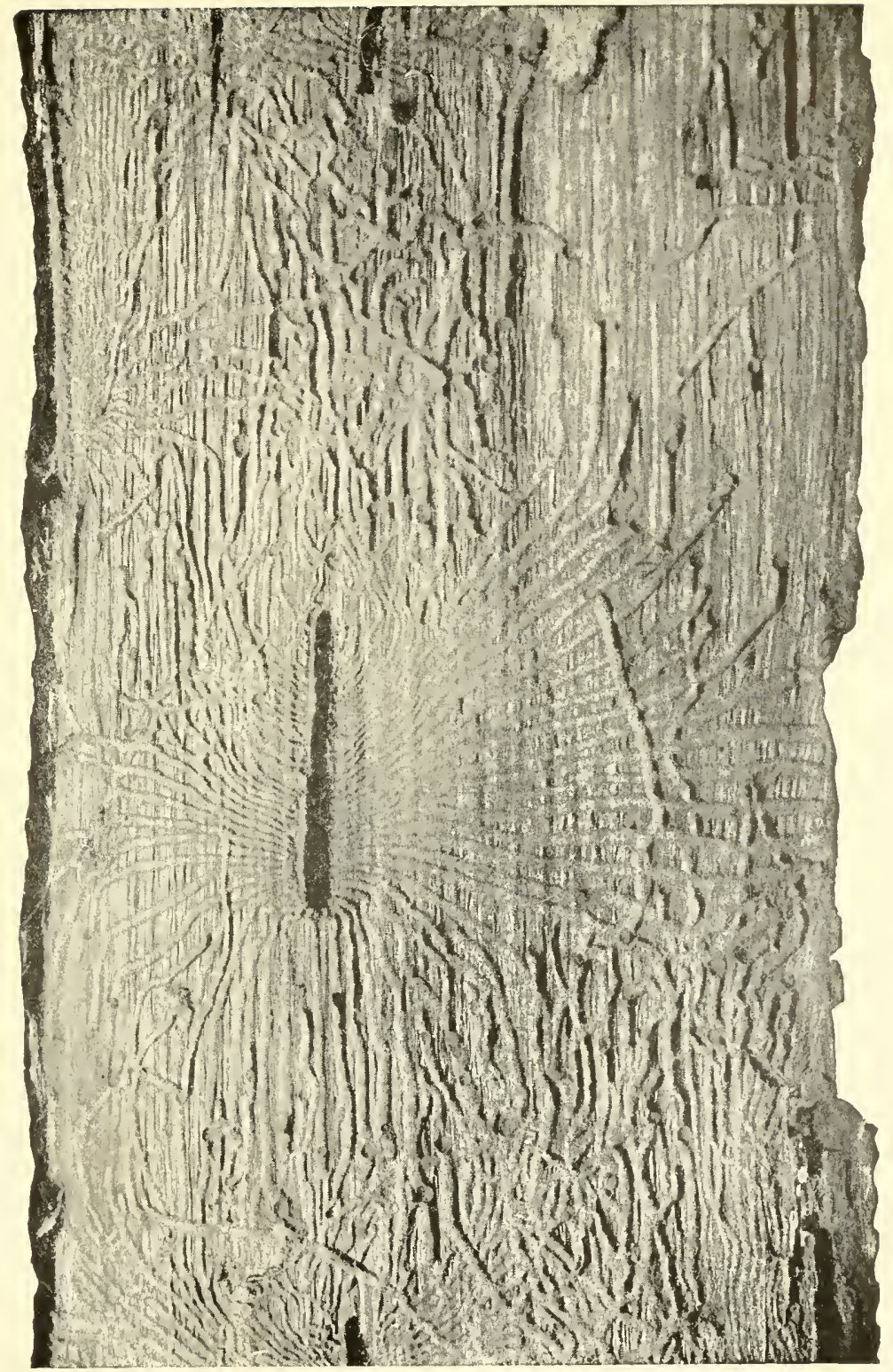

A piece of hickory bark, illustrating the work of Scolytus f-spmosus and its larva:

natural size. 
? 
These insects rarely attack sound, healthy trees, and this is at peculiarity of bark-beetles in general, though there are many exceptions. But just as soon as a tree becomes a little weakened through injury or from starvation, these little creatures attack it, and then its doom is sealed, unless vigorous measures are taken at once. Peach-trees are especially susceptible to injury, and the gummy oozings from the little holes seem to weaken them so rapidly that they succumb in a short time.

It is good practice to keep orchard trees in the best possible health and vigor at all times to enable them to resist naturally the attacks of these insects, but if one does become seriously infested it should be at once cut out and burnt. It is certain to die in a short time, and

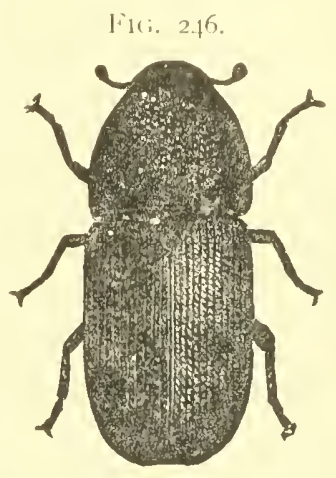

liruit-bark beelle, Solvtus rugulosus, much entarged. it is a constant menace to surrounding trees from the abundance of specimens which will be produced, ready to attack others at the least sign of weakness. Where a slight infestation is noticed on a tolerably healthy tree, it should be closely examined to ascertain the original source of weakness, and when this is removed the tree should be stimulated by means of appropriate fertilizers, and the trunk kept covered by whitewash to which Paris green has been added. Strong whale-oil soap-suds will answer the same purpose, and a little crude carbolic acid will add to its effectiveness. In all cases the application should be thorough, and should be kept intact until the tree has fully recovered and is able to take care of itself.

The same line of treatment is adlapted to other bark-beetles, varied according to the clifferences in life history.

To recapitulate in a general way, beetles and their larvæ are mandibulate and chew their food; therefore, whenever they feed openly upon plant tissues, they may be killed by arsenical sprays. Internal feeders must be dealt with as indicated by their life habits, but we must look rather to preventive than to remedial measures in such cases. 


\section{CHA PTER VII.}

THE LEPIDOPTERA.

\section{Butterflies and Moths.}

UNDER the term Lepidoptera are included those insects popularly known as butterflies and moths, in which the wings and body are more or less clothed with scales. These scales often differ greatly in form and size even in the same insect, and yet more in different yroups, so that a certain family or series may show types peculiar to it alone. Oddly enough, there is some-

FIG. 2.48.

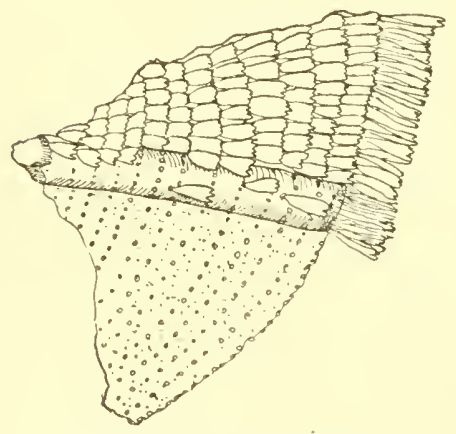

Scales on wing of butierfly.
FIG. 249.

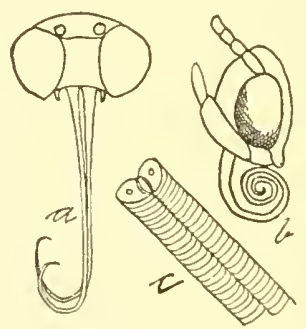

Head of a moth. - The tongue uncoiled at $a$; seen from side, partly coiled, at $b_{i}$ the appearance of tongue under a lens at $c$.

times a difference even in the sexes, certain kinds of highly developed scales occurring on the wings of the male only, usually confined to limited areas and sometimes concealed by folds.

In this order the adult insects are harmless throughout, capable of feeding only upon liquid food by means of a tongue which is usually coiled like a watch-spring on the under side of the head between the palpi. In some instances it is wanting, and on the other hand sometimes becomes enormously developed, reaching a length in some species of from five to nearly seven 
inches. Many of the Lepidoptera are useful in pollenizing flowers, some, indeed, depending entirely upon them for their continued existence, but, on the other hand, the caterpillars, as the larvæ are usually called, are among the most troublesome and injurious insects with which the agriculturist has to deal. The transformation in this order is complete, and a greater difference than that between caterpillar and butterfly can hardly be imagined; while in the clrrysalis or pupa we have a quiescent period where scarcely even the form of the future insect is indicated, and when it is absolutely incapable of motion.

Broadly, the order is divided into butterflies and moths, or, more accurately, the Rhopalocera and Heterocera. Rhopalocera are those in which the antennæ, or feelers, terminate in a more or less distinct knob or club at the tip, and in which at least the front pair of wings are elevated or vertical when at rest, so that the upper surfaces touch. The Hcterocera, on the other hand, have feelers, or antennee, of many different kinds, but never in our fauna distinctly clubbed. The wings when the insect is at rest are horizontal, folded on the back or close to the sides, oblique, roof-like, or spread out flat, but never habitually verticil. In general it may be said that the butterflies are on the wing during the day, and fly during the night only in rare instances; moths, on the other hand,

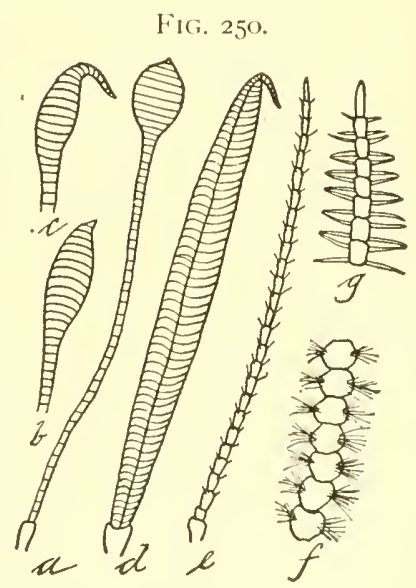

Antennæ in Lepidoptera. - $a$, clubbed antenna of butterfly; $b, c$, variations in form of club; $d$, prismatic and fusiform; $e$, ciliated ; $f$, bristletufted; $g$, doubly bipectinated. are night flyers, as a rule, though there are many exceptions, and a number of species occur commonly during the day.

The butterflies separate readily into groups based on the character of the feet and the situation of the antennæ. What may be called for convenience the "true butterflies" are distinguished by having the feelers set close together on the top of the head, the latter being proportionately rather narrow. The antennal 
club is abrupt at the tip and not drawn out into a hook or recurved. In the skippers, or Ilesperids, the head is broad, the eyes are comparatively small, the feelers are widely separated, set close to the eyes, and terminated by a pointed tip which is often recurved or hooked.

A large series of the true butterflies is distinguished by having the anterior pair of feet more or less aborted or imperfect, and these, the " brush-footed " butterflies, are classed in two families,

Fig. 25 I.

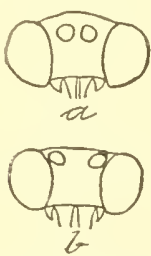

$a$, head of Papilio, showing where antennz are inserted; $b$, same of an Hesperid.
FiG. 252.

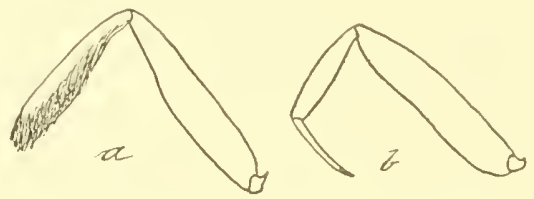

$a$, foreleg of a brush-froted butterfly entirely aborted ; $b$, of Lycana, male, tarsus one-jointed.

the $N^{\prime} y_{\text {mphalida, }}$ containing moderate-sized or large species, and the Lycanida, containing small species, in which the colors are blue or coppery, or have the under sides marked with fine, thread-like lines. They are the "blues," "coppers," and "hair-streaks."

Among our most common species of the first family is the "milk-weed butterfly," Danais archippus, quite a large redbrown insect, with the wing-veins broadly black marked. It becomes abundant in late summer and fall, and its caterpillar. green in color, marked with black lines, and furnished with rather long, black, hair-like tentacles, may be often seen feeding upon milk-weeds. This species will serve to typify the family to which it belongs, and is easily raised by any one curious to watch its transformations. If the caterpillar be confined with a sufficient supply of fresh leaves, it will grow to about an inch and a half in length, will then fasten itself by means of its hind feet to a little pad of silk, and will change to a chunky, bright-green chrysalis, or pupa, marked with small golden spots, one of the prettiest objects that can be imagined. In a few days the color will be- 
come darker, finally brown or blackish, and then the butterfly will emerge. This is not an injurious insect, and is only referred FIG. 253.
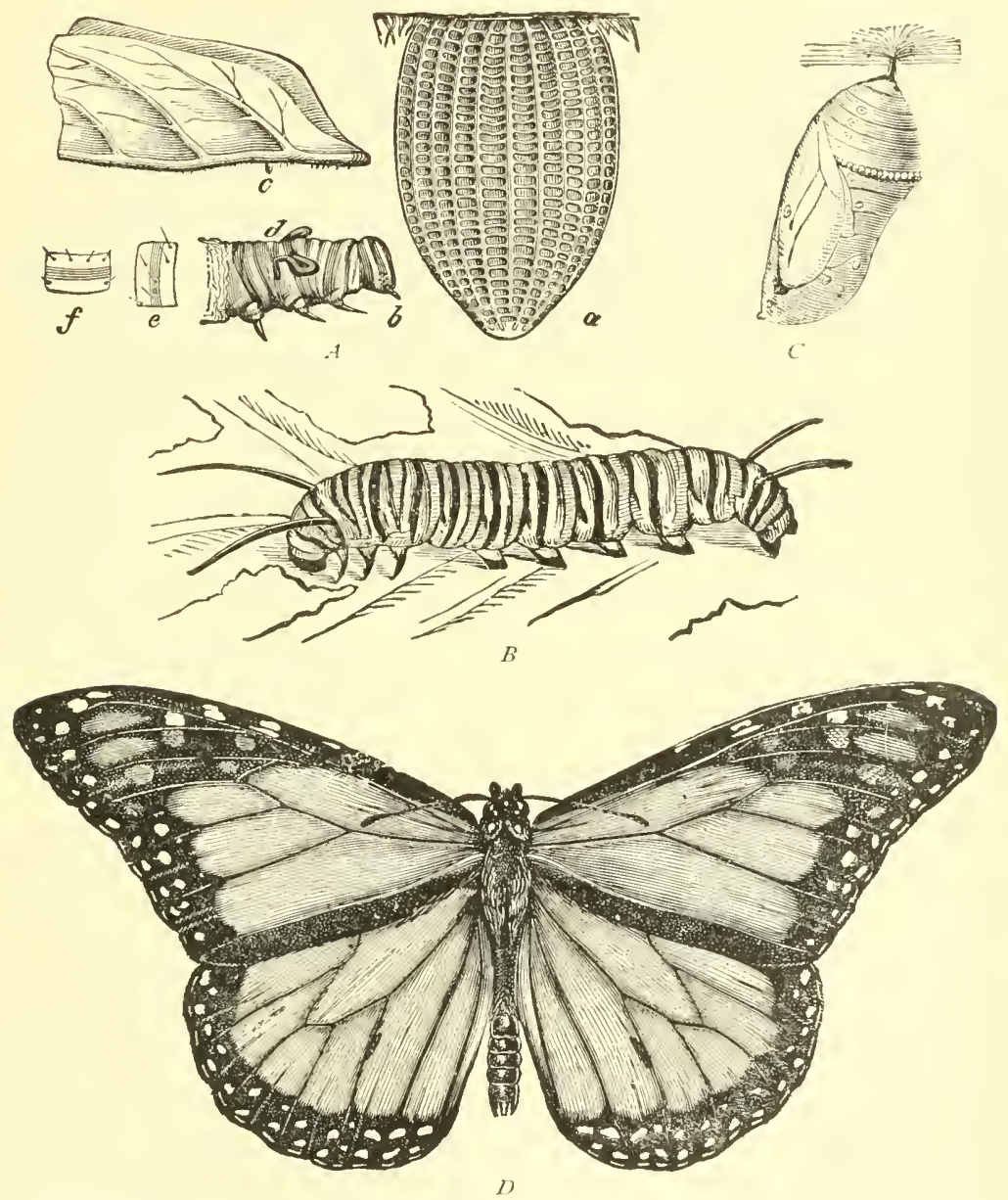

Milk-weed butterfly, Danais archippus, and its transformations.- $A, a$, egg enlarged thirty diameters; $b$, very young larva, showing how the tentacles are folded; $c$, egg, natural size, on a leaf; $B$, full-grown larva ; $C$, chrysalis; $D$, male lutterfly.

to here because it is easily raised and common throughout the country, -in fact, has spread all over the globe. 
We have many species of considerable size belonging to the genus Argynnis, which resemble each other more or less by

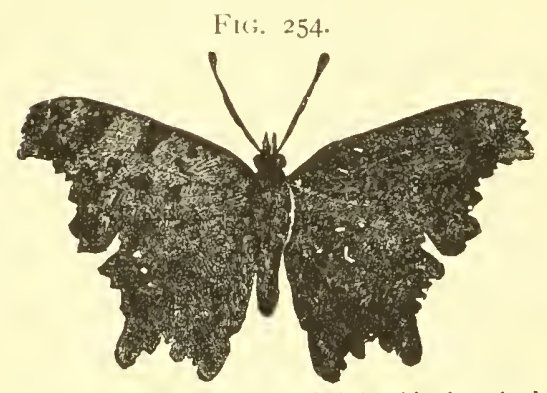

(i)apla progne.-Wings of right side detached to show under side; this is almost like $G$. comma. their tawny upper sides marked with black spots, and by having the under sides more or less marked with silvery blotches, especially on the hind wings. None of themare injurious, the larre feeding upon violets. In the genus Grapta there are species with strongly and irregularly angulated and toothed wings, quite dark brown in color, with irregular black or blackish blotches, spots, and lines, and a little silvery mark resembling a comma or semicolon on the hind wings beneath. Of these the caterpillar of G.comma feets upon the hop-vine, although it rarely does any serious injury. It is reddish or yellowish in color, with a black head and black branched spines, and forms an angular chrysalis which is suspended by the tail. The chrysalis is yellowish green in color, with prominently marked segments, and has the thorax produced into a somewhat acute process.

Another very common, almost cosmopolitan butterfly, is the lanessa antiopa, popularly known as the "mourning-cloak." It is of a very dark, rich-brown color, with a broad yellowish border on both wings. It winters in the butterfly stage, and may often be seen on warm days in midwinter, fluttering about in the woods, while it is the earliest of the butterflies to make its appearance in spring. The caterpillars feed upon quite a variety of plants, notably willow and poplar, and often in great colonies. When full grown they are two inches or more in length and black, with red-marked, branched spines. The chrysalis is suspended by the tail, and of a somewhat nouse-gray color, the segments marked with acute spines. This may under circumstances become a troublesome insect, but it is easily controlled, either by arsenical poisons, as the caterpillar feeds exposed, or by handpicking, which is easy because of the gregarious habit when 
young. A number of other common species belong in this family, but, as they do not feed upon cultivated plants in sufficient numbers to attract attention, they need not be further considered.

F1G. 256.

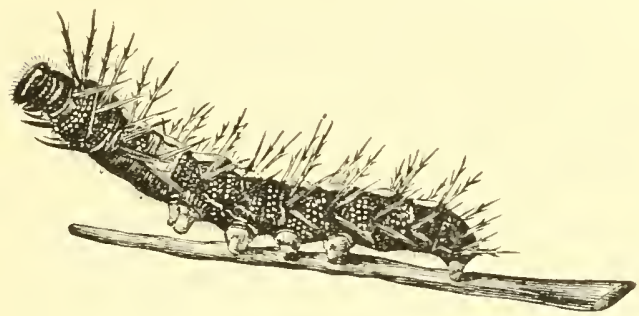

Larva and chrysalis of lanessa antiopa.

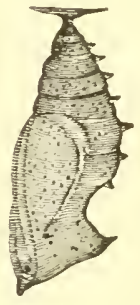

Quite early in spring we may see, fluttering along the roadsides, little blue butterflies expanding less than an inch when the wings are spread, and without prominent markings of any kind. These belong to the family Lycanida, usually to the typical genus Lycana, and from them the term "blues," as a popular name, has been derived. Later in the summer we find conmonly bright coppery butterflies, not much larger than the "blues" already spoken of, and on the upper surface, especially

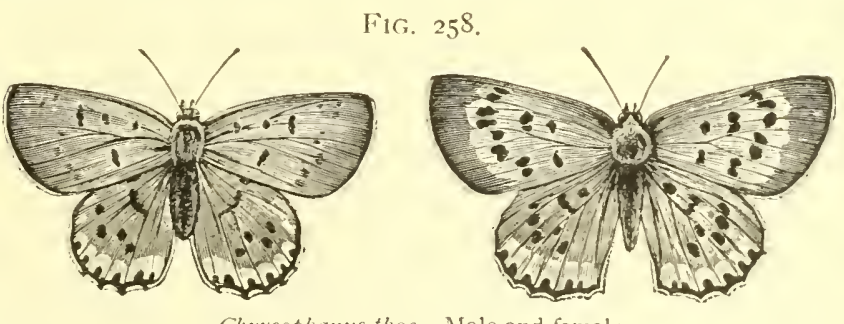

Chrosophams thoe.-Male and female.

of the fore-wings, are black spots varying in size and arrangement. To these the name "coppers" has been applied, and they belong to the natural genus Chrysophamus. The genus Thecla contains species that run larger than either of those previously mentioned, many of them sombre in color and marked on the under side by fine, hair-like streaks, differing in arrangement and not always present. These are called "hair-streaks." 
The hind wings are often furnished with one or two pairs of slender, thread-like tails, easily lroken off if the insects are carelessly handled. None of the members of this family are injurious, and the somewhat slug-like caterpillars are not often seen. Fenesica tarquinius looks like one of the "coppers," and is peculiar in that its larva feeds on the woolly plant-lice often found on beech and other trees. It is the onty butterfly larva in our country which is known to be predaceous.

The family Papilionida contains six-footed butterflies, the anterior feet being perfectly developed in both sexes, and here the antennæ are set rather close together at the base. It includes our largest and brightest species, the most prominent of them being known as "swallow-tails." There are two groups, the first containing smaller species, which are white or yellow in color, the hind wings without tails, but furnished with a fold along the inner margin, forming a groove, in which the abdomen lies. These are arranged under the term Picrina, and contain as typical forms the common cabbage butterflies. The most abundant and injurious of these is Pieris rapa, an insect imported many years ago from Europe, and which has now spread over the largest part of the United States and Canada. The wings expand about an inch and a half, are white or with a creamy tinge, with a single black spot in the fore-wings of the male, and two similar spots in those of the female. There is also a little black patch at the apex, and on the under side the wings are usually darker and a little powdery. These butterflies appear very early in spring, emerging from chrysalids that have hibernated, and lay their eggs upon almost any of the cruciferous weeds. They are not particularly choice, but perhaps the common Barbarea anlgaris is about as often selected as any in the Middle States, because one of the first to make its appearance. The first brood comes to maturity in less than a month, and then eggs are laid on early cabbage-plants. Soon irregular holes appear, first in the outer leaves, then in the head itself, and little piles of dirty-yellow excrement may now be found everywhere anong the folds. The caterpillars themselves are velvety green in color, almost like the cabbage-leaf, and, as they lie rather closely to the plant tissue, are easily overlooked until a little practice is gained in searching for them. They become more 
FIG. 260.

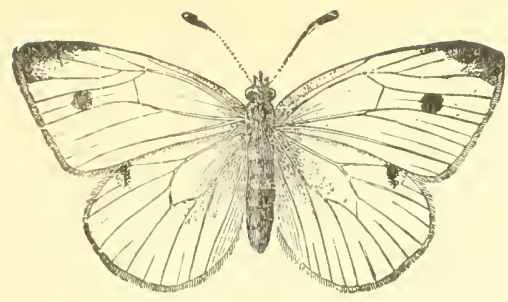

FIG. 26I.

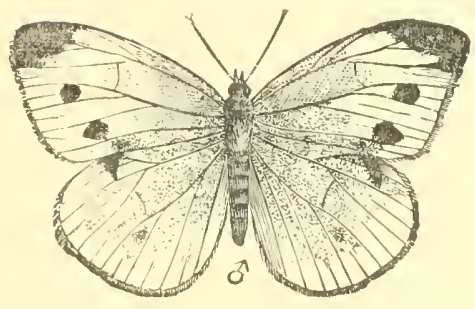

FIG. 263.

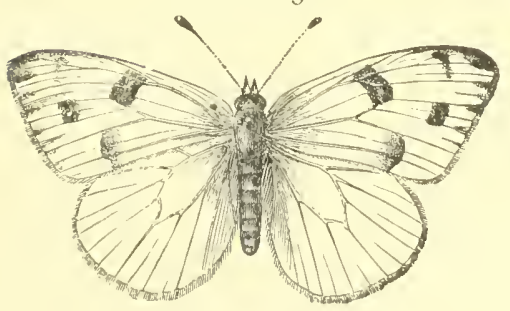

FIG. 264.

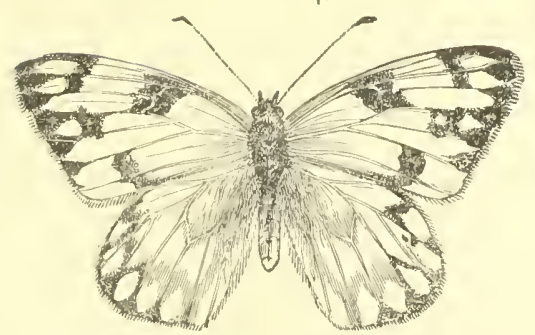

FIG. 265 .

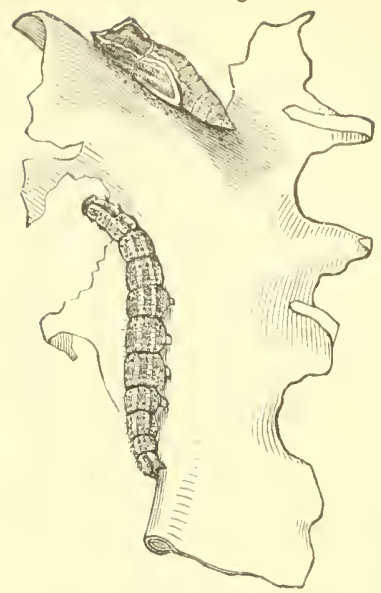

FIG. 259 .

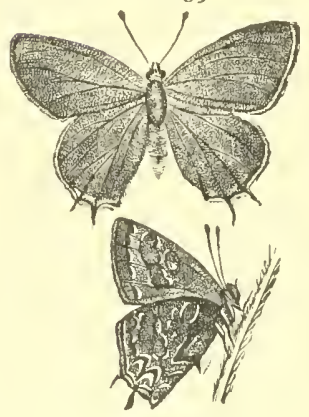

FIG. 262.

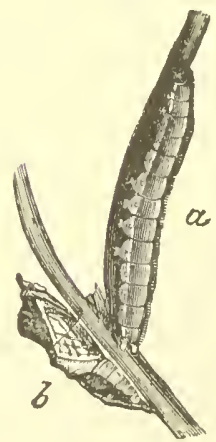

Fig. 259, Thecla strigosa. Fig. 260, Pieris rapa, male. Fig. 26r, Pieris rapo, female. Fig. 262, a, larva; b, chrysalis of Pieris rape. Fig. 263 , Pieris protodice, male. 1ig. 264, Pieris protodice, female. Fig. 265, larva and chrysalis of P. protodice. 
abundant as the season advances, and late cabbage often suffers seriously in some localities. By all odds the best remedy is spraying with the arsenites, at the rate of about one pound in one hundred and fifty gallons of water. A great many other remedies have been recommended, and some of them are undoubtedly useful, but nothing is so satisfactory and cheap as the arsenite, and without gross carelessness there is not the slightest danger in the application. The cabbage heads from within, that is to say, the leaves unfold from the centre of the head and do not fold together to form it ; therefore, whatever poison is put upon the plant can fall only upon the outer leaves, and not a particle gets into the head itself. The amount used to a single cabbage-plant is so minute that in order really to poison a man it would be necessary for him to eat about a dozen heads, outer leaves and all, and if death then resulted I would be inclined to attribute it rather to the cabbage itself than to the Paris green or other arsenite employed. The larvæ succumb to the poison very readily, and by making the application early in the season the later broods may be materially reduced in number. In ordinary farm practice the heads are cut out and shipped, and in preparing the cabbage for food, the outer leaves of these heads are generally taken off by the housewife because more or less bruised or injured, before they are cooked. Chemical analysis has shown that on a head so prepared, within a week after a heavy application of Paris green, not a trace of arsenic remained. As a matter of fact, the use of Paris green as against the insect is quite common, although little is said of it, to avoid exciting prejudice, and I have yet to learn of the first case of arsenical poisoning from eating cabbage so treated. From New Jersey southward and westward, one of our native species, $P$. protodice, becomes more common and assists its imported relative in making havoc among the cabbages, but this also may be easily controlled by the measures above detailed.

We find flying abundantly in our fields, and more common among clover, a bright, sulphur-yellow butterfly about as large as the $P$. rapa, with a single black spot on the fore-wings, and a broad black outer margin to both pairs. On the under side the hind wings have a central orange spot, often with a slight silvery tendency. These butterflies belong to the genus Colias, and the 
FIG. 255 .

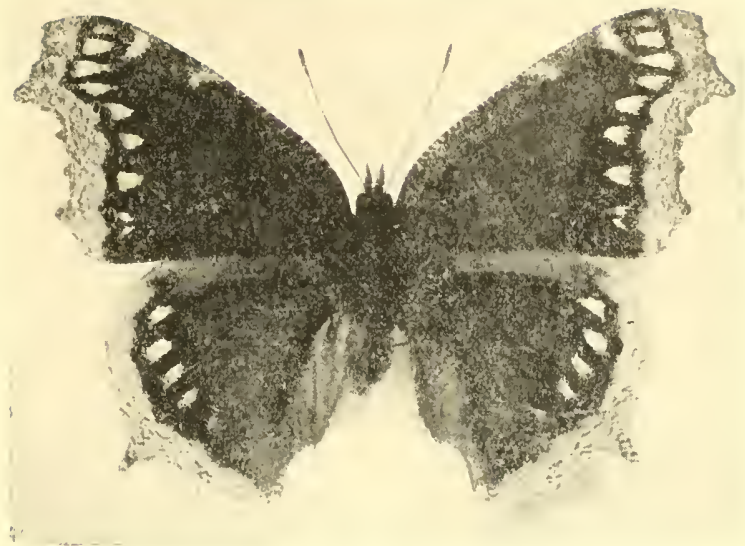

FIG. 266.

FIG. 257.
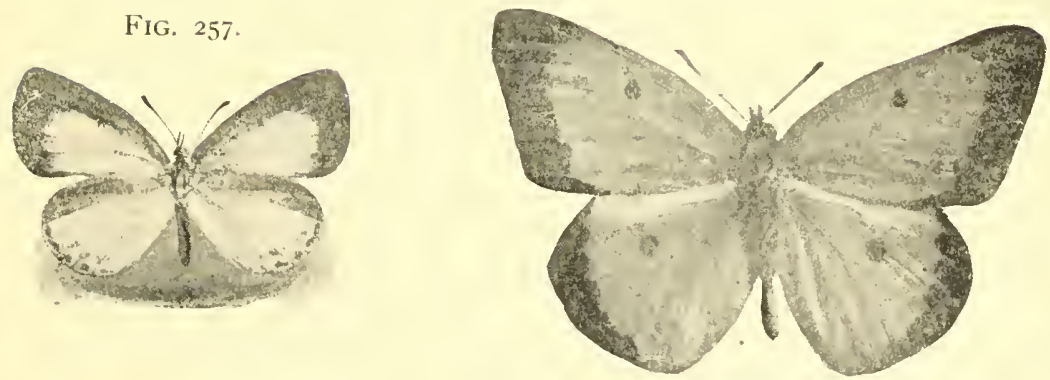

FIG. 267 .

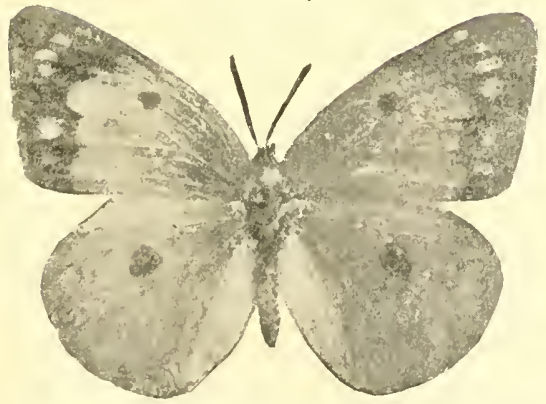

HIG. 272 .

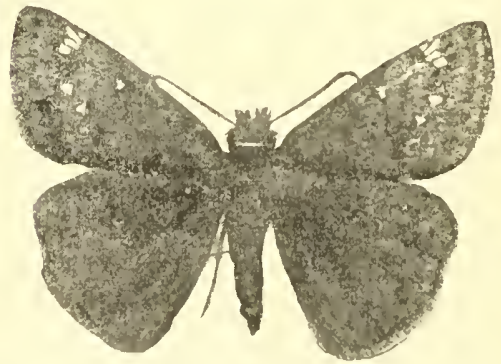

Fig. 255, mourning-cloak butterfly, Vanessa anhopa. Fig. 257, Lycona pseutargiolus. Fig. 206, Colias philodice, male. Fig. 267, same, femate. Fig. 272, Nisoniades juvenalis. 
common eastern species, extending westward to the Rocky Ionntinins, is C. philodice, whose larva feecls upon chover. It is " but although it may be quite abundant, rarely does injury enough to be noticed. As a rule, the larva is rather difficult to find, even where the butterflies are abundant, and practically no measures need be taken against it.

In the sub-family Papilionine we have in our country only the typical genus Papilio, containing species abundant enough to become of economic importance. Tlse most common of these is

Fif; 268.

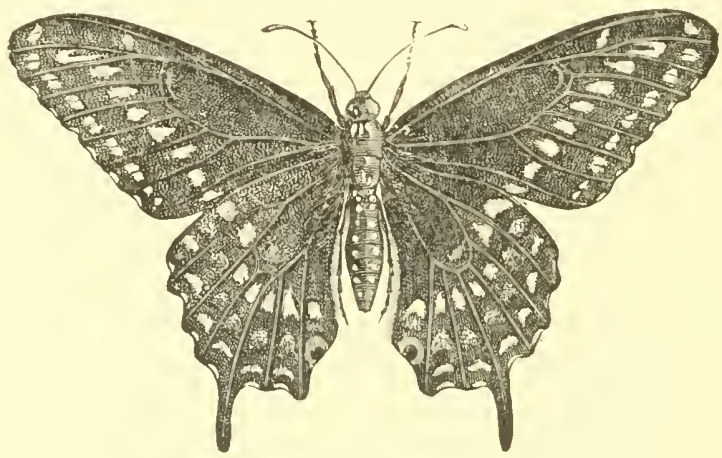

Papilio astivias, male.

P. asterias, a black " swallow-tail," expanding between two and three inches, the hind wings tailed and excavated on the inner margin, so that the abdomen is free, not enfolded in a groove. The male is somewhat smaller than the female, ancl has a cliagonal row of yellow spots crossing the fore-wings ontwardly and the hind wings nearly across the centre. Near the outer margin of both wings there is a row of yellow, lunate spots, and at the inner angle of the hind wings is a peculiar, eye-like spot, just at the margin. The female has the inner row of yellow spots very much reduced, sometimes altogether wanting, but on the hind wings the space between the faint series of yellow spots and the outer lunules is beautifully powdered with metallic blue scales. These butterflies lay their eggs on carrots, parstey, and other plants of the same natural family, and from them hatch bright 
green caterpillars with broken black bands. A peculiarity of this kind of caterpillar is that when touched or irritated in any way it shoots out from between the serments close to the head at forked, orange-colored process, which emits a very disagrecable odor, and this is its only means of defence. No trace of the pro cess is visible when the insect is at rest, and the horns are withdrawn just as soon as irritation ceases. When the caterpillar is full grown it leaves the plants upon which it has fed and travels to any convenient point in the vicinity where it can pupate. This pupa, or chrysalis, is fastened to a little silken pad by the tail,

FIG. 269.
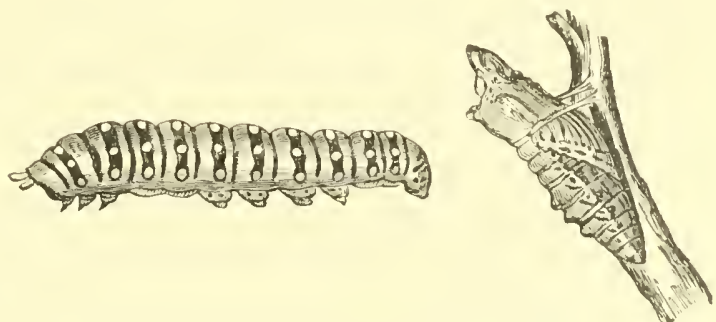

Papilio asterias.-Mature larva and pupa.

but is also sustained by a silken band in front of the middle, so that it is said to be girthed, and this same type we have in all the members of this family. These caterpillars are rarely abundant enough to become troublesome, but if they are, hand-picking is, perhaps, as good a remedy as any. They are quite prominent, and, therefore, easily and rapidly gathered, checking their injury immediately and completely. When they are small, spraying with the arsenites will answer, provided it be clone thoroughly.

Another species is $P$. philenor, of about the same size, black, without the yellow spots through the centre, but with the upluer surface overlaid with greenish, powdery scales, which give the insect a metallic lustre in certain lights, and this varies accordins to the angle at which the light strikes the wings. The caterpillars feed upon vines of Aristolochia, or "Dutchman's pipe," which they sometimes injure consiclerably. They are dull brownish red in color, with long, fleshy filaments on the segments, and when irritated also extrude fleshy horns such as 
already described and for the same purpose. The measures recommended for the parsley caterpillar may also be adopted against this insect.

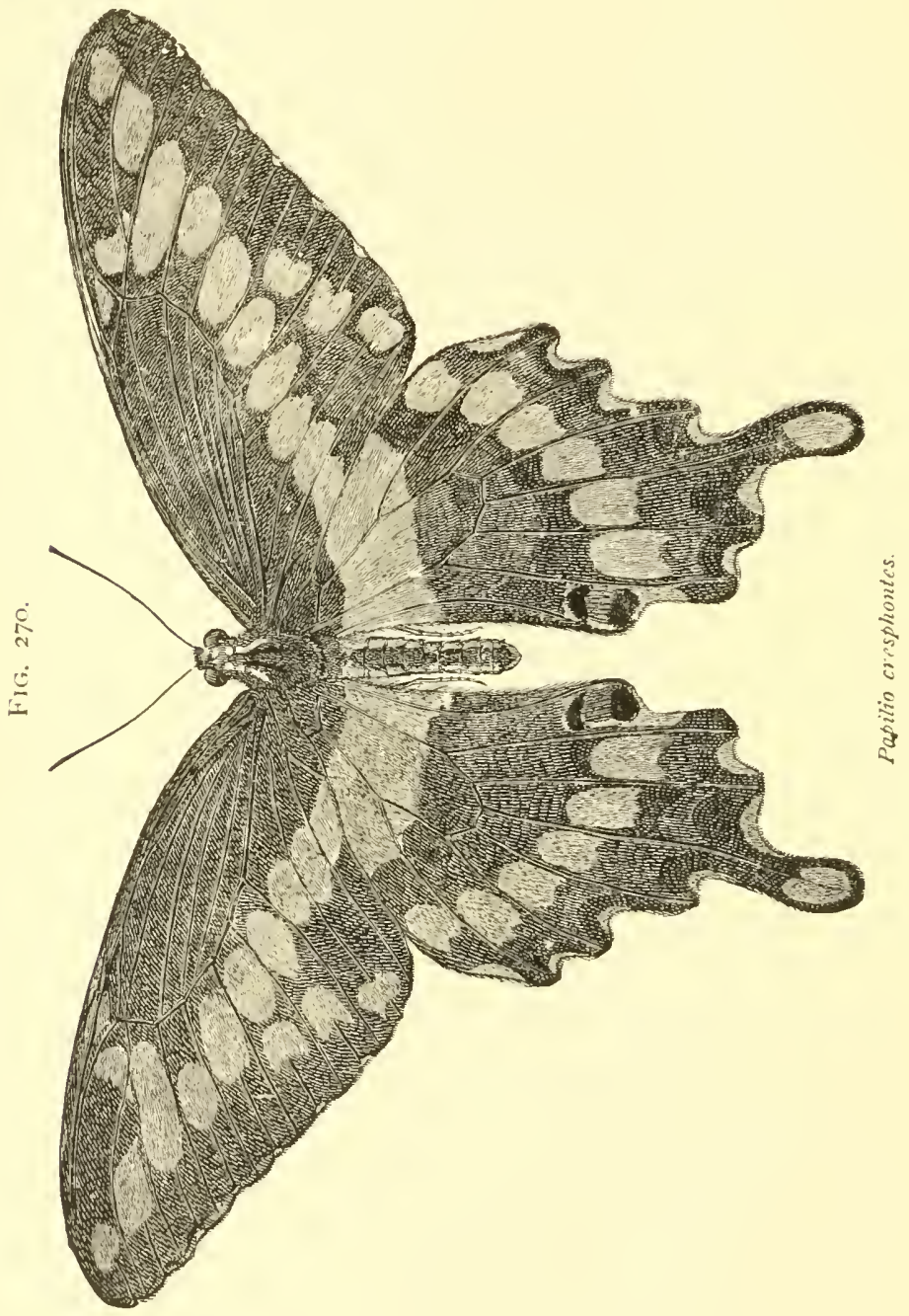

The largest of the common northern "swallow-tail" butterflies is the $P$. turmus, which expands from three to six inches, and is 
bright yellow in color, with transverse black bands. Towards the South and West, occurring rarely, however, as fur north as Canada, we have a form of the female which is black, but may be distinguished by its large size from our normally black species. The caterpillar is green, and distinguished by having two black, eye-like spots on the anterior segments. It feeds on a number of clifferent plants, but does not become economically important.

In Florida, $P$. cresphontes is abundant, and its caterpillar is known as the "orange dog," from its peculiar appearance and

FIG. 27 I.

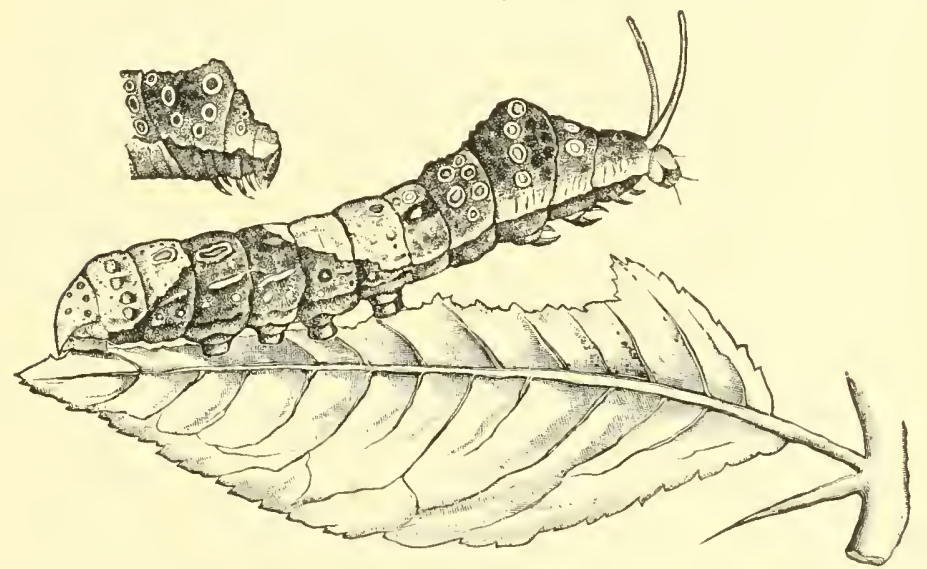

The orange dog, caterpillar of Papilio cresphontes, with osmateria, or scent-organs, extended; the detached figure shows the anterior segments normally retracted.

habit of feeding upon orange-leaves. The butterfly is even larger than the turmus, and is black, with a broad diagonal band of contiguous yellow spots extending from the tip of the fore-wings towards the base, reaching the inner margin very near to the base of the hind wings. There is also a band of yellow spots near the outer margin, which are especially prominent on the hind wings, and a yellow spot occupies the centre of the broad, lobed tail. The caterpillars are prominent, as already stated, and orangegrowers consider them among the greatest troubles of the young trees, especially in the nurseries, where a single specimen may defoliate a shoot in a little time. Hand-picking on small trees is a feasible and satisfactory remedy, and another is to capture the 
butterflies on the flowers which they frequent during the middle of the day. Mr. Hubbard has suggested shooting them with cartridges loaded with sand, and that can easily be done during mid-day from a veranda or other shelter when the butterflies hover around the flowers near by.

The "skippers," or Hesperida, differ from all the preceding by the broad head, clothed with bristly hair, and by the widely separated antennx, or feelers, the club being also terminated by a more or less marked and recurved slender hooklet. They are small or moderate in size, and get the common name from their jerky habits of flight, usually along roads, and practically confined to low herbage. There are two rather well-marked, though by no means sharply limited sections, distinguished by color, the first containing dark, blackish or sombre brown types, and the

FIG. 273 .

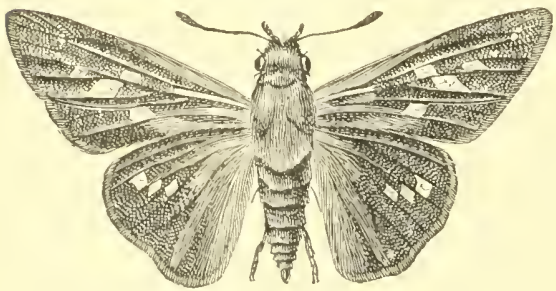

Pamphrta ethlius. other tawny yellow forms. The former is represented by the species of Nisoniades and its immediate allies, and the latter by the genus Pamplita and allies. In this latter series the fore-wings are much more pointed than in the other, and the body is proportionately more

robust. None of the species, so far as I am aware, are of economic importance, though our largest species, Megathy'mus yucca, does some injury by occasionally boring into the roots of the yucca plant. These insects have been considered intermediate between the butterflies and moths, and many species have the habit of elevating the front wings only, the hind wings being held horizontally.

The first of the Hetcroccra to be considered here are the Sphingide, or "hawk-moths," and these obtain the common name from their habit of hovering about flowers, and their rapid, darting motions. Most of them fly just about dusk, visiting (leep flowers like the "evening primrose," "petumia," or even "Jimson weed," and they succeed in reaching the very bottom of these by means of an unusually well-developed tongue. They 
gather their food while hovering, inserting the proboscis into the

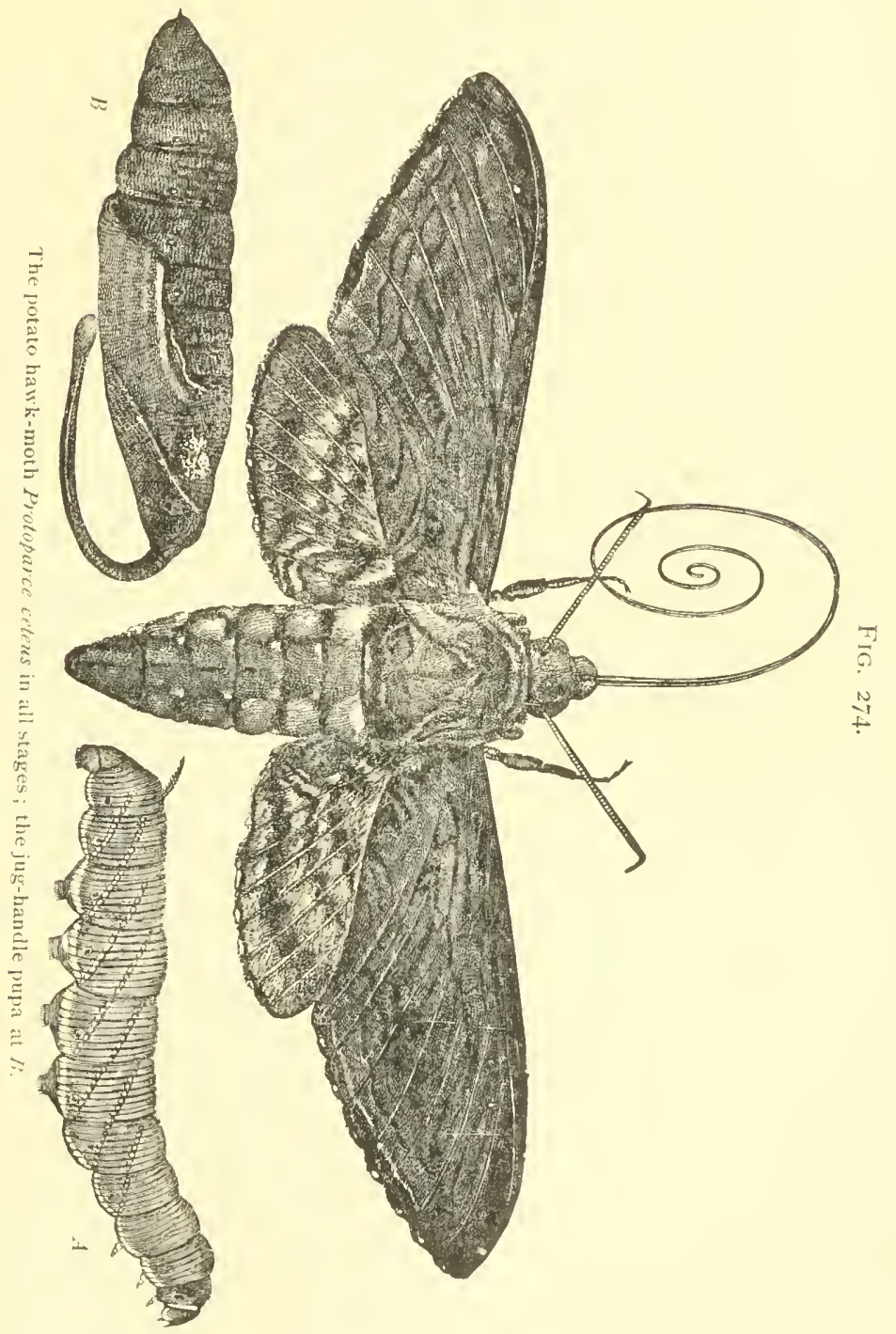

nectares, but rarely alighting. The antennæ are prismatic and 
spindle-shaped, and terminate in a little, recurved hook. The body is robust and well developed, supported in flight by means of stout, though rather narrow, pointed wings. The caterpillars are peculiar in having a eurved horn on top of the last segment, or in its place a hard, glossy, eye-like sput. When at rest, some of them have the habit of elevating the front part of the body and curling the head under a little, giving them a fancied resemblance to a Sphinx, and from this the scientific name has been derived. A very good example of a typical sphinx caterpillar is found in the large green species, the sides with oblique, lateral, white stripes, which is often found upon potatoes and tomatoes, occasionally doing considerable injury. The anal horn is quite often believed to be venomous, and all sorts of stories are told of people having been poisoned or stung; it is even said sometimes that a stream of poison is thrown from the end of the horn for some distance. As a matter of fact, nothing can be more harmless than these caterpillars; there is no poisonous secretion connected with the horn, and they can be handled with absolute safety. This same type of caterpillar also attacks tobacco and other Solanacec, and, when full grown, goes underground and changes to a mahogany-brown pupa an inch and a half to two inches in length, with a peculiar liandle-like process attached to the head, which forms a covering for the future tongue. This has given them the name "jugr-handle grubs" in some localities. The adults, when they emerge, expand from three to five inches or more, and are ashen-gray in color, the fore-wings with a little white spot near the centre, and crossed by irregular darker lines, the hind wings banded with black and white, while along the sides of the abdomen are five large yellow spots. This is the Sphin.r (Protoparce) carolina, which may be accepted as typical of the series to which it belongs. An allied species, Protoparce celeus, feeds on the same kinds of plants, and resembles the carolina rather closely, except that the yellow of the abdomen is paler, the lines on both wings are rather more distinct, and the insect is a little larger ; but the differences are not great, and need not be further detailed here. Other species of sphinx caterpillars are found on a variety of other plants, but they do not often appear in noticeable numbers, being much subject, from their large size, to the attacks of birds and parasitic insects; so, 
except for the species already mentioned, mature herself keeps down the insects to a reasonable number.

Another series of this same family is more brightly colored, with the wings angulate, dentate, or only a little sinuate at the outer margin, and of these we have several species that attack the vine. The caterpillars are rather more clumsy than those of the preceding series, and the head is often retracted into the enlarged thoracic segments. The horm is frequently wanting and replaced by a shining, usually blackish, eye-spot. These are known as "hog-caterpillars," and often appear in numbers sufficient to cause more or less injury in vineyards. The adults are brightly colored, either greenish with darker, blotchy markings, or reddish with brown markings, or a combination of olive green and rusty brown and gray. The figures herewith given illustrate the more common species, and as their habits are much the same, no special description of each is needed.

On the elm-tree we sometimes find a green caterpillar, the skin a little roughened, with the typical sphinx anal horn and, in addition, four little horns on the anterior segments. This is the larva of Ceratomia amyntor, or, as Dr. Harris called it, much more appropriately, quadricomis, which means four-horned. The moths produced by this caterpillar may often be found in midsummer on the trunks, and are dirty yellowish gray, streaked with blackish, and with white discal spots.

Sometimes we find, flying around flowers in bright sunlight, exceedingly active little creatures that at first sight resemble humming-birds, and are frequently considered such. If they be captured, however, we see that they are brilliantly colored moths, which have received the common name "lumming-bird hawkmoths." They ustutly have the fore-wings quite sparsely clothed, sometimes nearly transparent, while the body is covered by rich coppery or other metallic-colored scales.

The caterpillars in this family are all external feeders, and usually so large and prominent that they can easily be seen. In most cases, therefore, the simplest remedy is hand-picking, but when this is done no caterpillar should be destroyed which is covered with little, white, egr-like bodies, for these are the cocoons of parasites which do much to keep the insects in check. Where the larvet are abundant enough to make hand-picking 


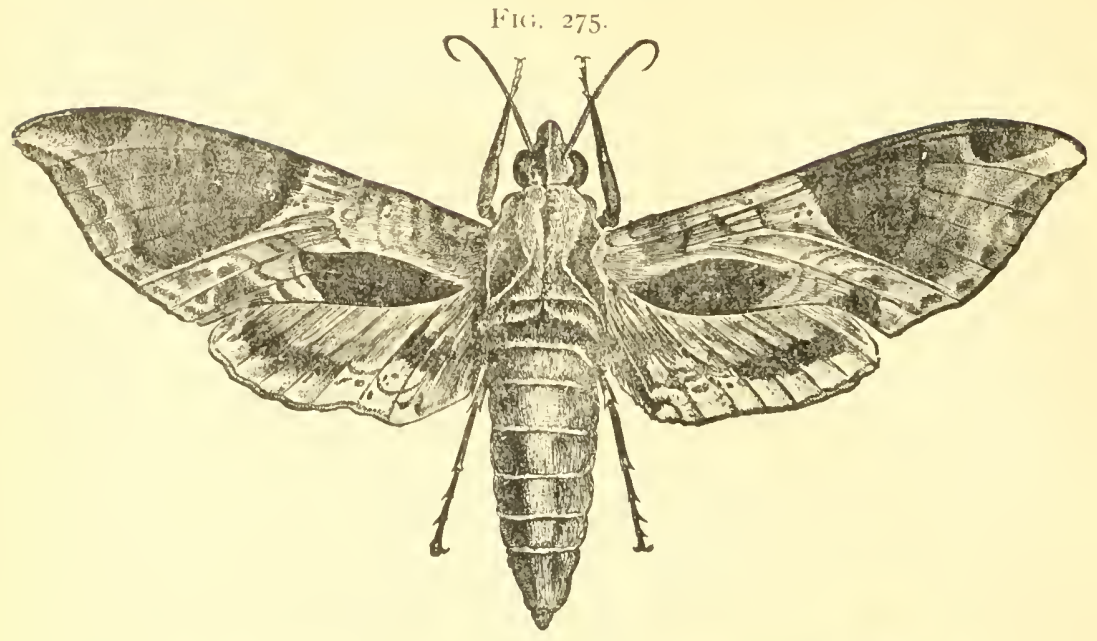

FIG. 276 .

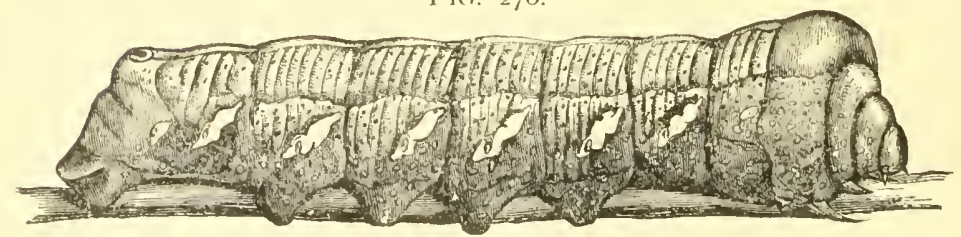

FIG. 277.

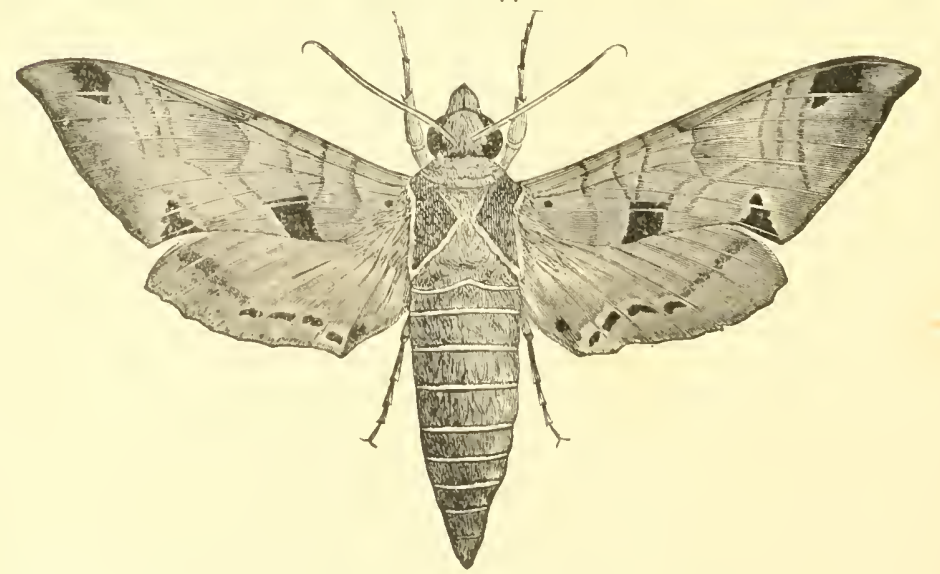

Fig. 275, Philampelus pandonus. Fig. 276, Philampelus achemon, larva. Fig. 277, Philampelus achemon. 
Fir. 27 S.

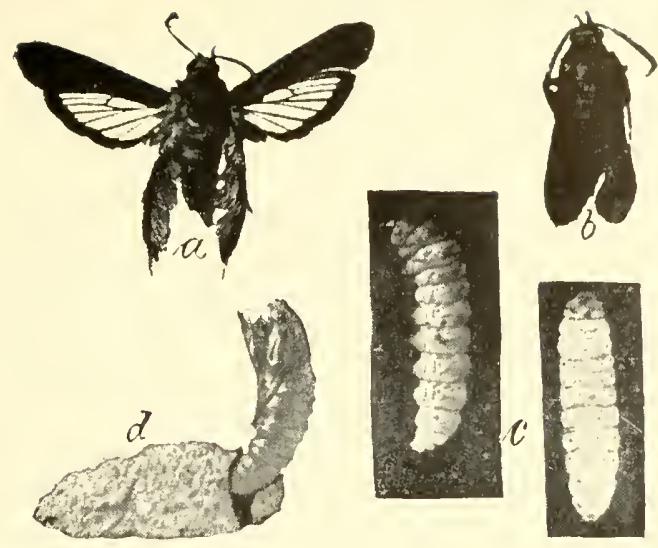

Fili. 279 .

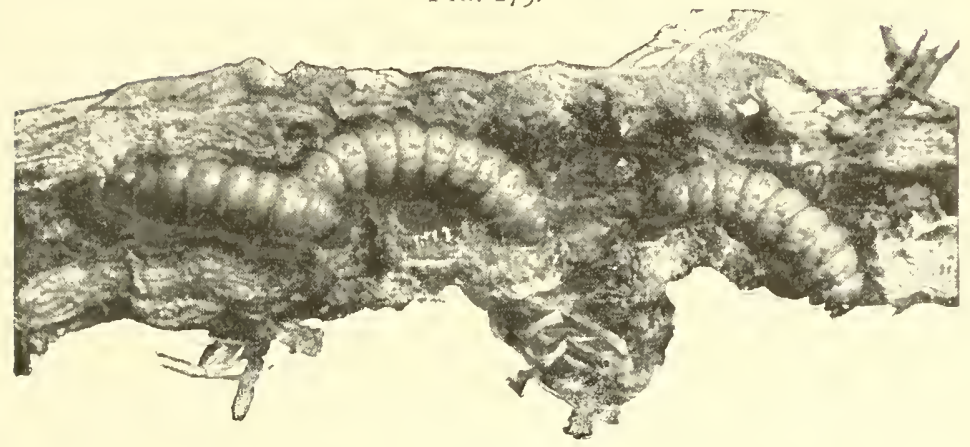

FIG. 280 .

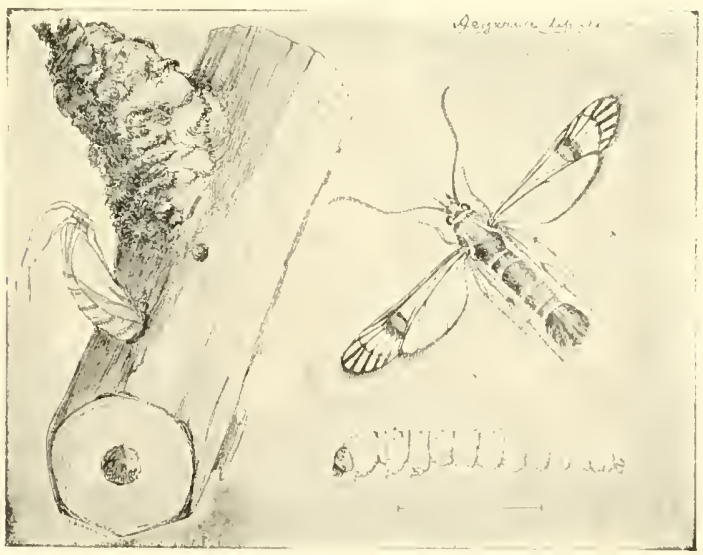

Fig, 278, Melittia ceto, the squash-borer: $a, b$, moth, the wings spread and at rest. $c$, young larvæ: $d$, cocoon with the empty pupa shell projecting. Fig. 279, squashborers full grown, in a section of squash-vine. Fig. 280 , imported currant-borer, Sesta tipulyuz., is; larva, adult, and pupa skin projecting from the cane. 

limpracticable, any of the arsenites may be employerl. The attempt has been made, not without a firir degree of success, to protect tobacco plants by killing off the moths while feeding in the flowers of the "Jimson weed," a few elrops of at poisonoms solution being placed in the bottom of each flower. It is periaps questionable whether the results obtained justify the method from a practical stand-point, and the direct application of poison to kill the larve is, all things consiclered, the most satisfactory.

Following the hawk-moths in our lists, but not in the least related to them structurally, are the clear-winged moths belonging to the family Sesiide. They are slender bodied, with quite long antenne, the wings narrow, often without scales, the colors metallic or at least glistening, and usually bright and contrasting. They often resemble and are considered wasps or hornets from their appearance, the more so because it is quite usual for them to have the abdomen banded with yellow. These creatures are the parents of borers that are among the most injurious to cultivated plants.

First in the series is the "squash-borer, Mclittia ceto. This is readily recognized in the adult stage by the opaque, greenish fore-wings, and by the unusually large, thickened hind legs, tufted with black and orange, giving the insect a characteristic appearance, different from any other common species. It may be found during late spring or early summer hovering about the squash or other cucurbit plants during the day, but in the evening and during the night resting exposed upon the leaves. It lays its eggs preferably on the vine just at the surface of the ground, if the soil is light even a little below, but it is by no means confined to this point, and may lay them anywhere, even on a leaf or leaf-stalk. They are brown in color, disk-like, and have a very brittle shell. The larva when hatched are white or nearly so, with a small brown head, a full complement of legs, and at once bore into the stem of the vine. Preferably they live just at the surface of the ground, really eating very little of the plant, but rather they suck the juices, causing its enfeeblement and ultimate death. When full grown in midsummer the larva goes a short distance underground and forms a very tough, parchment-like cocoon in which it rests until the year following. In spring the pupa, by means of its chisel-like head-case, cuts a 
circular lid from the encoon, wriggles its way to the surface, and through it into the open air. This has long been a pest to squash-growers, and the usual remedy is cutting them out when the wilting vines denote their presence. This is quite practical, but has the disadvantage of being very slow, besides having a tendency to injure the vines if the cutting is unskilfully clone. Care must be taken to cut only longitudinally, while the wounds should be rubbed with dry soil and covered with earth to facilitate healing. Covering the joints to induce rooting is atrantageous, because it gives new sources of supply for plant food ; so that even if the vine be entirely severed at the original root, it may mature fruit from the suckers. Where squashes are raised on a large scale, the best method is to trap the insects by a first crop of some summer variety, preferably crook-necks. These grow rapidly, and the moths reatlily lay their eggs upon them, the plants continuing to do well even when infested by the larve, and maturing an early crop of fruit. The late squashes, Hubbard or marrowfat, may be planted when the summer varietics are well under way, and by the time they are large enough to be attractive to the moths, most if not all the eggs will have been laid, and they will be practically exempt. As soon as the late varieties need the ground the sum-

Fig. 28I.
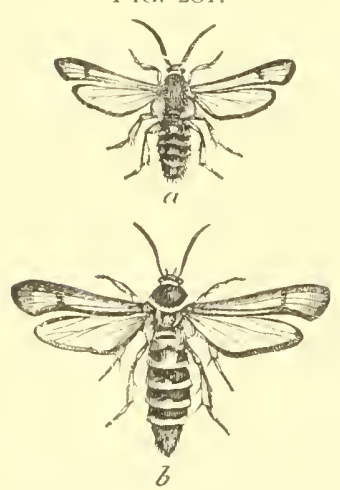

Bembecia marginata.-a, male: $b$, female. mer variety should be carefully removed, the plants being taken out entire and destroyed, and with them the brood of contained larvæ. In other words, the summer squashes are to be used as a trap crop to protect the Hubbard, marrowfat, or other main, late variety. It should be said that in the Central and Southern States there are two broods of these insects, and even on Long Island, New York, a few specimens are occasionally found in September. Vigorous war on the first brood, however, by means of traps will prcrent injury from the second.

Blackberries are often attacked by a similar larva at the surface of the ground or a little below it, boring sometimes a little dis- 
tance up or down the cane or completely aromel it, for which reason it has been called the "blackberry crown-borer." Signs of its presence are the sudden wilting and rapirl death of new shoots, and it comes to maturity in early September of the second year of its life, forming a pupat in the stalk itself. The resulting moth, Bembecia marginata, is black, very little marked with yellow, and the only satisfactory remedy is cutting out and destroying the larva as soon as its presence is indicated by the wilting leaves.

Perhaps the best known of all belonging to this series is the " peach-borer," Sammina exitiosa. This is the pest of peachgrowers all over the country, and the larva live between bark and wood a little below the surface of the ground in a mass of gum and woody material. They first make their appearance after midsummer, and become about threefourths of an inch long before winter sets in. In spring they resume feeding, attaining a length of a little more than an inch, then spin a cocoon of silk and bits of chips covered with gum, and change to a pupa. In this stage they remain a few days and then emerge as moths. The sexes are very unlike, the males black, with narrowly yellow-banded a b d o me $n$,

FIG. 282.
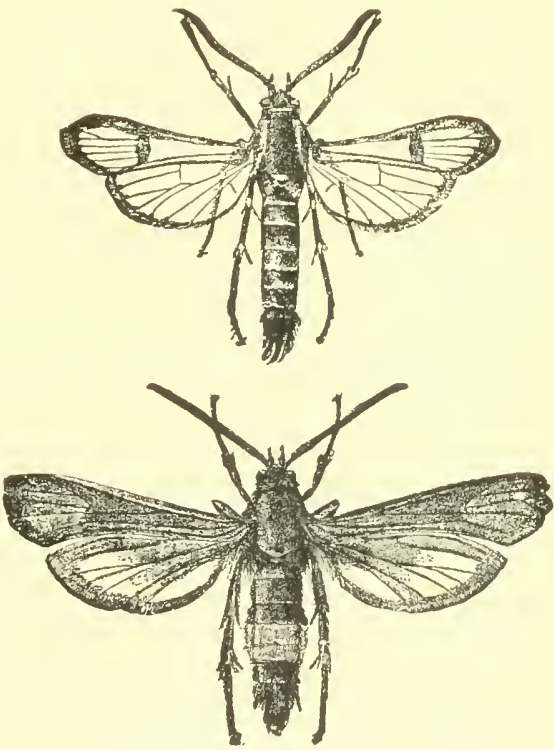

The peach-burer, Sannina exitiosa; male above, female below; both enlarged. and entirely transparent wings; the females much lirger, the fore-wings almost blackish brown and entirely covered with scales, the abdomen black, with a broad orange band at about the middle. The eggs are laid on the bark near the surface of the ground, and the larvæ hatch after midsummer in time to do con- 
siclerable feeding before winter arrives. "WVorming" peachtrees, or cutting out the larve, is a recognized mothod of getting rid of these insects, and has the advantage of being effective, if thoroughly done. It has the disadvantage of gashing the trees, and sometimes causing a considerable amount of injury before the insect is found. If carelessly done a few will escape, and sooner or liter the tree becomes girdled at the base, or so weakened that it proves attractive to bark-beetles, who complete the work begun by the borers. Our task is to keep the insects out if possible, and the best method is to cover the bark with some material upon which the insfet camnot lay its eggs or through which the young larve cannot penetrate. On old trees whitelead paint in boiled linseed oil is about as good as anything, but it should not be used on young trees, nor should turpentine be used to thin out the lead in any case. On younger trees whitewash thoroughly applied and kept on from quite early in the spring until after midsummer will answer the same purpose, but as this washes off readily, it must be renewed as often as the coating becomes imperfect. Quite a sitisfactory method is to wrap newspapers or tarred paper around the lower two feet of the trunk, hilling up against it at the base and tying at the top. This must be replaced yearly, but is an effective protection when well put on. Fine wire netting will answer the same purpose, and has the advantage of being more lasting; or an application of cement mixed with skim-milk, applied early in the season and maintained until midsummer, will serve. Anything, in fact, that forms a mechanical protection to the tree will answer, and this is the most satisfactory method of keeping out borers senerally.

There are other species of this family boring in maple, and their empty pupa shells may often be seen sticking out of the hark; and so plum, pear, and a great variety of other trees are sometimes attacked. Where maples are to be protected, the whitewash affords the best hope of success, unless wire netting much finer than the ordinary mosquito screening is employed. Sesia acerni, the "maple elear-wing," is a slencler-bodied little creature, prettily marked with red and yellow, and would be atble to oviposit through the meshes of an ordinary mosquito sereen without trouble. 
Currants and lilics are frequently attacked by borers of this family, and on currants considerable injury is sometimes done by Sesia tipuliformis. Here the best renedy is to cut out the dead stalks in spring, just as soon as leafing out shows where the attack is located, and every wilted shoot seen at any time should be cut off at once below the point affected. The cut stems must, of course, be burnt immediately. An occasional liberal pruning back will prove useful in keeping down the insects, and is some times a bencfit to the plants as well.

As a whole, we may say that our methods of treatment of this family are in the nature of prevention where the species attack trees, and cutting out where they attack shrubs or herbaceous plants.

Grape-vines, especially in city gardens or in villages, are often attacked by light-brownish caterpillars with black dottings, which are sometimes so abundant as actually to defoliate them. They become nearly an inch and a half in length when full grown, then bore into any soft, rotten, or even comparatively sound wood, where they pupate and eventually emerge as active little moths, expanding rather more than an inch, with black fore-wings having two pale yellow blotches, and black hind wings with two white spots, of which that near the base is much the largest. The shoul(ler tippets are yellow, and the insect is active during mid-day, hovering about the vines in the

FIG. 283.

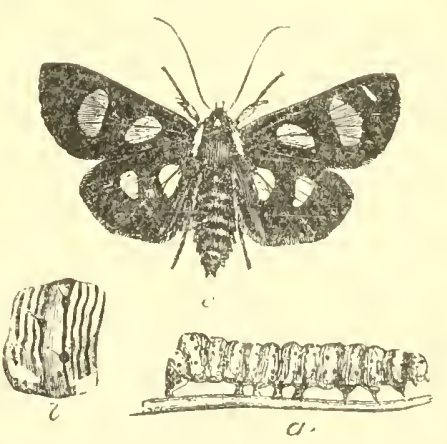

Alypia octo-maculata. 8-spotted forester. $-a$, larva; $b$, an enlarged segment $c$, the moth. brightest sunshine. It is the $1 / y$ pia octo-maculata, or 8-spotted forester, common throughout the Eastern and Central United States on wild as well as cultivated vines and I irvinia creeper, but rarely troublesome, except near or in cities or towns. The caterpillars feed quite exposed, and may be easily destroved by means of the arsenites. In city gardens, pyrethrum in the form of a spray, two ounces to a gallon of water, will prove sufficiently 
effective, especially if applied while the caterpillars are still quite small.

Arranged in the same family, Agaristide, are several similar caterpillars, producing quite different moths, but amenable to the same methods of treatment. One species, the larra of Psychomorpha cpimenis, folds the edges of the leaves and lives in the little pocket so formed; but they are usually so rare that they can hardly be termed injurious.

In that part of the Southern States where the " moon-vine," Ipomaa, flourishes, it is often attacked and sometimes defoliated by a yellow, hairy caterpillar, which appears in considerable

Fig. 284.

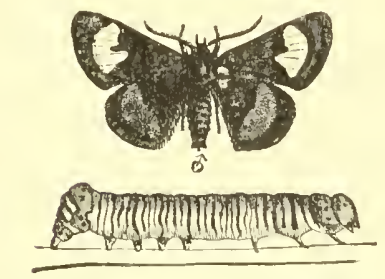

Psychomorpha epimenis.-Male insect and larva.
FIG. $2 \mathrm{~S}_{5}$.

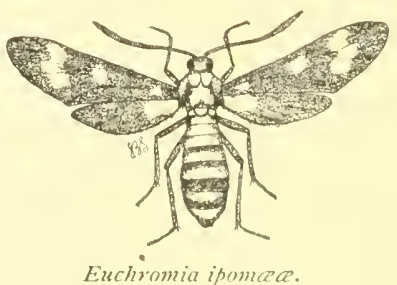

numbers. When this is full grown it denudes itself of hair, and with it and a few threads of sills forms a bright yellow cocom, from which issues in due time a wasp-like moth expanding nearly an inch, with narrow, white-spotted black wings, and a black, bright red or yellow banded abelomen. This is Euchromia ipomaa, which flies rather heavily and clumsily during the middle of the daty in bright sunlight. As against this insect the arsenites are indicated, or, where only a few plants are to be protected, hand-picking may be resorted to.

In vineyards there may be often seen feeding on the under sides of the leaves little, black-spotted, yellow, somewhat hairy larve, less than half an inch in length, ranged side by side as closely as possible, and retreating as they eat until a leaf is completely skeletonized. When this kind of larva is full grown it spins a white, flattened cocoon, in which it changes to a pupa and from which it emerges in due time as a little, narrowwinged, black moth wearing a red collar. This is the Harrisina 
americana, and certain varieties of grapes are occasionally injured by its larva. Feeding in colonies, as it does, the insect is easily checked by local applications of the arsenites.

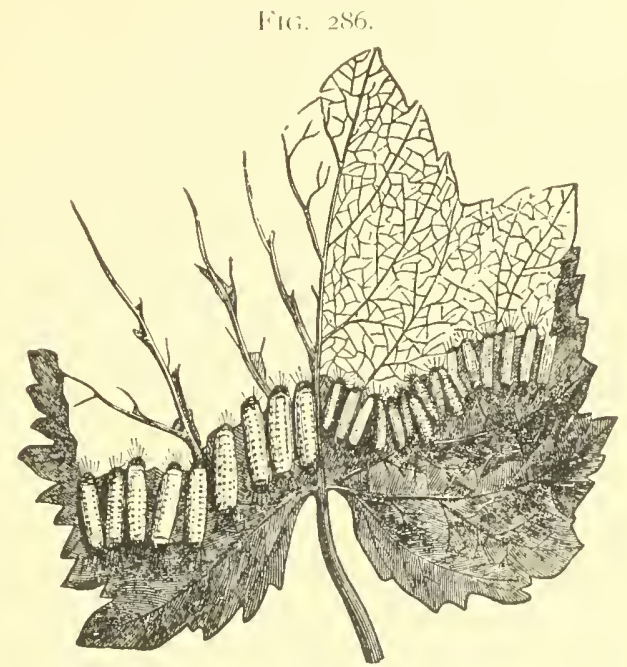

Grape-leaf on which larva of Harrisina ameriana are feeting.

We now enter into a series of species the caterpillars of which are known as "woolly bears," from the fact that they are all clothed with long hair. In some cases this hair is so dense that the body of the caterpillar itself cannot be seen at all, and all these are of the tretiid series. They spin a small ruantity of silk only, and use the hair with which they are clothed in conjunction with it to form the cocoon. Under the microscope it may be seen that it is furnished with small spurs or branches, by means of which the insect is able to produce a felt-like material, needing only a small quantity of silk to hold it together in a tissue sufficiently firm for its purpose. Perhaps the majority of the caterpillars of this series feed upon low plants, and frequently it cloes not matter much what. Plantain seems to be a common food for many species, but they eat grasses as well, and, incleed, almost anything. They are often found in gardens attacking lettuce and cabbage, and on cabbages they are sometimes trouble some in the field. Some are almost white or yellowish, and vary 
to brown or redelish, sometimes even to blackish, the hair being of the colors indicated, and the surfice of the body hardly visible. The commonest of all, perhaps, is the Spilosoma airginica, or "white ermine moth," and this is whitish or yellowish, producing a snow-white moth, the wings a little black dotted, the sides of the abdomen and front legs yellow. Another species often seen crawling about during late fall is Pyrrartiu isabellu, and

Fig. 287 .

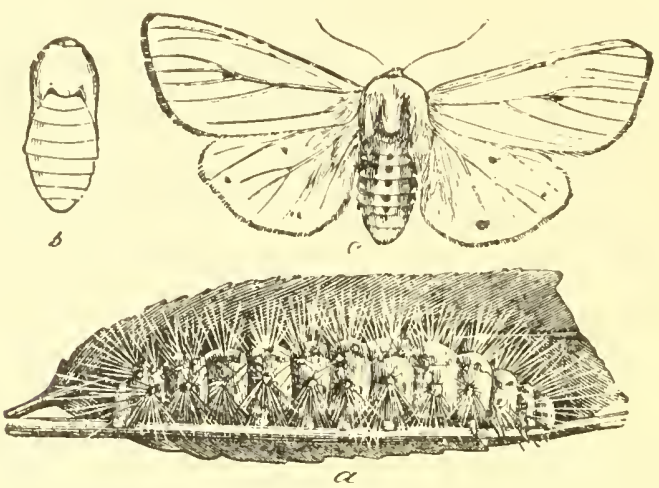

Spilosoma virginica, the white ermine moth.- $a$, larva: $b$. mpa: $c$, arlult.

this caterpillar may be recognized by having the central portions of the body red-brown, while the anterior and posterior segments are black. This produces a uniformly brownish-yellow moth. All the moths fly at night, and are but rarely seen during the day, and all the caterpillars, where they become troublesome, are within reach of the arsenites.

An exception to the general feeding habit we fund in Hyphantria cunea, the caterpillar of which is known as the "fall webworm." The moth is white, sometimes without spot or mark of any kincl, usually with only a few black dots, but occasionally with the spots forming more or less evident bands across the wing. The eggs are laid in masses on trees, and the larva, as soon as they hatch, form a little web in which they remain socially, except when feeding. They eat first the leaves within. then those close to their nest, yradually separating until sometimes an entire tree becomes defoliated from a single point. This 
species often becomes a serious pest in cities on shade-trees. There are two broods, the second being usually the one most

FIG. 288.

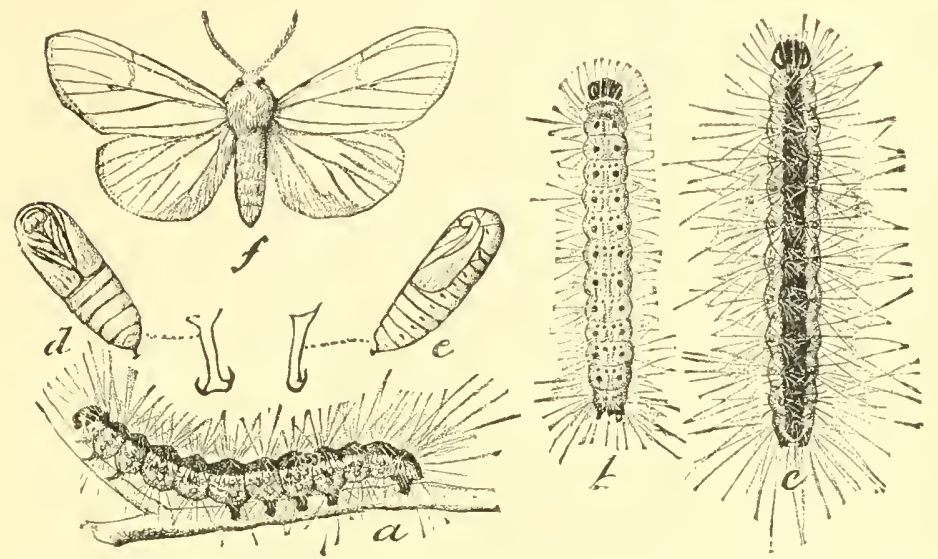

The fall web-worm, Hyphantria cunea. $-a, b, c$, varieties of larva: $d, e$, pupa; $f$, moth of the normal white form.

noticeable, whence the name "fall" web-worm, to distinguish it from the common orchard tent-caterpillar, which appears only in

FIG. 289.
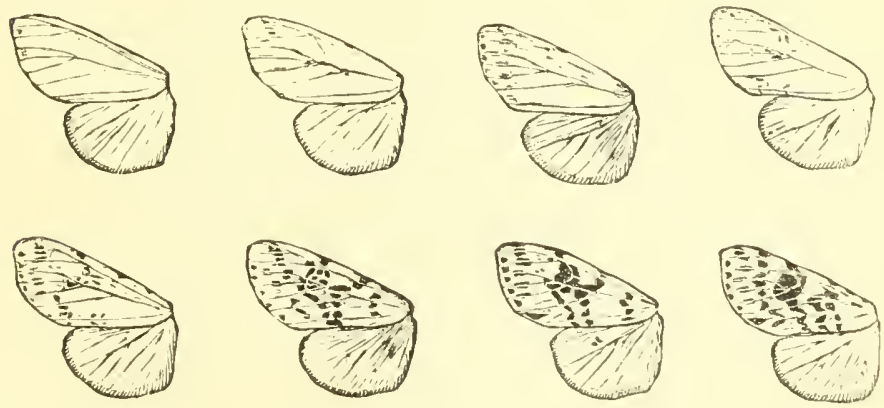

Hyphantria cunca: variations in the markings of the wings.

spring. A large variety of trees and shrubs is attacked by this insect, and where abundant it becomes a great nuisance. Usu- 
ally its naturil enemies keep it in check, but sometimes it seems (1) outrun then, and then for a series of years in succession it becones increasingly abundant until, as suckenly ats it increased, it disippears so nearly that nothing will be seen of it for a few years. If the insect is taken in hand as soon as noticed. cutting (lown and destroying the newly formed nests with all the caterpillars they contain will prove the most satisfactory remedy, or the foliage just surrounding them may be sprayed with an arsenical mixture.

There are other species in this series, like those belonging to the genus Halisidota, which sometimes infest shade trees, but rarely in numbers sufficient to be troublesome. The caterpillars may be distinguished by having slender pencils of hair, and sometimes a series of dorsal tufts. The moths are brownish yellow, with rows of semi-transparent and irregular, light-brown spots arranged almost in bands. Economically none others of the Arctians are troublesome, though we have many species that are common enough when sought for.

In the family Limantriade we have what are known as the "vaporer," or "tussock moths." Of these the Notolophus (Orgyia) lcucostigma, or "white-spotted tussock-moth," is the most common. It feeds on a great variety of trees in the

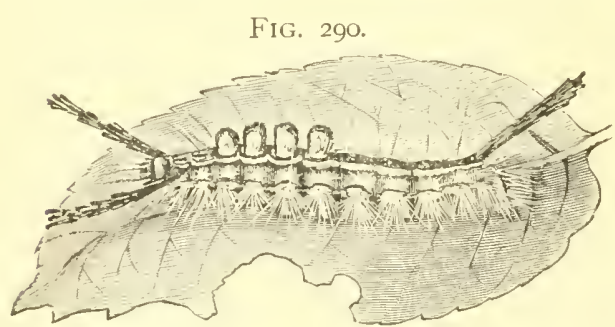

Caterpillar of Votolophus leucostigma. larval stage, and is seriously troublesome in cities and towns. The caterpillars are rather pretty creatures, with bright red heads resembling sealing-wax in appearance, and yellow bodies bearing a series of dense, abruptly cut off brushes on the middle of the back, and two pencils of black hair anteriorly. They are rather more than an inch in length, when full grown crawl down the trees, and, either on the trunk or somewhere in the vicinity, under any projecting point on fence-rail or the like, make their dirtywhitish cocoon of nixed silk and hair. In che time the adults emerge, the male bearing fully developed wings, while the 
female has no trace of them whatever. The wings of the male are dusty gray in color, crossed by rather distinct, blackish lines, and with a little white spot near the outer lower angle, which gives the insect its name, leucostigma. The antennae are prominently feathered or pectinated, and the forelegs are long, very prettily tufted, and held when at rest projecting some distance forward. The insect is not often seen during the day, and usually rests concealed until nightfall, when it seeks its mate. The female can be distinguished in the pupal stage by its larger size and the absence of wing pads. When it crawls ont upon the surface of its cocoon it is a grub-like creature with a very heavy

Fig. 291.
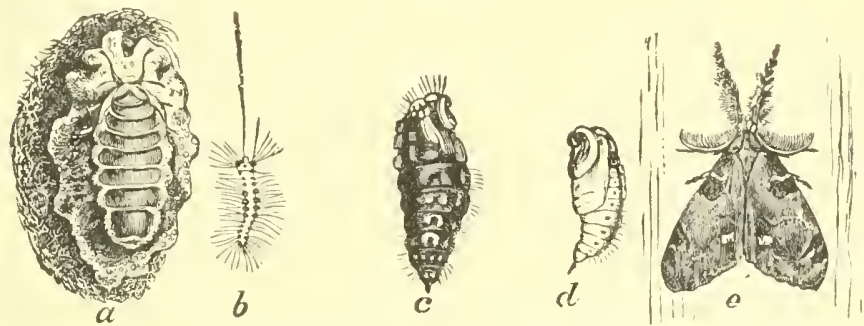

The vaporer moth, Nololophus leucostigma.-a, wingless female on her egg-mass; $b$, young larva ; $c$, female, $d$, male pupa; $e$, male moth.

body, rather short legs, small head, and very short antennæ. Neither of the sexes are capable of feeding, and as soon as the male has found the female, oviposition begins. The eggs are deposited upon the cocoon from which the female emerged, and as laid they are covered with a snow-white, frothy mass which hardens almost immediately into a brittle material that serves as a protection. The first brood of moths appears abont midsummer, and from the eggrs then laid the little caterpillars hatch in a few days; these in turn become aclult in fall, and eggs then laid remain throughout the winter, the prominent white masses soon turning gray and dirty, and hardly conspicuous on the trees or other surroundings to which they are attached. In the more northern States there is a single brood only. These insects when troublesome to shade-trees are easily dealt with : if all the eggmasses are removed and destroyed during the winter, the tree will remain clean churing the ensuing summer, provided caterpillars 
are prevented from crawling up the trunk from the surrounding points. A band of "dendrolene" six inches in width and half an inch thick on a sheet of heavy wrapping-paper will serve as a complete protection if the tree has been cleared of eggs during the preceding winter. It is easy to see how this is done; the female is absolutely incapalble of flight, and no eggs can be laid upon a tree until a caterpillar has first made its way upon it and has changed to a female moth. Insteal of "dendrolene" a broad band of fuffy cotton will answer for at time, as the caterpillars become entangled in and are unable to cross it. This sort of protection must be carefully watched, however, because otherwise the wet and dirt will harden and cause its failure to act as a bar. A trough of oil or an inverted tin cone tightly fixed to the tree may also serve, as will anything else that prevents the caterpillars from crawling upon the tree.

Belonging about here in the series comes the European "gypsy moth," Ocneria dispar, which, imported into Massachusctts in 1868, has caused enormous damage in that State, and has cost annually many thousands of dollars to keep it in check. The caterpillar when full grown is about one and one-loalf inches in length, of a creamy white, so thickly sprinkled with black that it seems dark brown, the ground color appearing in the broken dorsal and lateral lines. It is furnished with distinct dorsal and literal tubercles, blue anteriorly and crimson behind the fifth segment, from each of which arise tufts of long black and yellowish hair. It changes to a chocolate-brown pupa, held in place by a few threads forming the merest apology for a cocoon, from July to September, and a few days thereafter the moths emerge. The males expand from one and one-half to two inches, are brownish yellow in color, the secondaries paler with a darker outer margin, the primaries smoky with darker, irregular, transverse lines. The females are much larger and more heavily built, the wings often expanding two and one-half inches. They are creany white in color, the irregular, transverse lines gray or blackish. They lay their eggs in masses of from four hundred to five hundred in all conceivable localities, and cover them with yellow hair and scales from the end of the abdomen. They are deposited from July to late in September, and the larvæ hatch early the following year, ranging from April to June, according 
to temperature and location. The fight against this insect is told in the repurts of the Gypsy Moth Commission of Massachusetti, and these have been distributed wherever the insect has made its appearance. It has not as yet extended beyond Masisachusetts ; hence details as to its destruction are not in place here. It is, perhaps, the most dangerous pest ever introduced into the United States, and should the State of Massachusetts abandon its campaign against it, the annual charge upon the farmers of the country would become enomous, if not ruinous.

To the family Eucleida, or Limacodida, belong a series of rather modest green and brown moths, usually small in size, very

Fig. 296.
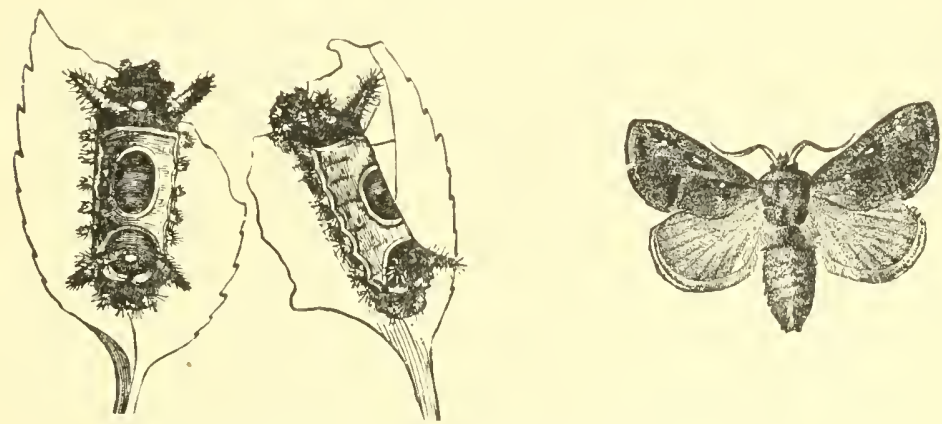

The saddle-back caterpillar and its moth, Empretra stmulea.

densely clothed with scales and hair, the head much reduced, and the tongue wanting. This, by the bye, is quite a general character in the types now under consideration, and which are termed "spinners," because most of the caterpillars make a more or less complete cocoon of silk. The Limacodids are rarely common, and only one species, Empretia stimulea, has become troublesome in the caterpillar state. This is a very curious, sluglike larva, somewhat flattened and oblong in shape, most of the body green in color, but with at quadrate, red-brown patch resembling a saddle on the middle of the back, and a brown patch at each end of the body, from the outer edge of each of which arises a long, fleshy process, set with stiff spines in all directions. Small warts or processes are found along the sides of the body, set with stiff hairs in the same way. It has no ap- 
FIG. 297.

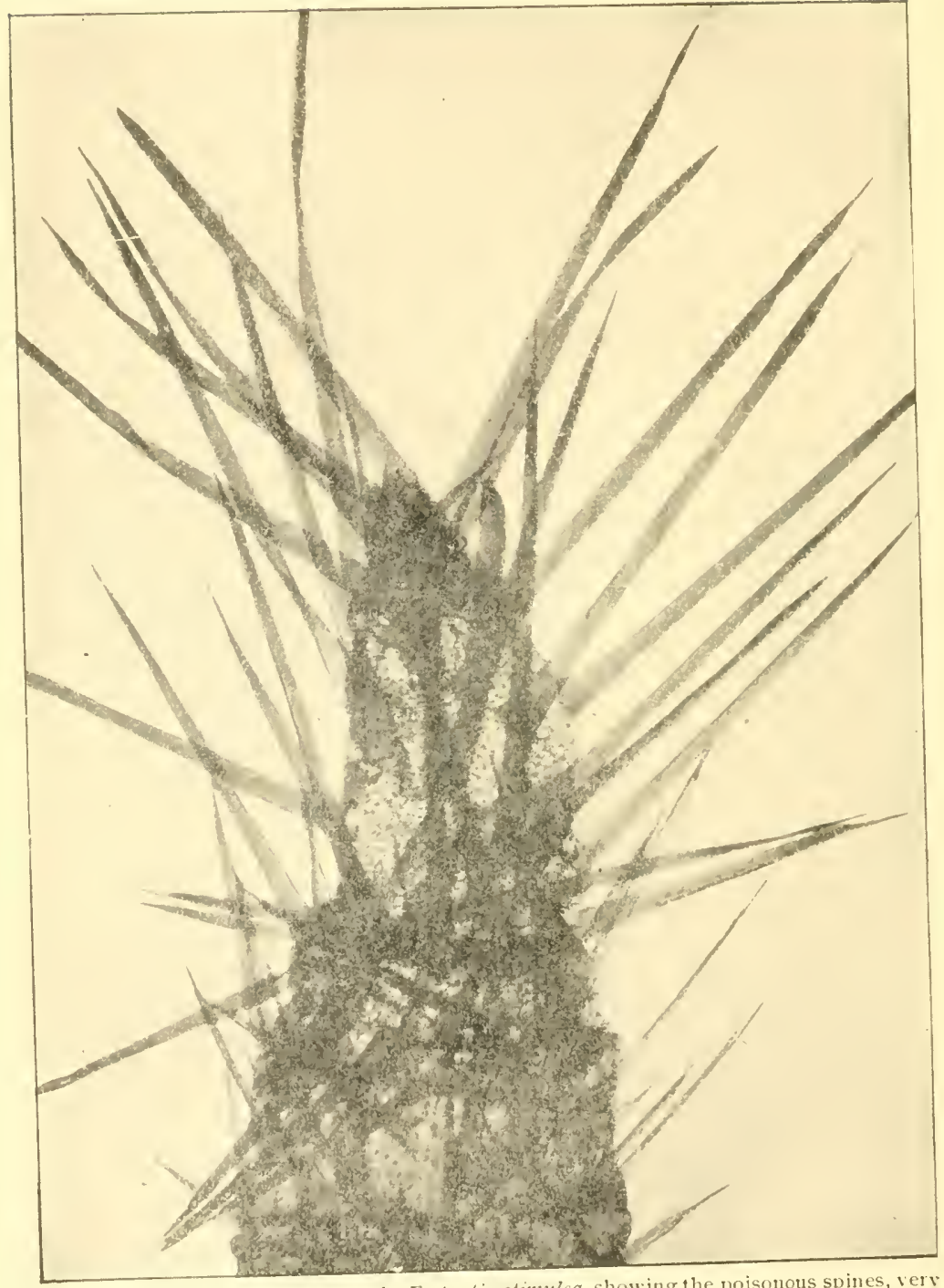
A tuberche from a saddle-hack moth, Empretia stimulea, showing the poisonous spines,
much enlarged. The short pointed tips break oft readily and remain in the wound. 
parent legs, but seems to crawl directly upon its belly, as do all the other caterpillars of this family, most of which have similir, though less developed, spinous processes. Another peculiarity which this species shares with others in the family is, that when handled, it causes a burning pain as if nettles had been touched. The hollow spines are terminated with easily detachable, very short, stiff tips, and at their base is a gland which secretes an urticating liquid. Handling the caterpillars roughly results in breaking off the little tips, which enter the skin and at the same time release a little drop of liquid, which, entering the wound, causes the burning sensation. With some persons this becomes a serious matter ; first inflammation, then swelling sets in, and in extreme cases a numbness or partial paralysis of the entire limb ensues. As a rule, however, the irritation is local, and no worse than would result from bandling a nettle. The prompt application of ammonia, bicarbonate of socla, or even strong brine will generally act as an antidote. This saddle-back caterpillar lives on a great variety of plants, including pear and rose, on which it is sometimes found in numbers. When full grown it spins an oval, brown, parchment-like cocoon, and in this remains unchanged until spring; then it transforms to a pupa, and from this issues a brown moth, expanding less than an inch, and known as Empretia stimulea. A number of other caterpillars of this family attack fruit-trees, but always in such small numbers that they can hardly be considered injurious.

The family Psychide is peculiar in that the larva are encased in sac-like structures which they carry about with them, and from which they derive the common term "bag-worms." The best known of these, "the" bag-worm, is Thyridoptery'r ephemeraformis. This is often common in orchards, and also attacks shade-trees, but is perhaps most injurious on arbor-vitæe hedges, which it sometimes kills. On deciduous trees the insects are usually noticed during the winter, when there may be found hanging to the twigs and branches cone-shaped bags of silk varying from a little less than an inch to an inch and a quarter in length, and studded with bits of sticks and leaves. If the smaller of these bags are cut open at this time there will be found an empty pupa shell, but in the larger there will be found a mass of yellow, fluffy material embedded in which is a great mass of eggs. 
In the spring these eggs hatch, and the little larva make their way out through the mouth of the bag and feed upon the leaves, at once constructing for themselves a case made of leaf fragments held together with silken threads. At this time the bags are carried upright, and the insects feed on the upper surface of the leaf. As the larva grows it enlarges its habitation, which soon becomes too heavy to be maintained in an upright position, and
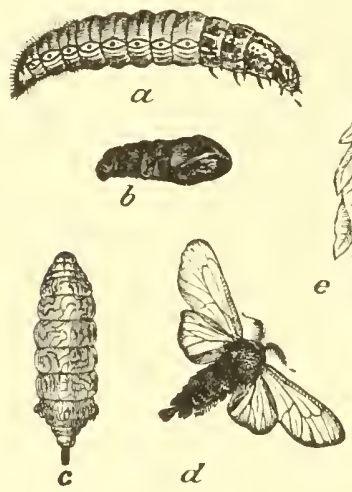

\section{IFIG. 298.}

The bag-worm, Thyrtoptery ephemeraformis. $-a$, larva: $b$, male pupa; $c$, female, $d$, male moth; $c$, bag of female cut open to show the mass of eggs; $f$, caterpillar with bag in normal position; $g$, young larvæ with bags carried upright.

drops; the insect continues to feed, attaching the bag by means of silken threads to twigs when not moving about from place to place. Late in summer the larva become full grown, and wander, sometimes leaving the trees altogether and fastening to fences or other shelter in the vicinity, and it is this habit that provides for the spread of the insects. When they have reached a place that suits them, the bags are firmly fastened, the opening is closed, and the caterpillars change to pupre. Shortly after the male emerges, and this is a black moth with transparent wings, short, feathered antenne, and an unusually long, tapering body: It is quite active and seeks the female, which forms only an imperfect sort of pupa, and even in the adult condition is a nondescript without trace of wings and almost without antennæ. 
It is, indeed, a helpless, grub-like creature that awaits the visit of the male without making an attempt to emerge from its sac, in which it remains even after impregnation. The eggs develop. finally fill up the bag, and then the female dies, the eggs resting in the fluffy mass already described until the spring following.

This species is best treated by picking off and destroying the bags during the winter, and if this is thoroughly done no caterpillars will appear on the trees in the spring, unless they crawl on from other points where an egg-sac may happen to be attached. The measures recommended against the "white-marked tussock moth" can be employed here as well, and trees once cleared can be kept free without much diffi. culty. When arbor-vitæ is attacked, the picking should be

FIG. 299.
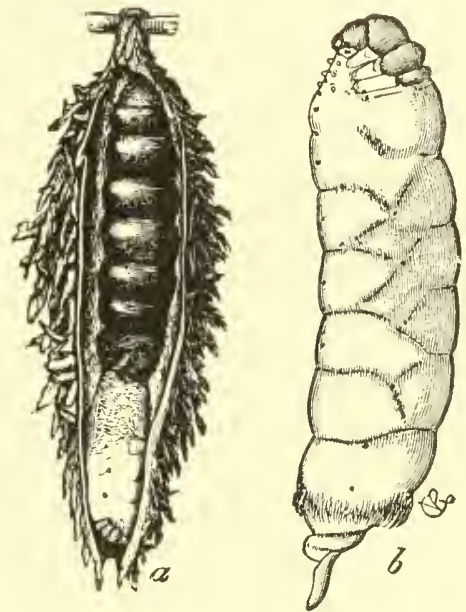

The bag-worm.- $a$, sack of female cut open to show the grub-like creature at its mouth; $b$, the female removed from the bag, much enlarged. thoroughly and carefully done, because these hedges suffer very rapidly, and once defoliated, usually die. In orchards where spraying is done against the codling-moth, the "bag-worms" are destroyed incidentally and no special measures need be taken against them.

Next follows the family of "prominents," so called from the fact that the moths frequently have a tooth at the inner margin of the fore wings, and the caterpillars are sometimes a littlc humped. They are technically termed Notodontida. Most of them have a small, retracted head, many of them a short or obsolete tongue, and some are more or less troublesome on cultivated plants.

One of the best known is the "yellow-necked caterpillar" often found fceding on apple-trees in colonies of from fifty to more than one hundred. When full grown it is nearly two inches 
in length, with a black head, a yellow neck, and the rest of the body yellow and blick spotted. It has a peculiar habit of holding by the false legs only and dropping the head and anal segments when at rest. The insects feed very rapidly and often defoliate large branches before their presence is realized. When full grown they descend to the ground, burrow a short distance beneath the surface, forming a conical pupa, and remain in that condition during the winter. In spring the moths emerge, and are of a brownish-ycllow color, crossed by rather even, narrow,

Fif. 300 .

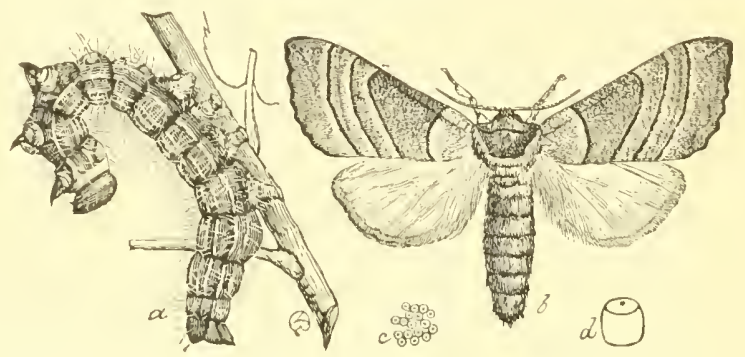

The yellow-necked caterpillar, $a$; its parent, Datana ministra, at $b$; eggs, natural size and enlarget, at $c$ and $\alpha$.

brown lines; and this species is Datana ministra. It lays its white eggs to the number of nearly one liundred on the under side of apple and other leaves in a single layer. Similar caterpillars may be found on a variety of other plants. The sumach is often defoliated, walnut- and oak-trees have their own species, and in all cases the moths have the general appearance already described. Insects that feed thus in company are controlled without difficulty, if we attack them as soon as the colony has hatched. They are then confined to a few leaves, and if these be picked off ancl destroyed, injury is avoided for the season. If this is not possible, or the colony has already spread too great a listance, then spraying the infested branch with arsenites will answer every purpose.

There are other caterpillars of this family that attack fruit-trees, but as a rule in such small numbers as to be harmless.

Oak-trees are occasionally attacked and defoliated by caterpillars about an inch and a quarter in length, with a yellow head. 


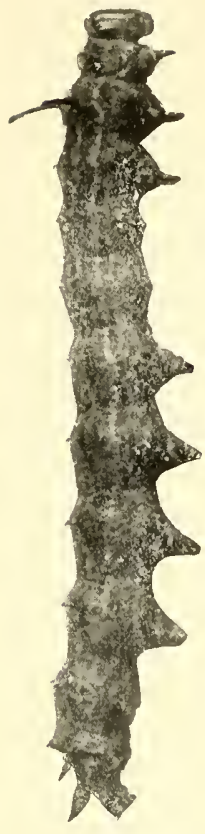

Iifi. 305.

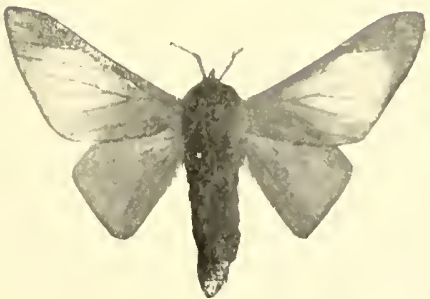

Fiti. 294.

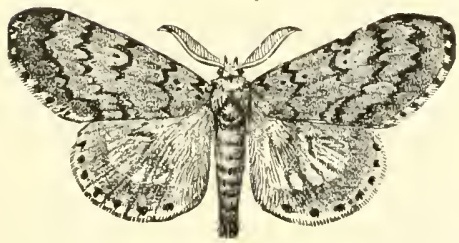

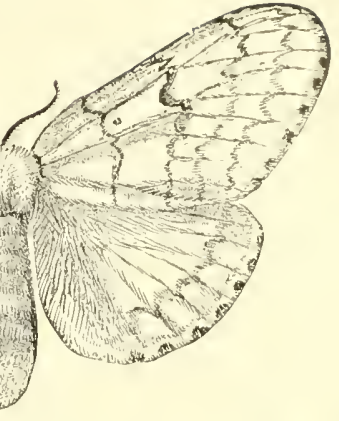

Fix. 316 .

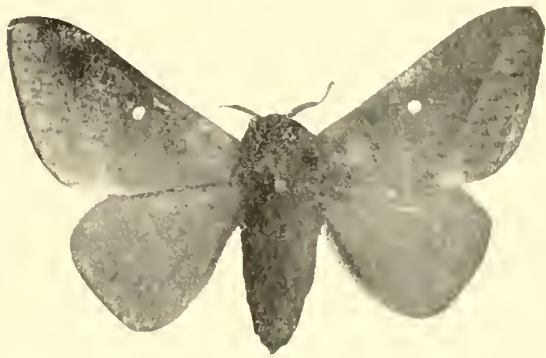

Fiti. 292.

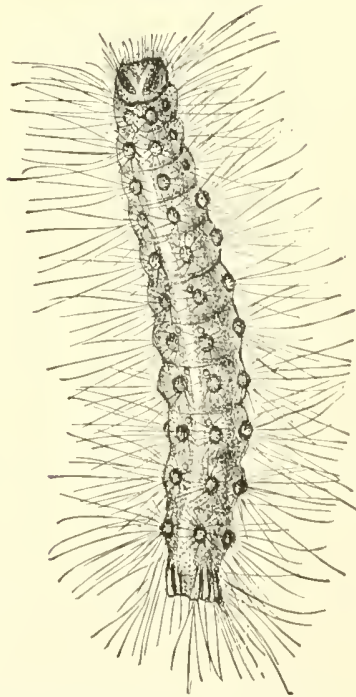

Fig. 292, larva of sypsy moth. Figs. 294: 295, gypsy moth, Ocneria dispar, male and female. Fig. 304, tnisota senatoria, larva. Figs. 305, 306. Anisota sinaturia, male and female. 

the body striped with narrow black or reddish-brown lines, ex cept at the sides, where it is gray or yellowish. Near the posterior extremity is a rather prominent, humped segment entirely red in color. When full grown they go underground, and from them come, in the spring following, moths gray in Fig. 301. color, mottled with brown, but the front of the body and a margin along the anterior edge of the forewings white or nearly so. These are called Edema albifrons. The body is rather cylindrical, heavy, extending somewhat beyond the hind wings and obtusely terminated.

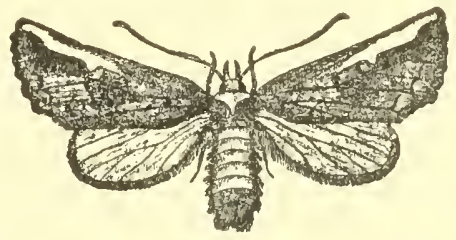

Feeding exposed as these insects do, they are readily destroyed by the arsenites.

One other caterpillar sometimes occurs in swarms on a great variety of plants, including some fruit-trees, and this is known as the "red-humped prominent." It is yellowish brown in color, pale along the sides and striped with slender black lines. The fourth segment is humped and of a red color like that of the

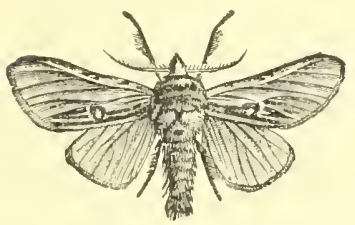

FIG. 302 .

Edemasia concinna and its larva, the "red-humped prominent."

head. There are a number of short spinous processes along the back, and some which are larger and more prominent on a hinder segment. The moth that emerges from this lirva is the Gidemasia concinna, and is of a light-brown color, the wings expanding a little more than an inch, the anterior pair dark brown along the inner margin and more or less gray tinged before. The 
measures already recommended are applicable to this species, and in fact none of the caterpillars belonging to this family need ever cause serious trouble or difficulty in their control.

Next come the Ceratocampide, containing only a few very large species whose caterpillars are more or less furnished with horns, spines, or similar processes. The moths are sometimes contrastingly colored and distinguished by having the antenna in the male feathered for unly a portion of the distance; the terminal third of the stalk lacking the pectinations, while towards the base there are two branches to every joint.

Occasionally we see a very large, green caterpillar, with black and red blotches, and with four very long horns, yellow at the base and black at the tip, on the first segments. This is an insect much dreaded, and known by the attractive name of "the hickory horned devil." The first part of the name is from the food plant upon which it is often found, the second from its prominent horns, and the third from its supposed evil inclinations. Yet the creature is absolutely harmless, incapable of inflicting the slightest injury upon even the most delicate subject, and it depends for protection entirely upon its formidable appearance. The moth resulting from it, Citheronia regalis, or "regal walnut-moth," is rare and seclom seen, flying only at night and not much then, because, having no tongue, it does not feed. It is, however, rather handsome, tawny brown in color, the veins streaked with red and with two series of more or less distinct yellow blotches. It expands from three to nearly six inches, and is one of the largest of our night-flying moths.

The species belonging to the genus Anisota are sometimes much more abundant, and occasionally become troublesome on oaks. I have seen acres of forest almost entirely defoliated by large yellow and black-striped caterpillars, with black head, two long, black filaments on the anterior, and numerous shorter black processes on the other segments. These are the "orangestriped oak worms," which, when mature, go beneath the surface of the ground, change to brown, roughened pupx, and in spring appear as brown moths; the Anisota senatoria. The males are much the smaller, have the fore-wings somewhat triangular and pointed, a little transparent towards the middle, and with a clear white spot near the centre. The females are rather 
lighter in color, the white spot is much smaller, and the wings are not in the least transparent, but irrorated with clarker, small spots, which give them a pcwdered appearance.

On maples, especially in the more southern States, we often find a smaller caterpillar, which is green, with black stripes, and marked with little red dots. The resulting moth is known as the "rosy Dryocampa," and has the fore-wings rose colored,

\section{FIG. 307.}
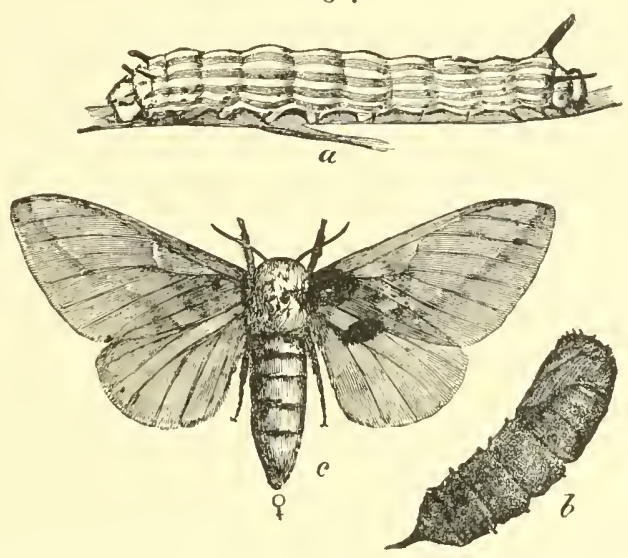

Dryocampa rubicunda.-a, its larva; $b$, its pupa; $c$, female moth: the rosy Dryocampa.

crossed by a broad pale-yellow band, while the hind wings are pale yellow, with a short rosy band behind the middle. It is rarely abundant enough to need attention, but when it does, the external feeding habit indicates the remedy at once.

Next we reach the series of species that are silk-spinners par excellence in the caterpillar state. They are known in a general way as bombycids from the term Bomby' $x$, which was for a long time applied to the "silk-worm." Among the largest of our Lepidoptera are the species of Attacus, which expand from four to eight inches, and are allied to the giants of the tropical region, which have a spread of wing of sometimes fully twelve inches. None of our species are ever numerous enough to be really troublesome, and they are interesting rather from the habits of the caterpillars, which, before changing to pupe, spin a very 
large and dense cocoon of silk, in which they remain until ready to transform into muths. The most common of these spinners

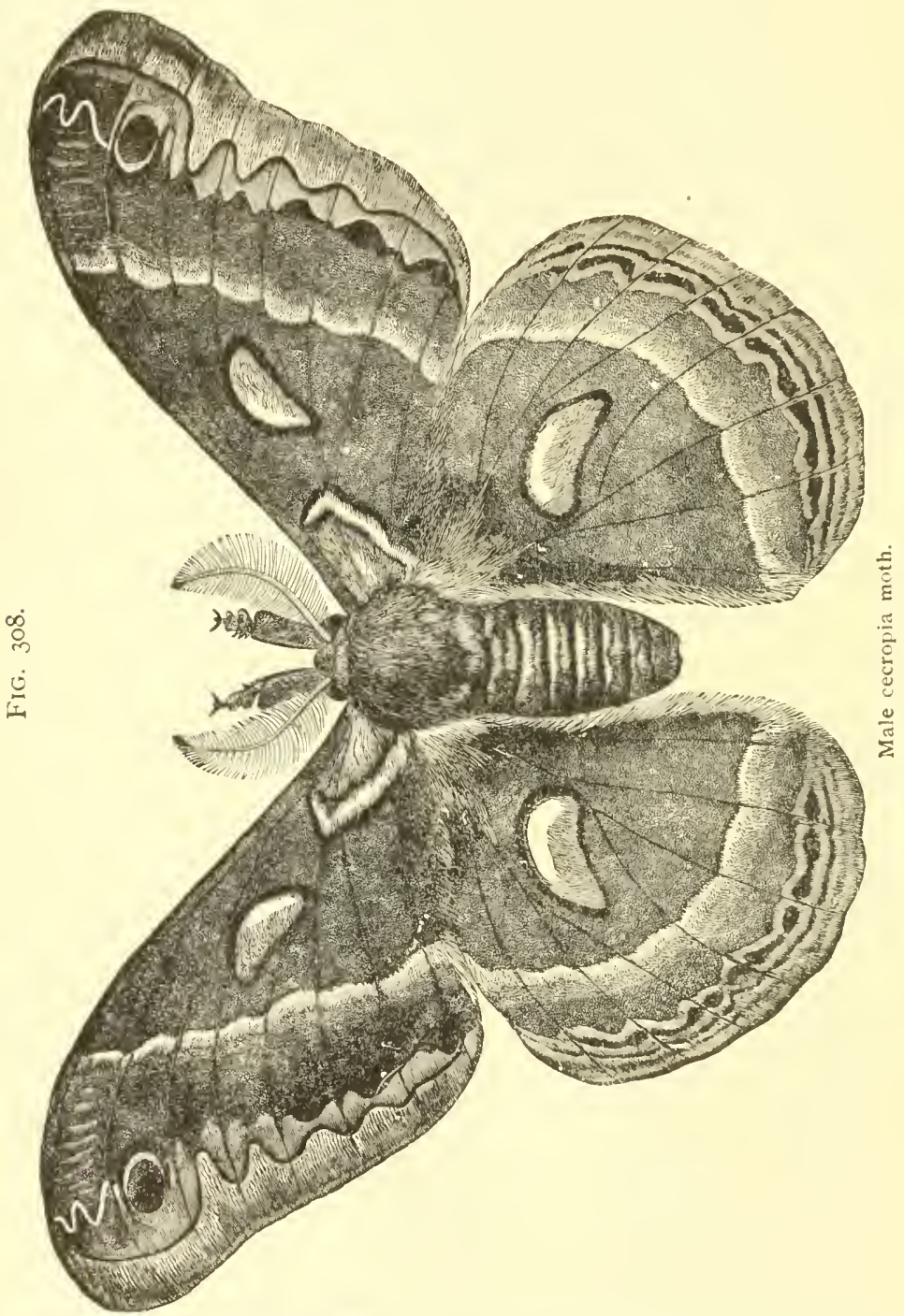

is the cecropia, Platysamia cecropia, the caterpillar occurring on a great variety of plants, including many of our fruit-trees and 
certain small fruits. It is green, and has six rather prominent warts on the thoracic segments, of which four are coral-red in color and the hinder two are yellow, sometimes with a reddish tinge. On the rest of the body are other tubercles which are furnished with little clusters of spurs and spines. The cocoon is sometimes spun in bushes, attached to a twig, sometimes at an angle of a fence, or wherever the caterpillar happens to consider it convenient. The resulting moth is dusky brown and powdery,

F1G. 309.

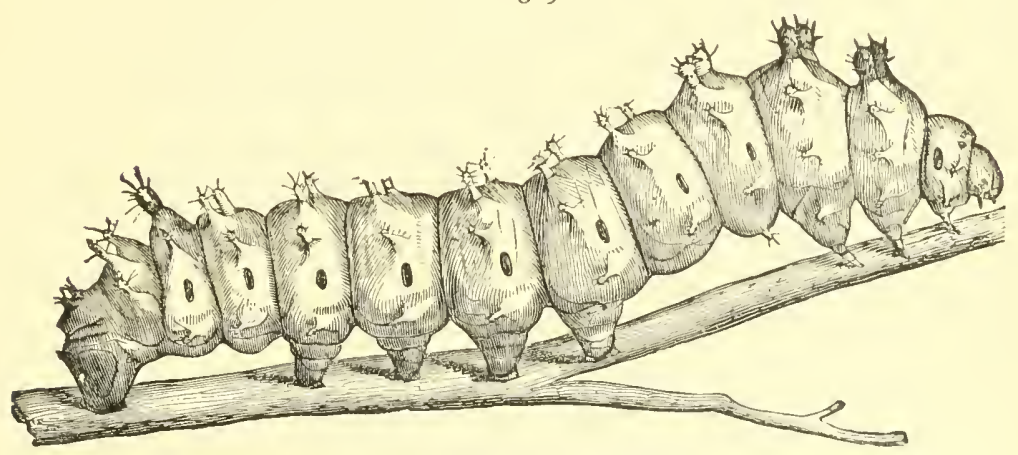

Caterpillar of the cecropia moth.

the hinder margins clay-colored, a kidney-shaped dull-red spot with a white centre and a narrow black edging is near the middle of each wing, and beyond the spot is a wavy dull-red band, bordered internally with white. The primaries near the base are dull red, and near the tip is an eye-like black spot within a bluish-white crescent. Several other species occur, all more or less resembling in general appearance the cecropia, and spinning much the same kind of cocoon.

Of a somewhat different type is the polyphemus, Telea poly' phemus, which has a green caterpillar without prominent tubercles, but with little, black, wart-like processes, giving rise to small, stiff bristles. This feeds upon oak and a variety of other trees, but is rarely abundant, and when forming its cocoon spins 11p) in a leaf, which later drops to the ground. This cocoon is oval in shape and completely closed, differing from that of cecropia and its nearest allies, in which it is open at one end. 
The moth is dull ochre-yellow in color, more or less cloucled with black in the middle of the wings, on each of which there

FIG. 310.

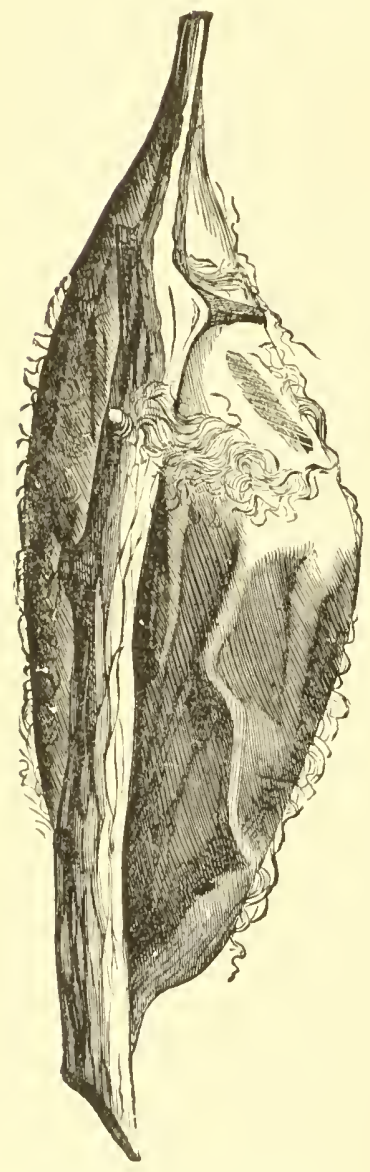

Cocoon of the cecropia moth. is a transparent eye-like spot, divided transversely by a slender line and encircled by yellow and black rings. Before and adjoining this spot in the hind wings is a large blue patch shading into black.

With a very similar caterpillar and cocoon, the luna moth, Actias hua, is entirely different from the polyphemus. It is of an even, bluish-green color, sometimes verging into yellowish, with a little eye-like spot on all wings, the anterior border of the forewings margined with scarlet, while the hind wings are each furnished with a long tail.

When these caterpillars are noticed on a cultivated plant they can be easily picked off and destroyed, but as a rule their natural enemies serve to keep them reduced to comparatively small numbers. These American species produce a much greater quantity of silk, of a much stouter texture than the Chinese silk-worm proper; but, unlike it, their thread cannot be reeled. It is this that makes it impossible to use our species successfully for the production of a cheap and strong silken fabric.

We sometimes find on corn, clover, apple, and other plants or trees a green caterpillar, with a brown stripe edged with white on each side of the body, covered also with little processes, from which arise clusters of prickly spines. These have urticating properties, so that if the larve are carelessly handled a certain anount of irritation may arise, though much less than is the case with the 
slug-like caterpillars previously described. They become rather more than two inches in length, spin a thin, irregular, and some-

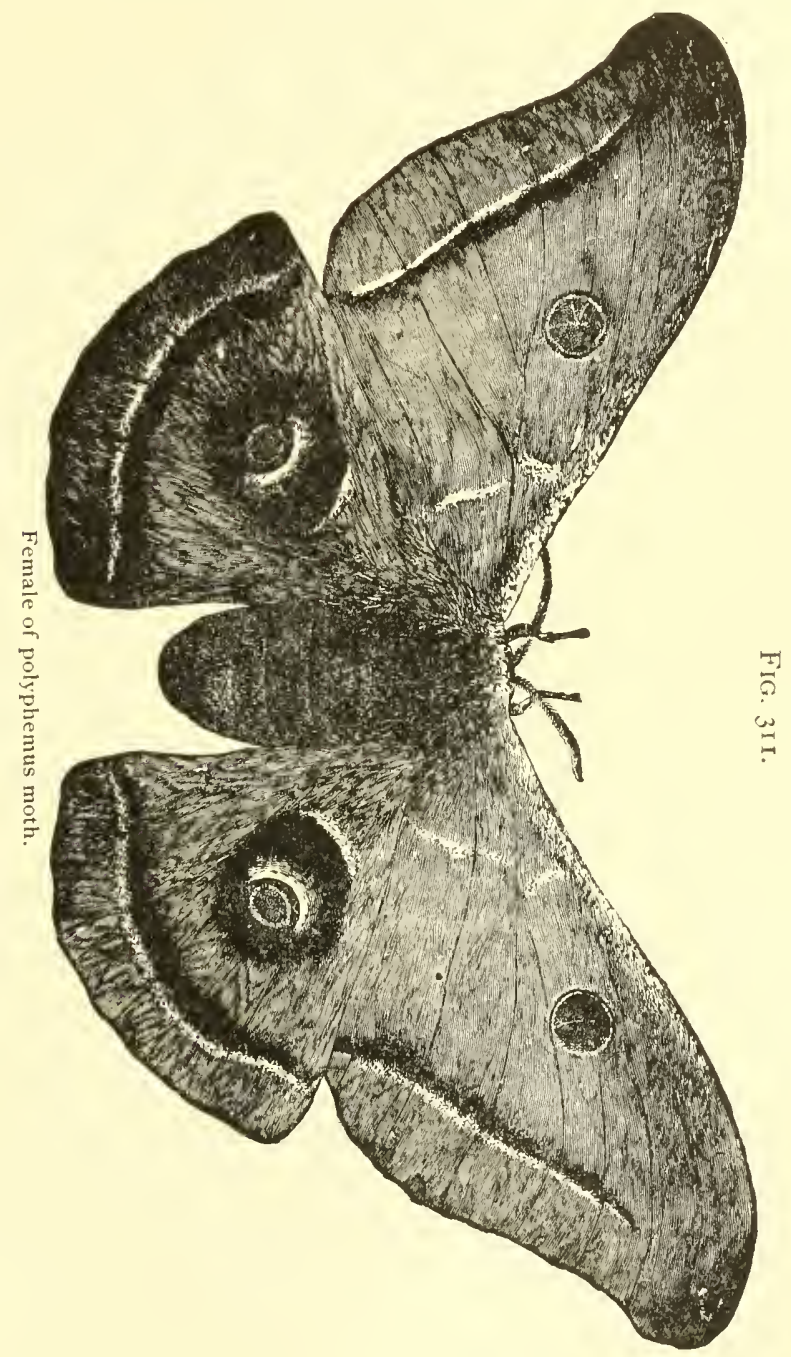

what parchment-like cocoon, and emerge in due time as "io" moths, - Automeris (Hyperchiria) io. The male is deep yellow, 
the pirimaries only a little banded with narrow lines, the wings reddish on the interior margin, with a narrow band of the same

FIG. 312.

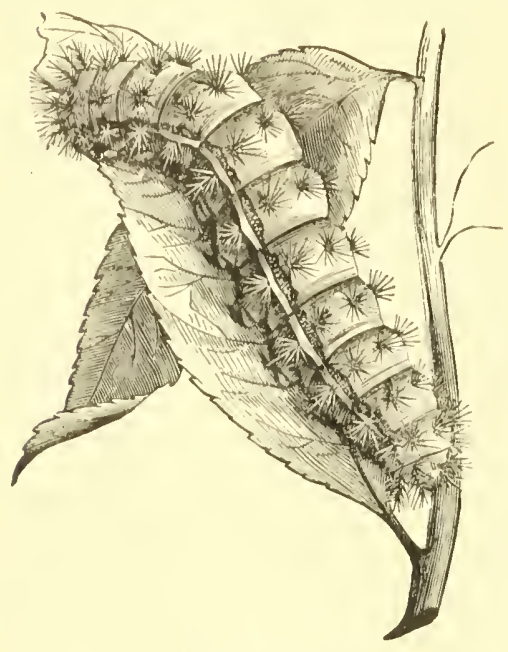

Larva of io moth.

color outwardly. On the middle of the hind wing is a large, round, blue spot, with a broad black border and a central white dash. In the female the primaries are purple-brown, the transverec lines gray and much more prominent, and there is a somewhat dusky, yale-margined, nearly kichey-shaped discal spot. The hind wings are essentially like those of the male, and altogrether this sex is larger than its companion.

The only other of the silkspinners to which attention need be called here are the species of Clisiocampa, which are interesting from the fact that most of them live in colonies and spin a tent of silk on the trees

\section{FIG. 313 .}

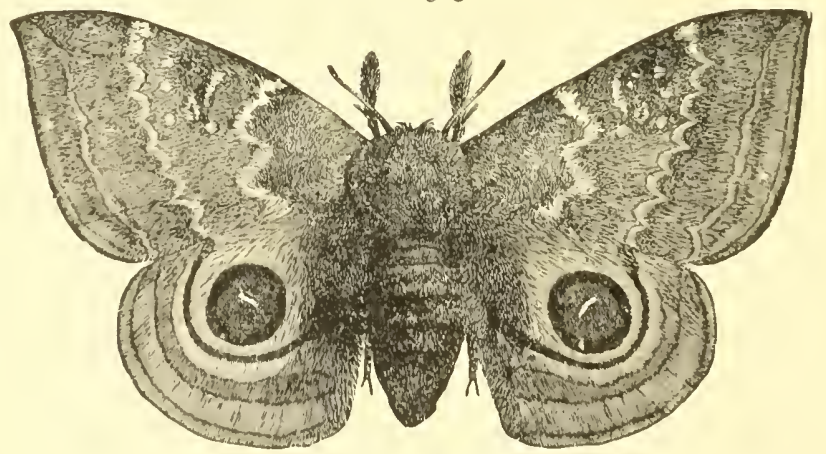

Aulomen is io, fomale.

attacked by them, whence they are called "tent-caterpillars." Our common species in the East is C. americana, found in apple 
orchards very early in the spring. During the winter we often find on the small twigs of the apple an incomplete belt of a very dark brown, wax-

like material. If we Fig. 314. examine this carefully we fund it to consist of a very large number of eggs soldered together, from which caterpillars hatch, sometimes before the leaves have started, which at once spin a litile web or tent in the ncarest fork. Here they live in company, moving out from time to time to feed upon the surrounding leaves, and increasing the size of their habitation as they grow. The "tents" form prominent and unsightly objects in neglected orchards, and are sometimes rather unpleasantly conspicuous in others that purport to be well kept. When full-grown the caterpillars abandon the nest, crawl to some convenient shelter in the vicinity, and spin a
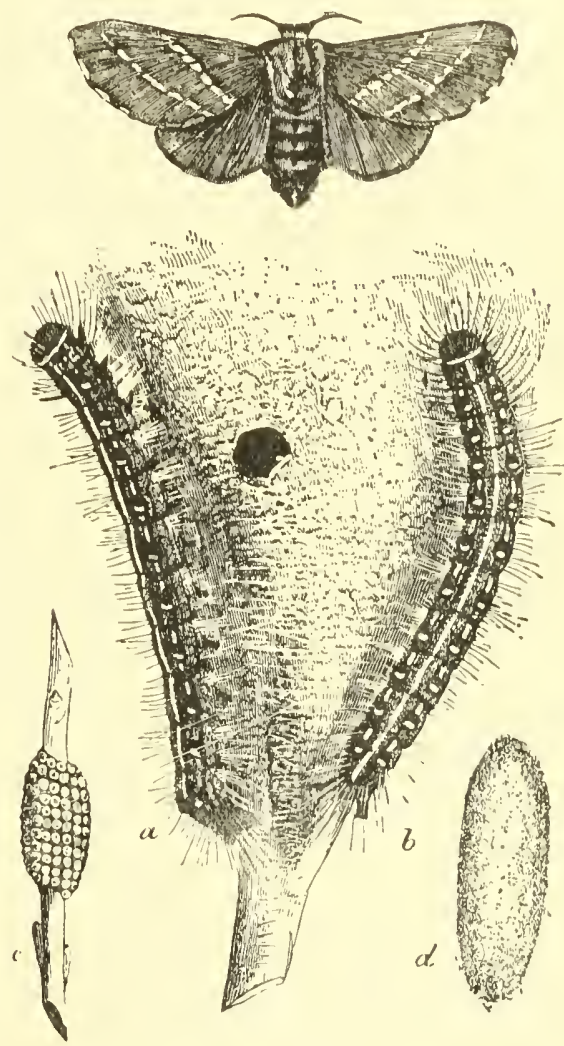

The American tent-caterpillars, \& and $b$, on the ontside of their tent near the entrance; $d$, coconn; $c$, egg-mass of an allied species; above all the female moth, Clisiocampa americana.

yellow, rather thin cocoon, which becomes covered with a fine yellow poweler. The moth is chull reddish in color, more or less brown-tinged, and the fore-wings live two oblicpue, pale stripes. The males are considerably smaller than the females, and as a rule darker in color, tending to have the wing between the lincs 
paler, while in the female we have, on the whole, an opposite tendencr. In the West, other species replace the amcricana, but their habits remain essentially the same, and they may be all treated in the same manner. During the winter the egg-masses are easily seen after a little practice, and they can generally be reached and cut down without trouble. Early in spring the nests are prominent objects and easily destroyed, with the entire colony. Where they are out of easy reach, simply spraying the branches nearest to their nest will destroy them in a day or two. In orchards in which spraying is systematically done for other pests, these insects rarely get a foothold.

The true silk-worm, Sericaria mori, though economically important, is hardly a proper subject for this work. Its history is so well known, and has so many special books devoted to it, that it is unnecessary to go into details here.

In the family Cossida we have a series of very peculiar moths, really low in the scale of development, but formerly placed about here in the classification and conveniently so treated. The caterpillars are all wood-borers, living from two to four years in the trunks or roots of trees. They are white, or with a faint red or yellow tinge, more or less black spotted, and with short, bristly hairs. The head is large and horny, usually black, and the jaws are stout and prominent. When full-grown they are from two to three inches in length, and change to a rather slender, cylincrical pupa an inch to an inch and a half in lengtl, depending

FIG. 3 I9.

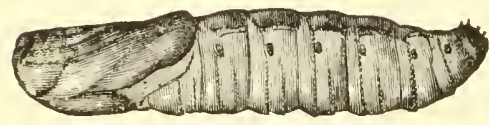

Pupa of the goat-moth. upon the species and sex. This pupa is furnished with a series of spines around the edges of each segment and sometimes also with a chisellike protuberance on the headcase. When ready to transform, it works itself by a twisting and wriggling motion through the bark and for half its length out into the open, holding fast by the spines on the abdominal segments. The adults, known as "goat-moths," from a rank odor peculiar to them, have rather narrow, pointed wings and a long conical abdomen. The females are heavy fliers, and both sexes are attracted to light, though rarely seen otherwise. The head is small, very much 
retracted, and the tongue is obsolete, so that the insect is incapable of feeding. None of our American species attack cultivated plants or trees so as to become injurious, though in forests
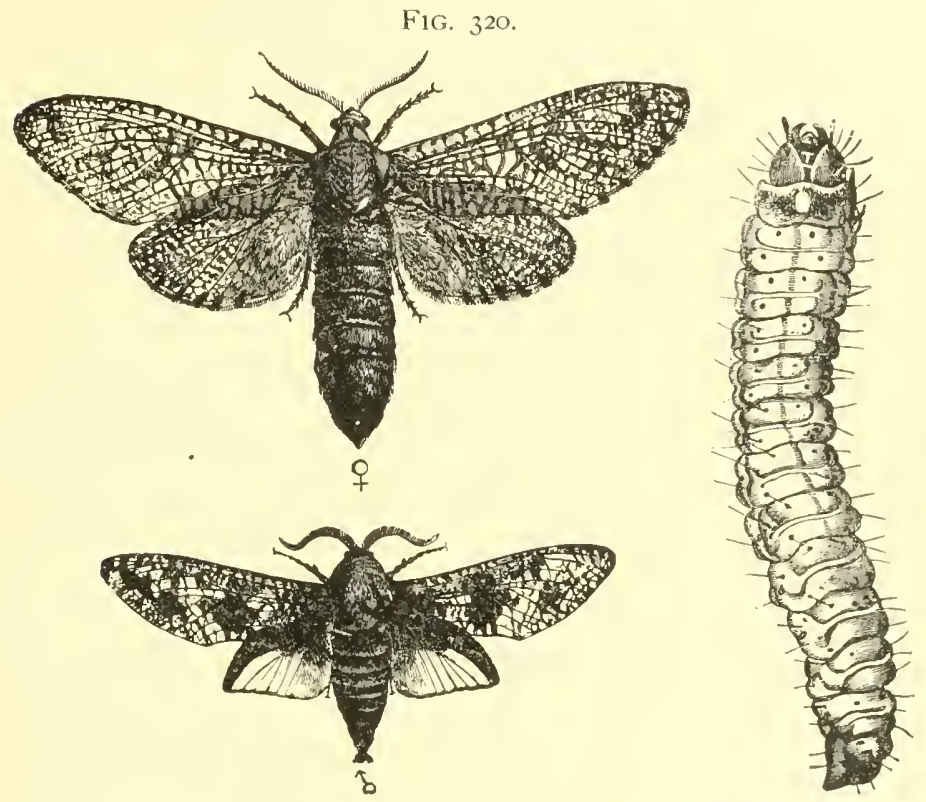

Goat-moths, Prionoxystus robma, female and male, and their larva.

young oak timber is sometimes badly injured by the Prionorystus robinice.

There has been recently introduced into the Eastern United States a European species known as the leopard-moth, Zcuzere pyrina, and this has become a pest on the shade-trees in several of our Eastern cities. The male moths expand a little more than an inch, the female over two inches, and both are white, spotted with black, whence the common name "leopard-moth." There is great difficulty in dealing with insects of this character, owing to their food habits. Fortunately, even in this imported form, the natural checks seem to prevent its doing much injury to orchards or country trees; but in the cities and towns it threatens the life of the shade-trees. The only recommendation to 
be made is constant watching by some man especially employed, who will destroy the borers just as soon as their presence is noticed, and who will gither the moths beneath the electric lights now found in most cities. Pans in which oil or some other substance is kept to kill the insects falling into them, properly arranged just beneath the lights, will prove of considerable

FIG. 321 .

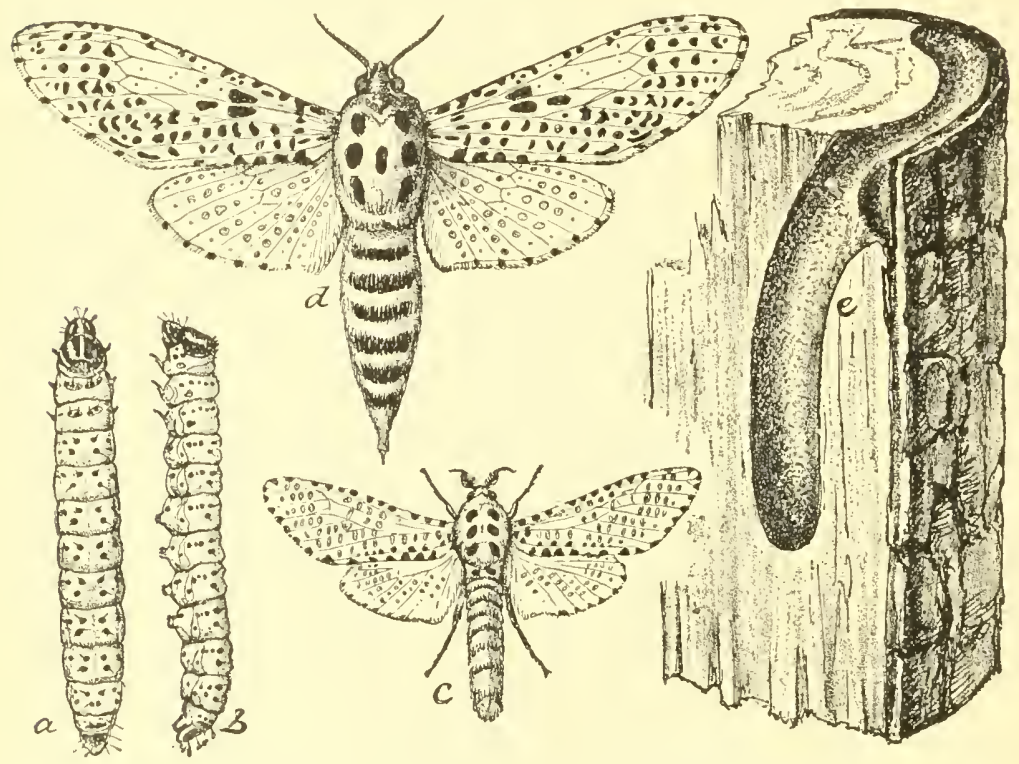

The wood "leopari-moth," Zeuzera pvrina.-a, $b$, larva, from above and side, about half grown; $c$, male, $d$, female; $e$, larval burrow, showing the tendency of the fullgrown caterpillar to girdle its food plant.

benefit; but it will take years of steady work to lessen the insects in some of our cities, and to remove them as a source of danger to the shade-trees.

In the fanily Noctuide, or "owtet-moths," we have a large number of species, and among them many that are troublesome to the agriculturit. The moths are, as a rule, sombre gray or hown, expanding when the wings are spread between one and three inches, averaging perhaps an inch and a half in the majority of cases. The fore-wings are comparatively narrow, rather short 


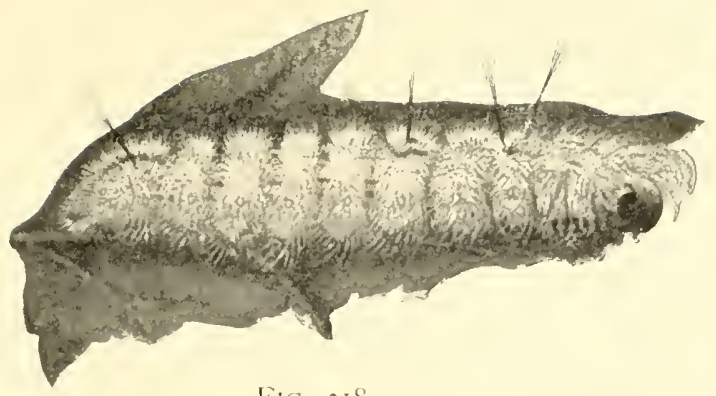

Fir. 3 IS.
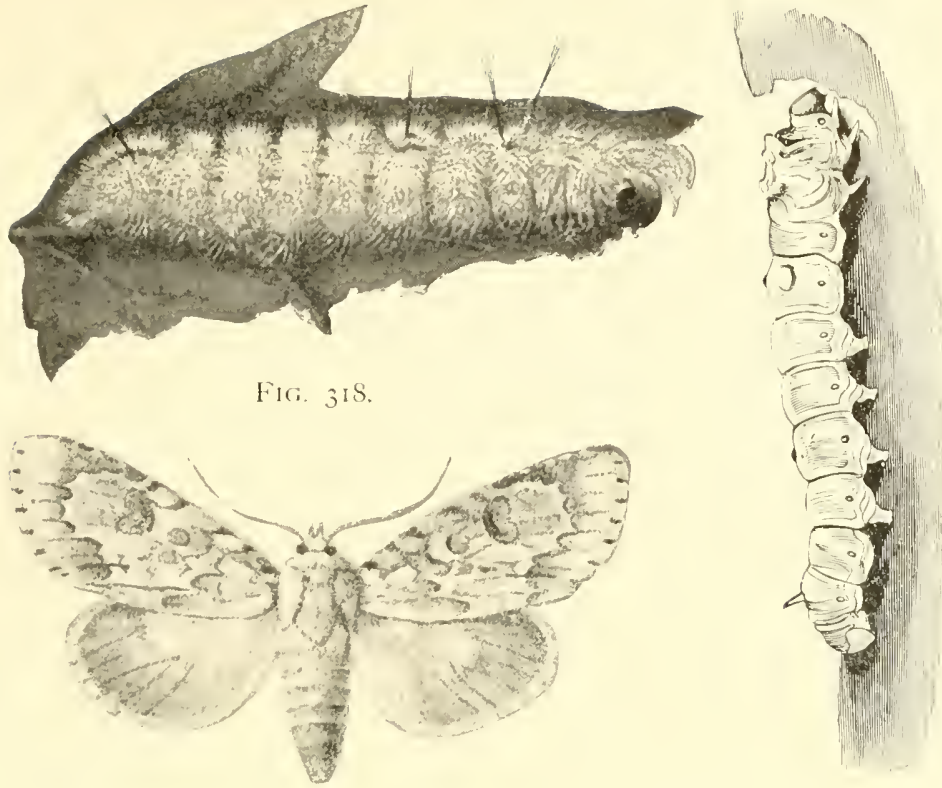

Fis, ? :

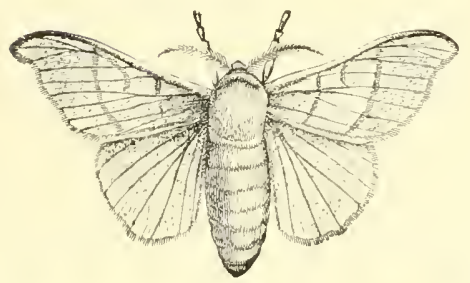

IKi. 316 .
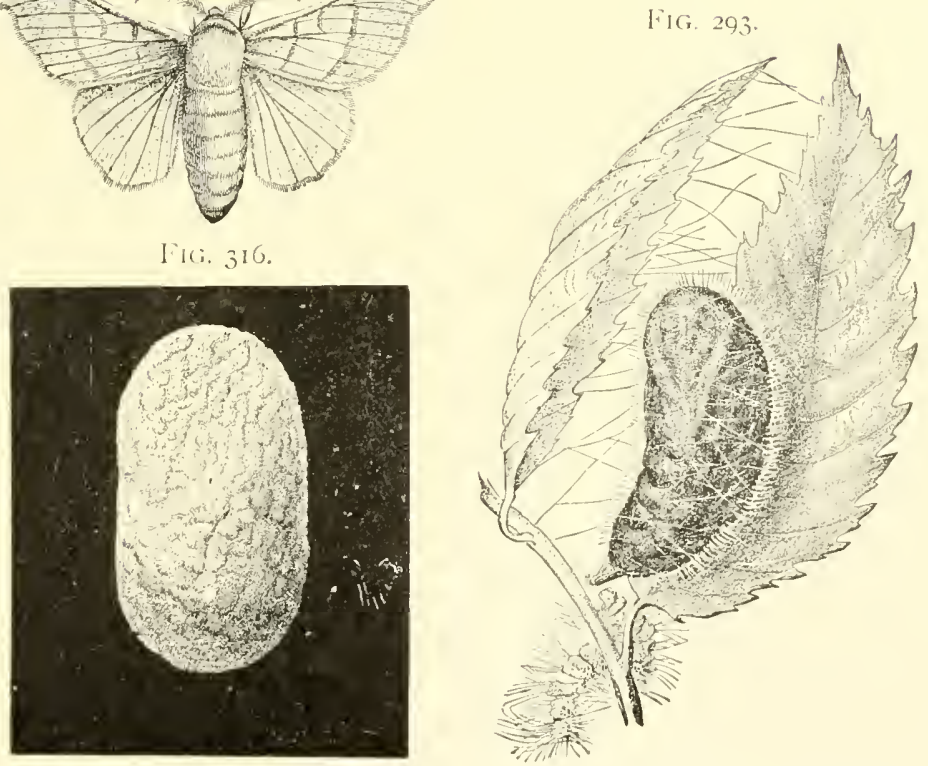

Fig. 293, pupa of Gypsy moth. Figs. 315, 316, 317, latra, cocoon, and male moth of Sericaria mon, the silk-worm. Fig. 318, moth, and Fig. 323, larva of Acronycta americana. 

and stout, crossed by a series of more or less marked crenulated or wavy lines, and with two usually darker or paler spots in the discal part of the wing. Of these, that nearest to the base of the wing is round or nearly so, and is called the orbicular; the other and larger, nearest to the outer part of the wing, is kidney-

FIG. 322.

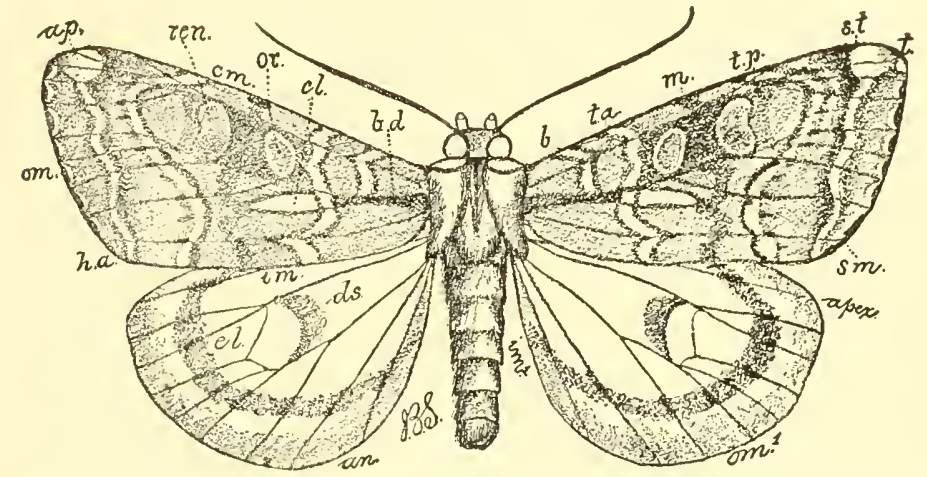

Wing of an owlet-moth, with all the markings defined and named.-Right wings: $b$, basal line; t.a., transverse anterior line; m., median line or shade; $t . p$. , transverse posterior line; st., suh-terminal line; $t$., terminal line; $s m$., sub-median vein; apex of hind wing; $o . m{ }^{1}{ }^{1}$, outer margin ; $i, m,{ }^{1}$, inner margin. Left wings : b.d., basal dash; $c l$, claviform; or., orbicular spot ; ven., reniform spot; ap., apical spot; c.m., costal margin; o.m., outer margin; i.m., inner margin; h.a., hind angle; d.s., discal spot; e.l., exterior line: an., anal angle.

shaped, or narrow-ovate, and is called the reniform. These terms are frequently used in economic literature, and the spots are in many cases characteristic. Taken as a whole, the species of the Noctuid family are very much alike, and no attempt will be made here to distinguish them, except in the most superficial manner. The hind wings are usually without markings, and when at rest are concealed by the fore-wings, which lie overlapping and covering them, either flat on the back or roof-like, a little oblique. In the early part of the series we have a number of species with hairy caterpillars that sometimes feed on shadetrees. We occasionally find a rather large yellow caterpillar, densely clothed with soft yellowish hairs and interspersed here and there a pencil of much longer, black hair. This is the caterpillar of Acronycta americana, one of the "dagger-moths," so 
called from the fact that on the fore-wings there are a number of shor black streaks crossing the transverse lines in such a way that the marks have a remote resemblance to a dagger, or to the Greek letter psi, $c^{\prime}$. They are all of some shade of gray, varying from very light ashen or nearly white to almost black; but none of them are serionsly injurious.

The more typical Noctuids are rarely seen during the day. They hide under bark or stones, in out-houses, or wherever they can find shelter. Occasionally they sit brazenly upon the trunks of trees or branches, or openly upon stones, their colors and markings blending so perfectly with their surroundings that they are invisible, except to the trained eye ; but at night they are active and fly readily, many of the species being attracted to light, and nearly all of them to sweets: for these insects are furnished with a well-developed tongue and require food. When the moths are examined in the dark, their eyes are seen to glow with a deep phosphorescence that is quite startling at first sight. The entomologist makes use of their sweet tooth by what is known as "baiting" or "sugaring," placing a mixture of molasses, beer, and rum in patches upon trees, fence-posts, or even stones, and visiting them after lark with a lantern. The moths are often attracted in great numbers to these lures, and many species not otherwise obtainable are thus adkled to our collections. Many of their caterpillars are known as "cut-worms," and when fullgrown average from an inch to an inch and a half, sometimes reaching, but rarely exceeding, two inches in length. They are naked, obscurely colored, usually varying from dirty gray to dirty yellow-brown, generally with feebly-marked longitudinal lines, and rarely with well-marked black spots. They hide during the day a little below the surface of the ground at the base of the plants upon which they feed, and during the night come out to feed upon whatever regretation they can find. Normally, the female moth lays her eggs in grass land after midsummer, but sometimes weedy fields are selected, or partly overgrown orchards, or, in fact, any location with a sufficient quantity of low vegetation to support the caterpillars. They are rarely laid directly on or in the ground, but may be deposited on trees, stones, or leaves. When the larve hatch, late in summer or early in fall, they feed upon whatever vegetation is in the 
Fig, 331.

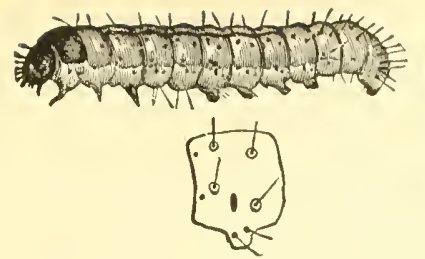

FIG. 327 .

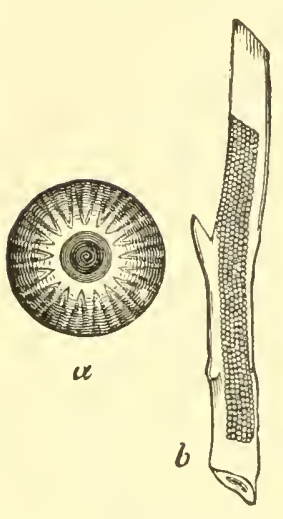

FIG. 330 .

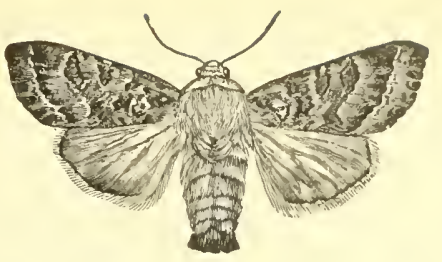

FIG. 326 .

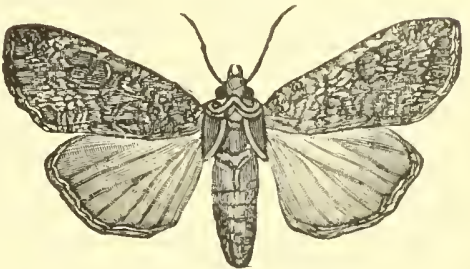

FIG. 329.

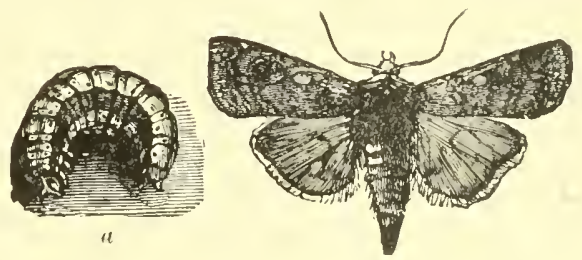

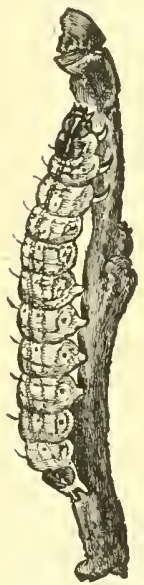

FIG. 325 .

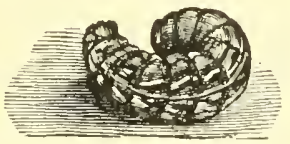

FiG. 324.

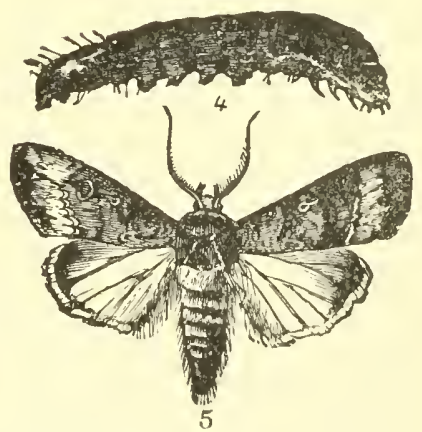

Cut-worms and owlet-moths.-Fig. 324, Agrotis ypsilon and its larva, the "greasy cut-worm." Fig. 325, larva of Noctua clandestina, the clandestine cnt-worm. Fig. 326, Peridroma saucia. Fig. 327 , eggs of the same, a single example enlarged at $a$. Fig. 328 , its larva, the variegated cut-worm. Fig. 329, Cameades messoria and its larva, the dark-sided cut-worm. Fig. 330, the climbing cut-worm, larva of Carneades scandens. Fig. 33I, Hadena devastatrix and its larva, the glassy cut-worm. 
fickds, being by no means nice in their choice, and only requiring that it be juicy and that there be plenty of it. They become about half-grown before winter sets in, and hibernate among the roots of the plants upon which they have been feeding, or uncler stones, logs, or other cover. In this condition they remain until the spring following, and then manifest quite a variety of habits. In orchards some of the species develop a climbing tendency, and make their way upon trees or shrubs to cut off the young shoots and buds. These have been tormed "climbing cutworms," but as a matter of fact a number of species develop this habit when the larva are in the proper location. Where there is an abundance of low plants, these are eaten off at about the surface of the ground, and the cut-worms fill themselves until they seem almost ready to burst with the juicy tissue. Where sod land has become badly infested by them, and is ploughed and planted in spring, very frequently everything is eaten off as fast as it shows above the surface. In some cases, where they are very numerous, it is absolutely impossible to obtain a stand of corn, and the crop must be abandoned in favor of some other which the insects do not attack, although this apparent exemption is frequently due to the fact that the insects have wandered off, or have become full-grown and changed to pupx. This change usually occurs some time during the latter part of June, or in July, and little complaint of injury from cutworms is heard after that period. The moths do not make their appearance until late in August or September, and lay their egg. during the latter month. Some species are double-brouded, and may be found even later than this, until November or even December. This, be it understood, is only a very generalized history of one group, and is not intended to apply even to all of the genera whose larvæ are cut-worms ; but for all practical purposes the injurious species may be assumed to have habits similar to those just described. The reason cut-worms are so injurious is that the abundance of plants in an overgrown field where the eggs are laid is replaced by a very small quantity set out by the farmer for his purposes. The result is that the cutworms, comparatively moderate in number in the first place, become exceedingly plentiful, and destroy the cultivated plants about as fast as they make their appearance or are set out. In 
regions where cut-worms are known to be troublesome it is a good plan to fall-plough sod-land as early in the season as conren ient. This will avoid egg-laying by the late moths, and caterpillars that have already hatched will be compelled to make their way to points where food is more plentiful, leaving the ploughed field free. It is a good plan also to put on at this time all the potash that is to be used on the crop in the form of kainit. The insects do not like this material on account of the chloride it contains, and many of them will be killed, while most of the others will be driven off. The potash is not lost, but will be as effective as if applied the season following. The field can be treated in spring as needed by the special crop, and will then be practically free from cut worms. If this method is not feasible for any reason, the cut-worms can be trapped by spreading on the surface of the ground, after it has been prepared, little heapi of poisoned vegetation,-for instance, clover; but any succulent plant will answer the purpose as well. The best way is to thoroughly spray a patch of clover or other vegetation with one of the arsenites, one pound to fifty gallons of water, then now it close to the ground. and spread in little heaps all over the field. The cut-worms, finding nothing else to feed upon, will eat this poisonous bait, and long before the corn or potatoes come up the fiel will be entirely cleared. On plants like sweet potatoes, c.lbbages, or tomatoes, that are set out, protection can be secured by putting at the base of each plant a tablespoonful of poisoned bran, using bran at the rate of fifty pounds to one pound of Paris green. This should be thoroughly mixed dry, then water, just a little sweetened with sugar, should be added until the whole is thoroughly wet but not sloppy. This mixture is exceedingly attractive to cut-worms, being preferred to plants in all the instances that have come under my notice. It will take about ten pounds to an acre of potatocs as ordinarily planted, and perfect protection can thus be secured. For one or two nights, perhaps, a few plants may be cut, but after that, except in rare instances, no further trace of the insects will be noticed. As against the climbing cut-worms a band of gas-tar or coal-tar will in most cases afford protection, especially if reinforced by a little mass of the poisoned bran at the base of each tree. A broad layer of fluffy cotton batting, tied at the 
bottom and fokled over to form it cone, is a good substitute for the tar.

Further on in the family we have a series of species which, with sinilar habits in the aclult, have quite different larval characteristics. The moths themselves are different in appearance, becoming white or yellowish, without obvious markings, except irregular streakings on the veins and a series of more or less marked black dots. These are usually members of the genus Leucania, and the caterpillars have been called in general "arnyworms," though to only one of the species can this term be properly applied. The "army-worm," Leucania unipuncta, has the fore-wings of a rather even, dull-reddish fawn, powdered with fine black speckles, some of which form a transverse row of dots

Fig. $33^{2}$.

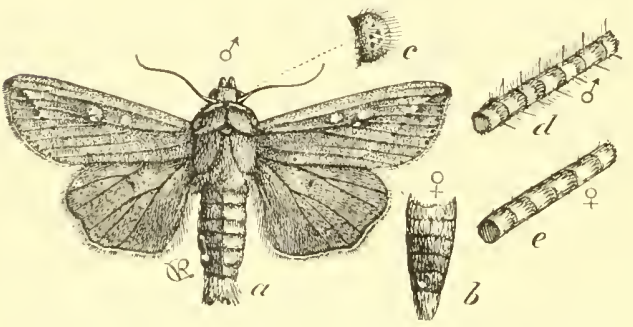

Moth of army-worm, Leucania unipuncta, at $a$; tip of abdomen of female at $b ; c, d, e$, structural details. on the veins beyond the middle. There is also a fine, oblique, blackish streak just below the apex, and at the end of the median vein is a small white dot, which gives the wing a rather characteristic appearance and the insect its specific name unipuncta. The moths fly at night, and are attracted to both light and sugar, forming in some seasons the most common of all the insects taken by the collector. The eggs are laid on the leaves or stems of grasses, using that term in its widest sense, and usually concealed. The moths favor rank vegetation, and the caterpillars, when they hatch, attack whatever is nearest at hand. When full-grown they are from one and a half to two inches in length, striped with yellowish on a clark-gray ground. The head is yellow, with fine dark lines, and the insect is easily recognized when it appears in numbers. In ordinary seasons, though the larve may be quite abundant, they are little noticed and do no particular injury ; but sometimes, by a combination of circumstances, the number of eggs deposited early becomes very great and the resulting army of larvæe so 
lare that they make havoc where they hatch. In this stage they are rioticed in wheat where it is heaviest, and thence the caterpillars spreal in every direction. They soon become full-grown, go a short distance underground to change to mahogany-brown pupe about three-fourths of an inch in length, and shortly thereafter the moths appear. They mate at once and lay another batch of eggs, from which we have about midsummer a second army much larger than the first. These soon eat everything on the ground first occupied by them, and are then forced by hunger to begin those marçhes which have given them their common name, "army-worm." It is an interesting, though to a farmer not a pleasant, sight to see the march of these insects from a stripped field to one that is still green and flourishing, and to note how quickly everything becomes covered and disappears, a sin-

FIG. 333.

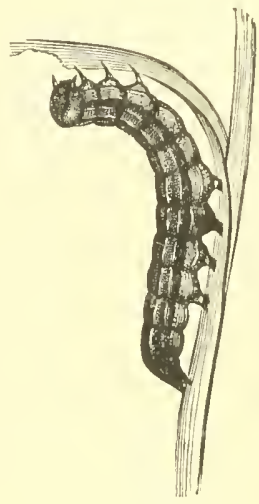

The army-worm. gle day sufficing to clear a large plot of every trace of vegetation. When full-grown these larve in turn go underground, and now there is a divergence in development. Some of the pupx remain unchanged all winter; some of them produce moths, and of these some will go into winter-quarters and hibernate, while others mate and lay eggs for a late brood of caterpillars, which becomes only partially grown. The insects may, therefore, winter in either the larval, pupal, or adult condition, though it is probable that the pupa stands the best chance of surviving. At all events, this explains how it is that caterpillars of all sizes may be found at all times, and that during the entire season moths may be found. In my own experience, there has not been a week in the collecting year when I have not taken this insect, while seeking better species. The remedies to be adopted are almost entirely mechanical. Where the larve are noticed at the first start in grain-fields or grass lands, the patches infested by them should be at once cut down and utterly destroyed by fire, and with them, of course, the larve. The work must be done thoroughly, because otherwise the caterpillars will simply crawl to adjacent plots, and the labor is wasted. The thorough 
application of an arsenical spray in the infested patch and immediately surrounding it is beneficial in some cases, but there is the practical difficulty that grasses do not hold a water spray easily. Using soapsuds instead of pure water will overcome this, however. If the insects become abundant enough to start on a march, a narrow strip can be ploughed in its line, harrowed and rolled, and then the roller can be kept going, crushing the insects as they come upon it. Or a very strong kerosene emulsion may be sprayed upon the caterpillars as they advance, and upon the fields that they are leaving. There will be no vegetation that need be considered, and therefore the mixture need be diluted five times only, which will be effective even against the nearly full-grown larve. It would seem that following one amy of caterpillars we would have next year a still more destructive invasion, but such is not usually the case. Fungus and other diseases appear and decimate their ranks, their enemies increase rapidly after the first large brood, and the result is that normal numbers only survive, unless the conditions which favor their increase one year continue also the next. As the land becomes more cut up and cultivated, the danger from this insect is correspondingly lessened, and where a reasonable amount of promptness is displayed on its first appearance no wide-spread injury need be anticipated. Everything depends upon the promptness and thoroughness with which early measures are adopted and carried out, and all delays will prove costly.

A near relative of the true "army-worm" is the insect known as the "wheat-head army-worm," Lencania albilinea. This is a rather brighter larva, also striped with yellow, never becoming quite as large as its ally, and peculiar in the habit of eating the grain or seed of wheat, rye, and other grasses. There are two broods of this insect also during the year, but that which does the injury makes its appearance in the nearly full-grown larval condition just when the grain is ready to ripen. At this time, when sufficiently numerous, their injuries to the crop are severe, because a single caterpillar may in a few minutes practically destroy the value of an entire head of wheat. The ears become ragged and the surface of the soil becomes littered like a barn floor after threshing. The moths from which these insects are derived expand a little more than an inch, and are of a rather 
pale clay-yellow, with a narrow, silver-gray margin to the outer edge of the fore-wing. There is also a dusky stripe through its centre, surmounted by a white streak, which gives the specific name albilinca, or "white lined." Practical measures against this insect are difficult. Where the stage of the grain warrants it in any way, the best thing is to cut it at once. This will save further injury, and the insects will distribute themselves to localities where their mischief will not count so heavily. As with the previous species, increase is dependent upon conditions which we do not entirely understand, and here also the parasites ordinarily obtain control before the year is out.

The wandering habit is somewhat developed in this species as well, and frequently they start in grass lands and emigrate to adjacent grain-fields when the wheat-heads are well advanced.

An insect somewhat similar in appearance in the caterpillar stage is the "fall army-worm," Laphy'gma frugiperda. It is smaller, however, the head dark with a prominent, white, $\mathrm{V}$-mark, while the lines are different and the body is covered with rather well marked black tubercles, giving rise to short, stiff, black hair. The creature is a general feeder, and appears in greatest numbers late in the season in fields of
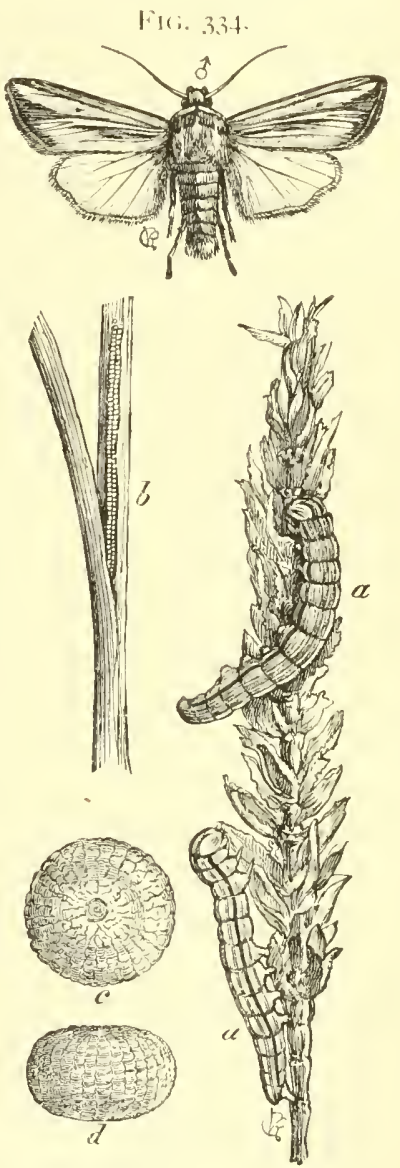

The wheat-hearl army-worm.$a$, $a$, eating out a head of grain; $b$, eggs under a leaf sheath; entargerl at $c, d$; the moth, Leucania albiline a surmounting all. dense vegretation of almost any kind. In general habits it does not differ much from the species already described, and, like them, it goes underground to pupate. There are always two, 
and sometimes three or more browds in the course of the year, and in fivorable seasons these become successively more numerous, so that the fall brond proves the most tronblesome. These furorable seasons, however, do not often occur, particularly in the Eastern United States, and here climatic influences or other natural conditions reach the insects during the winter, so that in the spring following only a normal number survive. Cultivating land in crops which admit of fall plunghing is best adapted to

Fig. 335 .

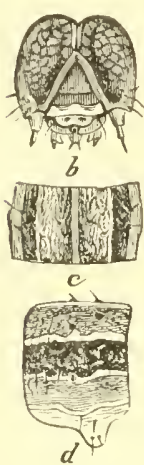

The latl army-worm- $-b$, its leat: $c, d$, its budy segments enlarged.
F1G. 336 .

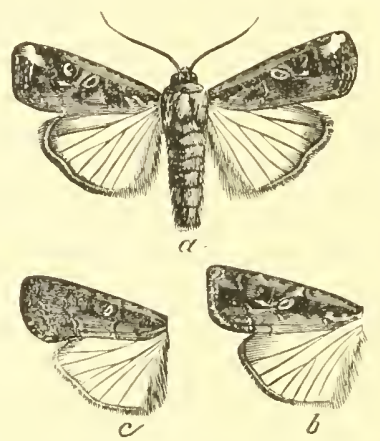

laphyma fiugipe's a and its variations.

avoid injury, and a frequent rotation will prevent them from becoming numerous enough to be lestructive at any time. The arsenites can be employed, of course, for the protection of crops that admit of being sprayed. Wheat-fields badly infested in fall are not necessarily ruined or even much injured, because wheat will stand cutting down almost to the ground during the latter part of the scason, and will yet come up vigorous and in good condition the spring following. The moth that produces this caterpillar is a modest, gray creature, expanding hardly more than an inch, and the hind wings are pure white and semi-transparent. It is a variable species, and ranges from an almost uniform gray to forms in which there is a considerable admixture of bluish white, the ordinary lines and spots of the owlet-moths being also well marked. 
We sometimes find boring in the stems of wheat, corm, potatoes, and a great variety of other plants a yellowish-white caterpillar with rather prominent black spots, furnished with "little soft hairs and with a black head. This is the larva of another Noctuid moth, the tchatodes zea. It sometimes does considerable, though usually temporary, injury to the infested plants, and is kept in check, as a rule, by its natural limitations. The moth which produces this caterpillar is broader winged than the species previously mentioned, and the primaries are of a deep, somewhat mottled, red-brown. The outer margin is rusty red, especially towards the tip of the wing, and none of the other markings are well defined. The species has not, in my experience, appeared in numbers large enough to make it necessary to adopt remedial measures, and this is fortunate, because from its method of feeding it is somewhat beyond our reach.

Occasionally we note upon grape-vines a smooth, greenish caterpillar with broken, rather inconspicuous, lateral lines. It attains a length of from one and one-half to two inches, and differs from the other greenish cater-
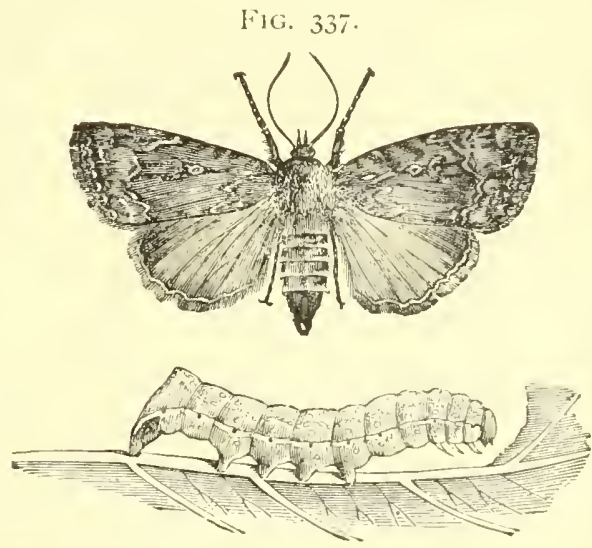

Pyrophila foramiduides and its tarva pillars of the vine by lacking all trace of either horn or eye-spot on the last segment. It pupates a little below the surface, and in due time appears as a moth which is distinctly flattened, has the fore-wings of a mottled, dull, smoky brown, and the hind wings of a dull coppery hue. It is the Pyrophila pyramidoides, and may be occasionally found during the day hiding in crevices, or under bark, for which its flattened body adapts it unusually well. At night it is attracted to light, and occasionally becomes rather common, though rarely abundant enough to need remedial measuret. When it does occur in numbers it is easily controlled 
by the application of a stomach poison, the caterpillar succumbing readily to any of those in ordinary use.

There is a series of decidedly depressed or flattened moths with narrow, long fore-wings, broad hind wings, a somewhat retracted head clothed with stiff, projecting vestiture, and a neat little tuft on the anterior part of the thoracic collar. These belong to the genus Xylina, or its near allies, and they appear late in fall, to hibernate as adults. In spring they reappear as soon as the weather becomes in the least warm, and moths of this kind are

F1G. 338.
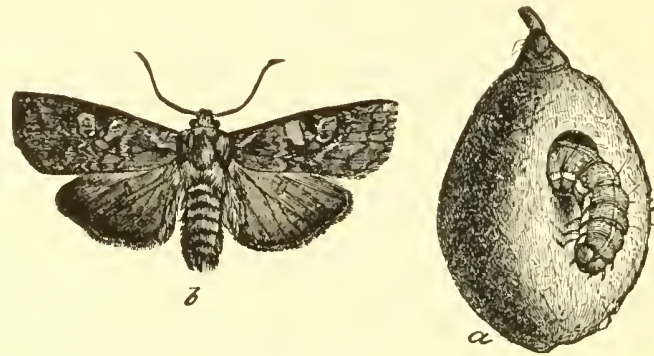

Nylina antennata: $a$, its larva in peach; $b$, adult moth.

often found in maple groves while sugaring is going on. Sometimes sap-pails are found in the morning with the surface of the liquid completely covered with these insects, which, taken as a whole, are northern, though some extend south and southwest, and even to the Pacific coast. One of the most common is the $X$. antennata, the caterpillar of which has been described by Riley as boring into fruits ; but it is a rarespecies, comparatively, and no marked injury is ever done.

Now we reach a group of moths in which the caterpillars usually lack one pair of the false or abdominal legs, and for this reason are known as "semi-loopers," having somewhat the methods of motion found in the "span-worm," but not to so marked an extent. Of this series we have several more or less troublesome species, and the most important are, the "cottonworms" belonging to the genera Anomis and Aletia, all of them feeding upon the leaves. The larve are similar in appearance, green, more or less narrowly banded at the sides, and spotted. 
The "cotton-worm" is the larva of Aletia argillacea, about which many volumes have been written, and whose life history has been thoroughly investigated under the direction of the United States Entomological Commission and the entomologists of the United States Department of Agriculture. To one especially interested in this insect these elaborate reports will be useful and must be consulted. It will suffice here to say that the caterpillars pupate in a loose cocoon spun on the leaves of the plants, and from the dark-brown pupa comes a dull, tawny or claycolored moth, with indistinct, dark, wavy, transverse lines, and a rather prominent leaden-white spot, more or less margined with black, near the middle of the fore-wings. There are several broods in the course of the year, but only the liater ones become seriously injurious, the plant then being sometimes entirely defoliated. A curious feature is that the insects probably do not spend F1G. 339.

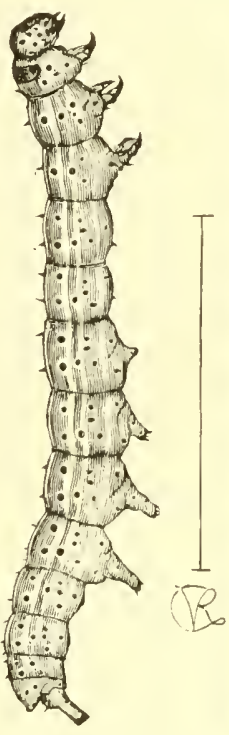

Cotton-worms, from

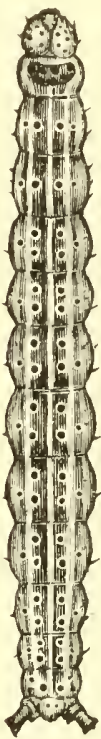

side and above. the winter in our territory, but adults immigrate each year from more southern regions. The migrating habit is marked in the later broods maturing on cotton in our country, and the moths have been often seen in great numbers as far north as Canada. As the wings are closely scaled, they do not readily show the wear and tear of long flight, and specimens have been taken in the far north as fresh and bright as if hatched there. It is possible that under favorable circumstances the caterpillars may support themselves on plants other than the cotton, but we have no positive information of their having done so. Of late years the insects are much less injurious than in times past, largely as the result of a diversified agriculture, which has made it less easy for them to increase in abnormal numbers. Planters have also learnt that a prompt application of the arsenites when 
the larve first appear is apt to lessen subsequent injury, if it does not prevent it entirely. The method of application now adopted is exceedingly simple, consisting of a moderately stout, rather elastic, pole, to the ends of which are attached sacks of a coarse ducking material containing Paris green. This pole is carried by a man on mulcback, who rides between the rows, continually jarring it so that the poison sifts through the sacks upon the

F1G. 340 .
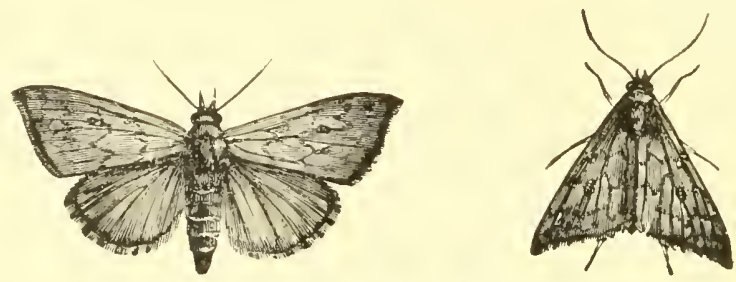

Aletic argillacea at rest and with wings expanded.

plants. It has been found that undiluted Paris green used in this way does not injure the foliage, while it is absolutely effective as against the larve. Sometimes the pole is made long enough to hold four sacks, so that four rows are dusted at one time. This is exceedingly simple and practical, and has the advantage of requiring no expensive outfit.

We have belonging to this series of semi-loopers a number of moths belonging to the genus Plusia, and most of these have somewhere in the middle of the fore-wing a dash, line, circlet, or other marking of silver or gold. Sometimes the entire surface is metallic or golden, and the species, as a whole, are very handsome, with the ground color in most cases velvety gray or brown. Bright colors or contrasting markings are rare. Several of the larvæ attack cultivated plants, but none as frequently as that of $P$. brassice, the cabbage Plusia. The caterpillar is green, with rather indistinct lateral lines, and is readily separated from the butterfly larva of Pieris rapa, because it lacks one pair of abdominal legs and is not at all velvety in appearance. Its fashion of "humping itself" also separates it from the other larva, which always rests fully extended. This may be dealt with as has been already recommended for the other "cab- 
bage-worn1," and as they infest the plants at about the sane time in mudsummer, one application of Paris green or London purpe wili answer for both insects.

F16. 341 .

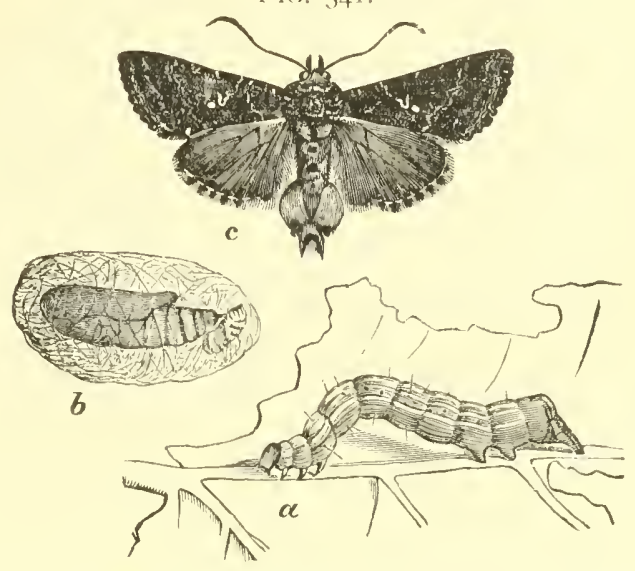

The cabbage Plusia, P. brassica.-a, larva; $b$, pupa in its thin cocoon; $c$, male adult.

Another series of usually bright-colored, active moths that fly during the day, sometimes in the hottest sunshine, is the /leliothini, which are usually white or yellow in color, and not infrequently have a glossy or metallic lustre. Taken altogether, the species are not common, and are much more abundant both in specimens and species in the WVest and Southwest. But we have one form, abundant throughout the Eastern United States, which is at once the largest, least conspicnous, and most destructive of those belonging here, yielding little, in the injury it does, to any other Noctuid. It is the Iteliothis armiger. whose caterpillar is locally known ats the "boll-worm" in the South, where it bores into cotton-bolls; the "con"w-worm" in the North, from its habit of eating into ears of corn, and the "tomato-worm" in some of the Eastern States, from its habit of boring into tomatoes during the early part of the season. The species is one of the most difficult to deal with directly, from its habit of feeding concealed in such a way that in most cases the application of arsenites is a practical impossibility. It has been found by experience that 
corn is the favorite food, and they will attack it in preference to everything else. Tlis preference is utilized by planting corn in cotton-fields in such a way that the ears are in attractive condition at the time when the moths would otherwise oviposit in the bolls. Before the caterpillars come to maturity they can be destroyed by hand in the ears, or the corn can be cut and fed to stock, together with the caterpillars. This is really the most

FIG. 342.

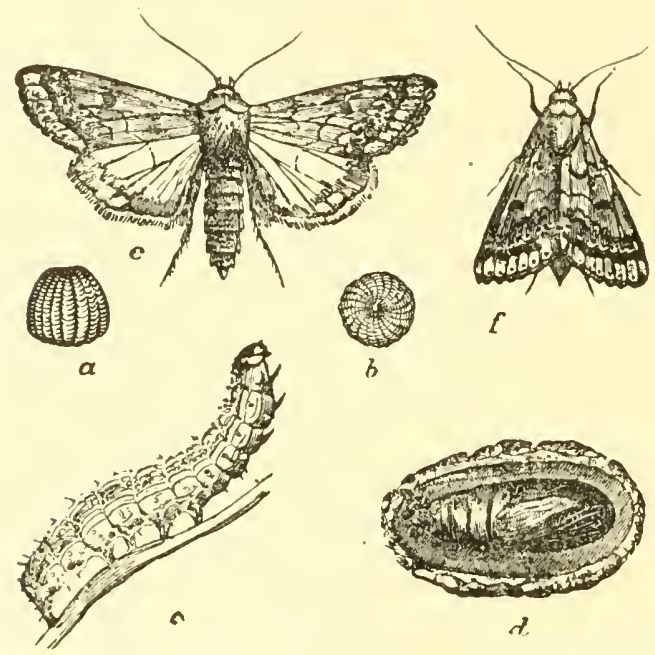

Hehothis armiger in all stages. $-a, b$, egg, enlarged; $c$, larva; $d$, pupa in its underground cell; $e, f$, moths.

satisfactory way of dealing with this insect in cotton-fields. By providing early corn for the early broods of larvæ, and destroying it before they mature, the species can be kept down to harmless numbers later in the season. The adoption of a more diversified agriculture will have a tendency to lessen injury to the cotton, and if systematic fall ploughing of corn-fields be practised, it will soon become insignificant. There are two or three broods in the latitude of New Jersey and even more southwardly, while in its most northern range a single brood only is normal. In September or early October the caterpillars that mature in corn go underground and change to pupe, passing the winter in this 
FIC. 343 .
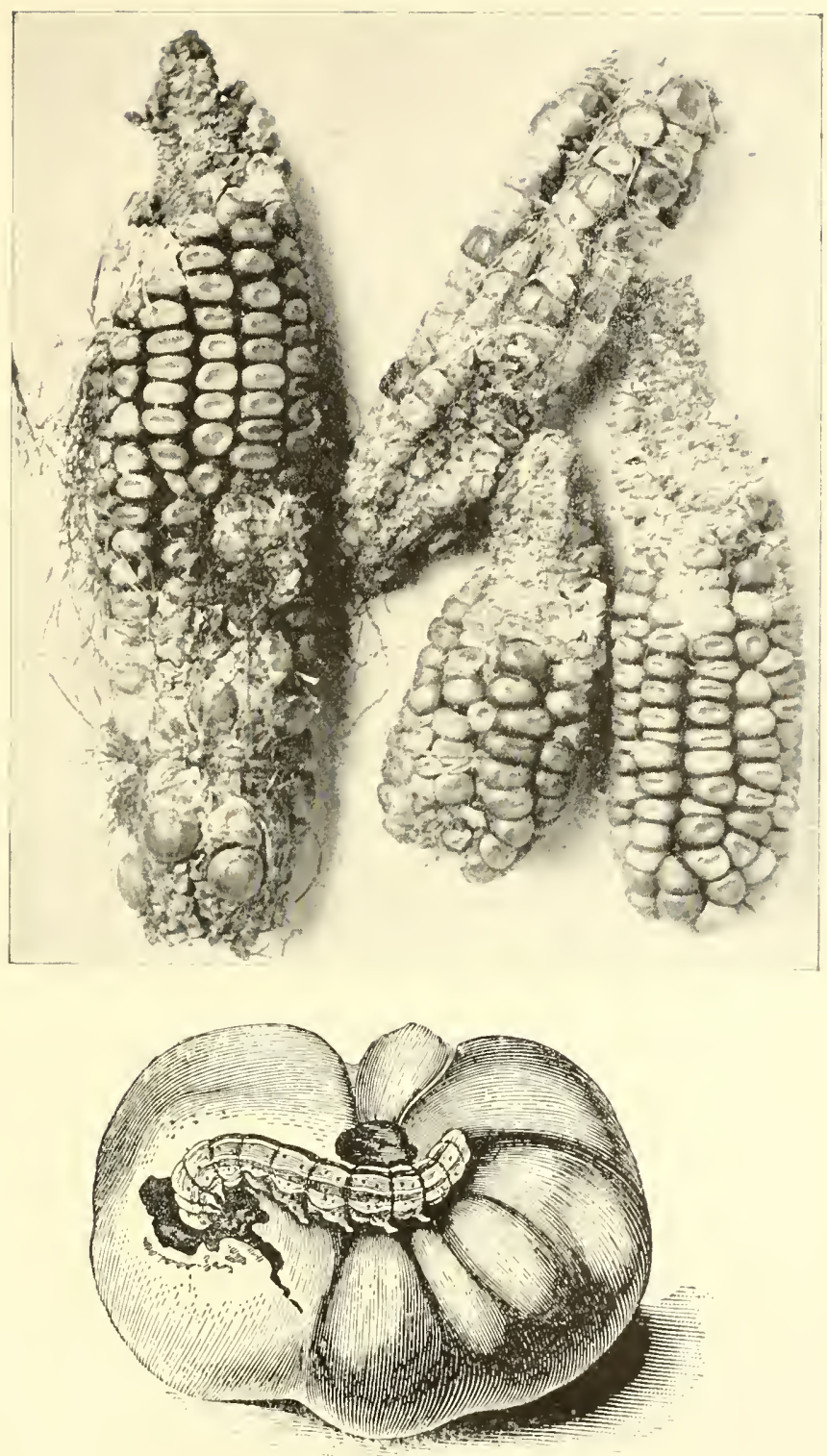

Work of the larva of Heliothis amiger in corn and in tomatoes. 

condition. Early in spring, if the ground remains undisturbed, the moths, which are of a dull clay-yellow, with indistinct markings on the fore-wings, and expand from one and one-half to two inches, make their appearance and lay eggs upon such plants as they can find. Early tomatoes are favorites, and, following them, peas are infested. The caterpillars bore at first into the stems of the tomatoes, but always attack the fruit as soon as it has set. The earliest tomatoes are thus frequently ruined, and as these usually have the greatest market value, the actual money injury is out of all proportion to the quantity of fruit destroyed. Sweet corn is next attacked, and the earlier it is the more abundant will the insects be found in it. Last of all field corn is taken, and this remains infested until it becomes hard and glazed, the caterpillars being able to make their way through and feed upon the perfectly ripe kernel. Fortunately, they are great cannibals, and where several infest a single ear of corn they fight until one alone remains. On tomatoes the insects cannot be satisfactorily treated, except by picking and destroying the infested fruit as soon as it is noticed, and the only practical means of keeping them in check is fall ploughing all corn-fields. It has been found by experiment and by practical experience that ploughing in the fall and breaking up the earthen cells in which the pupæ rest will in almost every instance result in their death, and this process alone offers a fair opportunity for controlling the pest.

There follow in the natural series a great number of small species, some of them very bright and pretty, many with interesting life histories, but none of practical importance from the economic stand-point. They are in turn followed by a series of larger species with broad wings and dull colors, the secondaries frequently crossed with lines much as in the primaries. The caterpillars are half-loopers in most cases, and bear a very strong resemblance to the "span-worms." The most common of the species belonging here are the clover moths, Drasteria erechtea and $D$. crassiuscula, which are so nearly alike that they have been confused in collections, and we need not trouble to separate them. Both are broad-winged, dirty gray or brown in color, with two more or less marked blackish or brown bands on the fore-wings, and a series of little black dots before the apex. The female is much more modest in color than the male, and the 
black markings are so reduced as to be scarcely visible, except on careful inspection. The caterpillar, which is green and narrowly striped, feeds on clovers, and, while abundant, is not practically harmful.

Among the pets of the lepiclopterist are the species of Catocala, a series of large moths with the hind wings black, or yellow and

Fis: 347 .

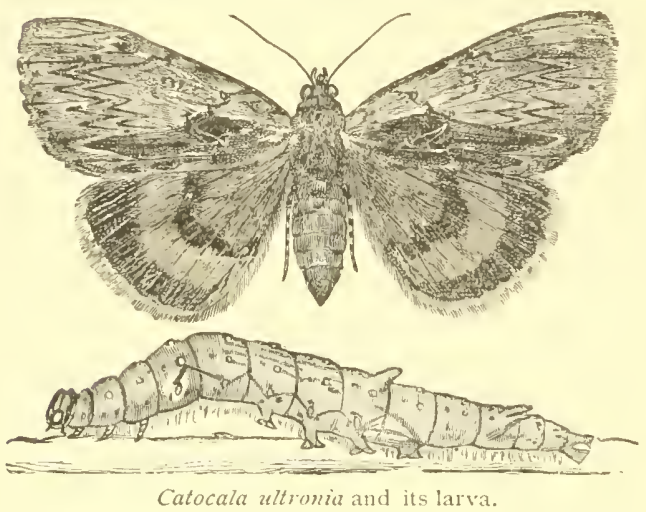
red banded with black. We have a great number of species, and while the hind wings are so prominently colored and marked, the fore-wings are mottled gray, brown, and black. They rest exposed during the day upon the bark of trees, entirely invisible because so closely resembling their surroundings, the gaudy hind wings being completely covered by the modest fore-wings. While some of the caterpillars feed upon cultivated plants, especially the plum, they are never abundant enough to attract attention.

Last in the Noctuids we have the "snout-moths," or deltoids, the latter tem applied from the fact that when the insects are at rest the outline bears somewhat a re-

FiG. 348 .

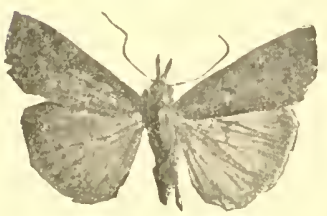

Hypena humuli, hop-vine molh. semblance to the Greek letter delta $\mathrm{J}$. The species are recognizable without much trouble by the musually long palpi, which in many cases point directly forward and form a decided snout. The only species that has occurred in numbers justifying the term injurious is the Hypena humuli, the caterpillar of which - a slender green creature-feels upon inops. Within my experience it hats never been sufficiently troublesume to make insecticinles necessary ; but should it ever 
become so, there would be no trouble in protecting the plants by means of the arsenites.

Now we reach the family Gcomctrida, in which the larve lack all save one or at most two pair of false or abdominal legs. In moving they first extend the body to its full length, then bring the posterior end close to the front legs, looping the body in the centre, then stretch out again and repeat the procedure, whereby they have gained the names " span-worms," "loopers," or "measuring-worms," and, indirectly, the scientific term Geometridæ. There is never any difficulty in recognizing the caterpillars, and the moths are easily known in most instances by their slender bodies, snall heads, and very broad wings, which are also, as a rule, frail and thin. The hind wings are here ornamented much as are the fore-wings, so that the lines of the one pair are often continued across the other. IVhen at rest, the insects keep the wings extended and flat, much as specimens are pinned in the cabinet. IVe have a large number of species, but comparatively few of them become troublesome.

Perhaps the best known of all are the "canker-worms," larvit of the species of Inisoptery $x$ and Paleacrita. These attack a considerable variety of trees, and are especially fond of apple and pear, which are sometimes completely defoliated. They are much more troublesome in the New England and Northern States, and I have often seen, in Massachusetts, orchards completely defoliated by them. In New Jersey and southward they rarely become troublesome. Here, as in some
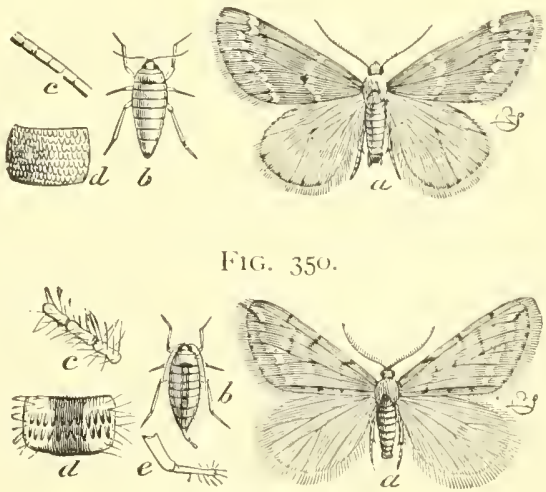

Fig. 349 , Paleacrila vernata. $-a$, male; $b$, female; $c$, $d$, structural details. Fig. 350, Anisoptery pometaria. $-a$, male; $b$, female; $c, d, e$, structural details.

of the Bombycids, the sexes are unlike, the males being winged, while the females are wingless. The caterpillars, when full- 
grown, descend to the ground to pupate; when the females emerge they crawl up the trunks of the trees, where they are fertilized by the males, and then continue their journey to the leaves, upon which they lay their exgs. This habit gives us control of the insects, for if we simply band the tree in such a way as to prevent either the female or the young caterpillars from ascending to the branches, it will be protected completely. Unless the female can get upon the leaves, the eggs are laid upon the

Fici. 351 .

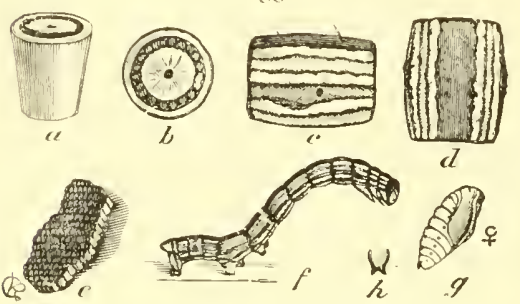

Canker-worm, larva of Anisopter.x pometaria. $-a, b$, ess enlarged; $c$, pat ch of eggs: $c, d$, body

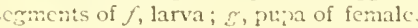

FIG. 352.

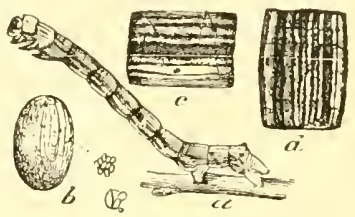

$a$, larva of Paleacrita vernata; $b$, an egg, much enlarged; $c, d$, body segments of larva.

trunk below any obstruction that it cannot pass. The young larve will attempt to get to the leaves, and will, if they find an impassable barrier, starve to death. The best materials, all things considered, are "raupenleim," or " dendrolene," preferably the latter, as it remains viscid for the full period during which the insects hatch, and forms a perfect barrier beneath or through which no creature can crawl and live. A band six inches in width and a quarter of an inch or more in thickness over thick wrapping-paper will prove a perfect protection. Fluffy wool or cotton may also be employed, and the former is the most lasting, but less certain than the "dendrolene."

A near relative of these canker-worms is the "lime-tree moth," Hyernia tiliaria, which also attacks a variety of trees, and has at times been decidedly troublesome. The application of the arsenites will prove a complete protection in this case : indeed, we may say of all the caterpillars belonging to this fimily, including the "canker-worms," that they can be controlled by the thorough application of stomach poisons to the plants upon which they feed. 
One curious feature is that nearly all these span-worms closely resemble little dried twigs, branches, or even the stens of the leaves upon which they feed. Many of them when at rest hold to the twig by the hind feet only and keep the body rigidly extended, seeming for all the world like a small process from the

FIG. 353 .

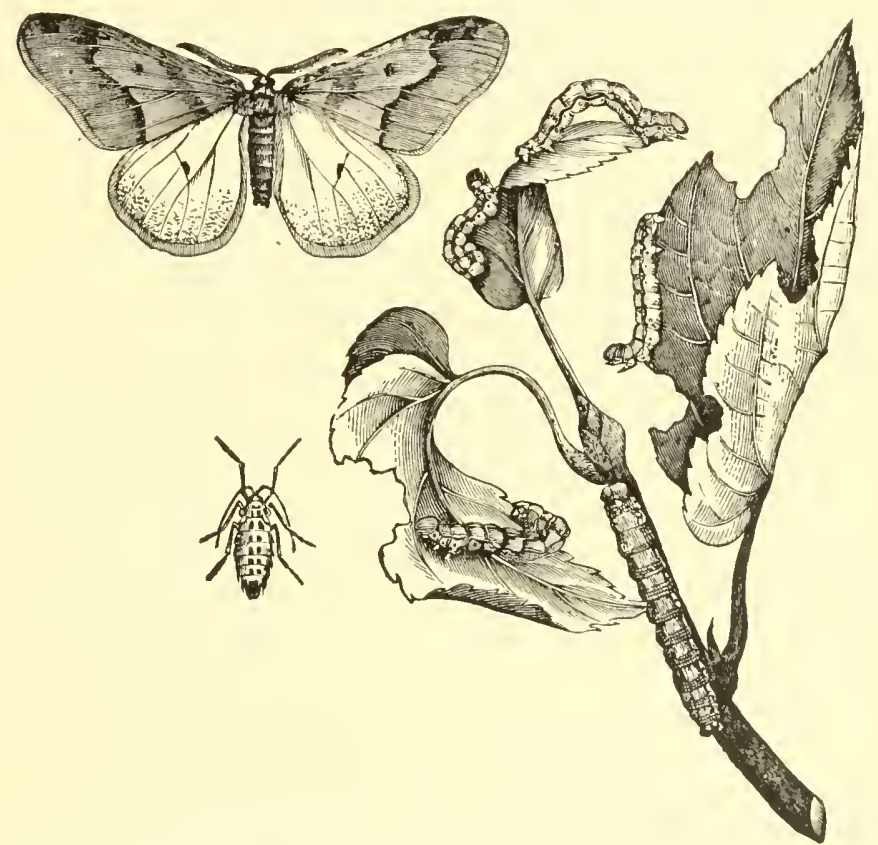

The lime-tree moth, Hybernia tiliaria.-Larva all siees; winged male and wingless female.

plant itself. I well remember one occasion when Cymatophora pampinaria was excessively abundant on certain cranberry bogs on Cape Cod. I saw the spaces that had been defoliated and saw the edge of the spaces unaffected, but, look as I would, I could not at first see the caterpillars. It was not until a little smoke was started over the edge of the attacked portion that larvæ were observed, and then it seemed as if all the little twigs and branches obtained life in an instant and started travelling. The insects so 
closely resembled the cranberry stems and twigs that even to an entomologist they were at first invisible.

The balance of the Lepidoptera are classed in a general way as "micro," or small, although as a matter of fact many of them are larger than some of the "macros." Yet, as a rule, the families contain small, and sometimes very small, forms.

At the head of this aggregation is placed the superfamily Pyralidide, which contains species of moderate size, varying greatly in appearance. IVe have one series, the Pyranstida, with slender bodies and rather thinly scaled wings. The primaries are banded, the secondaries are moderate in size, never larger than the fore-wings, and the colors are, as a rule, pale, usually at light clay-yellow, while the markings, which are wavy, are yellowish brown or black. The caterpillars in this series are narly always green, with pale stripes and spots; sometimes without any markings at all. The head is either black or yellow, hard and shining, and there is a hard shield of the same color ats the head on the first thoracic segment. Most of them have the abdominal legs crowned with a complete circlet of spines, and by this character, which is an easy one to see, we can tell with almost absolute certainty the caterpillar of a micro from that of a macro, in which the circlet of hooks is never complete, if we except the Hepialide and Cosside, which will not confuse us, on account of their great size and wood-boring habits. The prolegs are complete, - that is to say, there are four pairs, - and the

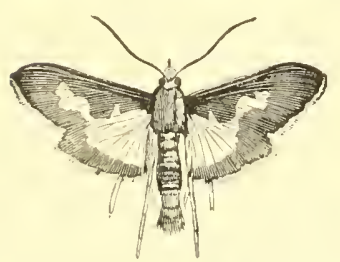

F1G. 354 .

The piekle-moth, Margaronia nitidalis, and its larva; the latter shown on a smalt cucumber which had been eaten into at $b$.

insects have, therefore, no appearance of or relation to the loopers, or Geometride. Many, perhaps most, of the caterpillars are silk-spimers, and often live more or less concealed in folded leaves held together by a few threads, or in tubes above or under 


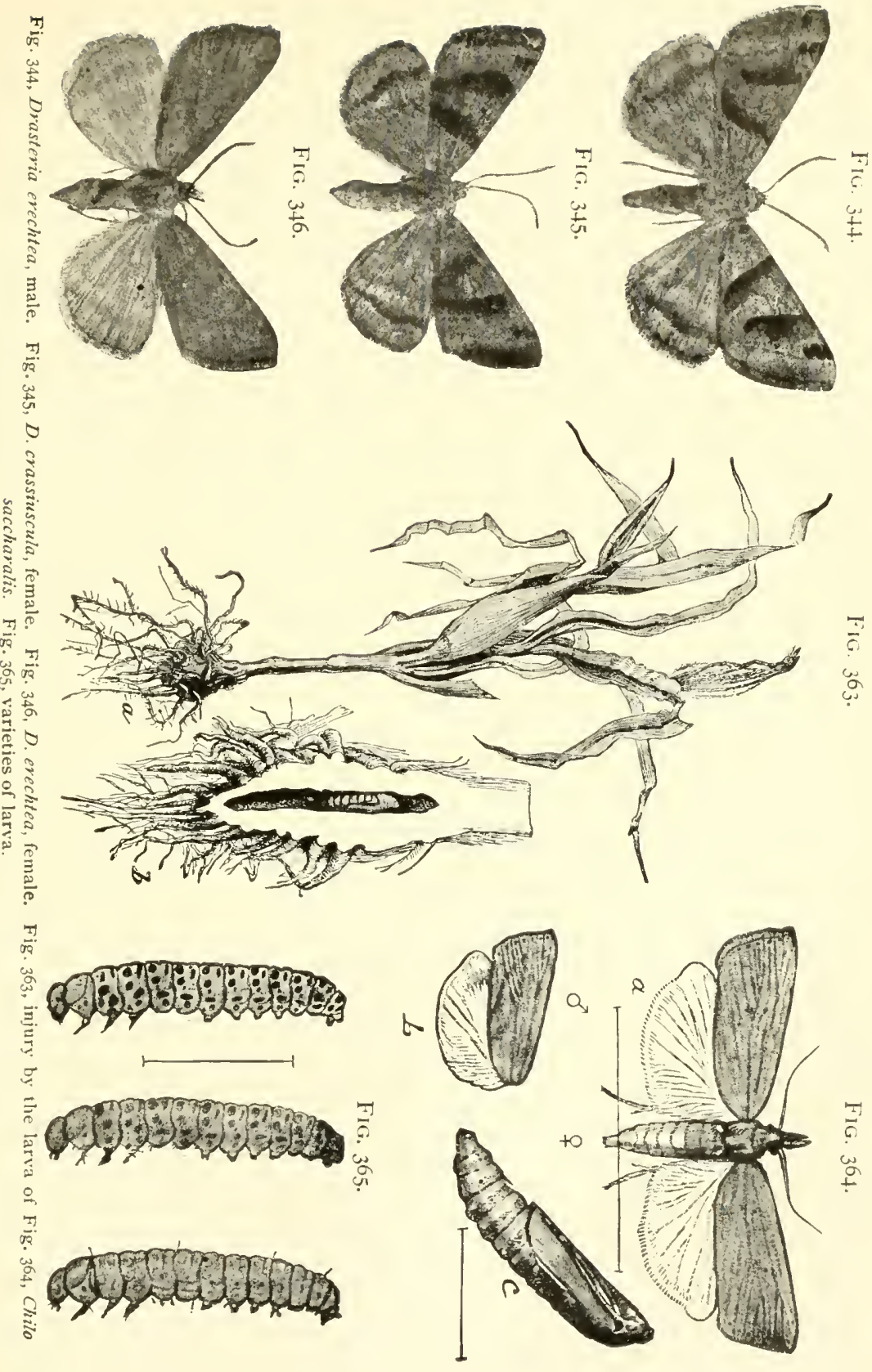



ground. Occasionally quite large nests are built, and the caterpillars are more or less gregurious, or live together in colonies. One of the injurious species is Margaronia nitidalis, quite a pretty brown-and-yellow insect called the "pickle-moth," because the caterpillar has the habit of feeding on the cucumber, boring into and destroying it when about half-grown. It is more common in the Western States, and no satisfactory recommendations for its control have yet been made.

The great majority of the caterpillars live upon low herbage generally, rarely in numbers sufficient to cause perceptible injury, and most of the species are classified under the genus Pyrausta. We frequently notice, in passing through patches of ferns, that the leaves, before they become entirely unfolded, are spun up and held undeveloped. If we look closely we find a typical Pyralid caterpillar, which is easily observed and bred, pupating in the web itself, while the resulting moth is typical of this genus.

The most troublesome species is the "garden web-worm," Loxostege similatis, or, as it used to be called, Eurycreon rantalis, and this is a great pest on vegetables of all kinds, seeming indifferent to the character of its food and spinning its small web everywhere on the plants.

It extends over most of the United States, and has been more or less injurious in almost every section; but, like many others, it seems to be troublesone a year or two and then escapes notice for several years thereafter. So far we have not been able to make out a regular peri-

F1G. 355 .

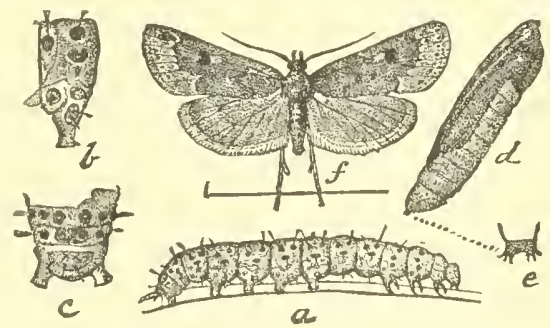

The "garden web-worm," Loxostege similalis; - $a$, larva; $b, c$, single segments of same; $d$, pupa; $e$, its tip; $f$, moth. odicity, and the remedy is Paris green or one of the other arsenites where it can be practically applied. The insecticide is sometimes a little slow to act because the insects are more or less sheltered, and it is only when they feed outside their web that they risk being poisoned. In some cases the kerosene emulsion is useful, and acts more promptly because of its ability 
to penctrate the webs and come into direct contact with the larvæ.

Sometimes insects of this series are not confined to green regetation, as in the case of the "clover-hay worm," Asopia costalis, which attacks the dry or partially dry product, webbing

FIG. 356 .

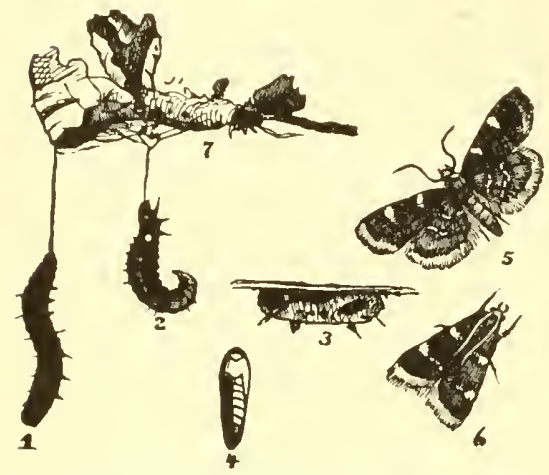

The clover-hay worm, I and 2 ; its cocoon at 3 ; the pupa at $4 ;$ the moths, Asopia costalis, at 5 and 0 ; at 7 the tubes made by the larva. it up and causing more or less injury. Its near ally, Pyralis farinalis, way be found in barns or bins where grain is carelessly stored, and the caterpillars make little tubes, formed partially of silk, partially of fragments of the grain and even of entire kernels, upon which they feed. Rarely, however, are they abundant enough to do serious injury, and as against both cleanliness will go far, while bisulphide of carbon will readily destroy the larvæ. As against the "clover-hay worm," nothing is better than to feed up clean from year to year. Never put new hay upon old, and if stacked outside, lay upon rails so as to get ventilation underneath. Salting the first two or three feet has also been recommended, and will probably be effective.

In the Phycitina there are many sombre-colored little moths, usually of some gray tint, with rather narrow fore and broad hind wings. The insects rest with the wings closely folded around the body, the head a little elevated, and the palpi projecting forward, giving them rather an impertinent appearance. The caterpillars are largely internal feeders, attacking fruits in many cases, sometimes living in the stems of plants, sometimes spinning up among leaves, in rare cases feeding openly. Occasionally they make a case or sac which they carry about with them, and in which they are more or less protected.

We have several more or less troublesome species that are 
rather difficult to deal with. One of these is the Mineola vaccinii, or "cranberry-fruit worm," which lives in the berry itself, feeding in the seed-capsule, causing the fruit to redden up prematurely, and then to dry and shrivel on the vine. A single caterpillar may eat into every berry upon a fruit stem in the course of its existence, then descends to the ground, and among the leaves and rubbish spins a tough little cocoon in which the pupa winters safely, even if covered by water. The eggs are laid about the middle of July, singly, on the berries where the blossoms have dropped off, under one of the little triangular flaps. Once the larve are in the berries there is no way of FIG. 357 .

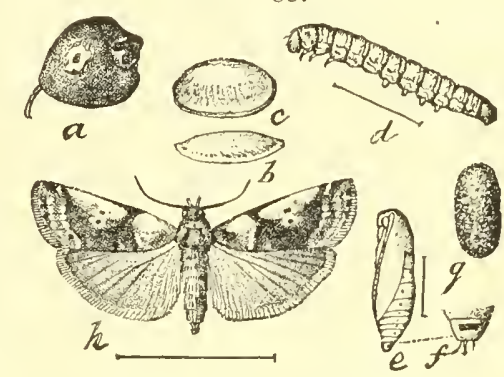

Cranberry-fruit worm, Mineola vaccinii.$a$, cranberry on which $(b, c)$ the eggs are laid ; $d$, larva; $e, f$, pupa and its tip; $g$, cocoon ; $h$, moth.

getting at them, and, practi-

cally, the only method of reducing their numbers is to pick the berries as early as may be, being careful to get in all that are infested. By sorting promptly these can be destroyed before the larvæ leave them, lessening greatly the number of moths for the following year. The insect is much more troublesome in New England than in New Jersey or in the northwestern marshes.

Nearly allied, but with totally different habits, is the Mineola indiginella, or " rascal apple-leaf crumpler," so called from its habit of making irregular, crumpled cases on the apple leaves upon which the insect feeds. It is rather easily reached, where it becomes troublesome, by the arsenical sprays, and in orchards where spraying is generally practised it is incidentally destroyed. Many other of these little species are found on our cultivated crops, but, as a rule, in such small numbers as to be hardly noticeable, and only occasionally a species becomes locally injurious.

One of the largest of our Eastern species is the Melitara prodenialis, which feeds inside the leaves of the prickly pear or common cactus of the sandy regions south of Long Island, while its near ally, $M$. dentata, is found in an allied cactus in Kansas 
FIG. 360 .
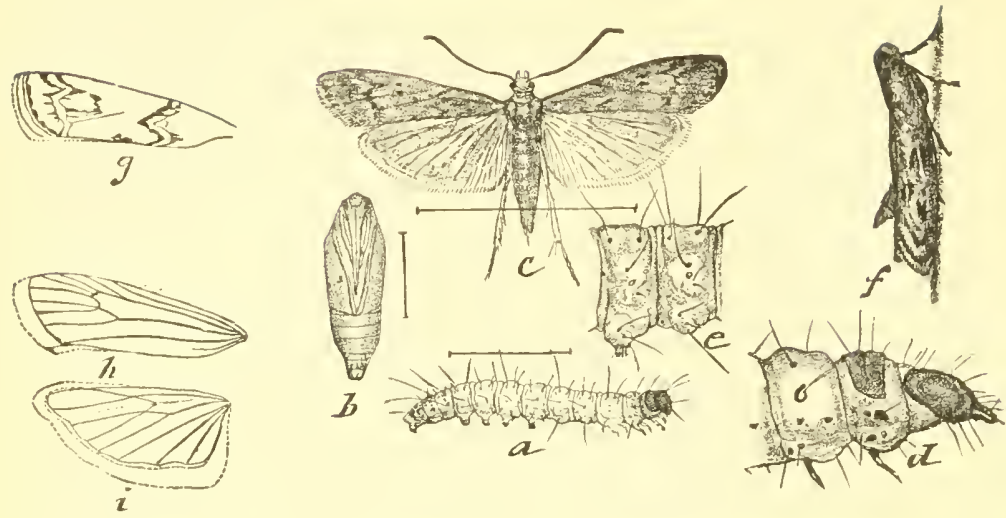

FIG. 36 I.
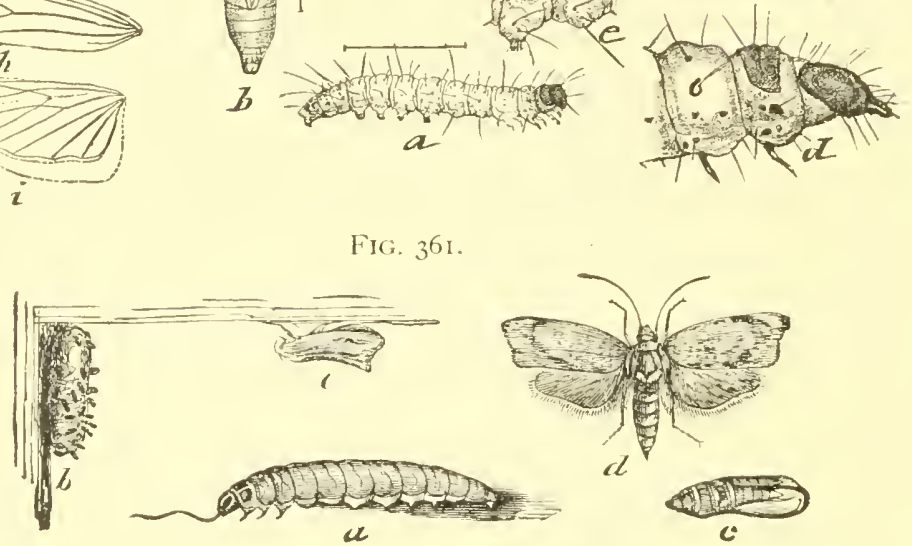

FIG. 35 S.
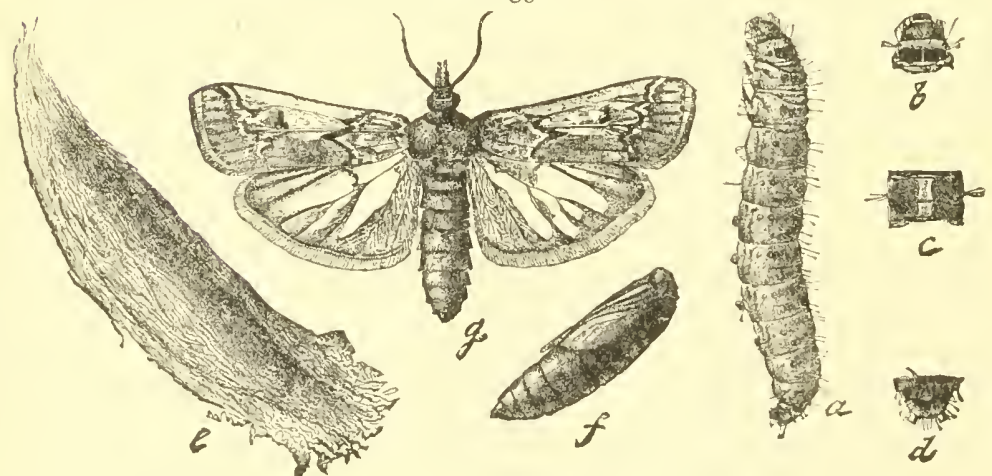

Fig. 360, the Vlediterrancan thour-moth, Ephestia kühniella.-a, larva; $b$, pupa ; $c, f$, allult with wings spread and at rest; $g$, wing of a variety; $d, e, h, i$, structural detiils. Fig. 358 , Melitara prodenialis. $-a$, larva; $b, c$, $d$, details of same; $e$, cocoon; $f$, pupa; $g$, motl. Fig. $3^{61}$, the bee-moth, Galleria melonella, $-a$, larva ; $b$, cocoon; $c$, pupa; $d, e$, moths. 
and the Western plains generally. This caterpillar, at first sight. resembles one of the Noctuids very closely, and is of a beautiful, quite unusual, bluish tint. The moth expands nearly two inches, and is, perhaps, the largest of those belonging here. It has the peculiar habit of laying its eggs one upon the other in a pile which mimics the spines on the cactus leaves; so, unless carefully sought for, they are easily overlooked. We find also in this group of variable habits a species that is carnivorous, Letilia

\section{Fí, 359 .}

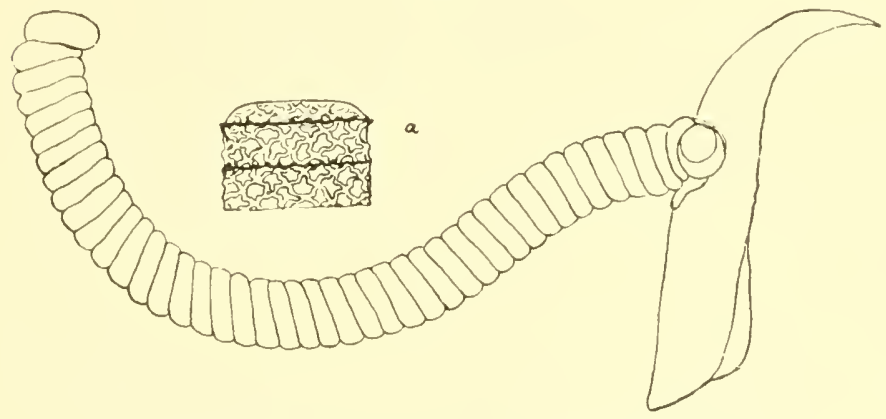

An egg-stack of Meltura prodtnialis.-Single eggs shown it a.

coccidizora, which, as its name indicates, feeds upon scale insects. Unfortunately, it is altogether too rare to be of any practical use, and is simply a curiosity, the carnivorous tendency in the Lepidoptera being extremely rare.

Ephestia kïhniclla is another troublesome species, commonly known as the "Mediterranean flour-moth." It is sometimes abundant in barns and mills, and, especially in the latter, may do much injury. Great complaint has been made during the few years lact past, the insects seeming to become more abundant and to cover an increasing portion of our territory. Cleanliness, of course, is primarily to be enforced; but where they are abundant enough to make it important, the insects can be cleared out by using bisulphicle of carbon. All the rooms should be tightly closed overnight, and enough bisulphicle evaporated to fill every nook and cranny with the poisonous fumes. In a badly infested establishment a second application may be necessary in some cases, but in most instances one has proved effectual. 
A very curiou species is the Galleria melonclla, or "beemoth," which infests beehives and feeds upon wax. A brood of these caterpillars sometimes invade a hive and bore into the wax out of sight of the bees, frequently demoralizing them to such an extent that they abandon their home, seeming unable to find a way of dealing with this kind of enemy. In the recent types of hives there is little opportunity for these pests to establish themselves, and if the bee-keeper is on the alert, he will at once perceive any such invasion. It is easy then, by transferring and cleaning out the infested frames, to save the swarm. The moths are rather curious creatures, mottled and streaked on the fore-wings, the outer margins of which are also a little excavated.

Under the general term Crambids we may describe a series of species with slender body, narrow, rather squarely cut off forewings, and broad hind wings. When at rest the wings are rolled

FIG. 362.

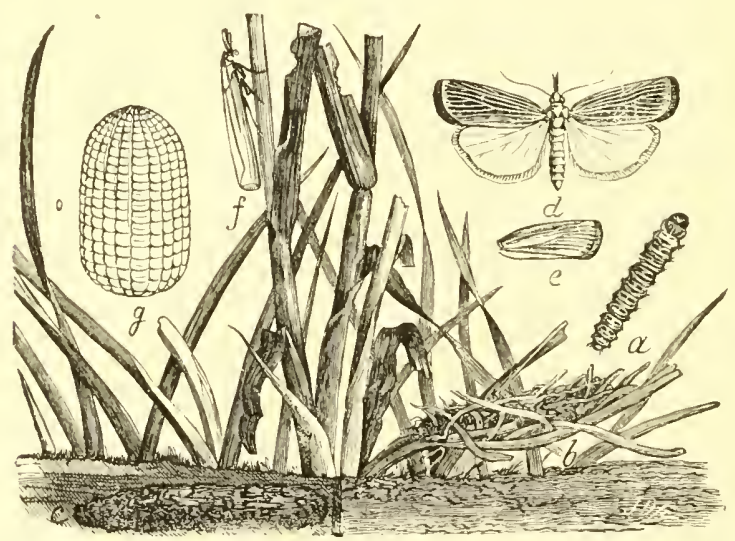

Crambus vulvivagellus. $-a$, larva; $b$, over-, and $c$, underground tube and cocoon; $d, e$, $f$, moths with wings spread and at rest; $g$, an egg much enlarged.

up or folded closely, giving the insect a little the appearance of a tiny cylinder. The head is small, not at all retracted, and usually furnished with very long palpi that project straight out like a snout; as a whole, resembling somewhat one of the groups of the (leltoid Noctuids. The fore-wings are generally white or yellowish, quite frequently streaked or spotted with silver and gold; 
but, of course, as in other groups, we have modest species in which gray predominates, and where the longitudinal markings are rather in the form of black lines or streaks. The majority of the species belong to the old genus Crambus, and a number of them are injurious in grass lands, where the caterpillars are known as "root web-worms." As in many other cases, it is not so much the grass that is injured as the corn crop which follows it, and, therefore, we usually find them injurious in proportion to the length of time that a field has been in grass before being ploughed for corn. Usually the moths appear quite early in spring, and the eggs are laid in grass some time in May, loosely attached to blade or stem, or sometimes simply dropped on the ground. The larva, when they begin feeding, make a loose web or tube of silk, sometimes on the surface, sometimes a little below it. Occasionally they feed upon the roots, sometimes on the stalk, and often they enter and bore into the plant itself. If an infested grass-plot is ploughed after eggs have been laid or after the caterpillars have hatched, such of them as survive attack the corn, if that is the crop planted. Occasionally entire fields are destroyed, while quite frequently much damage is done. The moths make their second appearance a little after midsummer, and are never troublesome then, because the eggs are laid in grass lands, where the caterpillars, though abundant, are not noticed. From this general life history it will be seen that fields can be kept clear by fall ploughing, or by turning the sod very early in spring before the moths have made their appearance or had an opportunity to deposit eggs. Bare ground will not become infested, nor, usually, will a corn-field if there is any grass in the vicinity. Where injury is caused on lands ploughed late, I have found that certain commercial fertilizers exercise a beneficial effect ; in fields fertilized with potash in the form of kainit or muriate, the exemption may be complete, while in adjacent plots fertilized with barnyard manure, injury may be serious. It is also possible to prevent trouble by planting some other crop between sod and corn, where such rotation can be profitably adopted.

In the genera Diatraa and Chilo we have insects resembling those already described, but rather larger, with often more slender pointed wings and longer palpi and abdomen. Here the larvæ are usually borers, some in corn, some in sugar-cane, and 
some in other plants. As with all other borers, there is difficulty in reaching them direetly, and besides destroying infested plants, nothing really satisfactory has been proposed. Diatraa saccharalis bores into sugar-cane and into corn, often doing much injury to the latter crop in the States south of the Potomac. There are two or more broods, depending on latitude, the last remaining through the winter in the larval stage in the cornstalks. IVe have thus an obvious remedy in removing and destroying or using these up completely before the spring following. In sugar-cane the matter is not so simple; but by burning tops, cutting close to the surface, and planting in fall from sound canes only, the injury can be at least much reduced if not en-

FIG. 366 .

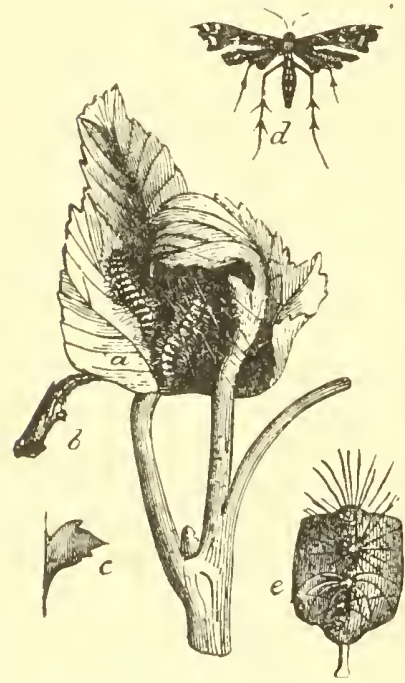

The grape plume, Oxyptilus periscelidactylus, $-a$, larve in a spun-up tip; $b$, pupa; $c$, its breast projection; $d$, moth; $e$, a single segment of larva.

O.ruptilus periscelidactylus. tirely avoided. It is another instance where an intelligent farm practice will answer every purpose, without a resort to insecticides of any kind. Mats, both flat and round, are especially to be avoided for affected canes.

An interesting little family is the Ptcrophorida, peculiar in having the wings split into feathers or plumes. Occasionally the primaries have only a cleft that does not extend beyond the middle, but sometimes they are split for the full length. The hind wings may be divided into from four to six feathers, the insects being therefore termed "plume moths," or "feather-wing moths." As a whole, few of the species are common, and I am acquainted with only one that is in any way injurious, - the "grape plume," The caterpillar of this is pale yellowish or nearly white, with little tubercles, from which rise tufts of pale hair similar to those of some Arctiids, or "wolly bears." It lives in the tips of young shoots of grape, webbing up the 
terminal leaves soon after growth has started, and eating out the heart. It would seem thus as if considerable injury might be caused, but really this is not so, because in most cases they (w) not attack the shoots until the buds have become freed,-that is to say, the shoots are attacked above the flower cluster, so that no injury is done to the resulting crop. When the insects disappear, which they do quite early, the shout simply sends out a new spur from the last leaf, and the effect of their presence is scarcely noticed. Practically, there is no method of checking their increase, except by picking off the infested tips or crushing the caterpillars within the webbed leaves.

We have another series of families grouped under the Tortricids, sometimes called "bell-moths," from their peculiar appearance when at rest, but more commonly "leaf-rollers," from the quite usual larval habit of folding or rolling up the edges of leaves. We have a number of troublesome insects in this series, and some of them are not easy to deal with. The moths are quite easily recognized by their broad, short fore-wings, forming a

FIG. 367 .

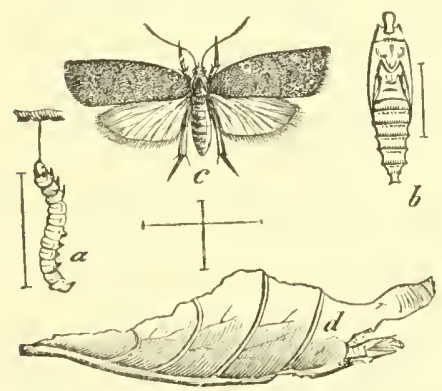

Teras mimuta.-a, larva; $b$, pupa; $c$, moth; $d$, case made on apple-leaf.

Fic. 368.

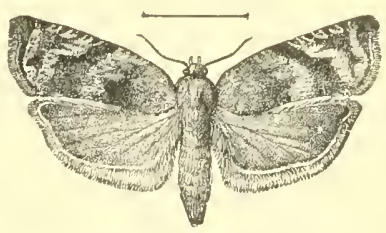

Khopobota iaccimana

more or less obvious shoulder on the front margin. These wings are held roof-like, the edges overlapping only a little at the middle of the back, and completely conceal the moderate or small hind wings. Their colors are frequently bright and contrasting, while in other cases they are uniform and sombre, the entire insect inconspicuous and unattractive. One of the common species is Teras minuta, whose larva attacks, among others, 
apples and crimberries: in apples simply feeding upon the leaves in a little case, but on cranberries often becoming seriously injurious by spinning up and eating the tips of the growing shoots. It also feeds on huckleberry and allied plants, and from them goes to cultivated cranberry bogs. It is there known as the "fireworm," and it is distinguished from Rhopobota raciniana, mother caterpillar with the same habits, by having a yellow instead of a black heal. Both these insects have similar larval habits, but the Rhopobota has only two broods, and hibernates 11 . the egg stage, while the Teras has three, and hibernates as an adult. There is a curious altenation of generations in this insect, the summer broods being yellow or orange, while the moths that hatch in the fall and hibenate are uniformly slate-gray. Cultivated cranberry bogs are covered with water during the winter, and the moths cannot hibernate on them ; so, as they lay their egges quite early in spring, if the bogs are kept covered until all other vegetation has started, they oviposit elsewhere, leaving the bogs free. Therefore, holding the water late, say until at least the midclle of May, is usually a fairly complete pro-

Fic: 369 .
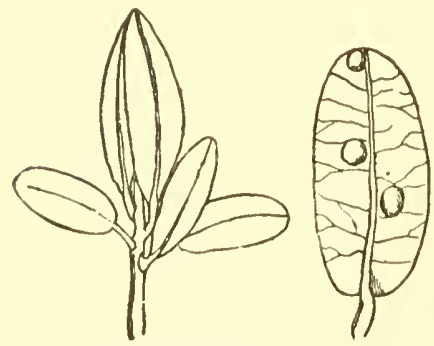

Cranberry leaf with egges of Rhopobola, and a spray spun up at tip by the larva. tection. The Rhopobotalays its eggs upon the cranberry plants late in summer. They remain unaffected by the water with which the bog is covered until spring, then hatch, and the larvie spin up the tips precisely as in the case of the Teras, the moths coming to maturity early in July. Eggs for a sccond brood are then laid, and these are sometimes sufficient in number to sweep entire bogs, giving them the appearance of having been burned over, wherefore this insect has also been called "fireworm." As against this species, late holding the water is not so effecturil, because it must be kept on until sufficiently warm to induce the eggs to hatch, the young larve dying as soon as they break the egre-shell, or stifling before they are really born. The method is feasible on a flat bog where water can be drawn down 
so as to warm up rapidly, but there is clanger in holding too long, because if the plants start nurler water, ats they sometimes do, the crop is rumed. Ocasionally, however, it pays to lose a crop, in whole or in part, to free the bog in completely of this insect, as they will then remain practically safe for several years in succession. Where water is abmulant and the bogs can be readily reflowed, the practice of the present day is to draw the water early to induce an early hatching of the insects, and as soon as the larve generally appear, reflow, leaving on the water at least twenty-four hours. This will not hurt the plants at that period of their growth, and will kill every caterpillas upon the bog. The effect depends largely npon the care with which it has been done and upon the judgment exercised as to the proper time. It shoukl be delayed until the great majority of the eggrs have hatched, but should not be delayed so as torun the risk of injuring the plants.

In the genus Cacrecia we have severat injurious species, and none mole annoying than C. rosaccana. This attacks a great vaFig. 370 .

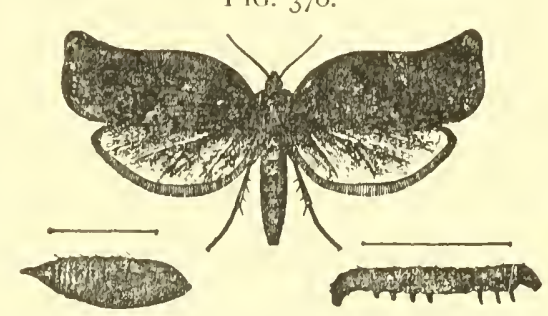

Rose leaf-roller, Cacaria rosaceana.-Larva, pupa, and adult. riety of plants, but it is most troublesome on roses, spinning and folding leaves and buds and so destroying the flowers. These larvar are not easily dealt with, but spraying the plants with pyrcthrum or kerosene emulsion as soon as the first signs of injury are observed will generally serve to keep them down. On a small scale they may be controlled by compressing the spun-up leaves and killing the caterpillar in its home.

Some of the species live in communities, making a nest or web, and such is the Caceria fervidana, the caterpillar of which lives on oak, and spins up the shoots of young trees or the tips of the branches of older ones. In some cases the nests become from three to six inches in diameter, and when the caterpillars have rached their full growth they pupate within it, wriggling out through the silken covering when realy to emerge as moths, 
and leaving the empty pupa cases projecting all aromind. Some species are occasionally so numerous that the nests constructed by them become enormous, - four or five feet in height, and covering young trees entirely. This and other species having the same habit can be dealt with by early spraying, or, when feasible, by picking off the webbed leaves or shoots.

The best known of all belonging to this family is the "codling moth," Carpocapsa pomonella, and there is no insect, except possi. bly the "plum curculio," that has done more injury to our orchardists. The moth appears at about the time the apple-trees are in

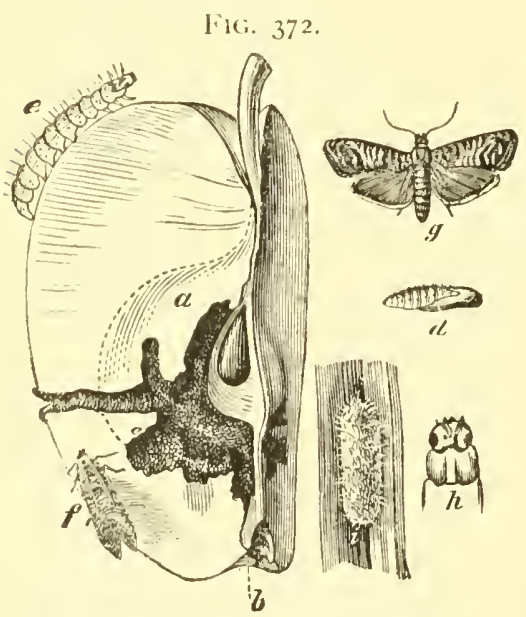

The codlung moth, Carpocupsa pomonclla.-a, apple cut to show bormgs of the larva ; $b$, place where the egg was laid and the larva slarted: $d$, pupa ; $e$, larva ; $f, g$, moths at rest and with wings spread; $h$, head of larva; $i$, cocoon. blossom, and lays a single egg upon the young fruit at the point where the blossom has clropped off. In a few days the caterpillar hatches, eats a little on the outside for a day or two, and then makes its way into the fruit itself, feeding around the seed-capsule or core, and making the well-known "worm" in the apple. Occasionally two or more moths may oviposit on the same fruit, and this accounts for the two or more larvæ sometimes found in one apple. Except in the northern part of the country, there are two broods, the first caterpillars becoming full-grown and leaving the apples about midsummer, changing very soon thereafter to moths, which lay the eggs for the larvæ found in the ripe apples. The second brood does not so usually oviposit at the blossom end, but seems to have a preference for the point where two fruits touch, for we often notice that in a little bunch of apples every one is infested, the entrance in all cases being just at the point of contact. In any event, whether there is one brood or two, the caterpillars of the last, when full-grown, leave the apples, find a hiding-place under 


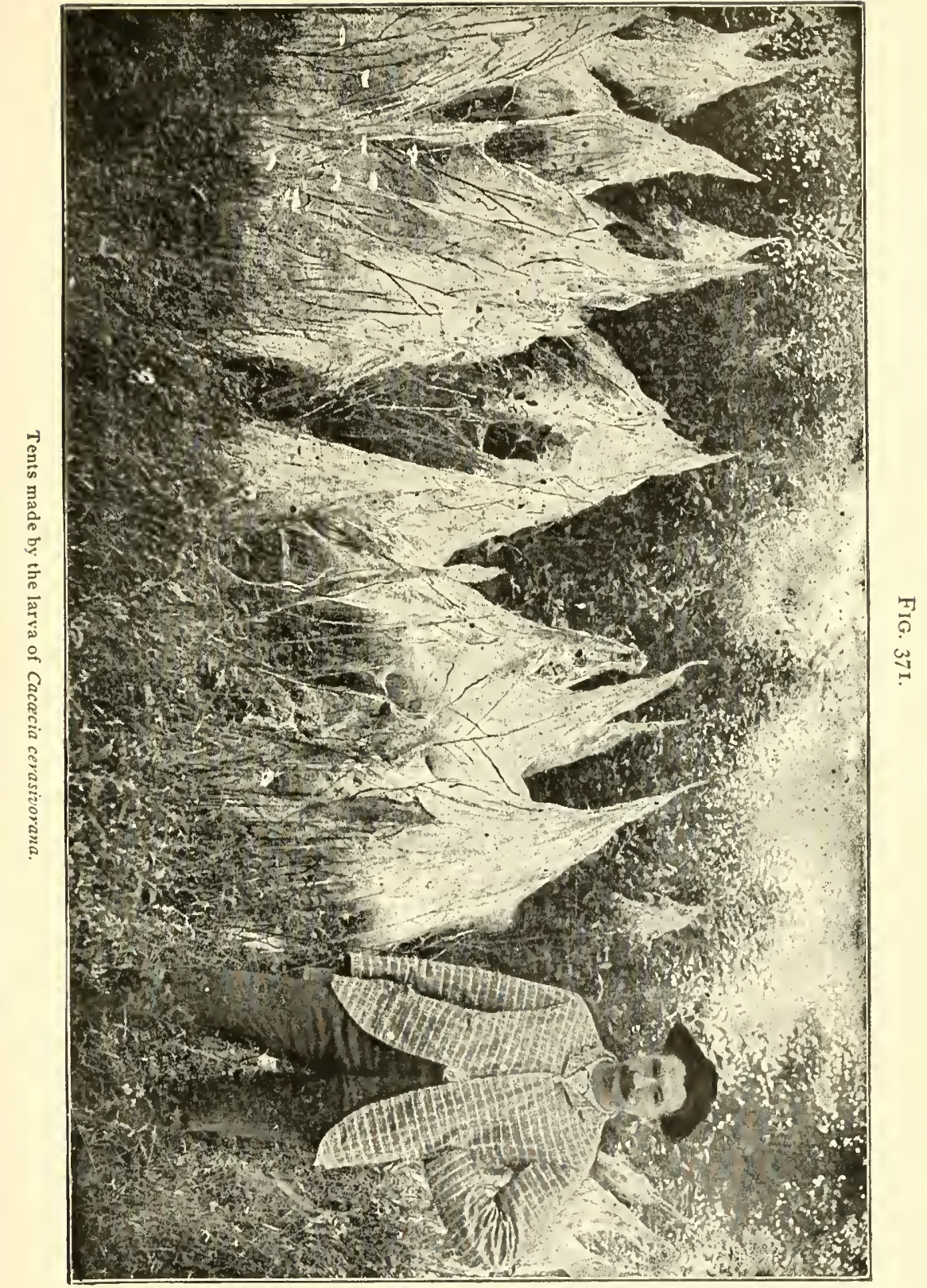



a scale of bark or in a little depression, and there spin a coroon, in which they remain unchanged during the winter. The change to the pupa takes place very early in spring, and the moths appear as already stated. It has been found that we are able to protect our trees by spraying them with one of the arsenites as soon as the blossoms have all dropped and the fruit is well set. At that time the young apples are upright, affording a favorable opportunity for lodging the poison in the calyx cup, and here it remains until the larva makes its first and, if the spraying is properly done, its last meal. Under favorable circumstances a single spraying is sufficient to prevent injury, but practically two sprayings are required at intervals of about a week, and a third if rain interferes to shorten this period, - that is to say, one just as soon as the blossoms are all off, and the second about a week or, if the weather remains dry, at most, ten days thereafter. This is to allow for the irregular hatching of the larvæ, the rapid growth of the young fruit, and to make certain that all may be reached. It is here that promptness and thoroughness will tell. To be effective the spraying must be done before the larvæ hatch, and the mixture must be on every fruit to be protected. In dry weather ten days between sprayings is not too much; in wet or showery weather three days may be too long. The young larva feeds externally for a day or two only, and unless it is then killed, is beyond our reach. Success is the result of keeping an unbroken film of poison on the flower end of each fruit until ail eggs are hatched. One pound of Paris green or London purple in one hundred and fifty gallons of water is a good strength, or fifteen ounces of arsenate of lead in one hundred gallons. Some growers, however, use a mixture of clouble this strength and find it advantageous; they spray carefully, use just enough to cover, and risk a little burning of the foliage.

The last series in the order is the Zineina, or the "Tineid moths," comprising the smallest of the Lepidopterous insects. There is an enormous number of species, and we know very little about the great majority of them. With few exceptions, the insects have long, narrow wings, the primaries pointed, the secondaries lanceolate, but their surface increased by enormously long fringes, which are in many cases broader than the wings themselves. They often have on the head a clothing of upright 
divergent scales, all of one height, giving sonewhat the appearance of at little plush cap. In their life habits the vary much. Some are leaf-miners, living between the upper and under surfaces, and each species eating out characteristic galleries that are visible as irregular brown lines or blotehes. Others are casebearers, making little houses of various shapes and texture, which they carry about with them, and in which they live, projecting the head and anterior segments just far enough to feed,

FIG. 373 .

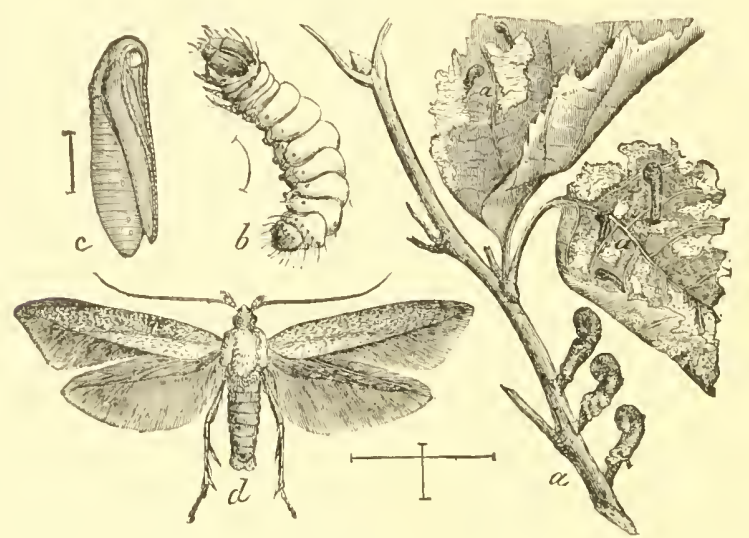

Apple case-liearer, Coleophora malivorella.-a, larval cases; $b$, larva; $c$, pupa, $d$, allult moth.

but retreating at the first signs of disturbance. A fow feed open]; while others are borers in fruits, seeds, or even twigs.

Among the best known are the "clothes moths,"---little, yellowish creatures often seen flying in houses early in the evening, and which generally arouse excitement and resentment in the breast of the careful housekeeper, for she knows that her woollens and furs are in langer. The caterpillars feed upon animal textiles of all kinds, and upon furs and feathers. They do not often attack vegetable fibre like cotton or linen. Their habit is to form a little flattened case of fibres from the material upon which they are feeding, and this is lined on the inner side with silk. In about three weeks the larva is full fed, changes to a pupa within its case, and the moth, when it emerges, leaves the empty she!l protruding for half its length. There are several species engaged 

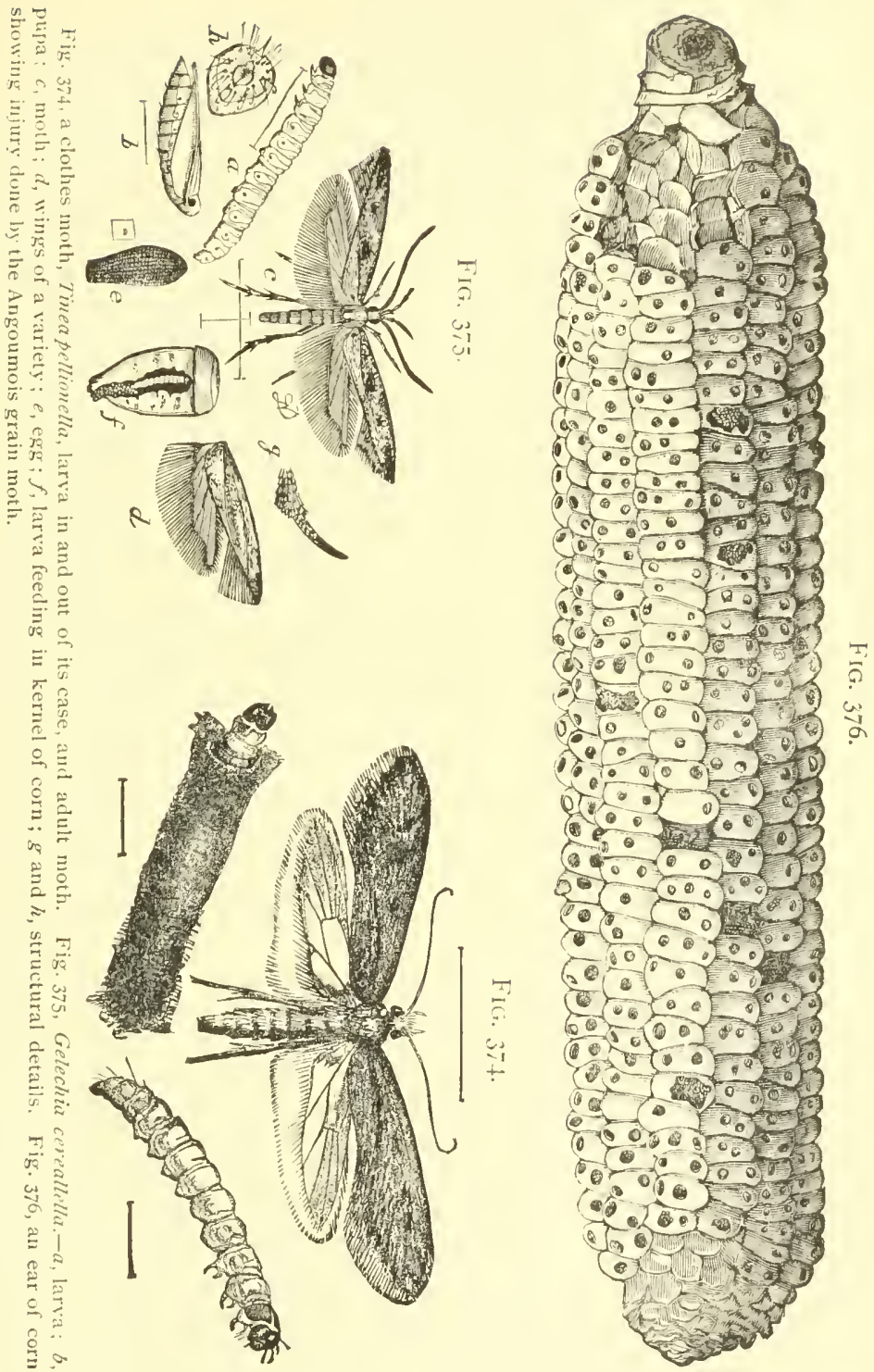
in this pleasant occupation, but they have habits so nearly similar that there is no necessity for differentiating them here. As to remedies, plenty of air, sunshine, and beating will keep clothing free, or, having been made free, it can be wrapped in stout paper in such a way as to make it impossible for the moths to enter and to lay eggs, or for the young catcrpillar to find a crevice through which to craw. A cotton or linen sack, if the material is sufficiently dense, will afford ahnost equit] protection. A closet or trunk in which plenty of naphthaline crystals have been strewn is also a safe place, and will be avoided by the moths, who cannot live in such an atmosphere. Where the insects get into carpets, they can be destroyed by saturating the infested spots with gasoline, as this is exceedingly penetrating and fatal to the insects wherever it touches them.

Another troublesome species is the Gelechia cercallella, or "Angoumois grain moth." Its larva bores into the kernels of wheat. rye, or corn, a single grain of wheat sufficing to bring one to maturity, while in a grain of corn two or three, or sometimes even four, lurve find sufficient nourishment, though two is, perhaps, the rule. The insects sometimes lay their eggs upon the grain in the fields, and when it is cut and brought into the barn they continue breeding in the mow so long as it remains there. Corn-cribs frequently become infested, and the insects breed as long as the temperature remains mild. Where grain is threshed and bulked the upper layers may be infested, but the insects are not able to get in very far, because the moth is unable to escape through any heavy layer, becoming worn out and dying before reaching the surface. The insect is much more troublesome southward than it is in the north, where the cold weather check. breeding before it has an opportunity to do much damage; but in regions where the temperature in the barns is moderate throughout the winter it frequently does great injury. The best remedy is threshing and bulking the grain as soon as possible, covering the bins to keep out the insects. If infection is noticed, it can be easily checked by eraporating bisulphide of carbon in a dish upon the surface. The vapor is heav'y and sinks through it to the bottom, effectually clearing out any insects that may be present. In corn-cribs the bisulphide can also be used, but the crib must be temporarily closed by canvas or 
sheeting, so that the vapor may become effective before it escapes. It has been fonnd by experiment that grain can be exposed to this vapor for a considerable time without losing in germinating qualities, but seed wheat should be, if possible, kept free from such insects. It should be selected early and kept in insect-tight vessels until needed for use. Open corn-cribs should be placed in such a way as to get the benefit of all the cold weather there is, and thus the multiplication of the insects will be checked so early that no serious damage will be done,

There are other species of Tineids infesting cultivated plants, but few are widely distributed and at the same time injurious. In most cases the application of arsenites to those forms feeding openly upon plant tissue proves more or less satisfactory, while against those feeding upon stored products we can use the bisulphide of carbon.

\section{CHAPTER VIII.}

THE DIPTERA, OR FLIES.

THE term Diptera means two-winged, and members of this order are separable from all other insects by possessing, normally, only a single pair of wings. These are borne by the middle segment of the thorax, and are, therefore, the first pair ; the second or hind pair are reduced to little club-like processes called " halteres," " poisers," or "'balancers." Their function is supposed to be indicated by the last of these terms, -i.e., to aid the insect in directing its flight and maintaining its position in the air. The members of the order are, therefore, easily recognizable in most instances, but the reference of individual specimens to the proper place in the system is a matter of greater difficulty. They are mostly of moderate or small size, sometimes quite fragile, and the character of the wing venation, upon which much reliance is placed in scientific classification, is not readily made out, except by the special student. Yet a little patience will generally lead to the proper group, and the habits or life history mathen be wsed to determine more closely. 
Before taking up the more typical forms, we mat briefly consider the Aphaniptera, or fleas, which are usually considered as flies that have lost their wings as a result of parasitic habits. They are small, transversely Hattened creatures, usually brown in color, with small heads, piercing mouth parts, and the merest rudiments of wing-pads. To replace wings, they are furnished with greatly developed posterior legs fitted for jumping, and in

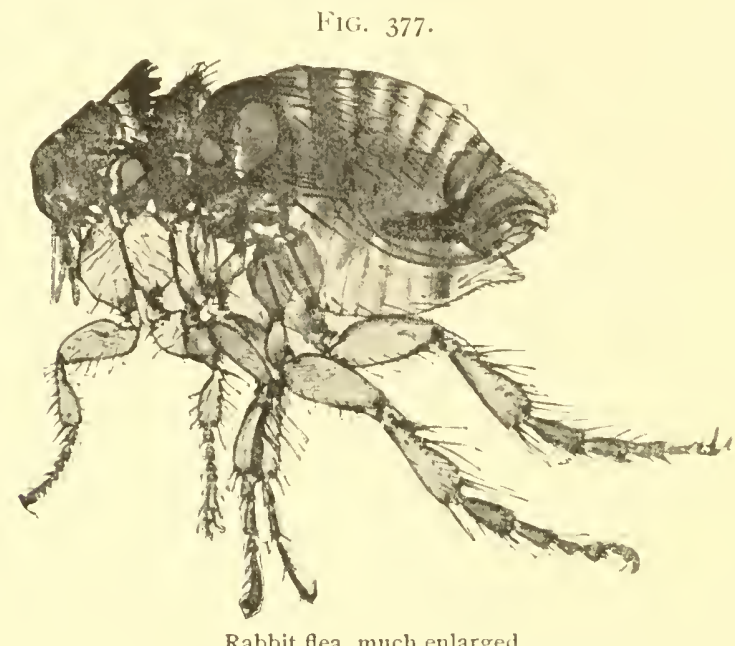

Rabbit flea, much enlarged.

proportion to their size their leaps are wonderful. They live in the adult stage among the hair of warm-blooded animals, sucking blood, their form enabling them to move about easily in even the thickest fur. So also the position of the spines clothing the body is such that every effort of the insect pushes it forward, which accounts for the difficulty in holding a specimen when captured.

The larve are whitish, small, worm-like creatures, almost cylindrical in form and with small brownish heads which bear fairly well developed mouth parts. They live upon partly decayed matter in or near the lairs of the animals upon which the adults feed, and the eggs are probably dropped at hap-hazild by the females while the host is at rest. A rug used as a bed for a dog or cat may be found full of eggs at almost any time during spring 
or summer, the larva finding food in any dust or clirt near by. The spaces between the boards of floors are often filled with them, and a little pile of moist sawdust or shavings maty harbol myriads. This led to a quite wide-spread and at one time popular belief that under such circumstances the insects were spontaneously generated. The period of development is very brief, and under favorable conditions a building may swarm with fleas in a month or two. No species of fiea specifically infests man in this country, though the Ceratopsyllus scrraticeps of the household $\log$ and cat often bothers him a little. In tropical and subtropical comntries several species attack him as readily as they do any other warm-blooded animal.

Where a house becomes infested, the dogs or cats, if any, should be washed with carbolic soap every other day to kill the adults on them, and if the animals be allowed to run throughout the house they will in a few days attract all the fleas to themselves, where they can be dealt with. The sleeping rugs of the animals should be thoroughly beaten or shaken out-doors every day, and the most rigid cleanliness should be everywhere observed.

Where dogs or cats are not available as traps, a liberal application of gasoline, following a thorough cleaning up, is the best remedy. It should be poured into every crevice in the floor and along the base-boards, and it will kill every larva and adult with which it comes into contact. The liquid is exceedingly inflammable, and must be used with that fact borne in mind. Pet animals can be cleaned by a free and frequent use of carbolated soaps or vaseline.

In hot countries fleas are often serious pests, not only to man and his pets, but to fowls as well, young chickens being frequently killed by the great numbers clustering around their heads. Here the free use of carbolated vaseline is indicated to keep off the insects and to act as an effective heaing agent. Cleanliness in its strictest form in the coops and houses is always indicated.

Rather more serious pests are the so-called "jigger" fleas, species of Sarcopsylla, or Vermipsylla, the females of which work their way under the skin, often of the feet of man, causing an ulceration in which the eggs and larva develop. If the case is 
neglected, amputation sometimes becomes necessary. Where shres are worn, the insects do not often succeed in reaching their favorite points of attack; but if they do, a prompt use of the needle or knife or a mercurial ointment will prevent trouble. A

FiG. 378 .
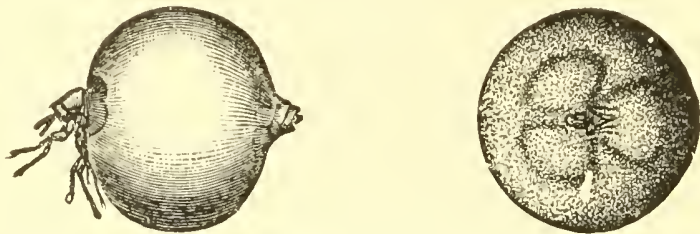

"Jigger" Hea, Surcopsylla penetrans.-Female distended with eggs, from side and front.

moist quid of tobacco bound over the infested spot usually results in killing the insects, so that the wound can be cleaned and left free to heal.

The metamorphosis of the fleas is complete, like that of the true flies.

Fici. 379 .

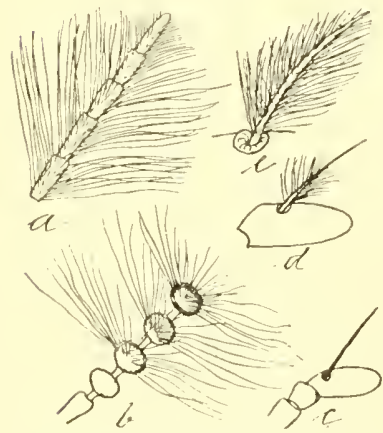

Antennit in Hies. $-a$, tijs of plu. mose antenna; $b$, juints verticiliate: $c$, aristate, the arista bare; d, arista plumose at base; $e$, arista plumuse to the tip.

The most obvious division among the true flies, for our purpose, is based upon the character of the antennx, or feelers. There are two series, those with long horns or feel. (r) much exceeding the head, and those with short horns, having usually only two or three visible segments, one of which is often furnished with a specialized bristle, or "arista." The divisions are by no means sharply limited scientifically, but are sufficiently distinct for the species of economic importance.

The Tipulide, or "crane-flies," is the first family of economic interest, and its members are recognizable by their resemblance to exaggerated mosquitoes. They are usually quite large, with many-jointed, slender, thread-like antenne and scarcely shorter maxillary palpi. The legs are abnormally long and ungainly, 
and the wings are narrow, so that the insect is awkward in appearance, as well at rest as in its flight, which is slow and heavy. The flies are most frequently seen in low, rank meadows, or along ditches or sluggish streams, flying preferably during the morning and late afternoon hours. The larve are slender, cylin-

FIG. 380.

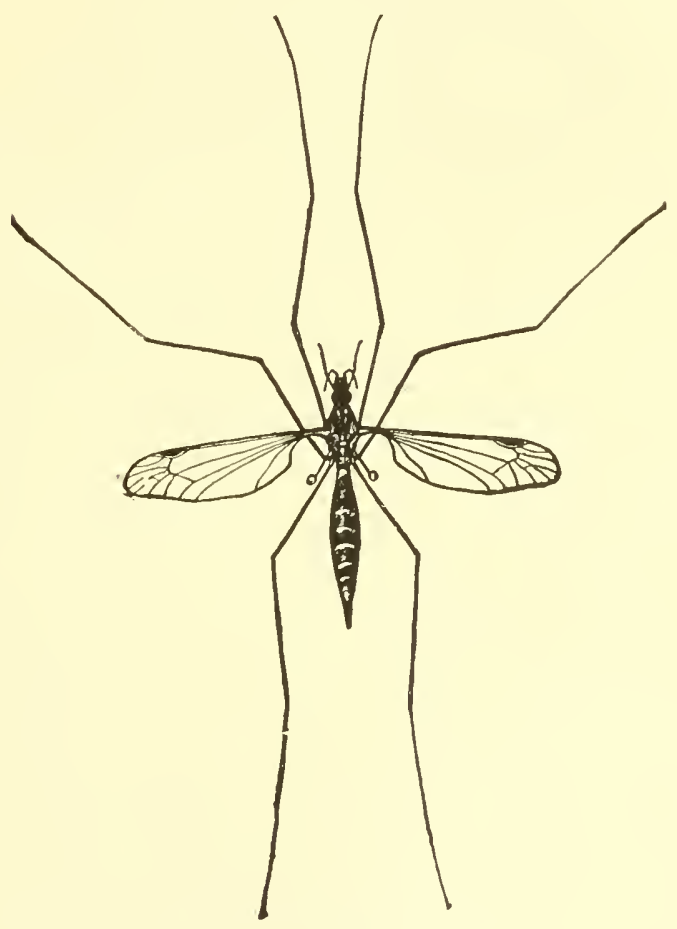

A crane-fly, Pachirrhina species.

drical, somewhat worm-like, of an extremely tough, leathery texture, and live underground on the roots of grasses, or in decaying wood. In Europe they are known as "wire-worms," and are often seriously injurious; but in North America none of the species have as yet proved very troublesome. It is probable that intelligent farm practice will be sufficient to control any of the species likely to become injurious with us. 
To the family Culicide belong the mosquitoes, characterized by a sender bouly, longe legs, lone antenna, and a small heal

liki. 3is.

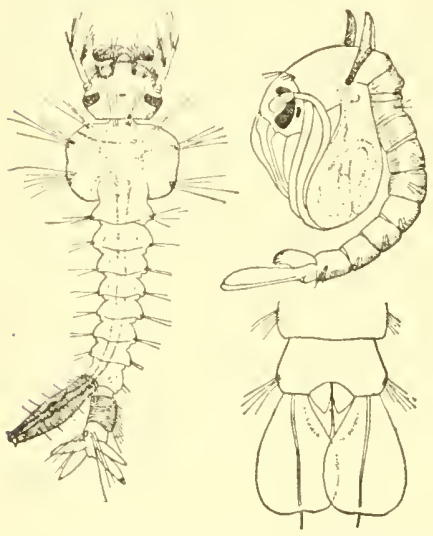

Larva and pupa of the Culex pungens. more enlarged. (From Howard, Bull, 25, 11. .., U. S. Dept. Agl., Div. Ent.) enlarged; with anal flaps of pupa yet

with mouth parts usually extenderl to form a beak or proboscis. In the male the proboscis contains a single lancet only, not fitted for puncturing animal tissues, and the antennce are plumose; in the female a series of five slender, bristle-like lancets forms an effective piercing structwre, and the antenna have the joints furnished with a few bristles unly. The wings are slender aml scaly along the veins.

The species are quite numerous, and while most of them are pests of the first order, a few seem to feed on other than animal juices. The more common species belong to the genus Culex, in which the wings are unspotted, the palpi of the female are shorter than the beak, and the body is held parallel with the surface upon which the insects rest. The species of thopheles are fewer in number, but are of relatively greater economic importance, because they have been proved to be intermediate hosts for the parasites causing "malarial" fevers. They are larger, as a rule, than Culer, the wings are more or less spotted, the palpi in both sexes are as long ats the beak, the body is more linear and is helel at an angle to the surface upon which it rests, the beak directed to a point almost midway between the fore and middle legs.

Some of the species of Culex fly or allow themselves to be carried by the wind for long distances, so that they occasionally appear ats pests many miles from any possible breeding-place. The mole of hibernation varies: in - Inopheles and some Culcr. the female adult survives; in other species of Culer the eggs lie over in suitable localities, and in one instance at least the partlygrown larva lives through the winter. 
The larve are commonly known as "wrigglers," and are of two general types, - one ustal in Culc.r and its allies in which the head is held down in the water and the tail or anal siphon is kept at the surface; the other peculiar to. Inopheles, in which the body rests for its full length on the surface.

All the larva breathe through a single spiracle at the end of the anal tube or siphon, and most of them must come to the surface at rather short intervals to secure the necessary supply of air. IVhen startled they make their way through the water by a peculiar jurky or wriggling motion, which gives them their common name.

Eggs are laid in various ways: sometimes singly on water or on regetation in water, or in dimp places where water is likely to come; sometimes they are laid in masses, forming "borats," which float on the surface of the water, and this is the habit of our most common species. Under proper conditions the eggs hatch quickly and the larve develop in accordance with the temperature; a week or ten days being sufficient to carry the insects from egg to adult in midsummer.

The larva must have water for its development, but there is none so foul and nonr so salt that some species does not breed in it. There is no space here for methods of dealing with these pests ; but meatsurable exemption from annoyance may be secured by a free use of the oil of citronella on exposed parts of the body.

Mosquitoes occur all over the world, and they are quite as numerous and troublesome in the arctics as they are in the tropics. In fact, the climatic peculiarities of parts of the frigid zone, griving a short hot summer over a surface soaked with water from melting snow, produce conditions which favor their development in great numbers. In permanent ponds or streams their natural enemies, of which there are many, keep them down to insignificant numbers.

Closely resembling mosquitoes in appearance are the Chironomida, which may be recognized by the naked wings and by having the thorax produced so as to hide the small head from above. The antennæ are feathered in both sexes, those of the male strikingly plumose. To this family belong the gnats or midges which may sometimes be seen dancing in swarms in the evening only a few feet above ground, generally early in the year and in damp places. The larve are mostly aquatic, and 
never economically important. The minute species of Ceratipogon are furnished with piercing mouth parts, and are often extremely irritating, but otherwise the adults are harmless, unfitted for blood-sucking. They are known as "sand-flies," " punkies,"

FiG. $3 S_{2}$.

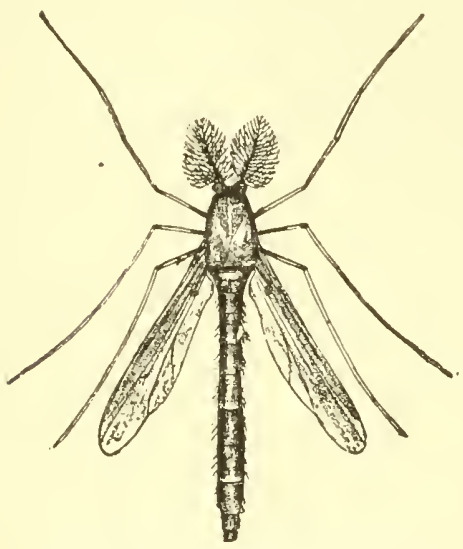

Chronomus species, male, enlarged. " gnats," "midges," and by other names, some of which are applied indifferently to species of diverse families.

The "fungus gnats" of the family Mycetophilida are also small, mosquito-like creatures, but, more compactly built, with shorter abdomen, stouter body and legs, and antennæe that are not plumose or feathered in either sex. They are smoky or blackish in color, as a rule, and frequent decaying vegetable matter or fungi, in which the larva feed. The latter are slender, white, worm-like creatures, with a distinct black head, and usually feed together in considerable numbers. They sometimes derelop a curious wandering habit when full-grown, marching in rope- or ribbon-like aggregations an inch or two wide and from six to ten inches in length. Some bands have been observed from four to five inches wide and twelve fect in length, piled up from four to six deep! Ordinarily no injury is done by these insects, which are rather scavengers than otherwise; but one species of Sciara becomes a serious pest to mushroom growers, eating into the plants and utterly ruining them. In fact, in many localities it is simply impossible to grow mushrooms after warm weather sets in. Measurable exemption may be secured by keeping the houses or cellars tightly closed and fumigating frequently with tobacco or pyrethrum to kill the flies. In a cellar the flies always get to any window or other source of light, and great masses can be killed in such situations by a fine spray of kerosene emulsion diluted ten times.

Quite recently Mr. Hopkins, of the West Virginia Experiment 
Station, hats found a species of this family concerned in producing a $10 \mathrm{rm}$ of potato scab in that State. He has named it Epidapus

F1G. $38_{3}$.
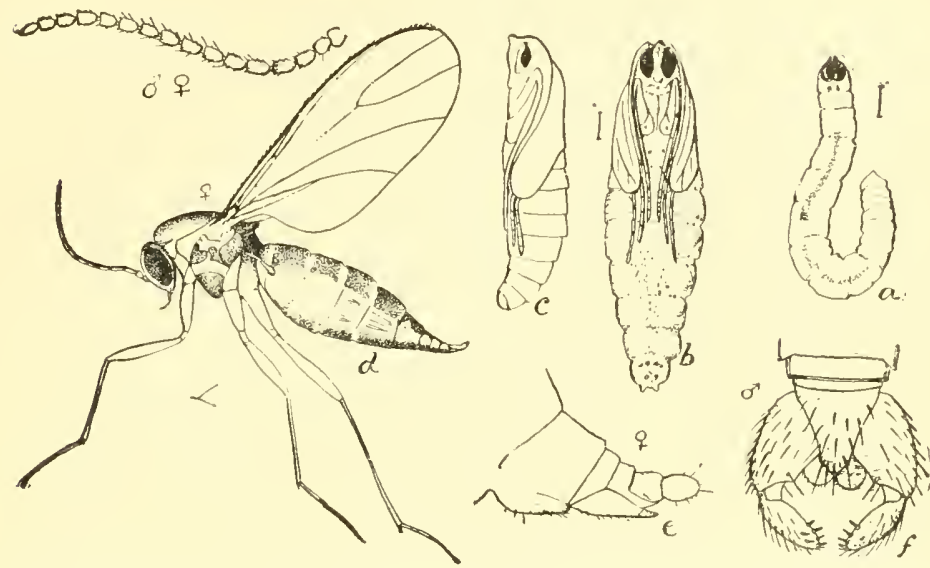

Sciara tritici-a, larva; $b, c$, pupa from below and side; $d$, female fly; $e, f$, tips of female and male abdomen.

sabci, and believes it to be responsible for much of the injury ustally ascribed to the germ disease. This may be locally true,

FIG. $3 S_{4}$.

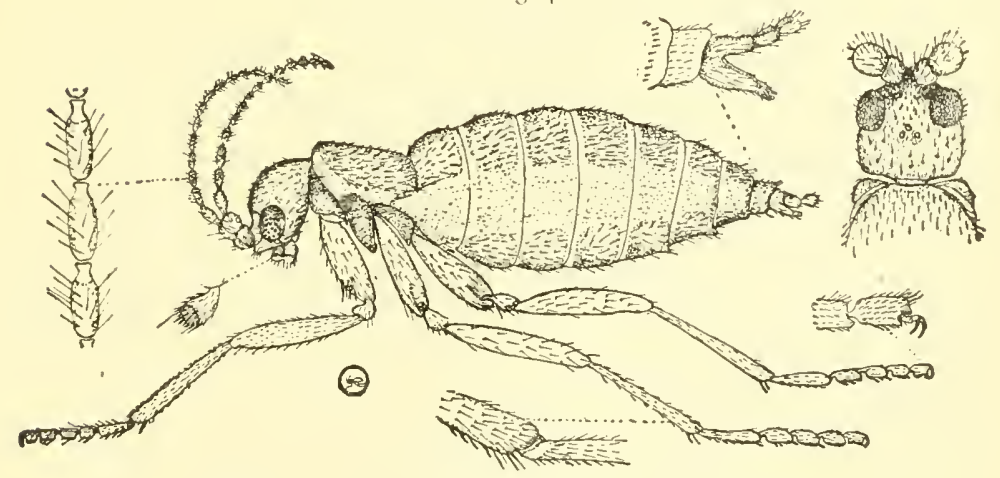

Epidapus scabei.-Wingless female and structural details.

but I have never found any trace of the insect in New Jersey, though I have examined many hundreds of scabby potatoes for 
that especial purpose. Fortunately, the measures used to prevent the scab due to the fungous disease seem to destroy the insects as

Fili. 395.

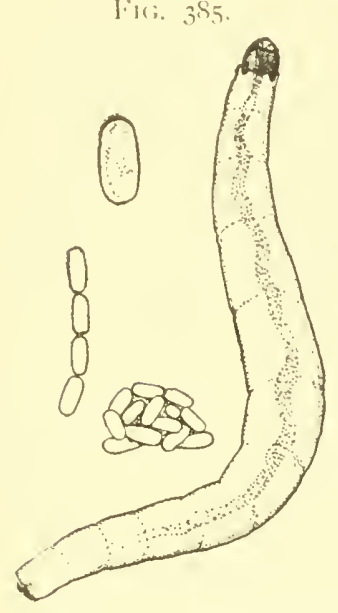

l.ggs and larva of liphlupus scabci, much enlarged.

well; hence the method of distinguishing between the two is not important.

In the family Cecidomyide, containing the midges, or "gall-gnats," we find the most injurious species of the order. They are also mosquito-like in appearance, but usually very small, with very long antennæ, which in the males are clothed on each joint with whorls of fine hair. The larve are ovate, quite broad, and a little flattenerl, the segnents well marked, and the apparent mouth parts formed in many species by a peculiar hormy process which is known as the "breastbone," from its situation. The species are numerous, and the larval habits and life histories are very diverse. In most cases growing vegetable tissue is the foorl, and, a.i a rule, a more or less marked gall-like swelling indicates the locition of the larva.

The most widely known species is the "Hessian-fly," Coci. omyia destructor; one of the most serious enemies of wheat, actually inhibiting its cultivation in some localities. The adult is rather linge for this family, smoky brown in color, and appears hate in the season, usually after the wheat is well above ground. Eggs are laid on the young plints, and the larve work their way into the stem at or near the surface, causing a slight gall or swelling and a deformity in plant growth. When winter sets in full size has been reached, and the "flaxseed" stage is entered upon,-so called because of its superficial appearance, though it is really the brown, dry, and hardened larval skin itself. In spring the pupa is formed, and soon afterwards the adult appears, ready to oviposit again in the now rapidly growing wheat. The flaxseed stage is again formed low down in the stalk before harvest, so that it usually remains in the stubble when the grain is cut. There it rests until the new wheat sprouts in fall, though flics may be found all summer, and it is more than likely that 
FIG. 386 .

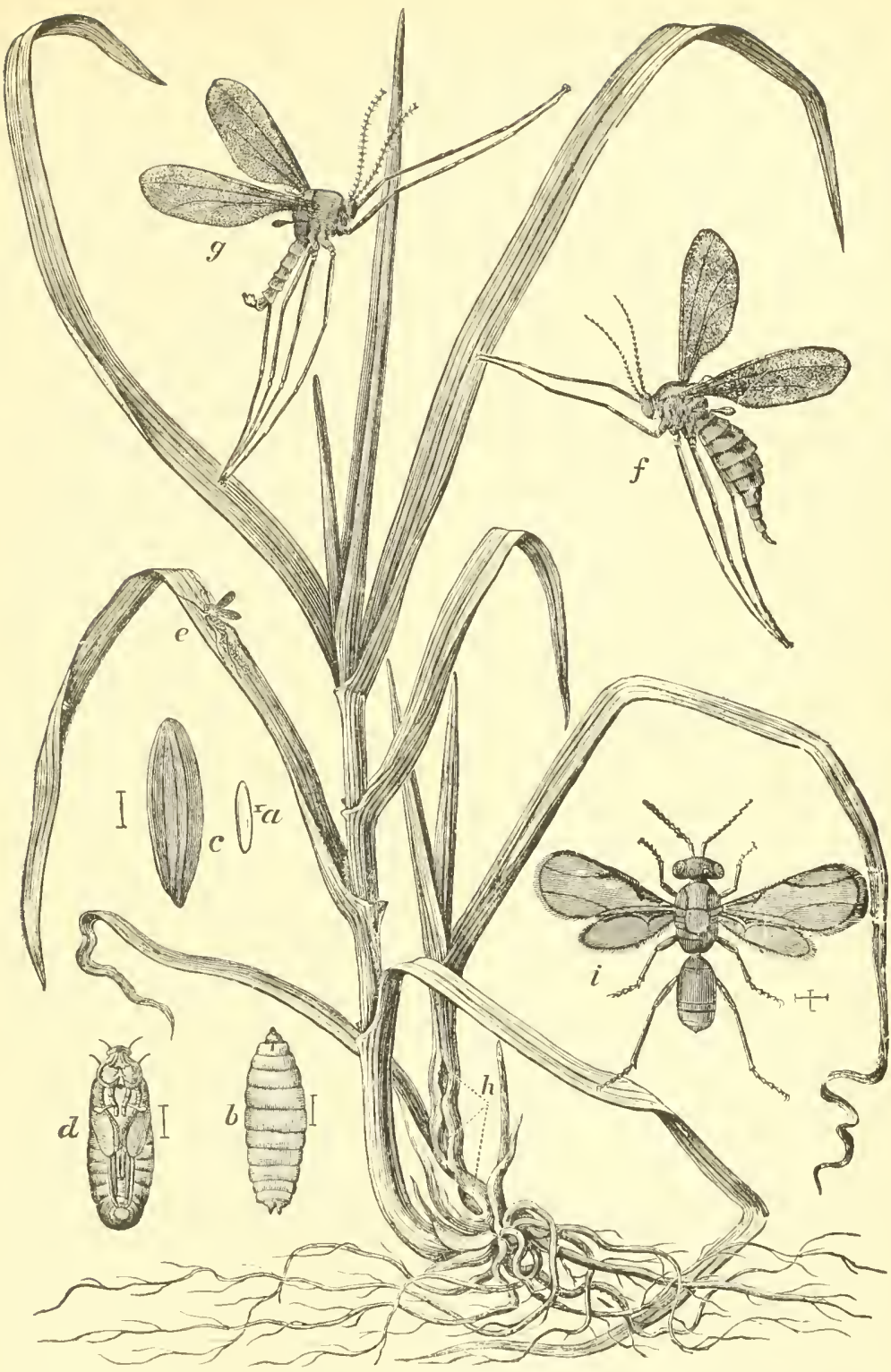

The Hessian-fly, Cecidomvia destructor:--On the left a liealthy stalk of wheat, and on the right one infested at $h$ by Hessian-fiy, showing the galls. a, egg; $b$, larva; $c$. "Haxseed ;" $d, p u p a$, all very much enlarged; $e$, fly ovipositing on leaf, natural size $; f$, female, and $g$, anale Hessian-fly, nuch enlarged; $i$, the parasite, Mcrisus destructor, much enlarged. 
certain grasses also sustain the species in the interval between harvest and seeding.

The injury is done by stunting and aborting the wheat plants in the fall, and in dwarfing stalks in the spring or so weakening them that they fall or "lodge" readily, preventing thereby the development of the "ear" or of the grain in it.

Insecticide applications are hopeless, and modified farm practice is the only satisfactory measure within our power. Very late sowing in the fall-as late as it is safe to do so-will force the insects to oviposit in volunteer shoots or grasses, and the later germinating crop remains exempt. As far as possible, infested stubble should be ploughed under deeply immediately after harvest to destroy a large percentage of the "flaxseeds," or it should be burnt.

Another, related pest, is the "wheat-midge," Diplosis tritici, which in the larval stage feeds upon the kernel of the grain, dwarfing it or causing its entire abortion. This larva is quite red in color, and the parent midges are about in June, ovipositing in the blossoms or on very young kernels. In this case also deep ploughing after harvest is advisable, and after threshing all chaff should be disposed of so as to destroy all chance of life for such insects as may yet be in it.

The "clover-seed-midge," Cecidomyia leguminicola, is also a dangerous enemy in some localities where seed rather than hay or fodder is desired. The midges lay their eggs in the flowers, and the resulting larva feed upon the forming seect, utterly destroying it. Where the insects are known to occur, cutting an early crop just when it is in full head and depending upon a second crop for seed is good pratetice. The midges oriposit in the Howers of the first crop, and those of later date will be practically exempt. The cutting can be high, so as just to include all the heads, which will be rapidly renewed from the vigorous stalks remaining. Fall ploughing infested fields is good practice, or ploughing under after cutting, and planting some cultivated crop that involves frequent stirring of the soil. The insects winter just below the surface among the roots, and the practice above suggrested looks towards winter killing them. A liberal use of lime and kainit after the crop is off is also good practice, and w:ll kill many of the larvæ then barely beneath the surface and not yet in their cocoons. 
The "pear-midge," Diplosis pyrivora, is an imported species appearing with the first buds of early spring and ovipositing in them as soon as they begin to show white. The young larva make their way to the ovary or seed-capsule of the setting fruit, and when this reaches the size of a nut, growth stops. The pears are then irregular in shape, a little knotty, and filled in the centre with a mass of orange-yellow larve. In June these become fullgrown, leave the pears, -which now crack open and decaly,-and drop to the ground, beneath the surface of which they pass the winter. The insect is especially fond of the "Lawrence" variety, and where such can be found in sufficient numbers, all others are exempt. The way in which this species can be controlled is by treating the ground beneath infested trees with a heavy top-dressing of kainit, - say one

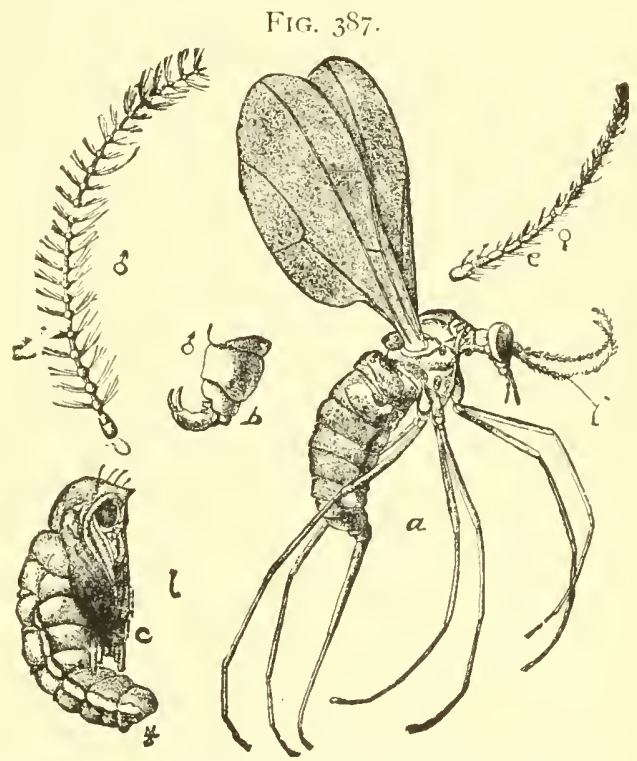

The pear-midge, Diplosis prrivora.-a, female adult; $c$, pupa; other references are to structural details.

ton to the acre,--applied between the middle and end of June. Planting "Lawrence" trees as traps and applying the above remedy to the soil beneath them will decidedly lessen the injury to the balance of the orchard, or their fruit may be gathered and destroyed in May, with all the contained larva.

Not all the gall-midges are injurious, however. Many species form galls or other distortions of growth on weeds or other plants of no special economic interest, or in such a way as to cause no real injury, and a few are actually predaceous and directly beneficial. Such is the species that feeds in the Phylloxera leaf-galls 
on the grape, and not inprobably other species occasionally found in leaf-galis are predatory upon the original producer. As a whole, the gall-midges are to be regarded as dangerous, and the measures to be adopted against them are, in almost all important cises, modifications of farm practice, since they are usually beyond the reach of insecticide substances.

This closes the series of long-horned, mosquito-like flies, none of which are of direct benefit to the farmer, while not a few are anong his most dangerous foes. As a whole, the species should be looked upon with suspicion and closely investigated when they occur in numbers great enough to attract attention.

Quite early in the season we nay see large numbers of loosejointed, maginly flies of moderate size, with long, stout legs, heavy body, short, stout, though many-jointed antenne, and

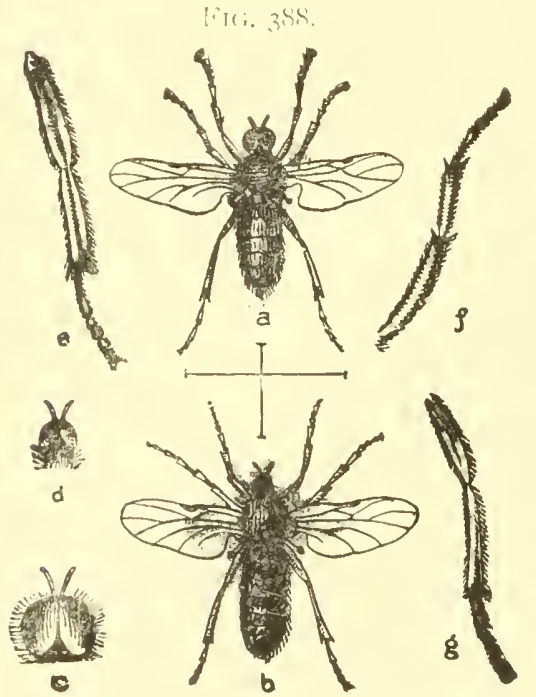

Bibio alhipennis.- $a$, male; $c$, its head; $b$, female: $d$, her head; $e, f, g$, other structural tetails. often, in the fenrale, a ridiculously small head. In color they are black, or black and yellow, or red. These belong to the family Bibionida, sometimes called "March-flies," from their early appearance ; and while their larve are sometimes feeders on yrass roots, they never become economically important. They are mentioned here because their early appearance in great numbers sometimes attracts attention. They are often plentiful in orchards just when the blossoms open, but seem not to be of any service in pollenizing.

"Black flies," or " gnats," are in some localities serious pests to man and clomestic animals. The "black flies" of the Northern woods and the "buffalo-" and "turkey-gnats" of the Southern and Mississippi States are good examples. They are rather 
undersized, chunky flies, dark in color, with the thorax well developed and somewhit produced forward so as to partially conceal the small head from above. Though the head is small in proportion to the insect, the mouth parts are exceedingly well developed and furnished with a formidable array of lancets for puncturing and blood-sucking. They belong to the natural family Simuliide, and are distinguished, in addition to the peculiarities enumerated above, by short, broad wings, in which the venation is almost obsolete, except along the front margin.

The larva are curious little creatures, living under water in rather swiftly flowing streams, clinging to rocks, sticks, or logs, and feeding upon vegetable matter. They are furnished with sucker-like structures at both extremities, by means of which they cling

F1G. 389.

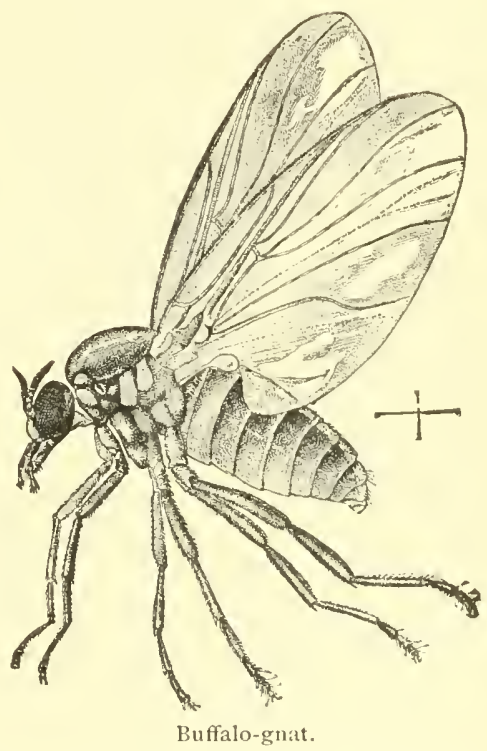
to their resting-place, and move from place to place, breathing by means of tracheal gills.

In favorable localities these insects may develop in enormous numbers, and, flying in the bright light of mid-day, attack any warm-blooded animal that comes in their way. Such is their number sometimes that they completely cover the animal attacked, first rendering it frantic by the pain inflicted and soon after weak from the loss of blood. Eventually death ensues, whether the animal be a man or a mule, unless repellents are employed or a rapid retreat out of the infested territory is accomplished.

Where the insects breed in shallow streams, the larve attached to stones, nothing can be done to check development, and the mixture already recommended for mosquitoes-viz., oil of tar: 
oil of pennyroyal, and sweet oil-must be resorted to for man, while fish oil, with an admixture of crude carbolic acid or creosote, will be found effective for animals. Smudges are often

FIG. 390 .

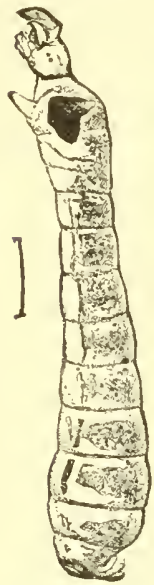

Larva of buffalogniat. used where buffalo-gnats are abundant, and the stock soon learn that in or near the smoke exemption from attack may be secured. Where

FIG. 39 I.

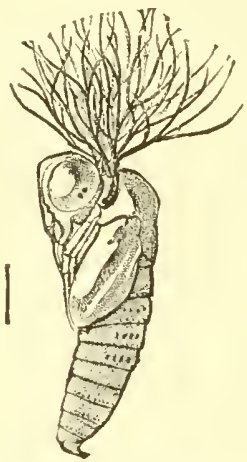

Pupa of buffalo-gnat. the water of infested streams is deep, unclue multiplication is frequently chargeable to an accumulation of logs or other material at certain points, afforcling suitable locitions for the development of the gnat larva. In such cases much good may be accomplished and sometimes practical exemption may be secured by cleaning out the streams and thus destroying the breedingplaces. Stationary rafts of log: should not be allowed, and the surface should be kept as free as possible of anything to which the larvæ can attach themselves.

The "horse-flies," or Tabanida, comprise another set of troublesome creatures, of medium or large size. They have short, broad heads, enormous eyes, and short, though manyjointed, feelers. The abdomen is oval, a little flattened, and the body is convex and powerful. The mouth parts are well developed, consisting of a series of five sharp-pointed lancets so rigid that they readily pierce the skin and draw blood almost as soon as they touch. These flies frequent woods or the edges of woodland, sometimes low meadows or marshy places, and occasionally prove serious pests to stock. They are often troublesome in woody roads, because with three or four of the large black flies buzzing about, horses may be driven almost frantic. Similar species occur in great numbers along the sea-shore, where they are known as "green-heads." In some localities they are known as "deer-flies," and some are called "goldeneyed Hles," having the eyes more or less banded or striped 
with metallic yellow or brown. The female only has the bloodsucking habit, the males feeding usually upon pollen, and being, therefore, rarely noticed, except by the collector. The larvæ are elongated, somewhat flattened creatures, some living in the soil, some in water, and some in marshes, preying upon whatever comes in their way. In this stage they might possibly be

FIG. 392.

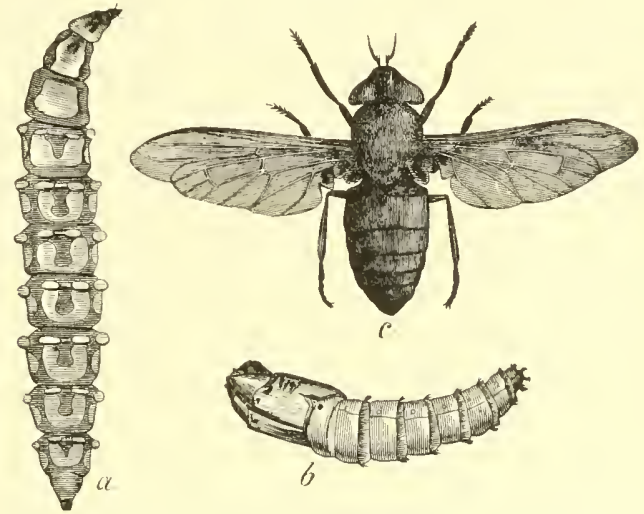

Horse-fly, Tabanus atratus.- $a$, larva; $b$, pupa; $c$, adult.

reckoned of some benefit, did they inhabit places frequented by injurious insects; but at best they are harmless, - unlike their parents in this as in all other respects.

Horses driven through districts badly infested by these insects should be furnished with a netting, and, if it is necessary to keep the animals for any time exposed to attack, the fish oil and carbolic acid mixture already recommended can be used to repel the flies. It need be applied only in such places as the animal cannot conveniently reach with its tail, or which is not sheltered by a netting.

Somewhat resembling "horse-flies" in appearance are the members of the family Strationyizda, or "soldier-flies," so called because of their often bright bandings of green and yellow. They have the same general shape but rather longer antennæ, with broader, much more flattened, abdomen. They are not troublesome in any stage, and are referred to simply because of 
their resemblance to, and to distinguish them from, the "horseflies."

Another series of large species we find among the "robberflies" belonging to the family Asilide, and these are quite different in appearance from any heretofore treated. The head is prominent, very hairy, with rather short, several-jointed antennæe,

FIG. 393.

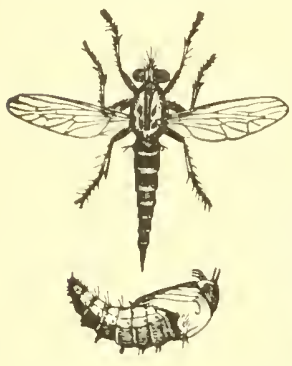

An Asilid fly.-Erat baslardi, larva, pupa, and adult. and with a short, stout proboscis, which is formed for piercing. The body is robust, also covered with hair, and the abdomen is long, slender, and cylindrical, tapering very gradually to the tip. The wings are long and narrow, the legs moderately long and very: powerful, densely clothed with spines, while the tips of the tarsi are supplied with musually long and stout claw's. The insects are called "robber-flies" from their habit of pouncing upon, piercing, and sucking the juices of other insects in mid-air, while holding then with their powerful legs. We have a great variety of species, some of them large and brightly colored, thongh the majority are of a sober gray, varying sometines to reddish, sometimes to yellow, and only rarely becoming black, except in the genus Laphria. Though predaceous, the insects can hardly be called beneficial, because they rarely attack injurious species, and in some cases become themselves injurious by attacking bees. The late Dr. C. V. Riley records having observed a single species kill forty bees in one afternoon. Professor Comstock notes their feeding upon the cotton-worm, and undoubtedly they do occasionally kill injurious insects, but can scarcely be credited with being a factor of much importance in keeping down troublesome forms. They never attick man or anmals, although, if carelessly handled, they are ready to sink their lancets into the flesh of their captor. The larva are also carnivorous, so far as known, and live in the ground or in decaying wood.

Yet larger in size and of the same general shape are the members of the family Nidaida. They are often contrastingly colored, sometimes uniformly dead blick or blue, though usually 
relieved by a bright red or yellow band or similar marking. The wings are quite generally blackish and the antennce are clubbed at the tip, differing thus from the previous family. In fact, the species are so peculiar that, having been once seen, they can scarcely be mistaken. They are also predaceous in habit, but not nearly so ravenous as the " robber-flies," besides being much less abundant.

A very interesting family is that of the "bee-flies," or Bombyliide, which derive their common name from the fact that they are more or less covered with dense, diverging, whitish or yellow hair, giving them a close resemblance to certain bees. Many of the species occur in open places, hovering over bare spots, especially in spring, and they may be found at other seasons flitting from flower to flower, often poised in mid-air between or over them. There are two rather distinct series, one of them with robust species resembling a bumble-bee, and with a very long tongue; the other much more slender, the species resembling flower-flies, with a much shorter proboscis and much less contrasting colors. The former are typified in the genus Bombylius; the latter belong to Anthrax and allied grenera. Their food is honey obtained from flowers, and the adults are at least innoxious. Among the species that occur early in the year, some are of direct benefit in the orchard, where they aicl in pollenizing fruit flowers. The hairs composing the vestiture are furnished with little spurs or processes, or are twisted, so that pollen grains adhere readily. They are especially useful in cross-pollenation from their habit of flying considerable distances. The larvæ, on the other hand, are parasites, and distinctly beneficial in many instances. They prey upon the larvæ of Lepidoptera, including many of the cut-worms, and also infest the eggpods of grasshoppers, forming one of the effective checks of the migrating or "Rocky Mountain locusts" in this country. They are less beneficial when parasitic upon bees and other Hymenoptera, but altogether the family may be said to contain chiefly useful species.

Sometimes we find in houses, under carpets, a slencler little larva nearly white in color, with a darker, rather indistinct, head, but without obvious legs. It is usually looked upon with suspicion because of the locality in which it is found, but as a matter 

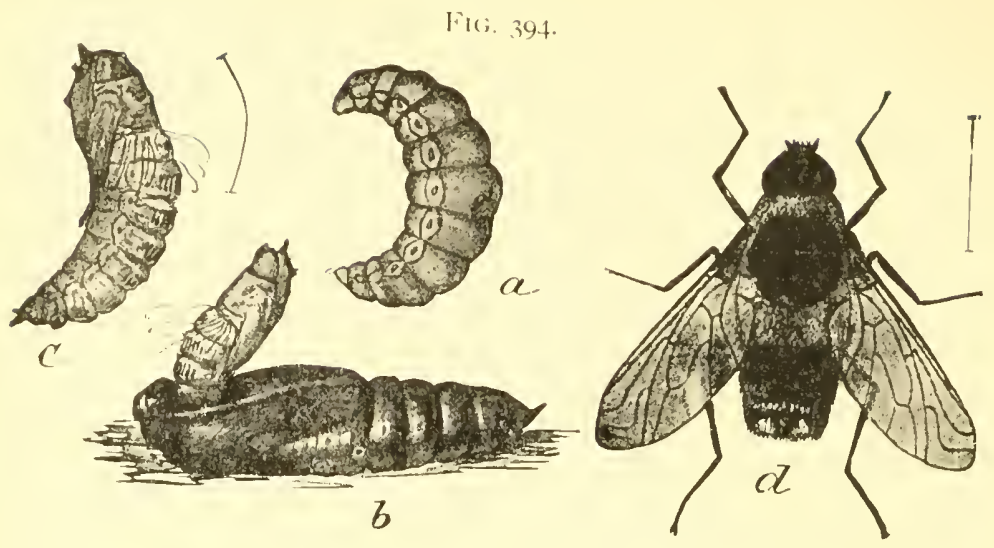

FIG. 395. .

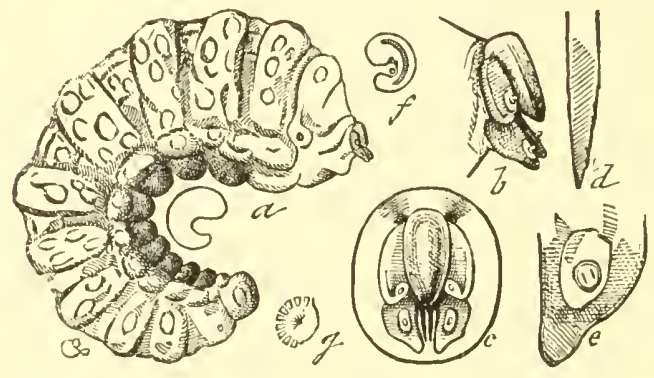

FIG. 396.

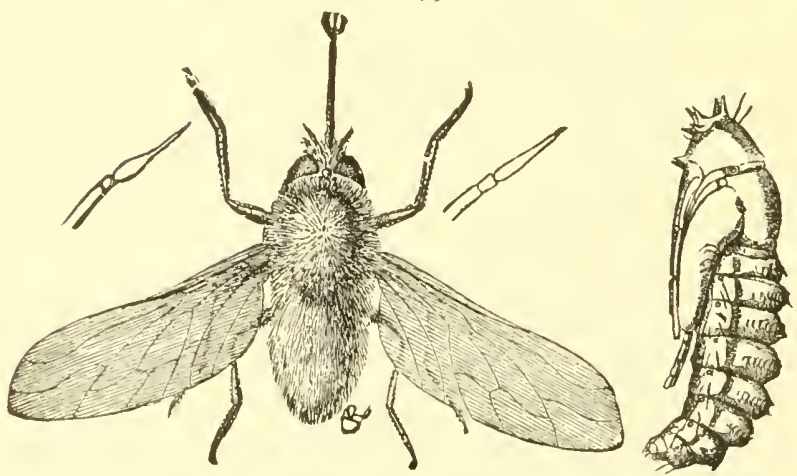

Bee-flies.-Fig. 394, Anthrar hipomelus: $a$, larva; $b$, the fly pupa projecting from a cht-worm pupa; $c$, pupa; $d$, adult. Fig. 395, larva, with details, of systochus oreas, warasitic in grasshopper egg-poils. Fig. 390, pupat and adult of Sistachus oreas. 
of fact it is predaceous in habit, and feeds upon the species really infesting carpets and similar material. 'Thus, "moths," the larvæ of the "carpet-beetle," "fish-moths," and numerous other insects likely to occur in such situations are destroyed by it. From this larva there comes in due time a small blue fly, a member of the family Scenopinida, slender and somewhat flattened in appearance, with yellow or reddish legs, and this may be sometimes seen upon the win-

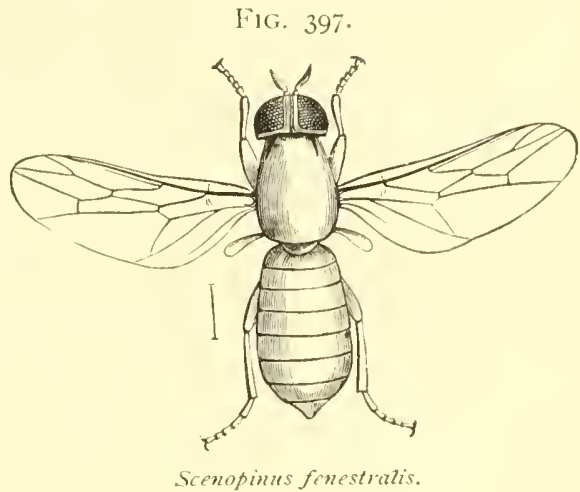
dows. These larve

have been often brought to me, and the little flies raised from them have always been Scenopinus fenestralis, from which Professor Comstock gives the group the name "window-flies."

The remainder of the Diptera have the antenne short, rarely more than three-jointed, and usually with a bristle or style, called an "arista," which may or may not be feathered or plumose, from the second or third joint. The first of the fanilies to which it is necessary to refer here is the Syrphida, containing a large number of species, most of them prettily colored, yellow, black, or bronze, patterned and marked in many different ways. They frequent flowers, hovering and often remaining suspended over them in mid-air for some time, then suddenly clarting away and again retuming. Their habits and appearance frequently give them a resemblance to bees and wasps, and in some species this is carried so far that they are easily mistaken for members of the order Hymenoptera by those not familiar with them. As a rule, the head is quite large, the body barrel-shaped, and the abdomen a little flattened, varying from very slender to broadly oval in shape. This abdomen is yellow and black, or bronze banded, sometimes entirely bronzed, more rarely blue or green, hut nearly always brightly colored in some way. Some of the flie; have the body distinctly covered with hair, though generally this 
vestiture is confined to the thorax or trunk, and such species are sometimes of use in pollenizing flowers. I have found several species abont fruit-blossoms in spring, moving from flower to flower, and, allhering to the vestiture, I have found pollen grains in consideralle number; so the insects are probably of some importance in this direction. We have one very large species, Eristalis tena.x, appearing late in fall, often in houses, and so closely resembling a honey-bee as to be generally mistaken for one : for which reason it has been called the "drone-fly." It is

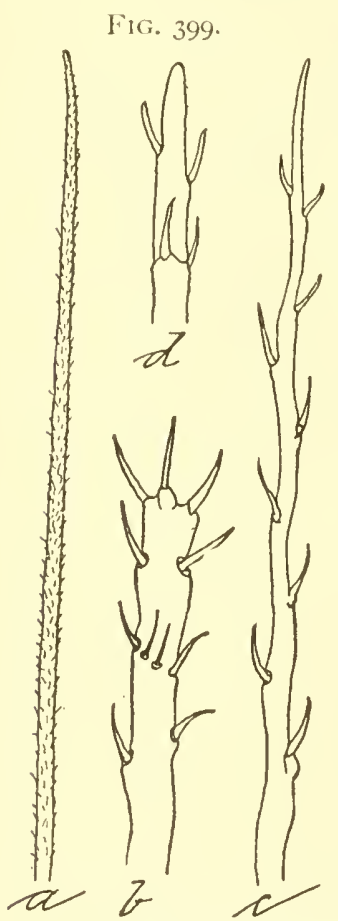

Body vestiture of Eristalis tenux: $a$, entire hair; $b, c, d$, parts of same; all greatly enlarged. frequent in greenhouses about the time that chrysanthemums are in bloom, and gardeners have assured me that pollenizing this flower is done by it entirely; hence they call it "chrysanthemum fly." It is not at all nulikely that this is the case; indeed, it is even probable, though sufficiently direct observations have not as yet been made in the matter. In this connection it is interesting to find that the body vestiture of the Syrphids is often composed of spurred and branched hair, similar to that found in bees, and in the "dronefly" this character is especially marked.

As widely divergent as the files themselves are the larve and their feeding habits. In fact, there is no sort of agreement; and while some are predaceous, feeding upon plant-lice or other insects, many feed in living or decaying vegetable substances, or in the foulest excrementitious material. Those forms that most concern the agriculturist are the feeders on plant-lice, and these may be found at almost any time during the summer in almost every aphid colony, busily engaged in lessening its numbers. The larva are cusily overlooked, as they are usually green or yellowish in color, like the insects anong which they feed. They 
Fir. 39.5.

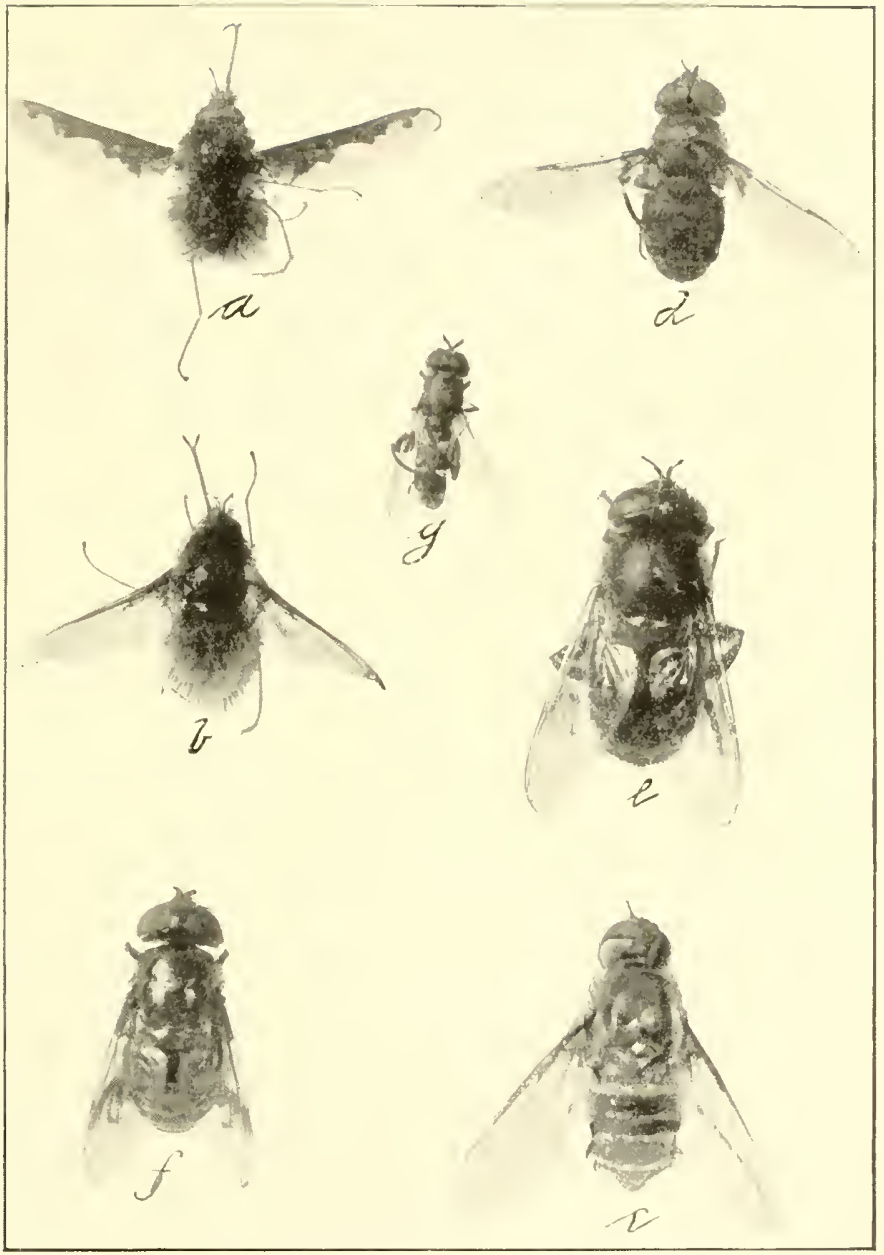

Bee-flies and flower-flies.- $a$, Rombrlius sp.; b. Bombrlius sp.: c, Anthrax sp.; $d$, Evistalis transversus; $e$. Fristalis tenax ; $f$, Eristalls saxarum; $g$, Syritta pipiens. Somewhat enlarged. From a photograph. 

are wrinkled and hairy when examined with a magnifying glass, soft in texture, thickened behind, and tapering almost to a point at the head, which is marked only by a pair of hooks and a little circular opening representing the mouth. They have no legs, and move by extending the body forward as far as possible, then clinging wih the anterior segments to the leaf or twig, and drawing the balance to meet the head. Awkwardly as they move, however, their progress is yet sufficiently rapid for their purpose. When once a larva has established itself in a colony of plant-lice, it never stirs until all in its immediate vicinity are destroyed; it then moves only far enough to bring into reach additional prey, and so continues until no more remain. The female lays her eggs close to, or actually among, an aphid colony, so that the larva finds food ready at hand as soon as it is hatched. It grasps a plant louse with the mouth parts, lifts it from the surface, and sucks its juices, leaving the creature to struggle for a time, helplessly kicking its legs in mid-air. When the juices are exhausted the empty shell is dropped and another specimen is taken. When full-giown, the larva draws itself up into a humped mass; the outer skin hardens, darkens in color, and forms an apparently solid covering or coarctate pupa, beneath which the

Fig. 400 .

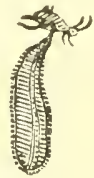

Syiphus larva devouring a plantlouse.

true or soft pupa of the $\mathrm{fly}$ is formed. Several broods of these predaceous flies occur in the course of the season, and they are among the most important checks that nature has provided against plant-lice increase.

Others of the species are not quite so useful, and occasionally we have a form that is almost parasitic, living in nests of bumble-bees or other Hymenopterous insects and feeding upon their larva. In such cases we often find that the flies greatly resemble in appearance the hosts among which they live. Among the feeders in vegetable matter we have a great variety of form, but they are usually more or less maggot-like and without legs. As they are not of particular economic interest. no more attention need be paid them here. The larva of the "drone-" or "chrysanthemum-fly," Eristalis tena.x, lives in masses of soft, decaying, or excrementitious matter. It is fre 
quently found in privies or cesspools, sometimes appearing so suddenly and in such numbers that a suspicion is engendered that the specimens have been passed by the individuals using the out-house. In fact, I have on more than one occasion received the larvæ with the positive statement that this had actually nccurred. They are curious creatures, maggot-like in general shape, with a long, extensile, tail-like appendage at the anal extremity. It is hollow or tube-like, and at the end is a spiracle, the use of this telescopic tail being simply to keep the opening above the surface of the filthy mass in which the insect lives, and thus to secure a supply of pure air. The

Fig. 401.

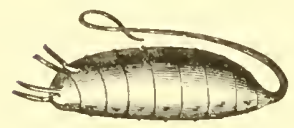

kat-tailed larva of Eristalis. larvæ are called from this peculiarity "rattailed." The reason why the flies are sometimes so abundant in greenhouses is that somewhere in their vicinity, among semi-liquid manure, the best breedingplaces can usually be found. Taken as a whole, this family Syophide contains no really noxious insects, and many that are decidedly beneficial. It should be noted, however, that the larve of some species feed upon pollen, and that others live in growing vegetable tissue; hence it is not impossible that in the future this general statement may have to

Fig. 402 .
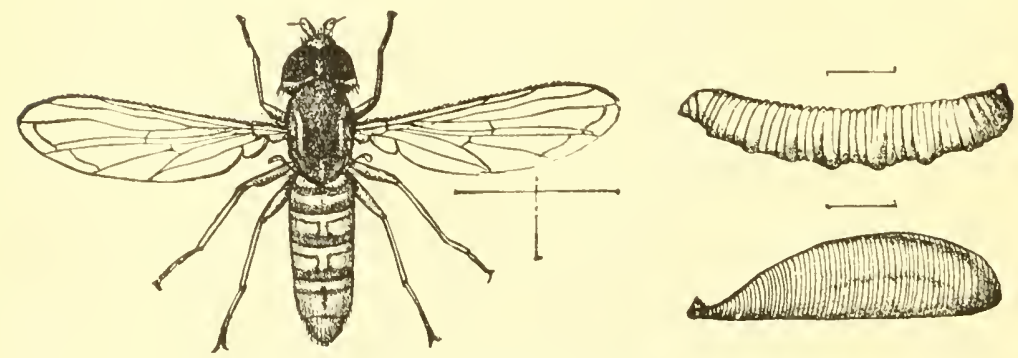

Mesograpta polita.-Larva, pupa, and adult; all enlarged.

be modified. One of the most common Eastern species, Mesograpta polita, has been found feeding in great numbers in the larvil stage upon corn pollen, but without causing any real injury.

Passing over several small families interesting enough in themselves, but not of importance to the agriculturist, we reach the 
little family Conopida, which is not at all injurious, but rather the contrary. Professor Comstock calls them "thick-head flies," and the term is not bad, because the head is usually very prominent and as wide or wider than the body. The thorax is unusually short, and bears a long abdomen having the basal joints very slender and the terminal joints enlarged, bulb-like, much resembling in appearance that of certain wasps. The flies are moderate in size, with the wings more or less brown or clouded, and they may often be found on flowers after midsummer, in company with the Hymenoptera, which they resemble. The larvæ are

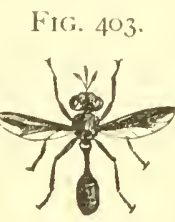

Conops libialis. parasites, chiefly, it is said, upon bumble-bees and wasps, in which case they are not beneficial ; but also on grasshoppers, in which respect they deserve our most distinguished consideration.

Distinctly injurious insects we find in the family Cistride, or "bot-flies." These are usually of good size, sometimes even very large, and peculiar by having the mouth parts almost entirely aborted. Snme of the species are very hairy, yellowish in color, and with rather a pointed abdomen; while others are very plump, robust flies, blue or blue-black in color, often with a whitish bloom like that of a plum, formiclable in appearance, though in fact entirely inoffensive in this stage. In the larval condition they are known as "bots," and live bencath the skin, in the intestines, or in the mucus-lined head passages of the animals infested by them. Thus, the "horse-bot," Gastrophilus equi, passes its life in the stomach, attached to the inner coat, and there remains until full grown, when it releases its hold and is passed in the natural way through the anus. It then crawls into some convenient place just below the surface of the ground, or even among rubbish on top of it, and changes to a pmpa. The adult lays its eggs on the hair, chiefly of the forelegs, at points easily reached by the tongue of the animal in licking itself. The eggs are thus removed, carried into the month on the tongue, and so into the stomach, where the larve hatch almost inmediately and at once attach themselves. It is readily seen that this habit gives us a certain possibility of controlling the insects, because if the horses can be prevented from licking off the eggs, they never can reach the proper location for their growth. 
Checking the animals up when in use accomplishes this, and a spiked muzzle, so arranged as not to interfere with feeding, will answer in the stable. Frequent brushing to remove the eggs is useful in bot-infested regions, and lessens the number that can reach the alimentary canal.

Numerous other species occur just under the skin of the animals infested, and one of the best known of these is the "ox warble," Hypoderma lineata. Here also the eggs are laid on the hair and are licked off in the same way ; but the larvæ, instead of allowing themseives to be carried into the stomach, pierce the œsophagus or other portion of the alimentary canal, and work their way through the muscular tissue to a point just below the skin. There they fix and increase in size, causing the swelling and suppuration so familiar to farmers in some localities. Of course the means just mentioned for preventing the entrance of stomach bots are also applicable in this case to avoid infestation. Where bots are already established on an animal, the best method is to incise the skin and press out the larva beneath it, or use a mercurial ointment, which, penetrating into the wound, will kill the larra, so that it can be readily pressed out later, or will suppurate ont easily. Some species of bot-flies undoubtedly lay their eggs on the skin of the animals at the points where the larva actually hatch, and the latter work their way through just there and form the swelling. Sonetimes special organs are attacked, as in the chipmunks and squirrels, where the testes of the males are selected and the creatures are actually emasculated. The fly has, therefore, been called the "emasculating bot," Cutcrcbra cmasculator. In rabbits a species is found close to the anal opening, and in fact most animals are more or less subject to bot attack. Even man is not excmpt, and several cases have come under my observation where flies had laid their eggs on the skin and the bots had developed considerably before the charac. ter of the trouble was understood. In southern countries this is nuch more likely to occur than in the north, possibly because a much greater part of the body is there habitually exposed.

Sheep suffer from a species known as CEstrus ovis, which lays its eggs on or in the nostrils. The larve make their way through the nasal passages in the mucus beneath the skin, and even into the lorus. They are often very troublesome, and cause one 


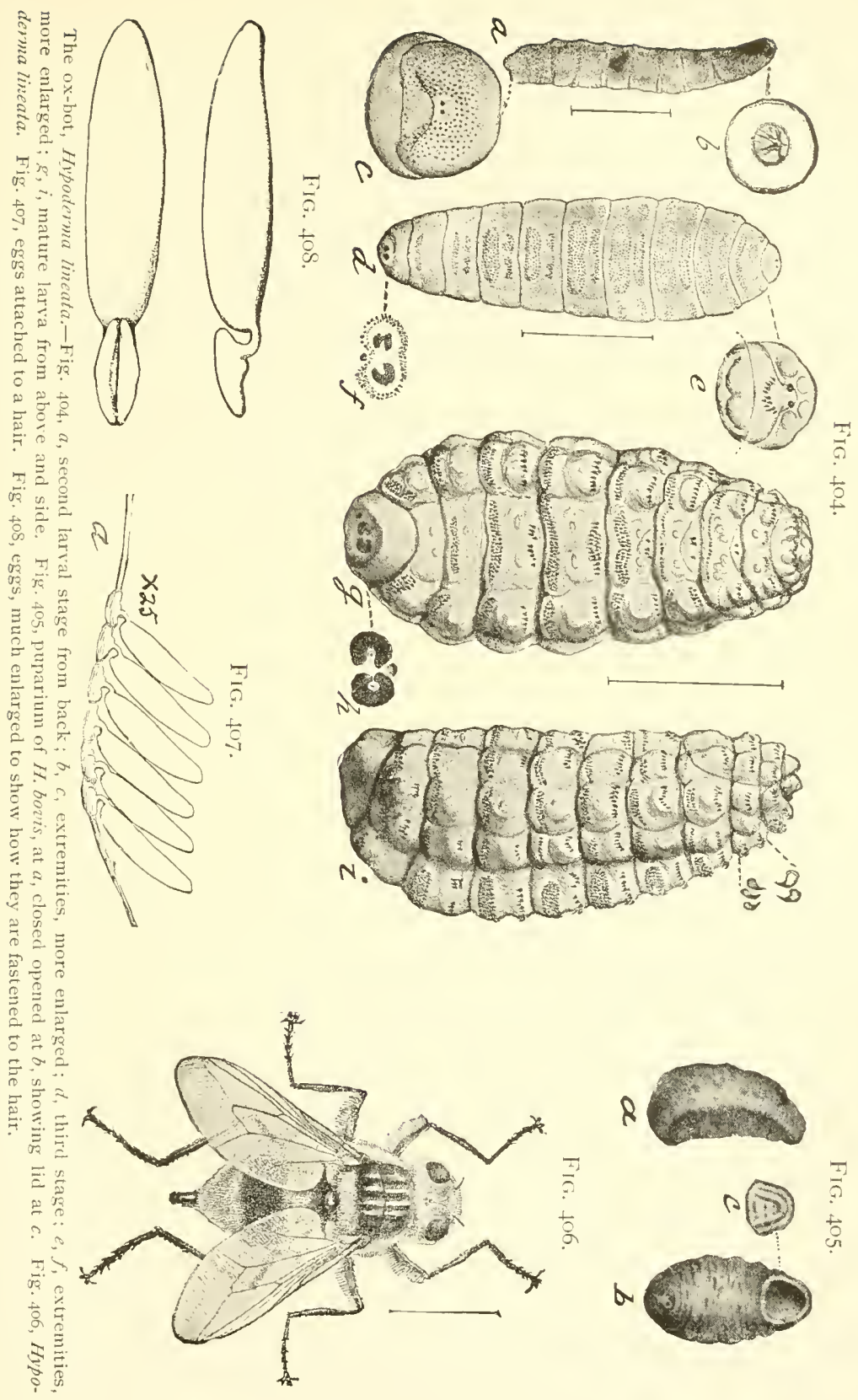



form of the disease known as "staggers," which is sometimes extremely destructive to herds.

From this description of the life histories, so briefly given, it appears that our efforts to avoid injury must follow in the direction of prevention. As against the species that must first be taken into the mouth, the mechanical ways of preventing a horse or an ox from licking any part of the body will prove sufficient ; or frequent brushing will at least moderate the injury.

In the case of the sheep-bot the natter is more difficult, because the flies are very persistent, and encircle the animals until they get an opportunity to dart to the nostril and deposit upon it an egg just ready to hatch, or already hatched, so that either immediately or in a very short time the maggot makes FIG. 409 .

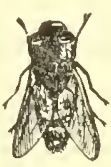

1

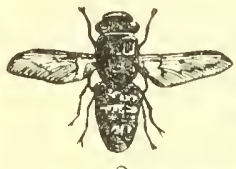

2

3
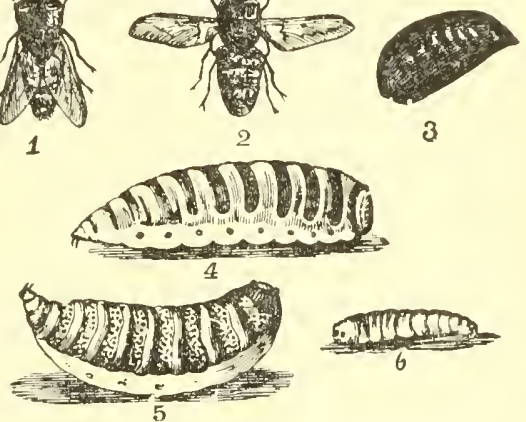

The sheep-bot, Estrus oris.-I, 2, flies ; 3, pupa : 4,5 , full-grown larva; 6 , young larva. its way up along the mucous membrane as fur as the passages allow it to extend. All sorts of devices have been arlopted to prevent this, but none are entirely satisfactory. Tar has been used as a repellent, smeared on the nose, and with more or less success. It is probable that fish oil and oil of tar, or carbolic acid, would answer the same purpose. Powdered tobacco, used to induce the sheep to sneeze and thus dislodge any maggots that had already made their way in, has also been more or less satisfactory. In the case of recently infested animals, a brush dipped in turpentine and carefully used in the nostrils, so as to reach attached larva and kill them, is sometimes found useful.

The family Muscide is the largest in number of genera and species in the order as well as the most difficult to classify. The common "house-fly," the "blue-bottle," and the "flesh-fly" are examples, and may be considered as typical forms, which most of the species resemble; not necessarily in color or mark- 
ings, but in general type of structure. It is almost impossible for any but the special student to distinguish betwcen even the sub-families, and yet these differ greatly in labit, some being decidedly injurious and others as decidedly beneficial in the larval stages. One of the peculiarities of all the members is very short antennæ, in which the terminal joint is long and stout and furnished with a bristle or arista attached near the base. The modifications of this bristle aid in distinguishing the groups.

The Tachina flies, for instance, have the bristle entirely bare, though otherwise many of them resemble the common "Heshfly" or the "blue-bottle." They are generally rather large, robust in appearance, always bristly, and sometimes formiclable looking from the array of sharp spiny points projecting in every direction. They are parasitic in habit, largely upon caterpillars, and among them perhaps preferably upon cut-worms. Frequently, where the latter are numerous, a large percentage will be noticed with one or several little white eggs attached on the anterior segments, just back of the head, in such a position that the larva cannot possibly reach or destroy them. These eggs hatch in a very short time into little maggot-like creatures that at once bore through the skin of the caterpillar and live within its body, feeding upon the fatty masses and muscular tissuc not absolutely necessary to life. When the maggots are full-grown and the welfare of the caterpillar is no longer a matter of importance to them, they feed on regardless of consequences, and the creature dies. The maggots, sometimes without even attempting to get ont of their host, then change to barrel-shaped pupre. This is accomplished by a contraction of the larval skin, which hardens and becomes brown in color, releasing its hold at the same time on the forming (true) pupa beneath. Occasionally the maggots leave their host and make their way a little below ground to pupate. Some of our large caterpillars attain their full growth with as many as thirty or even more of these maggots feeding upon their vitals. Some of the Hies are very handsome and strikingly colored, as, for instance, the Tachina vivida, in which the abdomen is bright red, set with black spines, - -it very remarkable looking species. Others are black, the abdomen banded with yellow; but as a rule they are of a modest gray color. the thorax rather obscurely streaked with blackish brown or gray. 
Fig. 4 I3.

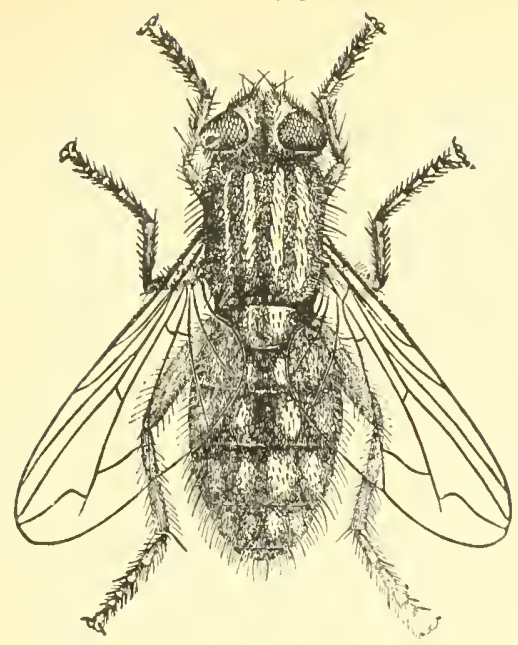

FIC. 4 IO.

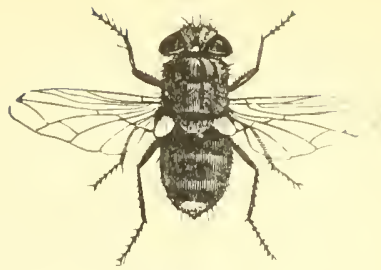

FIG. 4II.

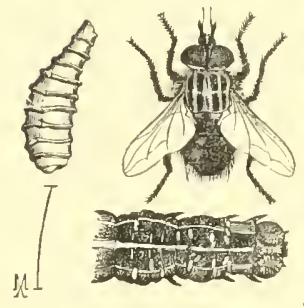

FIG, 4I5.

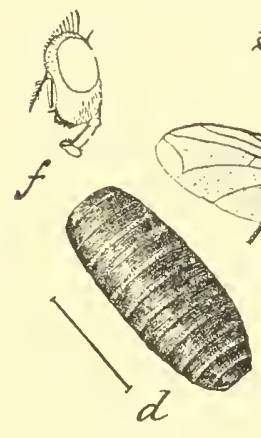

FIG. 4I4.

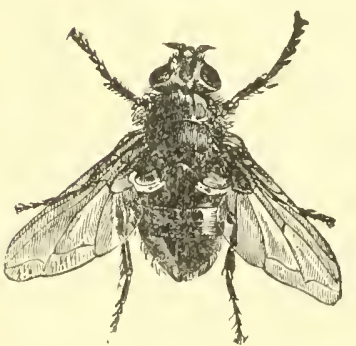

FIG. 4 I 2.

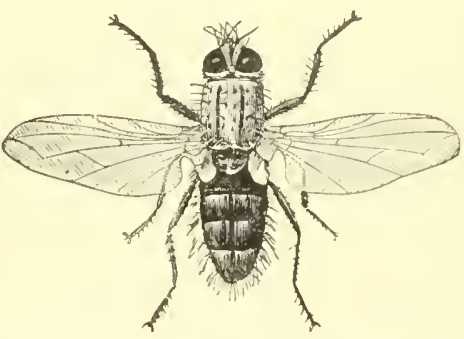

Muscid flies.-Fig. 410, Exorista flavicauda, yellow-tailed Tachinid, Fig. 411, Nemorea leucanice, Tachinid on cut-worms: larva, pupa, adult, and the white eggs on the anterior segments of the caterpillar. Fig. 412, Lydella doryphorce, Tachinid on potato-heetle. Fig. 4r3, common flesh-fly, Sarcophaga carnaria. Fig. 414, the blowfly, Calliphora vomitoria. Fig. 415, screw-worm, Lucilia macellaria: $a, b, c$, larva and details; $d$, pupa; $e$, adult ; $f$, head from side. All are enlarged, and Fig. 413 very much so. 
These flies are among the most effective of nature's checks to caterpillars, especially cut-worms.

The "flesh-flies" greatly resemble the Tachina flies in appearance, but the arista or bristle of the antennx is feathered towards the base and is bare only at the tip. Some of these species also are parasitic. Others have larve that live in excre mentitious material, in fruits, in meats, or in decaying animal or vegetable matter generally. Such species usually produce their young alive, or at least as eggs just ready to hatch, and the majority are scavengers. None of the members of this family, so far as I am aware, are injurious, and they are always beneficial to the extent, at least, of assisting in the removal of offensive matter, animal or vegretable,

The typical Muscids differ from the other species in this series by lacking the spines of the thorax and abdomen, or having them confined, in a very reduced state, to the tip of the abdomen only. The arista or antennal bristle is feathered to the tip. The housefly is one of the best known of all insects the world over, and there seems to be no region where it does not occur and is not more or less annoying. It winters in our houses or out-buildings, hiding in some sheltered spot in cellar or attic, or remaining more or less active in our carefully warmed rooms. During the early days of spring a few specimens make their appearance here and there, sole survivors of the swarms of the preceding year. These are mostly females ready to reproduce, and they lay their eggs in any convenient pile of horse manure; or, if that is not available, in any decaying animal or vegetable matter. The maggots hatch in a day or two, in a week or ten days are fullgrown, change to pupæ, and in a very few days more a new brood of flies is matured, already sufficient in numbers to become more or less annoying. This process is repeated time and again during the season, and the insects increase in numbers until after midsummer, when they seem to lose activity to some extent, although breeding until cold weather actually sets in. Houseflies are not injurious in any true sense of the word, although they are distinctly annoying and may become dangerous by transferring disease germs from one point to another; as when, after alighting and feeding upon the sputum of a consumptive, they tickle the nose of a healthy sleeper a few minutes thereafter. So 
blood poisoning may be set up by a fly which has been feeding upon a putrefying carcass and then feeds upon an abraded surface or a cut or bruise on man. This, lowever, is not a common occurrence, and perhaps as a scavenger the insect is about as useful as it is annoying. A single female produces on an average about one hundred and fifty eggs, and this, with the short period required to bring them to maturity, accounts for the enormous increase of the insects. After a fly lias attained this stage it never grows more, and a small fly never makes a large fly, any more than the progeny of a large fly is ever a small fly.

The "blow-fly," Calliphora vomitoria, is the largest of the common species abundant enough to attract attention, and this has the body of a deep blue, almost black, color, the abdomen a little lighter and somewhat more shining. It is an obtrusive creature and noisy withal, especially when flying about on the windows or bumping against the ceilings of a room, making its presence obnoxious in more ways than one. Its eggs are laid on all sorts of animal and regetable matter in an incipient stage of decay. Meat exposed in summer is almost certain to show, in a very short time, little piles of elongate white eggs scattered over the surface here and there. Fish are especially subject to attack, and I have myself had the experience that a little string of fish laid in the shade of a bush on the bank was covered with such eggs before I was ready to go home. Of course they could be readily washed off, and it is not usual for this insect to retain the eggs until they hatch within the abdomen, yet I have found specimens that have done so. This species also requires but a very short period for its development, and its rate of increase is so great that it has given rise to the saying that a pair of flies will devour an ox more rapidly than will a lion. A carcass left in the fields during midsummer becomes, in fact, in a few days a mass of maggots, which soon leave nothing but hide and bones.

A somewhat smaller species than this blow-fly, of a very much brighter green or bluish color, with four longitudinal lines on the thorax, is the "screw-worm" fly, Lucilia macellaria. This is a common species throughout a large portion of our country, and ordinarily feeds upon dead or decaying animal mitter. Under some circumstances, however, it attacks living animals, and in the Southern and Southwestern States occasionally becomes a 
terrible pest. On such occasions it lays its eggs on man or animals wherever there is the slightest trace of a wound, bruise, or offensive discharge of any kind. The larve bore directly into the living flesh, causing intense pain as well as suppurating sores. Living larve are produced as well as eggs almost ready to hatch, and into any opening from which there is a discharge of any kind eggs may be deposited. Sleeping humans with an offensive breath, or with a fetid discharge from the nostrils or mouth, have had eggs laid at these points, and larva have made their way into the head, in some cases causing the death of the individual. Eggs have also been laid in the ears of uncleanly people, and the channels and passages of this organ have been penetrated into the head and destroyed. Animals are troubled in the same way, and where the insects are abundant, their attacks often become fatal. The only remedy is cleanliness. Wounds, even of the most trifling nature, on cattle should be smeared with an antiseptic ointment. As far as possible, all materials in which the flies can breed should be destroyed; no accumulation of animal refuse should be allowed under any circumstances, and by strictest attention to surroundings, the breeding of the insects should be prevented. Attacking live animals is not a usual habit, although very readily assumed when the insects become abundant.

Another insect, a trifle larger than the house-fly and much like it in appearance, though a little more robust, is the ordinary stable-fly, Stomory's calcitrans. This has the mouth parts formed for piercing, and annoys animals by alighting upon and sucking the blood of parts that cannot be reached by them with head on tail. Sometimes these insects also attack man, especially late in the season or in heary weather. They have an especial fondness for human shanks, and readily bite through stockings ; sometimes through trousers as well. This bite is painful, though it rarely leaves a swelling or perceptible inflammation. The larve develop in horse and cow manure, and their increase in stables can, therefore, be checked to some extent by promptly removing and placing this in pits, or mixing with plaster or other material that will absorb the moisture and fix the ammonia.

A close ally of the stable-fly is the so called "horn-fly," Hamatobia serrata, a recent introduction into the United States, which has spread over the country with almost phenomenal 
rapidity. This insect derives it common name from the fact that it seems to prefer clustering in great numbers at the base of

Fic. 416.

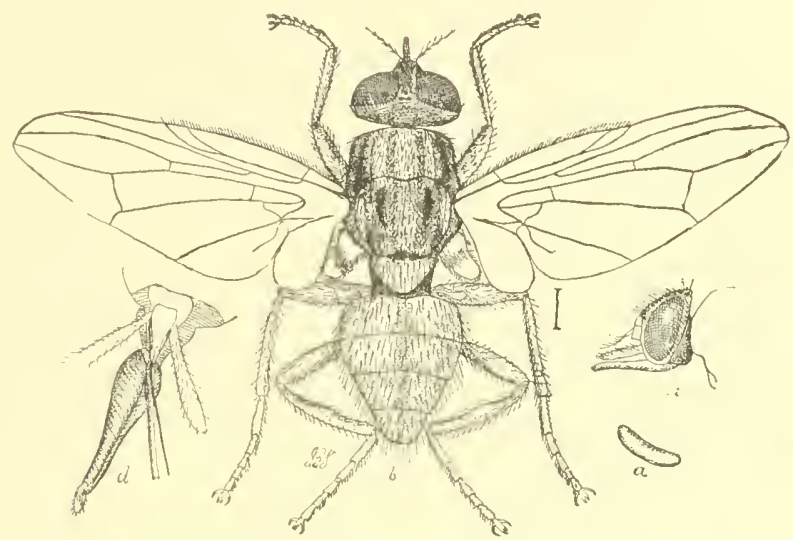

Horn-Hy, Hesmatobit serrata.-a, egg; $b, f y ; c$ and $d$, head and mouth parts; all enlarged.

the horns of cattle, although it is really just as abundant on the flanks, upon the udder, and in other places where it cannot be readily reached by the animals. The fly seems to confine its attacks to horned cattle, althouglt it has been seen on mules in the State of New Jersey. Like the stable-fly, it is a blood-sucker, and both species are often found on animals at the same time, keeping them in that state of constant irritation which prevents their proper feeding and digesting, and keeps them poor and in no conclition to produce a free flow of milk. Not only in the fields or pastures are the cattle annoyed by these insects, but in the stable as well, so that the animals get no rest night or day. Eogs are laid in fresh cow-dung, and before this has an opportunity to dry under ordinary conditions, the larve are full-grown and ready to pupate.

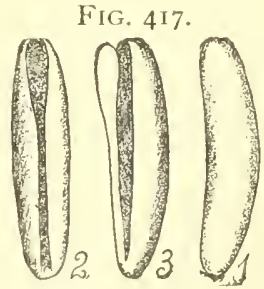

Egg of lorn-fly.-I, tulıatched, from side; 2, hatched, from front; 3. same, from side, to show lid-like structure; all enlarged.

It is the immense number of these insects that makes them dreadful, and when the 
species first made its appearance in the Eastern United States, horrible tales were told of the destruction caused among herds of cattle. As a matter of fact, except for the irritation, it causes no injury. Much can be done to prevent the increase of this insect by destroying the brecding-places. In the stable, the stalls and their surroundings should be kept absolutely clean, and whitewash should be liberally applied. The manure should be mixed at once with either kainit or land plaster, which absorbs

FIG. ${ }_{418} 8$

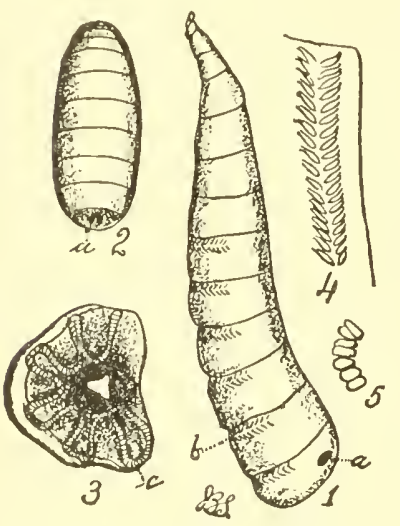

Larva of horn-fly, I; its pupa, 2; structural details, $3,4,5$; enlarged. the moisture and makes the mass unfit for the larva, while at the same time it does not injure its value as a fertilizer. A boy should be sent through the pasture every two or three days with a shovel, and directed to spread out every dropping in such a way as to cause it to dry up or wash away readily before the larvæ can complete their development. The flies can be kept from the animals by the use of fish oil and crude carbolic acid, applied to those parts not readily reached by the tail. The proportions of fish oil and carbolic acid are not important; enough of the crude acid to give a decided odor is all that is necessary, and one application will usually suffice to protect an animal for five or six days.

Another series of decidedly troublesome flies we find in the Anthomyiids, whose larva are frequently root-infesting maggots. The adults closely resemble the common house-flies, but are usually somewhat smaller in size and slighter in build. They are found in fields on the ground, on vegetation of all kinds, and also commonly enough in our houses on the windows, where they are usually mistaken for the true house-fly. Recognition of the species of these flies is a matter of no great importance practically ; but it may be assumed, where flies resembling the ordinary household pest in all save size are noticed in any number about crops subject to infestation by root-maggots, that we have members of this Anthomyiid series to deal with. They are often very 
injurious to cabbage and cauliflower, as well as to onions, radishes, turnips, beets, and other root crops, while other species attack planted seeds like those of melons and even corn. Occasionally, instead of attacking roots, the maggots are found boring in thick or fleshy leaves, and then they make mines or galleries between the upper and lower surfaces, often doing much injury. Sometimes their habits are more like those of the housefly. and the larvæ are scavengers, while a FIG. 4 I9.

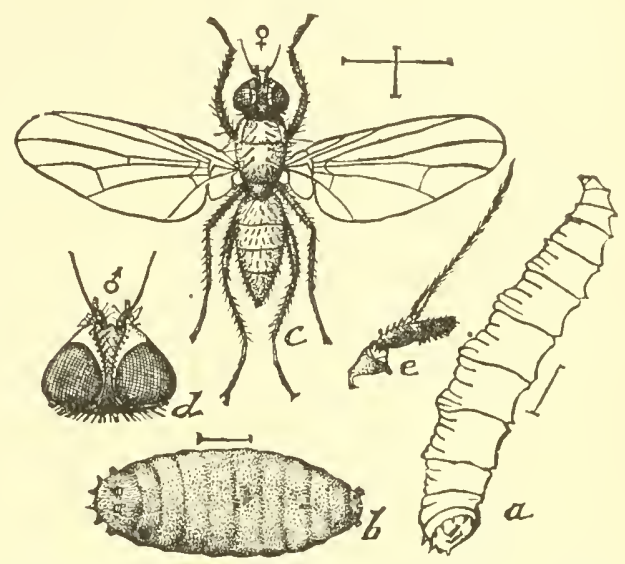

Cabbage-maggot, Phorbia brassica.- $a$, larva ; $b$, pupa $c$, adult; $d$, its head; $c$, antenna.

few have been recorded as parasites on other insects. The group, therefore, is one with diverse habits, but usually to be looked upon with considerable suspicion. Perhaps the best known of the root-maggots is the larva of Phorbia brassica, infestino cabbage, cauliflower, and other plants of the same natural family. Eggs are laid on the ground soon after the plants are set out in the fields. The larve make their way into them as soon as they are hatched, gnawing or rather scraping the tissue, so as to enable them to absorb the plant juices, for they have no jaws for mastication. Decay sets in where the insects work, and this favors their feeding, so in a few days they destroy the tissue of the plant and stem a little below the surface so completely that it dies. Later crops are not so much harmed, as a rule, and if plants can be preserved until they reach a good size, they frequently sustain considerable maggot attack without serious injury. As to the best remedies against this particular insect we are yet somewhat uncertain. Putting a pad or disk of tarred paper on the stems of the plants when they are set out has been found successful in preventing the adult from laying eggs, or the 
larve from getting at the desired point, since they seem to be unable to live exposed to sunlight. Ground tobacco, kerosene and sand, plaster, soot, ashes, and other materials placed at the base of the plants act like the tarred paper ats a mechanical protection, and must be applied before the eggs are laid, else they will prove ineffective. Bisulplicie of carbon injected below the root system has been used with a considerable degree of success, the fumes filtering through the soil and killing the insects at work on the plant without injuring the plant itself. An injector devised for the especial purpose has been mate by Mr. J. J. McGowen, of Ithaca, New York, and perhaps the apjlication of this substance is the most certain and satisfactory remedy that has been proposed. It should be used when the soil is moist, but not water-soaked. There are two or three broods in the course of the year, according to latitude. The winter is passed either as a pupa below the surface or as an adult in barns, houses, etc., and the species is tided over between cultivated crops by the cruciferons weeds. Hence clean culture and the prompt removal of all crop remmants are urgently indicated. Carbolic acid and kerosene, emulsified with soap according to the formulas elsewhere given, have proved effective as killing agents when the maggots have begun feeding. Pour about half a pint around the base of the infested plant, diluting the carbolic acid emulsion thirty times and the kerosene emulsion twelve times.

Radishes frequently suffer from the attacks of the same maggots, and they are more difficult to deal with here, because they puncture the fleshy root and make channels through it in every direction, safely beyond the reach of any insecticide application. It rarely pays to put expensive substances on radishes, because the margin of profit is too small; but considerable benefit may be derived from proper methods of fertilizing, and the mixture that seems to offer the best chance for success is

$$
\begin{aligned}
& \text { Nitrate of soda . . . . . . . } 700 \text { pounds. } \\
& \text { Ground rock . . . . . . . . . . rooo pounds. } \\
& \text { Muriate of potash . . . . . . . . . } 300 \text { pounds. }
\end{aligned}
$$

Apply soon after the plants are up, or when the leaves are about an inch long, at the rate of five hundred pounds per acre, and before or during a rain. The application made at this time seems 
to reach the maggots just when they are hatching, and becomes effective for that reason. Applied later, when the insects have already made their way into the radishes, it would be useless. Here the farmer must necessarily make a few observations of his own to determine the proper tine for applying the fertilize remedy, and this is not difficult. The flies lay the eggs in little masses on the surface of the ground near to the infested plants. They are white, slender, and cylindrical, nearly one-sixteenth of an inch in length, and quite visible on close examination. When these eggs are found generally distributed over the fields the time to make the insecticide application has arrived, beciuse they hatch only a few days after they are laid, and the young larvie must be reached then or not at all. The carbolic acid emulsion diluted thirty-five times may also be applied with good prospects of success in killing the maggots, or the ground tobacco may be used over the rows just as soon as the plants are up.

The onion-maggot, Phorbia cepamm, is, perhaps, next in importance, and its habits are essentially the same as those given for the cabbage-maggot, - that is, the eggs are laid by the fly quite early in spring, next the onion stems or leaves at the surface of the ground, and preferably in young onion beck. In the latitude of New Jersey this occurs in May, but the date varies somewhat according to the season and to the time at which these plants are started. The larva work their way into the bulb at once and begin their scraping and gnawing, leading to FIG. 420 .

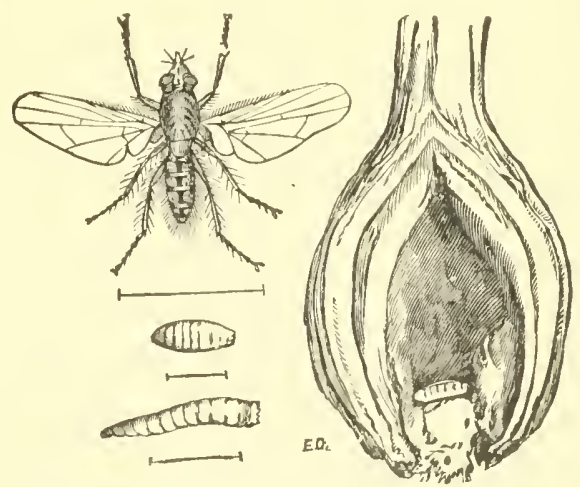

The onion-maggot.-Larva, pupa, adult, and section of an infested onion. the rapid decay and death of the plant. Matters are even more serious here than in the cabbage, because where a bulb has been started in decay, it usually continues, even if the maggots are destroyed, and in the case of scullions, they become unmarketable. 
The maggots attain their growth about the end of May or early 1n June, and before the middle of that month a second brood of flies may be found in the fields. This second brood is often much the most injurious, and quite frequently it attacks seedling onions, ruining entire beds. The older plants, if they have reached this date mharmed, are usually sife for the year. Exactly low many broods there are has not been accurately ascertained, and probably the number varies somewhat accorling to latitude. We do know that the insects pass the winter partly in the pupa stage in the ground, and partly as adults in barns, farm-houses, and other sheltered localities. Many measures to prevent injury have been proposed, none with any marked success, except those here mentioned. The most promising is sand soaked in kerosene, one cupful to a pail of dry sand, and placed at the base of the onion plants along the rows. This prevents egg-laying by the fly, kills any young larve that may attempt to work through it, and seems to have been quite satisfactory where tested; but it is obviously not a suitable measure for application on a large scale. In New Jersey tons of onion seed and sets are raised annually, and the following practice has been found uniformly successful. Keep a close watch for the first signs of maggots ; carefully lift out and destroy all infested plants that have wilted down so far that they cannot survive, and so kill the more advanced maggots. Turn away the earth from the rows with a hand-plough so ats to expose the root system in part, then apply broalcast about six hundred pounds of kainit and two hundred pounds of nitrate of soda per acre; turn back the earth to the plants, and this will put a period to the injury. The application is best made just before or during a rain, or immediately after a shower that has wet down pretty thoroughly. The object is to get the salty fertilizers dissolved rapidly and brought into direct contact with the roots of the plant, and, of conrse, with the insects as well. This method has proved entirely satisfactory in New Jersey, and on light lands it will probably act equally well in other localities; but it has never been tested on heary land, and the action may not be entirely the same. The application of the fertilizer has the actvantage of imparting adclitional vigor to the plant, and stimulates it to overcome such injury a's ma have been already caused. It is a good plan always and under any circumstances to care- 
fully take out and destroy plants that have wilted down beyond recovery, because in this way the maggots are destroyed or prerented from coming to maturity.

Other root-maggots may be treated on the lines just laid down, and nothing can be gained by multiplying instances. Too little is known of most of the leaf-miners to give any general directions concerning the methods which may be used to check them; but one remecly, or rather preventive measure, is always useful. A crop of infested leaves should always be disposed of as soon as possible. For instance, if beet leaves are attacked at the time the roots are harvested, they should be at once destroyed, and with them the insects yet in the plants. In this way much can be done to lessen their number for the ensuing season. Direct applications for leaf-miners are unsatisfactory, because of the difficulty of reaching them.

The remainder of the Muscid flies differ from all the preceding in that they have no perceptible winglet or alulet just below the anterior wings. If the "blow-fly" or the "house-fly" be exanined, it will be found that just behind the base of the large wings there is a little flap resembling in appearance a minute wing. This is called the "winglet" or "alulet," and it is more or less obvious in all the Muscids of which we have heretofore spoken. It is absent in all the other groups, and serves to divide this large family into two fairly distinct series.

We find it absent in a large series of flies belonging to the Trypetids and Ortalids, which are usually small in size, often metallic in color, and with the wings frequently banded or mottled. Some of the species have the habit of strutting up and down with the wings elevated and spreat out, and this has given them the name "peacock flies." They are gracefully built in most instances, and are noticeable by keeping the wings in constant motion even when feeding or walking about on flowers, where they are most frequently found. They fly rather slowly, and, as a rule, are easily captured. The abdomen of the female frequently ends in an extensile, horny-tipped ovipositor, by means of which the eggs are laid in the plant tissue in which the larvæ feed. Most of the members of the series feed in plant tissue of some kind, either in lenves, in stems, or in fruits, and a number of them are gall-makers. The most notable instance of 
the latter type in the Eastern United States is seen in the round swellings so frequently found on the stems of golden-rod. A number of species are locally injurious to fruits, but there seems to be no one injurious form gencrally distributed throughout this country. In the Northern and Eastern United States the socalled "apple"-maggot, Trypeta pomonella, is the only one causing trouble, the fly laying its eggs in the tissue of the apple by

FIG. 421.

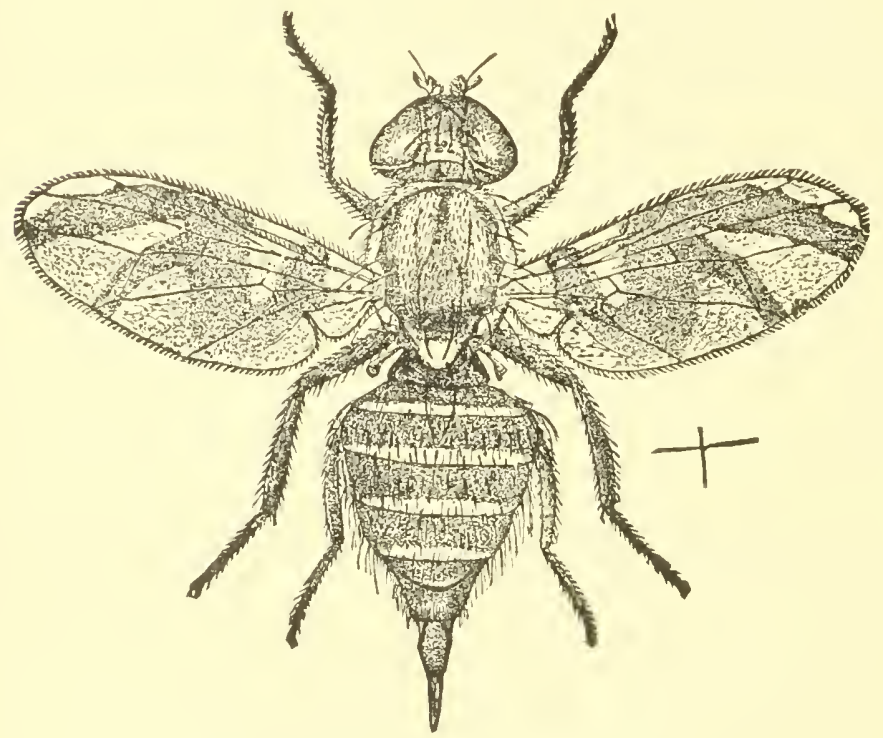

Trypeta pomonella, parent of the apple-maggot.

piercing the skin with its horny ovipositor. The little maggots channel the fruit in every direction, causing it to rot or become unsalable. When full-grown they pupate below the surface of the ground, or even among rubbish on the surface, or in crevices. Indeed, they are not at all particular, and transform wherever they can find an opportunity to do so, including the barrels, boxes, or bins in which infested apples have been kept. None of these fruit flies can be reached by insecticicles, nor is there any fair chance of reaching the adults, and the only method that is effectual is the prompt removal and destruction of infested 
fruit. Windfalls should be picked up constantly and destroyed at once. Summer varieties, especially sweet types, are most infested, and these should be sent to market at once if the apples are marketable, or if they are not, they should be disposed of in some effective manner to prevent the maturing of the flies. They secm to be more common in the Northeastern States, extending southward only to Central New Jersey. Suuth of this point they seem to be unknown, or so rare as not to be injurious.

Probably every one has noticed in the fall, at cider making, or when grapes are pressed for wine, or, in fact, whenever there is an accumulation of fruit of any kind in which fermentation or decay has started in ever so slight a degree, that swarms of little, yellowish flies make their appearance, easily distinguished by the bright coral-red color of the eyes. No specimens may have been noticed previously: but just as soon as the material attracting them makes its appearance, swarms are seen coming from no one knows where. They lay their eggs in the fermenting or decaying mass, and a few hours afterwards there will be an abundance of small, white, wriggling maggots. These become mature in three or four days, and after another day or two in the pupa state, they develop into adult "pomace flies,"

Fic. 422 .

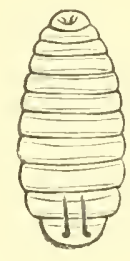

A pomace fly and its larva, Drosophila species; enlarged. species of Drosophila. The insects are sometimes annoying and a little troublesome, but scarcely injurious, and it is only because they are so common and occur so suddenly in large numbers that they are mentioned here. Little attention is paid to the larvæ either in wine or cider making, because they are thrown out in the process of fermentation, and do not in any way affect the quality of the resulting product.

To this same family belong the "skippers" which are found in cheese and sometimes in other kinds of provisions. The term is derived from the habits of the larva, which move about by a series of little jumps somewhat resembling those of the larva 
of the Cecidomyida. They produce a little black fly, Piophiia casei, similar to the house-fly in appearance, but much smaller, and the only way to protect provisions is to keep them constantly coverel. They sometimes become an intolerable nuisance in smoke-houses, attacking ham, bacon, and the like during the

FiG. 423 .

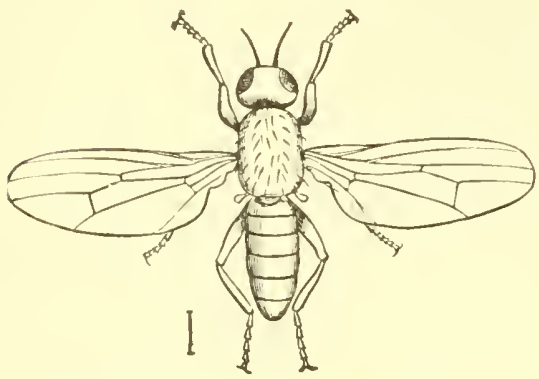

Piophila casei, parent of "skippers" in cheese, etc.

process of smoking, or before they can be cased, and the value of the provision is frequently impaired by the development of these maggots. Where a house is once thoroughly infested, the flies are found in swarms everywhere, ready to attack the meats as soon as there is the least opportunity. Under such circumstances thorough measures are necessary to get rid of them. In the first place, windows should be closely screened to prevent their entry from outside; the walls should be whitewashed frequently, so as to keep all crevices filled up ; the floors should be kept clean, and should be as solid and smooth as possible, to prevent the development of maggots in crevices filled with greasy substances. The flies can be killed by fumigating with tobacco or pyrethrum, and this should be done by closing up the rooms tightly in the evening after work is done, or on a Sunday or other day when work ceases, and a sufficient quantity of either tobacco or pyrethrum should be burnt on live coals to completely fill all parts of the rooms. They should be left tightly closed anywhere from eight to twenty-four hours, and at the end of this time the flies will have been destroyed, but the maggots will not, and it will be necessary to repeat this operation two or three times, at intervals of (at most) a week, to destroy the flies as fast as they hatch, and before they have an opportunity to lay their eggs. In some cases bisulphide of carbon may be user to fumigate; but this must be done when there is no fire on the premises, and the house should be left closed twelve hours at least, and should then 
be arred until no trace of odor remains before fires are again introduced.

The last family in the Diptera to which we need call attention are the "louse-flies," or Hippoboscida, freqnently separated as a sub-order under the term Pupipara, the latter being applied because of the curious method of reproduction. The flies are parasites, living largely upon birds, but sometimes upon animals, and the egg not only develops within the body of the female, but the larva becomes nearly full-grown in the same position, and practically attains the pupa state before it is extruded. In these species the abdomen is somewhat flattened and oval in form, of a thick, leathery conF1G. 424.

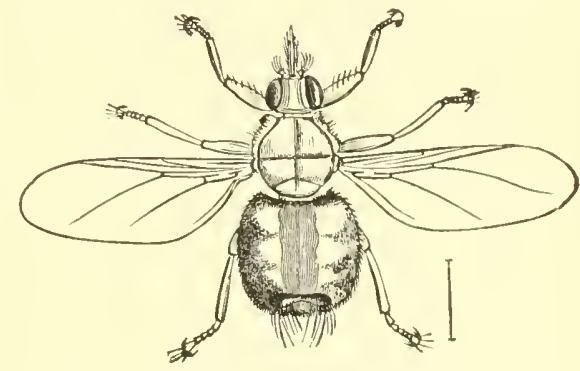

A louse-Ay, Olfersia species. sistency, with a very large anal opening, and from the circumstances of the case only one larva at a time is produced, so that the flies produce young only at considerable intervals. The whole body is depressed or flattened, and birds of prey are most usually affected. It is rare to find a hawk, eagle, or owl upon which several specimens of these peculiar flies cannot be found. They move about rapidly, and their first impulse is always to seek shelter when driven from their original host. Thus, in handling hawks that have just been shot, the flies frequently dart upon the hunter and make their way under his clothing and to his body.

A few species are wingless, and among them is the so-called "sheep-tick," Mclophagus ovimus, which is usually looked upon as a louse, and resembles one in the prominent

FIG. 425 .

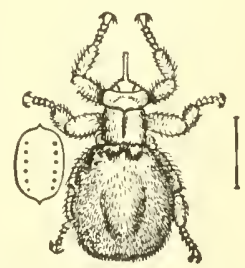

Sheep-tick, Melophagus ovinus. proboscis, the lack of wings, and the strongly developed legs, on which the claws are very prominent. This "sheep-tick" is the only troublesome species, and it can best be kept in check 
by frequent dipping, using a carbolated dip which readily destroys the insect. Thorough washing after shearing will usually clear the animals completely, and if the entire herd be once freed, it will remain so until infested animals are introduced. The parasites are able to move from one to the other only when the animals are herded close together.

Yet more louse-like in appearance is the little whitish creature, Braula caca, found upon the honey-bee as a parasite; but it

Fig. 426 .
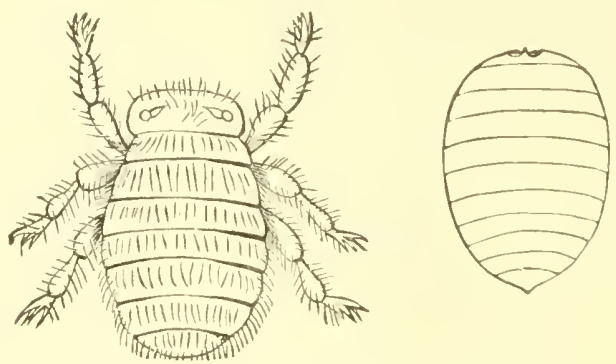

Bee-louse, Braula caca, and its larva; much enlarged.

seems to be rather rare, and, in our country at least, does not assume the dimensions of a serious pest.

\section{CHAPTER IX.}

THE HYMENOPTERA.

Bees, llasps, Ants, Sar'-flies, etc.

THERE is no order of greater interest than this, containing as it does the bees, wasps, and ants, the most useful as well as the most intelligent of the insects. By treating them last, the intention is not to suggest that they are lowest, but rather that they are the culminating point in the development of the class. Here we find social organizations not unlike some of our own systems of government, but more complete and running much more 
smoothly. We find division of labor carried to an extreme; combination for special purposes ; skill and energy in the preparation of homes; and, finally, we discover the helpless young cared for by parents or nurses. It is only in the Hymenoptera among insects that we find true babies, - that is, young that must be fed and tended until they are ready to assume the adult form. Nowhere else do we find larvæ fed on anything but simple, natural food; but by many bees a mixture is prepared and fed ; not honey or pollen alone, but a combination of the two in defi. nite proportions is given, and these proportions vary with the sex of the larva.

Members of the order Hymenoptera may always be distinguished by the presence of four transparent wings, the anterior always the larger, the secondaries frequently very small. They are not covered with scales, but are often set with small hair, and the cells and veins are comparatively few in number ; never netted as in the Neuroptera. The mouth parts are mandibulate, or formed for biting, but in many of the families there is also developed a large tongue-like structure which serves for lapping, none of the $\mathrm{Hy}$ menoptera being strictly haustellate, or sucking insects. The metamorphosis is complete.

Taken as a whole, the order contains beneficial insects; but as there is no rule without exceptions, so we find here also one series the species of which are vegetable feeders. These are included in the families Tenthredinida and Urocerida, the "sawflies" and "horn-tails."

The term "saw-flies" is used to indicate a series of species peculiar by the structure of the ovipositor, which is made up of a number of parallel blades toothed at the edge, by means of which the insects are enabled to cut pockets or slits in leaves or other vegetable tissues to receive the eggs. They are further peculiar by having the abdomen sessile, or joined for its full width to the base of the thorax, and the wings are rather larger in proportion to the body than in other groups. The larvæ are caterpillar-like in appearance, but they always have at least one more pair of prolegs than any caterpillar,--six pairs or more, of which one pair is anal, - which renders them easily distinguishable. They are often more or less slimy in appearance and to the touch, and perhaps a majority have the habit of coiling the posterior por- 
tion of the body around the edge of the leaf or twig while feed. ing. This is quite a characteristic peculiarity, and there is rarely excuse for mistaking the larva of a saw-fly for that of a Lepidopteron, even without counting the prolegs. Many of these larva are injurious to cultivated plants, and some of them are known to farmers as "slugs" or "worms;" for instance, we have the "currant-worm," the "grape-slug," the "rose-slug," and the " "pear-slug." When these larvæ are full-grown they form thin, tough, parchment-like cocoons, in which they change to pupæ, sometimes on the plant on which they feed, sometimes a little below the surface of the ground.

Perhaps none of the members of this family are better known than the "currant-worm," or "slug," Nematus ribesiz, which is an imported insect, and annually does great injury where its food plant is raised on a large scale. The flies, which are easily distinguishable by a rather deep yellow body, may be seen sitting

FIG. 428.

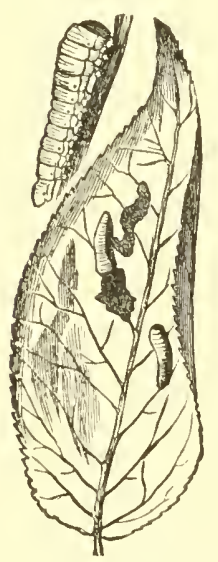

Pear-slug, larva of Eviocampa cerasi. upon the foliage, or flying about heavily as soon as the leaves of the currants are tolerably well developed in spring, and we may, even at that time, find on the under sides, arranged along the veins, series of little white eggs laid by them. The larve soon make their appearance and feed ravenously, frequently stripping a bush completely in the course of a few days. I have seen rows of currants covering an acre or more almost entirely devoid of leaves and the fruit hanging to bare twigs. There are two or three broods in the course of a season, depending upon latitude, the latter rarely as abundant as the first and second, and practically not nearly so destructive. The larva is green, dotted with black, and nearly an inch in length.

On pears we frequently note a very dark green slug, the larva of Eriocampa cerasi, which is more or less slimy to the touch. On young trees this sometimes does much injury by scraping the upper side of the foliage until it dries and withers, falling to the ground in midsummer. 


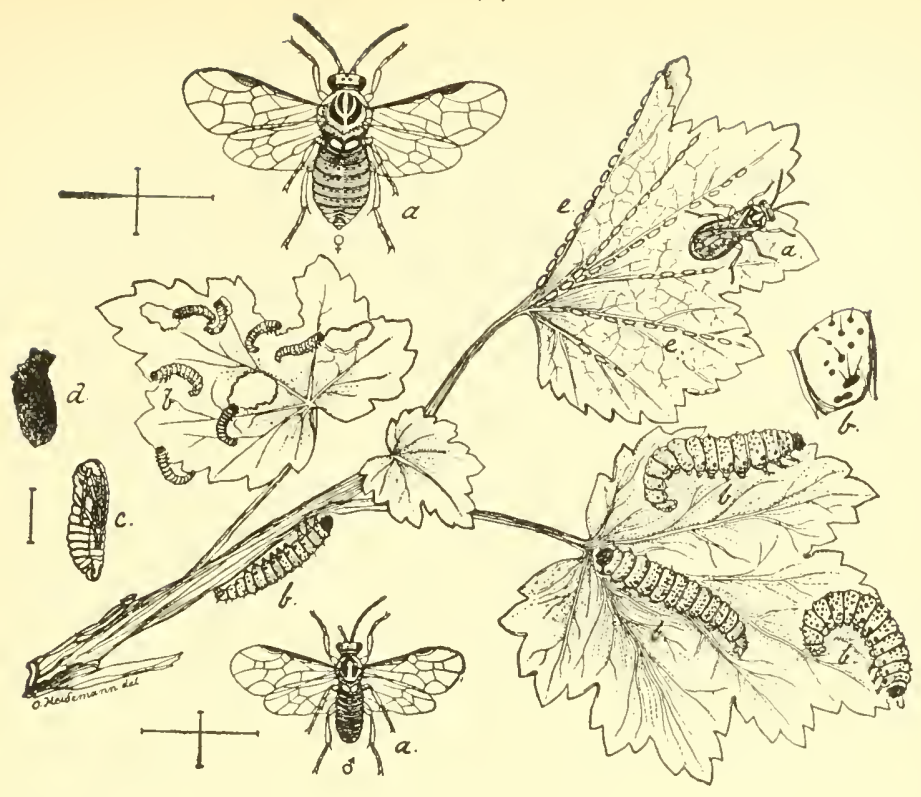

FIG. 43 I.

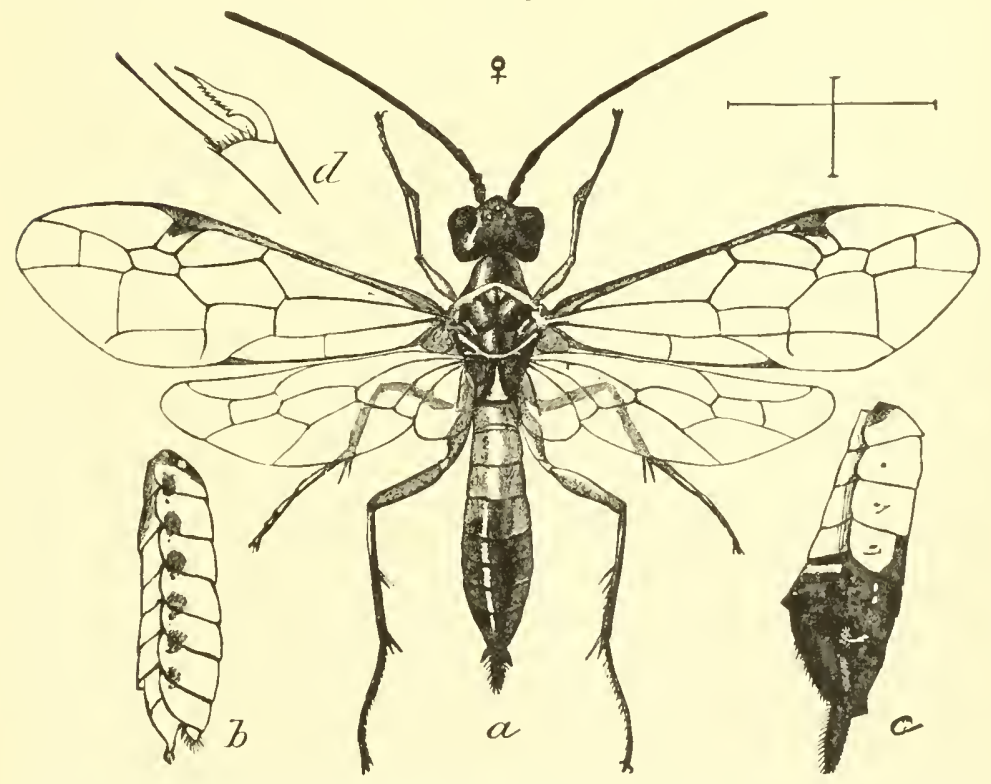

Fig. 427, currant-worm. $-a, a$, male and female adult ; $b$, larvæ; $c$, pupa in $(d)$ cocoon ; $e$, eggs. Fig. 431, Phyllocus faviventris. $-a$, female adult ; $b, c$, male and fersale abdomen; d, spur of anterior tibia. 
On grapes there are often black-dotted slugs, the larva of blennocampa pygmaea, that do some injury ; and on roses almosi

Fig. 429.
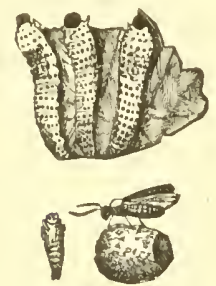

Grape-slug, larva of Bien. nocampa pygmuea. every grower has been annoyed by numerous green slugs, the larva of Monostegia rosa, which make their appearance early in the season.

Raspberries are sometimes severcly injured by iittle spiny slugs, the larve of Monophadnus rubi, that appear in June or early July, first eating round holes in the leaves, but eventually, when they become numerous enough, taking the foliage completely. Many other cultivated plants, including the strawberry, are attacked by these saw-fly larva ; bu: their habits are very similar, and the remedies to be adopted against them are also very much the same.

The largest of our American species, Cimbex americana, is found on willow, sometimes in considerable number, as a powdery, whitish larva an inch and a half in length, with a broad dark stripe on its back.

Experience has shown that all these species are very susceptible to the influence of white hellebore, and that even a small quantity is quickly fatal. Infested plants can, therefore, be cleared in a few hours by a thorough drenching with a decoction of white hellebore, used at the rate of one ounce in one gallon of water ; or the plants may be dusted with the powder, undiluted or mixed with several times its own bulk of cheap flour. Any stomach poison- $c . g$. , the arsenites or tobacco-will answer as well as hellebore, while on the slimy types even fine road-dust will quickly choke them to death. Air-slaked or dry hydrate of lime burns through them in less than an hour when carefully applied. These insects are so easily killed that it is the fault of the farmer himself if he suffers injury.

The "horn-tails" resemble the "saw-flies" in a way, but the character of the ovipositor is different and rather more like an auger or borer than like a saw. So, too, the species are, as a rule, internal feeders instead of eating openly upon the foliage. The larva are usually slender, white or nearly so, and in fest plants ranging from the stems of wheat to the trunks of 
trees. Some forms live in blackberry and raspberry canes, others in grasses; I have taken a species from alder, and in fact a very large number of plants are infested by these boring Hymcnoptera. The largest of our species is the "pigeon Tremex," T. columba, the larva of which attacks quite a consider-

FiG. 430 .

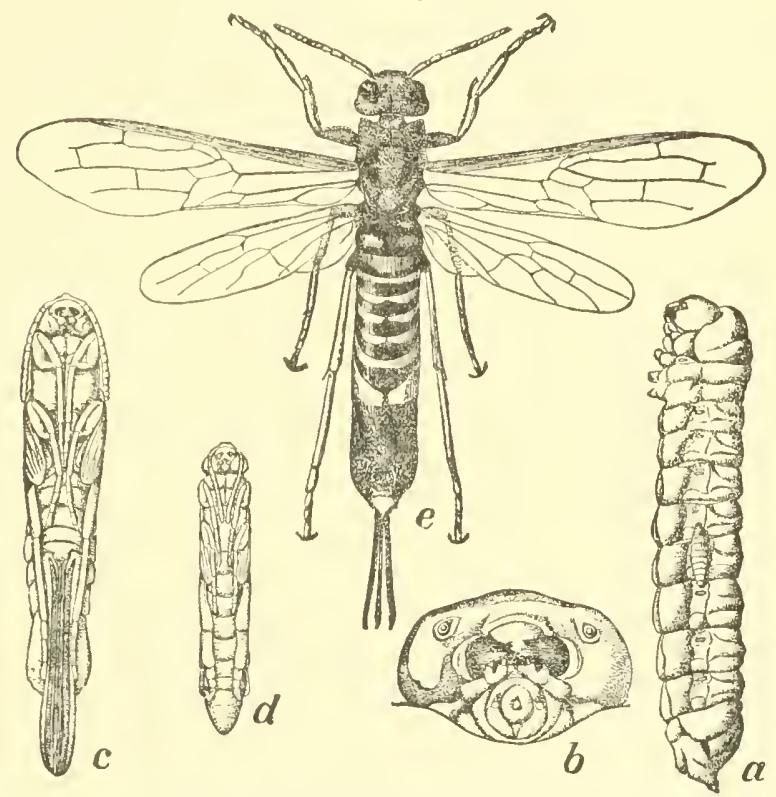

Pigeon Tremex, T. columba.-a, larva, with young larva of Thalessa fastened to its side; $b$, its head ; $c, d$, female and male pupæ ; $e$, female.

able variety of trees, including maple, elm, hickory, and beech, and bores into the solid wood, usually when the tree is beginning to die, or is even dead, but not decayed.

Dealing with these insects is always rather a difficult matter, because we have no means of getting into the infested plants with insecticides. We are again reduced to farm practice, and must arrange our methods of cultivation in such a way as to reach and destroy the insects by depriving them of food. Thus, with the Phyllocus infesting blackberry, if the canes are topped about midsummer, or a little before, the larve never mature, because 
the wood dries, becomes unsuitable for food, and, as the insect is incapable of travelling, it starves to death.

In the case of Cephus pygmeus, the insects boring in wheat, they spend the winter either low down in the infested sta!k-i.e.,

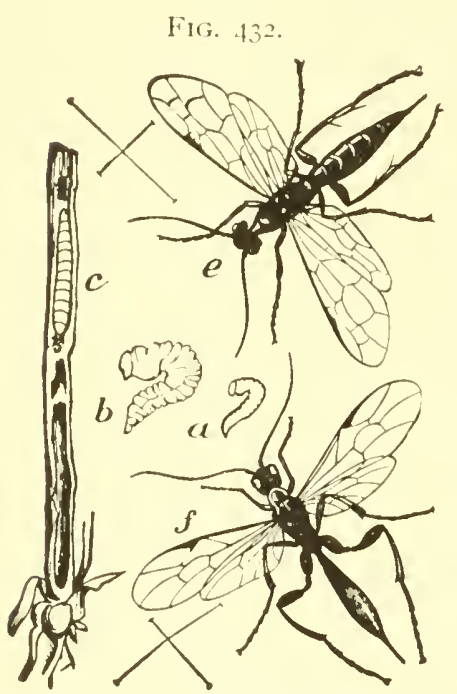

Cephus pygmous, wheat-stem saw-fly. - $a$, outline of larva, natural size; $b$, larva enlarged; $c$, larva in wheat stalk, natural size; $e$, adult female; $f$, female parasite, enlarged. in the stubble-or in the soil just below the surface, in either the larval or pupal condition. The proper remedy is to burn the stubble as soon after harvest as possible, or to plough it under deeply. This destroys the insects and results in preventing injury the year following. We have no means of reaching the larva while it is actually working in the stem of the plant. The remedy is radical, and were it universally resorted to, would need to be applied only at intervals of several years.

The "gall-flies," belonging to the family Cynipida, are curious creatures. They resemble minute wasps in form, and generally have a very short, chunky body, which is often compressed and joined to the abdomen by a very slender petiole or stalk, in sharp contrast to the species heretofore written of. These gall-flies are mostly true parasites on plants. They derive their common name from the fact that they produce swellings, protuberances, or " galls" of great variety on vegetable tissues; sometimes on leaves, on twigs, on trunks, or even on roots; and perhaps, of all others, the oak is the favorite of the insects of this family, bearing the greatest variety of galls on all its parts. I say these insects are mostly plant parasites, and intend to express by this that they do not actually eat the infested vegetable tissue. The irritation caused by the larva induces an abnormal growth in the part of the plant infested, and in a cell in this growth it has its home. Here the insect reaches maturity with- 
out devouring any part of its vegetable envelope, changes to a pupa, and emerges from the gall, leaving it intact, except for the hole through which it emerged. It seems, therefore, as if certain abnormal plant exudations secreted in the gall form the actual food of the larva, and it is a curious and interesting fact that the same species invariably produces in the same place the same kind of gall. In other words, the appearance of the gall is an unfailing index for the special student to the

FIG. 433 .

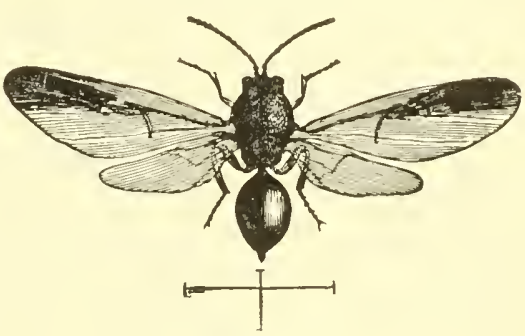

An oak gall-fly. species that made it. Many interesting problems are connected with the study of these gall-flies; for instance, in some species both sexes are present early in the season, but in the second or midsummer brood females alone make their appearance. The FIG. 434 .

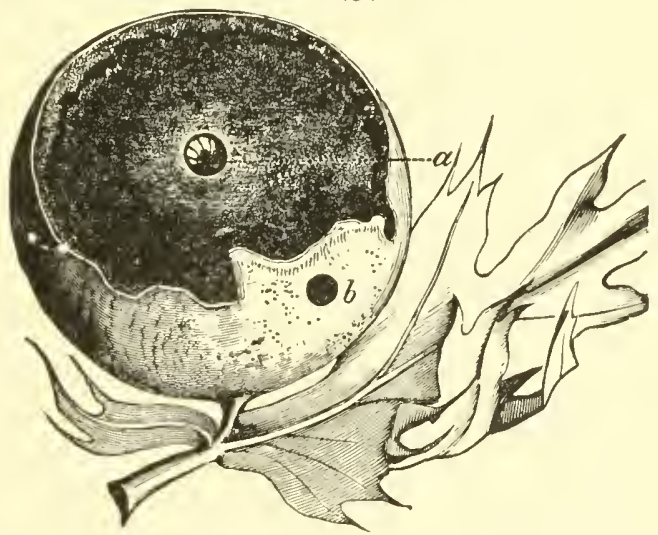

Gall made by the larva of Cynips $q$. spongifica.- $a$, larva in its cell; $b$, point of exit of adult.

progeny of this female form, which may or may not resemble the spring form, in turn produces males as well as females. Of other species no males are yet known, and, so far as we have 
any evidence at present, there is a continuous breeding by female individuals only.

There are only a very few injurious species among these gallflies. Occasionally we find on blackberry stems an irregular, warty swelling, and if

FIG. 435 .
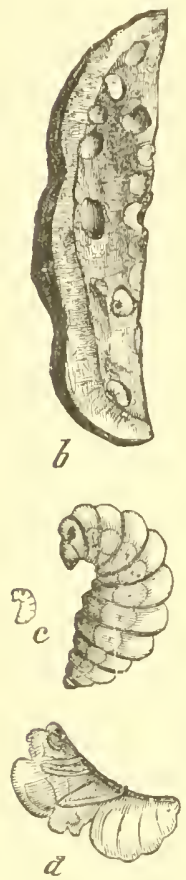

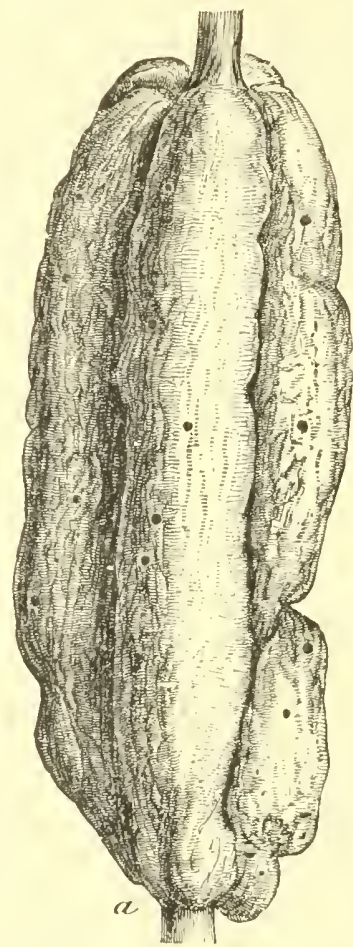

a, Pithy gall on blackberry, made by Diastrophus nebulosus; $b$, section to show cells; $c$, larva; $d$, pupa. this be cut into, it will be found full of cells occupied by these little Cynipid larvæ. This kind of gall is known as "multicellular," because inhabited by numerous specimens. Sinilar galls are found on the roots of rose and plants of the same natural family, and in a few other cases cultivated plants become subject to gall growths. As a matter of fact these galls are scarcely injurious, because in most cases the plant continues growing beyond them, or even if a shoot is lost, permanent injury is rarely done. Certain species of oak-yalls produce a black stain, and these were at one time almost iniversally employed in making an ink of remarkable permanence, Even yet the law in some States requires for certain records an ink of which oak-galls is one of the ingredients.

It is a small step from parasitism upon vegetation to parasitism upon animals, and hence it is not surprising to find that some species of this family are parasitic on other insects. The differences between these forms and the true gall-makers are not easily 
pointed out, since the insects are usually small in size ; indeed, it is a matter of little importance to the farmer, because in any case he can look upon these gall-wasps with indifference, and without much fear of possible injury to himself.

There is a very large series of parasitic Hymenoptera, and it contains a number of families, nearly all the species of which are beneficial. To the practised eye a doubt rarely exists as to whether an insect is parasitic or not; but that the student may be able to decide this matter for himself if he chooses, it may be pointed out that the trochanter, the little segment between the coxa and femur of the leg, is rather peculiarly developed here. It is nomally composed of one joint only in all the bees, wasps, and ants, whatever their size or appearance, but it is two-jointed in all the parasites. This character can be easily seen on large FIG. 436 . specimens with or without a lens, but on
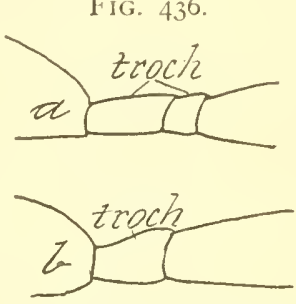

$a$, two-jointed trochanter of parasitic Hymenoptera. $b$, normal structure.

minute species it becomes more difficult; and, after all, in most cases the farmer is justified in assuming that most of the minute wasp-like creatures that he notices are parasites and beneficial.

One feature characteristic of a great number of species is an external ovipositor, or egg-laying tube, and this may vary from a scarcely visible projection to an enormously developed hairlike appendage five to six or even more inches in length.

There may be frequently seen on the trunks of various trees a quite large ichneumon, a Thalessa, yellow or black in color according to the species, which has its long, bristle-like ovipositor forced deep into the wood, and so firmly fixed, occasionally, that it is unable to withdraw it, and perishes miserably. Wherever this occurs the trees will be found infested by borers, and all but universally this ichneumon is accused of being the parent of the larva that produces the injury. The circumstantial evidence is all against it; but we really have here a beneficial species which is after the wood-boring larva of the "pigeon Trenex." The insects seem able to recognize an infested tree, and pierce the trunk until the ovipositor reaches one of the burrows of the wordfeeding larva. In this an egg is laid, and the larval parasite, 


\section{FIG. 437 .}

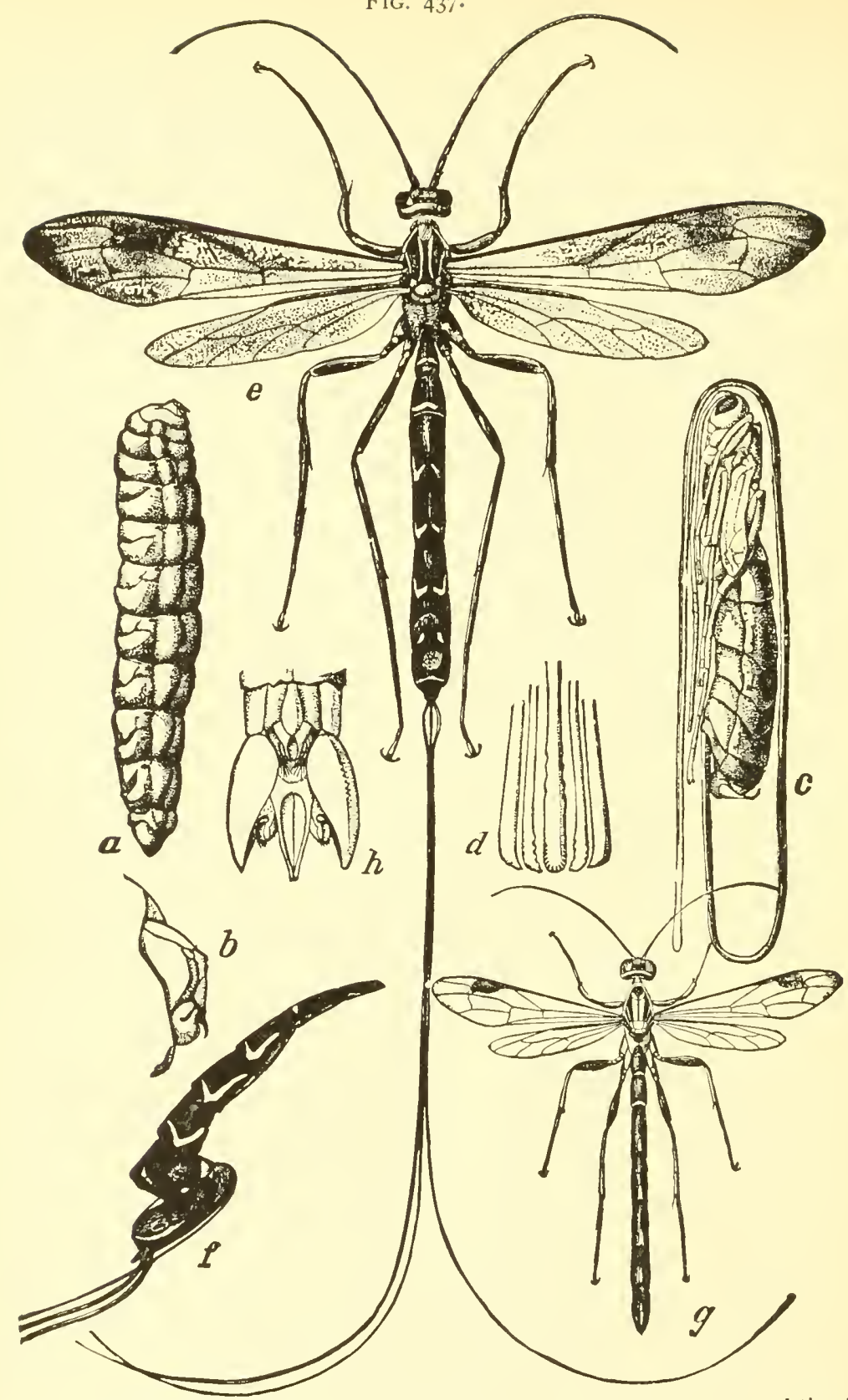

Long-tailed ichneumon, Thalessa lunator.- $a$, larva; $b$, head of same; $c$, pupa; $d$, tip of pupal ovipositor $; e$, female adult; $f$, tip of abdomen, seen from the side; $g$, male adult; $h$, tip of abdomen. 
when hatched, crawls along the burrow until it comes into contact with its host. It then punctures the skin and remains fixed to the outside, sucking the juices and gradually killing the borer.

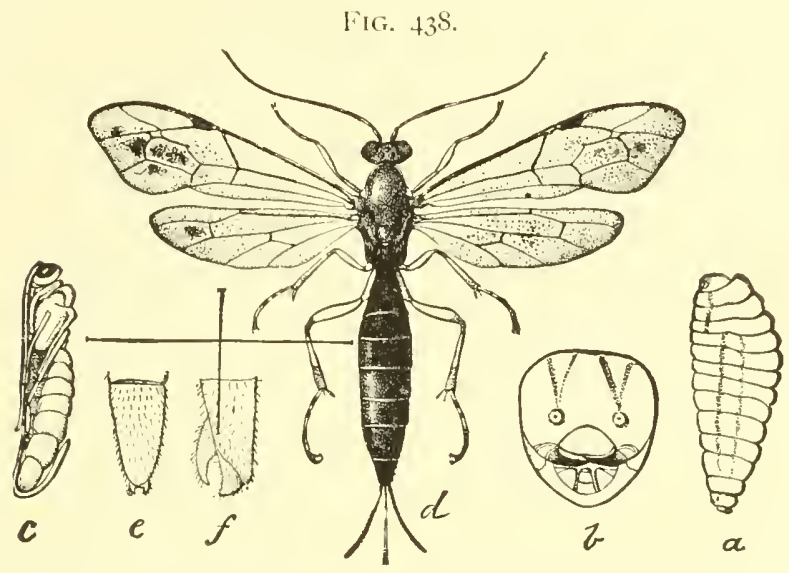

Pimpla conquisitor.- $a$, larva; $c$, pupa; $d$, adult; other references are to structurai details.

By no means all of our "ichneumons," even of those belonging to the family Ichneumonida, have external ovipositors; yet there is a distinctive character in their appearance which is easily recognized but hard to describe. The species belonging to the typical genus Ichneumon have rather long, slender forms, with flattened abdomen and no external ovipositor. They are often gaudily colored, the antennæ are frequently banded with yellow, and many are metallic blue or green. The species are usually parasites on caterpillars. One of the largest

FIG. 439 .

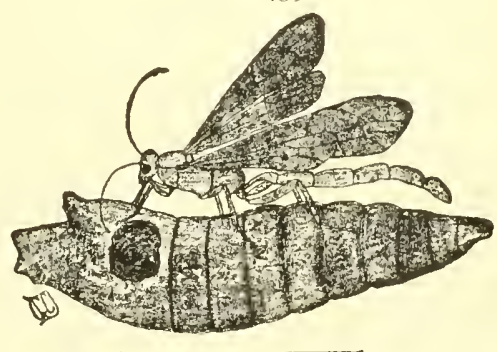

Trogus exesorius on a chrysalis of Papilio, from which it has emerged. and most frequently noted species is that which infests the larve of the common "swallow-tail" butterflies. It is orange-yellow in color, with smoky-black wings, the body nearly an inch in 
length, and the wings expanding fully an inch and a quarter or even more. This makes the species easily recognizable, and it will serve very fairly as a type of this particular branch of the family. Species of this size usually lay only a single egg in the host, and in the case of the "swallow-tail," the caterpillar retains strength enough to change to a chrysalis ; but from this chrysalis there emerges through an ugly hole in the side the Trogus exesorius, which has just been described. Frequently, however, in smaller species, a consielerable number of parasitic larve develop in one caterpillar.

Of yuite a lifferent type, as compared with those just described, are the species of Ophion. These are large or very large creatures, black or honey-yellow in color, and the bodies are

Fig. 440.

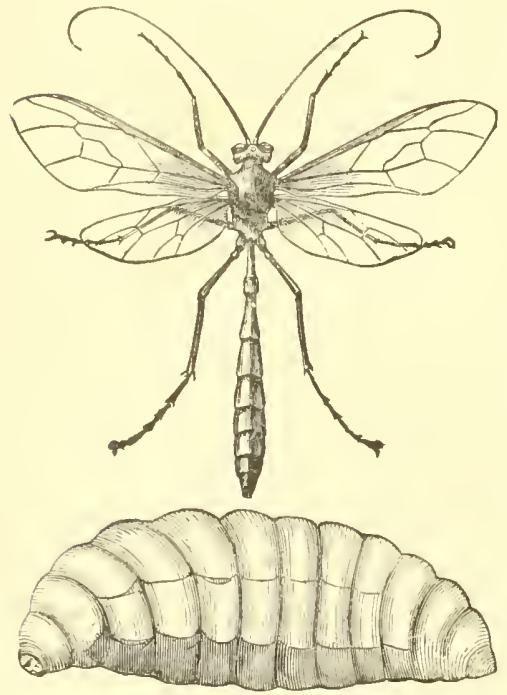

Long-tailed Ophion, Ophion macrumm, and karva. transversely flattened and squarely cut off at the posterior extrenity. They are thus blade-like in shape, and the ovipositor rests concealed in a groove in the squarely cut off ent segment. Though these insects are not stinging Hymcnoptera, strictly speaking, yet the ovipositor is so short and sharp that the insects make use of it as a means of defence. They should be carefully handled, therefore; though the sting, if "hot" for a few moments, seems not to be so poisonous as that of the bees and wasps.

In the family Braconide the species are smaller, as a rule,--sometimes very small indeed, - and all are parasites. The difference between the previous and the present family is in the venation, and is not easily made out, except by the special student; nor from a practical stand-point is the matter an important one. It is among the members of this fanily that we find many of the minute creatures 
that infest aphids. If, at any time during the summer, a leaf badly infested with plant-lice be examined, there will be usually found a few specimens that seem abnormally swollen and livid gray in color rather than green or yellow. Such specimens are parasitized, and if they be removed to a closed vessel, there will be found in it, in a few days, minute blackish or brown wasp-like creatures, and on each of the infested plant-lice will be seen a little round hole, which shows where the insect emerged. They are usually examples of minute Braconids, and are the most important of those natural checks that prevent the increase of plantlice above a certain point. Unfortunately, that point does not coincide with the limit at which the insects become injurious to the farmer; hence, though the parasites accomplish their purpose, they do not, therefore, confer any direct benefit upon him.

At almost all periods during the season, but especially late in summer or fall, caterpillars may be seen, bearing upon their backs and sides white or yellowish, egg-shaped bodies. These are often supposed to be the eggs of the caterpillars, but as a matter of fact they are cocoons of Microgaster or Apanteles, little parasites belonging to this family; and if the caterpillar be confined for a few days it will be noticed that from the tips of each of these ego-shaped bodies a little circular lid is lifted off and a little wasp emerges. If, late in summer, a number of the large sphinx caterpillars infesting potato or grape-vines are watched when they yet show no signs of infestation, one may fre quently see the little larve boring their way through the skin, wriggling until they have emerged for more than half their length, and it is then easy to watch the formation of the small silken cocoons. The caterpillar soon becomes an odd-looking sight, with anywhere

FIC. 4.1 .

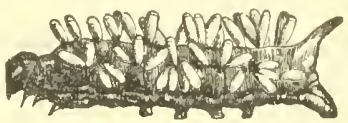

Sphinx larva covered with, $/ /$ crogaster cocoons. from a dozen to fifty or even a hundred of these little maggots, all engaged in spinning cocoons, projecting from it in every direction. The egg-like cocoons are attached merely by a little point, so that they may be easily removed. But the caterpillar has been drained of its strength and of the substance for the formation of the future butterfly: it collapses and dies, unable to complete its transformation to the pupal stage. 
Most of these parasites have the disadvantage of not influencing in the least the amount of injury done by the host ; they simply prevent it from changing to an adult. It often happens that spinning caterpillars even complete their cocoon, and in this we find the mass of parasitic cocoons instead of the Lepidopterous pupa. On the other hand, some of them complete their

Fig. 412 .

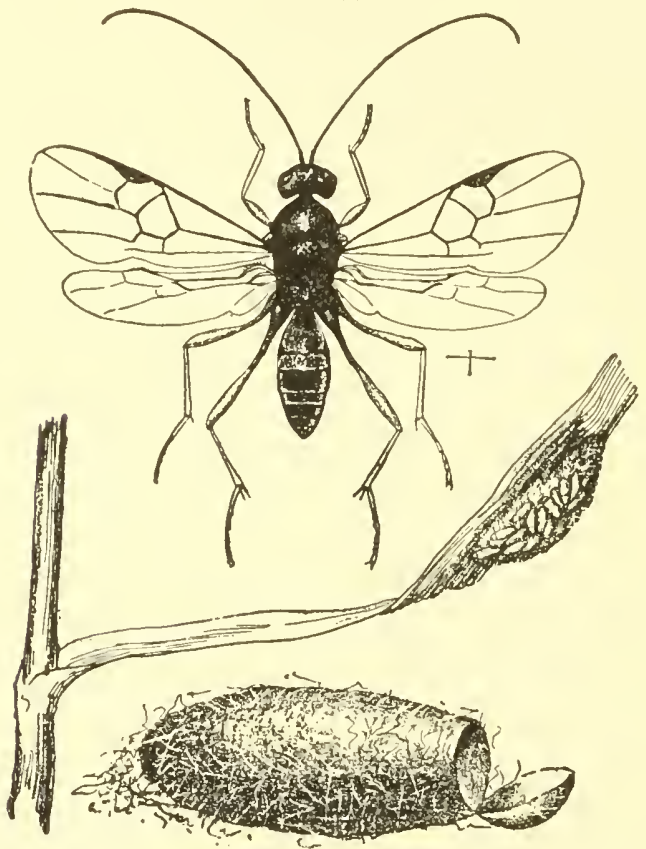

Apanteles species.-Little mass of cocoons on leaf, replacing an infested larva; a single cocoon below, from which adult has issued; much enlarged.

development and kill the caterpillar before it is much more than half-grown. Many of these cocoon-forming species belong to the genus Microgaster, and they are typical of a very large series in the family. The plant-lice-infesting forms frequently belong to the genus Aphidius. As in the previous family, many of these insects have an external ovipositor.

While the preceding series of parasites contain a very fair proportion of large species, the next family, Chalcidida, contains 
very few, except small forms, which are quite usually metallic black, bronze, or green. The wings are without venation, except for a strong vein running parallel to the costal margin, but not reaching quite to the tip, and the antennæ are geniculated or abruptly bent at the end of the long first joint. Few of these have the ovipositor visible, and usually it lies in a groove on the under side of the tip of the abdomen, issuing before the apex. These Chalcidid flies are exceedingly numerous, and are parasitic on

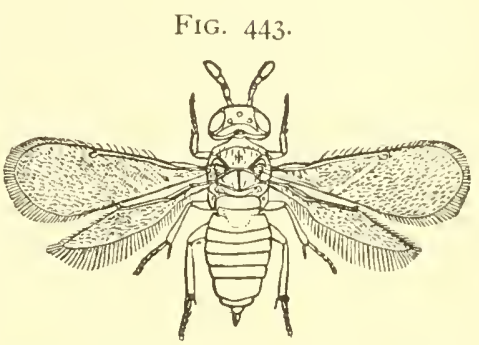

Aphelinus mylitaspidis, parasite on scale insects; much enlarged. a great variety of other insects.

They are rather more robust in build than the other small parasites, and this fact, with their usually brilliant metallic coloration, is a tolerably good guide to the family, of which the species infesting the common cabbage butterfly may serve as a good example. If, early in the spring, a large number of chrysalids of the cabbage butterfly be collected, - which can be easily done along the fences bordering last year's cabbage-field, - it will be found that some of them have a rather warm gray color and move the joints of the abdomen freely, evidently showing life. Others will have a peculiar, dead, straw-yellow color, and the abdumen is brittle and will break rather than move. If it does break, the interior of the chrysalis will be found completely filled with little, greenish-gray, maggot-like larvæ, in which the segments are well marked and a little darker in color. If such infested chrysalirls be removed to a warm room and kept in a covered vessel, there will emerge in due time dozens of Pternmalus pupanum, a greenish-bronze Chalcidid, instead of the common white cabbage butterfly.

Though these insects are minute, being scarcely one-eighth of an inch in length, yet they are giants compared with others which live in scales and even in the eggs of other insects. Very frequently such Chalcidids are bred from galls, and they are here either parasitic upon the actual gall-maker, or they may live in the abnormal tissue produced by the Cynipid larvæ. We find 
the little fellows everywhere, infesting almost all kinds of insects, and undoubtedly they do much to prevent the increase of injurious species. Especially is this true of those ovipositing in eggs of other forms, for they are then "nipped in the bud," so to speak. Their work in the destruction of scale insects is also of great importance, and frequently we find on a scale-infested tree a large proportion with little round holes, showing where a para-

FIG. 444.

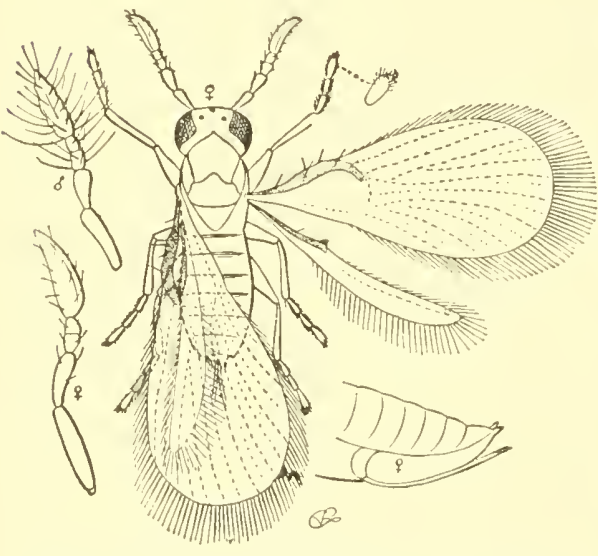

Thichogramma pretiosa, a parasite in insect eggs: a dot may represent natural size.
FIG. 445 .

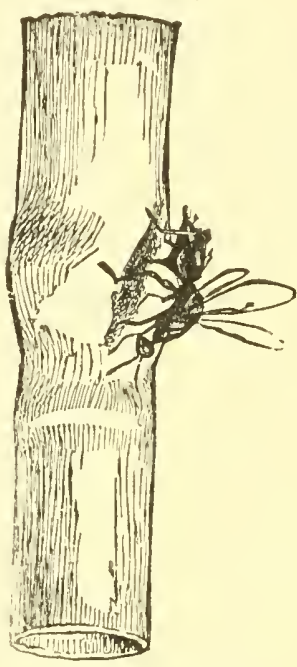

Female Isosoma ovipositing in stem of wheat.

site has emerged. It is a pity that in a family so generally useful we should find, exceptionally, some injurious species; but there is no doubt that members of the genus Isosoma lay their eggs in the stems of grasses, including wheat, and the larvæ, working as they do in the joints, have received the name "joint-worms." The stem hardens where the larva punctures it, and this interferes with the nourishment of the plant above that point, lessening or entirely preventing the formation or maturing of the grain. There is but a single anmual brood of these insects, and the winter is passed in the straw, from which the adults emerge in spring. In localities where this insect is sufficiently abundant to make it necessary to use remedial measures, the utilization of 
the straw during the winter will check injury to a great extent. It is certain that some near allies of Isosoma and perhaps some other genera of Chalcidids are, at least in part, vegetarians; but, so far as I an aware, none other has proved in any true sense of the word injurious to cultivated crops. Hence, although, especially in the central and western parts of the United States,

Fig. 4.6 .

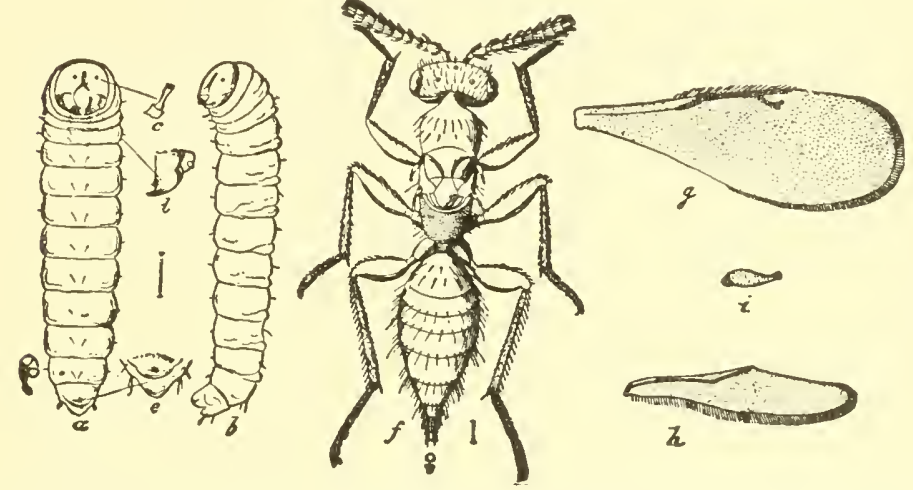

Isosoma tritici.- $a, b$, larva; $f$, adult female; $g$, fore-wing: $h$, hind wing; other letters are structural details.

the "joint-worm" may do some damage, yet it is so easily controlled that it scarcely affects the value of the family as a whole.

The smallest of all our parasitic insects belong to the family Proctotrypida, and even the largest of them would be ordinarily considered as small insects. Among them we find the greatest number of egg parasites. As compared with the Chalcidids, these insects are rarely metallic in color, usually black or brown, sometimes yellow, and much more slender in build ; the body longer in proportion to the thickness. Their habits may be said to be in general like those of the other parasites, and they are not easily distinguished from them, except by the special student ; but they rarely have the geniculated antennæ described for the Chalcidids. None of these Proctotrypids are injurious, so far as we know, or feed on vegetable matter, though some are found in galls, apparently parasitic upon the original gall-maker.

Taken as a whole, the parasitic Hymenoptera belonging to 
the various families heretofore mentioned constitute one of nature's means of kepping within bounds the insects of other orders, and, indeed, the various parasites themselves. Not only are the little creatures parasites upon almost all other insects, but as a matter of fact they are parasitic even upon each other, or hyperparasitic, so that it is a clear case of "dog eat dog."

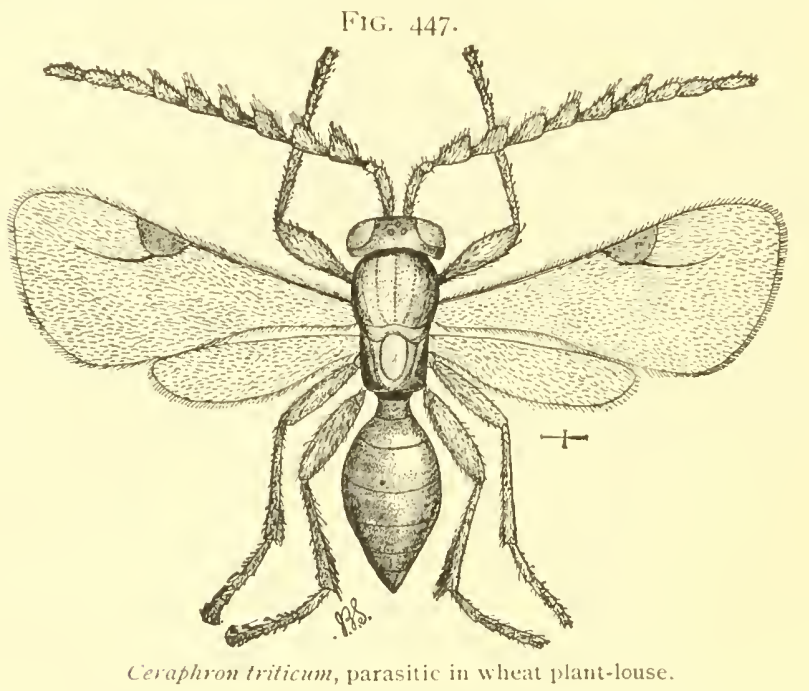

They undoubtedly check injurious species, but also each other; in this way preserving a balance from year to year which keeps all the forms at about the same relative level. Of course the "hyperparasites," as the forms infesting the other parasitic species are termed, are distinctly injurious from the agriculturist's stand-point ; perhaps even more so than the forms actually feeding on vegetation.

The question of making economic use of parasites belonging to this order has been frequently discussed, but no practical results have yet been obtained. Occasionally several species attack a single host, and yet, withal, they seem to produce no effect upon it in the long run. Even though we may breed out of a lot of caterpillars more parasites than butterflies or moths, in the season following the caterpillars will be just as abundant as they were the year before. Just where the checks to parasite 
increase come in is not entirely clear in all cases. Take, for instance, the cabbage butterfly alrealy spoken of. I have, in collecting chrysalids in spring, found scarcely one in twenty that was living, and from which I obtained a butterfly. All the others produced parasites, chiefly the little Chalcidid already spoken of : hundreds of them for every butterfly! It would seem, then, as if there were parasites enough here to attack every caterpillar that hatched from the eggs of this first brood; yet somehow they seem to be almost entirely free, and the butterflies increase normally until after midsummer. It seems almost impossible, in fact, to get a parasitized larva until August or September, and not until we get the last brood of caterpillars do the parasites seem to resume activity, after all the injury has been done to the cabbage crop. Perhaps ninety per cent. of all the caterpillars will be found infested at this time, and a mere fragment of the brood comes to maturity the following spring.

IVe are unfamiliar with the complete life history of most of these little species, and, indeed, a great many yet remain to be described. It would be rash to say that we can never use them for our own purpose,-that is, in checking injurious species ; but if so, it is certain that we must know very much more about them than we do at present.

A very curious creature sometimes found flying through open woods is the Pelecints polyturator, for which the family Pelecinidce has been established. The female is remarkable for the length of its slender abdomen, each of the joints being almost as long as the head and body, and the entire insect is sometimes nearly four inches in length, the abdomen alone measuring more than three. The insect is so very odd and so often noticed that it Fig. 448.

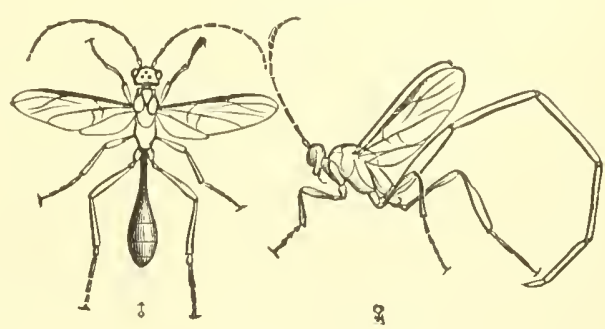

Pelecinus polyturator, male and female. is mentioned here to answer a frequently asked question as to its character. It is not at all rare in some localities, but its habits 
are yet unknown to us. It is believed to be parasitic, but upon what sorts of species no one has yet discovered.

The remainder of the order has been roughly classed as Aculcate, or " stinging" forms, the majority of the species being provided with an ovipositor modified into a sting like that of the bee, having connected with it a more or less well-developed poison-sac. From the fact that the sting is a modified ovipositor, or egg-laying tube, it follows that it can be found in the female only; hence the males of bees and wasps of all kinds have not the power of stinging, and may be safely handled. The use of the sting varies in the different families, and this subject will be further spoken of.

One little group is separated off under the title "'Tubulifera," and contains the single family Chrysidide, bees of a brilliant metallic blue and green, deeply punctured or pitted, and, as a

FIG. 449.

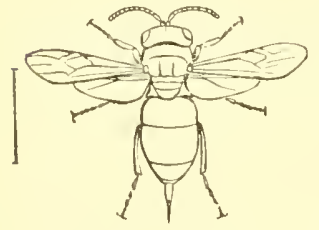

Chrysis species. whole, of rather robust build. They are among the most beautiful of all the $H_{y^{\prime}}$ menoptera, are of fair size, and are peculiar in the structure of the abdomen, which is telescopic. From three to five segments only are visible, the others being retracted, but capable of a tube-like extension, at the end of which the minute sting is situated. They have been called "cuckoo-bees" from their habit of laying eggs in the nests of other solitary bees and wasps. The larva is supposed to hatch before the true owner of the food supply, and to devour the store, leaving the other hapless baby to starve to death. Economically, the species are of no importance, save as they form a check to the increase of certain other bees and wasps.

Few insects are better known to the average observer than the ants that are found everywhere: in our houses, in fields, in woods, in the ground, under stones, in trees, in roots, and in all other likely and unlikely places. They are abundant in temperate countries, more rare to the northward, but become veritable pests by their enormous numbers in the tropics. They have many peculiarities of habit, and their development is remarkable in certain directions. We find among them architects and builders, agriculturists, masons, tailors, and many of the other 
trades and professions are represented. We find communities governed in some directions despotically by a queen, yet at the same time forming the most perfect republic, in which every individual has its rights firmly established and absolutcly beyond the control of the nominal head of the colony. We have organizations that make war, keep slaves, lay in stores, and provide for contingencies; they seem able to forecast the future in some directions and intelligently provide for it. In other words, they offer some of the most interesting problems that can possibly be studied. It is unnecessary to waste words in describing the appearance of an ant, and it need only be said that all the true ants are distinguished from the other Hymenoptera by the possession of one or more scales or nodes on the petiole or stalk of the abdomen. We find also, in this series, the development of what are known as " neuters," or workers, --that is to say, female individuals in which the sexual characters are not perfected, which are incapable of reproduction, and whose function in the nest is simply to perform the mechanical labor necessary to keep up the colony. These workers have no wings, and in their appearance and the relative proportion of the parts they frequently differ considerably from their parents. There are sometimes several forms of workers found in nests, differing from each other in the development of certain parts for special purposes, but attention will be called to these hereafter, where necessary. Though the ants agree in their general habits and peculiar social organization, yet no less than five different families have been recognized, based upon structural characters, principally of the abdomen and head.

The most numerous in species of these families, containing most of our common forms, is the Formicida, in which the petiole is formed of a single joint only, and the abdomen is smooth, without constriction between the segments. In this family the "queens," or females, have no sting. They build their nests in all sorts of localities. We find them commonly in our fields; often in woods, where the large black "carpenter ants" are the most prominent; while some occur under stones or around the roots of trees. It would be easy to write a book on ants alone, but necessarily our notes of them must be confined here to the features of economic importance. And first 
let us have their general life history. In a colony of ants, however large, there is usually a single "queen," or female, the

FIG. 450.
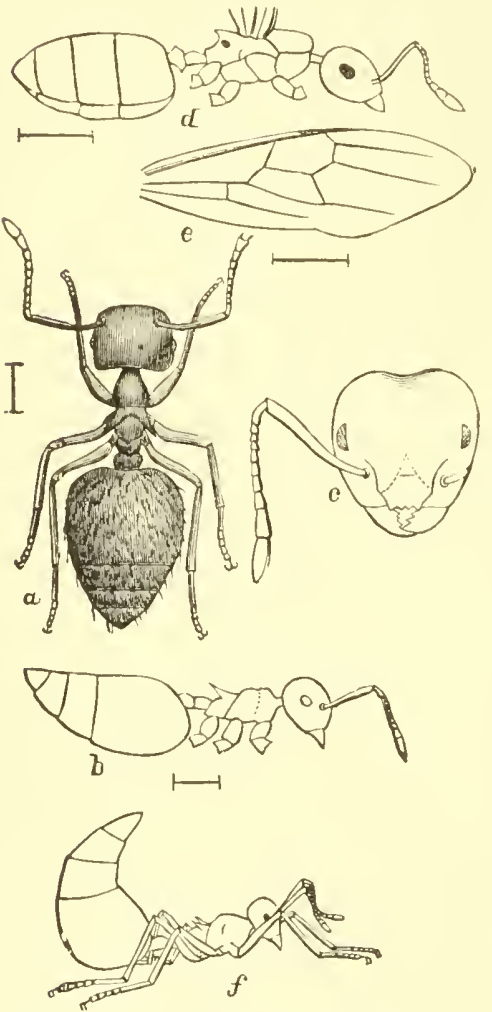

Cremastogaster lineolata. $-a, b$, large worker; $c$, its head; $d$, female ; $e$, its wing : $f$, small worker. Family Formicide. nominal head of the establishment, and she attends to the business of laying the eggs, which are white, cylindrical, and a little elongated. They are taken in charge by the workers, cared for, and in about a month-the time varying with the specieshelpless grubs are produced. These are carefully tended and fed, because absolutely unable to help themselves, are periodically cleaned and moved about from place to place in the nest, that they may have the proper degree of warmth and dryness or moisture, and after about six weeks of this coddling they are full grown. Then they either spin an oval cocoon, in which they change to pupæ, or change directly without forming such a covering. The cocoons are cared for as tenderly as were the larve themselves, and these are what is usually known as "ants' eggs." They may be found at midsummer, or thereafter, in almost any colony of ants, and usually in the upper chambers of the nest, where they get a full supply of warmth from the sun. The adults hatch from these cocoons late in summer, and at once take part in the work of the nest, so far as they are workers. Of the latter there may be two "orms, known as "worker minors," or small workers, and "worker majors," or large workers, each with different duties. 
There are also two kinds of winged forms, males and females, both larger than the workers, and the females considerably larges than the males. All the insects work their way down to the lower levels or inmost galleries of the nest on the approach of cold weather, and hibernate in the adult stage in a dormant condition. In spring, with the approach of warm weather, activity is resumed, and, usually some time during the early part of the season, on a particuliarly bright, warm day, the newly developed males and females leave their old home and "swarm." By this is meant that they leave the nest in which they were hatched and fly about for a short time. They mate soon after, and are then ready to start colonies of their own. None of them ever get back to the old home, and if they do not succeed in founding a "hill," they perish in the course of a day or two. Exactly how the different species start their colonies is not known, but in some cases, certainly, the impregnated female strips off her wings and starts a small nest in some convenient place, doing the best she can under the circumstances, and laying only a few eggs. These she brings to maturity, and they are usually of the small or "worker minor" type. When fully developed, these relieve their parent from further mechanical work, increase the size of the nest, and gather food as well as attend the young that are still continually hatching. If circumstances favor, the nest grows rapidly, and it may eventually become enormous in size, containing millions of individuals, and ramifying for distances that we have not yet succeeded in following to the end. The life cycle of all the ants has not been definitely determined as yet, but " queens" have been kept as long as seven years and workers for three or four. The food of ants is variable, - sometimes animal, sometimes vegetable, and quite usually both. The same species may feed upon fragments of insects and other animal matter, and also upon plant tissue of various kinds. They are usually fond of liquid food, especially if it is sweet, and some species gather and store honey like the bees, although in quite a different manner. In the more temperate parts of the United States ants are only indirectly injurious, although they are never beneficial. There is quite a common belief that ants destroy the plant-lice among which they are frequently found; but this is exactly contrary to the fact, for plant-lice play a very important and curious 
part in the economy of certain species of ants. As we learnt in the chapter on plant-lice, these insects are furnished with a pair of honey-tubes near the end of the abdomen, through which there is excreted a sweet, almost transparent, liquid, of which the ants are very foud. In many cases aphids live on the roots of plants during the whole or a part of their life, and such species are in nearly every instance carefully tended by ants. We may find, on lifting up a large stone at the foot of a tree near the edge of a wood, that all the little rootlets covered by it are clustered as thickly as possible with plant-lice, and that around them the earth has been carefully tunnelled out; in other words, we have the roots forming part of the nest system of an ant colony. As the plant-lice increase in number, additional roots are laid bare, and the young are transported to them that they may always find an abundance of food. In return, the ants, whenever the desire seizes them, call upon one or more of the aphids, and, by touching them with their antennæ, induce them to give up a drop or two of their sweet secretion. Exactly how large a proportion of the food of the ant colony this kind of material forms is yet undetermined; but certain it is that plant-lice constitute a very important element in the supply of some species, and fully represent our cattle for all ant purposes.

Little brown ants about three-sixteenths of an inch in length occur very abundantly in the fields throughout almost all parts of our country, building small underground nests. These ants belong usually to the grenus Lasius, and may be found, especially early in the year, on the leaves of all sorts of plants infested by aphids. In melon and sweet potato fields they are often extremely abundant, and it is more than likely that they are active in transporting from one plant to another the lice infesting these particular crops. Of the Lasius brunneus, we know that it tends the corn-root louse, gathering the young larva in the fall and preserving them during the winter safe beyond the reach of any natural enemies, colonizing them in spring upon the roots of corn plants. Inclirectly, therefore, these ants are decidedly injurious through their relation to the plant-lice. Other species gather plant-lice eggs and care for them during the winter, colonizing the young upon proper food plants in spring.

We find certain other species making their hills in our lawns 
and gardens, or in grass-plots, and they are sometimes decidedly troublesome in such localities. Where this occurs, there is nothing better for getting rid of them than bisulphide of carbon. Pour a quantity into each of the openings of the disk or hill, closing them up by stepping on each as it is treated. The fumes will penetrate the chambers in every direction, and if a sufficient amount has been used, will kill not only all the adults, but all larvæ as well. A single application is usually all that is necessary ; but in a very large colony it may sometimes happen that the farther chambers are not reached by the fumes, and that the nest reappears near by ; rarely in the old spot. When that occurs, a second treatment is tolerably certain to be effective. It has been recommended that, to get the best results, holes be poked with a stick into different parts of the hill, but I have not found this of any great advantage. It has also been recommended that, after pouring a considerable quantity-say three or four ounces -into the main opening of the nest, the vapor be exploded by means of a match held at the end of a stick. When this is done the nest is completely wrecked, and the poisonous vapor is forced to every portion of the galleries, so that escape is almost impossible ; while larve and pupæe are buried so thoroughly that they can never make their way to the surface, even if not killed by the fumes. This is a very good method where a large nest is to be dealt with ; but whoever attempts it must remember that the vapor of the bisulphide is exceedingly inflammable, and must make certain that he is far enough from the opening of the nest to prevent being caught by the flash. Ants are never desirable in a cultivated field; they have no business there, and are certainly of no benefit to the farmer, even if they do not directly feed upon plant tissue.

Wherever the corn-root louse is injurious, late fall ploughing should be practised to destroy the nests of the ants. If the ploughing be done before the ants have gone into winter-quarters, they will either build a new nest sufficient for their purpose, or will move with their belongings to a spot in which they are able to winter; so no good will be accomplished. If the ploughing be deferred until frosty nights and cool days discourage activity, the ants will be unable to repair damages, or will not have sufficient time to re-establish themselves before they become torpid. 
The ploughing should be deep and as thoroughly done as possible, so as to not only disturb and break up the nests completely, but to scatter the plant-lice, eggs, or other material that the ants may have gathered. By this simple meams injury may frequently be prevented during the year following.

Incidentally it has been mentioned that some species of ants gather honey and store it ; and, curiously enough, instead of building cells for its reception, as clo the bees, a special form of

FIG. 45I.
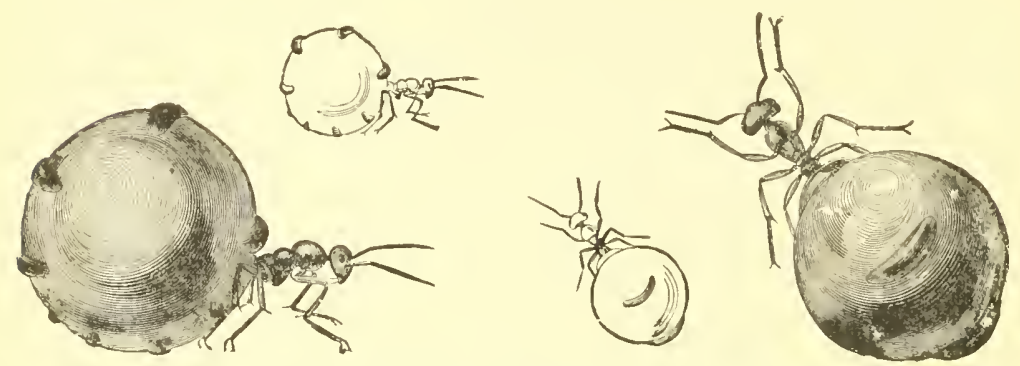

Honey-ants, Mrmecocystus melliger, filled with honey.

worker is developed, with an unusually elastic crop and abdomen. These specimens are simply stuffed by the other workers until they become of the size of a small cherry, utterly helpless and incapable of motion. In this conclition they cling to the walls of the nest until, in the course of time, their stock is used up, when they again resume activity.

Three of the other ant fanilies to which reference has been made contain no species of particular interest to the farmer, however interesting they may be to the student.

But in the family l/ymicide we again find species that are numerous and of more or less importance to man. Here the petiole of the abdomen is two-jointerl, differing thus from the other important family, Fomicida. Nany of the species have the sting well developed in workers and "queens," and are formidable creatures by reason of this weapon ; but not all our forms are so furnished, as is known by those who have suffered from an invasion of small red ants in houses. This little creature, llonomorizm pharaonis, sometimes occurs in myriads, and nothing is 
safe from it. Sugar is especially attractive, but almost anything is attacked, nothing more readily than a bone from which the meat has been roughly scraped, and which is yet a little bloody. It seems impossible to get rid of these creatures, because they avoid poisoned food and anything that has the appearance of a trap. A few specimens may be killed, but very soon the character of the mixture is recognized, and it is left untouched. "Insect-powder"' - pyrethrum - is effective, but it is practically impossible to get it everywhere, and the ants simply avoid it. Carbolic acid and naphthalene are both useful as repellents: the insects dislike the odors intensely, and will not approach these materials; but while certain closets may Fig. 452. be protected in that way, the odors are not particularly desirable near food products, and are as repugnant to many persons as they can possibly be to the ants themselves. The simplest method, perhaps, is mechanical destruction, as follows: Where meat is used every day, the bones, or some of them, should be cut out before it is cooked and placed in a main line of insect travel. When they become thorouglnly covered with hundreds or even thousands of ants, the whole mass should be thrown into the fire. If this process is repeated two or three times a day, a few days in succession, the ants seem to be seized with a panic, and usually abandon the house completely. Instead of bones, a sponge dipped in sugar water and loosely pressed out may be used; or, better yet, there should be two sponges. The sweetened one should be placed where the ants run, and the news of its presence will spread throughunt the entire house in a remarkably short time. When the first sponge is entirely filled with ants, the second should be prepared in the same way to replace the first, which is to be taken up and put into boiling water. This destroys the insects at once, and the sponge can be washed out, again dipped in the sugar water, and used to replace sponge number two when that is filled with insects. Here the same effect is obtained: the insects are seized with terror, and seem to realize the presence of a force that they do not understand. The sudden lessening of their numbers 
strikes them with such horror that they abandon not only their nest but the house itself. I have myself used this method on two occasions, and have recommended it frequently to others; in every case with the best results.

To this family belong the so-called "agricultural ants" of Texas and the Southwest, some species also occurring in Florida and other parts of the Sonthern United States. These build immense molergronnd nests, and keep on the surface a cleared space varying in diameter according to the size of the colony. They cultivate grasses on these plots, of the seeds of which they are especially fond, and which they store in their galleries. Their food, in fact, consists mainly of seeds of various descriptions, and these they gather from whatever plants there may be in the vicinity. The insects are very abundant in some localities and are great muisances in cultivated fields, not so much from what they actually destroy by cating, but from the fact that they tolerate nothing in their vicinity except what suits them. They have no particular use for corn or cotton, and ruthlessly cut down every stalk that encroaches on their domain. The only substance that has been employed against them with any degree of success is bisulphide of carbon, and this should be used in quantities depending upon the size of the nest. In these cases the vapor should be exploded in order to produce the best results. The nests extend for so long a distance underground that the insects will not be reached otherwise, and when the material has entirely evaporated, the galleries are again useful to them. On the other hand, the explosion shatters the entire nest, and the insects that escape in remote galleries are not likely to start again on the same soil, unless the queen also has escaped. It has been already indicated that such a nest is a complicated oramization. It contains not only its owners with all their races and castes, but frequently also slaves, - other species of ants that have been conquered and stolen while in the larval or pupal state, and which now perform all or a great portion of the manual labor of the colonies. It often contains also not only plant-lice, but coccids, which are cared for in the same way, and occasionally other species of Homoptera, such as tree-hoppers. We find, in addition, numerous species of insects that seem to take the part of guests. Some of these are scavengers, and they evi- 
dently keep the nest clean and remove decaying particles; others may be of some use to the ants by excreting certain sweet substances which induce their toleration; while yet others have no use at all, so far as we can discover. Such are certain crickets which are always found associated with ants, and certain caterpillars. What functions these insects have in the ant-lills is as yet somewhat obscure.

In the tropics there are species that occasionally change their camps, and are known as foraging ants. When the whim seizes, or unknown causes determine them, they leave their nest, bag and baggage, attended by all the insects that lived with them, and start upon a march straight forward, destroying everything that attempts to prevent their passage. A house or a village is no barrier; they pass through or over it, destroy every living thing it contains, and devour all the provisions. The inhabitants of countries subject to these foraging expeditions soon learn to recognize their character, and immediately seek safety in flight. The ants continue their march, and soon the house or village can be reoccupied, with the certainty that, if all the provisions have been cleared out, so also have all the vermin : rats, mice, snakes, roaches, and similar creatures being all killed and eaten.

The battles of ants have been described by more than one author; but as this is the function of another kind of work, nothing more will be said here about these very interesting creatures.

Next in the orderly series come the Fossores, or " cliggerwasps." Here the two normal sexes only are developed, and they are solitary, - that is, they never form communities. They often build their nests underground, preferring sandy spots; but the families vary much in this respect. The females are always provided with a sting, which they use on slight provocation, and they differ from the next family of true wasps by having the wings always flattened and never longitudinally folded in repose. Sometimes, instead of burrowing underground to form their cells, they use the stems of pithy plants like alder and sumach, and often nests are built of mud, in sheltered localities against houses, barns, or other convenient places, or even attached to twigs or shrubs, 
Uccasionally we fund, rumning on sandy spots, an insect that looks like a large ant, very prettily colored and banded with bright scarlet and black, rusty red or mottled yellow. If one of these apparent ants be picked up, the result

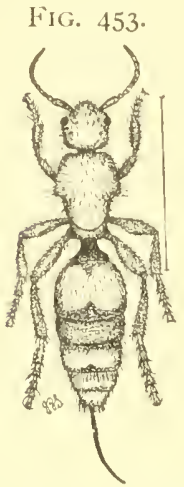

A velvet ant, Sphar. ophthalma acciden. Lalis. is usually a surprise in the form of an enormously long sting, for we really have a wingless " digger-wasp," which from its appearance and habits has been called a "velvet ant." Just what the breeding habits of these Mutillidee are is not known, but they are supposed to be parasites, or at least to lay their eggs in the nests of other species of Hymenoptera. There is considerable difference between the sexes, and the males are winged even when the fenales are wingless, the wings being usually blackish in color.

Another series of "diggers" belongs to the fanily Scoliida, and these may often be seen quite early in the spring, flying close to the surface of the ground, with a buzzing noise. Often they are found visiting flowers, particularly the males, which are sometimes quite abundant when raspberries are in bloom. These in-

Fig. 454 .
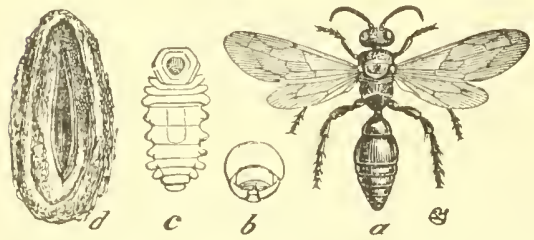

White-grub parasite, Tiphia inurnata- $a$, imago; $b$, head of larva; $c$, larva; $d$, cocoon. sects, so far as we know their habits, lay their eggs in underground larvæ, which are then devoured by the young of the wasp. The common "white grub," the larva of Lach nostema, is subject to the attacks of one of these species, Tiphia inomata, a black wasp, rather sparingly clothed with fine white hair, and sometimes attaining the length of three-fourths of an inch; and there are others that attack our injurious underground species of all orders.

In the family Pompilide we have a series of rather stout, black forms, quite frequently banded with red on the abdomen. while sometimes the entire insects are more or less red. They 
usually have a velvety appearance, or look as if they were covered with a whitish bloom, and the wings are also either black or yellow, like the prevailing colors of the body. They lay their eggs in spiders, which they bury, and in which the larvæ develop. Perhaps this is a good place to mention the fact that these digger-wasps make use of their stings and the poison se-

FIG. 455 .

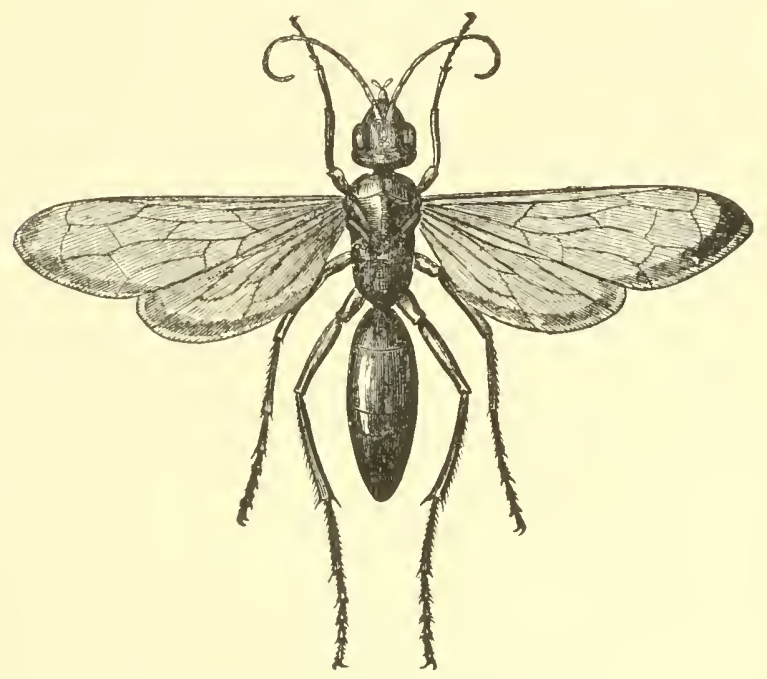

Pepsis formosus, tarantula-hawk.

creted by them for preserving from decay and in a conditior suitable as food for their young the larvæ, spiders, and other insects upon which they feed. They sting their prey very carefully, in such a way as to paralyze and render it motionless, while yet it does not die; and the larvæ, when they hatch, begir feeding very carefully, so as not to kill their host until they them selves are sufficiently developed. The poison introduced seems to simply suspend life, or rather allows it to go on without a waste of tissue. Spiders of all kinds are attacked, and even the fierce tarantula of the South and Southwest has its enemy in an enormous species of Pepsis known as the " tarantula-hawk."

Perhaps the most common forms belonging to this series are those in which the abdomen ends in a small bulb-like structure 
connected with the thorax by means of a long stalk or pedicel. These belong to the family Sphcida, of which the majority build their nests underground and provision them with spiders, caterpillars, or other larvæ. Others, known as "mud-daubers," species of Pelopcus, plaster their nests against out-houses, in all

Fic. 456 .

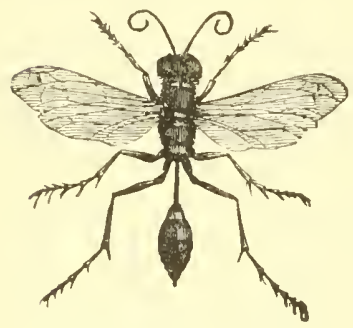

A mud-dauber, Peloparus species. sorts of corners and under all sorts of shelters. They are sometimes built singly, but usually in groups, and may consist of either a shapeless mass of mud, or may be regularly arranged, often with ribbed sides. The insects that build these nests are either metallic blue, or black marked with yellow, and here the pedicel connecting the abdomen with the thorax is unusually long and slender. The mud is carried by the insect with its forelegs and jaws, and is applied carefully, pellet by pellet, to the nest, until the cells are completed. Then they are stored with some one kind of insect as food for the larva. If the insect begins on caterpillars, it continues to collect caterpillars, all of the same species, stinging, as already described, so as to paralyze them, and then packs them away in the cavity as closely as possible. Finally, when a cell is full, an egg is introduced; and now, when the young wasp hatches, it finds food in abundance at hand, and simply lives upon chis supply, taking one caterpillar after another, or one spider after another, as the case may be. Some small species store their nests with plant-lice. These insects are to be considered as decidedly beneficial, and if the nests are sometimes unsightly and the wasps themselves a nuisance, yet, taken all in all, they deserve encouragement. The number of caterpillars destroyed by them in the course of a season is enormous. I have counted thirty canker-worms in a single cell, and have sometimes opened nests in which there were an even greater number of small Tortricid caterpillars. Any insects which destroy as many caterpillars as do these wasps deserve our best consideration and should not be wantonly destroyed. Another peculiarity to be noticed in opening the nests is, that the insects, whether caterpillars or spiders, are all of just about the same size, as if the mother had 
exercised great care in portioning out the food to the best advantage. The adults may often be found on flowers, and when the golden-rod is in bloom in late summer, some of our largest and most attractive species, like Sphex ichneumonea, make their appearance in great abundance.

The allied "diggers" belonging to the Larrida have the abdomen more closely joined to the thorax, and provision their nests, which are made underground, with small grasshoppers. The insects are not nearly so common or so numerous in species as those previously mentioned, and are chiefly inhabitants of the more southern States.

In the Bembecida we have many large, brightly colored species, some of which prey upon cicadas, stinging so as to render them helpless, and carrying them off to their nests as provision for their young. It is interesting to watch a specimen of Sphecius speciosus when it has a large cicada to be transported. If the insect is captured and paralyzed upon a tree, the wasp drags it along the branch to some convenient point, and from it flies as directly as possible towards its nest. Sometimes its strength is not sufficient to sustain the weight, and then it is drawn gradually to the ground. In such case it again drags the insect to the top of some convenient shrub or tree, and makes another effort, again flying as far as possible before allowing itself

FIG. 457 .

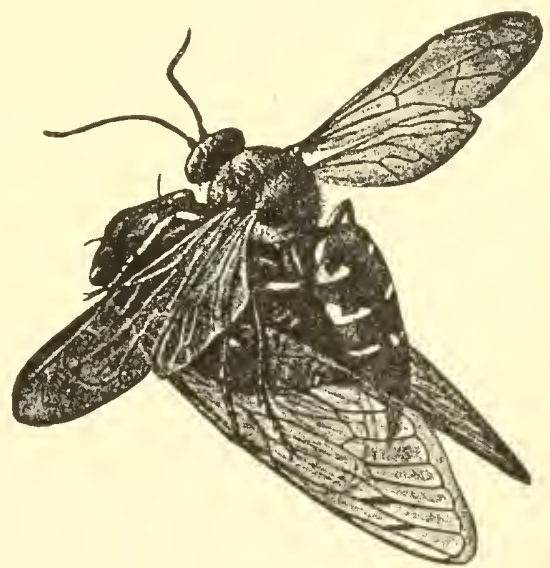

Sphecius speciosus carrying a cicada to its home. to be pulled down, but always arranging matters so that it is able to make a new start from an eminence. In other words, the wasp is often unable to lift the cicada from the ground in direct flight, but is able to drag it to an elevation sufficiently great to fly a considerable distance before being drawn to the ground, and in this way, after a time, it manages to reach its nest. These Bembecids 
are equite numerous, and the abdomen is conical in shape, connected with the thorax by a very short and slender neck, or peelicel, more resembling the true wasps than any other of the species that we have been considering.

There are several other families with similar habits, differing in appearance to some extent, and varying in the character of the insects used in storing their nests. Among the fimilies containing the smaller species we find those types that burrow in pithy plants and prefer small insects for provisioning their nests:flies, plant-lice, and small spiders being the most usual supplies.

Taken as a whole, all the digger-wasps are useful insects, and they require for food, in the conrse of a season, a very large number oi specimens injurious to plant-life.

The "true wasps," or lespida, are distinguished from the " diggers" by the fact that the fore-wings are folded longitudinally" when at rest, and this is a character easily seen and quite distinctive. We have among them solitary and social forms, - the solitary types so called beciuse only the two nomal sexes are present, and because they lo not hive in colonies. There is a great variation in habit, and we find species that bore in woody tissne, some that inlabit pithy plants, some that burrow in the earth, and

Fig. 460 .
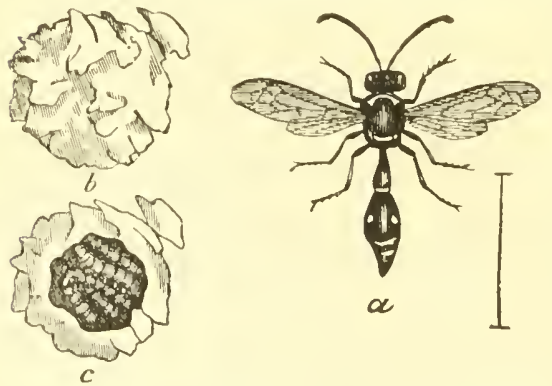

Fraterual polter-wasp, Eumines fraterna. $-a$, wasp : $b$, it cell; $c$, same broken open to show the cacerpillars stored in it. others that make mud nests. The mud nests vary in form and are often quite pretty, those of Eumenes resembling a jug or vase attached to the twigs and stems of plints. It is not always possible to distinguish between the cells and nests of the diggers and those of the true wasps, and practically it is a matter of no importance, beciuse the habits of the insects are similar, - that is, they store their cells with insects upon which their larva feel. All solitary wasps are beneficial, therefore, and should be encouraged by the farmer. 
Fis. $45 \mathrm{~S}$
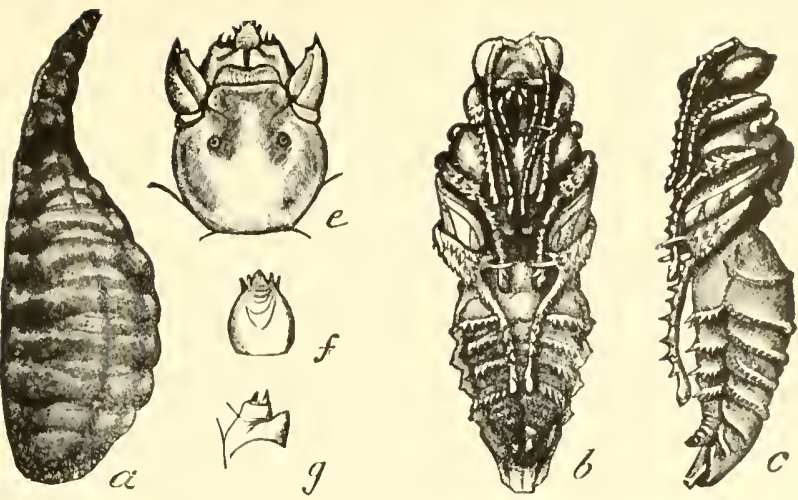

FII. 459 .

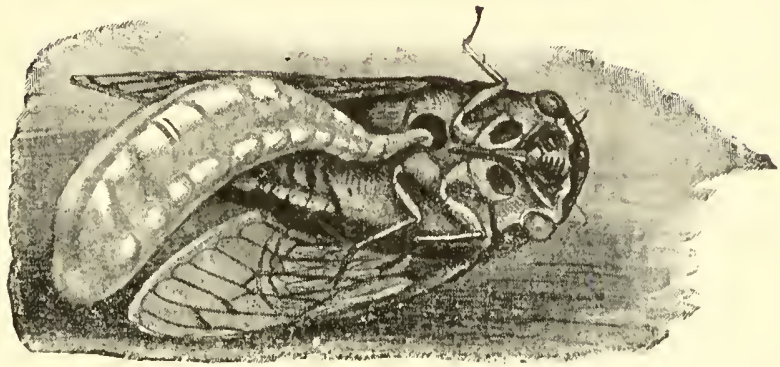

Fig. 461.

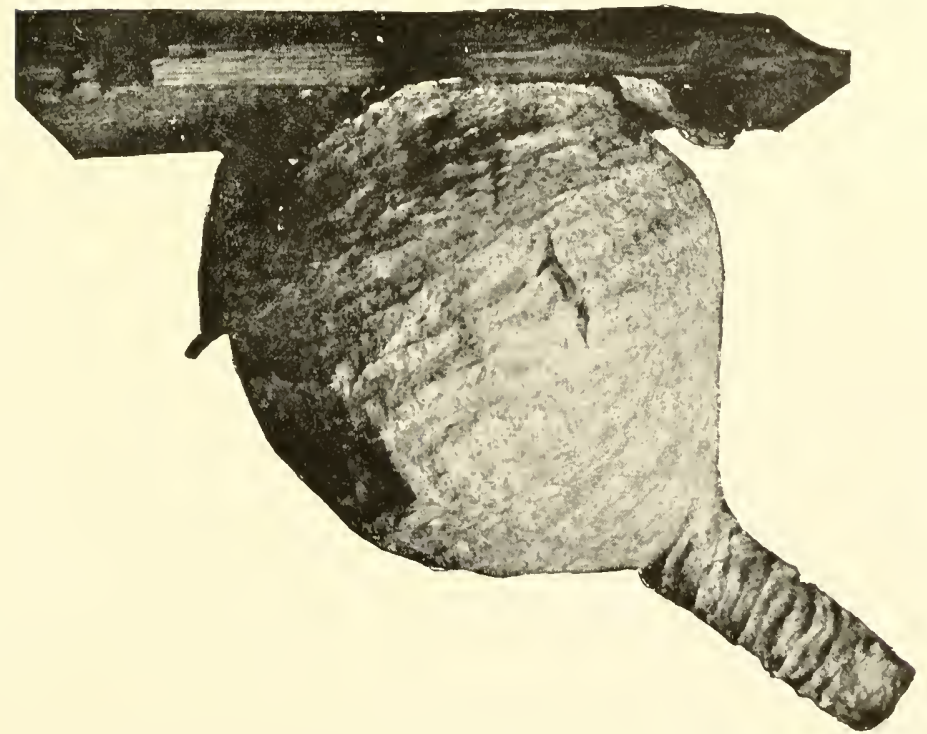

Fig. 459, $a$, tarva; $b, c$, pupa, from beneath aud sisle: $e, f, g$, structural details, of Sphecius speciosus, Fig. 459, larva of Sphecius speciosus feeding on cicada in its under. ground burrow. Fig. 46r, nest of lespa maculata, just started. 

In the social wasps we find a step towards the organization found in a beehive, sometimes well and sometimes very poorly marked; but in all cases, besides typical males and females, there is a worker caste, which, as in the ants and bees, is composed of sexually undeveloped females. Briefly stated, the history of these wasps is about as follows: Males and females appear in fall; the females are impregnated and live through the winter in such shelter as they are able to find; in the spring, with the approach of warm weather and the opening of the flowers, the females revive, and at once begin reproducing their kind. They start a small nest of only a few cells, and lay eggs in them as soon as they are well started. In a few days the larva hatch; the female increases the size of the cells and adds to them, and to her other duties is now added the care of the newly hatched young, which must be fed and tended daily. In three or four weeks the first larva become full-grown, and the cells are then capped by the mother. In this closed cavity the change to the pupa takes place, and in due time an adult appears. This adult is a worker, or undeveloped female, and at once begins to help the original mother in the work of attending to the brood and increasing the size of the nest. Until midsummer, at least, workers only are produced; but then, when the brood of workers is sufficient to relieve the stem mother of all necessity for labor, eggs are laid that produce sexually complete forms, - males and females, - which generally issue during the first days of September. The old female now dies, and when cold weather sets in the workers and males also succumb, leaving only the impregnated new females to live through the inclement season. Of course there are many modifications of this general life history, and some colonies become very much larger than others. In some instances the cells seem to be used over and over again, and no more are manufactured than is necessary to accommodate the brood. In other instances it seems as if the cells are used only once, and new ones are built for each individual larva. The locality in which the nests are built also varies, although the general character of the comb, or cell, is nearly always the same. As a home, some species, like the "yellow-jackets," select a little cavity underground; some, like the giant l'espa crabro, a hollow tree; some a favorable spot among the branches. Others build un- 
protected combs in the shelter of a projecting ledge of rock, or under the eaves of houses, or even under fence boards; while yet others build their globe-shaped structures openly upon bushes, and these are usually termed "hornets." The material of which the nest is composed is a sort of wood-pulp paper. The insect scrapes a small bit of wood-fibre from an exposed surface, mixes it with saliva, kneads it into shape, and then, by means of the mandibles and forelegs, spreads it in a thin layer and attaches it to the surface at which the nest is to be started. Lilyer after layer of fibre is added in this way until the nest is completed.

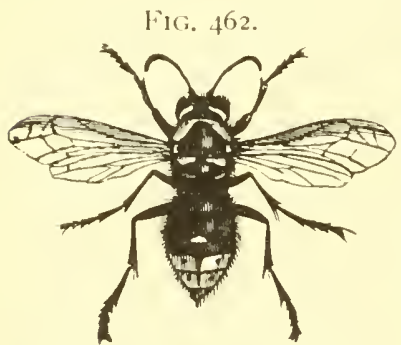

White-faced wasp, lespa maculata.

The enormous structures made by the "white-faced" wasp, l'espa maculata, are excellent examples of what can be accomplished by numbers and persistence. As to feeding habits, these social wasps are usually predaceous, but they are also fond of sweets, and may often be found on flowers, gathering honey, or on ripe fruits, sucking their juices. We also find them occasionally in butcher-shops, and they have a fondness for chewing into raw meat and lapping the blood. They feed their larvæ honey and other plant juices, and also the masticated fragments of insects. That is to say, they prepare the animal food by first chewing into a pulp before feeding it.

Two types of these wasps are common throughout the United States, - the first rather slender, with a spindle-shaped abdomen, and usually a more or less red-brown color, often marked with yellow. These belong to the genus Polistes, and the build their paper combs openly, -that is, without any covering, and suspended by a single, short, central stalk. The colonies rarely become very large, but they are very numerous in most parts of the country.

The true "wasps," or members of the genus Vespa, have the abdomen cylindrical, squarely cut off where it joins the thorax, and are very often contrastingly marked with white or yellow, occasionally with red or brown on a black ground. These are the "hornets" and "yellow-jackets," and their colonies some- 
times become of enormous size, many hundreds of individuals being found in a single nest in the latter part of the season. Durability is not looked for by the insects, and the winter storms and snows disintegrate the paper structures, so that in spring it is rarely possible to find them, however abundant they may have been during the summer previous.

Wasps are beneficial, as a whole, since they feed largely upon other insects and never directly upon crops. They are a nui-

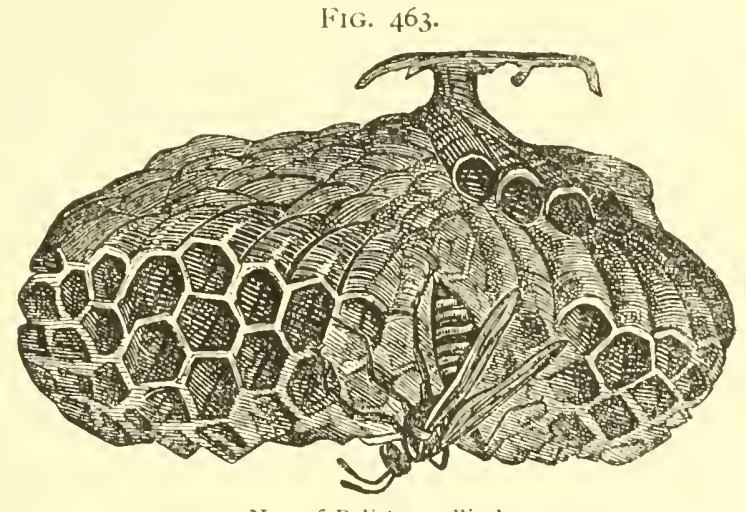

Nest of Polistes gallicola.

sance sometimes in the orchard, where they are apt to attack all fruits that show the least trace of injury or decay, and they have been accused, as, indeed, have the bees as well, of actually puncturing juicy specimens to get at the liquid contained in them. Some of the species are undoubtedly useful in pollenizing fruit flowers, but there are none of pre-eminent advantage in this direction.

The last family in the order contains the bees, and these, as in the wasps, may be either social or solitary. The solitary bees are those in which male and female only are developed, and their habits in nest-building resemble in many cases those of the wasps. Thus, we have species that build in the ground, those that make cells in the pith of plants, others that are true carpenters and bore tumnels in solid wood, and, in short, we may find bee homes in much the same situation that we find wasp domiciles. Their cells may be distinguished, however, in all cases by 
the fact that they are stored with a mixture of pollen and honey, or honey or pollen alone, instead of with insects, and it is this habit of collecting pollen that makes the bees so highly useful to the farmer, by their incidentally pollenizing the flowers from which the material is gathered. There are several interesting structural modifications in the bees to facilitate the work of gathering both pollen and honey, and, incictentally, of accomplishing pollination to the best advantage. Thus, the clothing, insteact of being composed of simple cylindrical processes, is composed, in large part, at least, of bristly, plumose or twisted hair,-that is to say, each hair is furnished with little spurs, or long, slender branches, making it resemble a plume uncler the microscope. Or it may be twisted like a screw, or furnished with a knob at the tip. The result is, that as the insects move over the flowers, the pollen grains adhere to the vestiture. and this also accounts for the fact, probably noticel by every observant fruit-grower, that bees frequently bury themselves completely in the blossoms, or roll over every part of them. Such insects are after pollen, not honey, and by so rolling about the pollen grains are brought into contact with and adhere to the surface of the insect. Incidentally, also, as soon as the bee flies from one flower to another, and repeats this operation, a sufficient number of pollen grains from the first flower adhere to the stigma of the second and pollenize it; while in flying from one tree to another, cross-pollination is accomplished. The flowers visited in this way by a single bee are very numerous. When a honeybee becomes more or less covered with pollen, it cleans itself by means of specialized structures on the legs, which enable it to literally comb out its entire body covering. The masses of pollen gathered in that way are then rolled into a lump and fistened to the upper side of the posterior tibia, where lateral fringes of long hair hold it in place and actually form a baskct. These combing arrangements are situated on the first joint of the hind tarsi, which is broadened for that purpose in the social bees, and is usually much longer than the other tarsal segmenti. Some bees have pollen baskets not only on the tibia, but on the femur and coxa as well, and occasionally the whole posterior portion of the thorax and the space between the thorax and abdomen is utilized to store the pollen masses. Sometimes the under side of 
FIG. 464.
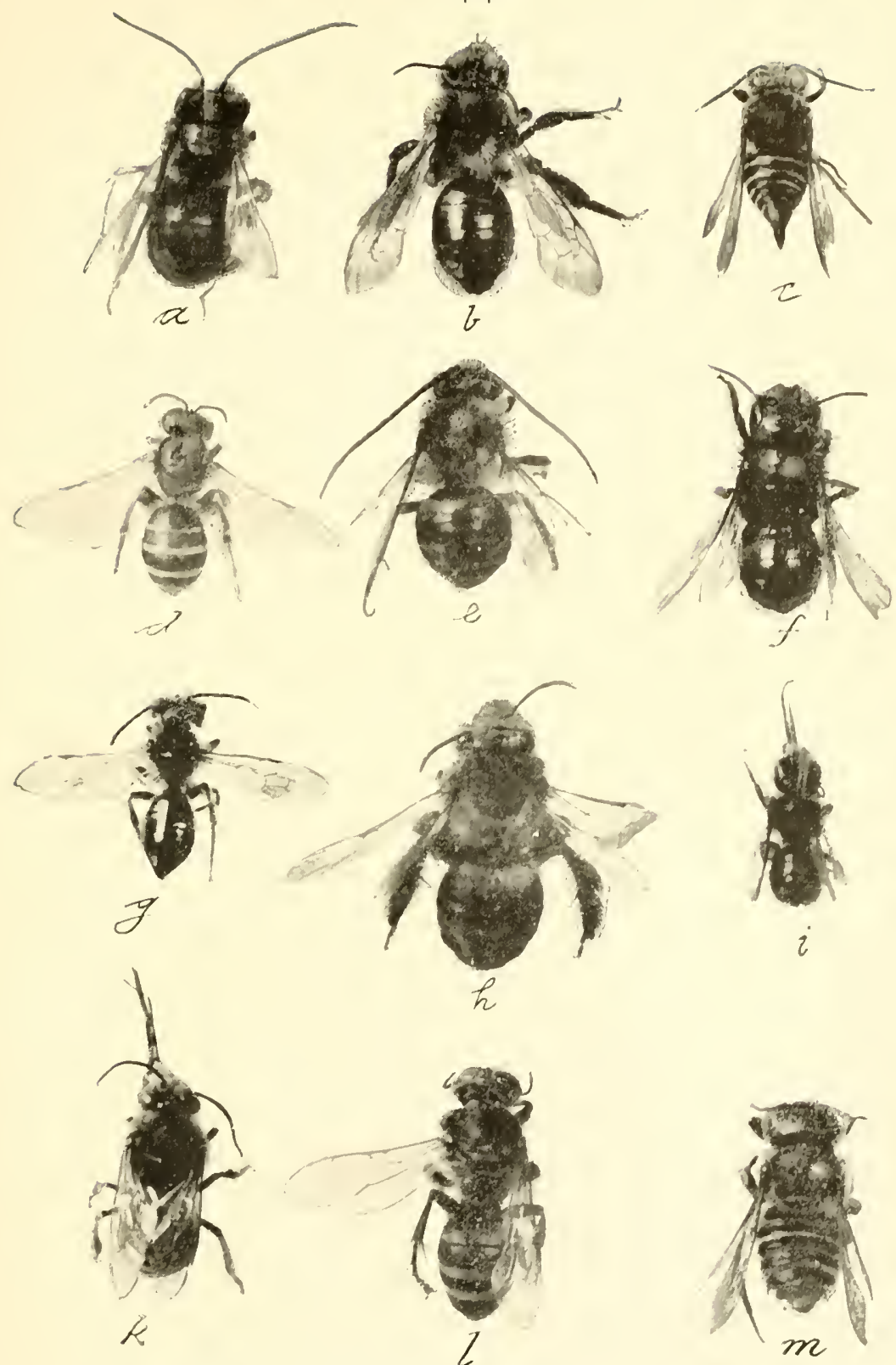

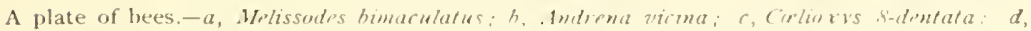

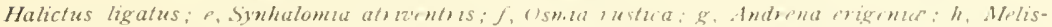
sodes nigripes; $i$, Megachile mendica; $h$, lenoglossa pruma; l, Tachvtes mandibularis; m, Megachile latimanus. All rather more than twice natural size. 

3) 9

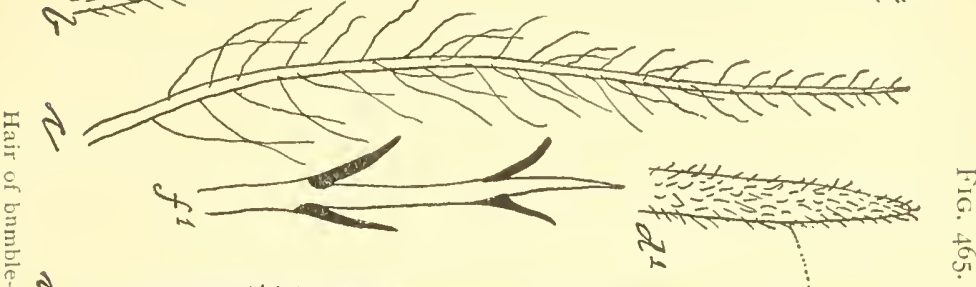

ก ب़

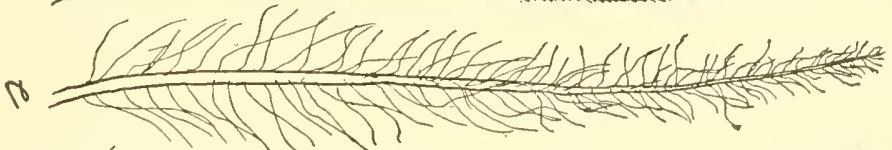
$h=\frac{12}{12}$

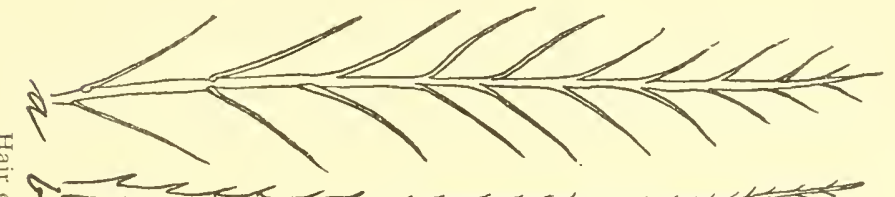

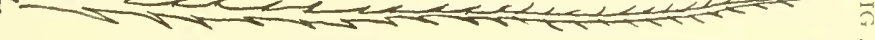

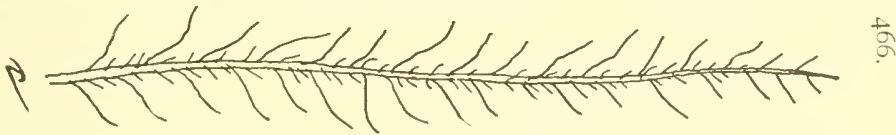
\&

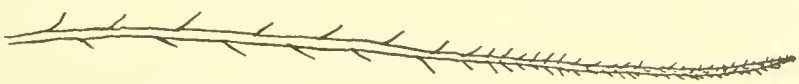

ঐ

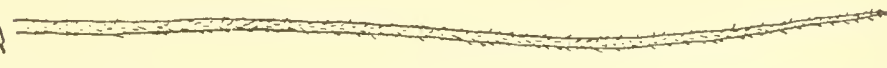

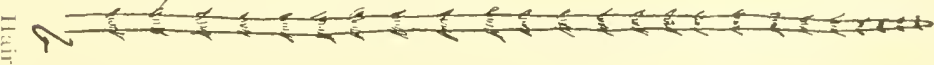
용
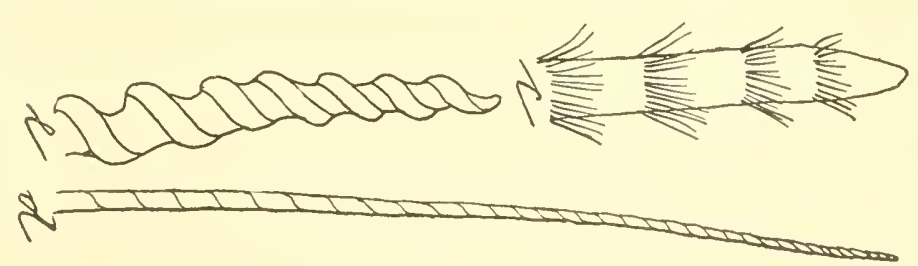
the abdomen contains the pollen-gathering structure, - that is to say, the segments of the abdomen are furnished with brushes of long, twisted or knobbed hair, and all the pollen gathered by the

Fig. 468 .
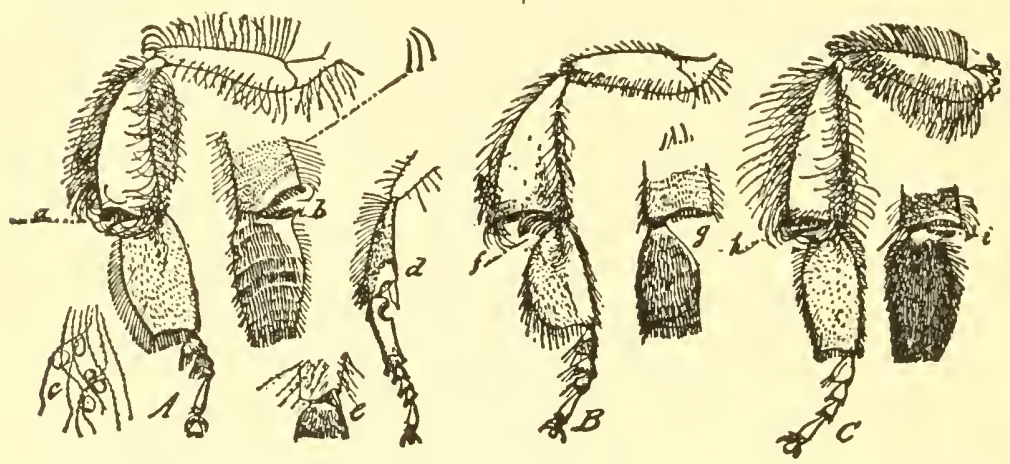

Mulifications of the hind legs of different bees.-A, Apis: a, wax cutter and outer view of leg; $b$, inner aspect of wax cutter and leg; $c$, compound hairs; $d$, anterior leg, showing antennal scraper. $B$, Melipona: $f$, peculiar group of spines at apex of tibia: $g$, inner aspect of wax cutters and first joint of tarsus. $C$, Bombus: $h$, wax cutter; $i$, inner view of same and first joint of tarsus; all enlarged.

insect is stored among it, ready for transportation to the nest. Pollen, however, forms only one portion of the food of the larva, and it must be mixed with honey to form "bee bread" of a proper

F1r. 460 .

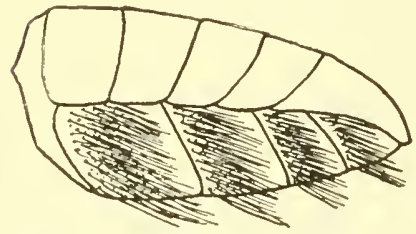

Abdomen of Megachile fitted for gathering pollen. composition. This honey is also gathered from flowers, and the mouth parts are modified to this especial end.

We have two series of bees distinguished by the character of the mouth parts, - the short-tongued and the long-tongued,-both of which may be either solitary or social. The short-tongued bees have the lower lip modified into a bladder-like structure, more or less pointed at the tip, and set with regular rows of short hair or flattened processes, an ideal tongue for gathering up the liquid nectar and bringing it into the mouth. Many of these bees are diggers, and build their nests in the ground, usually forming a single vertical burrow from which lateral branches diverge into 
small cells, each containing a supply of food sufficient for a single larva. The mother bee constructs a cell, fills it with a mixture of pollen and honey, and lays an egg in it. Then she closes up the chamber, and her work as to this particular larva is completed. When the egg hatches, the larva finds a food supply immediately at hand sufficient to bring it to maturity. When it is fully grown it changes to a pupa, and eventually to an adult, which then makes its way from the earthen home into the sunlight. The mother bee having completed one cell, at once begins the construction of another, and thus the work is continued until the supply of eggs is exhausted. The open face of sand- or clay-banks is a favorite place for these insects, and sometimes they build their nests together in great numbers.

The long-tongued bees are so called because the ligula or glossa is extended into a flexible ribbonlike structure, ringed but not segmented, set with circles of long hair, and frequently tipped with a little button-like structure. This enables the insect to reach the honey in deep flowers like the clovers, and in fact there are only certain bumble-bees with a tongue long enough to reach the nectaries of the red clover flowers; hence

Fig. 470

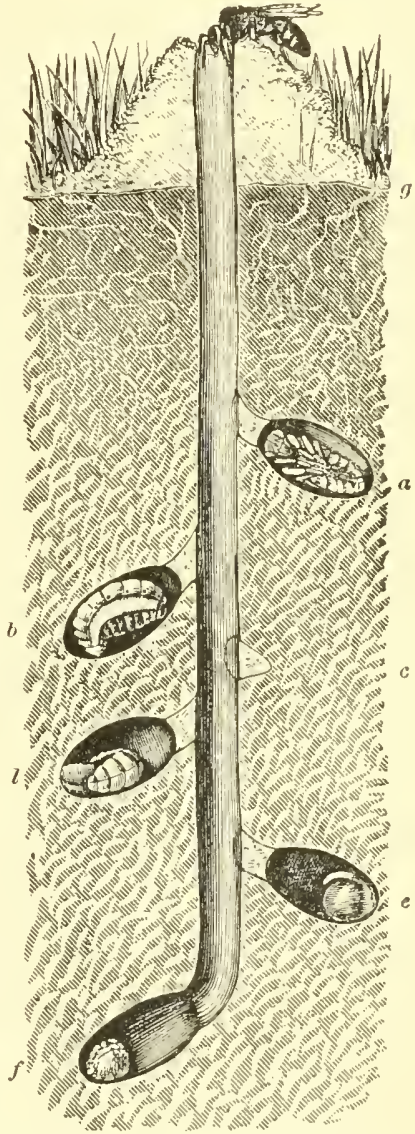

Burrow of Andrena, show ing cells it order of completion; the lirst at $a$, the last at $f$, in which an egg has just been laid.

they are entirely dependent upon these for pollination. Destroy the bumble-bees, and no red clover-seed can be obtained. It is a suggestive fact that in many localities where ruthless war is waged 
against bumble-bees, it is becoming increasingly difficult to obtain clover-secel, and for this particular purpose those insects should be curcfully cherished. They are sometimes a nuisance when in the course of mowing or reaping a nest is clisturbed, but the slight annoyance then caused scarcely warrants the complete destruction of the nest which so uniformly follows. The farmer who destroys every nest of bumble-bees on his land destroys a series of insects than which none are more useful to him, particularly if he raises fruit or has any desire to obtain red clover-seed.

The long-tongued bees may be either social or solitary, and there is no superficial character known to me by which the solitary bees can be readily distinguished from the social forms, except by the presence of the wax-producing organs in the latter. The habits of the bees differ greatly: some are cuckoos, some have been supposed to be parasitic, while the majority are undoubtedly honest workers and provide decently for their families. Nany of them, as has been already stated, are carpenters, and some of them are tailors or upholsterers as well, - that is to say, after having bored out the wooden tunnel in which the family is to be raised, the cells are constructed of leaf fragments. Rose leaves or those of other plants of the family Rosacca are frequently noticed with circular or semicircular pieces cut from the edges. This is done by a bee of this tribe, usually a Megachile, and these little fragments are used in constructing a somewhat thimble shaped cell. When one of them is completed it is filled with pollen and honey and an egg is laid in it ; then another is built on top of it, and so on until the burrow is completely filled. As the undermost specimen matures first, it bores to the surface through a hole at the end, to avoid the necessity of working its way through all its younger relatives above it. The largest of our carpenters is the Xylocopa virginica, which is generally mistaken for a Bombus, being fully as large, as robust, and colored yellow and black, with a metallic blue reflection on the abdomen; but the head is very much broader than in any bumble-bee, and equal to the width of the thorax itself. The eyes also are larger and white or yellowish in color, distinguishing the insect at once from true Bombus. This species makes galleries half an inch in diameter in the solid wood, and raises a considerable family in the course of the year. The partitions between the cells are made in this 

case of little chips of wood cemented together. They are very common and sometimes troublesome where they make their

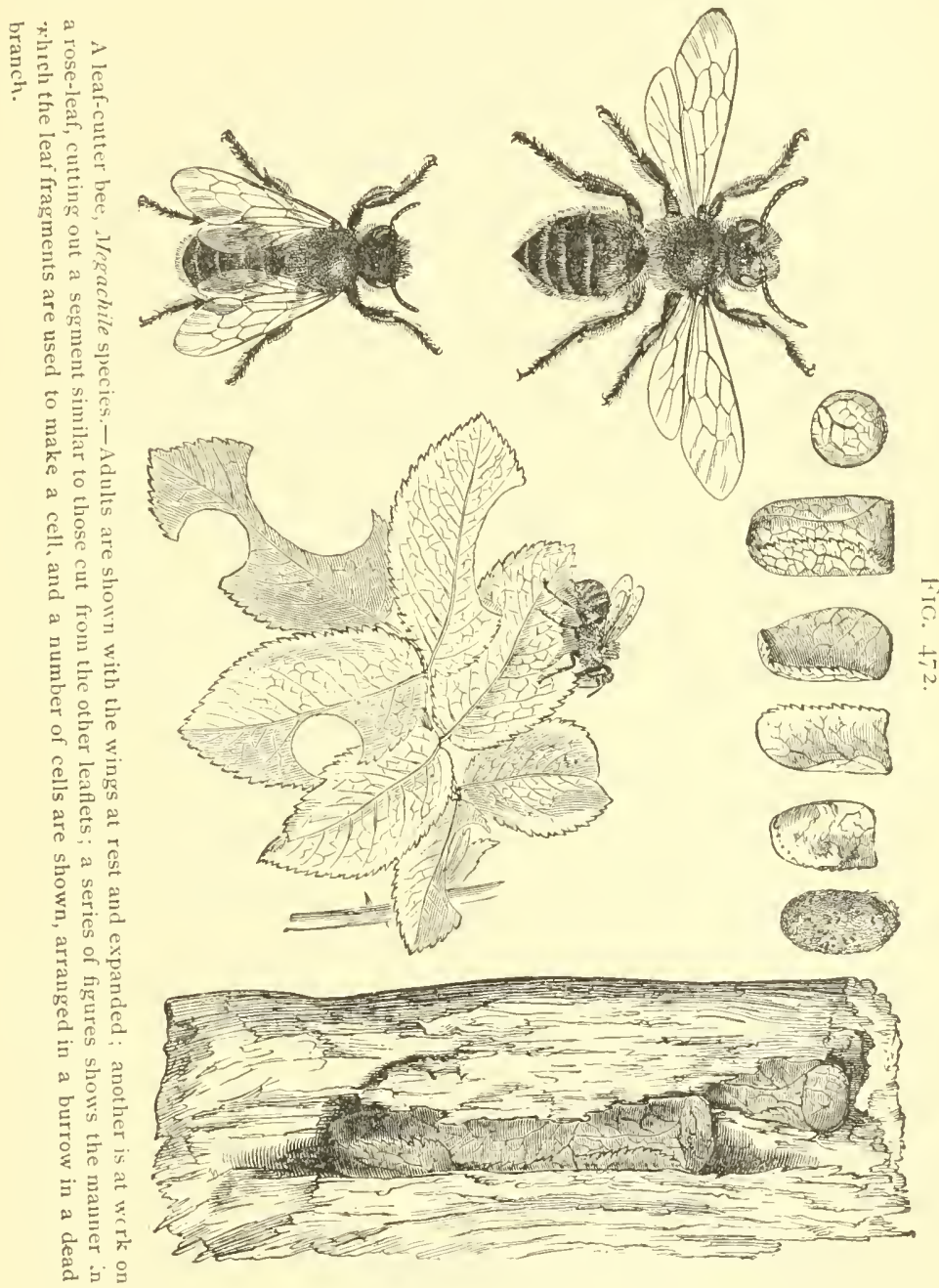

galleries in the wood of piazzas and out-buildings of country houses. Nothing will be gained by giving detailed descriptions of these solitary bees, since their general habits are practically 
alike, and it need only be said that all are useful and none are in any true sense of the word injurious.

The social bees are among the most interesting of all the insects, yielding only to the ants in the perfection of their colonial organization. The domesticated honey-bee, Ipis mellifica, maty be accepted as the type of the highest development in this fimily. Here we have in each hive a cuseen, or fully cleveloped female, who is often, under normal conditions, the mother of every individual contained in it. She dues not labor, is carefully tended by workers who provide for all her wants, and her only function is to supply a sufficient quantity of eggrs for the broodcells. The comb made by the hive-bee is so universally known that no time need be wasted in describing it ; nor is it important to say just how the wax is produced, save to state that it is excreted by special glands on the uncler side of the abdomen of the workers in plate-like masses. These are gathered together, kneaded by the jaws, and placed in position on the comb. These waxen cells are used either as cradles for the young or for storing the honey against such time as no food can be obtained; for, unlike the bees previously spoken of, the whole colony lives through the winter, and requires a certain amount of food to maintain it until work can be resumed the spring following. Of these storing habits man has made use; but there are a number of wild species belonging to other genera than Apis that have similar tendencies. The life in a hive proceeds something as follows: the workers, who are the real rulers, determine about how many young should be raised during the season, and build the proper number of brood-cells, making three distinct sizes. The smaller are intended for workers, which here, as elsewhere in the Ifymenoptera, are simply uncleveloped fomales; the larger are to contain males or drones; while a very few, irregular, somewhat flask-shaped cells are plastered at the sides of the combs, and are intended for new queens or perfect females. The queen lays an egg in each of the brood-cells, and never makes a mistake in its character. She lays drone eggs in the drone cells, and drones only are produced from them. In the worker cells workers only are matured, while in the queen cells fully developed females are raised. It is interesting to note that the insects have the matter of sex under perfect control, and it is believed that 
the eggs producing drones are not fertilized: this matter being under direct volition of the female. The larva are carefully fed by the workers, and each variety receives a different kind of "bread," especially prepared for it. The workers are fed on what seems to be best adapted for them; the drones receive another kind; while the future queens live on a specially prepared product, or "royal food," supposed to be much richer in nitrogenous materials. When the larve are full-grown, the cells are capped and the pupe form insicle of them. In dine time the adults issue, either drones or workers. In the former case they idle about, doing nothing, except to find foot for themselves. In the latter case they at once assume their full share of the duties of the hive, gathering honey or pollen, or attending to whatever else is to be tone. Of course, by this continuous increase the hive soon becomes overeroweled, and then the question arises, Is the colony in condition to stind a swarm? If the store combs are tolerably well supplied, and everything is running smoothly, the question is decided in the affirmative, and arrangements are made to have a portion of the inhabitants leave it. Meanwhile the queen larve have continued to develop, and are now rady to assume the adult form. When this period arrives, the ruler of the hive becomes uneasy, and does her best to get at the queen cells to kill her maturing rivals. If the workers have decided that they neet a swarm, she is kept from doing mischief and they simply block her way. When the new females have issued, every effort is made to prevent a meeting between the young and olel, or even between the young queens, if there is more than one. With the new queen or queens fully developed, and a larger number of workers than can be reatlily accommodated, the members of the hive become uneasy, cease work, anel, from the noise, appear to be holding a caucus, which finally results in a considerable proportion leaving the hive under the leatership of either the oll or one of the new queens. This is a "swarm," and it flies a longer or shorter clistance before it settle's in a solid mass, usually surrounding the queen. If the swarm is not hived at once, the bees sooner or later fincl a hollow tree or other cavity, where they start a colony ; but if the insects are under the care of a proper keeper, the inclications are noted, and when the swarm leaves the hive it is induced to alight near by, 
either through a jet or spray of water directed upon it, or by beating tin pans or making some other noise. When the swarm has settled, the bees can be shaken into a receptacle, and if the queen is contained in the mass, as she usually is, they make themselves at home readily in any hive to which they maty be transferred, especially if it contains a small supply of food or a piece of comb, full or empty. Work is then started at once, and the colony is soon in full swing. From a sound colony there may be several swarms in the course of a season; but if times have been bad and the bees have not increased sufficiently to warrant it, there is no swarming, and nothing is placed in the way of the old queen to prevent her from killing her immature rivals, unless, indeed, the bees decide that she is worn out and incapable of supplying a sufficient quantity of eggs, in which case they permit one or more young queens to come to maturity and let them fight it out. The victress remains queen of the hive, and if it is the young female, the inhabitants transfer their allegiance to her without question, and serve her as faithfilly as they did their original ruler. If by any chance the bees lose their queen, and have no royal larva, they take worker eggs or very young larvie, and by proper care and feeding make queens of them: royalty in this case being a mere matter of diet.

As to the practical part of bee-keeping, and the details necessary, there are many books especially written to give that information, and it forms no part of the purpose of the present treatise. The object here has been to give merely a sufficient insight into the working of the hive to indicate the use that is made of the pollen and its importance in the economy of bee life. It is the necessity of having food for the larve that keeps the insects constantly at work and makes them so effective as pollenizers. Visiting, as they must do, a great number of flowers to obtain sufficient pollen for a load, they call at many trees, often far apart and of different varieties, securing the cross-pollination so necessary to many plants. They usually visit one kind of flower only, and I have tested several specimens by microscopic investigation, finding always one form of pollen only.

Bumble-bees have been already mentioned, and resemble in their economy somewhat the hive-bee, save that here, as in the wasps, the colony, excepting only the fully developed females, 
FIG. 473 .
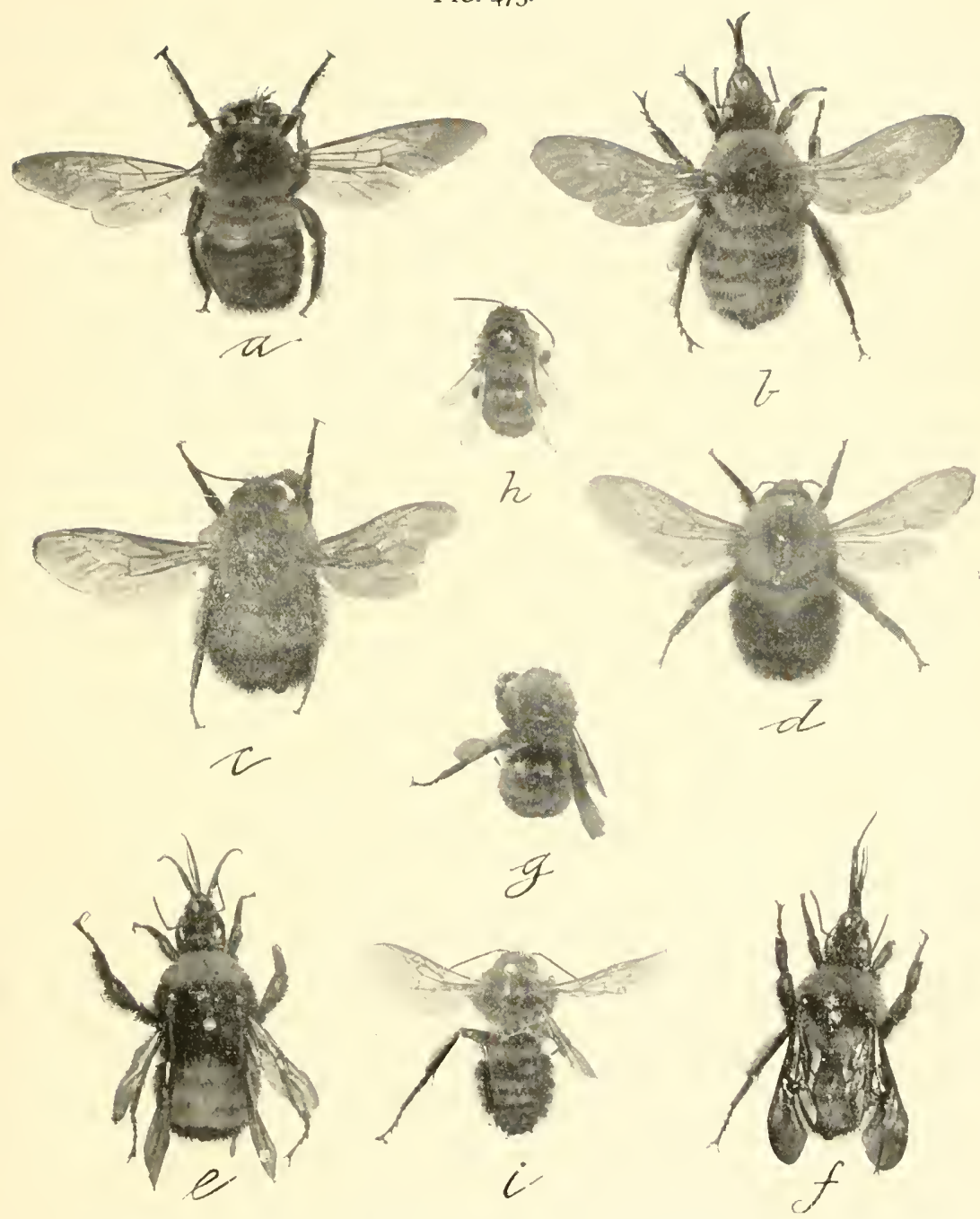

Our common bumble-bees, $-a$, Ivlucopa virginica; $b$, Bombus fervilus; $c, B$. consimilis; $d, B$. virginicus :,$B$. americanorum (queen) ; $f, B$. ferridus: $g, B$. americanorum (worker), to show pollen mass on hind tibia; $h, E$. vagans; $i$, Apathus elatus. All somewhat more than natural size. 

dies each year. We see early in the spring, when the fruittrees are in bloom, many specimens droning about on the flowers, but often also along road-sides, especially where there is a declivity ; or in fields where there are a few rocks, or where there are holes in the ground. There we often notice an indi. vidual buzzing over one spot for several minutes at a time, apparently subjecting it to the closest kind of examination. This is indeed what the insect is doing: she is seeking a place to start a home. This she finds in an abandoned mouse-hole, or other cavity in the ground, and here begins her nest, lining it with moss, with fragments of leaves or grass, or with whatever inay be most convenient. Then she gathers a mass of pollen, upon which a number of eggs are laid. No comb is built; but the larvae, when they hatch, burrow into the pollen mass, to which the mother adds constantly as necessity requires. When full-grown each forms a. smooth cavity, which it lines with a silken cocoon and clianges to a pupa. The cocoon is strengthened from the outside by the mother, witl wax, and in due time we have a little brood of worker " bumbles" resembling their parent in all except size and the incomplete sexual development. Not until after midsummer does the queen, reinforced by the workers which she has raised, lay eggs that produce males and females, and these are fed upon food gathered by the workers. The old female dies when the new brood of sexually complete individuals has hatched. The latter mate, and the workers and males also die on the approach of cold weather, leaving only the now impregnated females to survive.

Taken altogrether, the order Hymenoptera contains insects that are decidedly beneficial to the farmer. The first series only, to which the "saw-flies" and the "borers" belong, are injurious, and these may always be recognized by the fact that the abdomen joins the thorax by its whole width, instead of being fastened simply by a stalk or petiole. Of course, the ants are sometimes troublesome and indirectly injurious, but, as a whole, the species are so overwhelmingly beneficial that the order deserves to be encouraged in every way possible. Bees, wasps, and hornets are particularly desirable inhabitants of a locality, and in a quiet way do much to destroy injurious insects, - as much, perhaps, as the parasites which also belong to the order; while the bees of all kinds are simply indispensable to the fruit-grower as pollenizers. 


\title{
PART III.
}

\section{INSECTICIDES, PREVENTIVES, AND MACHINERY.}

\author{
CHAPTER I.
}

PREDACEOUS INSECTS, PARASITES, AND FUNGOUS DISEASES.

IT has appeared throughout this book that, while we have a great many insects that are feeders upon vegetation, there are also a great number that are predaceous upon the herbivorous forms, and yet many others that are parasites, living upon or within others of the same class. It is a tempting proposition that we may, perhaps, be able to array the forces of nature against each other; that we may keep predaceous forms, and set them free at the proper season to feed upon those injurious to farm crops. I say it is a tempting proposition, and it looks feasible, but that it should be successful involves a great deal more than is apparent at first glance. In the course of the ages through which this world has existed there has been gradually established, by the influence of surroundings, a certain ratio between all existing life, vegetable and animal. There is a struggle among the plants themselves as to which shall keep the ground, and upon the plants feed animals, including insects, which form a factor in determining the relative abundance of the different species. With the development of the plants their enemies also have developed, and always in proportion to the amount of injury that the plant can stand. That this must be so is evidenced by the fact that the plants exist at all. One of nature's ways of preventing the plant-feeding insects-for we will confine our remarks to insects from this point on-from obtaining control of and exterminating the plants is to provide enemies of various 418 
kinds for them. These enemies in turn must be checked, that they may not exterminate the species they themselves feed upon. Thus there has been established, gradually and naturally, an elaborate system of checks and counterchecks, by means of which a certain proportion is maintained year in and year out between predaceous, parasitic, and plant feeding insects. Under perfectly natural conditions this ratio does not change much from year to year, and there is no preference on the part of nature for one class as against any other. Any interference with this established course is almost certain to be disadvantageous in some directions, and man, in his dealings with natural conditions, has persistently created for himself a series of troubles arising from his own acts. By planting large areas of one crop, he has favored the increase of the insects feeding upon that crop. By cultivating the land, keeping it cleared of rubbish, stones, sticks, and the like, he has destroyed the shelter needed by predaceous insects, and the result is that he has in two ways given those insects, which he now calls injurious, an advantage. The consequences, of course, are against him ; and so long as these conditions continue, favoring one class at the expense of another, man must suffer, unless he himself fulfils the functions previously assigned to the predaceous forms. True parasites have not been so much influenced by his actions, and the species, perhaps, suffer as much from them as they ever did; but the natural checks in operation against the parasites also continue, and while, perhaps, they have increased somewhat in number, they have not been able to make up for the loss of the predaceous insects. Furthermore, the feeders upon vegetation suffered also from the attacks of insectivorous animals, like toads, frogs, and snakes among the reptiles, and many small animals and birds, which now also find life insupportable among the artificial conditions. The result is that there has been an actual increase in the number of specimens of injurious insects, and their parasites bear somewhat less than their original ratio to them,- - that is, each year a certain proportion or percentage of a brood is destroyed by its parasites, and this percentage it is beyond our present power to change to our advantage. In other words, the farmer cannot, except in isolated instances, count upon parasites or natural enemies of any kind to keep down injurious insects. 
Even though in each year a certain species may be, in the long run, controlled by its parasite, this does not necessarily help the farmer. Let us take, for instance, the cut-worms that are so abundint each year. If we gather from an infested field two or three hundred specimens, we find that anywhere from fifty to seventy-five per cent. of them are parasitized. This looks like at huge destruction; but when we consider that the parasites do not, as a rule, alfect the larve until they have done all their feeding, what benefit has the farmer derived? What difference cioes it make whether the cut-worm that destroys his plants is parasitized or not? At the end of the season we may note that twenty-five per cent. only of the cut-worms develop into moths: half of those may be males, and the remainder are females which will each lay anywhere from three to five hundred and sometimes more than one thousand eggs; amply sufficient to pro. duce in the next brood fully as many caterpillars as existed in the beginning! Let us further take the case of the cranberry Teras as an illustration. The first brood, early in the season, has scarcely any parasites; the second brool, in mid-summer, is parasitized to the extent of nearly fifty per cent. ; while from the third brood, in the fall, we get fully seventy-five per cent. of parasites to twenty-five per cent. of moths. Yet, notwithstanding this enormous increase of the parasites in the course of the season, some combination of circumstances destroys so many of them during the winter that in the spring following the first brood is again almost free from attack; and thus it goes, year after year. The action of the parasite is only to keep its host within a certain fairly well denned limit, and if that limit is at a point where the host becomes injurious to the farmer, he must himself take a hand in its destruction to derive any benefit. I do not mean, in anything I say here, to lessen the clains of parasitic and predaceous insects to our consideration. They have an extremely important function in nature, and without them there would be no possibility of an existing vegetation. But, on the other hand, it is just as certain that unless there was some check imposed upon the multiplication of parasites, etc., they would in a short time destroy the insects that they feed upon, and the destruction of their host would, logically, carry with it their own destruction. Nature never works in that way: 
her effort is always to give all her creatures an equal chance to exist.

Man has further disturbed the natural conditions by introducing into new countries insects that have become adapted to the surroundings in others. Sometimes an insect so introduced does not find the new circumstances to its liking; but, on the other hand, it may find them very much better than those under which it was originally developed. In such cases we get a multiplication out of all proportion to the normal habit of the species, and there may be such a thing as the destruction of the plants that they feed upon. Let us take, for instance, the elm-leaf beetle, introduced into this country many years ago, and apparently without natural enemies suitable for its control. The circumstances which it finds here are so much to its liking that, if allowed to increase unchecked by the efforts of man, it may in the course of time destroy all the European elms in the regions infested by it !

The whole object is to show that, since man has introduced artificial conditions, he must bear the burclen of the change caused by them ; and if this means that there are certain injurious insects feeding upon the plants he wishes to grow for his own benefit, he must replace by his own efforts those natural checks which he has removed by the artificial conditions introduced. Those efforts on his part consist in the adoption of measures to prevent increase, or to destroy the injurious insects by means of poisons or otherwise, and this subject will be considered in another chapter.

A fascinating theory in connection with this subject is the possibility of importing parasites or predaceous forms from other countries for the destruction of pests here. This leaves out of consideration the fact that it would require a readjustment of matters to induce foreign parasites to feed upon American insects, and it has never been proved that such a thing is possible within a reasonable period of time. The case of the Australian l'edalia, imported to prey upon the fluted scale, Iccrya purchasi, is frequently cited as an example of what can be done, but always without considering the fact that we had an imported insect to deal with in the first place, which increased abnormally in our country because of the fact that its enemies were not brought 
in with it. When this Australian insect enemy was introduced, it found nothing that it recognized except the lierya, and, in consequence, devoted itself entirely to that species, totally suppressing it in a short time. All that was done here was to restore the balance of nature, because the scale insect is a tolerably rare species in Austrilia, owing to the number of its enemies. Nothing can be argued from this case as to the possibility of introkucing foreign species to control strictly American pests with which they are not acquainted. An effort was made in this direction in Virginia, the object being to import European enemies of bark-borers to check the invasion which seemed to threaten the forests of that State. The utmost that can be said for the experiment is that the imported insects have not quite died out, and that occasionally one is seen out of many hundreds brought in. But, on the other hand, the invasion which they were imported to check has been disposed of by nature herself, an unusually severe winter destroying the pests so completely that, instead of being abnormally abundant, they have become almost rarities. We can frequently do good where we have imported insects, or insects occurring also in other countries, by finding and introducing their parasites; but it seems rather an utopian scheme to train predaceous insects of other countries to feed upon our native species with which they are not acquainted.

The subject of fungous or contagious diseases of insects is an interesting one, but which must be dismissed here with a brief reference only. WVe know that insects often suffer from disease, and that epidemics sometimes occur among them, destroying myriads. Some of these diseases have been studied, and elaborate attempts have been made, chiefly in Kansas and Illinois, to make use of them practically. The chinch-bug has been the insect most experimented upon; and while it has been demonstrated that it is possible to cultivate the disease and to infect previously healthy bugs with it, it has also developed that the disease demands certain definite conditions of climate and atmosphere for its own propagation. Thus, dry, warm weather is unfavorable for the growth of the disease, while it favors the multiplication of the bugs; but moist or wet weather, which retards development in the bugs, favors the disease. Until we can control climatic conditions, or otherwise secure the intelligent 
co-operation of the weather, our results are likely to be uncertain. Nevertheless, there may be great possibilities in this direction, and in the minute organisms requiring a powerful microscope to make them even visible we may yet find our most effective help in checking destruction by insects.

\section{CHAPTER II.}

\section{FARM PRACTICE TO PREVENT INSECT ATTACK.}

Throughout this work reference has been frequently made to methods of ordinary farm practice for preventing insect attack. It is desirable to look a little closely into this subject, and to detail somewhat the methods that may be resorted to with good effect. Prevention is always better than cure, and very frequently serious injury may be averted by doing ordinary farm work at just the right time, or in exercising care in the selection of fertilizers or in the rotation of crops.

Far above everything else is cleanliness on the farm, and this term is to be construed as strictly as possible. Cleanliness means clean culture; the destruction of weeds; the removal of crop remmants as soon as the crop is done; picking up and destroying dropped fruit in orchards ; removing, burning up, or otherwise destroying all rubbish that cumbers the ground in winter; keeping buildings painted or whitewashed in good shape. Allow no rubbish, weeds, or shrubbery to grow among the fences, and in all other respects leave the farm as nearly bare as possible of everything save what strictly belongs there. The object of all this is to do away with possible hiding-places for insects during the winter, and to prevent their reaching maturity during the summer. A large proportion of insects live through the winter in the adult stage, or in the partly grown condition, and a great many of them hide under rubbish. Sometimes they get just a short distance below the surface of the ground among the roots; sometimes they crawl into crevices of fences, of logs, or of boards, -wherever, in fact, there is the least opening for them to get 
into. A tree with rongh bark, covered with moss, lichens or other unnecessary growth, often harbors hundreds of specimens, and one object of the farmer should be to destroy all hidingplaces that may be of service to the insects for winter-quarters. Therefore, if possible, all fences should be whitewashed, as well as all out-buildings. Insects do not like lime, and where a dozen specimens may be found on a plain board fence, sarcely one will venture on one that is limed. This kind of campaign is especially effective against certain forms of plant-bugs, a large proportion of which live through the winter in the half-grown or achult condition. Offer them a bare soil wherever that is agricul. turally feasible, and at all events never give them the opportunity of hibernating in a weedy field-one that has been allowed to grow up after harvest with the idea that it is to be turned under in the spring. Such fields are veritable nurseries for insect pest.s.

It frequently happens that a famer is through with a crop before the plants stop growing, and occasionally they remain in the field weeks after they have ceased to be of any practical use. During all this time the insects peculiar to that crop are multiplying, coming to maturity undisturbed, and providing for their increase during the ensuing year. For instance, with cabbages: if, after the heads are taken out, the butts and outer leaves are left in the ground, the cabbage-lice will there increase and prepare for the winter. If the butts are taken out and fed up, or destroyed in any other satisfactory manner, it will put an immediate stop to their development ; and if the practice is continued systematically, and cruciferous weeds are also kept down on the farm, cabbage-lice will soon become so reduced in number as to be practically harmless. So, from melon vines only a portion of the crop is often gathered, and they are then left to grow and decay naturally upon the ground. The vines may be infested by borers, or they may harbor squash-bugs, or melon-lice, or a number of other pests. By removing and destroying as soon as there is no further use for them, a period is at once put to the increase of these insects. They will be compelled to look elsewhere for food or will starve to death.

In corn-fields, leaving the roots and stumps in the ground throughout the winter offers a premium for the increase of insects that depredite upon this crop. Such pests as "corn-worms" 
can be easily kept in check by fill ploughing and burning the butts and roots, and a good effect will also be produced ats against the corn-root-louse and sinilar pests. Instances might easily be multiplied without adding to the force of the suggestion that the ground should be kept as free as possible from all growth that might afford lodgement or shelter for insects.

Another important operation which can be made use of is ploughing at the proper time, and, among other things, fall ploughing, whenever possible, is to be recommended, especially of sod land. Many different kinds of insects live in sod, among them cut-worms and wire-worms, both well-known and important pests. A great deal can be done in the direction of destroying these creatures by ploughing the land late in fall. Under the proper headings will be found the reasons why such an operation proves beneficial in special cases; but in general we can say that, by disturbing the land after the insects have prepared for their winter rest, they are exposed to their natural enemies when more helpless than usual. A great many are then in the pupa state, absolutely unable to help themselves, and breaking their cells at that time means death to them. A very large percentage of reduction in the number of injurious insects can be effected by this practice alone. I am aware that fall ploughing is inadvisable on some kinds of land, but it is directly beneficial on others. It is a measure that must be used with judgment, and each farmer should know enough about his own land to decide whether or not fall ploughing is advisable. I distinctly recommend it wherever it is possible. As a rule, where the ground is to remain bare, the ploughing should be done as late in the season as possible, that the insects may not be able to re-establish themselves; for instance, when the corn-root-louse is the object of the attack, early ploughing allows the ants that shelter them to construct new galleries and gather in their belongings to safe shelter, while very late ploughing makes it impossible for the ants to work, so that they and the lice both perish: the latter almost certainly. The date of ploughing, other than in fall, is sometimes important ; thus, against the root web-worms in fields after grass, if the sod is turned very early, before the moths have appeared and laid their eggs, the crop remains free. If delayed until the sod has become stocked with eggs, the corn is almost certain to suffer. 
Sometimes, where land cannot safely be left bare during the winter, it may be ploughed earlier, and some catch crop, simply to cover the surface, can be put in, and it matters very little what this is. It may be crimson clover, rye, wheat, - anything, in fact, to get a covering, provided it is something radically different from what was on the ground before the ploughing was done. Corn-fields should be treated in this way after the crop has been harvested, if late ploughing is undesirable, for it is always a mistake to leave them unturned until the spring following. It is a good plan, just as soon as one crop is off, to put in something else, which, as already suggested, should be quite different in general character; and this brings up the question of rotation. It is impossible to make any generally applicable statements on this subject. No two regions of our country are entirely alike in their practice, in the crops raised, or in the rotation adopted; but so far as possible a rotation should be selected which will keep the ground covered all the time, the crops that follow each other being unlike in their natural family, - that is, grass should not follow wheat or rye, if it can be avoided; nor should potatoes be followed by egg-plants or tomatoes; or cabbages by mustard or radishes; but in all instances crops as diverse as may be should follow each other, and as rapidly as possible. Where wire-worms are the chief sinners, crimson clover may sometimes be usefully employed. Plant this in fall, and in spring it will be in excellent condition to attract the adults to lay eggs. Turn it under late in Nay or early in June, after cutting for hay or as a green manure, and plant any suitable crop. The very young larva will be incapable of doing injury, and will fail to maintain themselves under the new conditions. It must be remembered, however, that this practice will favor cut-worm increase, and measures must be held in readiness for these when the planted crop makes its appearance.

Another good pian is to have a considerable number of chickens, and to train them to follow the plough. This can be very easily done, and after a few are once trained, they will in turn teach the entire flock, while the young learn readily from the older. Chickens following a plough will pick up almost every insect that is turned up, be it in the larval, pupal, or adult condition, and they are especially effective in fields infested by 
white grubs. Badly infested fields may even be ploughed more than once, and in different directions, just to give the chickens an opportunity of picking up the insects. I have seen flocks so well trained that whenever the plough harness was put upon the horse they gathered together, waiting until he was taken to the field.

Turkeys are exceedingly useful where grasshoppers are to be dealt with, because they are especially fond of these insects ; and for the same purpose Guinea-fowls are also advisable. Here again the practical farmer will find, with a little observation, just about the range of usefulness of the various fowls, and will be able to adapt his cultivation somewhat to their peculiarities.

In the matter of the fertilizers to be used we have also an opportunity for careful selection. We may say generally, that manure and all vegetable matter in a decaying state favors the development of insects. It affords both food and lodgement to many species, and when it is put on in the fall or winter in a coarse condition, it is a direct benefit to insects that hibernate, even when ploughed under. On the other hand, the mineral fertilizers, especially those containing a considerable percentage of salt, are unfavorable to insects of all descriptions, and to some they are deadly. Experience has shown that plant-lice are susceptible to the action af the salty fertilizers, and that cut-worms and wire-worms are affected by them to a considerable extent. Among corn insects, injury from the root web-worms may be entirely avoided by using the mineral fertilizers instead of barnyard manure, if fall or very early spring plougining is not feasible. So the time of application is important, as is the amount to be applied. For instance, in land infested by wire-worms and to be put into corn, the best time for the application is just after it has been prepared and after the seed has been planted. Then all the potash should be put on, in the form of kainit, in one application, while as much as is desirable of the nitrogen should be put on in the form of nitrate of soda. In this way the soil becomes impregnated with a rather concentrated salty mixture which is fatal to many of the insects. The same amount of fertilizer distributed in several applications, or put on the ground in fall, or when vegetation covers it, would be entirely ineffective. Mineral fertilizers are advisable wherever their use is otherwise 


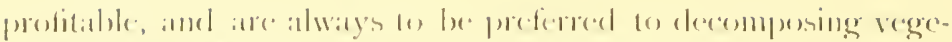
table malter, from the insed stand-point. The details of the applications to be mate atre linmel where the inseres themselves

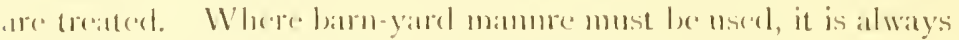

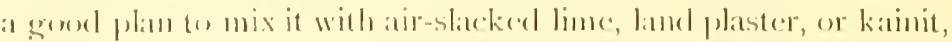
and this call he dome as fan as it is male in the stable. It will add to its value, will hold the ammomiat, and will make the mixture

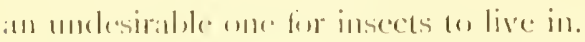

(ibiss lame maty lx kept toldrably frec fom undeairable pests inlestims the routs ly using as fertilizer a mixture of one hum-

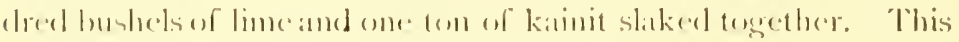

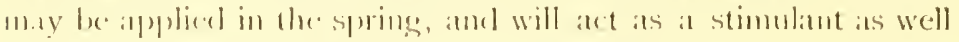
as alestroy many of the insects inhahitimg the soil.

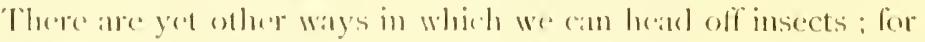
instance, in the selection of the time of planting. It hatpens firepuently that insects make their appearance alt a very definte

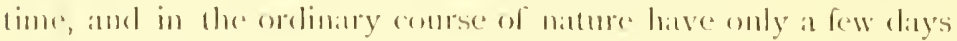
within which they must lay their egges amel provide for the con-

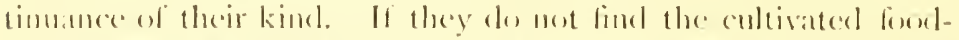
plant, they are ammelled to make use of some sulstitute wild plut, on which they de met thrive as well ; or they may not be ahle to oviposit at all, and a lange proportion will periah without

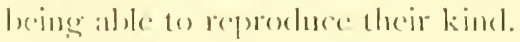

When the life history of a serionsly injurions insert is kmown,

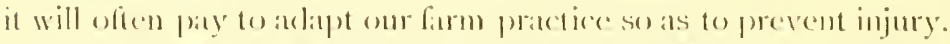

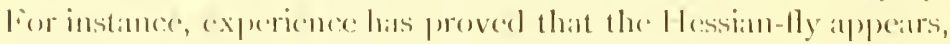

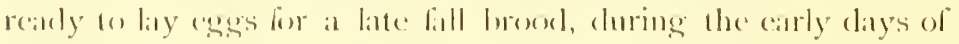
September. By delaying planting mutil after the miklelle of that month, or aven later where the lationde makes this leasible, the

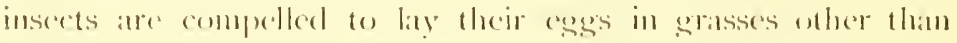
wheat, w in the voluntere grain that they fime in fickls or along the rouls.

Cranberry growers take alvantage of their knowledge of the life history of the Feres infesting that crop log kecping the loges coscred with water mutil after the miclelle of Maty, thus compelling

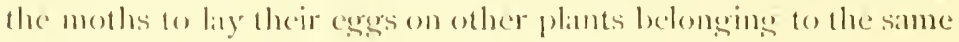
nattural limily.

In a similar way we can sometimes induce the insects to oviposit in a traplecrop planted especially to attract them and pro- 


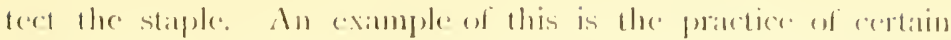

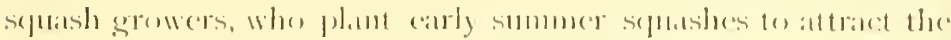

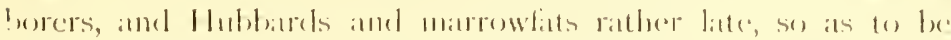
mattractive to the moths as compotred with the vigonoms raty

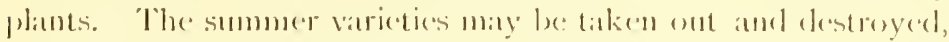
with all their contents of borers, after all carly crop has lecen preked from them, and this will leave the litter vatrieties free, while it alse accomplishes the destruction of an entipe browe of larvat. So it has been formed praticable in the Somth to protect

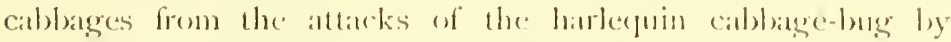
planting an cirly trip) (wop) of mustard, to which fle insects are attracted, and from which they can be salthered by hamel or destroyed by spritying with pure: kerosenr.

An instance of the use of metheds of coltivation we find in the practice of blackbery growers, who, to prevent injury from the red-necked ranc-horer, cut off diring the latter part of June all

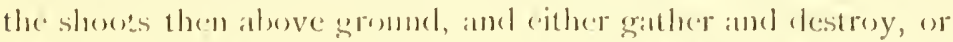
mesely allow them to wilt and die. The beedles have all (lisitppeared at this time and all their egges ane in these shoots. The new canes that come mp after this trimming become sufficiontly mature and are in sufficient mumber to make next year's crop) whice they are free from any possible locelle attack.

There are many other ways in which ferm practice may prevent injury from insects, and to the intedigent former these methods will commend themselves much more than the indiscriminate use of insecticides after damage has been cinseel. The prevention of attack is always better thats the destruetion of the insects after injury has been acoomplisherl, and somse of these methrols bave the advantige of effecting at permanent recluction of the injurions species. Fimbere deatils are harelly in place here, lum what has becn said will explain lhe reatson for many of the recommendatuons made in the body of the work. 


\section{CHAPTER III.}

PREVENTIVES.

THERE are many serionsly injurious insects which it is difficult to reach with insecticides of any kind or to destroy in any way ; and first among these are the borers of all orders. Special destructive, remedial, and other measures have been indicated throughont this work, where the offending species are described ; but perhaps a grouping here, of what may be termed preventive measures, will be of some use.

It is the grower of orchard fruits that suffers most from borers ; for while some small fruits are subject to this kind of attack, the greatest and most permanent injury is done to trees. Peach-trees are grirdled at or near the surface of the ground by a Lepidopterous borer ; apple, pear, quince, and similar trees are attacked on all parts of the trunk, yet preferably near the base, by Coleopterous larva; and most of our fruit trees are subject to the attacks of bark-beetles. Many of the shade trees suffer in a similar manner, and some species attack indiscriminately both orchard and forest growtl. It is easier, as a rule, to keep borers out than to destroy them after they once get in ; and to do that, we must resort to mechanical measures. The simplest and usually a most effective method is the use of a rather close-meshed wire mosquito netting on the younger orchard trees. The parents of both the round and flat-headed apple borers are quite large, and unable to lay their eggs through such a netting, provided that it be kept half an inch from the bark at all points. In this way apple and other trees subject to similar injury may be effectively protected, and trees once netted will need little attention, save occasional retying for several years. The netting should be galvanized, lacquered, or thoroughly painted, and should have sufficient lap when first put on to allow the tree to make considerable growth. It must be closely tied to the trunk at the top, or the interval must be filled with cotton or a similar material, so that the insects cannot get inside the cage. In like manner, the soil must be hilled around the wire at the base to prevent entrance at that point. Should the trees be already infested, such beetles 
as might emerge would find themselves in a prison from which there is no escape, and would die shortly, if, indeed, they be not killed through the netting.

Wrapping with newspapers or similar material is also a tolerably effective measure, and such a wrapper will last a season without attention, except a possible retying. Tarred paper has been recommended, and is more lasting; but it seems to cause injury on thin-barked trees, especially peach and young apple, in some sections of the country. The tar really adds nothing to the effect, and, as there is an element of danger, the use of such paper is not recommended. Such wrappings are mostly used to keep out borers that enter near the base: they should cover completely, should extend at least eighteen inches from the surface, should be well tied at the top with a soft twine that will yield to some growth without breaking, and should extend an inch or two below the surface. Besides keeping out borers from points so protected, the coverings would tend to keep in such insects as might develop, and would prevent their emergence and propagation.

Instead of wire or paper coverings, a coating of tree-lime, Raupenleim, bird-lime, printer's ink, or other sticky substance is sometimes employed. Some of the materials once suggested, like dendrolene, turned out to be unsatisfactory, because the vaseline they contained gradually worked through the bark, into the sap-wood, and caused serious injury. A complete covering with any such material is no longer recommended; but as a banding to prevent the ascent up the trunk into the tree some of them serve an excellent purpose.

Several such tree coverings are on the market at present, and almost any of them applied in a ring from four to six inches wide will serve to keep crawling insects from getting into the tops. They are especially useful as against canker-worms and the like by keeping off the wingless females and, later, the caterpillars.

Gas-tar, coal-tar, and similar materials are sometimes advised for use at the base of peach-trees, and all of them have a record for effectiveness and safety in the hands of careful experimenters ; unfortunately, these same substances have proved dangerous in other hands and in other localities. Climatic conditions seem to be of importance in some inexplicable way, and nothing that has been ever known to cause injury should be extensively used by 
any grower until he has first tested it in a small way. White-lead faint is in somewhat the same case, and, if used at all, should be ipplied only on well-established trees, and should not be mixed with turpentine.

Lime in the form of whitewash is an excellent application to the trunks and lower limbs, and will in itself serve to keep them measurably free from scale attack; the wash should not be so thick ats to scale off, and sialt should be added to improve its adhesive qualities. When trees are sprayed with Bordeax mixture, the trunks and larerer branches may be especially well covered or sprayed more than once to insure a thorough coating, and this, repeated at intervals through the season, will serve a similar purpose. Hydratic cement, or " water lime," mixed with water of, better, skim-milk, to form a thick paint, makes a covering that lasts all season, and has proved about as effective in keeping borers out of peach-trees as anything that I have used. On smaller trees it is as cheap as the paper banding; on larger trees it is more expensive. In any case, it causes no injury to the most tender bark.

A great variety of other coverings has been used, from a mixture of cow-dung and claty to simple soft soap, and in so far as they form a mechanical coating all are good. Whale-oil soap forms the basis of many such washes, and kerosene or carbolic acid is sometimes added. It is probable that the carbolic acid is of some use in this connection at the rate of an ounce or two in a gallon of soap mixture; most of the others are useless, if not actually harmful.

Keeping the trees clean, free from all ahnormal growths and loose, dead bark is always advisable. It destroys the hiding places of any hibernating species, and prevents the formation of cocoons by the larva of the codling moth and other caterpillars. If the trunks are washed with a strong solution of canstic soda or potash, say one pound in two gallons of water, the lichen and other plant growths will be destroyed, and the bark will be cleansed and stimulated.

To prevent climbing cut-worms, canker-worms or similar creatures from ascending a tree, a band of cotton batting can be satisfactorily used in many cases. Make the band from eight to twelve inches wide, and long enough to go around the trunk with an allowance for a two-inch lap; tie tightly at the bottom of the 
band, - smooth side, if any, to the trunk, - and then turn down from the top like an inverted funnel. This prevents a matting of the inside of the funnel by rains and, under ordinary circumstances, forms a complete bar to the ascent of wingless insects.

Finally, the most effective of all preventive measures is good farming. Keep crops of all kinds in the most vigorous possible condition, with plenty of readily available plant food, and in orchards allow no dead wood of any kind to remain over winter. Dead and dying branches should be cut, carted out, and burnt wefore the first warm spell of spring, and dying trees should meet the same fate. There will be nothing to encourage insects to come in, uncler such conditions, or to remain if brought in. The term "good farming" has a wider application than I have made here, but this subject has been incidentally referred to on other pages, and needs no further elucidation here.

\section{CHAPTER IV.}

\section{INSECTICIDES.}

BROADLY speaking, insecticides are of two kinds-those that kill by being eaten, or stomach poisons, and those that kill by contact. Some substances, such as hellebore and tobacco, belong to both categories; but are most effective within their range as contact poisons.

Of the stomach poisons the various preparations of arsenic stand first, and, indeed, arsenic forms the basis of all the insecticides that kill by being eaten, so far as they are known to me. The fact that some of the preparations are advertised as "harmless" does not alter this, for they are "harmless" only because the amount of poison is so small that under ordinary circumstances it would be almost impossible for a man to eat enough of the sprayed material to cause death. In almost all the insect-killers that are to be applied dry, undiluted, and are sold under a fancy name, from twenty to twenty-five parts of the bulk is makeweight,--plaster, lime, ashes, and the like, - which are charged at many times their value, and on which the farmer pays freight in 
addition. As a rule, it is safer to purchase only materials of known composition from a reputable firm and prepare as needed.

White arsenic is the cheapest, simplest, and most ative material of this class, and is effective at the rate of one pound in from two hundred and fifty to three hundred gallons of water. The objection to it is that so much of the arsenious acid is soluble in water that it burns foliage seriously, and at any strength at which it is fatal to insects becomes fatal to the plants as well. To neutralize this, three pounds of lime should be adcled for each pound of arsenic, as follows: to three pounds of good stone lime add water enough to slake completely; mix the arsenic with water enough to make a thin paste and add to the slaked lime; add water as needed and stir thoroughly until the lime is completely reduced and forms a thin milk of lime; strain to get rid of coarse particles and reduce with water to spraying strength. The lime forms a combination with the white arsenic, unites with the soluble arsenious acid, and forms an insoluble arsenite of lime which may be applied with reasonable safety at about half the strength at which Paris green is used.

A somewhat more effective way of combining the arsenic and lime is to boil one pound of the former and two pounds of the latter in two gallons of water, and then dilute as required. This combination is especially useful as an addition to the Bordeaux mixture where a combined insecticicle and fungicicle is desired, and it also is used in half the amount of Paris green.

Yet another combination is made as follows : In an iron pot boil one pound of white arsenic with four pounds of sal soda in one gallon of soft water until the arsenic dissolves, leaving only a small muckly sediment. The product is an arsenite of soda which may be kept in a closely stoppered jug until needed, though not longer than the season for which it is made. To prepare for use, take tro pounds of lime, slake, and dilute with two gallons of water and add one pint of the arsenite of soda solution. IVhen this is thoroughly combined, add water to make forty gallons. This equals Paris green at the rate of one pound in one hundred and sixty gallons of water, and remains in suspension about three times as long; in fact, all the arsenic and lime preparations have the advantage over Paris green in this respect. The arsenate of soda is very destructive to foliage in any dilution, and should never be used alone. 
The advantages of the home mixtures are their low cost and their known strength. If carefully made, they are always uniform in composition and similar effects may be expected from similar applications. Care in securing a proper combination is essential ; otherwise serious injury is certain to result.

Paris green is the most widely used of all the arsenical poisons, and is a combination of arsenious oxide, about sixty-eight per cent., with copper oxicle, about thirty per cent. The percentage of arsenic may range from fifty to seventy without necessarily proving adulteration; but carelessness in the manufacture may make a product unreliable, and may lead to material differences in effect on foliage as well as insects. In its usual form Paris green is crystallized, and the size of the particles has a great influence upon its effect. When coarse, they sink readily, necessitating constant stirring, and are unevenly distributed on the leaves; when fine, they remain in suspension longer and spread more evenly on the sprayed surface. Only a small percentage of the arsenic is soluble, and at strengths ordinarily used no addition of lime is necessary ; but when the mixture is strong and the sun is hot it will be better to add one pound of lime to each pound of green, slaking the lime to a thin wash and then adding the poison, which is better first made into a thin paste with just enough water to do so.

As Paris green is the most generally used material, all others must compare with it in the amount employed. Against young larve and most slugs one pound in two hundred gallons of water is effective; but so great a dilution is rarely used except on sensitive foliage. On peach this poison should never be used at all. As against codling-moth, one pound in from one hundred and fifty to one hundred and seventy-five gallons of water is used, and that forms a good average strength for most leaf-feeding insects, rarely injuring the foliage unless used in excess or allowed to settle so as to make the sprayed solution irregular in its effect. On potato beetles, one pound to seventy-five gallons is usually effective, but some farmers use it at the rate of one pound in fifty gallons, or even stronger, and claim good results as well as safety to foliage.

Crystaflization of Paris green is not necessary to its usefulness as an insecticide, hut a positive detriment, because it increases the weight of the particles and the cost of making. There has 
been a tendency, therefore, to place upon the market an arsenite of copper whose composition is like that of Paris green, but which, not being crystallized is much finer, remains in suspension much better and is somewhat cheaper.

London purple is a waste product containing about forty-one per cent. of arsenious oxide, about twenty-five per cent. of lime, and the balance of thirty-four per cent. made up of iron, alumina, dye-stuff, etc. It is less effective than Paris green because of the smaller percentage of arsenic, and more dangerous to foliage because a larger proportion of it is soluble. The addition of an equal weight of lime obviates the danger to plant tissue, and the fine particles enable it to remain in suspension much better: hence, at one time it was considered a more desirable insecticide. Unfortunately, being a waste product, it varies so greatly in composition that its use is lessening constantly in favor of the homemade arsenites.

Arsenate of lead is a combination of eleven parts of acetate of lead (sugar of lead) with four parts arsenate of soda, forming an insoluble compound which may be applied on foliage of any kind, at any desired strength, without danger to even the most delicate plant tissue. As the percentage of arsenic is very low, it requires about two and one-half times as much in weight as of Paris green to gain the same effect, and it is therefore much more expensive. For orchard use it will hardly come into favor, except on peach ; but in the garden and for use on certain shade trees it is unsurpassed. It is the only combination that can be safely applied on conifers, and its adhesive qualities are such as to make up in part for its high price. It will be better, ordinarily, to purchase the commercial preparations, whether known as arsenate of lead, gypsine, or disparene; but where much is to be used, it will be cheaper to buy the materials and make it up as needed, care being taken to secure a good grade of acetate of lead and arsenate of soda. For a barrel of spraying mixture the following will serve :

Dissolve in one gallon of water in a wooden pail eleven ounces acetate of lead (sugar of lead), and in another, in half a gallon of water, four ounces arsenate of soda. Pour the arsenate solution into the lead solution, stir thoronghly, and pour into the barrel, which should be half full of water; stir again, add water to fill up, and spray at once. The particles are very light, remain in 
suspension a long time, and eventually settle into a pasty mass at the bottom.

In spraying with any of the arsenical poisons the water serves only as a carrier to spread the material over a greater area. When the water evaporates, it leaves a thin film on the surface, and this serves as a protection against leaf-feeding insects for a longer or shorter time. On a rough leaf, the particles will lodge in the depressions and may remain for months; on a smooth leaf, the first heavy shower may remove almost everything. The finer the material, the better it settles into the leaf tissue, and from that view-point Paris green is the poorest and arsenate of lead the best of the stomach poisons. Glucose or molasses at the rate of two quarts per barrel adds materially to the sticking qualities of any mixture; but some plants, like cabbage, have the leaves so smooth and waxy that even that is not sufficient.

The following resin mixture has been found effective :

\section{Stock Solution.}

Pulverized resin . 5 pounds

Concentrated lye . . . . . . . . . I pound

Fish or other cheap animal oil ... . . . . I pint

Water ............... 5 gallons

Place the resin, oil, and one gallon of hot water in a kettle and boil until the resin is thoroughly softened. Then dissolve and add the lye slowly, stirring constantly until thoroughly mixed. After this add four gallons of water, and boil until you get a clear amber-colored liquid which will mix readily with cold water. It will take about two hours to prepare this solution, and if there are less than five gallons when through boiling, add water enough to bring it up to that amount.

It is only on cabbage, cauliflower, and similar waxen-leaved plants that this mixture is needed, and for use take one part resin mixture and sixteen parts water ; stir thoroughly, add three parts milk of lime in the same way, and finally Paris green at the rate of one pound in eighty gallons of the solution. This must be used at once, for if allowed to settle it cannot be satisfactorily mixed again : the order of mixing also must be closely followed to prevent a flocculent precipitation and consequent formation of an insoluble soap.

The addition of soap of any kind at the rate of one pound per 
barted adels to the spreading power of the mixture, and some-

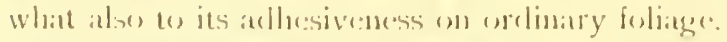

l'aris green may be ayplied dry, modiluted, on many kinds of plants with a dester or any sort of appraratus that sprearls it over at very large surface. More generally it is mixed with abent fifty parts of plister, flome, lime, or other carricer, which spreads it

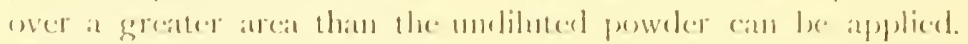

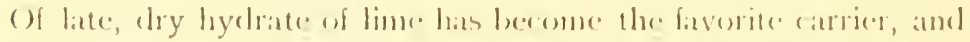

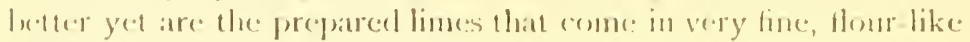
form.

Dry hychate of lime is simply lime slaked with just (omomgh

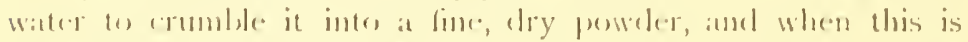
sereened amel mixed with laris green it ean le applied ats an fine dest with fim lefowers, several kinds of which are mow on the markel. As to effectiveness, it is eflat to at watter spraty for most purposes, and is more quickly amel cheaply applienl, It is not so genel where the mole sirle of folditge must be reached, and, as a

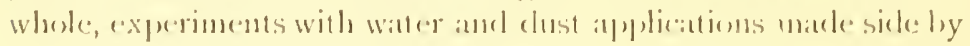
side, have ustally shown a balance in faten of the water catrier. lint where water is scaree or must lo bromeght from a distance, the dest application will give very genel sitisfaction.

l'aris green or white arsenic maty atso be mixed with from fifty lo seventy five parts, by weight, of bratu, to attrate and kill cutwoms. The latter will eat hram in preference te green vegetation, and therefore the prisened bran, mesistensed with sugat watce mutil it can be laclled out free from drif), may le used to clear an infested fiedel before the crop is set, or to protect it afterwirrels.

Cinsshoppers have an abommal fomdness for moist horsematume, and great aumbers an be killed ofl and erops protected by mixing one ponmel of the arsenic with three gallems of clopepings, and spreating these where the insects are most numerous or where injury is anlicipated. It is better to use small quantilies several days in surecession than latge quantities at one time, beratuse ats the material dries out it loses its attratetion.

Bordedur mithere is mot primarily an insecticiele, yol few insects care lo call a surface covered with it, and many seales will not set on trunks or bramelues conted with the matterial. $\Lambda$ s against the potate fleaterecte it is almest a specifie, amel there is mothing mene discomatging to the rose-bugs. As against insects it is 
rancly used alone; but combined with any of the arsenites it is

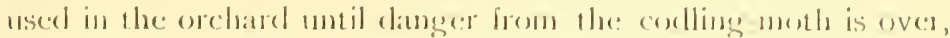
and in potate ficlds is used to hit both blight and beteles.

The formula for the Bordeamx mixhure is as follows:

Sulphate of copper

Quicklinuc

Water
6) prounds

1 poumuls

22 gallons

Dissolve the sulphate of coppere in one gallon of hest water and slake the lines in amother vessel with an equal quantity ; reduce to a creamy milk of lime and acld slowly to the (1)

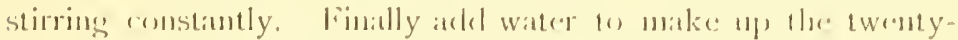
two galloms, amel this gives the old foll strength mixtures It is rancly uscel now at this concentration, lifty galloms of water

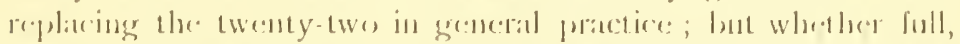

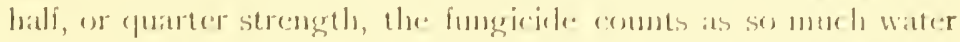

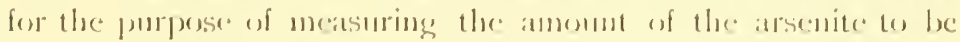

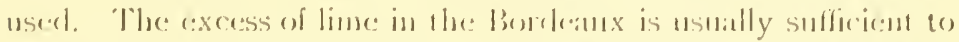
nentralize the soluble: arsenic in l'aris green, and in the arsenic

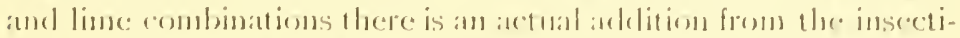
cirle. Nome of the onler fumgicieles have: alphroved themselves so

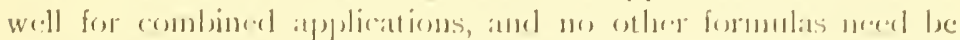
griven here, through in special instances others may lu useful.

Birhlorite of merrery, on "comesive sublinate," is an extremely violent poisone of which some: ase has leen mate, lut on the whole with small sathisfaction. Tle: matsin of siffety leetwecen effectiveness atgainst inseres and safety to plants is ses small that its use is not advised.

It mily be well to arle that all the so-callecl stomach peoisons are useful agaiust chewing or mandilulate inscects only ; as agranst plant-lice and other specoes that live by sucking plant juices, mene: of the ansenites ate in the least effective.

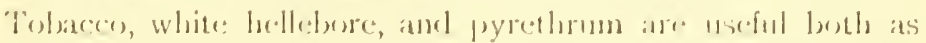
stomath and contace insecticides, fungh as a lule: used in the latter forms.

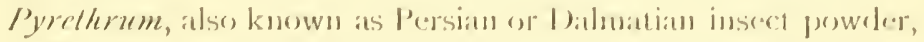

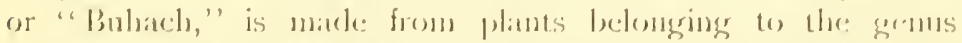
Pyrethrum which bear aster-like flowers. It is solel in the form of a finc, ycllowish powder with a pleasint and someshat pungent odor, which it luses rapidly on exposure to the air. It is at 
powerful contact poison as against plant-lice, satw-fly and other slugs, and most small naked caterpillars. It may be mixed with twice its bulk of cheap flour, and if allowed to stand forty-cight hours, in a closed jar, all parts of the mixture will be cepuatly effective. A destructive tea ma be made by stecping one ounce in one (quart of hot water and cliluting with enough warm water to make one gallon. This is excellent for sprays on house or garden plants infested by plant-lice, and is the deanest of all insecticides used for that purpose. In the fictel the cost is too great to make the material available, and its rapid deterioration on exposure to the air limits its range of usefulness. Wrhen caten, or when brought inte contact with the surfice of a larvat it causes convulsions, vomiting, and, in a short time, death. It has been used by burning to drive out llies and mospuitues, and the smoke acts as a narcotic and repellant; but the insects recover in a short time.

White hellebore is the ground root of the leratrum album, and has rather a narrow range of uscefulness. It is almost specific in its action on sitw-fly larva, and affects those insects in the sime mamer as pyrethrum. Ontside of this its action is similar to that of pyrethrum, but much less violent, and very litte is now used except against currant worms. It may be applied dry, ats a powder, or as a decoction, two ounces stecped in boiling water, being diluted to make one gallon of spraying mixture. This same decoction has been highly recommended ats against the cabbage maggot; but the reports are too contradictory to make it a safe reliance. As a contact poison the material remains effective for a short time only; but as a stomach poison remains active for several days.

Tobaceo has much the widest range of this class of materials, and may be used dry or ats a decoction. If used dry it should be ground very finc, and the dust is fatal to many plant-lice and small naked larve of all orders. As a contser powder it is useful against root-lice, especially those on peach-trees, by being worked liberally into the top soil over the root system. As the tobacio is worth nearly as much ats it costs as a fertilizer, a double advanlage is gained from its stimulating effect. Ground tobacen has been used with some suceess around cabbaye plants to prevent attacks by maggots, and in melon hills to prevent injuries by the striped beetles. Stems aromed fruit or other trees are unde- 
sirable, becuse they shelter rather than repel insects, and the water falling upon them takes out the nicotine too stowly. An extract may be made by boiling chopped stems and other refuse until one pound of tobaceo is completely extracterl in one gallon of water. This extract is effective against most plant-lice and leafhoppers, and against soft-bodied insects generally ; it is also an almost perfect protection against flea-bectles, and will kill many of the smatler leaf-feeders. Under orelinary conditions it does no injury to plants, but may spot delicate foliage or flowers. Extracts are now on the market that are condensed to a soft paste, and these, when diluted, are as effective as the: boiled material, and of course much less troublesome to preprare. As a stomich proison tobacco is not much relied upon in fielel work, and as a contact poison the sorap and petrolemm mixtures are cheaper when large quantities are used; bur in the garden and in the conservatory it holds its own. In the greenhouse, tobacen is the main reliance for green fly and many other pests, and fumigation is commonly practiced. Of late, smearing the pipes with the extract to secure the effects of a slow fumigation has been much resorted to ; lunt greenhouse plants (liffer so much in susceptibility that it is impossible to prescribe generally ; each case must be worked out by individual experience. 'Tobaceo extract is sometimes added to soaps and the combination is quite effective, though not enough so to authorize payment of the prices chargecl for it.

Lime as a whitewash has been already referred to, and the: usefulness of the dry hydrate as a carrier and the method of making it have been described. But this same dry hydrate is in itsclf useful for many purposes. If properly prepared it is yet quite caustic, and each particle of line needs one more particle of water to complete the change to the carbonate. Applied to any moist, soft-bodied slug or other larva, it gets that extra particle of water, and incidentally burns a looke through the skin of the insect. The larve of asparagus bectles may be reached by this form of lime better than in any other way; the fine, feathery foliage offers no loold to insecticides, and stomach poisons are therefore of litule use; but a clusting of the diry lime early in the morning reaches the moist larvar, and few escape a thorough application. Any other soft-bodied, shrg-like larve may be similarly dealt with, when clirect poisoning is not feasible. 
Allied to the lime, becausc of their caustic action, come the various combinations of lime and suphur, with or without salt, formed by boiling, by using the beat of the staked lime alone or by using caustic or sal solate aid the union. The result is a sulphide of line which is very corrosive, an absorbent of moisture, and which decomposes slowly, setting free a poisonous vapor. This is suitalle for winter use only, on dermant trees; is particularly applied against scale insects, and, in the liast, almost exclusively igainst the pernicious or San José scale.

The wash is originally a Californian preparation, and a generally accepted formula is :

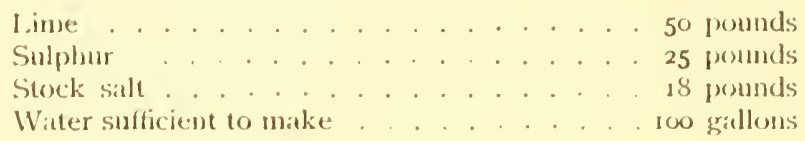

The proportions vary greatly in different localities, but long continuel, thorough beiling is always insisted on. There is no doubt that on the Pacific coast these combinations, properly made and applied, are entirely successful, and, incidentally, they have proved usceful in the control of certain fungens discascs. In the last, a great variety of expreriments hatve been made under guite different clinatic conditions, and contradictory results have been obtained ; but, as the net profuct of all the experience, it serms a fair conclusion that under favorable conditions the lime-sulphur combinations are reatsonally certain in their effects on the scale insects, and sife (n) all varieties of trees when fully dormant.

Cleemically, it recpuires less than one pound of lime to combine ome pound of sulphur, and anything more than is mecessiary is mere whitewash; but a slight excess is not harmful, and the formula that I have found most satisfactory is :

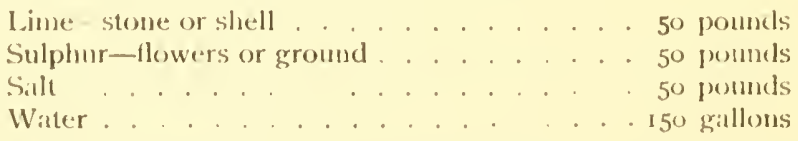

Slake the line with warm water enough to do it theroughly, and during the process add the sulphur, preferably mate into a thin paste. Buil one hour with water enough to prevent buning, and until the mixture becones a deep amber color. I) issolve the 
salt in water enough to do it quickly, and add slowly to the boiling mass. When all is thoroughly mixed together, and has boiled at least one hour, add water enough to make up the one hundred and fifty gallons and apply as soon as possible thereafter. The mixture spreads better and works easier while warm; if allowed to settle, so that crystals begin to form, the wash is useless. The salt adds nothing to the effectiveness of the combination, but doess add to its adhesiveness and to the mechanical condition which favors asy spraying. It may be materially reduced or omitted altogether; but I favor its retention. If ground sulphur is used, the boiling should be continued a little longer to make sure of a perfect solution. Many formulas demand a greater proportion of lime, lut I consicler that at disadvantage, because it thickens the wash, makes it take nore to cover, prevents it from gretting into crevices so well, and fatvors early scaling off. The boiling may be done in open kettes, or in barrels by steam, which may be furnished by any type of briler.

Instead of salt, blue vitriol is favored in Oregon and some other localities ats arleling to the fungicidal qualities of the wash, and four and one-half pounds of crystals may lec used instead of the fifty pounds of salt. The crystals are dissolved in hot water, and the solution is addecl gradually to the boiling lime and sulphur.

Next to the boiled wash in effectiveness are the combinations in which caustic soda is used to help the union of lime and sulphur. The formula that has succeederl well in my hands originated in New Vork State, and is as follows:

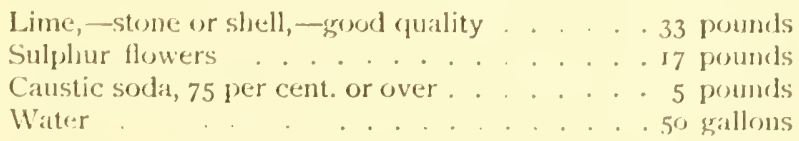

Slake two-thirels of the lime with hot water enomgly to prevent burning or drowning, and during the process sift over and stir in latf of the sulphur. Then add the remaineler of the lime with more hot water, and, as the boiling continues, stir in the balaner of the sulphur; adel water as needed, stirring to help the combination. While the mixture is yet steaming adls two promels of caustic soda, which will cause a violcnt boiling, and before that is 
over add two pounds more. If the mixture has not then reached a brick-red color add the remainder. Care must be taken not to use more water than necessary, otherwise the combination will be delayed. When the proper color is obtained, add warm water enough to make fifty gallons and use at once.

A Georgia modification is as follows:

Stone lime . . . . . . . . . . . . . . 16 pounds

Sulphur flowers . . . . . . . . . 8 pounds

Caustic soda, 75 per cent. or over . . . . 8 pounds

Water . . . . . . . . . . . 50 gallons

Mix the sulphur into a thick paste with a small amount of boiling hot water. Then add the caustic soda slowly, in lumps, keeping the mixture thoroughly stirred. Continue the addition of the soda and the stirring, adding hot water as may be necessary to prevent the mixture from getting too thick. The soda should dissolve all the sulphur in a few minutes, producing a clear, deep red liquid; if it does not, heat until no part of the sulphur remains undissolved. To this clear liquid add the lime, and while it is slaking keep well stirred. The compound mixture will have the characteristic greenish-yellow tinge, and may then be diluted with water to make up the fifty gallons for immediate applications.

Yet another formula, originating in New York, is as follows :

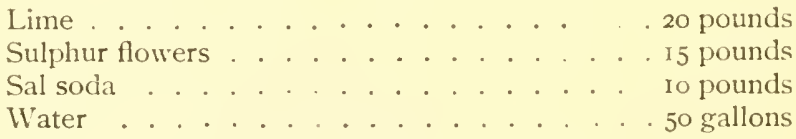

Put five or six pails of hot water in a barrel, add the lime, follow quickly with the sulphur and sal soda in the order named, and stir until slaking is completed. Add a little cold water, if necessary, to keep the mixture from boiling over. When the boiling is done cover the barrel with burlap and allow it to stand half an hour or more; then strain "and dilute with fifty gallons of cold water.

The simplest combination is to use two parts good stone lime to one part of flowers of sulphur; place the lime in a barrel; make the sulphur into a thin paste with hot water and pour over the lime; add hot water enough to slake thoroughly and cover 
with a blanket so as to retain all the heat. Stir from time to time and add hot water until every particle of lime is reduced. Then stir again and reduce with three gallons of water for every pound of sulphur used.

A Connecticut formula is ;

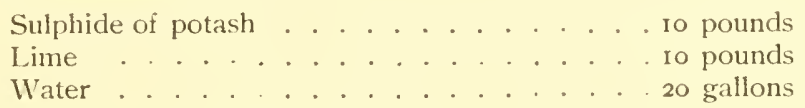

Dissolve the sulphide of potash in warm water, and with the solution slake the lime. Mix thoroughly and add water to make up the full amount.

All these mixtures have their advocates, and all are useful to a greater or less extent. A great deal depends upon the making, and it becomes a matter of practice to recognize the completed sulphide. Half an hour of boiling has been declared sufficient in some cases, and two hours in others was not enough.

As to the best time for making such applications, that is just before the trees become dormant in fall or before they begin to make a start in the very early spring. The mixtures may be employed in place of whitewash in hen-houses and stables, and will prove useful in destroying lice and mites. They are also good disinfectants and germicides for such organisms as are readily affected by sulphur.

Sulphur alone is chiefly used against mites, in either greenhouse or orchard. Red spider is sometimes controlled in houses kept moist and warm by simply scattering flowers of sulphur on the surface, the products of the slow decomposition being sufficient to destroy the insects. In greenhouses, a barrel with broken lump sulphur may be placed in a warm corner and filled with water, stirring from time to time until the luke-warm liquid becomes impregnated with decomposition products. This makes an effective spray, and water may be added as fast as used so long as any sulphur remains. In orange and other citrus groves where mites are injurious, sulphur scattered over the soil is useful, but more so in the moist climate of Floricla than in California. Sulphur dissolved with caustic potash, as described for the Georgia wash on p. $4+4$, may be directly diluted with water so as to make one pound of sulphur for twenty-five gallons of water, and this is useful as against mites and red spider of all kinds. 
Caustic soda or potash at the rate of one pound in from one to five gallons of water makes an excellent winter wash for tree trunks and branches, cleanmg them of abnormal vegetable growths, destroying fungus spores, and many of the insects that hibernate on rough or lichen-covered bark. As against some of the thimner scales it forms an excellent protection, but as against the more densely armored forms it is useless.

On the Pacilic coast resin washes are much used against scale insects, usually with good results; but in the East the mixtures have not met with such favor.

A good summer wash is made as follows:

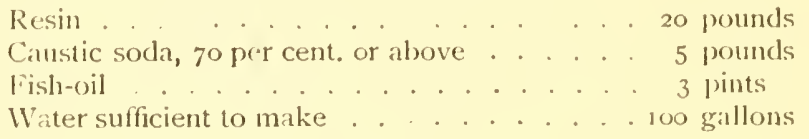

This is effective against scale larve and recent sets, plant-lice, and other species of that character. It acts by clogging the breathing pores, and sometimes by sealing recent sets to the surfarce, this latter effect being much more marked in dry regions than in those that are moist or rainy. It may be safely applied to the foliage of most fruit trees.

The winter wash is as follows:

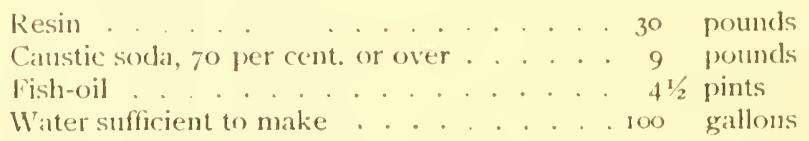

This is really a thin varnish, and is fatal to foliage and young shoots when applied at other than the dormant stage. As a varnish it is readily solnble in water, hence in the wet last is not so effective as in the dry W'

To make these washes boil all the ingredients together with about twenty gallons of water until thoroughly dissolvecl, adding hot water from time to time as needed, but never enough to stop the boiling after it once begins. Three hours will be recpuired for a complete mixture, hot water to make up fifty gallons being gradually adcled, and the stirring continuous. After this the balance of the one humdred gallons may be added in cold water.

All seaps have an insecticide value, and they usually kill by 
clogging the spiracles, and so choking the insects. It follows that, as a rule, only those insects with exposed openings can be reached, and that the application must be so mate ats to cover completely. Soaps that are sticky and lather freely, leaving a scum when dry, are better than those that are clean. Therefore, fish-oil soaps are more useful than those made from animal fats. Sometimes soaps serve only as carriers for petroleum, quassia. tobacco, or carbolic acid ; but more usually only enough of such materials is added to give a distinct odor, and nothing is gained except a larger price by the makers.

There are several good fish-oil soaps on the market,-usually called whale-oil, though there is no whale-oil in them,-and these, whether emulsified with soda or potash, sell for from two and one-half to five cents per pound according to the quantity ordered; in single pound lots for even a higher price. At a strength of from one pound in four to one pound in six gallons of water they reach most plant-lice and larval scales. One pound in six is usually the extreme dilution that is effective against insects, and when stronger it becomes necessary to watch for injury to foliage. Mature foliage suffers less than such as is immature, and in late summer most fruit trees will stand one pound in one or two gallons when it is necessary to check scale development. A very satisfactory soap can be made according to the following formula, first suggested by the New York (Geneva) Station :

Caustic soda, 75 per cent. or over . . . . . . 6 pounds
Water . . . . . . . . . . . . . . . . . . . . . 6 quarts
Fish-oil . . 22 pounds

Dissolve the canstic soda in warm water until it is thoroughly fluid; then pour in the oil slowly, stirring thoroughly and constantly until the combination is complete. Complete and thorough stirring is essential to success, and the oil should be warmed to eighty degrees Fahrenheit, or thereabouts, so as to make it thoroughly fluid before adeling to the soda solution. Almost any kind of fish-oil will answer, and the amounts above given will make about forty pounds of soap. For smaller quantities, one-sixth of the amount may be used, and one pint of oil may be reckoned as a pound. This makes a cheesy mass when cold and is stronger than the commercial article, so that one pomnd in seven gallons of water will do as well as one pound in six gallons of the latter. 
For winter use as against armored scales, two pounds in one gallon of water are necessary, and this must not be used until after michinter, as otherwise severe injury may be caused to fruit buds or even twigs and branches. At this strength the application is intensely caustic, and the scales are corroded, lifted, and dried out, while the soap, dissolved by rains, penetrates through the covering to the insect beneath.

Petroleum or naphtha soaps, or soaps containing a greater or less percentage of mineral oil in solution, are better than ordinary laundry soaps, but not so effective as fish-or " whalc-oil" soaps. The percentage of petroleum is usually small, and without a guide as to the actual amount their use is uncertain. Besides, at the prices charged, the ordinary kerosene emulsion is cheaper

Among the contact poisons none rank higher than the mineral nils, whether in the form of the crude petroleum or the refined kerosene; but their effect on plant life is often severe and not ahways identical.

As against scale insects that hibernate in the partly grown condition, there is nothing better than crude petroleum of forty-three degrees specific gravity on Beaumé scale, and, when properly applied, it is safe on almost all kinds of trees when they are dormant. Given an oil of the proper gravity, with a vaseline base like all those from the Allegheny region, it should be applied slightly warm-about seventy degrees Fahrenheit-through a fine vermorel nozzle, with a good force behind it, on a dry day to a dry tree, and just enough to wet thoroughly. The oil is very penetrating, soaking through the dry scale covering at once, and coming into contact with the insects. The light nils evaporate in a few minutes, and there remains a film of paraffine and vaseline which is either absorbed in time by the surface or by the dust that settles on it. The vaseline coating gives the application its lasting power, and sooner or later it gets through the thickest layer of scales; but it also constitutes the danger, for when the oil is applied in excess the outer bark becomes soaked, and on the smaller twigs and branches the bast as well as the tissue dies. In the hands of the experienced man there is no more effective material than crude oil; in the hands of the careless laborer there is nothing more dangerous to plant life.

Emulsions of crude oil have not proved satisfactory and mechanical mixtures made by emulsion pumps are equally unreliable. 
The best of the pumps that were supposed to spray definite proportions of oil and water, failed under ordinary field conditions, and after a period of popularity have been almost entirely abandoned.

Of late, chemists have found means to treat the crude petroleum, both of paraffine and asphaltum base, in such a way as to make it readily and directly miscible with water. These soluble petroleums are still unduly high in price, and are sold under such names as Kill-O-Scale, Scalecide, and the like; but they have really solved the problem of using petroleum safely and effectively. They are essentially winter washes, but may be safely applied at almost winter strength (one to twenty-five) any time after October $\mathrm{r}$, and at full strength (one to twenty) up to the time that the buds open in the spring. The range of usefulness for summer work has not yet been determined; but the way having been opened, it seems probable that this most effective of insecticides will shortly be developed so as to make it safe on all sorts of plants at all times.

Kerosene is a distillate from crude petroleum, and equally fatal to insects. It lacks the lighter oils and the paraffine, vaseline, asphaltum, and other heary remnants, and hence evaporates completely and rather rapidly. I have used it in a fine spray, undiluted, on trees and plants in full foliage without causing the least injury, and it has been so used by others; but it is a dangerous application in careless hands, and not to be resorted to unless there is danger to the tree from the insect attack. Made into an emulsion so as to mix with water, it has a great range of usefulness wherever an active contact insecticide is needed. Kerosene emulsions or preparations which make the oil readily miscible with water may now be purchased from several manufacturers of insecticides, or may be made as follows :

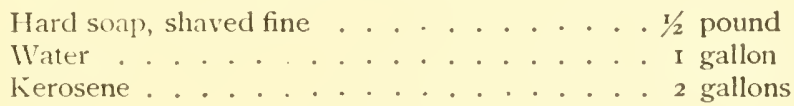

Dissolve the soap in boiling water; warm the kerosene and add the boiling hot suds to it; then churn with a force-pump for a few minutes, and we get first a milky appearance, which yields rapidly to a cream, and this to a soft, butter-like mass. When cold, it will adhere to glass without oiliness, and the emulsion 
thus made, containing sixty-six per cent. of kerosene, will remain unchanged for some time, and may be mixed with water to any extent. Soft water must be used for best results, and with very hard water a real emulsion cannot be obtained at all without the addition of borax sufficient to soften it. Diluted from nine to twelve times, this emulsion is very effective against plant-lice, many scale insects, and such others as yield to contact insecticides in general. Plants vary in their resistance to this material, not only absolutely but relatively, under different climatic conditions. Diluted nine times, few insects resist its effects, and only the hardier plants can be safely treated ; diluted fifteen times, only the green plant-lice are affected, while some foliage shows material injury. Where plants do not readily stand a dilution of twelve times it is better not to use the emulsion at all. For winter use, the emulsion is useless as against dormant scales, and more injurious to trees than the undiluted oil.

In a mechanical mixture, applied with emulsion pumps, much larger percentages of kerosene may be safely used, and as a winter application, twenty to twenty-five per cent. of oil, is quite effective against dormant scales when thoroughly applied.

Another method of mixing oil and water is by using one of the prepared finely ground limes or the very fine dry hydrate as follows: Pour the kerosene into a barrel, and for each gallon stir in four pounds of lime, keeping the mixture in continuous motion until it forms a thin, sloppy mass. In case a little k erosene separates add more lime to absorb it. To this add water in quantity equal to the kerosene, stir vigorously to get it well mixed, then add as much more water as is needed to get the desired percentage, and pump the mixture back into itself until a thorough emulsion is secured. It is then a smooth mixture, which flows freely through any nozzle, provided it is well agitated and no foreign matter gets in.

This kerosene lime, or K-I, reduced so that it contains twenty to twenty-five per cent. kerosene, has been effectively used as a winter wash against dormant scales, and it is safe if reasonably used. As a summer wash, ten per cent. may be safely used on most foliage. The lime here takes the place of soap as emulsifying agent, but adds nothing to the effect against the insect nor danger to the tree. Crude oil cannot be used in this way because it forms clots. 
The addition of pyrethrum extract to the kerosene emulsion has been advised, but the increased effect has been small while the cost is considerable; hence the mixture is not now in use or recommended. So the kerosene mixture of one quart of soft soap, two quarts water, and one pint kerosene, where the water is so hard as to make an emulsion impossible, has fallen into practical disuse.

Speaking broadly, the mineral oils are extremely useful insecticides in most portions of our country, when their use is understood and the applications are intelligently made; otherwise, they are better left alone.

Gasoline, a much lighter oil, is useful as a contact insecticide in a limited number of cases. It can be applied to textiles infested with " moths," or to carpets infested with "beetles." It is very penetrating, kills everything it touches save eggs, and evaporates rapidly without injury to the fabrics, or to the colors, except of the poorest. It is also the best remedy for reaching bed-bugs and other parasites that hide in crevices The material is very inflammable, and must be used with that fact in mind at all times.

Turpentine is rarely used as an insecticide, but it is occasionally added at the rate of one pint to a bushel of lime to keep off the striped beetles from melon plants.

Carbolic acid is valuable to a limited extent. It may be added to the whale-oil soapsuds at the rate of one ounce of crude acid to one gallon of suds, and this adds materially to its effectiveness, especially as against the black plant-lice; but as the same result can be obtained by using less water in the soap mixture, it becomes a mere question of expense and simplicity.

Where lime is to be used as a repellent, the addition of one pint of the crude acid to every hundred pounds of the dry hydrate increases its efficiency, and very few insects will touch a surface so protected. The acid is mixed with the water used in slaking the lime.

As an emulsion it is prepared as follows: Dissolve one pound of hard soap, shaved fine, in one gallon of boiling water ; add one pint of crude carbolic acid, and churn with a force-pump until a smooth, creamy emulsion is obtained. This remains stable for a long time, and may be diluted with thirty parts of water for use against root-maggots affecting cabbage, onions, and the like. It 
is to be applied freely around the hase of the infested plants, and probably, in part, depends for its effectiveness upon the large amount of soap it contains. In any case, the earlier the application is made the greater will be the effect.

Carbolic acid in varying proportions is often added to mixtures that are applied to tree trunks to prevent the entrance of borers. It cloes no harm, at any rate, and there is some evidence that the carbolated applications are more completely protective than are those that contain no such material.

Quassia, in the form of a decoction, has been recommended for insects of various kinds, notably plant-lice, but in my own experience the results have been unsatisfactory.

Water, either hot or very cold, has some value as an insecticide; but the margin of safety is small. Boiling water is quickly fatal to most insects and to vegetation as well. At one hundred and twenty-five degrees Fahrenheit it is fatal to most insects and safe on foliage generally; at one hundred and forty degrees Fahrenheit it is still safe on most foliage, but above that danger begins, and, at one hundred and sixty degrees Fahrenheit it kills all vegretation on which I tried it. At first blush this seems a very simple remedy, but the practical difficulties of getting the water on at the right temperature are so great that it is rarely used, and then only when it can be applied at short range.

Very cold or ice-water is effective against plant-lice under some circumstances, and I have known of trees and bushes completely cleaned by one application. But our present knowledge of the effect of cold on insects and plants is too small to make practical recommendations possible.

Repellents are those materials which are intended to prevent insects from injuring plants that would otherwise be attacked, and it is generally believed that it is the odor that repels. The vapors of some substances, like turpentine, kerosene, naphthaline, camphor, or the like, are absolutely poisonous when breathed, and insects keep away because of the choking sensation produced. Therefore, lime or plaster with turpentine repel the striped melon beetle, while tar-water will not. Other substances have an odor so strong as to disguise that of the food plant so that the insect does not recognize it ; therefore ground bone or fish scraps will attract small rove beetles, but not melon beetles to the melon hills so protected. 
Gas-tar is sometimes used as a repellent, but is rarely of any practical value; it protects where it covers, but no further. So tar-water has been used against plant-lice, sometimes with a measure of success; but it is not sufficiently reliable to make its use advisable for general purposes.

Naphthaline in the form of crystals volatilizes slowly, and in a close space makes the air unfit for insects; therefore it is used to protect stored products, and packed with clothing, woollens, or other fabrics in a tight box or closet preserves them from " moths." It has been said that a sprinkling of the crystals on the surface of grain in bins will keep off " moths," "weevils," and similar pests, and, no doubt, that is true to some extent.

In all that is said here concerning insecticides and their effect, the general experience is quoted; but it should be remembered that many of them are affected by differences of climate or meteorological conditions. More correctly stated, both plants and insects differ in different regions in their susceptibility to certain insecticides; hence the progressive and careful farmer will, before trying any of the recommended materials on a large scale, either test them in a small way or inquire of the experiment station or other growers in his vicinity. In general, the statements made are based upon the work done in the Eastern, Central, and Northern United States.

Bisulphide of carbon is a foul-smelling liquid that volatilizes readily at ordinary temperatures and produces a heavy vapor that is deadly to insects of all kinds when they are confined in a closed space and must breathe it. It is especially useful against species infesting stored products, like grain and other seeds, or even in mills and provision houses where they become overrun with "skippers" or Dermestids. When used to kill insects in bins and closed receptacles, a drachm or, roughly, a teaspoonful to each cubic foot of space, will answer. It should be placed in open vessels on top of the grain in the bin or other receptacle, and the vapor, being heavier than the air, will sink to the bottom, where there should be a few screened openings to permit the escape of the material No length of exposure will injure grain for milling or feeding purposes; but seed grain may lose germinating power if exposed longer than twenty-four hours. Its use against certain plant-lice and other underground insects has been 
previously referred to. Bisulphide of carbon is very inflammable and explosive, and in no building where it is used should a firc or open light of any kind be allowed. Lighted pipes and cigars must be avoided, because even a spark may cause an explosion; but with ordinary precautions entire buildings may be safely and effectively treated. In all cases where vapors are used their effect depends on their poisonous action when breathed; therefore, the rooms, enclosures, bins, or other spaces must be as tightly closed as possible, and in large spaces an excess of material should be used, that they may be more rapidly and completely filled.

Hydrocyanic acid gas is a vapor cxceedingly destructive to all life; but more fatal to animals than to plants. Its use has increased to such an extent during recent years, that the general term fumigation has come to have a specific application to the exposure of infested plants to the action of this gas, produced as follows :

Cyanide of Potassium, 98 per cent. pure . . . . I ounce Sulphuric acid, specific gravity $1.83 \ldots 2$ ounces Water ................... 4 ounces

Use a glazed earthenware vessel of any kind. Put in first the water, then pour in the acid slowly, then, in a thin paper bag, drop in the cyanide broken into small lumps, and get out. The amount above given is sufficient to fill one hundred cubic feet of tightly closed space with a vapor that will kill dormant scales or, in fact, any other animal life in an hour, and will be harmless to all dormant stock save peach, and to most trees other than conifers, which should never be fumigated.

This whole matter of fumigation has become so important that Professor IV. G. Johnson, now editor of the American Agriculturist, has published a book to cover the subject. Naturally, a brief reference is all that is possible here; but a few well-established points may be noted as essential :

First. - The fumigating house, box, tent, or cover must be as nearly gas-tight as it can be made, and should hold the gas, practically intact, for at least one hour.

Second. - The chemicals should be as nearly pure as possible, and the cyanide, especially, should be of high grade.

Third.- The order of mixing should be followed absolutely according to formula, to avoid unpleasant results. 
Nurserymen can clear their trees of most of the scale pests by fumigation, and almost atl insects, not in the egg stage, may be killed by this process. In the orchard, the Pacific coast horticulturists have developed a practice that must be described at length to be understood. In the East, fumigation has made little headway, and there is no prospect of great improvement in the near future. In the conservatory or greenhouse, Prof. Johnson's book is a reliable guide; but practically every kind of plant must be separately studied before the gas can be safely and effectively used. In factories, mills, or houses, when infested by insect pests of any kind, this cyanide fumigation offers the best remedy, provided the inclosures can be made tight and no human beings are exposed to the gas. It must always be remembered that this combination is about the most poisonous mixture that can be generated, and that it requires only a little carelessness to result fatally.

For some unknown reason, the gas acts more fatally upon insects and less harmfully upon plants in the dark; hence fumigation should be made at night, under black tents or in dark inclosures. Where tents are used to cover trees, or where nursery stock is to be covered in bulk, eight-ounce duck soaked in boiled linseed oil is the best material and most nearly gas-tight. Treatments should never be made in the middle of a hot day nor, when it can be avoided, on deciduous trees when in foliage.

A few words must be said of patented insecticides or mixtures sold under fancy names. In general such should be avoided, for, though some are meritorious, they cost altogether too much. The name has often covered a mere mixture of Paris green and land plaster at druggist's rates, and, practically all of the combinations intended to reach chewing insects have an arsenical preparation as a base. It is also advisable to warn against plausible schemes for preventing insect injury-i.c., placing some substance into the body of a tree to be carried into the circulation to repel or kill insects inclined to feed on the foliage. All such preparations heretofore used have been frauds, and in the same category belong those mixtures into which seeds or tubers are to be dipped to prevent the attack of insects on the foliage that comes later. 


\section{CHAPTER V.}

\section{MACHINERY.}

Having determined the character of an injurious insect and the remedy to be applied, it remains to decide the method in which the application is to be made; and that necessitates some information concerning pumps, nozzles, bellows, and the like. A few years ago advice was easy, for the choice was restricted ; now there are dozens of pumps, ranging from bucket to power sprayers, and each farmer must be left to select that type of machine most suitable to his needs. Indeed, matters have progressed so far that many fruit-growers order outfits of their own design to suit their particular conditions. Consequently, only general principles can now be offered under this heading, and the first of all is that, whatever the outfit, be sure that it is amply sufficient for the purpose intended. Thoroughness is essential to a satisfactory result in any case, and that is unattainable with inadequate machinery. The pump should have the working parts of brass, the valves metal, the handle so adjustable as to give the maximum leverage for the stroke; the air chamber should be of good size to secure equality of pressure, and the whole should be put together in such a way as to be easily taken apart for cleaning or repair, in case that becomes necessary. Simplicity and power,-the maximum effect with the minimum effort, - these are the desiderata! Too large a cylinder is not desirable, because pressure rather than large capacity of discharge is clesired. It is better in all pumps of any size to provicle for two discharge outlets, and half or three-quarter is better than full hose, because the tubing can then be made both stronger and lighter.

For ordinary spraying work, nothing is better than the Vermorel nozzle, or one embodying the principle of a rotary chamber; and where a group of three is employed, a great ball of fine spray can be produced that will cover a large surface in a very short time. For geared machines used in the field to spray several rows of potatoes or other crops at once, nozzles of the Bordeaux type, throwing a flat spray, are better, because they are more readily cleared when they clog. Such nozzles are also 
more desirable when lime or similar thick washes are to be applied.

As to tanks, anything that holds water will serve; and the farmer should so arrange matters as to make the best use of what outfit he already has. Nothing will be gained by describing the various arrangements for reaching the tops of trees or all sides of a row of any field crop. These are details that must be worked out by the individual with the aid of the catalogues which manufacturers will be glad to send on request.

Gasoline and steam engines are used to produce power where large orchards of large trees must be sprayed, and in cities where shade trees are to be dealt with, such machines are usually built for specific needs. A recent type is a machine in which the axles are geared to an air-pump and the power is furnished by the air so compressed.

The simplest type of power machine is a steel tank from which the mixture is forced by the pressure of liquid carbonic acid gas. This machine has the power under the most absolute control, and requires no exertion to produce it.

A good machine for applying an insecticide must distribute it quickly, thoroughly, and economically ; and whatever the outfit may be, it must be adapted to do its best work under the conditions of the locality where it is to be used.

Brief mention may be made of the atomizers and compressed air sprayers of small capacity for garden use, which may be purchased of almost any seedsman or hardware dealer, so that not even the city gardener need be without his spraying outfit.

Applications in dry form are gaining in favor in localities where the water supply is limited; and in place of the oldfashioned hand bellows there are now fan-blowers of all sizesdusters that will cover half a dozen rows of potatoes or a large apple-tree with equal ease and thoroughness! Simple methods of distributing dry Paris green in cotton fields through a pair of sacks are in local use ; but are not available to an equal extent elsewhere.

Combination or emulsion pumps, spraying oil and water in a definite percentage, have been on the market for some vears, but have not proved satisfactory in all respects. So long as they work well the results obtained are good: but the two pumps or suctions do not always work evenly, and the least disturbance to one 
disturbs the proportion of oil and water, and the results are seen in injury to trees and lack of effect on insects.

l'ractically, then, the whole matter of selecting an outfit for applying insecticides from the wide range of those on the market is on exactly the same plane as the selection of any other bit of farm machinery. The lowest priced machine is not always the cheapest, nor is the highest priced always the best-simplicity and durability at a moderate cost should be aimed at.

Special apparatus for a special purpose is occasionally proposed, placed upon the market, and then abandoned. Such was the McGowen injector for applying bisulphide of carbon to underground insects. The instrument was fully adapted to its purpose, but the demand was not sufficient to warrant its continued manufacture.

So, local needs develop collectors for definite purposes; like " hopper-dozers" for gathering grasshoppers or leaf-hoppers ; or

F1G. 474 .

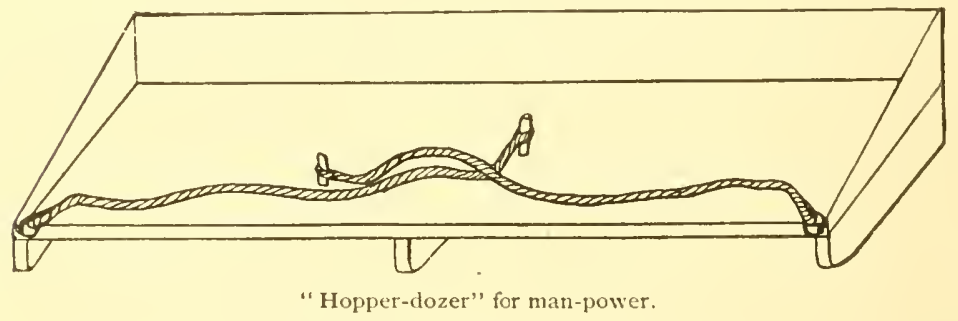

"curculio catchers" for collecting the pestiferous plum curculio : or fans or other machinery for gath ering grape-leaf hoppers, etc., etc. Such special devices are usually brought to the notice of those that need them through the agency of the experiment stations; their detailed description would enlarge this chapter out of all due bounds.

Finally, a few words as to fumigating outfits. Since the advent of the San José or pernicious scale in the Eastern and Central States, and the general adoption of the hydrocyanic acid gas treatment for nursery stock, so many kinds of boxes, tents, and other coverings have been described that even the mere enumeration would make quite a page. Briefly stated, the requisites for successful fumigation are a tight covering and pure chemicals. 
FIG. 475 .

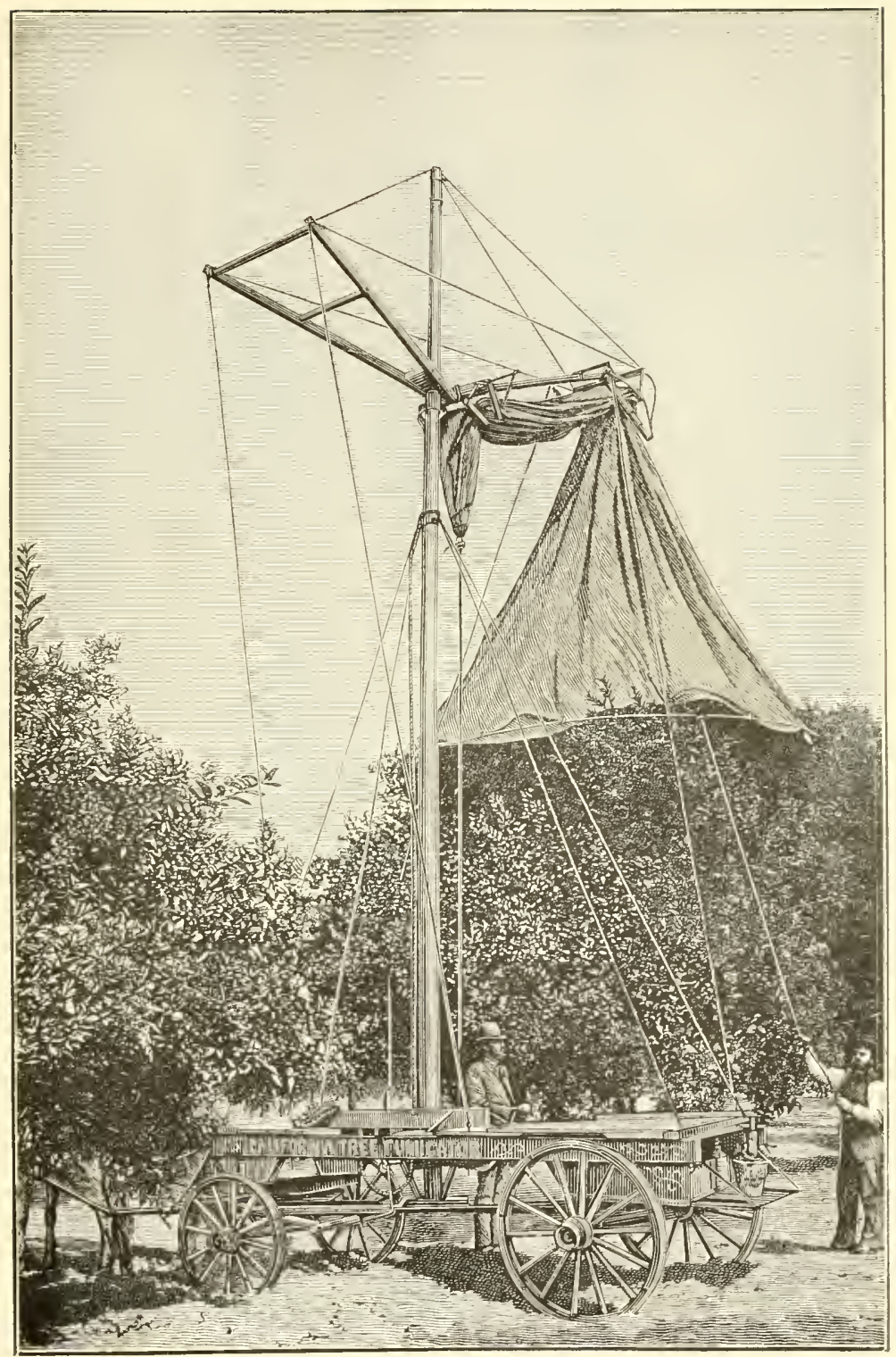

The Wolfskill fumigator. 

For the nurseryman this is an easy proposition, because he builds a house of suitable size, of proper material, and so arranged that it will close tightly, excluding light and air and retaining the gas. For the orchardist the matter is less simple. He must have a cover to fit around or over his trees, and the moving of a large box always requires considerable help or mechanical aid. If the trees to be treated are large, there must be a tent of oiled canvas of great size and weight, and a special derrick or other mechanical contrivance to move it. No two trees being quite equal in size, the amount of chemicals must be calculated for each.

Professor W. G. Johnson's book covers all these points, and should be consulted by anyone intending to consider orchard fumigation in the East. On the Pacific coast conditions are so much different that either a community owns an outfit and has trained men to operate it, or it becomes a commercial matter, and outfits nay be hired, the owner of the trees simply footing the bills. 



\section{N D E X.}

Abdomen, how made up, 26. Acanthia lectularia, I55.

Achatodes zeae, 299.

Acrididre, defined, 85 .

life history, 89 .

Acridium species, 89 .

Acronycta americana, 289.

Actias luna, 282.

Aculeata, defined, 390 .

Adalia bipuncta, $17+$.

Adephaga, defined, 165 .

Adhesive mixture, 437

Agallia sanguinolenta, 147 .

Agaristidæe, 264 .

Agricultural ants, 398 .

Agrilus ruficollis, 186 .

sinuatus, 187 .

Air-sacs or blardders, $3^{6}$.

-tubes, extensile, 37.

Alaus oculatus, 183.

Alder-blight, 133 .

Aletia argillacea, 301 .

Aleyrodes citri, I22.

Aleyrodidx, I21.

Allorhina, species, 203.

Alulet, 365 .

Alypia octo-maculata, 263.

Ambulatoria, 8I.

American blight, I33.

Amphicerus bicaudatus, 195.

Anabrus simplex، 97.

Anal glands and secretions, 30 .

Anasa tristis, 160.

Anatis I5-punctata, 174 .

Andrena species, $4 \mathrm{II}$.

Angoumois grain moth, 326 .

Anisopteryx species, 307.

Anisota senatoria, 278.

Anomala lucicola, 202.
Anomis species, 300 .

Antenna, function of, 20 . general characters, $\mathbf{1} 9$.

Anthocoridre, 156 .

Anthomyiids, 360 .

Anthonomus 4-gibbus, 232. signatus, $23 \mathrm{I}$.

Anthrax, species of, $3+5$.

Anthrenus scrophularize, I79

Ant-lions, 76 .

Ants, described, 390. and plant-lice, 127, 394.

ipanteles species, 383 .

Aphaniptera, 328 .

Aphelinus mytilaspidis, 385 .

Aphidida, 123.

Aphidius species, 384 .

Aplis-lions, 74 . mali, 134 .

parasites, $3^{8} 3$.

persica-niger, $\mathbf{1} 34$.

Aphodius, 198.

Apis mellifica, 4 I4.

Apple, Anthonomus on, 232.

blight-louse, 133 .

case-bearer, 324 .

codling moth on, 322 .

flat-head borer in, 186 .

leaf-crumpler, 313 .

long-horned twig-borers, 209.

-louse, 134.

-maggot, 366 .

oyster-shell scale on, II 5.

round-head borer in, 209.

tree-hoppers on, 138 .

twig-borer, 195 .

yellow-neck caterpillar, 275 .

Aquatic forms, how they breathe, 36 .

Aramigus fulleri, 228. 
Arbor-vitic, bag-worm on, 273.

Arctiidie, 266.

Argynnis species, 2.4.

Arista of flies, 330 .

Armored scales, I I4.

Army-worm, 294.

Arsenate of lead and its use, 436 .

Arsenic and lime combinations, $+3+$.

Arsenic as an insecticide, 434 .

Arsenites and their use, $433-438$.

Ascalaphus species, 76 .

Asilidae, 344.

Asopia costalis, 3 I 2.

Asparagus beetle, 2 I I.

Aspidiotus perniciosus, II 8 .

Atomaria species, 177.

Atomizer sprayers, 457.

Atropos species, 69 .

Attacus species, 279 .

Auditory sense of insects, 43 .

Automeris io, 283 .

Bag-worms, 273.

Balancers of flies, 327 .

Balaninus species, 234 . .

Bandings of printers' ink, etc., 43 I.

Bark-beetles, 237. -slippers, 207.

Beak of bug mouth, I6.

Bean lady-bird, 175. -weevils, 223.

Bed-bug, I 55 .

Bcech blight, I33.

Bees, 407. long- and short-tongued, $f$ ro.

Bee-flies, 345 . -louse, 370 . -moth, 316. mouth, 19.

Beet-leaf maggots, 365 .

Beetles, chapter on, I64. classification of, 165 .

Bell moths, 319 .

- Belostoma americana, i 50.

Bemberia marginata, 260.

Bembecide, 403.

Bibionidæe, 370 .

Bichloride of mercury, 439 .

Bill-bugs in corn, 236.
Bipectinated antennac, $2 \mathrm{I}$.

Bisulphide of carbon, 453 . against hen-lice, $7 \mathbf{I}$. against Termites, 67.

Biting lice, described, 70 .

Bittacus, 77.

Black beetles, their habits, 82 .

Blackberry cane-borer, 186. crown-borer, 260.

pithy gall, 378 .

root-borers, 206.

saw-fly borer, 375 .

Black flies, 340.

Blattidx, described, 8I.

Blennocampa pygmæa, 374

13 lissus leucopterus, $5_{58 .}$

Blister beetles, 225.

Ijlood of insects, 33 .

Blow-fly, 257.

Blues and coppers, 245.

Boly-louse, life history, 105.

Boiled lime wash, $44^{2}$.

Boll-worm, 303.

Bombardier beetles, I68.

Bombyliidae, 345 .

Bombylius species, 345 .

Book-lice, 68.

Borax, against roaches, 82 .

Bordeaux mixture and its uses, $43^{8}$.

Boreal lady-bird, I75.

Borers, remedies for, I88. 430 .

Boreus, 77 .

Bostrychus, I93.

Bots on cattle, 352 .

Bot-flies, 35I.

Brachinus, 168.

Brachystola magna, $9 \mathbf{I}$.

Braconida, 382.

Brain in insects, 39 .

Bran and Paris green, 438 .

Braula creca, 370 .

Breast-bone of gall-gnats, 336 .

Breathing of insects, 33 .

Bristle-tails, 53 .

Bristled antennæ, 22.

Bruchidæ, 223.

Brush-footed butterflies, 242.

Buffalo gnat, 340 .

grasshopper, 9 I. 
Buffalo moth, I79.

tree-hoppers, 138.

Bugs, defined, Ioo.

Buhach, 439.

Bumble-bees, $4 \mathrm{II}$.

life history, $4 \mathrm{I} 6$.

Buprestidæ, 185.

Buprestis, 185.

Butterflies, chapter on, 240.

classified, 24I.

mouth of, 16 .

Byturus unicolor, 180.

Cabbage butterflies, 246 . harlequin bug on, 162 .

-lice, I34.

-maggot, 361.

Plusia, 302.

thrips, IO2.

-worms, parasites on, 385 .

Cacœcia fervifana, 321.

rosaceana, 321 .

Caddice-flies, 77.

Cadelles, I82.

Cæcal tubes or pouches, 30 .

Calandra, species of, 237.

Calliphora vomitoria, 357 .

Camel crickets, 97.

Canker-worms, 307.

Capsidæ, 156.

Carabidæ, 166.

Carbolic acid and its uses, $45 \mathrm{I}$.

Carbon disulphide and its uses, 453.

Carnivorous beetles, $\mathbf{1} 65$.

Carolina locust, 88.

Carpenter ants, 39 I. bees, $4 \mathbf{I} 2$.

Carpet beetle, $\mathbf{I 7 9 .}$

Carpocapsa pomonella, 322 .

Carpophilus hemipterus, I8I.

Carrion beetles, I7 1 .

Cassida bivittata, 222.

Cassidæ, 222.

Catch crops, use of, 426 .

Caterpillar hunters, I68.

Catocala species, 306.

Caustics, how they kill, 39 .

Caustic potash and soda washes, 446 .

Cecidomyia destructor, 336 .
Cecidomyia leguminicola, 338 .

Cecidomyidze, 336 .

Cecropia moth, 280.

Cephalo-thorax, defined, 34.

Cephus pygmæus, 376 .

Cerambycidæ, 205.

Ceraphron triticum, 388 .

Ceratocampidæ, 278.

Ceratomia amyntor, 257.

Ceratopogon species, 334 .

Ceratópsyllus serraticeps, 329 .

Ceresa bubalus, I39.

Cerci, defined, 26.

Cercopidæ, defined, I 46 .

Ceroplastes, I I 2 .

Chretocnema confinis, 2 Ig.

Chalcididæe, 384 .

Chalcophora, 185 .

Chauliodes pectinicornis, 72 .

Chauliognathus, IgI.

Chermesinæ, defined, I28.

Cherry-louse, I34.

Chestnut weevils, 234.

Chicken-fleas, 329.

-lice, 7 I.

Chickens versus insects, 426 .

Chilo species, $3 \mathrm{I} 7$.

Chilocorus bivulnerus, I74.

Chinch-bug, life history, I58.

Chinese silkworm, 286.

Chionaspis furfurus, II9.

Chironomidæ, 333.

Chitine, peculiarities of, I4, 38 .

Chortophaga viridifasciata, 88 .

Chrysalis, defined, 50.

Chrysanthemum fly, 348 .

Chrysididæe, 390.

Chrysobothris, 186.

Chrysomelidæ, 205, 210.

Chrysopa, 74 .

Chrysophanus, species of, 245 .

Chylific ventricle, 30.

Cicada, defined, I39.

septendecim, Iq0.

Cicindelidæ, I66.

Cigarette beetle, 193 .

Ciliated antennæ, 22.

Cimbex americana, 374 .

Circulation in insects, 33 . 
Citheronia regalis, 278.

Classification in general, 52 .

Clavate antenne, 21.

Clavicornia, defined, 105.

Cleanliness, to clueck insects, +23 .

Clear-wing moths, 259 .

Cleridae, I92.

Clerus apivorus, 192.

Click-beetles, 182.

Climbing cut-worms, 292.

Clisiocampa americana, 284 .

Clothes moths, 32.4 .

Clothilla, 69 .

Clothing of bees, 408 .

Clover hay-worm, $3 \mathbf{I} 2$.

leaf-beetle, 229.

seed-midge, 338 .

stem-borer, 176 .

Coccidæ, defined, 106.

Coccinella 9-notata, 174 .

Coccinellidæe, 172.

Cochineal insect, 106.

Cockchafer, 201.

Cockscomb gall on elm, 132

Cocoon, described, 50.

Corlling moth, 322.

Colcoptera, defined, 54,55 .

chapter on, 164 .

classification of, 165 .

Colias philodice, 250.

Colon, described, 30.

Colopha ulmicola, $\mathbf{1}_{32}$.

Colorado potato-beetle, 213 .

Commercial fertilizers as insecticides, 427 .

Complemental sexes of Termites, 66 .

Complete metamorphosis, 50.

Compound eyes, 42 .

Cone-nosed grasshoppers, 96 .

Conocephalus, 96 .

Conopidre, 35 I.

Conorhinus sanguisuga, ${ }_{52}$.

Conotrachelus crat:xgi, 234.

nenuphar, 232.

Contact poisons, how they act, 38 .

Coppers and blues, 2.45 .

Copris carolina, 198.

Coptocych aurichaicea, 223.

Corejlie, defined, I6o.
Corimelænidx, defined, 163.

Corn bill-bugs, 236 .

-root Diabrotica, $2{ }_{5} 5$.

-root-louse, I34.

-root web-worm, 3I7.

-worm, 303.

Cornicles, defined, I26.

Corisa, habits of, 150 .

Coriscus, 153.

Corrodentia, 68.

Corrosive sublimate, 437 .

Corticaria, 177.

Corydalus cornutus, 72 .

Corynetes rufipes, 193.

Cossidæ, 286.

Cotalpa lanigera, 202.

Cotton boll-worm, 303 . red-bug on, ${ }_{57}$.

-stainer, I 57.

-worms, 300.

Cottony cushion scale, 108.

maple scale, i ro.

Cow-lice, how destroyed, $7 \mathbf{I}$.

Coxa, defined, 26.

Coxal cavity, defined, 26 .

Crab-louse, ro5.

Crambids, 3 I 6.

Crambus species, 317.

Cranberry firc-worm, 320.

fruit-worm, 3I3.

span-worm, 309 .

Teras, reflowing for, 428 .

Crane-flies, $33^{\circ}$.

Cremastogaster lineolata, 392 .

Crepidodera, 219.

Crickets, 97.

Crioceris asparagi, $2 \mathbf{I I}$. I2-punctat Us, 2I I.

Crop, described, $3 \circ$.

of lepidoptera, $3 \mathbf{1}$.

Crop remnants should be removed, +2.4 .

Croton bugs, 82 .

Cruciferous weeds, lice on, 134 .

Crude petroleum, $4+8$.

Cryptephagus, 177.

Cuckoo-bees. 390.

Cucumber caterpillar borer, $3 \mathbf{I} \mathbf{I}$.

flea-beetle, 2I 9.

striped beetle, $2 I_{4}$. 
Cucujidae, 176 .

Culicida, 332.

Curculio, defined, 228.

Currant borer, 263.

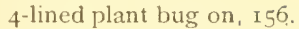
long-horned borer in, 208. worm, 372 .

Cursoria, defined, 81.

Cuterebera emasculator, 352.

Cut-worms, life history, 290. remedies for, 293.

Cyanide fumigation, 454.

Cyclone nozzle, 456.

Cydnidæ, defined, I62.

Cyllene pictus, 208 . robinice, 208.

Cymatophora pampinaria, 309.

Cynipidæ, defined, 376.

Cyrtophyllum concavum, 94 .

Dagger moths, 289 .

Danais archippus, 242.

Darkling beetles, 224 .

Dascyllidæe, $\mathbf{I} 82$.

Datana ministra, 276.

Day-flies, 59.

Death-watch, 69 .

Delta moths, 306.

Deltoids, 306.

Dendrolene and raupenleim, 43I.

Dermaptera, 79.

Dermestes lardarius, 178 . vulpinus, $I 78$.

Dermestida, I78.

Devil's darning-needles, 60.

Diabrotica longicornis, 2 I 5 . I2-punctata, 2 I 5 .

vittata, 214 .

Diapheromera femorata, 86.

Diaspinæ, defined, I I 4 .

Diaspis rosæ, I I9.

Diastrophus nebulosus, 378 .

Diatræa saccharalis, 3 I8.

Dicerca, I85.

Dictyophorus reticulatus, 9 I.

Digestive system, described, 28-30.

Digger wasps, 399, 403 .

Diplosis pyrivora, 339 .

tritici, 338.
Diptera, chapter on, 327 .

defined, 54, 55 .

Diseases of insects, 4 I8.

Dissosteira carolina, 85 .

longipennis, 85 .

Dobson, 72.

Dog-flea, 328.

Dorsal surface, 25.

Dorsum, is upper surface, 25.

Doryphora Io-lineata, 2 I 3 .

Dragon-flics, 60 .

Drasteria crassiuscula, 305 . erechtea, 305 .

Drone-fly, $3+8$.

Drosophila species, 367 .

Dryocampa rubicunda, 279.

Dry powders, how applied, 457 . how they kill, 39 .

Dynastes, 203.

Dysdercus suturellus, I 57 .

Dytiscidæe, I69.

Ears of insects, 43 .

Earwigs, life history, etc., 79.

Economic entomology, development of 9.

Ectobia germanica, 82.

Edema albifrons, 277.

Eggs, number laid by insects, 45 .

of mantidæ, 84 .

of roaches, $8 \mathrm{I}$.

stage described, 48.

Eight-spotted forester, 263 .

Flaphidion species, 207.

Elateridæe, I82.

Electric-light bugs, I5I.

Elm, cockscomb gall on, $\mathrm{I}_{32}$. leaf-beetle, 217 . 4-horned splinx on, 257.

Elytra, I64.

Emasculating bot, 352 .

Empretia stimulea, 27I.

Enemies of insects, 45 .

Ephemeroptera, described, 59.

Ephestia kühniella, 3 I5.

Epidapus scabci, 335 .

Epicauta cinerea, 227.

pennsylvanica, 227.

vittata, 225. 
Epidemics among insects, 45 .

Epilachne borealis, 175 . corrupta, 175 .

Epipharynx, function of, 15, 43.

Epitrix, 219.

Eriocampa cerasi, 372 .

Eristalis tenax, 348,350 .

Erotylidie, 175 .

Erythroneura vitis, I 48.

Euchromia ipomæe, 264 .

Eucleidar, 271.

Eumenes, nests of, 404 .

Euphoria inda, 204.

Euplexoptera, 79.

Eupogonius, 209.

Eurycreon rantalis, $3 \mathbf{I}$.

Eyes, compound, 22.

of insects, 41 .

Fall army-worm, 297.

plowing, effect of, +25 .

web-worm, 266.

Family, defined, 52 .

Farm practice to prevent insect attack, 423.

Feather-wing moths, 3 I 8.

Feeding habits, how determined, I 4 .

Feelers are antennæ, I9.

Femur, defined, 26.

Fenesica tarquinius, 246 .

Fertilizers as insecticides, 427.

Firlia viticida, 2 II.

Filicornia, defined, 165.

Filiform antenna, $2 \mathbf{I}$.

Fire-flies, described, I90

Fish-moth, 53, 56.

-oil soap, use and formula, 447.

Flat-head borers, 185 .

Flax-seed stage of Hessian fly, 336 .

Flea-beetles, 2 I9.

Fleas, described, 328.

Flesh-flies, $35^{6}$.

Flies, chapter on, 327.

Flower-beetles, 192.

-flies, 347 .

Fly, experiments with, $f$ I.

Foraging ants. 399.

Forficulidae, defined, 79.

Formicide, 391.
Fossores, 399.

Four-lined plant-bug, 156 .

Fowls, affected by lice, $7 \mathbf{I}$.

Frog-hoppers, 1.46 .

Frnit bark-beetle, 238.

Fulgorida, defined, 146 .

Fuller's rose-beetle, 228.

Fumigating apparatus, 458 .

Funicle of antenna, 22.

Fungus diseases of insects, 418,422 . gnats, 334 .

Galeruca xanthomelæna, 217.

Gall-flies, 376.

-gnats, $33^{6}$.

-lice, described, 132.

Galls, ink from, 378 .

Galleria melonella, 3 I6.

Ganglia, described, 39.

Garden web-worm, 3 II.

Gas sprayer, 457.

Gas-tar as an insecticide, 43I, 453.

Gasoline as an insecticide, 451 .

Gastrophilus equi, 351.

Geared machines, 457.

Gelechia cereallella, 326 .

Geniculate antennæ, 22.

Genus, defined, 52.

Geometridæe, 307.

Geotrypes, 198.

Gills, of aquatic insects, 37 .

Gizzard, described, 30.

Glow-worms, I9o.

Gnats, 334,340 .

Goat-moths, 286.

Goldsmith beetle, 202.

Gouty gall on blackberry, 186.

Grain-weevils, 237.

Grape, American Procris on, 264. chafers on, 202.

8-spotted forester on, 263 .

flea-beetle, 219.

leaf-hopper, 148 .

phylloxera, 128.

plume-moth, 3 r 8 .

Pyrophila on, 299.

-root-worm, 206, 212.

- slug, 373.

Grapta comma, 244. 
Grass, leaf-hoppers in, I.t7. thrips on, IO2.

Grasshoppers, life-history, etc., 89. long-horned, 93. short-horned, 85.

Green-striped locust, 88.

Ground-beetles, described, I66.

Grouse locusts, life-history, 92.

Gryllidae, defined, 97.

Gryllotalpa, 98.

Gryllus, species, 99.

Gypsy moth, 270 .

Gyrinidae, I70.

Hrematobia serrata, 358 .

Hair-streaks, 245.

Halisidota, species, 268.

Halteres, of flies, 327.

Haltica chalybea, 2 I9.

Ham-beetle, I93.

Hammer-head borers, 185 .

Harlequin cabbage-bug, I62.

Harrisina americana, 264.

Harvest-flies, I39.

Haustellate mouth-structures, I6.

Hawk-moths, 25.

Head and its appendages, If. -louse, I03.

Hearing of insects, 43 .

Heart, described, 32.

Heliothini, 303.

Heliothis armiger, 303.

Hellebore and its use, $44^{\circ}$.

Hellgrammites, 72.

Hemerobiidre, described, 72

1 Hemerobius, 74 .

Hemiptera, chapter on, 100. defined, 53, 55 .

Hen-lice, 7 I.

Hermaphrodites, $4^{6}$.

Hesperidae, 254.

Hessian fly, 336. effect of late planting, 428 .

Heterocera, 24I, 254 .

Heteromera, defined, I65, 224.

Heteroptera, defined, 53, I00. treated, 150.

Hickory horned devil, 278. phylloxera on, 130 .
Hippiscus discoideus, 88.

Hippoboscide, 369 .

Hippodamia, I74.

Hispidie, 221.

Histeridæ, 180 .

Hive-bee, $4 \mathbf{I} 4$.

Hog-caterpillars, 257.

-louse, Io.4.

Homoptera, defined, 53, I00, 106.

Honey-ants, 396.

-bee, $4 \mathrm{I} 4$.

-dew, I 26 .

-tubes of plant-lice, 126.

Hop, Grapta on, 24.

-louse, life history, 125.

snout-moth, 306.

Hopper-dozers, 92, 458 .

Horn-fly, 358.

-tails, 371,374 .

Hornets, 406.

Horse-bot, $35 \mathrm{I}$.

-flies, $3+2$.

House-fly, 356 .

Household pests, 56, 82, I 55, 356, 396 .

Humming-bird hawk-moths, 257.

Hybernia tiliaria, 308.

Hydrate of lime, dry, $438,44^{\mathrm{I}}$

Hydrobatidae, defined, I 5 I.

Hydrocyanic acid gas, 454 .

Hydrophilidæ, 170 .

Hymenoptera, chapter on, 370.

defined, 54,55 .

Hypena humuli, 306.

Hyperchiria io, 283 .

Hyper-parasites, 388 .

Hyphantria cunea, 266 .

Hypoderma lineata, 352 .

Hypopharynx, structure and function, I6, 43 .

Icerya, Vedalia against, 421 . purchasi, 108.

Ichneumon flies, 38I.

Ichneumonidre, $38 \mathrm{I}$.

Ileum, described, 30 .

Indian Cetonia, 204.

Incomplete metamorphosis, 50.

Injectors, 458 .

Inoculation of trees, 455 . 
Insect powder, +39 .

Insecticide, chapter on, 43I-455.

Insects, defined, 11, 12, 54 .

Insidious flower-bugs, 156 .

Introduced insects, 421 .

Introductory, 9 .

to moth, 284 .

Ipomiea, larvie on, 264.

lps fisciatus, 181

Isabella moth, 266.

lsomera, defined, 165.

1 sopteria, 64 .

Isosoma species, 386 .

Jassidx, defined, It7.

Jigger-tleas, 329 .

Joint-worms, 386.

Jug-handle grubs, 254 .

Jumping plant-lice, $\mathbf{3} 37$.

June-bugs, 200.

Kainit, against root-lice, I3I.

Katydids, described, 94.

Kermes, described, I Io.

Kerosene as an insecticide, 4 \%.

how it kills, 38.

Kerosene-Lime-K-L. +50.

Labium, structure and function, I6. Labrum, structure and function, 15 .

Lace-wing flies, their habits, etc., 74

Lachnosterna, 201.

Lady-birds, described, I72.

Laxtilia coccidivora, 315 .

1,amellate attennæ, 2 I.

Lamellicornia, defined, 165, I96.

Lampyricle, 190.

Lancets of fly mouth, 18.

Languria mozardi, 176.

Lantern-filies, described, ${ }_{4} 6$.

J aphria, species, 3.t.

Laphygma frugiperda, 297.

Larder-beetles, I78.

Larrida, 403.

Larva distinguished from worms, II.

Larval stage, $4^{8}$.

Lasioderma serricorne, I93.

Lasins species, 394.

Lawns, ants on, 395.
Leaf-beetles, described, 210.

-chafers, 199.

-hoppers, described, I 46 .

life-history, 1.7 .

-roller caterpillars, 319.

Leather-beetle, 178.

Lebia grandis, 168.

Lecanium, definerl, 112.

Legs, where located, 25.

structure of 25 .

Lema trilineata, 211.

I.eopard-moth, 287 .

Lepidoptera, chapter on, 2 fo.

defined, 54,55 .

Lettuce, root-lice on, 127 .

Leucania albilinea, 296. unipuncta, 294.

Lice, biting, their habits, etc., 70. on domestic animals, 71, 105. sucking, IO4.

Life-history, defined, 50. economic importance of, 50

Ligyrus rugiceps, 203.

Limacodidæ, $27 \mathrm{I}$.

Lime and kerosene, 450.

and sulphur washes, $+42-+45$.

as a preventive, 432 .

as an insecticide, $438,4+7$.

-tree moth, 308.

Limnophilus rhombicus, 78 .

Litargus, I77.

Lixus concavus, 230.

Locomotion, organs of 25 .

Locust borer, 287.

leaf-beetle, 222.

Locustidx, defined, 93.

Locusts or cicadas, I fo.

Locusts, destructive species, go. remedial measures, 92.

London purple, +36 .

Long-horned beetles, 205.

Loopers, 307 .

Losses caused by insects, 9 .

I couse-flies, 369 .

Loxostege similalis, $3 \mathrm{II}$.

Lubber grasshoppers, 91 .

Lucanidæe, 196.

Lucanus species, 197.

Lucillia macellaria, 357. 
I.una-moth, 282.

J.ycæna, species of, 245.

Lycænidæe, $2+2$.

Lygaida, defined, I58.

Lymantriidxe defined, 268.

Machinery, chapter on, 456- 459 .

Macrobasis unicolor, 227.

Macrodactylus subspinosus, 199.

Malachiidre, I91.

Mallophagidar, 70 .

Malpighian tubules, 30 .

Mandibles, structure and function, I $_{5}$.

Mandibulate mouth, I 5 .

Mantidat, described, 83 .

Mantis religiosa, 8.4.

Mantispidæe, 76.

Manure, favors insects, +28 . podurids breed in, 57 .

Maple-borer, 208. clear-wing borer, 262. scale, life-history, I 10.

March-flies, 340 .

Margaronia nitidalis, $3 \mathbf{I}$ I.

Mask of dragon-fly larva, 62 .

May-beetles, 200.

-flies, their habits, etc., 59.

Maxillat, structure and function, I5.

MeGowen injector, $45^{8}$.

Meadow-grasshoppers, 96 .

Meal-worms, 22. .

Mealy-bugs, described, 106. remedies for, 108 .

Measuring-worms, 307.

Mechanical preventives, 430.

Mecoptera, 77.

Mediterranean flour-moth, $3 \mathbf{I} 5$.

Megachile species, +12.

Megathymus yucca, 254 .

Megatoma, 179 .

Megilla, I74.

Melanophila, 185 .

Melanoplus atlanis, 90 . femur-rubrum, 90. spretus, go.

Melitara dentata, 313 . prodenialis, 313 .

Melittia ceto, 259.

Meloidae, 225.
Melon-louse, life history, I26.

Melophagus ovinus, 369 .

Membracidae, defined, 138 .

Mesothorax, 23.

Mesograpta polita, 350.

Metathorax, 23.

Metamorphosis, defined, 48 .

Microcentrum retinervis, 94 . laurifolium, 94, 95 .

Microgaster, 383 .

Micro-lepidoptera, 310.

Micropyle, defined, 47.

Miclaidæ, $3+4$.

Midges, $33+336$.

Migration in plant-lice, 126.

Milk-weed butterfly, $2+2$.

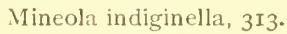
vaccinii, 313 .

Mole-crickets, 98.

Monilicornia, defined, 165 .

Moniliform antennæ, 22.

Monomorium pharaonis, 396 .

Monophadnus rubi, 37 .

Monostegia rosæe, $37+$.

Mormon ericket, habits of, 97.

Mosquitoes, 332.

Mosquito-hawks, 61 .

Noths, chapter on, 2.40.

Moulting of insects, 48 .

Moults, number of, 49 .

Mourning-cloak butterfly, 244.

Mouth of bees and wasps, $\mathbf{I} 9$. importance of, I4, 16.

indicates remedies, $\mathbf{1} 6$. of flies, 18.

types of, I. .

Mud-daubers, $f 02$.

Multicellular gall, 378 .

Murgantia histrionica, $\mathbf{I} 62$.

Nuscidae, 353, 356.

II uscles, structure and character, 28

Mushroom-gnat, $33+$.

Mutillidæ, 400.

Mycetophilidx, 334.

Myrmeeocystus melliger, 396.

Myrmeleonidee, described, 75 .

Myrmicidae, 396.

Mytilaspis pomorum, I I5.

Myzus cerasi, I3t. 
Nabidce, defined, 153.

Nabis fusca, $15 \%$.

Naphthaline against book-lice, 69 . and its uses, 453.

Natural checks to insect increase, 418.

Necrophorus, 17I.

Negro-bug, I63.

Nematus ribesii, 372 .

Nervous centre in flies, $4 \mathrm{I}$. system of insects, 39 .

Neuroptera, defined, 53,54 . chapter on, 58 . described, 72 .

Neuters in ants, $39 \mathrm{I}$.

Newspaper barriers against borers, 43I.

Nisoniades, species of, 254

Nitidulidæe, I8I.

Nits of lice, 105.

Noctuidæ, 288.

Notodontidæ, 275 .

Notolophus leucostigma, 268.

Nozzles types of, 456 .

Nut-weevils, 234.

Nymph, defined, 49 .

Nymphalidx, 242 .

Oak, Edema albifrons on, 277.

galls, 377 .

leaf-rollers, $32 \mathrm{I}$.

orange-striped worm on, 278 .

pruners, 207.

Ocelli, described, 4I. location of, 22.

Ocneria dispar, 270.

Odonata, described, 60 .

Odontota dorsalis, 222.

Ecanthus species, 100 .

Edemasia concinna, 277.

Edipodinze, described, 87.

Esophagus, described, 30.

Estridæe, 351.

Estrus ovis, 352.

Oil of Citronello, 333 .

Olfactory organs, described, 44.

Olfersia, species, 369 .

Oncideres species, 210.

Onion maggot, 363 .

thrips, IO2.

Ophion species, 382.
Orange, Aleyrodes on, I22.

cottony-cushion scale, 108. -dog, 253.

mealy-bugs on, Io6.

oyster-shell scales on, II6. red-bug on, 157 .

Termite attack on, 67 .

Orange-striped oak-worm, 278.

Orbicular spot, 289.

Orchelimum species, 96 .

Orcus, I74.

Orders of insects, 52, 54 .

Orgyia leucostigma, 268.

Ortalids, 365 .

Orthoptera, chapter on, 79 . defined, 53,54 .

Orthosoma brunneum, 206.

Ovaries, described, 46.

Oviduct, described, 46 .

Oviposition of Acridiıdæ, 89 .

Chrysopa, $7+$

dragon-flies, 62.

field-crickets, 99.

grasshoppers, 89 .

katydids, 96 .

locusts, 94.

tree-crickets, Ioo.

Ovipositor, described, 46 .

in crickets, 97 .

of parasites, 379 .

Owlet moths, 288 .

Ox-lonse, 104 .

Ox-warble, 352.

Oxvptilus periscelidactylus, 318.

Oyster-shell bark-lice, II 5 .

Pain in insects, to.

Pale-striped flea-beetle, 22I.

Paleacrita species, 308.

Palm-weevil, 236.

Palpi, structure and function, 16.

Pamphila, species of, 254 .

Panorpida, described, 77.

Paper-making wasps, 406.

Papilio asterias, 250.

cresphontes, 253.

philenor, 251.

turnus, 252.

Papilionidæe, 246 . 
Papilioninæ, 250 .

Parasites on plants, 377 .

Parasitic liymenoptera, 379 . insects, chapter on, 418 .

Parasitica, defined, IOI, IO3.

Paria aterrima, 212.

l'aris green, analysis of, 435 .

Paroxya, 90.

Parthenogenesis in plant-lice, $\mathbf{1 2 3}$.

Passalus cornutus, 197.

Pea-weevils, 223.

Peach-borer, 26r.

-louse, 134.

Peacock-flies, 365 .

Pear-midge, 339.

-psylla, life history, I 37.

sinuate borer in, 187 .

-slug, 372.

Pectinated antennæ, $2 \mathrm{I}$.

Peddlers, 222.

Pediculus species, I03.

Pelecinus polyturator, 389 .

Pelidnota punctata, 202.

Pelopœus species, 402.

Pemphigus, described, 132.

Penis of insects, 47.

Pentatomidæ, defined, I62.

Pentilia misella, I74.

Pepsis species, 4 OI.

Perception, sense of, 45 .

Periodical cicada, I 40 .

Periplaneta orientalis, 82 .

Perlidæ, described, 64 .

Pernicious scale, II 8.

Persian insect powder, 439.

Pezotettix, 9I.

Phasmidæ, described, 84 .

Philampelus achemon, 258. pandorus, 258.

Phorbia brassicæ, 36 I. ceparum, 363 .

Phosphorus against roaches, 82 .

Photinus pyralis, Igo.

Phthirius inguinalis, 105.

Phycitinæ, 3I2.

Phyllodromia germanica, 82.

Phyllœcus flaviventris, 373 .

Phyllotreta vittata, 221.

Phylloxera, life history, I28.
Phymata, habits of, I54.

Phymatodes amøenus, 207.

variabilis, 207

varius, 207.

Physopoda, IOI.

Phytonomus punctatus, 229.

Phytophaga, described, 205.

Phytophagous beetles, defined, 165 .

Pickle-moth, 3 II

Pierinæ, $2+6$.

Pieris protodice, 2.48 . rapæ, 246.

Pigeon tremex, 375 .

Pimpla conquisitor, $38 \mathrm{I}$.

Piophila casei, 368.

Pissodes strobi, 230.

Plagionotus speciosus, 208.

Plant-lice, defined, I23.

life history, I24.

on roots, I 27.

remedies against, $\mathbf{I} 35$.

Planting, date of, important, 428 .

Platyptera, described, 64.

Platysamia cecropia, 280.

Plecoptera, described, 63.

Pleurum or side, 25.

Ploughing, to reduce insect injury, 425.

Plum curculio, 232.

Plume-moths, 3 I 8.

Plumose antennie, $2 \mathrm{I}$.

Plusia brassicæ, 302.

species, 302 .

Podurids, 56.

Pocilocapsus lineatus, 156.

Poisers, of flies, 327.

Polistes species, 406.

Pollen basket, 408.

Pollination, due to bees, 408 .

Polyphemus moth, 282.

Pomace-flies, 367 .

Pompilidæe, 400 .

Potash as a winter wash, 450 .

Potato-beetle, old-fashioned, 225. striped, 213.

three-lined, 2 I I.

flea-beetle, 219.

stalk-borer, 234.

scab-gnat, 335 . 
Potato-sphinx, 256.

Pouktry-lice, $7 \mathbf{I}$.

Power punips, 457.

Praying Mantis, habits of, 84 .

Predaceous bugs, 152.

insects, chipter on, 418 .

Ireventives, chapter on, $430-433$.

l'rinters-ink hands, 431.

Prionidus cristatus, 152.

Prionoxystus robinize, 287.

Prionus laticollis, 206.

Proctotrypidae, 387.

l'rolegs, clefined, I2.

Prominents, 275.

Prothorax, 23.

Protoparce carolina, 256. celeus, 256.

Psenocorus supernotatus, 208.

Pseudo-neuroptera, defined, 53, 54. 58.

Psendo-trachea of $\mathrm{fly}, 20$.

Psocidæe, described, 68.

Psocus lineatus, 69.

Psychidre, 273.

Psychomorpha epimenis, 264.

Psylla pyricola, 137.

Psyllide, defined, I37.

Pteromalus puparum, 385 .

Pterophoride, $3 \mathbf{1 8 .}$

Ptinidae, I93.

Pubescent antennæ, 22.

Pulvilli, defined, 26.

Pulvinaria innumerabilis, IIO.

Pumps, for spraying, 456-459.

Punkies, 334.

Pupa, defined, 19

Pupipara, 369.

Pyralidida, 3 Io.

Pyralis farinalis, 3 I 2 .

Pyratista speeies, 3 I I.

Pyraustidie, $3 \mathbf{I O}$.

Pyrethro-kerosene emulsion, 45I.

Pyrethrum and its uses, 459 .

Pyrophila pyramidoides, 299.

Pyrrharctia isabella, 266.

Quassia as an insecticide, 452 .

Queen bees, 4 I5.

Quince-borer, 209.

-curculio, 234.
Radish-maggot, $3^{62}$.

Raphidia, 72.

Raptoria, defined, 81 .

Raspberry, Byturus, I80.

- slug. 374 .

Rat-tailed larve, 350.

how they breathe, 37.

Raupenleim and dendrolene, 43 I.

Receptaculum seminis, 46 .

Rectun, described, 30 .

Red-bug on cotton, I57.

-humped prominent, 277.

-legged locust, go.

-necked cane-borer, I 86.

Reduviidæ, defined, I5I.

Reflowing cranberry bogs, 428 .

Regal walnut-moth, 278 .

Reniform spot, 289.

Reproduction among insects, 45 .

Resin washes, use and formulas, $44^{6}$

Respiration in insects, 33 .

in dragon-fly larve, $5 \mathrm{I}$.

in water-beetles, 36 .

economic bearing of, 33,38 .

Retina, described, $4 \mathrm{I}$.

Rhipicerida, 182 .

Rhizobinze, described, 127.

Rhizobius, I7t.

Rhopalocera, defined, 24 I.

Rhopobota vacciniana, 320 .

Rhubarb, weevil on, 230.

Rhynchophora, I65, 228.

Rhynchophorus palmarum, 236.

Roaches, life history, $8 \mathrm{I}$.

Robber-flies, 3+t.

Rocky Mountain locust, 9o.

Root-lice, remedies for, 130.

-maggots, 360 .

web-worms, 3 I 7 .

Rose-beetle, Fuller's, 228.

-bug. I99.

-chafer, I99.

leaf-hopper, I 48 .

leaf-rollers, 32 I.

-scale, irg.

-slus, 374 .

Rosy D ;ocampa, 279.

Rostrum, defined, I7.

Rotation, use of, +26 . 
Round-headed borers, 205.

Rove-beetles, I72.

Saliva and its uses, 3 I.

Salivary glands, 30, $3 \mathrm{I}$.

Saltatoria, defined, 8I.

San José scale, i I8.

Sand-crickets, 97.

-flies, 334 .

Sannina exıtiosa, 26I.

siap-beetles, I8I.

Saperda candida, 209.

Sarcopliaga carnaria, 355 .

Sarcopsylla, species of, 329 .

Saw-flies, 37 I.

Scale insects, Io6.

remedies for, 108, I 20.

Scape of antenn: 22.

Scavenger beetles, I72, I97.

Sicarabeidae, 197.

Scenopinidae, 347 .

sicenopinus fenestralis, 347 .

Schistocerca americana, 89 . peregrinum, 89.

Schizoneura, described, I33. lanigera, 133.

Sciara species, 334 .

siclerites, defined, 23.

sicoliidæe, 400.

sicolytidæ, 237.

Scolytus rugulosus, 238.

sicorpion flies, their habits, etc., 77 .

Screw-worm fly, 357 .

Sicudderia species, 94.

Sicurfy scale, described, I I 9.

Scutelleridiz, defined, 163.

icymnus species, 174 .

Segments in insects, $3 \mathbf{I}$.

Semi-loopers, 300.

Seminal receptacle, 46.

Sensation in insects, 40.

Sericaria mori, 286.

Serrate antennæ, $2 \mathbf{I}$.

Serricornia, defined, 165.

Sesia acerni, 262. tipuliformis, 263 .

Sesiidre, 259.

Seventeen-year locust, I 40.

Sex in insects, f $^{6}$
Sheep-bot, 352.

-tick, 369.

Sialidae, described, 72 .

Silk-worm, 286.

Silpha species, I7I.

silphidre, I7 I.

Silvanus surinamensis, I76.

Silver-fish, 56.

Simuliidxe, 34 I.

Sinoxylon, I93.

Sinuate pear-borer, 187.

Sitodrepa panicea, I93.

skippers, 254 .

in cheese, 368.

slugs, beetle larva, 2 I I. saw-fly larve, 372.

Smell, sense of, 43 . organs of, in antennæe, 20.

Snake-doctors, 60.

Suapping beetles, I82.

Snout-beetles, described, 228. what are, I65.

Soap mixtures, how they kill, 38 .

Soaps as insecticides, $44^{6}$.

Social bees, $4^{1} 4$.

life among Termites, 64 .

wasps, 405.

Sioft scales, described, I ro.

soldier beetles, I9I.

flies, 343 .

Solitary bees, 407.

Spanish flies, 225.

Span-wornis, 307 .

species, defined, 52.

Sphecidre, defined, 402.

Sphecius speciosus, 403.

Sphenophorus, species of, 236 .

Sphex ichneumonea, 403.

Sphingidae, 254.

Sphinx carolina, 256.

celeus, 256 .

Spilosoma virginica, 266.

Spiracles, described, 33.

how protected, 34 .

Spittle insects, $\mathbf{I}_{4} 6$.

Spraying machinery, 456 .

spring-beetles, I82. -tails, 53, 56 .

sipotted vine-chafer, 202. 
Squash-borer, 259.

-bug. I6o.

lady-bird, 175 .

Stable-fly, 358 .

Stag-beetles, I96.

Stagmomantis carolina, 84 .

Staphylinida, I72.

sitem-mother in plant-lice, I23.

Stenopalmatus, 97.

Sternum or breast, 25.

Stinging Hymenoptera, 390.

Stommch poisons, how they act, 32.

stomoxys calcitrans, $35^{8}$.

sitone-flies, 63.

Stored produce, Termites in, 67.

Strategus, 203.

Stratiomyida, 343 .

Strawberry-root borers, 2 I2. weevil, 23 I.

Stridulating organs, 03 .

Striped cucumber-beetle, 2 I 4 .

Structure in general, I I.

Subterranean forms, breathing, $3^{6}$.

Sucking lice, 103. nouth, 17,

Sugar-cane beetle, 203.

borers, 317.

Termite injury to, 67 .

Sulphur as an insecticide, $\$$.

Sutures, defined, 23.

sivallow-tail butterflies, 250 .

Swarming of bees, what is, 415 .

Sweet-potato flea-beetle, 2 I9. tortoise-beetles, 222.

Syrphide, 347 .

Systena blanda, 22 I.

Tabaniclæe, 342.

Tachina flies, 354. vivida, 354 .

Tactile organs, what are, 44 .

Tarantula hawk, 40 I.

Tarred paper against borers, $43 \mathrm{I}$.

Tarsus, defined, 26.

Taste in insects, 43 .

Tegmina, defined, 79 .

Telea polyphemus. $28 \mathrm{I}$.

Telephorus, I9I.

Tendon, described, 28.
Tenebrionidæ, 224.

T'enebrioides, $\mathbf{I} 82$.

Tent-caterpillars, 28.4 .

Tenthredinidxe, 37 I.

Teras and its parasites, $\$ 20$. minuta, 319.

Termes flavipes, 65,67 .

Termites, their habits, etc., 64 .

Testes, described, 47.

Tettiginæ, described, 9r.

Thalessa species, 379 .

Thecla, species ol, 245 .

Thick-head flies, 35I.

Thorax, structure and function, 23.

'Ihree-lined potato-beetle, 2 I I.

Thripidæe, defined, IoI.

Ihrips, life history, IOz. remedies for, 102 .

'Thyridopteryx ephemeraformis, 273

Thysanoptera, defined, IOI.

Thysanura, defined, 53, 54. chapter on, 55 .

Tibia, defined, 26.

Tiger-beetles, described, 166.

Time of planting, important, 428

Tingitidæ, defined, I54.

Tinea pellionella, 325 .

Tineina, defined, 323 .

Tiphia inornata, 400 .

Tipulidae, $33^{\circ}$.

Tobacco and its uses, 440. against root-lice, I3I.

beetle, I93.

sphinx, 256.

thrips on, 102.

Tomato fruit-worm, 303.

Tortoise beetles, 222.

Tortricids, $3 \mathbf{I} 9$.

Touch in insects, 4.

Trachea, described, 34 .

Tracheal gills, 37 .

Tracheates, defined, 34 .

Transformations, how observed, 50.

Trap crops, 428.

Tree-crickets, Ioo. -hoppers, 138.

Tremex columba, 375 .

Tribolium species, 225 .

Trichobaris 3-notata, 234 . 
Trichogramma pretiosa, 386 .

Trichoptera, defined, 77 .

Triphleps insidiosus, 156 .

Triungulin of meloid larva, 227.

Trochanter, defined, 26. in parasites, 379.

Trogoderma, 179.

Trogositidæ, 182.

Trogus exesorius, 381 .

Trox, 199.

Trypeta pomonella, 366 .

Tryxalinæ, described, 87.

Tubulifera, 390.

Tumble-bugs, 198.

Turkey-gnat, 340.

Turkeys versus grasshoppers, 427 .

Tussock moths, 268.

Twig-girdlers, 207, 210.

Two-striped tortoise beetle, 222.

Uroceridæ, 371, 374 .

Urticating hairs, 273.

Vagina, described, 46.

Valves of the heart, 32 .

Vanessa antiopa, 244.

Vaporer moths, 268.

Vedalia cardinalis, I73.

versus Icerya, 42 I.

Velvet ants, too.

Venation, defined, 25 .

Vermipsylla, species of, 329.

Vermorel nozzle, $45^{6}$.

Vespa species, 405, 406.

Vespidæ, 404.

Vestiture of bees, 408 .

Vitriol, lime and sulphur, $4+3$.

Viviparous plant-lice, 123. scaic insects, II 4 .

Vision of insects, 4 I, 42 .

Walking-leaves, life history, 85 .

-sticks, life history, 85 .

Washing trees in winter. 432 .

Wasps arc beneficial, to7.

Water as an insecticide, 452.

-beetles, I69.
Water-boatman, 150.

-scavengers, 170.

-striders, 151.

Wavy-striped flea-beetle, $22 \mathbf{I}$.

Waxy scales, I08, I I 2 .

Web-worms, 266, 311, 317 .

Weevils, defined, 228.

Whale-oil soap, 447.

Wheat-head army-worm, 296.

Hessian fly in, 336.

-midge, $33^{8}$.

saw-fly borer, 376 .

stalk-borer, 299.

Wheel-bug, described, 152.

White ants, life history, 64 .

ermine moth, 266 .

-faced wasp, 406.

-grubs, 196.

-pine weevil, 230.

Whitewash, usefulness of, +32 .

Whirligig beetles, I69.

Willow saw-fly, 374 .

Window flies, $37 \mathrm{r}$.

Winglet, defined, 366 .

Wings, number and location, 12.

structure of, 25.

Wings of the heart, 33 .

Winter washing of fruit-trees, 432 .

Wire netting against borers, 430 .

Wire-worms, crane-fly larvæ, 33I described, 182. remedies for, 184 .

Wcolly apple-louse, I33. bears, 265 . plant-lice, 133 .

Worker-ants, 391.

Wrigglers, 332 .

Xiphidium species, 96 .

Xylina antennata, 300. species, 300 .

Xylocopa virginica, $4 \mathbf{1 2}$.

Xyloryctes, 203.

Yellow-jackets, 405.

-necked caterpillar, 275.

Zeuzera pyrina, 287. 






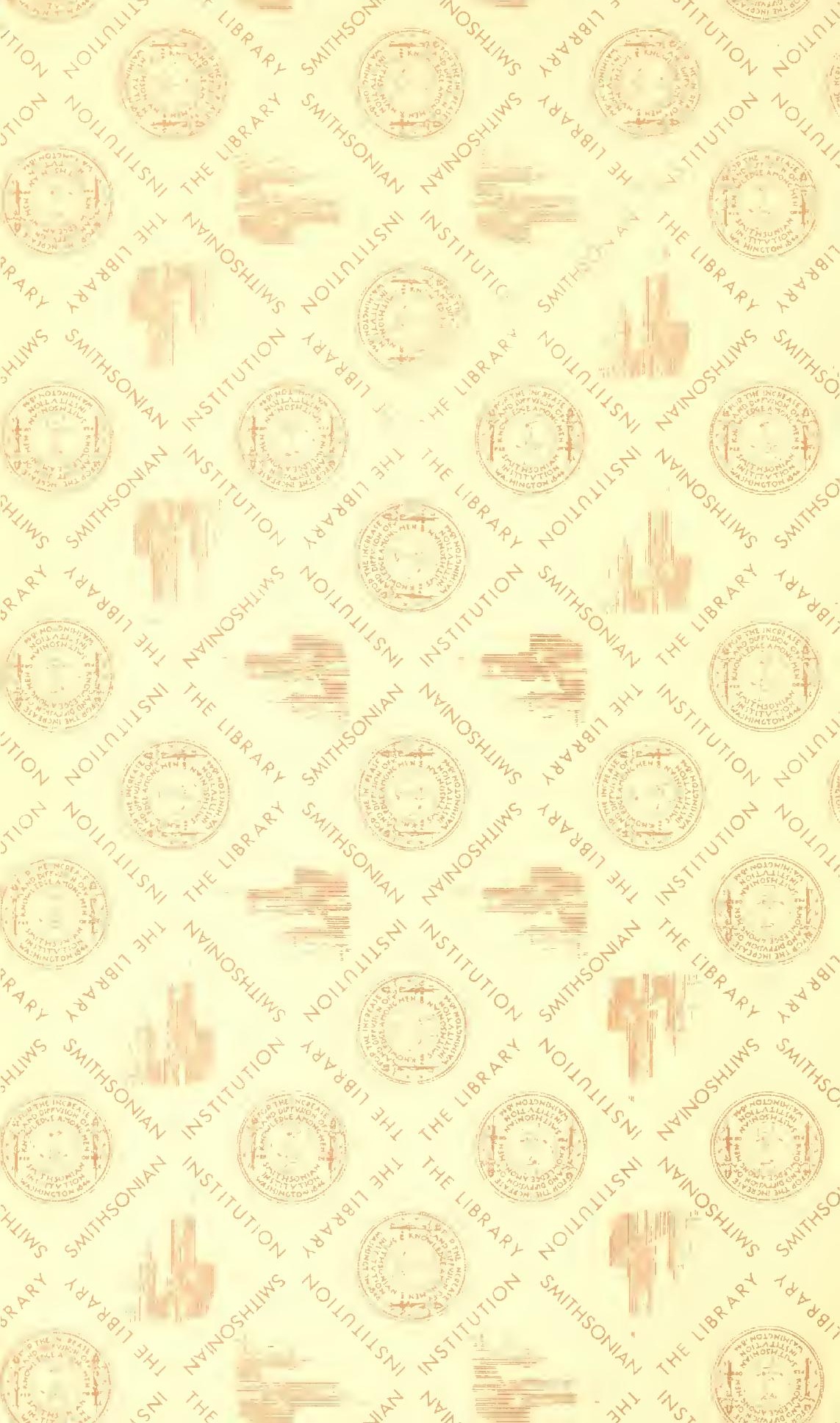




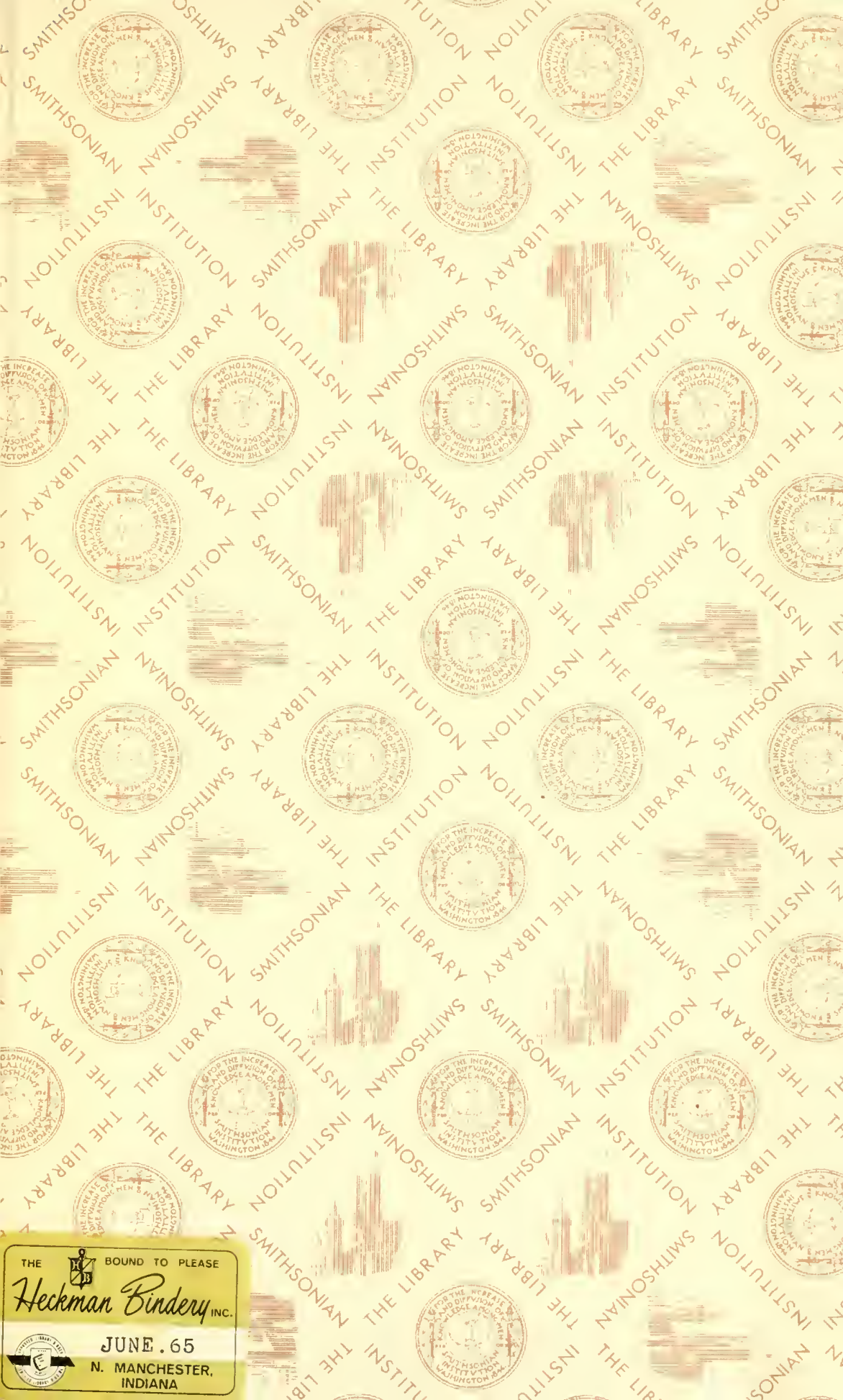




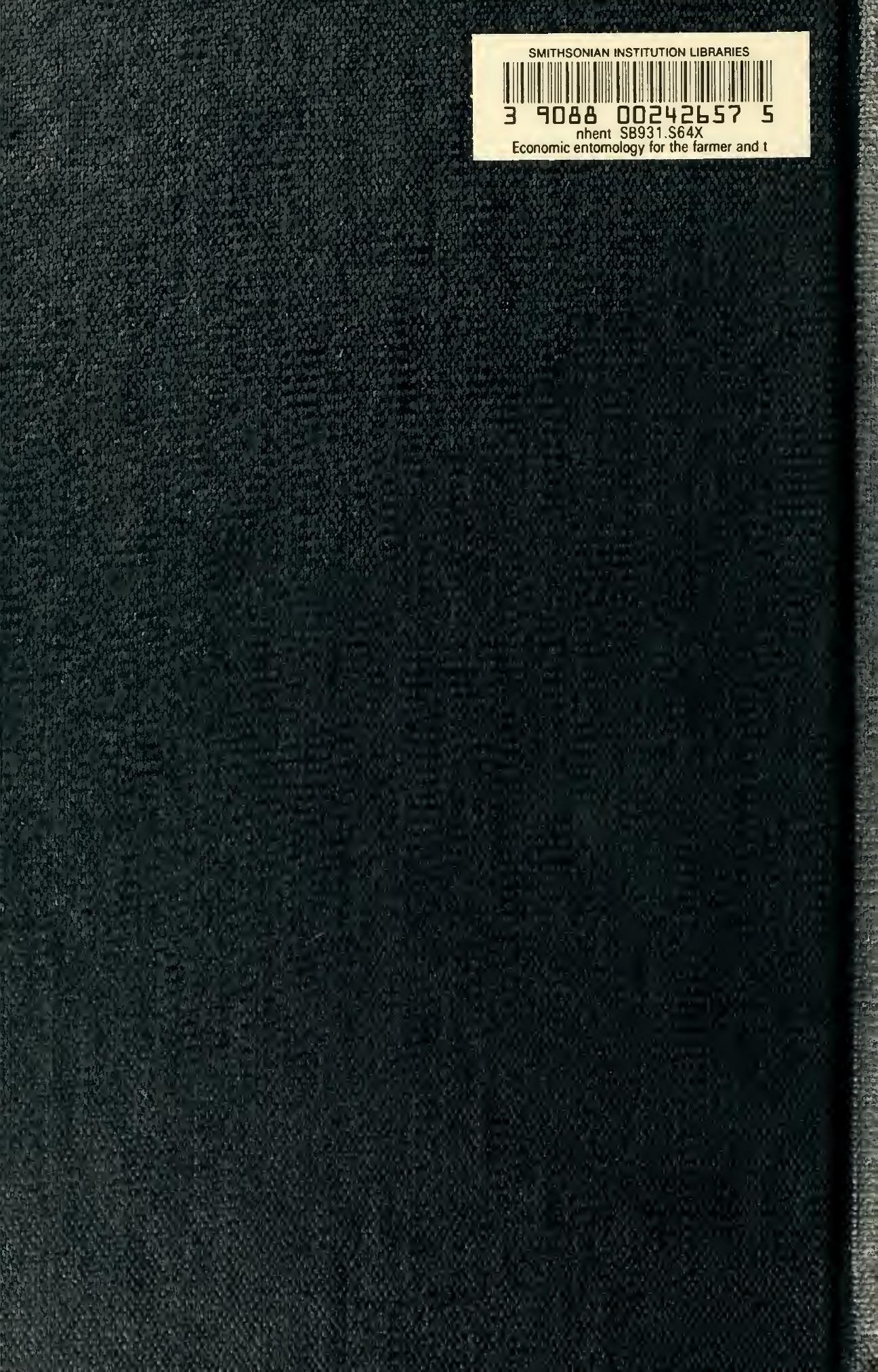

